\title{
RUDOLF FRIEDERICH
}

Die Postwertzeichen Spaniens

und seiner Kolonien

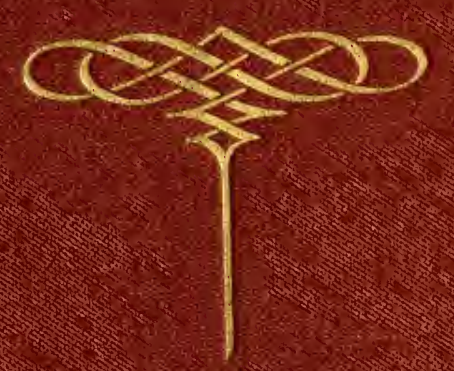




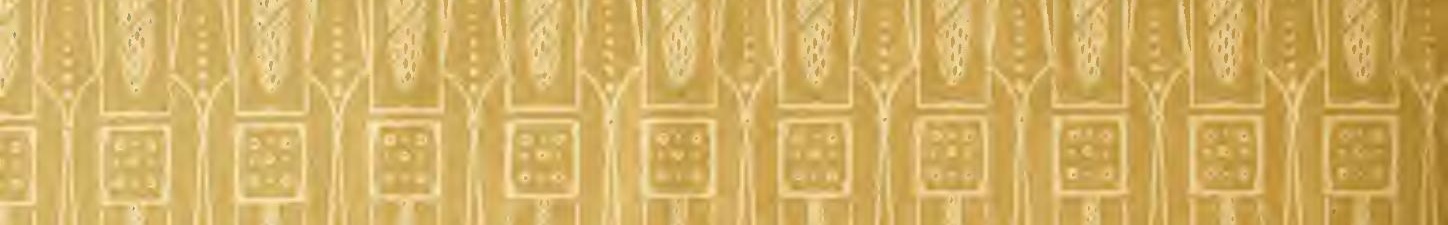
I

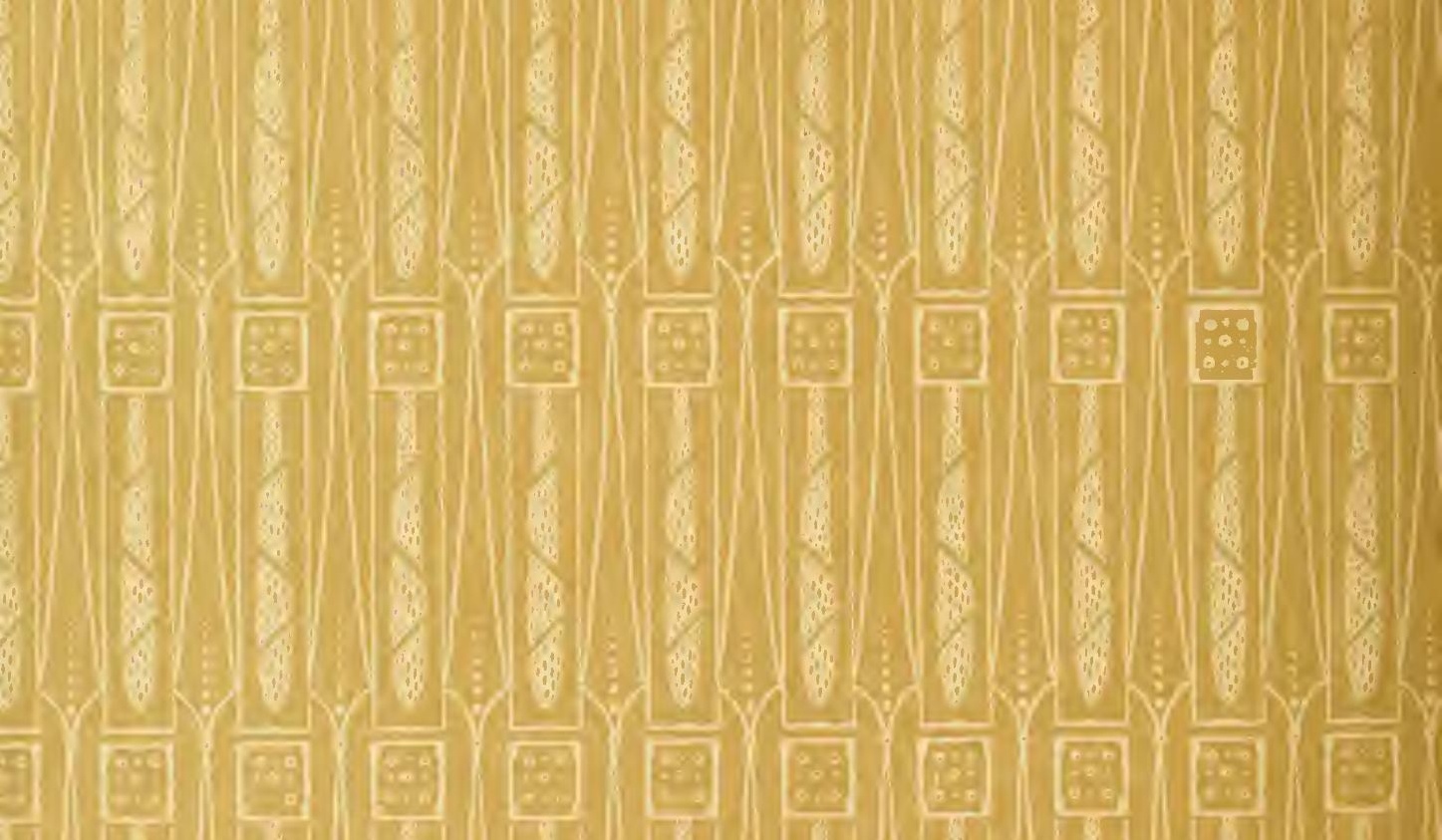



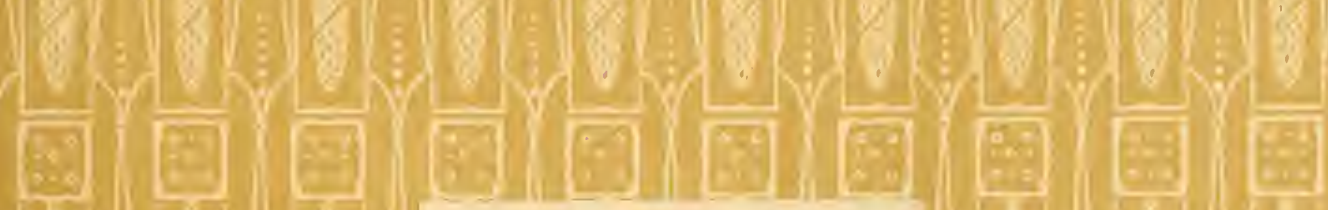
Ex Sibris
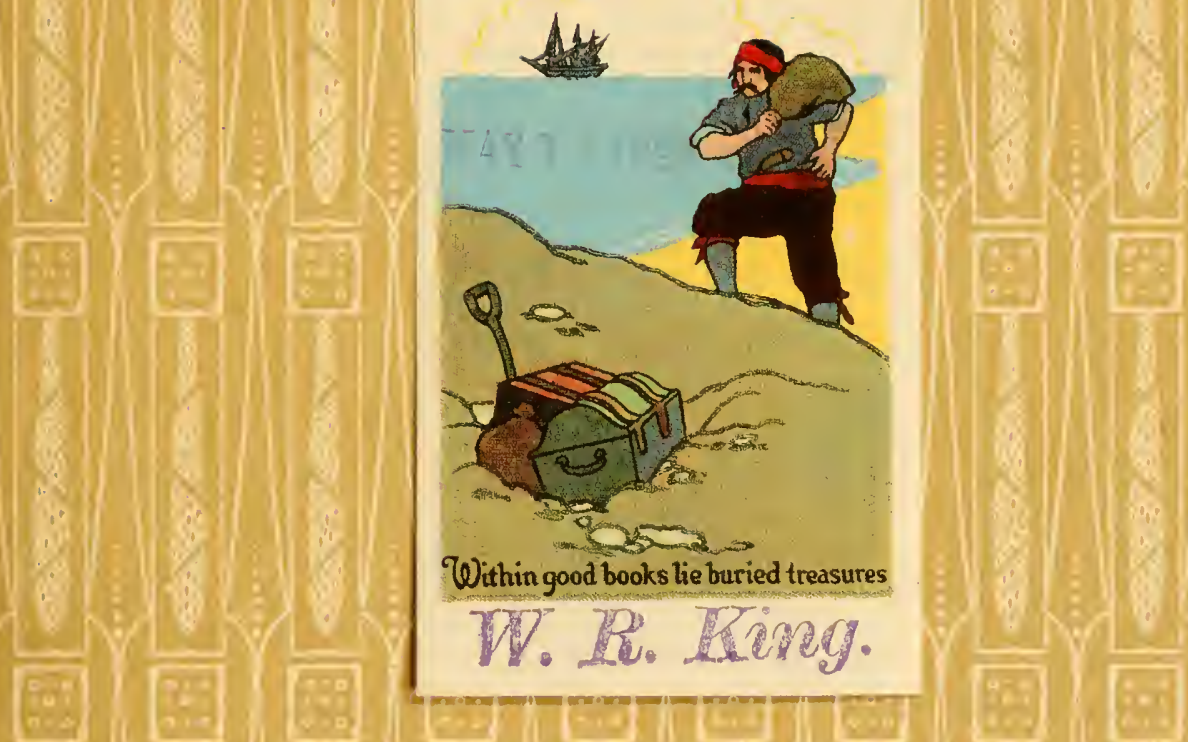

Within good books lie buried treasures
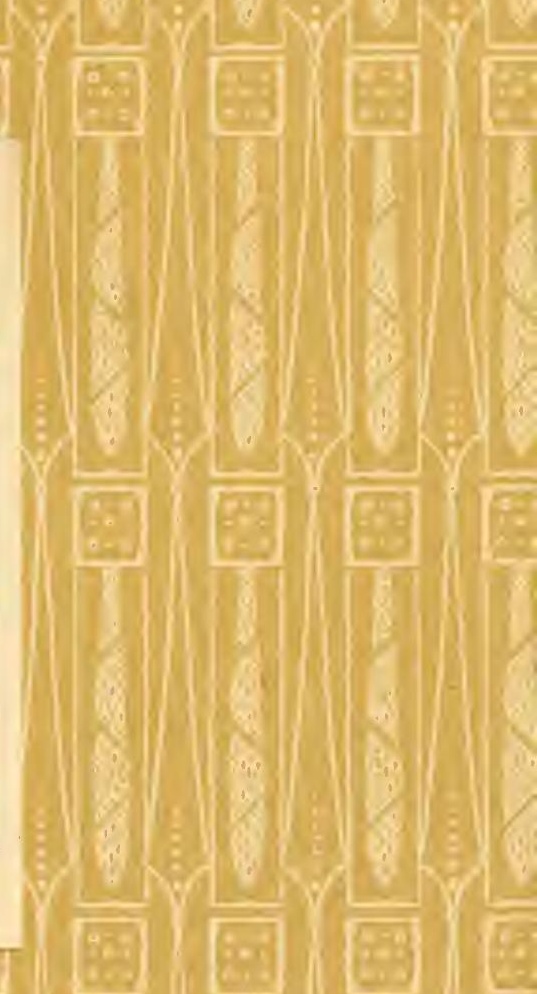

$$
\text { W. R. Ring. }
$$

intions
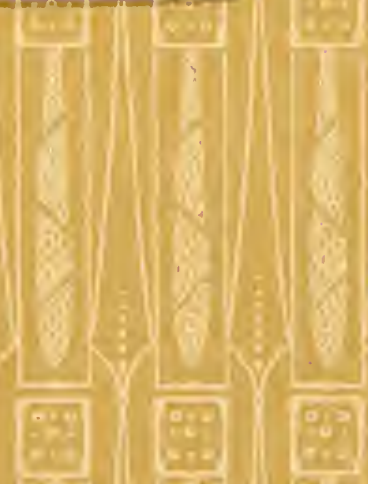

Git 9

GEORGE T TURNEK 




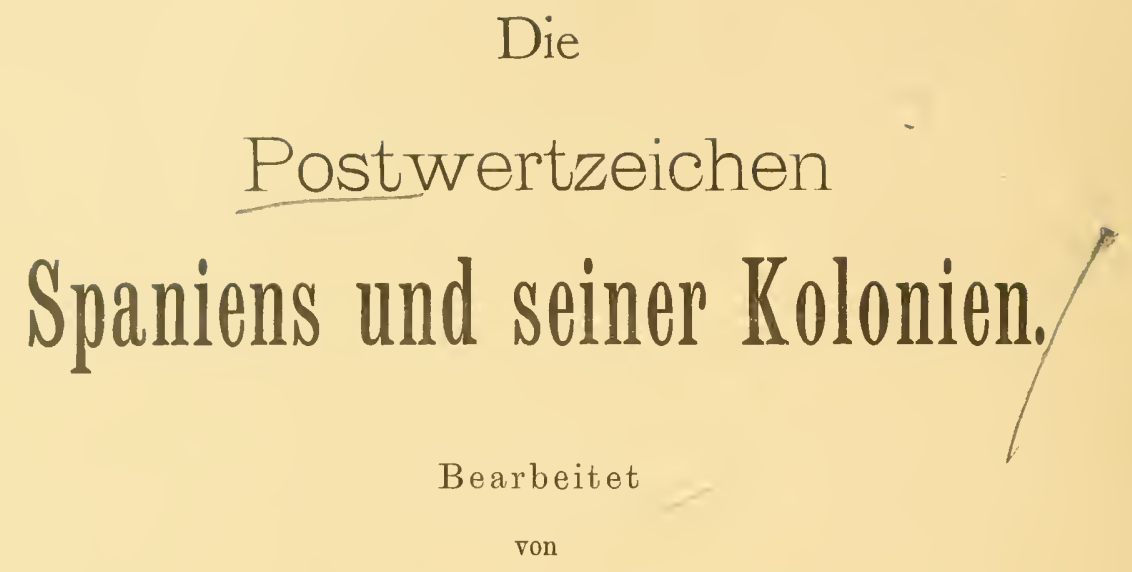

Rudolf Friederich,

Mitglied des Berliner Philatelisten-Clubs.

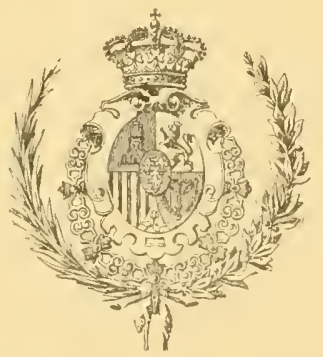

Mit 20 Tafeln in Lichtdruck und zahlreichen Abbildungen im Text.

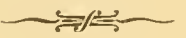

BERLIN 1894.

Verlag von Dr. H. Brendicke,

Potsdamer-Strasse 61. 
Die

\section{Postwertzeichen Spaniens.}

Von

\section{Rudolf Friederich,}

Mitglied des Berliner Philatelisten-Clubs.

Zweite Auflage.

Mit 13 Tafeln in Lichtdruck und 63 Abbildungen im T'ext.

BERLIN 1894.

Verlag von Dr. H. Brendicke,

Potsdamer-Strasse 61. 
Alle Rechte vorbehalten. 


\title{
Den Mitgliedern
}

\author{
des
}

\section{Berliner Philatelisten-Clubs}

freundschaftlichst zugeeignet

rom Verfasser. 



\section{Vorwort zur zweiten Auflage.}

Die „Postwertzeichen Spaniens" erscheinen hiermit in zweiter, völlig umgearbeiteter und bedentend erweiterter Auflage. War die erste Anflage ihrer ganzen Veranlagung nach nur für kleine und mittlere Sammler bestimmt, so soll die Neubearbeitung anch weiter gehende Anforderungen befriedigen, selbst dem Spezialisten auf diesem Gebiete als zuverlässiger Ratgeber dienen.

Die allgemeine Einteilung und Gliederung des Stoffes wurde beibehalten, da sich dieselbe als praktisch erwiesen hatte, nur wurden Dienstmarken, Kriegsstenermarken und die Postwertzeichen des carlistischen Aufstandsgebietes in besonderen Abschnitten behimlelt: es geschah dies einerseits des eigentïmlichen Charakters und Ursprunges dieser Narken wegen, andererseits anch, um die offiziellen A usgaben und Narken durchgehend nummeriren zu kömnen.

Was die Behandlung des Stoffes anbelangt, so strebte ich danach, alle Errungenschaften philatelistischer Forschmng nutzbringend zu verwerthen. Die Zahl der zu Rate gezigenen und durchgearbeiteten Bücher und Zeitschriften hat sich dementsprechend bedeutend vermelrt und es dürfte kaum einen lesenswerten Aufsatz geben, dessen Inhalt ich nicht mit meinen eigenen Erfahrungen und Forschungs-Ergebnissen verglichen hätte.

Die Postwertzeichen werden, wie in der ersten Auflage, in der chronologischen Reihenfolge ilıres Erscheinens behandelt und zwar folgt nach einem beschreibenden Teil, welcher zugleich eine genaue Angabe aller existirenden Niiancen enthält, unter „Bemerkungen“ alles für den Philatelisten Wissenswerte in Bezug 
auf Geschichte, Fälschungen, Essais, Abstempelungen u. dergl. Im Besonderen bemerke ich hierzu:

1. Die Beschreibung der Marken, welche in Bezug auf Genauigkeit in der ersten Auflage vielfach zu wïnschen übrig liess, wurde einer grïndlichen Durchsicht mnterzogen. Die Angabe der existirenden Farben- und Papierunterschiede dürfte wohl nahezu erschöpfend sein, da mir ansser meiner eigenen, melırere der grössten Spezialsammlungen zur Verfïgung standen. Ich bin weit davon entfernt, jeder unbedeutenden Farbenabstufung einen philatelistischen Wert beizulegen und weiss selrr wohl, dass kleine Unterschiede in den Farbentönen auf einem und demselben Bogen vorkommen können; nichtsdestoweniger aber halte ich es für erforderlich, dass ein Spezialwerk bestrebt ist, anch nach dieser Richtung hin vollständig zu sein.

2. Die Aufzählung der Narken erfolgt in der Reilhenfolge ihres Geldwertes, eine Nenerung, welche hoffentlich bald von unseren Alben und Katalogen nachgeahmt wird, da die bisher ïbliche Katalogisirungsweise geradezu sinnlos ist und zu ganz falschen Vorstellungen in Bezug auf Wert und Verwendung der Marken führen muss.

3. Der Schilderung derjenigen Momente der spanischen Geschichte, welche sich anf irgend eine Weise anf den suanischen Postwertzeichen wiederspiegeln, wurde ein verhältnismässig breiter Raum gewährt: auch wurde nicht unterlassen, diejenigen postalischen Verfügungen, welche anf die Entwickelung des spanischen Postwesens massgebend einwirkten, im Anszuge mitzuteilen. Ich ging dabei von der Ansicht aus, dass für den denkenden Plilatelisten eine Postwertzeichen-Sammlung nicht blos eine Liebhaberei oder ein Sport sein darf, sondern dass er in ihr einen zwar kleinen, aber nicht uninteressanten Beitrag zur Kulturgeschichte eines Volkes, eine Illustration zur Entwickelungsgeschichte eines der wichtigsten Verkehrsmittel unseres Jahrhunderts erblicken muss. Nur so aufgefasst, erscheint es wenigstens begreiflich und gerechtfertigt, wenn Männer jerlen Standes und Alters so vie] Zeit und Geld auf diese Sache verwenden. 
So viel Wert ich aber auch auf die Darlegung des Zusammenlanges von Postwertzeichen und Landes- und Post-Geschichte legte, so habe ich mich doch ängstlich davor gehïtet, des Gıten zu viel zu thun: alles Unwichtige, Alles, was der Sammler in einem Conversationslexikon oder Geschichtswerke zu finden vermag, wurde weggelassen: aus gleichem Grunde worde auch daranf verzichtet, die fostalisehen Erlasse pp. in Wortlante wiederzugeben, sondern nur diejenigen Stellen ans ihnen mitgeteilt, welche lïr den Sammler von thatsächlichem WVert und Interesse sind. Ein anderes Verfahren hätte nur den Umfang des Werkes, zugleich aber anch die Kosten desselben ohne Zweck auf das Dopnelte erhöht.

4. Fehldrucke und soustige Kuriosa wurlen, soweit sie bekannt sind, getreulich registrirt, dagegen konnte ich mich nicht entschliessen. den hie und da vorkommenden Doppeldrucken eine besondere Aufmerksamkeit zuzuwenden. Tch hatte in Mardrid mehrfach Gelegenheit, mich ron der gänzlichen Wertlosigkeit dieser auf natürlichstem Wege entstehenden Vaculaturwaare zu iberzeugen und selbst die seltensten fïr wenige Céntimos per Stiick zu kaufen. In gleicher Weise habe ich darauf verzichtet, ein Verzeichnis der als Postwertzeichen benutzten fiskalischen Wechsel- und Stempelmarken zu geben. Die Verwendung derselben zur Brieffrankatur ist in Spanien seit vielen Jahren auf das strengste rerboten und wem trotzdem eine grosse Zahl derselben eine postalische Austempelung tragen oder auf ganzem Brief beîndlich verkauft werden, so kamı man unter hundert Fällen neun und neunzigmal überzengt sein, es mit einem Gefälligkeitsstempel z.u thun zu haben.

5. Von den Fälschungen wurden, um dem Buche keinen allzugrossen Umfang zu geben, nur diejenigen näher beschrieben, welche thatsächlich dem Sammler gefährlich werden können. Hierher gehören meines Erachtens weder die ganz schlechten, noch auch die künstlerisch getren angefertigten Nachbildungen. Erstere wird ein Jeder selbst leicht erkemmen können, letztere erstrecken sich nur auf einige der seltensten Werte der ältesten Ausgaben, welche 
wohl zumeist mit den nötigen Vorsichtsmassregeln und unter Garantie gekanft werden. Einer Schröder'schen Lichtdruckfälschung gegenüber ist die grosse Masse der Sammler völlig wehrlos und anch eine noch so genane Beschreibung wird ihnen wenig nützen. Hier giebt es nur ein Mittel, sich vor Schaden zu bewahren: Nur aus völlig reellen Händen und unter Garantie kaufen, sowie Untersuchung durch Kenner ersten Ranges. Gefährlich, selbst für den grösseren Sammler, sind dagegen diejenigen Marken, welche, ohne Kunstwerke zu sein, doch gut genug ansgeführt waren, nm die Postbeamten zu täuschen und die sich daher in grosser Zahl postalisch verwendet vorfinden. Die Zahl derselben ist in Spanien ansserordentlich gross.

6. In Bezng anf Essais bin ich zumeist den Angaben von J. B. Moens, welche im übrigen zum grössten Teil schon in älteren Jahrgängen des Timbre-Poste veröffentlicht waren, gefolgt; ich war hierzu umsomelır gezwungen, als meine eigene Essaissammlung, wie anch diejenigen meiner Freunde zumeist aus dem Moens'schen Geschäft herstammen. Die Sammlung des Reichs-Postmuseums, eine sehr schöne Sammlung der Herren Wassermamn in Berlin, besonders aber die Sammlung des Postwertzeichen - Museums zu Unter-Döbling, welche mir Herr Friedl mit grosser Liebenswürdigkeit zur Verfïgung stellte, gaben mir die Mittel, die Moens'schen Angaben wesentlich zu vervollständigen.

7. Die Abstempelung der spanischen Postwertzeichen wird zum erstenmale einer Bearbeitung unterzogen, und hier wird jeder, der darauf ausgeht, scharfe Kritik zu üben, eine wohlfeile Gelegenheit dazu vorfinden. Bei dem Mangel an offiziellen Daten und bei der zahllosen Menge der in Spanien in Gebrauch befindlichen Stempelmodelle wäre es selbst für einen im Lande der Kastanien Lebenden schwierig gewesen, hier Erschöpfendes zn bringen. Jeder unbefangen Urteilende, jeder, der nicht ron der nemerdings grassirenden Stempelmanie befallen ist, wirl jedoch zugeben müssen, dass die Summe der über Abstempelungen gemachten Angaben völlig ansreiclend ist um sich einen richtigen Ueberblick über diesen Teil der 
Philatelie zu verschaften und sich die auf den Marken und Briefen befindlichen Stempel zu erklären.

Wenn ich somit glaube, alles gethan zu haben, um ein allen berechtigten Anforlermngen entsprechendes Werk zı liefern, so wirl der gestrenge Kritiker doch Gelegenheit haben, auf manche Lücke anfmerksam zu machen. Die Anzahı der Marken auf den Bogen der verschiedenen Ausgaben, deren Angabe ein Kritiker der ersten Ausgabe wïnschte, fehlt anch diesmal, die Zeitungsfrankirungsstempel, sowie diejenigen für Soldatenbriefe u. a. blieben völlig unbeachtet. Was die Markenzahl auf den Bogen anbelangt. so war dieselbe trot\% meiner Bemiihungen bei den älteren Ausgaben nicht zu erfahren, ich liess die betreffenden Angaben deshalb anch bei den neuen Emissionen fort: den zahllosen Frankirungsstempeln Spaniens wird von den deutschen Sammlern, wie ich glaube mit Recht, absolut kein Interesse entgegengebracht, sie sind anch zum grüssten Teil äusserst schwer zu erlangen und ihre Reproduktion würde die Kosten des Buches wiederum ohne praktischen Zweck bedentend erhöht habelı.

In Bezug auf die Ausstattung des Werkes hat der Verleger keine Ausgaben gescheut, den weitgehendsten Wünschen derSammles gerecht zu werden. Das gute, holzfreie Papier, der tadellose und vor allem eine gute Uebersicht gewährende Druck und die musterguiltigen Abbildungen in Liclitdruck diurften wohl allgemein Beifall finden. Ein jeder mit den Herstellungskosten eines solchen Werkes nur einigermassen Vertrante wird aus dem niedrigen Preis desselben entnehmen können, dass er es hier nicht mit einem Produkte buchhändlerischer Spekulation. sondern mit einem Buche zu thun hat, dessen Bestreben es ist, Gemeingut aller Philatelisten, anch der weniger bemittelten zu werden. Um das Werk vor einem allmählichen Veralten zu bewalıren, wird der Verleger in gewissen Zeiträumen Tekturen erscheinen lassen und dieselben den Käufern zum Selbstkostenpreise zugänglich machen.

Es bleibt mir nun zum Schlusse nur noch die Erfiillung der' angenehmen Pflicht übrig, allen denjenigen, welche mich bei der Abfassung des Werkes unterstiitzt haben, meinen herzlichsten Dank zu sagen. Die Zahl derselben ist zu gross, um sie hier sämtlich namentlich aufzuführen, jedoch kann ich nicht umhin, die Herren Landgerichtsdirektor Lindenberg, Amtsrichter Fränkel und 
Dr. Kalckhoff als diejenigen zu bezeichnen, welchen ich mich zı grösstem Dank verpflichtet fühle. Dieselben haben mir nicht nur allzeit mit ihrem stets das Richtige treffenden Rat zur Seite gestanden, sondern mir auch mit grösster Bereitwilligkeit die Schätze ihrer philatelistischen Bibliotheken und Sammlungen zur Verfügung gestellt. In gleicher Weise waren mir auch die Herren Theodor Haas in Leipzig und Richard $\mathrm{Hummel}$ in Coethen stets hilfsbereite Mitarbeiter. Den hervorragendsten Anteil an der jetzigen Gestaltung des Werkes hat jedoch Herr Pfarrer Eckardt in Prag. In fast dreijähriger Korrespondenz hat er mir in allen schwierigen Fragen mit dem reichen Schatze seiner Erfahrungen hilfreich zur Seite gestanden, mich auf alles Neue und weniger Bekannte aufmerksam gemacht, mir alle ihm zum Kauf angebotenen Seltenheiten zur Ansicht übersandt. Damit nicht genug, unterzog er sich mit nicht genug zu rühmender Aufopferung der schwierigen Arbeit, das umfangreiche Manuskript Seite für Seite aufs genaneste durchzuarbeiten. Zahlleiche kleine Verbesserungen, Zusätze und Bemerkungen, durch welche sich das Werk vor andern auszeichnet, stammen ans seiner Feder und wenn schliesslich die Abbildungen der Abstempelungen ein einigermassen abgerundetes Bild des Entwickelungsganges dieses Teiles des spanischen Postwesens geben, so war es wiedertum seine Sammlung, welche die meisten Originale dazu hergab. Möge er in der Brauchbarkeit des Buches den Lohn fïr seine Bemühungen finden!

Schliesslich noch eine Bitte an alle Sammler: Ein gutes philatelistisches Werk entsteht nicht auf einmal, ein Einzelner ist anch, namentlich wo es sich um Spanien und seine Kolonien handelt, nicht imstande, Mustergültiges zu leisten; nur aus der vereinten Arbeit Vieler, dem gemeinsamen Streben einer Menge Gleichgesinnter kann Vollkommenes entstehen. Möge das Buch deshalb viele Leser, sachgemäss urteilende Kritiker und zahlreiche Mitarbeiter finden!

Berlin, Pfingsten 1894.

Der Verfasser. 


\section{Benutzte Bücher und Zeitschriften.}

Don Antonio Pirala - Historia contemporánea. Anales desde 1843 liasta la conclusion de la actual guerra civil. 1875. 6 Bäıde.

Wilhelm Lauser - Feschichte Spaniens von dem Sturze Isabclla's bis zur Throubesteigung Alfonso's. 1877. 2 Bände.

Rudolf Friederieh - Militärisch-Politische Studien aus der neuesten Geschichte Spaniens. Glasenapp 1878/79.

Saturnino Gimenez - Secretos del Campo Carlista. 1876.

D. Antonio Fernandez Duro - Reseña histórico-descriptiva de los sellos de correos de España.

D. Francisco Lopez Fabrá - Los sellos para el franqueo de correspondencia. (Revista de Correos. 1867-68.)

D. Esteban Argiles - Apuntes para la historia y descripcion de los sellos de correos, telégrafos y tarjetas postales emitidos en España.

Dr. Thebussem - Legislacion philatélica en España desde 1849 á fin de 1875 .

Dr. Thebussem - Cartas para el correo (Unión filatélica 1893).

D. Joaquin Rodriguez San Pedro - Legislacion ultramarina. Aprobada y autorizada por el Ministerio de Ultramar. 1865.

J. B. Moens - Catalogue Prix-Courant de timbres-poste, 7 me edition.

J. B. Moens - Histoire des timbres-poste employés en Espagne. 1891.

Le Timbre-Poste. 1863-1894.

Bulletin de la Societé Française de Timbrologie. 1883-91.

Le Timbrophile. 1864-71.

Le Collectionneur de timbre-poste. 1865.

L'Union Postale. 1892.

Philatelic Society London - Catalogue of Postage stamps, stamped enveloppes and Post-Cards. (Spain and Colonies.)

E. L. Pemberton - The Stamp Collector's Haudbook. 1878.

E. B. Evans - The Philatelic Catalogue. 1888.

The Philatelist. 1866-76.

The Philatelic Record. 1879-92.

The American Philatelist. 1887-91.

The Philatelic Journal of Amerika. 1885-91.

The Stamps News. Monthly Illustr. Journal. 1890. 


\section{XIV}

Berger-Levrault \& Sohn - Beschreibung der bis jetzt bokannten Briefmarken. 1864.

Dr. Moschkau - Handbuch für Postmarkensammler. 1880.

F. Meyer - Handbuch für Postmarkensammler. 1881.

P. Lietzow - Handbuch der Philatelie. 1880-86.

C. Lindenberg - Grosses Handbuch der Philatelie (Cuba und Fernando Poo). Magazin für Briefmarkensammler. 1863-66.

Illustrirtes Briefmarken-Journal. 1874-93.

Der Philatelist. 1880-93.

Vereins-Mitteilungen des Bayerischen Philatelisten-Vereins. 1883-87.

Das Postwerthzeichen. 1888-90.

Illustrirte Briefmarken-Zeitung. 1888-93.

Philatelia. 1888-91.

Mitteilungen des Oesterreichischen Philatelisten-Clubs. 1886-91.

Beiträge zur Postwertzeichenkunde. 1890-92.

Vereins-Mitteilungen des Berliner Philatelisten-Clubs. 1888-93. 


\section{I $\mathrm{n} \mathrm{h}$ a $1 \mathrm{t}$.}

soite:

\section{Einleitung:}

Geographisches

Geschichtliches

Heraldisches

Verkehrswesen

Geldwährung

Gewicht

\section{Briefmarken :}

A. Marken aus der Zeit der Regierung der Königin Isabella II $1850-1868$.

I. Ausgabe 1850 . . . . . . . . . . . . . . .

II. Ausgabe 1851. . . . . . . . . . . . . . . . 12

III. Ausgabe 1852 . . . . . . . . . . . . . . . . 16

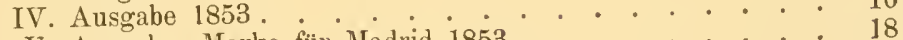

V. Ausgabe: Marke fur Madrid 1853 . . . . . . . $\quad 18$

VI. Ausgabe: Marke für Madrid 1853/54 . . . . . . . 22

VII. Ausgabe 1854 . . . . . . . . . . . . . • . . 24

VIII. Ausgabe $1854 / 55$. . . . . . . . . . . . . . . . . 52

IX. Ausgabe $1855 / 60$. . . . . . . . . . . . . .

X. Ausgabe $1860 / 62$. . . . . . . . . . . . . . $\cdot 34$

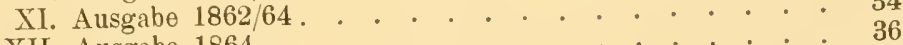

XII. Ausgabe 1864. . . . . . . . . . • . . • . • 38

XIII. Ausgabe 1865 . . . . . . . . . . . . . . . . 48

XIV. Ausgabe 1866 . . . . . . . . . . . . . . . • 43

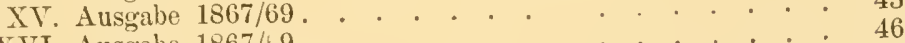

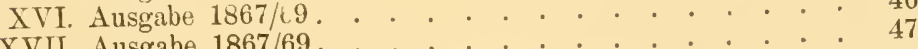

B. Marken der provisorischen Regierung 1868-1872.

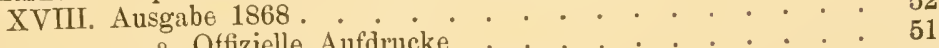

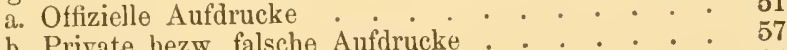

XIX. Ausgabe 1869 . . . . . . . . . . . . . . . . 64

XX. Ausgabe 1870/72 . . . . . . . . . . .

C. Marken aus der Zeit der Regierung des Königs Amadeo. 1870-1873. 73

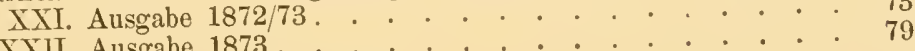

D. Marken der Republik 1873-1874. 81

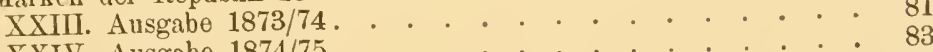

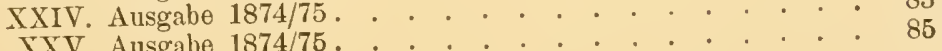


E. Marken aus der Zeit der Regierung Alfonso's XII. 1875-86.

XXV1. Ausgabe 1875/78. . . . . . . . . . . . . . . 87

XXVII. Ausgabe $1876 / 78$. . . . . . . . . . . . . $\quad . \quad . \quad . \quad 89$

XXVIII. Ausgabe 1877. . . . . . . . . . . . . . . . 92

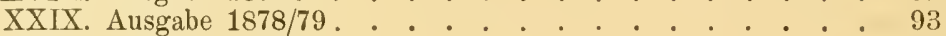

XXX. Ausgabe $1879 / 89$. . . . . . . . . . . . . . . 95

XXXI. Ausgabe $1882 / 89$. . . . . . . . . . . . . . . 97

F. Marken aus der Zeit der Regentschaft der Königin Maria Christina bezw. der Regierung des Königs Alfonso XIII. von 1889 bis hente

XXXII. Ausgabe 1889 . . . . . . . . . . . . . . . . 99

II. Dienstmarken, Marken für Privatpersonen, Kriegssteuermarken:

A. Dienstmarken.

I. Ausgabe 1854 . . . . . . . . . . . . . . . 106

II. Ausgabe $1855 / 66$. . . . . . . . . . . . . . . 107

B. Marken für Privatpersonen . . . . . . . . . . . 108

C. Kriegsstenermarken . . . . . . . . . . . . . . . . 111

I. Ausgabe 1874 . . . . . . . . . . . . . . . . . . 119

IJ. Ausgabe 1875 . . . . . . . . . . . . . . . . 120

III. Ausgabe 1876/79 . . . . . . . . . . . . . . . 120

IV. Ausgabe 1877/79 . . . . . . . . . . . . . . . 121

\section{Marken des Carlistisehen Aufstandsgebietes:}

Geschichtliches. Organisation des Carlistischen Postwesens . . 125

A. Marken für die baskischen Provinzen und Navarra:

I. Ausgabe 1874 . . . . . . . . . . . . . . . . 129

II. Ausgabe $1874 / 75$. . . . . . . . . . . . . . . . . . . . 132

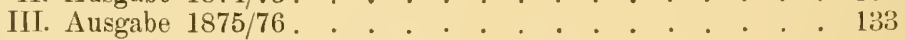

B. Marken für die Provinz Catalonien:

IV. Ausgabe 1874/76. . . . . . . . . . . . . . . 135

C. Marken für das Maestrazgo:
V. Ausgabe 1874/76. . . . . . . . . . . . 136

IV. BriefumschIäge, Postkarten, Kartenbriefe:

Bricfumschläge . . . . . . . . . . . . . . . . 141

Postkarten . . . . . . . . . . . . . . . . . . 143

A. Postkarten der Republik 1873/75:
I. Ausgabe $1873 / 75$. . . . . . . . . . . . . 144

B. Postkarten aus der Zeit der Regierung Alfonso's XII.:
II. Ausgabe 1875 . . . . . . . . . . . . 148

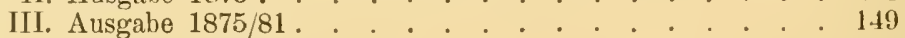

IV. Ausgabe 1882/84 . . . . . . . . . . . . . . . 151

V. Ausgabe 1884/89. . . . . . . . . . . . . . . . . . . . 152

C. Postkarten aus der Zeit der Regentschaft der Königin Maria Christina

bezw. der Regierung des Königs Alfonso Xlll., von 1889 an:

VI. Ausgabe 1889. . . . . . . . . . . . . . . . 155

VII. Ausgabe 1890. . . . . . . . . . . . . . . 157

VIII. Ausgabe $1891.0 . \div 158$

IX. Ausgabe 1892 . . . . . . . . . . . . . 158

Kartenbriefe 1893. . . . . . . . . . . . . . . . 160 


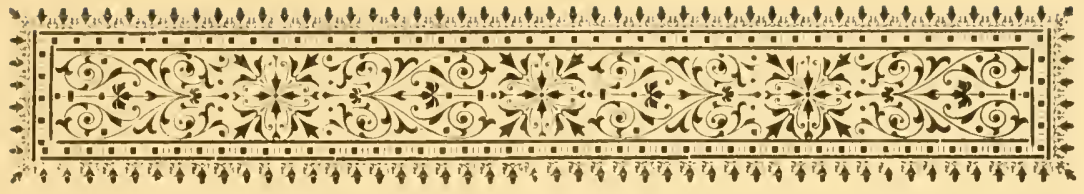

\section{Einleitung.}

Geographisches. Das Königreich Spanien, spanisch España, erstreckt sich, den bei weitem grössten Teil der Pirenäischen Halbinsel einnehmend, zwischen $36^{\circ} 1^{\prime}$ und $43^{\circ} 47^{\prime}$ nördlicher Breite und $9^{0} 22^{\prime}$ westlicher und $3^{0} 20^{\prime}$ östlicher Länge von Gr. und grenzt gegen Norden an Frankreich, an die Republik Andorr' und an den Meerbusen von Vizcaya, gegen Westen an den Atlantischen Ocean und Portugal, während es im Uebrigen vom Atlantischen und Mittelländischen Meer bespiilt wird. Es zerfällt nach dem offiziellen Sprachoebranch in das eigentliche Spanien (la península española), die benachbarten Besitzungen (los adyacentes): Balearen, Pithyusen, die Presidios in Afrika, die canarischen und die Chafarinen-Inseln an der Nordküste Afrikas und in die ïberseeischen Kolınien (el ultramar). Von den Letzteren abgesehen beträgt sein Flächeninhalt 504,552 qkm mit 17,565,632 Einwohnern. Es ist gegenwärtig in 49 Provinzen eingeteilt, seine Hanptstadt ist Madrid.

Geschichtliches. Die ältere Geschichte Spaniens hat für die Zwecke unseres Buches kein Interesse und es genïgt zum Verständnis der auf den spanischen Postwertzeichen vorkommenden Wappen daran zu erinnern, dass sich in den Kämpfen 
mit den Mauren eine Reihe kleiner, aber thatkräftiger Königreiche (Castilien. Leon, Aragon u. A.) gebildet hatte, welche sich allmählich im Laufe der' Jahrhunderte teils durch Heirat, teils durch Erbschaft, teils durch Eroberung um Castilien, als das mächtigste dieser Länder', krystallisirten. Das hente regierende Haus Bourbon kam im Jahre 1700 auf den Thron. Unter der Königin Isabella II. (1833-1868) wurde in Spanien die Frankiıung vermittelst Briefmarken eingefiilıt. Das Verdienst dieses Fortschritts gebührt dem General-Post-Direktor Don Fermin Caballero, der schon im .Jahre 1843 die elste Anregung hierzu gab, ınd dem Grafen San Luis, der im Jalıre 1849 die Ideen desselben zur Ausführung brachte.

Eine im September 1868 ausbrechende Revolution verjagte die Königin Isabella. Eine provisorische Regierung verwaltete das Land bis zum 4. Dezember 1870, an welchem Tage der zweite Sohn des Königs Victor Emannel unter dem Namen Amadeo I. den Thron bestieg. Aber schon am 11. Hebrual 1873 legte derselbe, müde der uniberwindlichen Schwierigkeiten, die ihn von allen Seiten entgegentraten, die Krone nieder; geräuschlos trat die Republik an seine Stelle. Anch sie wal nicht in Stande, diese Schwierigkeiten zu beseitigen; drei Aufstände, vor allem der Karlistenkrieg und der Aufstand auf Cuba lähmten die Kuaft der Regierıng und liessen das unglückliche Land nicht zur Ruhe gelangen. Die Verwirrung und Auflösung im Immern erleichterten den Uebergang zur Monarchie: Als General Martinez Campos am 29. Dezember 1874 zu Murviedro den Sohn der vertriebenen Königin Isabella als Alfonso XII. zum König von Spanien ausrief, fand dieses Pronunciamiento die allgemeine Billigung des Landes. Leider sollte die segensreiche Regierung dieses intelligenten Monarchen nicht lange daneru, er starb schon am 25. November 1885, sein Land unter der Regentschaft der Königin Marie Christine zurïcklassend. Am 17. Mai 1886 genas dieselbe eines Sohnes, Alfonsos XIII., auf dessen jugendlichem Haupte heute die Krone Spaniens lastet.

Heraldisches. Auf den spanischen Postwertzeichen findet sich nur das sog. "kleine Wappen" vor". Es ist dies ein in vier" Felder abgeteilter Sclild, mit einem Mittelschild, welcher durch das Wappen des Hauses Bourbon-Anjou, drei goldene Lilien im 
blanen Feld, gebildet wird. Von den vier Feldern zeigen je zwei kreuzweise gegenüberliegende das nämliche $\mathrm{IV}$ alpen und zwar das erste und vierte Feld rlasjenige von Castilien, Schloss mit drei 'Thïrmen, golden in rotem Feld, das zweite und dritte dasjenige von Leon, gekrönter roter Löwe in silbernem Feld. Zwischen den beiden untersten Feldern befiulet sich das IVappen von Granada, ein anfgesprungener Granatapfel in rotem Felk. Das ganze Wappenschild ist von der Kette des goldenen Vliesses umgeben und ron der Königlichen Krone bedeckt.

Nach der Thronbesteigung Amadeos I. ändert sich in diesem Wappen das Mittelschild, indem an Stelle der Lilien von Bourbon das einfache Krenz von Savoyen tritt.

Unter der Republik verschwinden natïrlich alle diejenigen Insignien, welche an das Königtum und das Haus Bourbon bezw. Savoyen erinnern: die Königskrone, an deren Stelle die sog. Manerkrone tritt, das Mittelschild und die Kette des goldenen Vliesses. Ausserdem tritt bei den unter der Herrschaft der Republik alssegebenen Postwertzeichen mit Wappen in die beiden unteren Felder anstatt der Wiederholung der Wappen von Leon und Castilien dasjenige von Aragon, vier rote Pfälıle in goldenem Felde, und von Navarra mit dem nationalen Morellaspiel. Manchmal sehen wir anch die sonst gewöhnlich nur bei dem grossen Wappen befindlichen Säulen des Herkules, mit dem seit der Entdeckung Amerikas von den Königen Castiliens angenommenen Wallspr'uch: Plus ultra.

Von sonstigen Wappen finden wir auf spanischen Briefmarken nur noch dasjenige der Stadt Madrid und zwar auf einem Essai vom Jahre 1869 in grosser, bei den bekannten Stadtpostmarken in kleiner Ausführung. Erstere zeigt drei Felder mit einem goldenen Drachen in blatem Feld oben links, einen Bären, Früchte von einem Erdbeerbaum herabholend oben rechts und unten zwischen beiden auf goldenem Feld einen Eichenkranz mit karmoisinrotem Band. Das kleine Wappen hat nur den Bären, umgeben von einem blanen Rahmen mit sieben goldenen Sternen, das gleichnamige Sternbild andeutend. 
Verkehrswesen. Spanien besitzt gegenwärtig ca. $10,000 \mathrm{~km}$ Eisenbahnen, 25,300 km Telegraphenlinien und etwa 2700 Postbureaux. Die Zahl der im inneren Verkehr versandten Postsendungen betrug im Jahre 1889:
a. Briefe
$99,751,000$ Stiilck,
b. Postkarten . 918,000
c. Drucksachen II. Waarenproben $34,727,000$
d. Wertbriefe
89,000

Im internationalen Verkehr wurden versandt:
a. Briefe
$12,479,000$ Stiick,
b. Postkarten . 220,000
c. Drucksachen u. Waarenproben
$15,974,000$
d. Wertbriefe 25,000

Hierzı kommen noch im Transit-Verkehr:
a. Briefe
121,000 Stïck,
b. Postkarten . 2,000
c. Drucksachen
51,000

An Depeschen wurden im dahre 1890 anfgegeben:
a. im inneren Dienst
$3,191,478$
b. im internationalen Verkehr
$1,098,388$
c. Dienst-Depeschen
147,402 .

Obwohl Post und Telegraphie in Spanien noch lange nicht auf der Höhe der Entwickelung stehen, welche dieselben in den übrigen Kulturstaaten Europas erreicht habelı, so ist es dennoch unbestreitbar, dass die Postverwaltung die am besten organisirte und am geschicktesten verwaltete Behörde der spanischen Regierung ist, dass sie sich von Jahr zu Jahr mehr vervollkommuet und jedenı Fortschritt zugänglich zeigt.

An der Spitze des Postwesens steht die General-Direction, der auch das Telegraphenwesen unterstellt ist. Oberste Aufsichtsbehörde ist das Ministerio de la Gobernacion, welches unserem Ministerium des Innern entspricht.

Die Post-Anstalten des Königreichs gliedern sich in das Haupt-Postamt zu Madrid, in Post-Aemter I., II. und IJI. Classe, in Estafetas, Carterías und Administraciones ambulantes. 
Das Haupt-Post-Amt zu Madrid (Administracion central) verinittelt den Verkelr der Hauptstadt mit den Provinzen. PostAemter I. Classe giebt es nur fünf, sie befinden sich in den Hauptcentren des Handels: Barcelona, Cadiz, Santander, Sevilla und Valencia.

Post-Aemter II. Classe giebt es neun und zwar in: Badajoz, Cordoba, Coruña, Granada, Malaga, Oviedo, San Sebastian, Valladolid und Zaragoza. Alle übrigen Provinzialhauptstädte besitzen Post-Aemter III. Classe, im Ganzen giebt es deren neununddreissig.

Jedem dieser Post-Aemter ist eine grössere oder geringere Zahl Post-Anstalten zweiter Ordnung, etwa unseren Post-Expeditionen entsprechend und Estafetas genannt, unterstellt, von denen wiederum eine wechselnde Zahl von sog. Carterías (Post-Agenturen) abhängen. Für den Verkehr mit dem Auslande dienen 22 Estafetas de cambio (Grenz-Post-Aemter), welche an den Grenzstationen oder in den Hafenplätzen installirt sind und welche direkt unter einem der Haupt-Post-Aemter stehen. Die Administraciones ambulantes entsprechen unseren Bahnposten.

Der Dienst wird versehen durch etwa 7500 Postbeamte, die Beförderung der Postsendungen geschieht durch Eisenbahnen und Wagen, Boten zu Pferd und zu Fuss, sowie durch 14 Postschiffe.

Geldwährung. Spanien hat vom Jahre 1850 bis heute nicht weniger als dreimal seine Münzeinteilung gewechselt, sodass es einigermassen schwierig ist, sich rasch in den betreffenden Angaben zurecht zu finden.

a. bis Dezember 1865:

1 Peso duro $=20$ Reales $=4$ Mark.

1 Real $=8 \frac{1}{2}$ cuartos $=100$ céntimos $=20$ Pfennig.

1 Cuarto $=4$ maravedis.

b. vom Januar 1866 bis Juni 1867 :

1 Escudo $=100$ céntimos $=10$ Reales $=2$ Mark.

1 Real $=81 / 2$ cuartos $=34$ maravedis $=20$ Pfennig.

c. vom Juli 1867 bis September 1872:

1 Escudo $=1000$ Milésimas $=10$ Reales $=2$ Mark.

d. vom Oktober 1872 an:

1 Peseta $=100$ céntimos $=4$ Reales $=80$ Pfennig. 
Gewicht. Bis 1867:

1 libra zn 16 onzas $=460,5$ Gramm,

1 onza zil 16 adarmes $=28,756$ Gramm,

1 adarme $=1,797$ Gramm.

Seit 1867 ist das auch in Deutschland eingefïhrte metrische System (Gramm, Kilogramm etc.) in Anwendung.

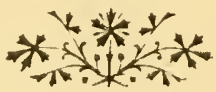




\section{I. \\ Briefmarken.}

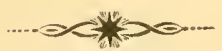





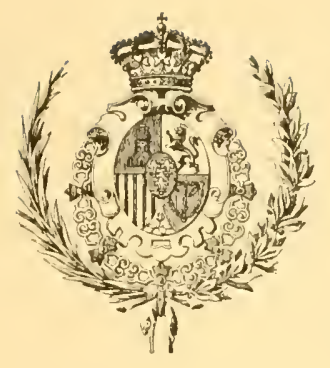

\section{A. Marken ans der Zeit der Regiermug der Kininin Isabellia II.}

\section{Ausgabe:}

vom 1. Januar bis 31. Dezember 1850.

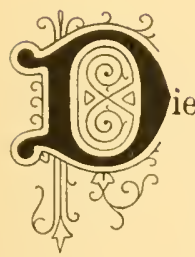

e Ausgabe besteht aus fïnf Werten von verschiedener Zeichnung. Allen gemeinsam ist Folgendes: Kopf der Königin Isabella II. mit Krone innerhalb eines viereckigen Rahmens: Grund schraffirt; in Rahmen oben: Wertangabe, unten: Jahreszail, links: CORREOs', rechts: FRANCO oder CERTIFICADO. Grösse der fünf Typen verschieden.

In Kupfer gestochen und dann lithographisch gedruckt auf verschieden starkem, weissem oder gelblichweissem Papier; ungezähnt.

I. Type: Kopf der Königin nach links; im Ralımen oben: 6 CUARTOS, rechts: FRANCO: Buchstaben und Ziffern weiss auf farbigem Grund: Grösse: 18:221/2 und $17^{1 / 2}: 22^{1 / 4} \mathrm{~mm}$.

1. 6 CUARTOS schwarz oder grauschwarz auf verschiedenem Papier. (Taf. I, 1.)

I a) 6 CUARTOS schwarz auf dickem, weissem Papier,

I b) 6 " grauschwarz auf dicken, weissem Papier,

1 e) 6 " "grauschwarz auf dicken, gelblichweissem Papier,

1 d) 6 schwarz anf dünnem, weissem Papier,

1 e) 6 grauschwarz aut dlinuem, weissem Papier.

$1 \mathrm{f}$ C " grauschwarz auf dünnem, gelblichem Papier. 
II. Type: Kopf der Königin nach rechts; Rahmen weiss mit farbiger Inschrift und Verzierungen; Grösse: $17 \frac{1}{2}$ und $17 \frac{1}{4}: 21 \mathrm{~mm}$. (Taf. I, 2.)

2. 12 CUART lila in vier Schattirungen auf verschiedenem Papier.

2a) 12 CUARTS lila auf dickem, weissem Papier,

2b) $12 "$ helllila auf dickem, weissem Papier,

2c) $12 "$ graulila auf dünnem, weissem Papier,

2d) $12 "$ lebhaft graulila auf dünnem, weissem Papier.

III. Type: Kopf der Königin nach rechts; Inschrift und Verzierungen im Rahmen weiss auf farbigem Grund; CERTIFICADO (= versichert, eingeschrieben) anstatt FRANCO : Grösse: $17^{3 / 4}: 21^{3 / 4}$ und $18: 22 \mathrm{~mm}$. (Taf. I, 3.)

3. 5 REALES bräunlichrot in zwei Abstufungen auf verschiedenem Papier.

3 a) 5 REALES bräunlichrot anf dickem, weissen Papier,

3 b) $5 \quad$ fleischfarben auf dickem, weissem Papier,

3 с) $5 "$ brïunlichrot auf dunnem, weissem Papier.

IV. Type: A ehnlich der vorigen, unterscheidet sich nur durch abweichende Verzierungen in Rahmen, sowie durch die Grösse, welche nur 171/2:21//4 orler $17 \frac{1}{\mathrm{~s}}: 21 \mathrm{~mm}$ beträgt. (Taf. I, 4.)

4. 6 REALES blau in zwei Abstufungen auf verschiedenem Papier.

4a) 6 REALES blau auf dickem Papier,

4b) $6 "$ helles, lehhaftes blau,

4c) $6 "$ helles blan anf etwas dilnnerem Papier.

V. Type: Aehnlich der dritten und vierten Type; Zeichnung des Kopfes etwas kleiner; Inschriften und Verzierungen im Rahmen farbig anf weissem Grund; REALES abgekürzt in REALs; Grösse: 17\% und $18: 22 \mathrm{~mm}$. (Taf. I, 5.)

5. 10 REAL: grün in drei Abstufungen auf verschiedenem Papier.

5a) 10 REALs grin auf dickem, weissem Papier,

5b) 10 . blassgrün aut dickem, weissem Papier,

5c) $10 \quad, \quad$ grin ant dnnem, Weissem Papier,

bd) $10 "$ hellgrim anf' dinnem, weissem l'apie't' 
Bemerkungen (vergl. auch Seite 20-22).

1. Die durch Verfügung von 24. Oktober 1849 festgesetzten Portosătze waren folgende:

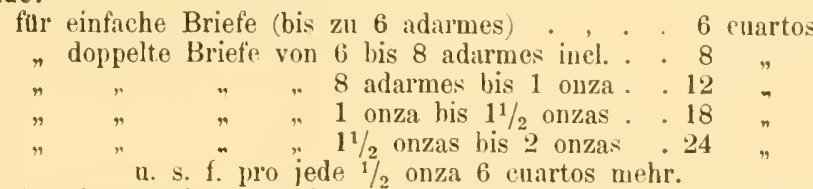

für eingeschriebene Briefe .. . . . . 5 Reales

$"$ doppelte eingeschr. Briefe bis zu 1 onza. . 10 "

$"$ " $"$ von 1 biszu $11 / 2$ onzas $15 "$

$" \quad " \quad$ von $1 \frac{1}{2}$ biszu 2 onzas $20 "$

u. s. f. pro jede weitere onza 5 Reales mehr.

Eingeschriebene Briefe nach den Kolonien kosteten

das Doppelte, solche ins Ausland . . . 6 Reales

Porto fur Drucksachen pp. wurde nach Gewicht berechnet.

Das vom Empfänger zu zablende Porto für unfrankirte Briefe war wesentlich

theurer, für eingeschriebene Briefe herrschte Frankirungszwang.

2. Die I. Ausgabe wurde derart hergestellt, dass zuerst das Bild der Marken in Kupfer gestochen wurde; von diesem Stempel wurden so viele Abzilge auf lithographischem Papier genommen, als Marken auf einen Bogen kommen sollten. Diese Abzüge wurden dann zusammengesetzt und auf den Stein ibertragen und sehliesslich die Abzuge auf dem Stein, da wo dies erforderlich war, nachgravirt. Auf diese Weise entstanden bei einzelnen Werten die kleinen Abweichungen, die dem Spezialsammler bekannt sind, dieselben sind in ubrigen zu minimal, um hier eingehender beschrieben zu werden.

Die Grössenunterschiede, welchen von einigen Sammlern vielfach eine allzugrosse Wichtigkeit beigelegt wird, kommen auf Rechnung des verwandten Papiers. Da der Druck auf angefeuchteten Papier ausgefihrt wird. dunnes Papier aber sich beim Trocknen stärkel zusammenzieht, als dickeres, so ist es erklärlich, dass sich kleine Differenzen in der Grösse der fertigen Marken herausstellen müssen, dies umsomehr, wenn schon bei der lithographischen Uebertragung - wie es hier der Fall gewesen $\mathrm{zu}$ sein scheint - verschiedenes Papier zur Verwendung kam.

3. Die Marke zu 10 Reals existirt in einigen sehr seltenen Sticken ohne den unteren Teil des Rahmens, also ohne Jahreszahl. Die Entstehung dieser Abart ist wahrscheinlich auf Unvorsichtigkeit beim Druck zurückzufuhren.

4. Um den Grad der Seltenheit dieser Marken beurtheilen zu können, mögen hier die von Duro auf Grund aktenmässigen Materials angegebenen Verkaufszahlen nachfolgen.

Es wurden verkauft:

\begin{tabular}{|c|c|c|c|c|c|c|c|c|}
\hline Iarken & $\grave{a}$ & Cuartos & & & & & $6,226,727$ & Sttlc \\
\hline " & à 12 & & & & & • & 51,926 & . \\
\hline . & & Reales & & & & & 47,863 & \\
\hline 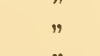 & $\begin{array}{lr}\dot{a} & 6 \\
\dot{a} & 10\end{array}$ & $"$ & & & - & . & $\begin{array}{r}13,016 \\
8,443\end{array}$ & \\
\hline
\end{tabular}

5. Fälschungen der I. Ausgabe wurden während der zwölfmonatlichen Verkehrsdauer nicht bekannt. sie sind das Produkt spïterer Zeiten.

6. Von Essais kennt man uur die Marke zu 12 cuartos in violett auf hellviolettem und die Marke zn 6 Reales in schwarz anf weissem Papier.

7. Die Abstempelungen der Narken der I. Ansgabe sind sehr mannigtaltig, namentlich in der ersten Hälfte des Jahres 1850. Man verwandte zur Entwertung 
der Marken neben den neu eingeführten Entwertungsstempeln auch die alten seit langer Zeit in Gebrauch befindlichen Orts- oder Orts- und Datumstempel.

Die meisten Postanstalten besassen den am 15. Dezember 1841 eingefürten Stempel No. 6 auf Taf. I. Er enthält oben den Namen der Postanstalt, unten denjenigen der Provinz, zwischen beiden eine Nummer, welche einen der 31 Postbezirke angiebt, in welche Spanien und seine Kolonien damals eingetheilt waren (Madrid hatte die No. 1, Manila 31), in der Mitte das Datum. Die Farbe ist meist rot.

Neben diesem Stempel existiren jedoch bei zahlreichen Postanstalten noch ältere Modelle, welche vielfach nur den Ortsnamen tragen. Einer der ältesten und interessantesten ist der Stempel der Administracion central in Madrid (Taf. I, 7), welcher über dem Datum nur ein gekröntes M trägt. Der Stempel stammt aus dem Jahre 1820 und scheint nach 1850 nicht mehl verwandt worden zu sein. Seine Farbe ist ebenfalls meist rot. Ortsstempel in anderer Form siehe Tafel I, 8 für Cazeres, Tafel III, 9 fïr Poza (Provinz Burgos).

Als Markenentwertungsstempel (matasello) wurde 1850 das bekannte Modell No. 11 Tafel I eingeführt. Es sollte derart auf die Marke aufgesetzt werden, dass das Mittelstück sich um den Kopf der Königin legte, die vier Pfeile nach den Ecken der Marke zeigten, eine Vorschrift, welche naturgemäss praktisch nicht ausfuhrbar war. Die Wahl der zur Entwertung der Marken verwendeten Farbe war den Postanstalten überlassen, wir finden daher den Stempel in den verschiedensten Farben, am häufigsten in schwarz, rot, braunrot, blau und blaugrün.

Zahlreiche kleinere Postanstalten besassen keinen Entwertungsstempel und benutzten entweder ihren Ortsstempel zur Entwertung oder vollzogen dieselbe durch Tintenstriche.

Der Ursprung der Abstempelungen No. 12 und 13 auf Tafel I ist mir unbekannt, erstere kommt auch mit schwarz ausgefiittertem Mittelstiuck vor, siehe Tafel $\mathrm{V}, 10$.

Der Aufdruck A in verschiedenen Typen auf Tafel I, 14 ist das Zeichen der Administraciones ambulantes (siehe Einleitung: Verkehrswesen), welches vielfach auch in Tinte aufgesclirieben wurde.

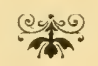

\section{Ausgabe:}

vom 1. Januar bis 31. Dezember 1851.

Kopf der Königin mit Perlendiadem nach rechts innerhalb eines ovalen Rahmens auf glattem Grund; Verzierungen in den Ecken; im Rahmen oben: FRANCO oder CERTIF (Certificado) mit darauffolgender Wertangabe: unten: CORREOS und Jahreszahl.

Farbiger Buchdruck anf weissem, verschierlen starkem Papier: ungezähnt. (Taf. II, 16.) 
6. SEIS (6) CUARTOS schwarz oder grauschwarz auf verschieden starkem Papier.

6 a) SEIS CUARTOS schwarz auf dinnem Papier,

6 b) SEIS " grauschwarz auf' dümem Lapier,

6 e) SEIS " schwarz anf dickem Papier.

7. DOCE (12) CUARTOS lila in drei Schattirungen.

7 a) DOCF CUARTOS lila,

7 b) DOCE " blasslila,

7 c) DOCE " $\quad$ graulila.

Die nachfolgenden Werte laben CFRTIE"! anstatt FRANCO:

8. DOS (2) REALES orangerot in zwei Schattirungen.

8 a) DOS RFALES orangerot,

$8 \mathrm{~h}$ ) DOS " blassorangerot.

9. CINCO (5) REALES rosa und karmin in vicr $\Lambda$ bstufungen.

9 a) CINCO REAL LiS blassrosa,

9 b) CINCO " karminrosa,

9 c) CINCO " lebhaft karmiu,

9 d) CINCO " dunkelkarmin.

10. SEIS (6) REALES blau in vier Abstufungen.

10 a) SEIS REALES blan

10 b) SEIS " blassblau (milcbblau),

10 c) SEIS " indigoblau,

10 d) SEIS " $\quad$ dunkelschieferblan.

11. DIEZ (10) REALES grün in vier Schattirungen.

11 a) DIEZ REALES griun,

11 b) DIEZ " blassgrün,

11 c) DIEZ " dunkelgrtiu,

11 d) DIE' " gelbgrỉn.

Bemerkungen (vergl. auch Seite 20-22).

1. Von der Marke zu 2 Reales hat ein angeblicher Fehldruck in blau s. Zt. riel von sich reden gemacht und zahlreiche Veröffentlichungen hervorgerufen. Derselbe, postalisch entwertet bis jetzt nur in einem Exemplar gefunden und gegenwärtig in der Ferrary'schen Sammlung sich befindend, wird jedoch von Moens und anderen Kenneru unter die Essais verwiesen.

2. Verkauft wurden von der II. Ausgabe:

\begin{tabular}{|c|c|c|c|c|c|c|c|}
\hline Marken & & cuartos & . & & & $8,745,483$ & $S$ \\
\hline , & à 12 & & . & & & 82,003 & $"$ \\
\hline 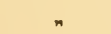 & & reales & & & & 1,432 & \\
\hline & & $"$ & & & & 42,323 & , \\
\hline & à 6 & $"$ & . & & & 10,860 & \\
\hline & à 10 & 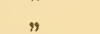 & & & & 15,898 & " \\
\hline
\end{tabular}


3. Von Essals sind bekannt:

6 cuartos in hlauer und schwarzer Farbe anf dicken weissem Papier,

12 cuartos blau auf dicken weissem Papier,

2 reales blau auf dünnem weissem Papier,

2 reales orange auf dickem weissem Papier,

2 reales schwarz anf dickem gelblichem Papier,

2 reales mit der Jahreszahl 185, schwarz auf dickon weissem Papier,

5 reales braunrot auf dïnnem weissem Papier,

5 reales schwarz auf dicken weissem Papier.

Die Platten wurden später durch kleuzförmige Einhiebe unbranchbar gremacht, Nendrucke sind daher unmöglich. Abdrïcke von den so verstiummelten Platten - im Jahre 1870 gemacht - existiren von den Marken zı 12 cuartos und 2 reales in schwarz auf dicken weissem und grïnlichem l'apier. (Taf. 11. 17.)

\section{A usgabo:}

rom 1. Januar bis 31. Dezember 1852.

Kopf der Königin mit Stirmreif nach links innerhalb eines Kreises auf glattem Grund: in den Ecken Verzierungen; oben im viereckigen Rahmen: FRANCO bezw. CERT'! nnd Wertangabe, unten: CORREOS und Jahreszahl.

Farbiger Buchdruck auf weissem, verschieden starkem Papier: ungezälınt. (Taf. II, 18 ı. 19.)

12. $6 \mathrm{C}:$ (cuartos) rosa in vier Schattirungen auf verschiedenem Papier.

12 a) 6 Cs rosa,

12 b) 6 CS blassrosa,

12 c) 6 CS karminrosa,

12 d) 6 CS bräunlichrosa,

12 e) 6 CS rosa auf dünnem Papier,

$12 \mathrm{f)} 6 \mathrm{CS}$ bräunlichrosa auf dunnem Papier,

$12 \mathrm{~g}) 6 \mathrm{CS}$ rosa auf dunnem, öligem Papier.

\section{12 C? lila in fünf Schattirungen.}

13 a) $12 \mathrm{C}: \mathrm{lil}$,

$13 \mathrm{b)} 12 \mathrm{C}$ : bräunlichviolett,

$13 \mathrm{c)} 12 \mathrm{CS}$ blassbrännlichviolett,

$13 \mathrm{~d}) 12 \mathrm{CS}$ rötlichviolett,

13 e) $12 \mathrm{CS}$ graulila. 
Mit CER'T" anstatt FRANCO:

14. 2 R: (Reales) orange in drci Abstufungen.

14 a) 2 lis orango,

$14 \mathrm{h)} 2$ R. blassorange.

14 c) 2 Rs orangerot (zinnober).

15. $5 \mathbf{R}:$ grün in drei Abstufungen.

15 a) $5 \mathrm{R}$. griul,

15 b) 5 R: hlassgrun,

15 e) 5 Rs dunkelgelbugrill.

16. $6 \mathrm{R}$. blaugrün in drei Schattirungen.

16 a) $6 \mathrm{R}$ : blaugrin,

16 b) $6 \mathrm{Rs}$. dunkelblaugrin,

16 c) 6 ks hlassblaugrtin.

Bemerkungen (vergl. auch Seite 20-22.)

1. Von der Marke zu fi ruartos uiebt es Stiicke mit deformirter 2 in 1852. von derjenigen zu1 5 Reales solche ohne Punkt in der Ziffer 5 der Wertangahe.

2. Fälschungen dieser Ausgabe wurden zur Zeit ihres Gebrauches nicht benerkt, jedoch wird in einer Reile postalischer Berichte jenes Jahres daritber geklagt, dass infolge schlechter Stempelschwär'ze Iarken vielfach nochmals gebrancht würden.

Von der Marke zu 12 Cuartos wird in den meisten Catalegen ein Frhldruck in grünblaı aufgeführt; Moens erklärt denselben als chemische Fälschung.

3. Verkauft wurden vou dieser Ausgabe:

\begin{tabular}{|c|c|c|c|c|c|c|c|c|}
\hline Marken & à 6 & Cuartos & & & & & $11,252,886$ & Stück \\
\hline$"$ & à 12 & & & . & . & . & 145.014 & " \\
\hline 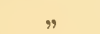 & a 2 & Reales & & & & & 3394 & \\
\hline & à 5 & $"$ & . & . & & & 79,484 & \\
\hline & 6 & , & & & & & 21665 & \\
\hline
\end{tabular}

4. Von Essais sind nur die Marken zu 6 Cuartos uud 5 Reales in schwarz bekannt. Die Platten wurden später durch kreuzförmige Einhiebe unbrauchbar gemacht, sodass Neudrucke nicht möglich sind. Im Jahre 1870 machte man von den so verstümmelten Platten einige Abziige in schwarz auf weissem und griinlichem Papier. (Taf. II, 20.)

5 Der Entwertungsstempel No. 11 auf Tafel I hatte sich nicht bewährt, einesteils brachen bei längerem Gebrauch häufig die Spitzen ab, andernteils bedeckte er die Marken nicht hinreichend, um einen nochmaligen Gebrauch derselben unmöglich zu machen, man fưhrte deshalb im Januar 1852 ein neues Modell, den Gitterstempel No. 21 Tafel II ein. Einige, wahrscheinlich neu geschaffene PostAnstalten erhielten ihn schon etwas fruher, wenigstens sieht man ihn, wenn auch sehr selten, auf Marken der II Ausgabe; andererseits beweist No. 23 anf Tafel II, dass auch der abgeschafite Stempel noch in einzelnen Fällen im Jahre 1852 vorkommt. Der Gitterstempel wurde von einigen Post-Anstalten bis in die neueste Zeit gebraucht (No. 22, Tafel II). 
Mit dem Jahre 1852 heginnt die lauge Reihe von Erlassen der GeneralPost-Direktion über die Entwertung der Marken, dadurch hervorgerufen, lass: sich die von vielen Post-Anstalten beuutzten Stempelfarben gegen Wasser oder chemische Mittel nicht als widerstandsfähig genug erwiesen, um ein Reinigen der Marken und damit eine nochmalige Benutzung derselben zu verhindern.

Während bisher, wie oben erwähnt, die Wahl der zur Entwertung benutzten Stempelfarbe den Post-Anstalten überlassen war, schreibt ein Erlass der G. P. D. vom 17. April 1852 die aussehliessliche Verwendung del schwarzen Farbe vor und zwar mit starkem Z/usatz von Oel. Der Erlass scheint nicht iiberall die genügende Beachtung Seitens der Beamten grefunden zu haben, wenigstens teilt ein Rundschreiben vom 4. August 1852 den Post-Anstalten mit, dass ihnen auf ihre Kosten eine vor'sehriftsmässige Stempclschwärze zugehen würde und droht mit der Anwendıng "anderer Nlittel" im Falle der Nichtverwendung derselben.

Der Handstempel $1 \mathrm{RS}$ in roter Farbe (Taf. 11, 24) bedeutet das von dem Empfänger zul erhebende Porto; au seine Stelle tritt später - das 1)atum lässt sich nicht genau bestimmen, jedenfalls aber seit 1860 oder 1861 der Stempel: "Franqueo insuficiente" $=$ ungenügende Frankirung. (Taf. V, 25.)

\section{Ausgabe:}

vom 1. Jannar bis 31. Dezember 1853.

Kopf der Königin mit Krone nach rechts innerhalb eines Perlenrahmens auf glattem Grund; oben anf viereckigem Schild: CORREOS mit Jahreszahl, unten auf ebensolchem: FRANCO) bezw. CERT. ${ }^{\circ}$ und Wertangabe. Die Ecken zwischen Oval und Schildern sind durch wagerechte Striche ausgefüllt.

Farbiger Buchdruck ruf verschiedenem Papier; ungezähnt. ('Taf.' Il, 26 und 27.)

\section{7. $6 \mathrm{C}$ (cuartos) rosa in vier $\Lambda$ bstufungen auf verschiedenem} Papier.

17 a) 6 C: rosia

17 b) 6 Cs karmin,

17 e) 6 CS karminrosa,

17 dı 6 CS karmin auf blänlichenı Papier,

17 e) 6 C dunkelkarmin auf bläulichem Papier.

18. $12 \mathrm{CS}$ rotviolett in zwei Abstufungen.

18 a) $12 \mathrm{CS}$ dunkelrotviolett,

$18 \mathrm{~b}) 12$ CS blassrotviolett. 


\section{Mit CERT ${ }^{\mathrm{DO}}$ anstatt FRANCO:}

\section{2 R (Reales) orangerot.}

\section{0. $5 \mathrm{R}$. grün in drei Schattirungen.}

20 a) $5 \mathrm{R}$. gelbgrtin,

20 b) 5 Rs blassgriin,

$20 \mathrm{c}) 5 \mathrm{RṢ}$ dunkelgrün.

\section{1. $6 \mathrm{R}$. blau in zwei Abstufungen.}

21 a) $6 \mathrm{Rs}$ blau.

21 b) $6 \mathrm{RS}$ dunkelblan.

Bemerkungen (vergl. auch Seite 20-22).

1. Verkauft wurden von dieser Ausgabe:

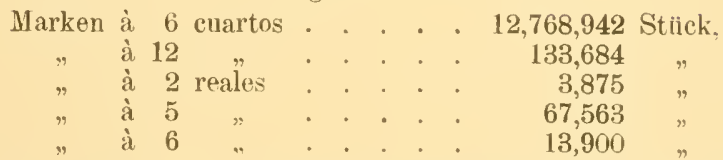

2. In Mai 1853 tauchten zu Granada falsche Marken dieser Ausgabe auf und erregten bei der Postverwaltung die grösste Bestürzung. Das bei Duro abgedruckte postalische Rundschreiben giebt jedoch weder die Werte an, welche gefälscht worden, noch die Kennzeichen der Fälschungen. Dank der sofort ergriffenen Vorsichtsmassregeln blieb die Zahl der in Verkehr gekommenen Falsifikate nur gering.

3. Von Essais sind nur die Marken zul 6 und 12 CS, erstere in schwarzer, letztere in grüner Farbe, bekannt.

Die Platten wurden durch kreuzförmige Einhiebe unbranchbar gemacht. In Jahre 1870 machte man von den so verstümmelten Platten einige Abzüge in schwarzem Druck auf weissem und grünlichem Papier. (Taf. II, 28.) 
V. Ausgabe:

vom 10. April bis 14. Oktober 1853.

Marke für Madrid. Wappen der Stadt Madrid: Bär auf einen Baum steigend in einem ovalen Rahmen, der sieben Sterne trägt (siehe Einleitung: Heraldisches): um denselben, innerhall) eines Achtecks mit dunklem Grund Lorbeerzweige, darüber die Königskrone; oben und unten je ein viereckiger Schild mit der Inschrift: CORREO INTERIOR bezw. FRANCO mit darauffolgender Wertangabe; zwischen den genannten Schildern und dem Achtecke wagerechte Striche.

Farbiger Buchdruck auf gelblichweissem Papier; ungezähnt, (Taf. II, 30.)

\section{3 CUARTOS bronzefarben.}

Bemerkungen (vergl. auch Seite 20-22).

1. Durch Königl. Erlass vom 3. November 1852 wurde auf Antrag des Chefs der Postverwaltung befohlen, dass in Anbetracht der grossen fusdehnung der Stadt Madrid in den entlegeneren Stadtteilen Briefkasten anzubringen und für den Stadtverkehr besondere Marken zu verweuden seien. Die Kosten dieser Eiurichtung hatten Stadt und Post gemeinsam zu tragen.

Das Porto für die Stadthriefe, für welche man Frankirungszwang einfuhrte, wurde wie folgt festgesetzt:

fur einfache Briefe . . . . . . . . 3 cuartos,

für doppelte Briefe bis zu 8 adarmes . . 6 "

für Briefe bis zu 1 onza . . . . . . 9 "

und von da an für jede weitere $1 / 2$ onza "3 cuartos mehr"; in dieses Porto waren Bestellgebiihren eingeschlossen.

Die Ausfuhrung dieses Erlasses verzögerte sich bis zum 10. April 1853.

2. Verkauft wurden von der Marke zu 3 cuartos 35,020 Stiick.

3. Im Juni 1870 wurden einige Neudrucke dieser seltenen, in Spanien mit dem Namen „El oso“ (der Bär) bezeichneten Marke hergestellt, die sich von den Originalen dadurch leicht unterscheiden lassen, dass sie auf glattweissem, dabei feinerem und glätterem Papier gedrnckt sind und keine Gummiruner hesitzen. 


\section{$-18-$ \\ VI. Ausgabe: \\ rom 15. Oktober 18553 his 31 . Oktoher 1854.}

Marke für Madrirl. Zeichnumg der vorigen Ausgabe, nur Aendermug der Wertangabe.

Farbiger Druck auf weissem Papier: ungezähnt. (Taf. II, 29.)

\section{1 CUARTO bronzefarben in zwei Abstufungen.}

23 a) 1 cuarto bronzefarben,

23 b) 1 euarto dunkelbronzetarben.

Bemerkungen (vergl. auch Seite 20-22).

1. Durch Königl. Erlass vom 8. Oktober 1853 wurde das Porto fiir einfache Briefe im Ortsverkehr der Starlt Madrid anf 1 cnarto herabgesetzt und dementsprechend die Nark zu 3 cuartos durch eine solche zu 1 cuarto ersetzt. Ausser diesem Porto, welches der Absender trug, musste vom Empfänger noch 1 cuarto Bestellgeld bezahlt werden. Bei Erhebung des letzteren machten sich jedoch sehr bald Unzutrüglichkeiten fühlbar. welche es wiinschenswert erscheinen liessen, beide Gebuihren auf einmal vom Absender zu erheben. So entstand eine IIarke zu 2 enartos, welche jedoch nicht mehr zu1 Ausgabe gelangte, da im Jahre 1854 für diesen Wert ein nener Typus eingefuhrt wurde. Im Laufe des Jahres 1853 waren nämlich in einer Reihe grösserer Städte Spaniens ehenfalls Stadtposten eingerichtet worden, für welche selbstverständlich die nämlichen Portosätze galten, wie für Madrid. Um nun für den Lokalverkehr dieser Städte nicht ebenfalls Spezialmarken verausgaben zu mïssen, wurde in der Ausgabe des Jahres 1854 ein neuer, bisher nicht vorhandener Wert zu 2 cuartos geschaffen, die Spezialmarke für Madrid, die nunmehr ihre Daseinsberechtigung verloren hatte, aber aufgebraucht.

2. Verkauft wurden von der Marke zu 1 cuarto im Ganzen 250,750 Strick.

3. Ancls von der Marke zu 1 cuarto, in Spanien „El madroño“ (Erdbeerbaum) genamnt, wurde ius Jahre 1870 ein Nendruck angefertigt. Kennzeichen desselben sind wiederum: Feineres, glätteres Papier ohne Gummirung.

4. Sowohl von der Marke zu 1 cuarto, als auch von derjenigen zu 2 cuartos gieht es eine Reihe von Essais.

Von ersterer sind bekannt:

1 cuarto in Golddruck auf weissem und granem Papier,

1 cuarto in Bronzedruck auf' weissem Papier,

1 cuarto in Golddruck auf weissem, satinirtem Papier.

$\checkmark$ on letzterer giebt es:

2 cuartos in blater, grïner, rotbrauner und grauschwarzer Farbe auf granem Papier,

2 cuartos in schwarzer, grauschwarzer und Gold-Farbe auf weissem, satinirtem Papier. 


\section{Allgemeine Bemerkungen $\mathrm{zu}$ den Ausgaben I-VI.}

1. $\mathrm{Zu}$ der auffallend grossen Zahl von Farben- und l'apierverschiedenbeiten ist Folgendes zu bemerken:

a) Keiner der abweichenden Farbentöne ist beabsichligt, sie verdanken ihr Dasein sämtlich dem Zufall, der Nachlässigkeit und Sorglosigkeit bei der Herstellung, auch dem niedrigen Stande der spanischen Technik jener Zeit. Manche abweichende Farbenschattirung mag anch durch im Laufe der Zeit eingetretene Farben-Zersetzung oder durch Behandlung von PortoDefraudanten, welche dureh chemische Mittel den Entwertungsstempel zu entfernen suchten, entstanden sein.

b) In gleicher Weise sind auch die verschiedenen Papiersorten nur eine Folge von Nachlässigkeit der Staatsdruckerei (Fábrica nacional de sellos) einerseits, andererseits der Postverwaltung, welche damals, wo man noch wenig an das Fälschen von Marken dachte, keinen Anstand nahm, Probebogen von der Druckerei abzunehmen und auszugeben. Sorgfältiger wurde man erst, als die ersten Fälschungen auftauchten.

2. Die Richtigkeit der angeführten Verkaufszahlen ist vielfach angezweifelt worden, speziell wollte man nicht zugeben, dass die Marke zu 2 Rs der li. Ausgabe nur in höchstens 1432 gebrauchten Exemplaren existiren könne. Eine Anfrage des Verfassers bei einem der hervorragendsten, der Postverwaltung nahestehenden spanischen Philatelisten erhielt folgende Antwort: "Die von Duro in seinem Werke: "Reseña historico-descriptiva de los Sellos de Correos“ angegabenen Zahlen über verkaufte Marken basiren auf den Akten der Postverwaltung und sind absolut richtig. Als im Anfange der $60 \mathrm{er}$ Jahre das Sammeln von Briefmarken allgemein wurde und auswärtige Händler dic alteı spanischen Marken aufkauften, als ferner D. Francisco Lopez in einem berühmt gewordenen Artikel in der Revista de Correos: "Los sellos para el franqueo de la correspondencia" den Wert dieser Marken nachwies, da wurde bei den verschiedenen Postbehörden, sowie in den Bureaux der National-Druckerei auf das eifrigste nach den etwaigen Resten der alten Bestände gesucht. Wie viel Marken der Ausgaben I-V noch gefunden wurden, lässt sich zahleumässig nicht mehr nachweisen. Was speziell die von Ihnen besonders hervorgehobene Marke des Jahres 1851 zu 2 Rs anbelangt, so dürfte sich dieselbe in spauischen Sammlungen kaum in einem Dutzend Exemplare vorfinden. Erwägen wir, dass sich die meisten und grössten Sammlungen in England, Amerika, Deutschland und Frankreich befinden, dass ferner die grossen Sammler meist in den grossen Stădten wohnen, so werden Sie einsehen, dass es sehr wohl möglich wäre, in Berlin allein 1-2 Dtz. Stäcke dieser seltenen Marke vorzufinden. dass es aber falsch sein würde, hieraus nach den Grundsätzen der Regel de tri Schlïsse auf das allgemeine Vorhandensein machen zu wollen. Keine der spanischen Marken ist ausserdem so häıfig und so vorzïglich gefälscht worden, als die 2 Rs-Marke von 1851 und Mancher, der sich im Besitze eines Schatzes glaubt, hat nur ein wertloses Stïckchen Papier in seiner Sammlung."

3. Unter den Marken der Ausgaben I-IV befinden sich eine grosse Zahl von Seltenheiten ersten Ranges, es gilt dies besonders von denjenigen mit der Inschrift "Certificado". Wie die Inschrift besagt, dienten diese Marken ausschliesslich für eingeschriebene Briefe, welche dem Frankirungszwang unterworfen waren und deren Porto nach dem auf Seite 11 mitgeteilten Tarif berechnet wurde. Aus der Höhe dieses Portos erklärt sich schon zur Genüge die seltene Verwendung dieser Marken und damit auch ihre grosse Seltenheit in heutiger Zeit. Das Verfahren der Post bei der Behandlung eingeschriebener Briefe musste diese Seltenheit noch steigern. Enthielt nämlich der einzu= schreibende Brief eine Geldsendung, so war der Absender gezwungen, den 
Inhalt des Briefes dem expedirenden Beamten zu zeigen und in Gegenwart desselben, also anf der Post, zu verschliessen. Alsdann erhielt er eine PostQuittung (Certificacion). An Bestimmungsort wurde der Brief wiederum auf der Post geöffnet, der Inhalt den Adressaten überliefert, der Umschlag aber als Belag zurïckbehalten. Whthielt der Einschreibebrief keine Geldsendung, so wurde der Umschlag vols dem expedirenden Beamten des Aufrabeorts mit zwei Siegeln verschlossen. Der Empfünger liatte dann den Brief in Gegenwart des Briefträgers zu öffinen, den Empfang auf dem Umschlag zu bescheinigen und letzteren dem Briefträger zuriickzugeben. Derselbe wurde alsdann an das Postbüreau des Aufgabeortes zuriickgesandt, wo ihn der Absender gegen Rückgabe der Post-Quittung erhalten konnte. Wurde er imnerhalb einer bestimmten "/eit nicht zuriick verlangt, so erfolgte die amtliche Vernichtung. - Daher die grosse Seltenheit dieser Narken. Das geschilderte Verfahren blieb bis zum 7. Mai 1889 in Gebranch.

4. Wie schon bei den cinzelnen Ausgaben bemerkt, wurden in den Jahren 1850, 1851 nnd 1852 Fälschungen spanischer Marken nicht bekannt, dieselben tauchten erst von Jahre 1853 an auf und zwar nicht zum Zwecke, die Sammler, sonderu die Postverwaltung zu tüschen. Die Fälschung der Marken der Ausgaben I-IV beginnt erst viel später, nachdem das Sammeln von Briefmarken eine Mode geworden war, die sich rasch iber die ganze Erde verbreitet hatte. Dass dabei die seltenen Werte zu 2, 6 und 10 Reales in erster Linie gefälscht wurden. ist selhstverständlich. Die älteren Fälschungen waren dem damaligen geringen Verkaufswert entsprechend, nur mangelhaft ausgefuhrt; sie lassen sich an der fehlerhaften Zcichuung des Kopfes, der verschwommenen Farbe und am Entwertungsstempel unschwer erkennen.

Die Zahl der Fälschnngen vergrösserte sich und ihre Ausführung wurde den Originalen immer ähulicher, als das Sammeln von Postwertzeichen allgemeiner und die Nachfrage nach den alten Ausgaben immer brennender wurde. Heute ist die Zahl falscher spanischer Marken so gross, dass es geradezu unnı̈glich ist, sio eingehend zu beschreiben und ihre Ausfuthrung ist zum Teil so vorzüglich, dass selbst Kenner die Unechtheit nur dann mit Sicherheit feststellen können, wenn sie ein zweifellos echtes Stack daneben halten. Den besten Berveis für die Wahrbeit des Gesagten liefert die Verurteilung des Markenhändler's Placido Ramon de Torres im Jahre 1889 in Bremen. Es wurden bei demselben 120,000 meist spanische Marken vorgefunden, darunter nach deu Ausspinch des als Sachverständigen zugezogenen Landrichters Lindenberg 4000 Fälsuhungen. Dio gefälschten Werte waren 6 und $10 \mathrm{Rs}$ von 1850,2 und $5 \mathrm{Rs}$ von 1851, 2 und $6 \mathrm{Ks}$ von 1853, 2 und $6 \mathrm{Rs}$ ron 1854 und 1 und 3 Cuartos der Stadtpost Madrid. Die Fälschungen waren nach dem Boricht des genannten Sachrerständigen sämtlich sehr gut und der Eindruck der Echtheit wurde noch urhöht durch eine vorzüglich nachgeahmte Abstempelung und durch Aufkleben auf altes Büttenpapier vol der Entwertung. Torres wurde zwar nach achtmonatlicher Untersuchungshaft wegen Betruges zu mehrmonatlicher Freiheitsstrafe verurteilt, sein Vorrat an falschen llarken im Gesamtwert von 58,000 Mark konnte ihm jedoch nach den bestehenden Gesetzen nicht abgenommen werden.

So gụt die Torres'schen Fälschungen aber anch ansgeführt waren und sind - denn dass sie ans der Welt verschwunden, wird wohl niemand glauben so sind sie doch geradezu harmlos im Vergleich mit den Kunstprodukten eines friheren Leipziger Lichtdruckers und späteren Markenhändler's Namens Schröder: Seine vermittelst Lichtdrucks hergestellten Fälschungen sind von so verblüfend tadelloser Ausführung, dass selbst der grösste Kenner nur nach längerer Untersuchung die Fälschung wird erkennen können. Der Nichtkenner wird um so eher die Echtheit nicht bezweifeln, als bei einigen Werten auch der Entwertungsstempel in vorzuglicher Weise nachgeahmt wurde. Gefälscht wurden ron Schröder die 2 Rs-Jarken von 1851, 1852 und 1853 und der 
Fehldruck der 2 Rs-Marke des Jabres 1851. Die ersteren lagen mir vor und wurden mit den Originalen auf das genaueste verglichen. Einen Unterschied in der Zeichnung konnte ich nicht finden, was ja auch bei Herstellung durch Lichtdruck selbstverständlich ist. Der Ton der Farbe stimmte nicht immer genau mit den in meinem Besitze befindlichen Originalen; da es jedoch von diesen mehrere Farbenschattirungen giebt, so ist hierauf wenig Gewicht zu legen. Auch das Papier, wenn auch nicbt ganz so fein und glatt, wie dasjenige der Originale, dürfte nur bei mikroskopischer Untersuchung auf eine Fälschnng hinführen. Dagegen ergaben sich bei genauer Messung nachfolgende Differenzen in den Grössen, welche zwar mit blossem Auge nicht erkennbar sind, die aber doch, da die Originale nur in einer Grösse vorkommen, ein Mittel an die Hand geben, sich vor Schaden zu bewahren:

echt falsch

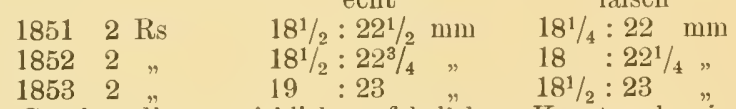

Wie viel Stücke dieser wirklich gefährlïchen Kunstwerke "in den Handel gekommen sind, lässt sich leider nicht feststellen.

Es ist daher jedem Sammler beim Ankauf von Marken dieser Ausgaben die grösste Vorsicht anzuraten.

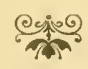

VII. Ausgabe:

vom 1. Januar bis 31 . Oktober 1854 .

Wappen Spaniens mit Königskrone, umgeben von der Kette des goldenen Vliesses auf farbigem Untergrund; in den Ecken Zweige; oben und nnten ein rechteckiger Schild mit farbiger Inschrift auf weissem Grund und zwar oben: CORREOS 1854, unten FRANCO hezw. CERT ${ }^{D 0}$ mit nachfolgender Wertangabe.

Farbiger Buchdruck auf weissem Papier; mgezähnt. (Taf. III, 31.)

\section{6 Cs (Cuartos) karmin in drei Abstufungen.}

24 a) 6 CS karmin,

24 b) 6 C: blasskarmin,

$24 \mathrm{c}) 6 \mathrm{C}$. dunkelkarmin.

Mit CERT' anstatt FRANCO:

25. $2 \mathrm{R}$. (Reales) zinnoberrot in drei Schattirungen.

25 a) 2 RS zinnoberrot,

25 b) 2 RS blasszinnoberrot,

25 c) $2 R_{\text {s }}$ bräunlichrot. 


\section{6. $5 \mathbf{R}$ grtin in zwei Schattirungen.}

26il) $5 \mathrm{R}$, grilin,

26h) 5 Rs gellogriln.

\section{2-. $6 \mathrm{R}$. blau in zwei Abstufungen.}

27 a) 6 RS blau,

26 b) 6 RS suukelblan.

\section{Bemerkungen.}

1. Die Marke zu 2 Rs blieb mit der nachfolgenden Ansgabe bis zum 31. März 1855 in Gebrauch.

2. Das Papier dieser Ausgabe hesitzt manclimal eine gelbliche Färbung, wohl mur eine Folge des Alters.

3. Von Essais giebt es die Marke zu 5 Rs in schwarzem Druck auf dickem,

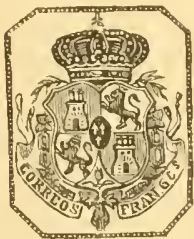
weissem Papier. Ausserdem folgende von der Regierung nicht angenommene Zeichnung: Spanisches Wappen mit Königskrone, umgebeu von der Kette des goldenen Vliesses; oben zu beiden Seiten Lorbeerzweige, unten anf jeder Seite ein flatterndes Band mit der Inschrift: CORREOS und FRANCO $6 \mathrm{Cs}$, schwarz auf dickem, weissem Papier.

4. Durch Verfügung vom 16. September 1853 wurde der alte, aus dem Jahre 1841 stammende Orts- nnd Datumstempel abgeschafft und ein neues Stempelmodell (Tafel III, 33) eingefïhrt. In allgremeinen Gebrauch kam dasselbe jedoch erst im Jahre 1854. Er ist kleiner', trägt wie der abgeschaffte oben den Ortsnamen, unten die Provinz, in der Mitte das Datum. Nummer des Post. bezirkes fällt fort. Der Name der Provinz ist vielfach durch eine Ziffer (Taf. II, 34) oder anch durch einen kleinen Steru er'setzt.

Bei den Entwertungsstempeln beginnt eine grosse Mannigfaltigkeit der Modelle einzureissen Dieselbe lisst sich nur dadurch erklären, dass man auf Einheitlichkeit der Form dieser Stempel keinen Wert legte und die Beschaffung derselben den Postbezirken, wenn nicht sogar den Postanstalten überliess. So befindet sich auf Mlarken der VII. und nachfolgenden Ausgaben der ovale Gitterstempel vielfach verändert (breitere Striche, wie in No 35 Taf. III) oder auch durch Stempel in viereckiger Form ersetzt. (Taf. III, 36 u. 37.) 


\section{Ausgabe:}

vom 1. November 1854 bis 31 . März 1855.

Wappen Spaniens mit Königskrone, umgeben von der Kette des Goldenen Vliesses auf weissem Untergrund, in den Ecken kleine ornamentartige Verzierungen; oben und unten auf rechteckigem weissem Schild Inschriften und zwar oben: CORREOS 1854 bezw. bei der Marke zu 2 C nur CORREOS zwischen zwei Steruchen, unten FRANCO und Wertangabe.

Farbiger Buchdruck auf verschiedenem Papier: ungezälınt. (Taf. III, 32.)

28. 2 C grün in drei Schattirungen auf verschiedenem Papier. 28 a) 2 Cs grün anf weissem Papier, 28 b) 2 CS gelbgrün auf weissem Papier, 28 c) 2 CS dunkelgrün auf weissem Papier, 28 d) 2 CS grin auf grünlichem Papier.

29. 4 C karmin in drei Schattirungen auf verschiedenem Papier.

29 a) 4 CS karmin auf weissem Papier,

29 b) 4 CS dunkelkarmin auf weissem Papier,

29 c) 4 CS karminrosa auf weissem Papier',

$29 \mathrm{~d}) 4$ CS karmin auf gelblichweissem Papier,

29 e) 4 CS karminrosa auf bläulichem Papier.

30. $1 \mathbf{R}$, blau in fünf Abstufungen auf verschiedenem Papier.

30 a) 1 R $\mathrm{R}_{+}$blauschwarz auf weissem Papier,

$30 \mathrm{~b}) 1 \mathrm{RL}$ dunkelblan auf weissem Papier,

30 c) 1 RL blau auf weissem Papier,

30 d) $1 R_{1}^{L_{1}}$ blassblau auf weissem Papier,

30 e) $1 R_{1}^{L}$ milchblan auf bläulichem Papier.

\section{Bemerkungen.}

1. Nachdem schon durch Erlass vom 21. Juni das Porto für eingeschriebene Briefe derart herabgesetzt worden, dass als Einschreibegebühr dem gewöhnlichen Briefporto ohne Rücksicht auf das Ciewicht nur eine Marke zu 2 Rs beizufügen war, erfolgte am 1. September 1854 folgende Aenderung der Portosätze:

für Ortsbriefe . . . . . . . . $2 \mathrm{Cs}$

für einfache Briefe innerhalb Spaniens . . . 4 "

für doppelte Briefe innerhalb Spaniens . . . 8 ", 
fur einfache Briefe nach Cuba und Portorico . I Rl fur einfache Briefe nach den Philippinen . . $2 \mathrm{Rs}$ für eingeschriebene Briefe innerhalb Spaniens . 2 " fur solche nach Cuba und Portorico . . . 4 " für solche nach den Philippinen . . . . . 8 "

Hierdurch waren die Marken zu 5 und 6 Rs überflüssig geworden.

Für eingeschriebene Briefe wurde die 2 Rs-Harke der vorhergehenden Ausgabe weiter verwandt.

2. Ein Neudruck dieser Narken ist unmöglich, da die Platte zur Herstellung eines neneu Harkentypus für die Philippinen benutzt und zn diesem Zwecke wesentlich verändert wurde.

3. Im Frühjahr 1855 wurde die Marke zu 2 Cs auf dickes bläuliches Papier mit Wasserzeichen (Schlingen, Papier der folgenden Ausgabe) gedruckt, jedoch nicht mehr ausgegeben, da die ganze Ansgabe am 1. April durch neue Marken ersetzt wurde.

4. Von Essais sind die Marken zu 2 und 4 cuartos, sowie diejenigen zu 1 real in schwarzem Druck auf weissem Papier bekannt. Von der 2 cuartos-Marke giebt es ein Essai mit CORREOS INT? im oberen Schild.

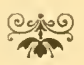

\section{Ausgabe:}

vom 1. April 1855 bis 31. Januar 1860.

Zeichnung der I. Ausgabe ron Spanisch-Westindien: Kopf der Königin mit Lorbeerkranz nach rechts innerhalb eines Perlenkreises; um den Kreis ein rechteckiger Rahmen, in demselben oben: CORREOS, nnten Wertangabe: an den Seiten und in den Ecken Verzierungen.

Farbiger Buchdruck auf in Farbe und Stärke verschiedenem Papier, mit und ohne Wasserzeichen: ungezähnt. (Taf. III, 38.)

A. Auf rauhem, melır oder weniger intensiv bläulichem

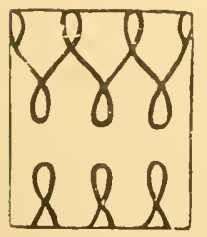

Papier; Wasserzeichen: Schlingen; angefertigt bis zum 31. Dezember 1855.

31. 2 CUARTOS grün in zwei Schattirungen.

31a) 2 CUARTOS grün.

31 b) $2 \quad " \quad$ gelbgrun. 
32. 4 CUARTOS rosa, karmin, rotbraun pp. in zahlreichen Abstufungen.

32a) 4 CUARTOS schmutzigrosa,

32 b) 4 " " bräunlichrot,

32 c) 4 " dunkelrotbraun.

32 d) $4 \quad$ rotviolett,

32 e) 4 " blassrotviolett,

32f) $4 \quad " \quad$ karmin,

32g) 4 " dunkelkarmin

32 h) 4 " lebhaft karmin.

33. 1 REAL blau in vier Schattirungen.

33a) 1 REAL blau,

33 b) 1 " blassblau,

33c) 1, dunkelblan,

33 d) 1 " grïinblau.

34. 2 REALES violett in zahlreichen Schattirungen.

34a) 2 REALES braunviolett.

34b) 2 dunkelbraunviolett,

34c) 2 , hellviolettbrann,

31d) 2 grauviolett,

34A) 2 " hraunviolett auf lickerem Papier.

B. A uf raulıem, grauw issem Papier: Wasserzeichen: gekreuzte Linien; vom 1. Januar bis 11. April 1856 angefertigt.

35. 2 CUARTOS grün in drei Schattirungen.

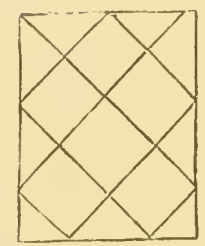

35a) 2 (UUART'OS grün,

35b) 2 . dunkelgriin,

35c) 2 " gelbgriin.

36. 4 CUARTOS rosa in zahlreichen Schattirungen.

36a) 4 CUARTOS karminrosa,

36 b) 4 blassrosa,

36 e) 4 " schmutzigrosa,

36 d) 4 " gelblichrosa.

$36 \mathrm{e})+$ gelblichrosa mit gänzlich verschwommenem Druek.

37. 1 REAL blau in drei Schattirungen.

37a) 1 REAL blau,

37 b) 1 " dunkelblau,

38c) $1 "$ grünlichblau.

38. 2 REALES violett und violettbraun in zahlreichen Schattirungen.

38a) 2 REALES violett,

38 b) 2 " grauviolett,

38 c) 2 " dunkelgrauviolett,

38d) 2 " braunviolett,

38 e) 2 " braun,

38f) $2 \quad "$ blassbraun. 
C. Anf glattem, weissem orler wenig bläulichem, verschieden starkem Papier, whe IVasserzeichen: vom 11. April 1856 bis 31. . Inuar 1860 in Gebrauch.

39. 2 CUARTOS grün in zahlreichen Schattirungen auf verschiedenem Papier.

39 a) உ CUARTOS' grün,

39 b) 2 " " blassgrüu,

39 c) 2 gelbgrin,

39 d) 2 hellgelbgrïn,

39 e) 2 olivengrïn,

39 f) 2 " griln auf leicht bläulichem Papier,

$39 \mathrm{~g}) 2$ gelhgrün auf weissem, dickenı Papier.

40. 4 CUARTOS rosa in zahlreichen Schattirungen auf verschiedenem Papier.

\begin{tabular}{|c|c|c|}
\hline 40 a) & 4 CUARTOS & rosa, \\
\hline $40 \mathrm{~b})$ & 4 & blassrosa, \\
\hline $40 \mathrm{c})$ & 4 & karminrosa, \\
\hline 40 d) & 4 & karmin, \\
\hline $40 \mathrm{e})$ & 4 & rosa auf leicht bläulichem Papier, \\
\hline $40 \mathrm{f})$ & 4 & rosa auf weisstm dickem Papier, \\
\hline $40 \mathrm{~g})$ & 4 & rosa auf dickem gelblichem Papier, \\
\hline 40 h) 4 & 4 & bräunlichrosa auf dickem Papier. \\
\hline 40 i) 4 & 4 & karmin auf dickem Papier, \\
\hline $40 \mathrm{k}) 4$ & 4 & bräunlichrot. \\
\hline
\end{tabular}

41. 1 REAL blau in zahlreichen Abstufungen auf verschiedenem Papier.

41 a) 1 REAL bal,

41 b) 1 . hellblau,

$41 \mathrm{c)} 1$, dunkelblan,

41 i) 1 . sehr lebhaft blau,

41 (i) 1 " mattes, glanzloses blaı,

41 f) 1 " grünlichblan,

$41 \mathrm{~g}) 1$ " lebhaft blan anf dicliem Papies.

42. 2 REALES lila in vier Schattirungen auf verschiedenem Papier.

42 a) 2 REALES lila,

42 b) 2 rötlichlila,

42 c) 2 " dunkelrotlila,

42 d) 2 " bräunlichlila,

42 e) 2 " bräunlichlila auf dickem Papier. 


\section{Bemerkungen:}

1. Durch Verfügung vom 15. Februar 1856 wurde für alle Briefe rom 1. Juli ab der Frankirungszwang angeordnet.

2. Die Marken der IX. Ausgabe werden vielfach auf Grund der Verschiedenheit des Papiers und der Farbe in drei Enissionen eingeteilt und getrennt behandelt. Es erscheint dies jedoch nicht zu'reffend, da wie die amtlichen Erlasse vom 28. Dezember 1855 und 11. April 1856 beweisen, der Uebergang zu einer anderen Papiersorte allein aus zufälligen technischen Gründen erfolgte und die Verwendung der Marken mit und ohne Wasierzeichen neben einander ausdriicklich gestattet war. Marken auf Papier des Jahres 1855 mit Entwertungsstempel vom Jahre 1860 sind hiernach nichts Auffallendes.

3. Keine Ausgabe ist leichtfertiger hergestellt, als die 1X.; es geht dies aus den zahlreichen fehlerhaften Dícken, besonder's aber aus den zahllosen Verschiedenheiten in Farbe und Papier dentlich hervor. Die oben angegebenen Farhen. unterschiede liessen sich mit Leichtigkeit auf die doppelte Zahl brıngen, wemn unsere Sprache die Möglichkeit darböte, sie zu benennen. Der Spezialsammler wird die vier Werte dieser Ausgabe olme viele IIühe in etwa 120 merklich von einander verschiedenen Farben- und Papier-Nïancen erlangen können.

Von fehlerhaften Drucken wurden bekannt:

zur Ausgabe A :

4 CUARTOS mit der Inschrift CORRFOS,

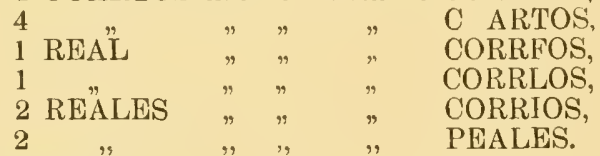

zur Ausgabe B:

1 REAL mit der Inschrift CORRLOS,

$1 ", ", \quad$ CORRFOS.

zur Ausgabe C:

\begin{tabular}{|c|c|c|c|c|}
\hline UAT & $m$ & ther & & \\
\hline ", & ", & ", & " & CORRFOS, \\
\hline & $"$ & ," & ", & CORRLOS, \\
\hline r & " & , & $"$ & CORRECS, \\
\hline neit & $"$ & $"$ & $"$ & CORRL \\
\hline
\end{tabular}

In allen Ausgaben:

4 CUARTOS ohne folgenden Punkt.

4. Von der Marke zu 2 REALES Ausgabe A existirt ein Fehldruek in blau, entstauden dadurch, dass ein Cliché derselben aus Versehen in die Platte der 1 Real-Marke eingefügt wurde. Der Fehler wurde schon beim ersten Abzug bemerkt und beseitigt, der Fehldruck ist daher eime der grössten Seltenheiten, die vielfach gefälscht wurde, da sich die violette Farbe auf chemischem Wege mit Leichtigkeit in grübblau verwandeln lässt. Es ist daher dringend zu raten, für diese seltene und interessante Marke nur dann eine grössere Sunme anzulegen, wenn man sie mit einem oder mehreren Stïcken der Marke 1 Real grünblau zusammenhängend erhalten kanı. Nur dann ist man vor jenem höchst gefährlichen chemischen Kunststück sicher.

5. Fast alle Marken Spaniens, besonders aber die ungezähnten und unter diesen wieder am häufigsten diejenigen der IX. Ausgabe fiudet man zuweilen in zusammenhăngenden Bogenstucken (Blocks). Es ist hieruber vielfach die Meinung 
verbreitet, als entstammten solche Bogenstucke, die manchmal 50-60 einzelne Marken enthalten, a!ten Vorräten, die vor dem Verkauf an die Händler postalisch entwertet worden seien. Dies ist jedoch irrig, denn die an die Händler verkauften Restbestände wurden durch Ueberdruck dreier parallelen Striche entwertet. Wohl abor verbranchten die Königl. Behörden, besonders die Justizbehörden, Marken oft in grossen Mengen, da ihre Alten nicht portofrei befördert wurden, die später eingeführten Dienstmarken aber nur unter ganz besonderen, gesetzlich vorgeschriebenen Verhältnissen (siehe: 11 . Dienstmarken pp.) verwendet werden durften.

6. Marken der Ausgabe A auf grauweissem Papier, die vielfach erwähnt werden, giebt es nieht. Sie sind entstanden durch Verblassen der blanen Papierfarbe: hält man sie gegen das Licht, se ist der blänliche Ton des Papiers meist deutlich zu erkennen.

7. Im Jahre 1858 wurden die ersten Versuche zur Zähnung der Marken gemacht und zwar mit der Marke zu 4 cuartos (sägeartig durchschlagen).

8. Ein im August 1859 zwischen Spanien und Frankreich abgeschlossener Postvertrag setzte das Porto für einfache Briefe auf 12 cuartos fest Dies führte zur Anfertigung einer Marke dieses Wertes in orangegelber Farbe, welche aber nicht mehr zur Ansgabe gelangte, da schon am 1. Februar 1860 eine Aenderung der Markenzeichnung eintrat (Taf. III, 39). Vou der genaunten 12 cuartos-Mlarke giebt es eine Abart ohne Punkt hinter Cuartos. Probeabzüge dieser Marke giebt es in grïner und schwarzer Farbe, auch auf satinirtem Papier.

9. Die leichtfertige Ausfihnung der IX. Ansgabe, sowie der mehrjährige Gebrauch derselben ermunterte zu Fälschungen. Keine Emission ist zablreicher und besser getälscht worden; die Post selbst war häufig nicht im Stande, die Nachahmung zu erkennen. Es kann daher keine Rede davon sein, hier alle existirenden Fälschungen zu beschreiben, doch sollen diejenizen erwähnt werden, vor deren Annahme und Verwendung seiner Zeit antlich gewarnt wurde, da sie sich postalisch entwertet vielfach in Sammlungen vorfinden.

Ein Rundschreiben des Chefs der Postverwaltung rom 4. April 1856 giebt whe Bezeichnung eines Wertes folgende Erkennungszeichen:

a) Die falschen IIarken sind auf glattem Papier gedruckt, während die echten bis jetzt rauhes, mit Wasserzeichen versehenes Papier haben.

b) die Büste der Königin zeigt kleine Abweichungen in der Schattirung, insbesondere der obere Teil des Kopfes;

c) am unteren Teil des Halses befindet sich bei den echten Harken ein Schattenstrich, der bei den falschen fehlt;

d) die Punkte hinter Correos sind bei der Fälschung dicker;

c) die Farben sind weniger fein und verändern sich unter dem Einfluss des Lichts und der Wärme.

Eine Verfiugung vom 6. September 1856 macht auf neue in Ecija und Malaga gefundene Fälschungen anfmerksam. Nach Moens sind die Kennzeichen derselben:

a) Correos in kleinen, schlecht ausgefuhrten Buchstaben;

b) das Gesicht der Königin ist zu klein, Nase und Mund ist abweichend;

c) der Perlenkreis steht auf der rechten Seite kaum $1 / 2 \mathrm{~mm}$ statt $1 \mathrm{~mm}$ von dem rechteckigen Rahmen ab.

Im August 1857 tauchen neue Fälschungen der 4 cuartos-Marke aut.

Eine Verfugung vom 13. August 1857 giebt folgende Kennzeichen:

a) gröberes und rauheres Papier,

b) Farben ungleichmässig,

c) kleine Unterschiede im Profil der Büste,

d) hinter den Ziffern der Wertangabe fehlt der Punkt. 
10. Fssais zur IX. Ausgabe giebt es in grosser Zabl. Abdrucke der angenommenen Zeichnung gieht es in allen Farben und auf verschiedenem Papier (ohne Wasserzeichen).

Es sind bekannt:

2 cuartos: grün und schwarz auf blauem Papier,

schwarz, violettbraun, chocoladenbraun und grüu auf weissem Papier, schwarz und braun auf grünlichem Papier,

4 euartos: rosa auf grauweissem Papier,

rosa in verschiedenen Abstufungen, weinrot, hell- und dunkelrotgelb, gelblichbraun in verschiedenen Tönen, gelb, gelbgl'ün, schwar'z, blan und blassblatu anf' weissem Papier, rosa, gelblichbraun und rotgeib aul blass-r'osa Papier,

lebhaft rosa auf blasskarmin Papier,

rosa, braun, getb und gelblichbramn auf grünlichem Papier, orange auf blauem Papier;

rosa anf gelbem Papier,

gelbgrün auf gelbrötlichem Papier,

1 real: blau anf blanem Papier,

schwar, blan und rosa anf weissem Papier,

2 reales: schwarz, blan und rosa auf weissem Papier,

brann auf blanem Papier.

Ohne Wertangabe: blan,

- Real: blau.

Ausserdm verschiedene Dopjeldncke und auf beiden Seiten bedruckte stutice.

Ton Essais in abweichender Zeichunng sind folgende bekannt:
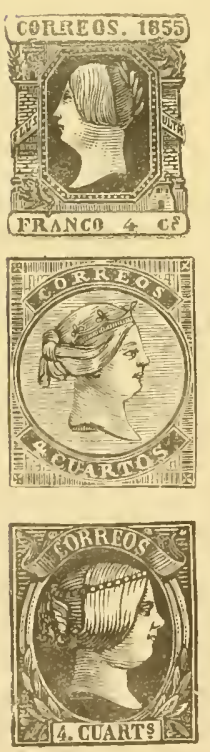

Kopf der Königin mit Lorbeerkranz nach links in einem achteckigen Rahmen; rechts und tinks eine Sänle mit der Inschrift: Plus ultra; oben und unter an der Säule Löwen und Thürme (Leon nnd Castilien); über den Sïulen anf rechteckigem Schild: CORREOS 1855, unten auf ebensolchem: FRANCO 4 Cs. Existirt in lebhaft roter Farbe anf weissem Kartonpapier.

Kopt der Konnigin mit Krone nach rechts in einem Kreise, dessen Untergrund mit wagerechten Strichen ausgefüllt ist; darüber auf einem Band: CORREOS, darmter: 4 CUARTOS. Existirt in blauer und rosa Farhe auf weissem Papier. (Mnster (ler englischen 4 pence-1larke von 1854.)

Kopf der Königin mit Perlenkrone nach rechts in ovalem Ralımen mit einfarbigem Untergrund; dariber anf flatterndem Banl: CORREOS, darmer anf viereckigem Schild: Wertancrahe: zu beiden Seiten Lorbeerzweige lis existirt in velschiedenen Farben auf verschiedenem Papier und zwar:

2 Cuarts blau auf rosa,

4 Cnart blau anf grin,

4 Cuart indigoblau auf chinesischem Papier,

2 Reales schwarzblau auf weissem Papier.

11. Dureh Verfügung vom 19. April 1857 wurde der Datumstempel No. 33 Taf. III abgeschafft und durch ein neues Modell ersetzt, welcher sich von dem 
bisherigen nur durch Grösse, kleinere Inschrift und schiefe Stellung der Monatsangabe unterscheidet. Der Stempol trägt wiederum oben den Ortsnamen, unten die Provinz, letztere entweder wie bei No. 40 Taf. III in Buchstaben, oder wie bei No. 41 Taf. III in Ziffern. Der alte Stempel bleibt, wie No. 33 Taf. V beweist, hei einigen Postanstalten noch längere Zeit in Gebrauch

Madrid erhält in dieser Zeit - das Einführungsdatum lässt sich nicht ermitteln - einen neuen Datumsstempel: Taf. IV, 42; dio im Jahre 1853 zuerst in Madrid ins Leben grerufene und dam in den nächstfolgendon Jahren auf alle grösseren Städte ansgedehnten Orts-P'ostanstalten einen Spezialstempel, welcher oben dio Bezeichnmes .. Interior" und darmiter die Zeit der Einlieferung: mañana (Vormittag) oder tarde (Nachmittag) angiebt, siehe 'Taf. IV, 43 ı. 44. Schliesslich findet man von . Jahre 1850 an fïr die. Fistaciones ambulantes den Stempel No. 45 Taf. IV, mit der Bezeichnung Ascendente orler Descendente, (Hinfahrt oder Riickfahrt).

Auch der bisherige Entwertungsstempel wird ersetzt, an Stelle des Gitterstempels tritt laut Verfigung vom 7.0ktober 1858 bei den Administraciones prineipales und den Post-Aemtern I. K̉asse ein kreisförmiger Stempel, weleher in der Mitte und am Rande fiünfimal die Nummer der Postanstalt trägt (siehe Taf. III 46), wahrend von den Post-Aemtern II. Kl. an abwärts die Entwertung der Marken mit dem Datumstempel, bei den Estafetas und Carterias (vergl. Einleitumg: Verkehrswesen), welche keinen Entwertungsstempel besassen, die Entwertung clurch Tintenstriche (Krenzform rorgeschirieben) erfolgen sollte (siele Taf. III und IV, 47).

Ein Rundschreiben der G. P. D. vom 2. Januar 1857 teilt den Post-Aemtern nit, dass sich die Portodefrandanten eines feinen, kaum sichtbaren Lackes zum Ueberzug der Marken hedienten, 1 m ein Eindringen der Stempelschwärze unmöglich zil machen und ein Alwaschen des Enfwertungsstempels zu ermöglichen.

\section{Ausgabe:}

vom 1. Februar 1860 bis zum 16. Juli heww. 1. Lugust 1862.

Kopf rler Künigin mit Krone nach links in einem an den vier Seiten durch Ornamente unterbrochenen Kreise: die den Kreis nmgebeuden Felder sind durch wagerechte Striche ansgefïllt; unten links ein Hermesstah. rechts ein Anker; über dem Kreis anf flatterndem Band: CORREOS, mten auf riereckigem Schild Wertangabe.

Farbiger Buchdruck auf leicht gefärbtem Papier; ungezälnnt. (Taf. III, 48.) 
43. 2 CUARTOS grün in vier Abstufungen auf grünlichem Papier.

43a) 2 CUARTOS lebhaft grün,

43b) $2 \quad$ " hellgrïin,

43c) 2 " gelbgrün,

43d) 2 " dunkelgelbgrïn.

44. 4 CUARTOS orange in fünf Schattirungen auf grünlichem oder bläulichem Papier.

44a) 4 CUARTOS orangerot auf grülichem Papier,

44 b) $4 \quad$ dunkelorange auf grïnlichem Papier,

44c) $4 \quad$ blassorange auf grünlichem Papier,

44 d) $4 \quad$ orangegelb auf grünlichem Papier,

44 e) $4 \quad "$ blassorangegelb auf grünlichem Papier,

44f) " " orange auf bläulichem Papier.

45. 1 REAL blau in drei Abstufungen auf gelblichgrünem Papier.

45a) 1 REAL, blau,

$45 \mathrm{~b}) 1$, hellblau,

45c) $1 "$ dunkelblau.

46. 12 CUARTOS karmin in drei Abstufungen auf verschiedenem Papier.

46a) 12 CUARTOS lebhaft karminrot anf gelblichem Papier,

46 b) $12 \quad " \quad$ helikarmin auf gelblichem Papier,

46c) $12 \quad " \quad$ karmin auf glattem chamois Papier.

17. 2 REALES lila in fünf Schattirungen auf blasslila oder bläulichem Papier.

47 a) 2 REALES hellijla,

47 b) 2 , dunkellila,

47c) $2 \quad "$ rötlichlila,

47 d) 2 " malvenfarbig,

47 e) 2 " dunkelviolett auf' dickerem bläulichem Papier.

Zı diesen fünf Werten tritt noch am 14. September 1861:

48. 19 CUARTOS braun in zwei Abstufungen auf hellbraunem Papier.

48 a) 19 CUARTOS braun,

48 b) $19 \quad$, dunkelbraun. 


\section{Bemerkungen.}

1. Die Marke No. 48 verdankt ihren Ursprung dom am 20. Februar 1861 mit Belgien abgeschlossenen Postvertrag, nach welchem das Porto für einfache Briefe anf 19 cuartos festgesetzt wurde. Sie blieb mit den übrigen Werten in Gebrauch his zum 31. Juli 1862.

2. Von der Marke zu 4 cuartos existirt ein Fehldruck mit der Inschrift CORRROS.

3. Im Juni 1862 tanchten an verschiedenen Orten Fälschungen der Marken zu 4 cuartos anf, weshalb dieser Wert vom 15 . Juli ab nicht mehr verausgabt wurde. Es existiren von falschen 4 cuartos-Marken vier verschiedene Typen, welche man vielfach in Sammlungen findet und welche daher in Nachfolgendem kurz beschrieben werden sollen:

I. Type: Perlen des rechteckigen Rahmens ungleich; das s von Correos und das Wort cuartos sehr sehlecht ausgeführt; die Ziffer 4 breiter; die Haare dichter, die Schattenstriche am Halse ahwoichend.

II. Type: Die Ziffer 4 schmal; correos und cuartos in längeren Buchstaben (hesonders auffallend das s von correes); der Kopf kleiner, die Haare zahlreicher, der Halsabsehnitt abweichend.

111. Type: Die Ziffer 4 abweichend; das $\mathrm{C}$ und das S in enartos zu offen, correos in zu kleinen Buchstaben (besonders das $\mathrm{C}$ und das $\mathrm{E}$ ); der Kreis auf der linken Seite zu weit vom Rahmen, die Perlen des letzteren nicht genug hervortretend.

IV. Type: Unterscheidet sich von den officiellen Marken nicht dureh die Zeichnung, sondern nur durch das Papier, welches viel dicker ist; soll durch Unterschlagung eines Clichés entstanden sein.

Aber auch die Narken zu 1 und 2 Rs wurden nachgeahmt. Die Fälschung der ersteren ist sehlechter ausgefiihrt und daher leicht zu erkennen: Nase der Königin dicker, Augen versehoben, Haare weniger zahlreich, Spitze der Büste zu weit vom Kreis, Perleu des Rahmens unregelmässig, das L von REAL hat koinen horizontalen Strich.

Von den Fälschungen der 2 Reales-Marke giebt es zwei Typen:

I. Type: Sehr gute Ausführung. Unterschied besonders in der Ziffer 2, welche zu kurz und zu dick ist; das S von REALES ist oben unvollendet, die Perlen des Rahmens sind weniger dick; das Gesicht ist vorzüglich bis auf die etwas zu dick geratene Nase.

II. Type: Perlen des Rahmens unregelmässig; Krois zu nahe am Rahmen, das zweite E von REALES ist unvollständig und steht zu nahe am S.

4. Die Essais zu dieser Ausgabe sind sehr zahlreich. Man kennt:

2 cuartos karmin, blau, orange und lila auf blasslila Papier,

lila auf blassgrün,

grün auf lebhaft rosa,

grïn und karmin auf weiss,

4 cuartos orange auf weiss und blassgrün,

dunkelblau, grün und rotbraun auf blassgriln, orange auf chamois,

hellblau und orange auf blasslila,

blassgriin und dunkelblau auf rootlich-chamois, dunkelblau auf weiss und weissem Karton, orange auf orange,

1 real schwarz und ultramarinblau auf weiss,

12 cuartos karmin auf hellehamois.

Ausserdem die 4 cuartes-Marke orange auf gelblichgrünem Papier mit Zähnung 15,5 . 
Von Essais in abweichender Zeichnung ist nur das folgende bekannt:

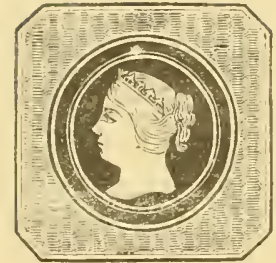

Kopf ähnlich der X. Ausgabe, jedoch en relief anf dunklen Untergrund innerhalh eines kreisförmigen Rahımens, der wiederum von einem $A$ cht-ck eingeschlossen ist; der haum zwischen Oval uud Achteck ist gunllochirt. Das Essai existirt ohne Wertangabe in weiss, rosia und zinnoberrot auf weissem l'apier.

\section{Ausgabe:}

vom 16 Juli bezw 1. August 1862 lis 31. Dezember 1863 bezw. 29. Fehruar 1864.

Kopf der Königin mit Diadem nach links innerhalb eines ovalen Ralmens; oben im Rahmen auf weissen Girund: Espraia, unten: Wertangabe: rechts und links anf dunklem Grund: Correos; in den Ecken Wappen von Castilien und Leon.

Farbiger Buchdruck auf verschieden gefärbtem Papier; ungezähnt. (Taf. IV, 49.)

49. 2 CUARTOS blau in drei Schattirungen auf gelbem und blassgelbem Papier.

49 a) 2 CUARTOS hlan auf gelbem Papier,

49 b) 2 dunkelblau auf gelbem Papier,

49 c) 2 " blau auf blassgelbem Papier,

49 d) 2 " dunkelblan auf blassgelhem Papier.

49 ө) 2 indigoblau auf blissgelbem Papier.

50. 4 CUARTOS braun in vier Schattirungen auf rötlichem oder weissgelbem Papier.

50 a) 4 CUARTOS' braun auf rötlichem Papier,

50 b) 4 dunkelbraun auf rötlichem Papier,

50 c) 4 " " " 4 "

50 d) 4 " kaffeebrann anf weissgethem Papier.

51. UN REAL braun in zahlreichen Schattirungen auf blassgelberı Papier.

51 a) 1 REAL, braun auf blassgelbem Papier,

51 b) 1 dunkelbraun auf blassgelbem Papier,

51 c) $1 "$ blassbraun auf blassgelbein Papier, 
51 d) 1 REAL braunrot auf blassgelbem Papier,

51 e) $1 "$ dunkelbraunrot auf blassgelbem Papier,

51 f) 1 " braun auf safrangelbem Papier,

$51 \mathrm{~g}) 1$ " rotbraun auf safrangelbem Papier

๑). 12 CUARTOS blau in vier Schattirungen auf mattrosa Papier.

52 a) 12 CUARTOS blau,

$\begin{array}{lll}52 \text { b) } 12 & - & \text { dunkelblau, } \\ 52 \text { c) } 12 & \text { blassblau, } \\ 52 \text { d) } 12 & \text { " } & \text { blauschwarz. }\end{array}$

ก3. DOS REALES grün in sieben Abstufungen auf hellrosa Papier.

53 a) 2 REALES grun,

53 b) 2 dunkelgrïn,

53 c) $2 \quad$ graugrün,

53 di 2 " gelbgrün,

53 e) 2 hellgelbgrün,

$53 \mathrm{f}) 2$ blassgrün,

$53 \mathrm{~g}) 2$ " saftgrïn (fettes glänzendes grün).

5). 19 CUARTOS karmin in zwei Abstufungen auf bläulichem oder gelbem Papier.

54 a) 19 CUARTOS karmin auf bläulichem Papier,

54 h) 19 blasskarmin auf bläulichem Papier,

54 c) $19 \quad " \quad$ blasskarmin auf gelblichem Papier.

\section{Bemerkungen.}

1. Die Marke zu 4 cuartos wurde infolge entdeckter Fälschungen schon am 31. Dezember 1863 ausser Gebrauch gesetzt, während die äbrigen Werte bis zum 29. Februar 1864 in Verkehr blieben.

2. Von den Werten zu 4 und 19 cuartos griebt es Exemplare auf weissem Papier, dieselben scheinen aber durch Verblassen der Papierfarbe entstanden zu sein.

3. Die im Jahre 1858 begonnenen Zähnungsversuche wurden auch im Jahre 1862 fortgesetzt und zwar wiederum nit der Marke zu 4 cuartos, die dementsprechend in einigen Stücken gezähnt vorkommt (Zähnung 91/2, 12 u. 15)

4. Die falschen 4 cuartos-Marken haben laut Rundschreiben des Chefs der PostVerwaltung vom 4. Dezember 1862 folgende Keuuzeichen:

a) Die falschen Marken sind $1 / 2 \mathrm{~mm}$ schmaler, als die echten;

b) das Profil des Kopfes ist etwas dicker in den Gesichtszingen, besonders ist die Nase etwas mehr gewölbt;

c) bei den echten Marken sind 2 Perlen des Diadems ausserbalb der Zeichnung des Kopfes, bei den falschen nur eine:

d) bei den echten trägt der Löwe in der rechten oberen Ecke den Kopf aufrecht und fast nach rückwärts geworfen und die Krone des Löwen zeigt deutlich 3 Spitzen; bei den falschen ist der Kopf des Löwen nach riäckwärts geneigt und die Krone obne Spitzeu hängt bis uber die Augen herab; 
e) die Schattirung des Gesichts besteht bei den echten Marken aus schön geschwoiften, bei den falschen aus mehr gestreckten Linien;

f) die Zahl "4" steht bei den falschen näher dem "C."

5. Von Essais sind bekannt:

Die Marke zu 2 cuartos in braun. die 4 cuartos-Malke in schwarz und braun und diejenige zu 1 real in blaner Farbe.

6. Die im Oktober 1858 erst eingeführten Entwertungsstempel werden bei zalilreichen Postanstalten im Frühjahr 1862 (?) wieder abgeschafft, ohne dass eine bezügliche Verfügung aufzufinden wäre, welche die Gründe für diesen Wechsel angiebt. Der neue Stempel besteht in einem Gitterstempel, dessen Striche in der Mitte zur Aufnahme der Nummer der Post-Austalt unterbrochen sind, siehe Taf. V, 50.

Neben diesem Stempel der Haupt-Postanstalten existiren zahlleiche Modelle völlig abweichender Form, iiber deren Angehörigkeit und Einfüurung nichts Sicheres zu erfahren ist. Man geht wohl nicht irre, wenn man aunimmt, dass es Entwertungsstempel sind, welche sich die Carterias und Estafetas, deuen, wie oben erwähnt, keine Stempel geliefert wurden, privatim anfertigen liessen. Es gelıören hierher No. 51 und No. 52 auf Taf. V.

Taf. V, 53 stellt den Dienststempel der Post-Verwaltungen dar (Inschrift oben: Administracion de Correos, unten: Ort); die Verwesdung von No. 54 Taf. $\mathrm{V}$ ist unbekannt.

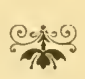

\section{Ausgabe:}

vom 1. Januar bezw. 1. März bis 31. Dezember 1864 .

Kopf der Königin mit Diadem nach links in ovalem, mit Ornamenten ausgefüllten Rahmen, welcher in den vier Ecken Kreise bildet: oben anf einem Band: CORREOS, unten: Wertangabe und Jahreszahl.

Farbiger Buchdruck auf verschieden gefärbtem Papier; ungezähnt. (Taf. IV, 55.)

55. 2 CTOS (cuartos) blau in drei Abstufungen auf hellila, manchmal fast weiss scheinendem Papier.

55 a) 2 CTOS blau,

55 b) $2 \%$ dunkelblau,

55 c) $2 \%$ blassblau. 
56. 4 CTus karmin und zinnoberrot in je zwei Abstufungen auf fleischfarbenem Papier.

56 a) 4 CTOS karmin,

56 b) 4 blasskarmin,

$56 \mathrm{c)} 4 \%$ zinnoberrot,

56 d) 4 " blasszinnoberrot,

57. $1 \mathrm{R}$ (Real) braun in drei Schattirungen auf bläulichem Papier.

57 a) $1 R_{i}^{L}$ braun,

57 b) 1 , rotbraun (rossbrann),

$57 \mathrm{c)} 1 "$ dunkelrotbraun.

58. 12 Cros grün in drei Abstufungen auf hellrosa, manchmal fast weissem Papier.

58 a) 12 CTos lebbaft grün.

58 b) $12 "$ gelbgrün,

58 c) $12 "$ blassgellogrün.

59. $2 \mathbf{R}$ (Reales) blau in zwei Abstufungen auf ebensolchem Papier.

59 a) 2 Rs blan,

59 b) 2 , hellblau.

6(). $19 \mathrm{C}$ ros lila in drei Schattirungen auf blassrosa Papier.

60 a) 19 CTUS lita,

60 b) 19 " hellilia,

60 c) 19, bräunlichlila.

Bemerkungen.

1. Die Marke zn 4 CTOS wnrde am 1. Jannar, die ubrigen Werte am 1. März 1864 ausgegeben.

2. Von der Marke zn 4 CTOS existirt ein fehlerhafter Druck mit Clos statt Cros.

3. Anch von dieser Marke wurde die 4 CTOS-Marke gefïlscht. Ein Rundschreiben des Chefs der Post-Verwaltung vom 19. November 1864 giebt folgende Kennzeichen:

a) Die Schraffirung des Halses ler Königin besteht bei den echten aus 18, bei den falschen aus 12 Strichen;

b) die Nase der Königin ist bei den falschen mehr gerade und gestreckt;

c) bei den echten Marken markirt sich die Linie der Oberlippe deutlich, bei den falschen existirt diese Linie nicht oder ist kaum erkenubar.

4. Von Essais sind simtliche Werte in abweichenden Farben bekannt und zwar: 2 cuartos: weinrot auf weissem Papier (gummirt),

4 cuartos: schwarz, blau, dunkelblau, grün, karmin, gelb und braun auf weissem Papier,

rot aut gelblichem Papier,

rot, violett und brann auf grun, 
1 real: braun auf griln,

12 cuartos: braun auf rosa und schwarz anf weissem Papier mit Wasselzeichen,

19 cuartos: schwarz auf weissem Papier.

Von nicht angenommenen Typen kennt man nur folgende: Kopf der Königin

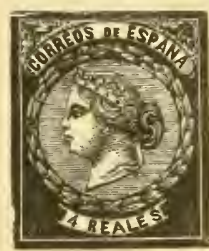
mit Krone nach links innerhalb eines kreisförmigen Lorbeerkranzes, Untergrund mit horizontalen Strichen ausgefülit: iiber den Kr'eis anf halbkreisförmigem Schild: CORREOS DE ESPANA, unter demselben Wertangabe, in den Ecken Oruamente. Das Essai kommt ausser in der nebenstehenden Ausführung auch ohne Ornamente in den Ecken vor, ferner ohne Ornamente und ohne Inschriften, schliesslich mit Ornamenten, aber ohue Inschriften. Schwarzer Druck auf chinesischem Papier.

\section{Ausgabe:}

vom 1. Januar bis 31, Dezember 1865.

Kopf der Königin mit Diadem nach links auf liniirtem Grund inmerhalb eines ovalen Rahmens, gebildet aus der Halskette des goldenen Vliesses; oben in den Ecken das Wappen ron Castilien und Leon, dazwischen: ESPAÑA, in den unteren Ecken Wertangabe. dazwischen: CORREOS.

Farbiger Druck in einer oder in zwei Farben anf weissem Papier. (Taf. IV, 56.)

A. Ungezähnt, mit Ausnahme von No. 62 bis zum Juni 1865 ausgegebelı:

61. 2 C rosa in drei Schattirungen.

61 a) 2 Cs rosa,

61 b) 2 CS karmin,

$61 \mathrm{c)} 2$ CS karminrosa,

$61 \mathrm{~d}) 2$ Cs lilarosa, fast lila.

62. 4 CS hellblau.

63. $\mathbf{1} \mathbf{R}$ grün in vier Abstufungen.

63 a) $1 \mathrm{R}$, gelbgrïn,

$63 \mathrm{~b}) 1 \mathrm{RL}$ hellgelbgrün,

63 ?) $1 \mathrm{R}$ । dunkelgelbgrun,

63 d) $1 \mathrm{R} \uparrow$ dunkelgrtin. 
61. $12 \mathrm{C}$ blau, Oval rosa in sechs Abstufungen.

(34 a) 12 C: blan, Oval rosa,

(itb) 12 CS blan, (Oval karminrosi,

6.4 c) 12 CS limllblill, ()val rosa,

(it d) 12 (S hellblau. Oval karminiosa,

6.te) 12 (s dunkelhlau, Oval rosa,

(i4f) 12 CS dunkelblau, Oval karminrosa.

6.). $2 \mathrm{R}$ in mehreren, stark von einander verschiedenen Farben.

65 a) 2 RS violett.

65 b) 2 R ! blassviolett,

$65 \mathrm{c)} 2 \mathrm{RS}$ violettrosa,

65 d) 2 Rs gelblichrosa,

65 e) 2 Rs karmin,

$65 \mathrm{f}) 2 \mathrm{R}$. ziegelrot,

$65 \mathrm{~g}) 2 \mathrm{RS}$ gelbbraun (lehmgelb).

66. $19 \mathrm{C}$ rbaun, Oval rosa in vier Schattirungen.

66 a) 19 CS rothraun, Oval rosa,

66 b) 19 rotbraun, Oval karminrosa,

66 c) 19 C: dunkelbram, Oval rosa,

66 d) 19 C: dunkelbrann. Uval karminrosa.

B. Gezälnt (14), rom 1. Juni bis 31. Dezember 1965:

67. 2 C rosa in zwei Abstufungen.

67 a) 2 (c) rosa,

67 b) 2 CS karminrosa.

68. 4 C blau in vier Abstufungen.

68 a) 4 CS blau,

68 b) 4 CS hellblau,

$68 \mathrm{c}) 4 \mathrm{Cs}$ dunkelblau,

68 d) 4 CS mattes, glanzloses blau.

69. $\mathbf{R} \mathbf{R} !$ grün in drei Schattirungen.

69 a) 1 RL grün,

69 b) 1 RL gellbgriü,

69c) 1 Ri dunkelgrün.

70. 12 C blau, Oval rosa in sechs Schattirungen.

70) a) 12 CS blan, Oval rosa,

70 b) 12 Co blan. Oval karminrosa.

70 c) 12 C: hellblau. Oval rosil,

70 d) 12 Cs hiellblau. Oval karminrosa,

70 e) 12 Cs dunkelblau, Oval rosa,

70 f) 12 Cs dunkelblau, Oval karminrosa. 
71. $2 \mathrm{R}$ in zahlreichen, stark von einander abweichenden Farbenschattirungen.
71 a) 2 RS violett,
$71 \mathrm{~b}) 2$ RS blassviolett,
$71 \mathrm{c)} 2 \mathrm{RS}$ braunviolett,
$71 \mathrm{~d}) 2 \mathrm{Rs}$ violettrosa,
71 e) 2 Rs gelblichrosa,
$71 \mathrm{f)} 2 \mathrm{RS}$ braun,
$71 \mathrm{~g}) 2 \mathrm{RS}$ fleischrot,
$71 \mathrm{~h}) 2 \mathrm{Rs}$ ziegelrot,
$71 \mathrm{i}) 2 \mathrm{RS}$ blassbraungelb.

\title{
72. 19 C braun. Oval rosa in vier Schattirungen.
}

\author{
72 a) $19 \mathrm{C}$ sotbraun, Oval rosa, \\ 72 b) 19 CS rotbraun, Oval karminrosa, \\ 72 c) 19 C: braun, Oval rosa, \\ 72 d) 19 CS braun, Oval karminrosa.
}

\section{Bemerkungen.}

1. Schon im Jahre 1862 hatte man - wie oben erwähnt - Versuche angestellt, dem Beispiele fremder Postverwaltungen zu folgen und die Marken zu zähnen. Diese Versuche wurdeı, da die ans Paris bezogenen Maschinen zu langsam und zu schlecht arbeiteten, wieder eingestellt. Im Jahre 1865 und zwar wahrscheinlich schon zu Mitte Januar wurden sie von Nenem aufgenommen und fielen besser aus. $\mathrm{Zu}$ diesen Versuchen hatte man ausschliesslich die 4 cuartosMarke benutzt, welche daher ungezähnt nur einige ''age existirte. Durch Verfügung des Chefs der Post-Verwaltung vom 11. April wurde die Zähnmung aller Werte angeordnet, ihre Ausgabe erfolgte an 1. Juni; die im Besitze des Publikums befindlichen ungezähnten Marken durften aufgebraucht werden.

2. Von der Marke zu 12 C\& giebt es sowohl ungezähnte, als auch gezähnte Exemplare mit verkehrt gedrucktem Kopf der Königin, oder richtiger: mit verkehrt gedruckt'm Rahmen, denn bei zusammenhängenden Exemplaren steht der Kopf der Königin gerade wie bei den abrigen Marken des Bogens. Hierans ist auch zu erklären, dass dieser Fehldruck lange Zeit unbemerkt blieb, also verhältnismässig zahlreiche Exemplare in Verkehr kamen.

3. Von diesem Fehldruck existirt eine gute Fälschung. Dieselbe lässt sich e1kennen an dem Untergrund des Ovals, dessen Linien weiter auseinanderstehen, sowie an kleinen Abweichnngen in der Zeichnung der Nase und des Mundes.

Auch von der Marke zu 2 Rs giebt es eine Nachahmung, welche man sogar hänfig postalisch entwertet findet; sie ist an der mangelhaften Ansführung leicht erkennbar.

4. Von Essais sind die meisten Werte in abweichenden Farben bekannt und zwar: 2 chartos: violett, gelh und grün,

4 cuartos: hellblan, dunkelblau, schwarzblau, indigoblan und schwarz, Nittelstïck stets rosa, ausserdem braun, gelborange, violett, rosa, gelbgrün, grün, blaugriin, lebhaft blau und schwarz mit gleichfarbigem Mittelstiick,

12 cuartos: rosa und karminrosa mit schwarzem Mittelstück,

19 cuartos: braun, Mittelstuck braungelb. 
Von 4 cuartos blan, Mittelstick rosa, nnd 12 cuartos rosir, Mittelstuck schwarz existiren auch Exemplare mit verkehrtem Rahmen, desgleichen von fast allen Werten Doppeldrucke.

In dem angenommenen Typus giebt es ferner zwei nicht zur Ausgabe gelangte Werte zu 4 reales und zu $20 \mathrm{~m}$ s (maravedis); ersterer kommt in schwarz und rosa anf chinesischem Papier und in schwarz und grin anf strohgellem Papier, letzterer in schwarzem Druck anf dickem, weissen Papier vor.

Von nicht angenommenen Entwiirfen wurde nur folgender bekannt:

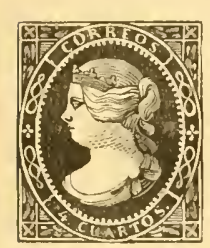

Kopf der Königin mit Krone nach links in ovalem Rahmen, dunkler Untergrund; im Rahmen oben: CORREOS, unten Wertangabe 4 CUARTOS; zu beiden Seiten Verzierungen: $1 \mathrm{~m}$ das Oval riereckige Einfassung mit Ornamenten. Existirt in indigoblaner Farbe auf weissem Papier.

Dasselbe Essai existirt mit kleinen $\mathrm{Ab}$ weichungen in der Ausführung, nämlich mit

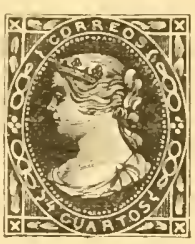

veränderter Schrift, liniirtem oder quadrirtem Untergrund und dergl. in blauer" oder brauner Farbe auf chamois Papier oder weissem Karton.

\section{A usgabe:}

vom 1. Januar bis 31. Juli bezw. 31. Dezember 1866.

Kopf der Königin mit Diadem nach links in einem Kreise mit liniirtem Untergrund; in den oberen Ecken zwei gekrönte Wappenschilder mit den Wappen von Castilien und Leon, dazwischen auf einem Band: CORREOS: unten Wertangabe.

Farbiger Buchdruck anf verschiedenem Papier: gezähnt 14. (Taf. $[\mathrm{T}, 57$.

73. 2 CUARTOS rosa in zwei Abstufungen auf verschiedenem Papier.

73 a) 2 CUARTOS rosa,

73 b) $2 \quad, \quad$ blassrosa,

73 c) 2 " rosa auf' bläulichem Papier.

74. 4 CUARTOS blau in zwei Abstufungen.

74 a) 4 CUARTOS blau.

74 b) 4 hellblau. 
75. 10 CENT. DE ESC? (céntimos de escudo) grün in vier Schattirungen.

75 a) 10 CENT. DE ESC! grün,

75 b) $10 \quad "$ hellgriin,

75 c) 10 " dunkelgrün,

75 d) $10 \quad$ gelblichgrün.

76. 12 CUARTOS orange und gelb in verschiedenen Schattirungen.

76 a) 12 CUARTOS orangeret,

76 b) $12 \quad "$ blassorangerot,

76 c) $12 \quad "$ dunkelorangerot,

76 d) $12 \quad$ gelborange,

76 e) $12 \quad \%$ gelb.

77. 2o CENT. DE ESC? lila in zwei Abstufungen.

77 a) 20 CENT. DE ESCo lila,

77 b) $20 \quad$ blasslila.

78. 19 CUARTOS braun in zwei Abstufungen.

78 a) 19 CUARTOS braum,

78 b) 19 " dunkelbraun.

An Stelle der Marke No. 77 (20 cent. de esc.) trat vom 1. August an eine Marke im Typus der XII. Ausgabe, nu mit geänderter Wertangabe und Jalreszahl.

Farbiger Druck anf weissem Papier: gezälnt 14. (Taf. V, 54.)

79. 20 CMus lila in zwei Abstufungen.

79 a) 20 CMos lila,

79 b) $20 \%$ blasslila.

\section{Bemerkungen.}

1. Im Jahre 1866 war in Spanien die neue Geldwährung in Escudos à 100 céntimos eingefïhrt worden; da sich aber die Werte in cuartos nicht genau in céntimos umrechnen liessen, man auch nicht die bisherigen Portotarife umändern wollte, so behielten die vier Cuartos-Werte ihre alte Benennung.

2. Von No. 79 giebt es einen fehlerhaften Druck mit CMUS anstatt CMos. Ein Fehldruck in grïn, welchen .The Philatelist" erwähnt, ist dagegen wahrscheinlich ein Essai oder chemische Farbenändernng.

3. Von den Marken zu 2 und 4 cuartos giebt os Fälschungen aus der Zeit ihres Gebrauchs, dieselbeu sind jerloch zu selten, als dass es nütig wäre, sie hier 
näher zu heschreiben. Fine Fälschung dor Marke zu 20 cént. de esc. (No. 77) bewog die P'ost-Verwaltung, diesen Wert schon am 1. Angust 1866 einzuziehen und Jurch die Marke No. 79 z. ersetzen. Dieselbe wurde im Typus der XII. Ausgabe hergestellt, weil es an '/eit zur Aufertigung einer wenen l'latte fehlte. So kurz dieselbe in Verkehr war, wurde sie doch sehr bald gefülscht. Man erkemut die Falschung an der abweichenden \%eichnumg der Haare, am grösseren Abstand der Büste vom Oval (unten), an der Zahỉ \& (in 1866) und dem Buchstaben O (in Correos), welche breiter sind, als bei den echten.

4. Von Essais ist nur die Marke zn 20 cent. de esc. in schwarzem Druck auf weissem Papier bekaunt.

\section{Ausgabe:}

vom 1. Januar bis 30. Juni 1867, 31. Dezember 1868 und 31. Oktober 1869.

Kopf der Königin mit Krone nach links auf liniirtem Untergrund in oralem Rahmen: im Rahmen auf farbigem Grund Inschrift in weissen Buchstaben und zwar oben: CORREOS DE ESPA $\widetilde{N} A$, unten Wertangabe: in den Ecken bei jedem Wert verschiedene Verzierungen.

Farbiger Buchdruck auf weissem Papier: gezähnt 14. (Taf. IV, $58-63$.

80. DOS (2) CUARTOS braun in vier Schattirungen.

80 a) DOS CUARTOS dunkelbraun,

$80 \mathrm{~b}) \quad$ " hellbraun,

$80 \mathrm{c}$ " gelbbraun,

$80 \mathrm{~d}) \quad$ dunkelgelbbraun.

81. CUATRO (4) CUARTOS blau in vier Schattirungen.

$\begin{array}{lcl}81 \text { a) } & \text { CUATRO CUARTOS lebhaft blau, } \\ 81 \text { b) } & " & \text { hellblan, } \\ 81 \mathrm{c}) & " & \text { hattblau, } \\ 81 \mathrm{~d}) & " & \text { himmelblau. }\end{array}$

82. 10 CENT. DE ESC. grün in zwei Abstufungen.

82 a) 10 CENT. DE ESC. bläulichgr'ün, $82 \mathrm{~b}$

hellbläulichgrun, 
83. DOCE (12) CUARTOS orangegelb in vier Schattirungen.

83 a) DOCE CUARTOS orangegelb,

83 b) $"$ gelb,

83 c) blassgelb,

83 d) " " bräunlichgelb (vielfach verschwommener

Druck, )

84. 20 CENT. DE ESC. lila in vier Schattirungen.

84 a) 20 CENT. DE ESC. lila,

84 b) " blasslila,

84 c) " " rötlichlila,

84 d) $\quad, \quad$ graulila.

85. 19 CUARTOS rosa in zwei Abstufungen.

85 a) 19 CUARTOS rosa,

85 b) "

\section{Bemerkungen.}

1. Ein Erlass vom 15. Mai 1867 verfügt infolge der Annahme der neuen Munzwăhrung folgende Aenderung in den Portotarifen:

für Briefe im Lokalverkehr . . . . 25 milésimas de escudo, für Drucksachen unter Kreuzband . . 10

für Briefe innerhalb Spaniens bis zu $10 \mathrm{gr} . \quad 50$ von $10-20 \mathrm{gr}$. 100

und dann für je $10 \mathrm{gr}$. mehr 50

Das Porto für Briefe nach dem Auslande erlitt keine Aenderung.

Infolge dieses neuen Turifs wurden am 30. Juni die Marken zu 2 und 4 cuartos eingezogen, während diejenigen zu 10 und 20 cent. de esc. bis zum 31. Dezember 1868 und diejenigen zu 12 und 19 cuartos noch ein Jahr länger in Verkehr blieben.

2. Die Marke zu 20 cent. de ese. findet sich in einigen sehr seltenen Exemplaren ungezähnt postalisch entwertet.

3. Von der Marke zu $12 \mathrm{Cs}$ existirt ein merkwüldiger, wenig bekannter Fehldruck mit: DOCEO CUARTOS; die Entstehung ist ganz unerklärlich. Ebenso rätselhaft ist ein Fehldruck der Marke zu 19 cuartos mit verunstaltetem UA in CUARTOS: die beiden Buchstaben sind statt weiss auf rosa Grund umgekehrt rot auf weissem Grund und vom A fehlt der Bindestrich zwischen den beiden Schenkeln $(\Lambda)$. (Sammlung Eckardt-Prag .

4. Die Marken der XV. Ausgabe sind vielfach gefäscht worden. Durch Rundschreiben vom 18. Juni 1868 macht die General-Post-Direktion auf Fälschungen der 10 céntimos-Marke aufmerksam und giebt folgende Kennzeichen derselben:

a) In der Krone der Königin ist bei den Fälschungen die mittlere Zacke grösser, als bei den echten. Im Reif der Krone befinden sich bei den echten Marken 5 Perlen, bei den falschen an Stelle der Perlen 5 undeutliche Streifen;

b) auf der Stirne der Königin befinden sich bei den echten Marken 5, bei den falschen nur 3 Schattenstriche. Das Auge ist bei den letzteren 
grösser und der Augapfel markirt sich nicht so scharf. Die Schattirung der rechten Ecke des Halses hesteht hei den echten aus 5, hei den falschen aus 4 Strichen;

c) der ovale Rahmen mit der Inschrift ist bei den Fälschungen kleiner. ebenso die beiden Krouzchen innerhalb desselben;

d) die Zähnung ist boi den Fälsehungen ungleich, auf' der längeren Seite der Marke befindet sich ein Zahn mehr, als bei den echten.

In August 1869 tauchton fialsche Marken zu 12 enartos anf. Ein Rundschreiben der F. P. 1). vom 4. September giebt folgende Kennzeichen:

a) Die Verzierungen in den Ecken stehen bei den Fälschungen etwas weiter ab von der ärsseren Linie des Ovals. In dem Wort CORREOS ist das $\mathrm{O}$ getrennt ron dem $\mathrm{C}$ und mehr an das $\mathrm{R}$ angenähert; in ESPANA sind die beiden A sehmäler; in CUARTOS ist das U unregelmässig, das $R$. sowio das $\mathrm{S}$ sind kleiner;

b) die Linien des Untergrundes sind bei den Fälschungen gröher, bei den echten Marken feiner;

c) das Profil der Stirne ist bei den echten mehr gebogen, dir Entfernung der Nase bis zum äussersten Teil des Haarknotens ist grösser, der ganze Kopf infolge dessen etwas grösser;

d) der innere Teil des Halses (links) hat bei den echten 5, bei den falschen 4 Schattenstriche

Da diese Kennzeichen leicht zu übersehen waren, so erhielt die 12 cuartosMarke vom September 1869 an eine rotorange Farbe (siehe XIX. Ausgabe, No. 121).

Die Marke zu 50 mils de ese. ist nicht weniger als dreimal gefälscht worden. Da hieriber kein postalischer Erlass vorliegt, ihre Kennzeichen ausserdem sehr zahlreich und leicht in die Angen fallend sind, so kann hier ron einer genaueren Beschreibung Abstand genommen werden.

5 Von Essais giebt es sämtliche Werte in abweichenden Farben auf dickem, weissem, satinirtem Papier und zwar:

2 cuartos in schwarz, orange und braun,

4 cuartos in blau und blassblau,

10 cent. de esc. in grün,

12 euartos in schwarz und gelborange.

20 cent. de esc. in lila.

19 cuartos in rosa. 


\section{Ausgabe:}

vom 1. Juli 1867 his zum 31. Dezember 1868 bezw. 31. Dezember 1869.

I) Ausgabe besteht ans drei Werten in zwei verschiedenen Zeichnungen.

I. Type: Zeitungsmarke: Grosse, weisse Wertziffer im Kreise mit farbigem Untergruml: un den Kreis viereckiger Rahmen mit Inschriften und zwar oben: ESPA NA. links: DIEZ MIL:, lechts: DE ESCUDO, unten: CORREOS; zwischen dem Mittelkreis und dem Rahmen when : FRANQUEO, unten: IMPRESOS: in den Ecken kleine weisse Kreise mit Wertziffern in farbigem Drnck.

Farbiger Buchdruck auf' weissem Papier; gezähnt 14. (Taf. VI, 64.)

86. DIEZ (10) MIL: DE ESCUDO (milésimas de escudo) braun in drei Schattirungen.

86 a) DIE\% MILS DE ESCUDO hellbraun,

86 b) " dunkelbraun,

$86 \mathrm{c)} \quad$ gelblichbraun,

II. Type: Kopf der Königin mit Krone nach links in ovalem Rahmen mit liniirtem Untergrund: innerhalb des Rahmens oben: CORREOS DE ESPA $\widetilde{N A}$, unten Wertangabe: um das Oval ein viereckiger Rahmen mit arabeskenartigen Verzierungen.

Farbiger Buchdruck auf weissem Pajper: gezähnt 14. (Taf. VI, 65.)

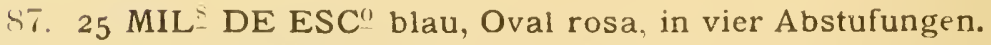
87 a) 25 MILS DE ESCo blan. Oval rosa, 87 h) $25 \quad$ dunkelblau, Oval rosa, 87 c) $25 \quad$ blassblatı, Oval rosa, 87 d) $25 \quad " \quad$ hlassblan, Oral karmin.

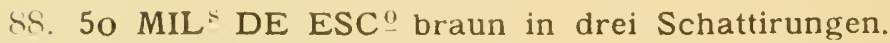

88 :1) 50 $111 \mathrm{~L}$. DE ESCO braum,

88 b) 50 dunkelbram,

88 c) $50 \quad$ gelblichbram, 


\section{Bemerkungen.}

1. Die Zeitungsmarke zu 10 mils hlieh bis zum 31. Dezember 1869, dio Marke zu 25 und 50 mils nur bis zua 31. Dezember 1868 in (iobrauch.

2. Von der Marke zil 50 Mile gieht es eine gute Fälschung. Kennzeichen derselben: Die Verzierungen in den Ecken sind etwas verzeichnet und zu weiss gehalten, die Buchstaben $\mathrm{S}$ und $\mathrm{P}$ weichen ab, die Verzierungen an den Seiten des Rahmens sind zu gross, Nase der Königin zu dick und zu rund, die Unterlippe zu tief herabhängend.

3. Von Essais sind bekannt: die Marke zu 10 mils in blau und diejenige zu 25 mils in lila und schwarz auf weissem Karton, erstere auch in schwarz auf weissem Papier. Die Zeitungsmarke zu 10 mils kommt mit dem Unterdruck der 50 mils-\$larke vor, auch giebt es ungezähnte, verkehrt und auf beiden Seiten gedruckte Stücke, desgleichen von der 25 mils-Marke solche mit verkebrtem Mittelstiick. Vergleiche hieriber: Vorwort zur zweiten Anflage.

4. Moens erwähnt die Marke No. 86 mit Aufdruck einer grossen schwarzen „5“. Diese Zahl hat fiir Sammler keine Bedentung, da sie, von französischen I'ost-Aemtern alligedruckt, das infolge ungenügenden Portos vom Empfänger nachzuzahlende Ergänzungsporto bezeichnet. Es kommt im iubrigen nicht blos Narke No. 86 mit diesem Aufdruck vor, sondern fast alle seit August 1859, dem Datum des zwischen Spanien und Fıankreich abgeschlossenen Postvertrages veransgabten Marken. Der Aufdruck bedeckt nicht immer die Marke, sonder'n berihh't sio häufig nur zum Teil oder sitzt an einer beliebigen Stelle des Umschlages. (Taf. V, 66.)

\section{Ausgabe:}

rom 1. November 1867 bis 31. Dezember 1869.

Zeitungsmarke: I. Type der XVI. Ausgabe, nur Veränderung der Wertziffer, Untergrund des Kreises liniirt und in den Ecken römische Zahlen.

Farbiger Buchdruck anf weissem Papier: gezähnt 14 . (Taf. VI, 67.)

89. CINCO (5) MIL؟ DEESCUDO grün in drei Schattirungen.

89 a) CINCO MILS DE ESCUDO dunkelgrüı,

89 b) " " hellgrün,

$89 \mathrm{c)} \quad$.. $\quad$ blangriin. 


\section{Bemerkungen.}

1. Die Marke wurde notwendig, weil durch Verfügung vom 7. Oktober 1867 das Porto für Drucksachen aut die Hälfte ermässigt worden war. Die infolge dessen iiberflüssig gewordene 10 mils-Marke wurde jedoch nicht eingezogen, sondern auf Grund eines Rundschreibens vom 20. Angust 1868 gleich der Marke No. 89 trotz der Bezeichnung "Impresos" zur Brief-Frankatur benutzt.

2. Marke No. 89 kommt ungezähnt postalisch entwertet vor.

3. Die bekannt gewordenen Essais zeigen die angenommene Zeichnung auf weissem satinirtem Papier in den Farben: schwarz, karmin, lila, blau und violett. Auch giebt es Doppeldrucke, sowie Stücke mit Unterdruck der 50 mils-Marke

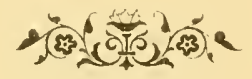




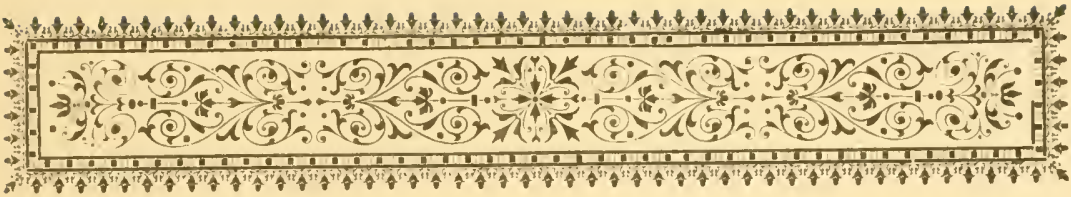

\section{B. Marken der provisorischen Regierung.}

eberraschend, wie ein Blitz aus heiterem Himmel, durchzuckte im September 1868 Europa die Kunde von dem Ansbruch der spanischen Revolution und der Vertreibung der Königin Isabella. Binnen wenigen Tagen hatte der durch die Proklamationen Serrano's und Prim's entfachte Freiheitssturm, immer mehr und mehr anwachsend, Spanien ron Cadiz bis zu den Pirenäen durchbraust und die Dynastie der Bourbonen wie einen altersschwachen Baum weggefegt. In eiliger Flucht rettete sich Isabella nach Pau, dem Schlosse, von wo einst ihr grosser Ahn, Heinrich IV', seine Laufbahn begonnen, und der Kanonendonner von Alcoléa war das letzte Lebewohl, das Spanien der fliehenden Königin nachsandte.

Vom 17. September an leitete eine „Junta revolucionaria“ P'ovisorisch die Regierung des Landes. Wie bei allen Revolutionen hatten auch hier die radikalsten Elemente anfänglich die Oberhand und wie zu allen Zeiten richteten diese anch hier zuerst ihr Angenmerk anf die Beseitigung an und für sich ganz gleichgiltiger und für den Augenblick ganz nebensächlicher Dinge: Entfernung der Königlichen Wappen und Insiguien an öffentlichen und privaten Gebäuden, Beseitigung des Bildnisses der Königin auf dem Geld, 
auf gestempelten Papieren, auf Post- und Telegraphen- Trertzeichen - alles Dinge, an deren Weiterbenutzung die revolutionsgewohnteren Franzosen bei solchen Gelegenheiten nie Anstoss zn nehmen pflegten. Den Forderungen der Presse nachgebend, verfïgte die ...Junta revolucionaria“ in Marlid sofort die Anfertignng nener Postwertzeichen. Da aber die in allen Zweigen der Stitatsverwaltung eingerissene Verwirung und Cnordnung, sowie die Leere der Staatskassen eine Ausführung dieses Befehls vorläufig ummöglich machte. es aber nötig erschien, sofortt ein äusseres Zeichen des Hasses gegen die monarchisclıe Vergangenheit des Landes zu schaffen, so ordnete die provisorische Regierung am 30. September an, alle gestempelten Papiere, sowie alle Post- und Telegraphenmarken mit dem Anfdruck: "HABILITADO POR LA NACION" zu rer'sehen. Damit wurden einige Serien der interessantesten spanischen Marken geschaffen, interessant deshalh, weil sich in diesem Aufduck das weltgeschichtliche Ereignis der Revolution und der Abschaffung: des spanischen Königtums weit mehr wiederspiegelt, als es die Ansgabe ganz nener Marken gethan haben würde. Nur Unkenntnis oder mangelnder philatelistischer Simn wird diesen Marken ihren Wert absprechen und sie in einen Topf werfen wollen mit den zahlrejchen Aufdruckmarken anderer Länder, die mit Recht die Antipathie aller Sammler ant sich gezogen haben.

Dem Befehl der „Junta revolucionaria“ vom 30. September konnte jerloch nm in beschränktem Masse nachgekommen werden, da sich die Anfertigung der vielen hierzı nötigen Stempel nuter den gegebenen Verhältnissen naturgemäss rerzögerte, die Fáhrica nacional de sellos aber mit der Teberstempelung von Formularen und Stempelpapieren derart beschäftigt war, dass sie erst an diejenige der Postwertzeichen denken konnte, als rie Ausgabe der nemen Marken täglich zu erwarten stand. Auch nachdem die Handstempel angefertigt nud in die Provinzen gesandt waren, wurden nur sehr wenige Marken überdruckt, da die Teberstempelung für die Beanten unbequem war, man anch schon nach kuzer Zeit einsah, dass das WVhl des Staates niclıt gefährdet wurde, wenn das Bild der Königin Isabella auch fernel in ungetrübter Schönheit auf den Briefmarken sichtbar błieb.

So ist die Zahl der ïberdruckten Marken tlıatsächlich sehr unbedeutend; in den Hauptstädten nud Hauptcentren des Handels, 
wo der Bedarf an Postwertzeichen ein grösserer war, wie in Nadrid und Barcelona, wurde nachweislich anch nicht eine einzige Marke ïberdruckt. Andererseits warteten die Heisssporne einiger Provinzial-Juntas die Anfertigung und Uebersendung der offiziellen Stempel nicht ab, sondern ïberdruckten ihre Marken mit Stempelı und Farben, die infolge ihres privaten Ursprung's meln oder weniger von den offiziellen abwichen. Die hierdurch entstanden'n Verschiedenheiten rler Habilitado-1Iarken, der dunkle Ursprung mancher Aufdrncke, die zahlreichen Fälschmngen und die Schwierigkeit, dieselben mit Sicherheit nachzuweisen, - Alles dies hat zu zahlreichen Fehler'n in den verschiedenen philatelistischen Handbüchern und Katalogen gefïlı't und eine kaum glanbliche Verwirrung hervorgerufen.

\section{a. Offizielle Aufdrucke.}

Am 30. September erliess, wie oben erwähnt, die .Junta rerolucionaria in Nadrid den Befehl. alle Staatsformulare, alle mit Stempeln versehenen Drucksachen, sowie alle Post- und Telegraphenmarken mit dem Anfdruck: "HABILITADO POR LA NACION" zu versehen. Es wurden zu diesem Zwwecke in der Casa de moneda (Mïnze) 2 Stempel (Matritzen) angefertigt, die:elben galranoplastisch vervielfältigt und an alle Provinzialbehörden (richtiger an die Bureans der Rentas Estancadas) versandt. Der Anfdruck erfolgte hier mit der Hand.

\section{1. 'Typus von Vizcaya,}

(Taf. IV, 68), so benamnt, weil man anfänglich irrtïmlicherweise

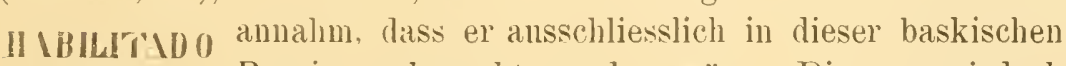
POR 1, Provinz gebraucht worden wäre. Dies war jedoch AACIOD. durchans nicht der Fall, er wurde vielmeln fast in ganz Spanien, wie anch in den Kolonien verwandt. 
Seine Abmessungen sind folgende:

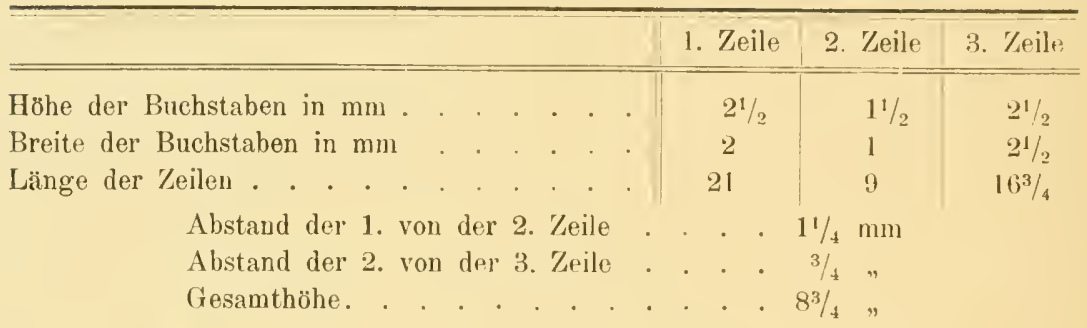

Die Maasse der Buchstaben in Höhe und Breite sind genommen beim Buchstaben $\mathrm{O}$, die Länge der Zeilen ist gerechnet ohne den darauf folgenden Punkt. Abuutzung der Stempel, flïchtige Abstempelung und andere natürliche Ursachen bewirken manchmal eine, wenn auch geringe Veränderung der angegebenen Grössenverhältnisse.

Die Farbe des Aufdruckes ist schwarz: Aufdrucke in roter und blaner Farbe sind entweder durch Laune eines Beamten entstanden oder es sind Sclıwindelprodukte.

Die Frage, welche Marken mit diesem Stempel iiberdruckt worden, beantwortet sich selır einfach durch folgende Betrachtuıg: Befohlen wurde der Auffruck am 30. September 1868, die Ausgabe der nenen Marken rer provisorischen Regierung, mit deren Erscheinen der Aufdruck naturgemäss abgeschafft war, erfolgte an 1. Jannar 1870. Alle diejenigen Marken, welche zwischen diesen beirlen Daten in Verkehr waren, können also mit diesenı, wie auch mit den später beschriebenen Aufdrucken ïberdruckt worden sein.

Wir verzeichnen daher:

\section{Ausgabe:}

von Mitte Oktober 1868 bis Dezemher 186 .

A. Zeichnung der XV., XVI. und XVII. A nsgabe mit dreizeiligem schwarzem Auftruck: IIABILITADO Por LA NAClON, sogen. Typus von Vizcaya. 
XV. Ausgabe:

90. 10 CENT. DE ESC. bläulichgrün in zwei Abstufungen. 90 a) 10 CENT. DE ESC. bläulichgriun,

90 b) $10 \quad$ hellblïulichgrilu,

91. DOCE CUARTOS gelb.

92. 20 CENT. DE ESC. lila in zwei Schattirungen.

92 a) 20 CENT. DE ESC. blasslila,

$92 \mathrm{~b}) 20$ rötlichlila

98. 19 CUARTOS rosa in zwei Abstufungen.

93 a) 19 CUARTOS rosa,

93 b) $19 \quad, \quad$ blassiosa.

XVI. Ausgabe:

94. DIEZ MIL: DE ESCUDO braun in drei Schattirungen.

(44 a) DIEZ MIL: DE ESCUDO hellbram,

94 b) DIEZ " dunkelbraun,

94 c) DIEZ ",$\quad$ gelblichbram.

45. 25 MIL DE ESC blau, Oval rosa, in vier Abstufungen.

95 a) 25 MIL: DE ESCo blau, Oval rosa,

$95 \mathrm{~b}) 25 \quad$ dunkelblat, Oval rosa,

95 e) 25 blassblac, Oval rosi.

95 d) $25 \quad$ " blassblan, Oval karmin.

96. 50 MIL" DE ESC" braun in drei Schattirungen.

96 a) 50 MILE DE ESC - braun,

96 b) 50 dunkelbraun,

96 c) $50 \quad$ gelblichbraun.

XVII. Ausgabe:

97. CINCO MILS DE ESCUDO in drei Schattirungen.

97 a) CINCO MILS DE ESCUDO dunkelgrim.

97 b) CINCO " hellgrtion,

97 c) CINCO $\quad, \quad$ blaugrîn.

\section{9. 'Typus von Cadiz.}

ILABLITADO Anch dieser Name ist nicht zutreffend, da dieser PUR LA NACION. Aufdruck nicht blos in der kleinen Provinz Cadiz, sondern fast im ganzen südlichen Spanien, in der Provinz Andalusien aber ganz ausschliesslich gebrancht wurde. Seine Farbe ist blau oder blauschwarz. (Taf. VI, 69.) 
Seine Abmessungen sind folgende:

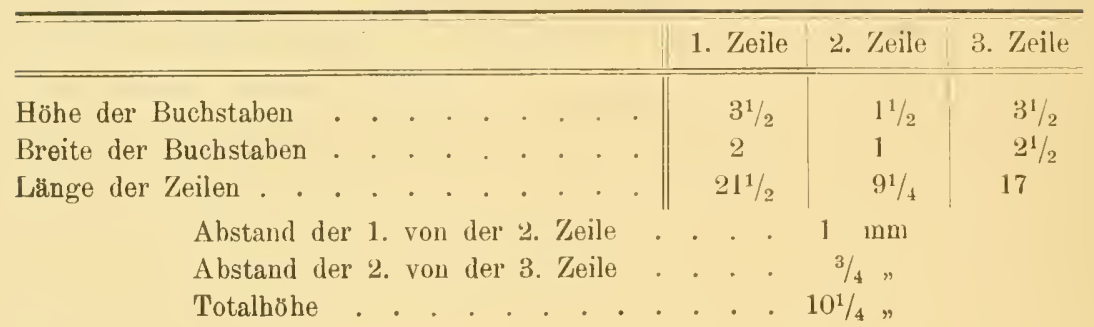

B. Typus der XV., XVI. und XVII. Ausgabe mit blanem dreizeiligem Aufdruck: HABILITAD0 P0k LA NACI0N, sogen. Typus von Cadiz.

XV. Ausgabe:

98. 10 CENT. DE ESC. bläulichgrün in zwei Abstufungen. 98 a) 10 CENT. DE ESC. bliulicbgriin, 98 b) $10 \quad$. hellbläulichgrïn.

99. DOCE CUARTOS gelb.

100. 20 CENT. DE ESC. lila in żwei Schattirungen. 100 a) 20 CENT' DE ESC. blasslila. 100 b) $20 \quad$ " rötlichlila.

101. 19 CUARTOS rosa in zwei Abstufungen. 101 a) 19 CUARTOS rosa. 101 b) $19 \quad " \quad$ blassrosa.

XVI. Ausgabe:

102. DIEZ MIL: DE ESCUDO braun in drei Schattirungen. 102 a) DIEZ MIL: DE ESCUDO hellhraun, 102 b) DIEZ " dunkelbraun, 102 c) DIE7 " " gelblichbraun.

103. 25 MIL` DE ESC? blau, Oval rosa in vier Abstufungen. 103 a) 25 MILS DE ESC blan, Oval rosa, 103 b) 25 dunkelblan, Oval rosa, 103 c) 25 ". hassblau, Oval rosa, 103 d) $25 \quad$ " blassblan, Oval karmin.

104. 50 MIL DE ESCo braun in drei Schattirungen. 104 a) 5U MILS DE ESCo braun, 104 b) 50 dunkelbraun, $104 \mathrm{c)} 50$ " gelblichbrauu. 
XVII. Ausgabe:

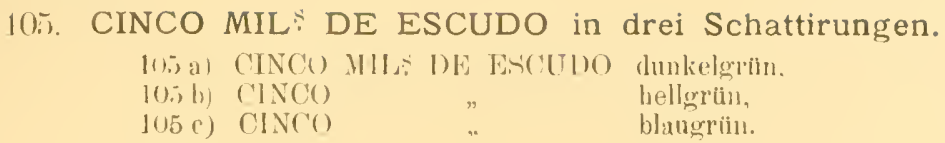

\section{Bemerkungen $\mathrm{zu}$ den beiden offiziellen Aufdruck-Typen.}

1. $D_{i l}$ die Marken zu 10 und 20 Cent. de esc. ebenso wie diejenigen zu 25 und 50 mils de ese. nur bis zum 31. Dezember 1868 in Gebrauch blieben, so sind sie kaum mehr als zwei llomate iberdruckt worden, müssen daher "gebraucht" seltener vorkommen, als die übrigen Werte.

2. Moens weicht in seinem vor kurzen ersehienenon Werke: "Histoire des Timbres-P'oste employés en Espagne" von obiger Darstellung ab, indem er nur den Typus von Vizcaya als offiziell bezeichnet. den Typus ron Cadiz aber moter die weiter untron zu besprachenden Provinzialanfdrucke rerweist. Fur litse Nbwejchung girlot Moens in seinem Buche keine Grunde an, dieselhen sind uns alier aus einem Brife an einen hekannten Sprozalsammler spanischer Marken, der ihn wrgen dieser Frage interpellirt hatte, bekannt geworden. Mnens sant in dies'm Bripfe, dass dir Toraussetzung zweier offizieller Aufdrucktypen anf der l)arstellung von Duro (.,Reseña historico-descriptiva de los sellos le correos de Espana") heruhe. Duro habe aber selbst nichts von Marken verstanden und seine Informationen von Leuten hezogen, die ebensowenig Kenntnis der thatsäehlichen Verhältnisse gehabt hiitten. Er schliesst mit der Gegenfrage, welche Grïnde wohl zu' Schaffung zweier verschiedener 'Typen hewogen haben sollten.

Demgegenüber lässt sich folgendes sagen:

Allerdings war Duro nicht JTarkenkemner in unserem lieutigen Sinne: er war nicht einmal Sammler und legte aut kleine Unterschiede in Farbe und P'apier ebensowenig Wert, wie auf' Wasserzeichen. Nichtsdestoweniger verdient seine Geschichte der spanischen Postwertzeichen im allgemeinen und seine Darstellung dè Habilitado-Jarken im besonderen die grösste Beachtung, la er stets beminht war, nach den hesten Quellen zu arheiten und er infolge seiner Stellung mit allen denjenigen Personen bekannt sein musste, die über diesen Gerenstand die beste Auskunft zu geben vermoehten. Er begann sein von der Akademie der Wissenschaften und der Postrerwaltung in gleicher Weise ausgezeichnetes Werk kurz nach der Revolution, wo es noch verhältnismässig leicht war, sich genaue Anskunft zu verschaffen. Seine mit anerkennenswertem Fleisse zusammengetragenen Angaben haben auch in der spanischen philatelistischen Presse keine Widerlegung gefunden und gelten jetzt noch dort als die allein richtigen. Was D. Feline Garcia Mauriño, auf dessen Untersuehungen die Angaben von Duro hauptsäehlich beruhen. anbelangt. so hat er, wie aus dem von Duro citirten Briefe desselben an Rothsehild hervorgeht. keine Mühr gescheut. um Licht in das Dunkel dieses Abschnittes der Philatelie zu bringen. Seine Darstellung ist so logisel, seine Gründe sind so überzeugend, dass ein Jeder, der spanisch 211 lesen versteht, nicht an der Richtigkeit der Ergebnisse seiner Forschungen zweifeln wird.

Es sind aher nicht nur Duro und Jauriño allein, welehe von 2 oftiziellen Aufdrucktypen sprechen, sondem noch eine ganze Reihe von hervorragenden spanischen Philatelisteu. Dr. Thebussem, einer der bedeutendsten Marken- 
kenner Europas, giebt in seiner "Leteratura Philatélica en España“ die Facsimiles beider Typen und beschreibt die Originalstempel bis zum Handgriff. Wenn einer, so musste aber Dr. Thebussem iiber diesen (iegenstand unterrichtet sein. Die gleichen Angaben machte auch D. Esteban Argiles in seinem Werke über die Postwertzeichen Spaniens, sowie eine Reihe ungenannter Verfasser von im „Diario de Cadiz“ erschienenen Aufsätzen.

Fur den offiziellen Charakter des Typus von Cadiz spricht aber ganz besonders das häufige Vorkommen desselben in unleugbar echten Stäcken. Während es sehr schwer sein dürfte, alle oben erwähnten Marken mit irgend einer der sogen. Provinzial-Aufdrucktypen zusammenzubringen, wälırend die grosse Mehrzahl derselben nur auf wenigen Marken gefunden sinf, einzelne sogar nur in einem Stïcke festgestellt werden konnten, ist es leicht. Aufdrucke der beiden offiziellen Typen auf allen zu jener \%oit in Verkehr befindlich gewesenen Marken zu erhalten,

Wenn Moens schliesslich mit der Frage, welche Gründe zur Schaffung zweier verschiedener Aufdrucktypen gefüh't haben sollten, andeuten will, dass damit einer Fälschung Thür und Thor geöffnet worden wäre, so ist dagegen zu sagen, dass eine derartige Fälschung der spanischen Postverwaltung völlig gleichgiltig sein konnte, wenn nur die henutzten Marken echt waren. Wie der Aufdruck der Worte: "Habilitado por la nacion“ hergestellt, war den spanischen Postbeamten bei Beförderung eines Briefes ganz einerlei, was schon daraus hervorgeht, dass anf mehreren Post-Anstalten nachweishich überhaupt kein Stempel benutzt, sondern diese Bezeichnung stets mit der Feder hergestellt wurde.

Es erscheint mir deshalb nach allem diesem richtiger, die spanische Darstellung als massgebend anzusehen, wenn nicht Moens für seine abweichende Meinung bessere und überzeugendere Griinde veröffentlicht. Wie dem aber anch sei, ob wir einen oder zwei offizielle Typen annehmen, das Eine mitssen wir stets im Auge behalten, dass die Zahl der mit ihnen wirklich überdruckten Marken nur gering gewesen ist und in keinem vernünftigen Verhältnis steht zu der Zahl der in Sammlungen oder im Handel befindlichen. Von diesen ist die grosse Mehrzahl erst nachträglich überdruckt worden, was keinesweg.: schwierig war, da die Stempel nach ihrer Einziehung auf den Bureaux der Provinzialbehörden auf bewahrt wurden und jedem Beanten zugänglich waren. Bei gebrauchten Marken lässt sich die nachträgliche Habilitirung oft leicht daran erkennen, dass sich der Aufdruck über dem Entwertungsstempel befindet; häufig findet man auch Marken, welche zwar den echten Aufdruck besitzen, deren Futwertungsstempel aber deutlich ein Datum trägt, welches vor dem 30. September 1868 liegt, ein Anachronismus, der auf den Kenner ebenso komisch wirkt, wie die prophetischerweise ïberdruckten Markeu mit dem Bildnis des Königs Amadeo. Auch Marken, die niemals überdruckt worden, wie die Marken zu 4 und 12 Cs 1865 fuslet man manchmal mit echtem Aufdruck. Dass daneben die Zahl der Fälschungen zahllos, ist bei dem hohen Wert, welchen diese Marken im Handel haben, leicht begreiflich. 


\section{b. Private bezw. falsche Aufdrucke.}

Mit der Feststellung der offiziellen Aufdrucktypen ist eigentlich die Frage der Habilitado-Larken gelöst, da alle iibrigen Aufdrucke, die sich als sogenannte Heimattypen einzelner Provinzen in die philatelistischen Handbïcher eingeschlichen haben, hiernach privaten Ursprungs sind und somit philatelistisch nur den Wert von Curiositäten haben. Man kann denselben selbst als Curiosa nicht einmal einen besonderen Wert zuerkennen, da sie ja s. Zt., mochten sie aussehen, wie sie wollten, von der spanischen Post anstandslos befördert wurlen, wemn nur die Marke, auf welche sie aufgedruckt waren, echt war'.

Wenn ich nun anch persönlich die Ansicht habe, dass die Sammler der Zukunft schon durch die alljährlich immer melır anwachsende Zahl der Postwertzeichen gezwnngen sein werden, ihr Geld nicht mehr für postalische Curiosa zweifelhaften W'ertes auszngeben, so herrschen doch heute noch ïber den Wert von solchen die entgegenstehendsten Ansicliten. Es erscheint deshalb gerechtfertigt, auch diese nichtoffiziellen Aufdrucktypen einer genanen Betrachtung zu unterziehen.

Was den [Trsprung dieser Provinzial-Auftrucke anbelangt, so ist er in den meisten Fällen dunkel. Einige von ihnen sollen ihre Existenz fanatischen Republikanern unter den Beamten verdanken, welche die Ankunft der offiziellen Stempel nicht erwarten konnten. um den Befehl der provisorischen Regierung rom 30. September auszufïhren: andere sind - wie nachweisbar - Abdrucke von Stempeln, welche anderweitigen fiskalischen und kommunalen Zwecken dienten und die durch irgend welchen Zufall auf Briefmarken kamen; andere - und dies ist ein beträchtlicher Teil sind Erzengnisse schlauer Spekulanten und Fälscher, welche aus der allgemeinen Verwirrung, welche in den Jahren 1868 und 1869 in allen Zweigen der spanischen Staatsverwaltung herrschte und ans der Schwierigkeit, diese Verhältnisse heute noch aufzuklären, Geld zu ziehen trachteten. Je nach diesem Ursprung treten sie in mehr oder weniger zahlreichen Exemplaren auf. Der Sammler wird daher gut thun, allen diesen Aufdrucken von vornherein mit grösstem 
Misstrauen entgegenzutreten, sie nul ans zuverlässigen Händen zu kaufen und auch hier noch einer eingehenten Prüfung zu unterziehen oder unterziehen zu lassen Demn wenn auch die in Nachfolgendem gegebenen Kennzeichen genan genug scheinen, wer will iiber die Echtheit oder Unechtheit einer Marke entscheiden, deren Dasein nachweislich nur in einem oder in einigen wenigen Exemplaren festgestellt ist: Auch der erfahrenste Händler selbst wird hier kaum Täuschungen entgehen können.

3. Aufdruck: "Halbilitudo por la .Juntu Relolurionurin" in 3 Zeilen und italienischen Lettern. Farbe: schwarz.

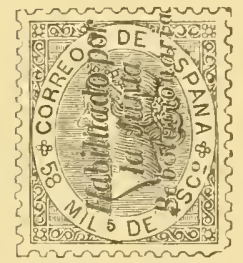

Dieser Aufdruck ist nach spanischen Autoritäten reines Schwindelprodukt, da genannte. Junta wohl das Habilitiren anordnete, aber selbst keine Aufdrucke anfertigte Auch ich schliesse mich dieser Ansicht an, schon wegen der Schreibweise „rebolucionaria" mit einem b, welche in Spanien gänzlich ungebräuchlich ist und auf ausländischen Ursurung schliessen lässt. Nach Moens ist der Aufdruck dagegen nnbestreitbar echt, kommt nach der "Histoire des'T'imbres- Poste employés en Espagne" ant den Marken zu 50 Mils und 20 rent de esc. vor und hat folgende Abmessungen:

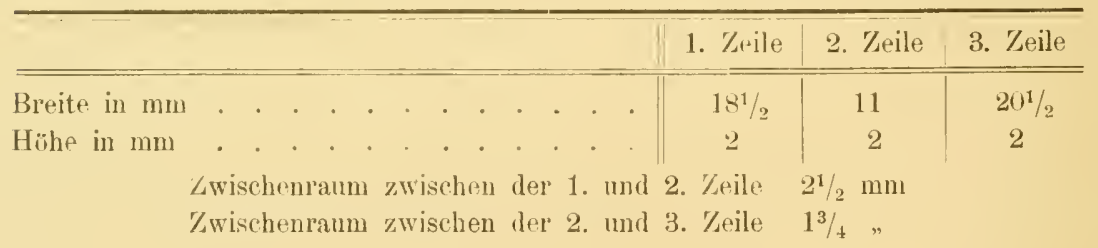

4. Auflruck: IABILITAD0 P0R LA NACI0N, in drei Zeilen, sogen. Typus vou Valladolid,

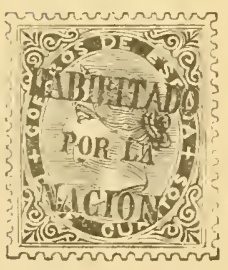

nach Moens unbestreitbar echt und in den Prorinzen Valladolid und Madrid gebraucht. Auch spanische Autoritäten wollen diesen Aufdruck in einigen Exemplaren gesehen haben, betonen aber, dass in der Provinz Marllid niemals eine Marke offiziell habilitirt worden und dass man auch auf den Bureaux der 
Regiermo in Valladolid ron diesem Aufdrucktypus nichts weiss. (Taf. VI, 70.) Die nallofolgende!! Abmessungen entnahm ich ron einem zweifellos echten Exemplar mit dem Stempel Valladolid:

\begin{tabular}{|c|c|c|c|}
\hline & 1. '/eile & 2. Zeile & 3. Zeile \\
\hline 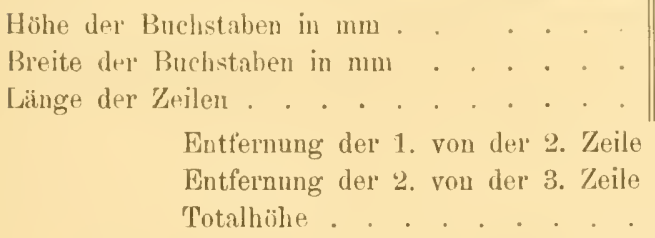 & $\begin{array}{l}23 / 4 \\
11 / 2 \\
16^{3 / 4} \\
. \\
. \\
.\end{array}$ & $\begin{array}{c}2 \\
1 \\
10 \\
31 / 4 \min \\
3 \quad n \\
4 \quad \cdots\end{array}$ & $\begin{array}{c}23 / 4 \\
11 / 2 \\
121 / 4\end{array}$ \\
\hline
\end{tabular}

Es wmrlen alle Werte mit Ausnahme der beirlen Zeitumgsmaken mit diesem Anfthrok gefunden.

5. Aufdruck: HPN immerhalb eines (Querorals, sugen. 'Typus von Hurcia.

Dieser Aufdrnck existirte im .Jahre 1869 knre Zeit in einigen wenigen. jetzt änsserst seltenen Exemplaren. Seine Verwendung ist zweifellos, sein Ursprnng ist ebenfalls nicht offiziell: der Stempel ist wah'scheinlich fiskalisch und berlentet nicht ..Habilitado por la nacion", sondern "Hacienda pública nacional".

Die Zahl der mit diesen Aufdruck rersehenen Marken ist so gering, dass sie im Jahre 1869 nur wenig bekannt wurden. Nichtsdestoweniger tanchten einige Jahre später in Auslande grosse Jengen dieser Narken auf, die man jetzt vielfach in den Sammlungen rorfindet. Dieselben. in Madrid hergestellt, waren sämtlich falsch und unterschieden sich ron den echten wie folgt:

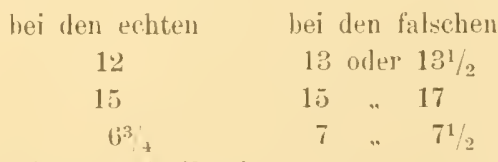

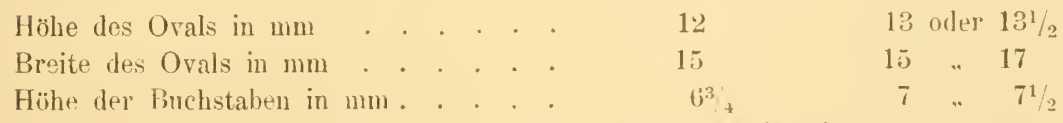

(Echter Anfdruck Taf. VI, 71, falscher Aufdruck 72.)

Nach Mnens existiren mit diesem Aufdruck nur die Marken zu 12 cs. 20 cents, 25 und 50 mils de esc.: ich selbst konnte bisher nur eines einzigen unbestreitbar echten Exemplares ansichtig werden. 
6. Aufdruck: HPN in grösseren Buchstaben ohne ovalen Rahmen, sogen. 'Yypus de las Canarias. Farbe: schwarz.

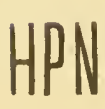

Höhe der Buchstaben $9 \mathrm{~mm}$,

Breite der 3 Buchstaben $93 / 4 \mathrm{~mm}$.

Er ist nur einmal und zwar anf einem Brief von Villaverde de Canarias mit der 50 mils-Marke gefunden worden. (?) Ich habe diesen Anflruck nie gesehen mul gebe daher seine Abmessungen nach Moens.

7. Aufdruck: HABILITADO POR LA NACION in doppeltem Queroval, sogen. Typus von Karagoza. Farbe: blan.

BILIT Auch dieser Aufdruck hat in einigen Exempor LA O plaren existirt, wem man anch seinen Ursprung nicht kennt. Die nämlichen Madrider Fälscher haben auch diesen Aufdruck gefälscht und ihn mnter obigem Namen in den Handel geluracht. In der Provinz Zaragoza hat man diesen Anfdruck offiziell nie gekannt.

Seine Abmessungen sind folgende:

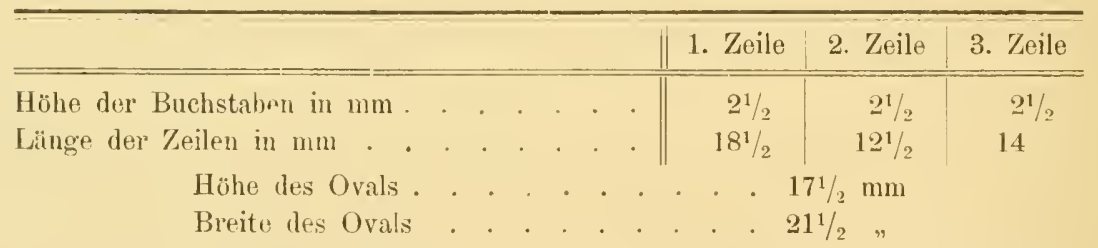

Der Unterschied zwischen den echten und falschen Aufdrucken besteht nicht in abweichenden Dimensionen, sondern in der Ausführung. Während bei den echten die Buchstaben schlank, dabei aber unregehnässig sind, das Oval schlecht gerundet nnd an den Seiten unterbrochen ist, sind bei den falschen die Buchstaben durchaus korrekt, nur etwas fetter und das Oval tadellos.

Nach Moens ist nur die Marke zu 50 Mil mit diesem Aufdruck gefunden. 
8. Aufdruck: HABILITADO POR LA NACION in 3 Zeilen, sogen. 'Typus von Salamanca. Farbe: schwarz und blan.

In Salamanca hat man niemals eine Marke habilitirt und diese Type ist daselbst nie bekamnt gewesen. Marken mit diesem Anflruck sind stets Fälschungen. Er wirl häufig mit dem offiziellen 'Iypus von Vizcaya verwechselt, der Hamptunterschied zwischen beiden bestelıt in dem Abstand der einzelnen Zeilen. Das , $\mathrm{O}^{*}$ in Habilitado ist ausserclem völlig ferunglïckt, d. h. zu sclimal. ('Tal. VI, 73.)

Seine Abmessungen sind:

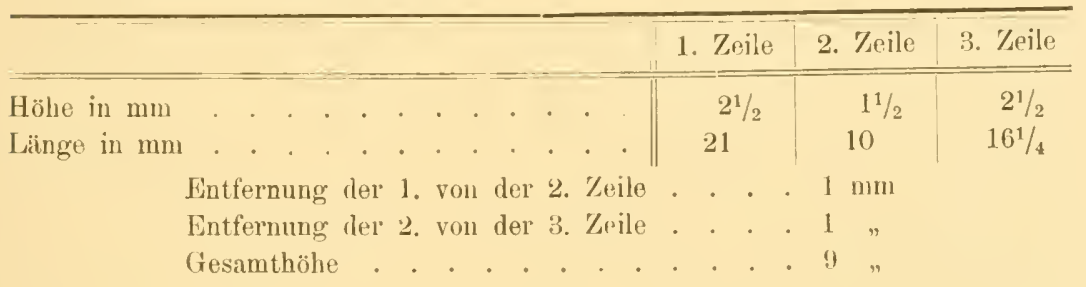

9. Aufdruck: IIABIITAD0 pol LA NACION, * in drei Zeilen, sogen. Typus de las Vascongadas. Farbe: schwarz.

Wurde anl einigen Briefen aus den baskischen Proviuzen gefunden. Sieine Abmessungen sind:

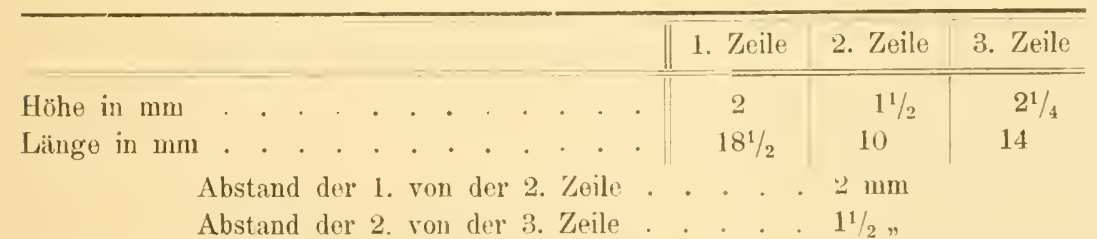

Soll anf den Marken zu $12 \mathrm{cs,} 10$ und 20 cents und 50 mils de esc. vorkommen.

* Anmerkung: Es ist sehr zu bedauern, lass Hoens diese Typo in seinem neuen Werke mit dem Namen „Vizcaya ${ }^{4}$ bezeichnet, whlırend er den in der 6. Auflage seilles Katalogs noch mit -Type dite de Biscaye ${ }^{4}$ aufgefihrten und von mir unter dieser bezeichnung erwhbnten Aufdruck

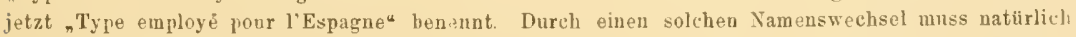
die Verwirrung in der Sammlerwelt noch gestrigert werden. Eiumal eingeflihrte und in weitereu Kreisen bekannt gewordene Bezeichnungen müssen meines Erachtens von Jedem respektirt und können nicht willkürlich gerndert werden. 
10. Aufdruck: HABILITADO POR LA NACION, in drei Zeilen, sogen.

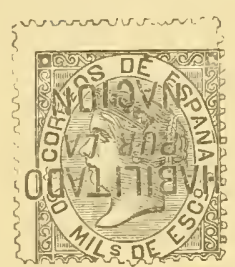
Typus von 0viedo. Farbe: schwarz.

Dieser Aufdruck diente in der Provinz ()vierlo zu fiskalischen Zwecken, er wurde nur auf dнr

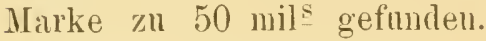

Seine Abmessungen sind:

\begin{tabular}{l}
\hline Höhe in $m m$ \\
Länge $\mathrm{in} m m$
\end{tabular}

Entfemung der 1, von der 2. Zeile . . . $1 \mathrm{~mm}$

Entfernung der 2. von der 3. Zeile . . . 2"

11. Aufdruck: H über, P N unter einem Löwen mit Fähnchen.

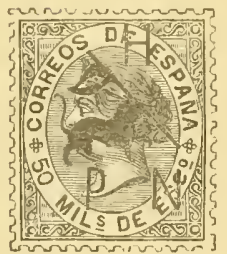
Farbe: schwarz.

Dieser häufig vorkommende Aufdruck ist reines Phantasie-Prorlukt.

12. Doppeltes Oval $(26 \times 19 \mathrm{~mm})$, oben in demselben: HABILITADO, in der Nitte: POR LA JUNTA, mten: REVOLUCIONARIA.

Ehenfalls die squatere Erfindung eines Schwindlers.

\section{Sehlussbemerkungen.}

Fassen wir nochmals das Ergebnis unserer Untersuchungen in kurzen Sätzen zusammen, so eryieht sich Folgendes:

1. Die "Zahl der s. "/t. mit dem Aufdruck: "Habilitado por la naeion" versehenen Marken war eine äusserst geringe und strht in keinem Verhältnis zu der \%ahl der heute in Sammlungen oder im Handel befindlichen; die grosse YehrzahI der letzteren sind entweder CieläligkeitsAufdrucke oder Fälschungen.

2. Von den 12 existirenden resp. bis heuto bekannt gewordenen Anfdrucktypen sind nur 2 offiziellen Ur'sprungs, die Typen vou Vizcaya und Cadiz, der Ursprung aller iubrigen ist dunkel. 
3. Die sogen. Typen von Salamanca, die rerschiedenen Aufdrucke: „Habilitado por la Junta revolucionaria". sowie der [öwentypus sind Filsehungen, alle ïhrigen sind entweder privaten Ursprungs oder dienten fiskalischen " Wwecken, gehören daher in die Klasse postalischer und philatelisticher Kiuriositäten.

4. Von sïmmtlichen Typen pxistiren so viele Fialschungen, dass diw grö̈ste Vorsicht beim Ankauf geboten ist.

Zum Schlusis mögen noch einige wichtige, beim Ankaif und der Untrisuchung zu bearhtende Regeln mitgeteilt werden:

Zur genanen Untersuchung dieser Marken gehöt eine gnte Lupe, welche lis Objekt nindestens $2-3 \mathrm{mal}$ vergrissert und ein Massital mit einer Einteilung his $211 \frac{1}{2} \mathrm{~mm}$. Den letzteren nimut man am besten : schrägter Seitenkante, weil sich auf dem Weiss les Elfenbeins die schwarze Einteilung am hesten ahlesen läst und die ahgrschrïgte Seite ein scharfes Anlegen an das zu messende Wort oder den zu messenden Buchstahen gestattet. Viertelmillimeter lassen sich hei guter Lupe nit Lrichtigkeit genügend genau abschätzen (Sehr zu empfehlen sind die von der Firma Hilckes, Kirkpatriek \& Comp. in London in den Handel gebrachten Elfeubeinmassstäbe „Universal“, welche sogar in Viertelmillimeter geteilt sind.)

An den zu untersuchenden Aufdruck gehe man mit dem grössten Misstraten, man halte ihn so lange fiur falsch, bis man deu Beweis für das Gegenteil rrlangt hat. Man traue keinem Verkänfer, weil unter den reellsten Bändlern viele sind, welch wenig oder nichts von diesen Marken verstehen und bona fide Fälschungen fiir echt verkaufen.

Nin betrachte genan das allgemeine Aeussere des Anfdrucks und sei besonder's misstranisch geren alle völlir undentlichen und rerwischten, aber auch gegen alle mit sichtbarer Sorgfalt nufgedrucliten Exemplare; erstere sind meist fillsch, letztere meist Gefälligkert-Anfitrucke. Der Beamte der Rentas Estaneadas, der anf eimmal mehrere hundert Jarken oder sogar Boyen zu ibberstempeln hatte, nahm sich selbstverständlich nicht die Mühe, jeden Stempel genan in die Mitte der Marke zu setzen und Sorge zn tragen, dass jeder Buchstabe scharf leshar war.

Jan betrachte genam die Farbe der Stempelschwärze. Bei alleu schwarzen Aufdrucken wurde dieselbe Schwärze benutzt, wie zu dem Entwertungsstempel. Weichen beide Farben von einander ah, so liegt, falls der Aufdruck iuberhanpt ceht ist, meist ein später aufgedruckter' Gelälligkeitsaufdruck ror.

Man untersuche genan den Entwertungsstempel. Hit guter Lupe lïsst sich meist konstatiren, ob der Entwertungsstempel iiber oder unter dem Aufiruck liegt. In letzteren Falle liegt natiirlich, wenn der Aubluruck sonst echt ist, ein GelälligkeitsAufdruck vor. Laisst sich das Datum des Entwertnngsstempels entziffern, so muss dasselbe zwisehen dem 1. Oktoher 1868 nnd dem 30. Dezember 1869 liegen.

In Bezug auf die Abmessungen der Worte mol Buchstaben beachte man sorgfaltig die oben remachten Angaben, berücksichtige jedoch dabei, dass Abnutzung der Stempel, Dicke der Schwärze und Flüchtigkeit der Stempelung häufig eine Verbreiterung der Buchstaben hervorrufen.

Man vergleiche schliesslich, wenn irgend möglich. den Anfdruck mit anerkannt echten Stiicken und suche sich durch vielfaches Betrachten ron solchen das Ange füı die Eigrentümlichkeiten jeder einzelnen Type zu schärfen.

Nur dureh strenge Befolgung dieser Hauptregeln wird man sich davor bewahreu, vieles Geld für wertloses Papier auszugeben. 


\section{Ausgabe:}

rom 1. Januar bis 31. Dezember 1863.

Die Ausgabe besteht ans sechs Werten, von denen fïnf in Typen früherer Ausgaben, nur mit Aenderung der Farbe und der Wertbezeichmung ausgeführt sind.

Farbiger Druck auf weissem Papier; gezähnt 14.

1. Typus der XV. Ausgabe (Taf. VI, 74 und 75):

a) mit schwarzem Aufdruck: "Habilitado por la nacion" im Typus von Vizcaya:

106. 100 MIL $\subseteq$ DE ESC. braun.

107. 200 MILS DE ESC. grün in zwei Abstufungen.

107 a) 200 MILS. DE ESC. griin,

$107 \mathrm{~b}) 200$ dunkelgriin.

118. 19 CUARTOS braun in zwei Abstufungen.

108 a) 19 CUARTOS braun,

108 b) $19 \quad$, hellbraun.

b) mit blanem Aufdruck: "Habilitado por la nacion" im Typus von Cadiz:

1199. 100 MIL DE ESC. braun.

110. 200 MILS DE ESC. grün in zwei Abstufungen.

110 a) 200 MILS DE ESC. grïn,

110 b) 200 " \#mkelgrün.

111. 19 CUARTOS braun in zwei Abstufungen.

111 a) 19 CUARTOS bram,

111 b) 19 hellbram.

c) ohme Auf'druck:

112. 100 MIL" DE ESC. braun.

11:. 200 MIL: DE ESC. grün in zwei Abstufungen.

113 i) 200 MILS DE ESC. grrin,

113 b) $200 \quad$ dunkelgriln. 
114. 19 CUARTOS braun in zwei Abstufungen.

114a) 19 CITARTOS braun,

114b) 19 hollbraun.

2. Yeichumg der XVJ. Ausgabe:

a) mit schwarzem Aufdruck: "Habilitarlo por la nacion" in 'Jypus voll Vizcaya:

115. 25 MIL: DE ESC" blau in drei Abstufungen.

115 a) 25 MIL: lle ES(Y) hlan,

115 h) 25 hellblau,

115 c) 25 dunkelblau.

b) mit blatem Aufdruck: "Habilitado por la nacion" im Typus voll Carliz:

116. 25 MIL: DE ESC" blau in drei Abstufungen.

116 a) 25 M11: DE ESCo blau,

116 b) $25 \quad$ hellblau,

116 c) $25 \quad$ dunkelblau.

c) ohne Aufdruck:

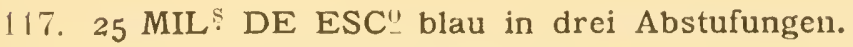

117 a) 25 MILS DE ESCO blau,

117 b) $25 \%$ hellblau,

117 c) $25 \quad$ dunkelblau.

3. Neue Zeichnung: Kopf der Königin Isabella mit Krone nach links in einem Oval mit liniirtem Untergrund; im Oval oben in weissen Buchstaben auf farbigem Untergrund: CORREOS DE ESPA $\widetilde{N A}$, inten Weltangabe. (Tat. V1, 76.)

a) mit schwarzem Aufdruck: „Habilitado por la nacion“ im Typus von Vizcaya:

118. 5o MILS DE ESC ${ }^{0}$ violett in vier Schattirungen.

118 a) 50 MIL: DE ESCo violett,

118 b) 50 dunkelrötlichviolett,

118 c) $50 \quad " \quad$ blassrotviolett,

118 d) $50 \quad " \quad$ bräunlichviolett. 
b) mit blauem Aufdruck: "Habilitado por' la nacion" im Typus von Cadiz:

119. 50 MILS DE ESC 0 violett in vier Schattirungen.

119 a) 50 MILs. DE ESC $\underline{\text { violett, }}$

119 b) 50 dunkelrötlichviolett,

119 c) $50 \quad " \quad$ blassrotviolett,

119 d) $50 \quad " \quad$ bräunlichviolett.

c) ohne Aufdruck:

120. 50 MILS DE ESC violett in vier Schattirungen.

120 a) 50 MILS DE ESCQ violett,

120 b) 50 dunkelrötlichviolett,

120 e) $50 \quad " \quad$ blassrotviolett,

120 d) $50 \quad " \quad$ bräunlichviolett.

4. September 1869, Zeichnung der XV. Ausgabe, nur Farbenänderung; ohne Aufdruck:

121. DOCE CUARTOS rotorange.

Bemerkungen.

1. Die Ordnung der Marken dieser Ausgabe weicht von der in anderen Handbüchern uhlichen etwas ab, sie ist jedoch durchaus logisch, denı wenn auch die sub a, b und c aufgeführten Marken thatsächlich zu gleicher Zeit in Umlauf waren, so durften sie doch, dem Gesetze vom 30. September 1868 entsprechend, eigentlich nicht ohne den Aufdruck: „Habilitado por la nacion" gebraucht werden.

2. Es erscheint befremdlich, dass noch nach dem Sturze der bourbonischen Dynastie neue Marken mit dem Kopfe Isabellas in Umlauf gesetzt wurden, allein dieselben waren schon im Herbst 1868 zur Ausgabe fertig gestellt, zulr Anfertigung neuer Platten fehlte es aber an Zeit und Geld.

3. Ueber die Ausgabe der Marke zu 19 cuartos in braun giebt es keine genauen Angaben, vielfach wird dieselbe schon in Dezember 1868 verlegt.

4. Mit Aufdrucken nicht-offiziellen Ursprungs kommen dis Marken der XIX. Ausgabe wie folgt vor:

19 cuartosmit dem Aufdruck : „Habilitado por la nacion“ im Typus von Valladolid, 25 Mils de esc. mit dem Typus von Valladolid,

$50 \mathrm{MilS}$ de esc. mit den Typen von Oviedo, Valladolid und de las Vascongadas, 100 u. 200 Mils de esc. mit den Typen von Murcia, Valladolid und Vascongadas. 
5. Die Marke zu 12 cuartos, deren Farhenänderung infolge von Fälschungen nötig wurde (siche Ausgabe $\mathrm{XY}$, liemerk. 4), ist nit Auffluck nicht bekannt, wie überhaupt von Sommer 1869 an wohl nur noch wenige Marken habilitirt wurden.

6. Von der Marke zu 50 Mils de esc. giebt es zwei Fïlschungen, welche hauptsächlich beide an den schlecht ansgeführten Inschriften, ausserdem aber anch daran erkenubar sind, dass die erstere eine Zähnung von $14 \frac{1}{2}$, die andere cine solche von $13 \frac{1}{2}$ besitzt; bei der letzteren fehlt ïberdies der Tilde uber dem $N$ von ESPANA.

7. Ton Essais giebt es: 50 mils de esc. in rosa, schwarz, dunkelviolett und gelbbrann auf dünnem, weissem, Papier, 200 mils de esc. in schwarz und karmin auf dickem, weissem, satinirtem Papier, sämtlich ungezähnt. Ausserdem existiren aber noch eine Reihe sehr schön ausgeführter Entwürfe, deron Annahme durch die Revolution verhindert wurde:
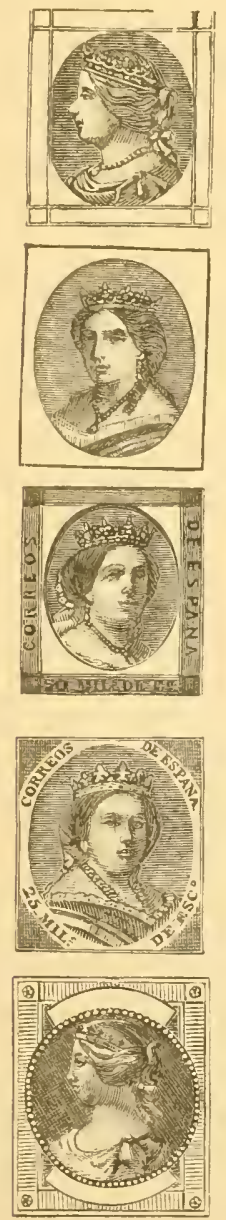

Büste der Königin mit Krone im Profil nach links imuerhalls eines Ovals mit quadrirtem Untergrund; um das Oval viereckiger Rahmen, ohne Inschrift pp. Das Essai ist in Stahlstich ausgeführt und in roter, blauer und schwarzer Farbe auf' weissem Papier, letzteres anch anf weissem Karton gedruckt.

Büste der Königin mit Krone zu $3 / 4$ nach links innerhalb eines Ovals mit quadrirtem Untergrund; um das Oval viereckiger Rahmen, ohne Inschrift pp. Kommt in Kupferstich in blaner und schwarzer Farbe anf weissem Papier oder Karton ror.

Büste der Königin mit Krone zu $3 / 4$ nach rechts innerhalb eines Orals mit quadrirtem Untergrund; um das Oval ein viereckiger Rahmen mit liniirtem oder weissgelassenem Untergrund und folgenden Inschriften: links: CORREOS, rechts: DE ESPANA, unten: Wertangabe. Kommt vor, in Kupferstich ausgeführt, in blaner, zinnoberroter und schwarzer Farhe anf Papier oder Karton, mit und ohne Inschriften.

Büste der Königin mit Krone zu $3 / 4$ nach rechts innerhalb eines Ovals mit quadrirtem Untergrund; um dieses Oval ein weisser Rahmen mit Inschriften und zwar oben: CORREOS DE ESPANA, mnten: 25 MILS DE ESCo; die Eeken sind wieder quadrirt oder auch meiss gelassen.

In Kupferstich mit quadrirten Ecken in blau oder sehwarz auf weissem Papier, ohne solche in zinnoberroter Farbe aut weissem Karton.

Büste der Königin mit Krone im Prolil nach links innerhalb eines Perlenkreises mit quadrirtem Untergrund; über und unter dem Kreise weissgelassene bogenförmige Schilder zur Anfnahme der Inschritten: um das Ganze ein viereckiger, mit Strichen ausgefüllter Rabmen.

Ist, in Kimpe stich ausgeführt, nur in rosa und olivengrüner Farbe auf weissem Karton bekannt. 


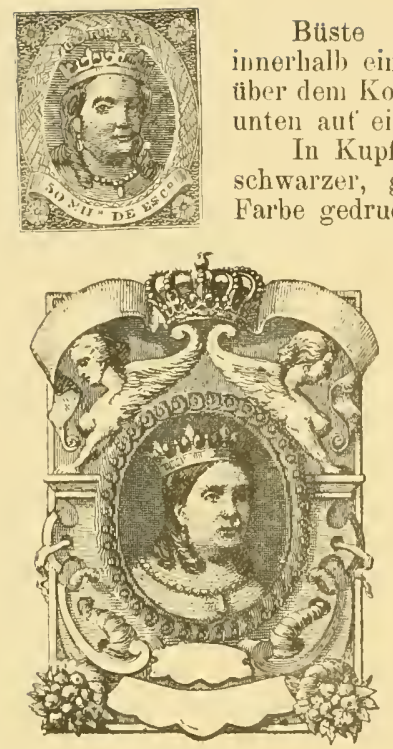

In vergrösserter Ausfuhrung (49:38 mm): Kopf der Königin mit Krone und Halskette zu $3 / 4$ nach rechts in ovalem Rahmen, Untergrund schraffirt; über dem Rahmen Krone auf nach beiden Seiten herabfallendem, zur Aufnahme der Inschriften bestimmtem Band, darunter rechts und links geflügelte Frauenköpfe (Sphynxe); ınter dem Rahmen auf jeder Seite ein Fullhor'n mit Blumen und Früchten, zwischen beiden zwei weiss gebliebene Schilder zur Aufnalıme iler. Inschrift.

Das Essai kommt in volziiglichem Knpferstich auf dickem, weissem Papier in schwarzer, blauer und roter Farbe ohne Inschriften vor.

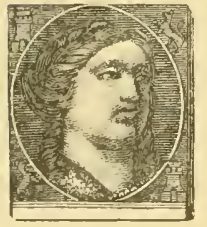

Frauenkopf nach rechts (von Moens irrtumlich als Isabellia $I 1$. bezeichnet) in einem Oval mit liniirtem Untergrund; in den Ecken Wappen von Castilien und Leon; unten weiss gelassener viereckiger Schild ohne Iuschriften.

In Kupferstich ausgeführt, in versehiedenen Farben auf Papier oder Karton, und zwar:

in schwarz. grün, blau, ultramarin, violett, violettrosi, braun und blassrot anf weissem Karton,

in schwarz auf rosa und blassgrïnem Karton,

in karmin, violett und zinnoberrot auf weissem und in schwarz auf blauem Papier.

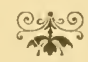

\section{Ausgabe:}

vom 1. Januar und 9. Juni 1870 bis 30. Septeuber 1872.

Frauenkopf mit Manerkrone, die España darstellend, darüber ein Stern, in einem Oval mit liniirtem Untergrund; iiber dem Oval auf einem sich um dasselbe schlingenden Band: CONUNICACIONES (Verkehr, Mitteilungen), unten Wertangabe; an Halse die Initialen des Kupferstechers E. J. (Eugenio Julia). 
Farbiger Buchdruck auf weissem Papier; gezähnt14. (Taf.VI, 77.)

A. 1. Tannar 1870:

120. 25 MIL: $\mathrm{DE} \mathrm{E}^{0}$ (milésimas de Escudo), lila in fünf Schattirungen.

122 a) 25 MIL: DE Eu lila,

122 b) $25, "$ blasslila,

122 c) $25 \quad " \quad$ graulila,

122 d) $25 \quad$ violett,

122 o) $25 \quad$ blassviolett.

123. 50 MILः DE E 0 blau in drei Schattirungen.

123 a) 50 MILS DE EO ultramarinblau,

123 b) $50 \quad " \quad$ blassultramariublan,

123 c) 50 mattblau.

124. 100 MILS DE E braunrot in fünf Schattirungen.

124 a) 100 MIL: DE EO braunrot,

124 b) $100 \quad "$ dunkelbraumrot,

124 c) $100 \quad "$ dunkelrot,

124 d) $100 \quad " \quad$ weinrot,

124 e) $100 \quad " \quad$ blassgelbbrïuulich.

125. 12 CUARTOS braun in fünf Schattirungen.

125 a) 12 CUARTOS bramrot,

125 b) 12 " dunkelbraunrot,

125 c) $12 "$ hellbraunrot,

125 d) 12 " gelblichbraun,

125 e) $12 \quad$ bräunlichgelb.

126. 200 MILS $\mathrm{DE} \mathrm{E}^{0}$ braun in zwei Abstufungen.

126 a) 200 HILs: DE EO dunkelbraun,

126 b) 200 hellbraun.

127. 19 CUARTOS grün in drei Schattirungen.

127 a) 19 CUARTOS gelbgrün,

127 b) 19 , blassgelbgrün,

127 c) $19 \quad " \quad$ blassgrin.

128. 400 MILS DE E $E_{-}^{0}$ grün in vier Schattirungen.

$\begin{array}{llll}128 \text { a) } & 400 \text { NIL: DE E } 0 \text { griin, } \\ 128 \text { b) } & 400 & " & \text { blassgrin, } \\ 128 \text { c) } & 400 & " & \text { blaugrün, } \\ 128 \text { d) } 400 & " & \text { gelbgrïn. }\end{array}$

129. $1 \mathrm{E} \div 600 \mathrm{M}$. lila in vier Schattirungen.

129 a) 1 Eu 600 Mș lila,

129 b) " blasslila,

129 c) " $\quad$ lebhaft lila,

129 d) $\quad$ bräunlich lila. 
130. 2 ESCUDO blau in drei Abstufungen.

130 a) 2 ESCUDOS blau,

130 b) $2 \quad "$ blassblan,

130 c) $2 \quad$, himmelblau.

B. 9. Juni 1870. Ergänzungswerte. Farbiger Druck auf verschierlen gefärbtem Papier:

131. 1 MILA DE $E^{0}$ violett in vier Schattirungen auf fleischfarbenem oder chamois Papier.

131 a) 1 MILA DE EO violett anf fleischfarbenem Papier,

\begin{tabular}{|c|c|c|}
\hline $131 \mathrm{~b}) 1$ & & dunkelviolett aut fleischfarbenem Papier, \\
\hline 131 e) 1 & & lila auf fleischfarbenem Papier, \\
\hline $131 \mathrm{~d})$ & & lila auf chamois Papier, \\
\hline $131 \theta)$ & & violettbrauu auf chamois Papier. \\
\hline
\end{tabular}

132. 2 MIL DE E $E_{-}^{0}$ schwarz und braun auf fleischfarbenem oder chamois Papier.

132 a) 2 MIL: DE Eo schwarz auf chamois Papier,

132 b) 2 schwarz auf fleischfarbenem Papier,

132 e) 2 " tiefschwarz auf fleischfarbenem Papier,

132 d) 2 " braun auf fleischfarbenem Papier.

133. 4 MILs DE E E $_{-}^{0}$ bäunlich in zwei Schattirungen auf weissem Papier.

133 a) 4 MLLS DE E 0 gelblichbraun,

133 b) 4 bräunlich.

134. 10 MIL\$ DE E

134 a) 10 MILs DE Eo rosa,

134 b)

$134 \mathrm{cl}$

$134 \mathrm{~d})$

$\begin{array}{ll} & \text { blassrosa, } \\ & \text { bräunlichrosa, } \\ \text { karminrosa. }\end{array}$

Bemerkungen.

1. Nach dem Sturze der Königin Isabella forderte die Regierung die Academia de historia in Madrid auf, zum Zwecke der Herstellung von Mïnzen, Postund Telegraphenmarken pp. eine allegorisehe Figur der España zu entwerfen. Ein Aussehuss von Akarlemikern schlug vor, die Esspaña darzustellen als sitzende Franengestalt mit einem Oelzweig in der rechten Hand; auf dem Kopte eine Krone, als Symbol des Friedens und der Volkssouveränität. Ein entsprechender Entwurf wurde auch für Münen und fiskalische Marken angenommen, für die Postwertzeichen beschränkte man sich auf Wiedergabe des Kopfes allein.

2. Durch Erlass vom 8. Dezember 1869 wurde befohlen, dass in Znkunft tür Post und Telegraphie die nämlichen Marken zu verwenden seien und diese deshalb nieht mehr die Bezeichnung: "Correos" bezw. "Telegrafos", sondern: "Comunicaeiones" zu führen hätten. Die für Telegraphenzwecke verwendeten Markeu erkennt man, soweit sie gebrancht sind, an der Durch- 
lochung, welches System für die Entwertung der Telegraphenmarken eingefiihrt war. Die Marken zu 400 Mils, 1 Esc. 600 Mils und 2 Escudos dienten fast ausschliesslich zur Frankirung von Telegrammen, weshalb sio gebrancht meist durchlocht, postalisch entwertet sehr selten sind.

3. Die Ausfithrung der Marken diesel Ausgahe ist infolge übelangebrachter Sparsamkeit und der Notwendigkeit eiliger Herstellung äusserst schlecht; die Klagen über die unschönen MIarken füllen daher vielfach die Spalten der Zeitungen jener Zeit und dies umsomehr, als sich während des Jahres 1869 namhafte Künstler mit Entwürfen zu nenen Marken beschäftigt hatten. Dio mangelhafte Ausführung ermunterte natülich zu Fälschungen. Die ersten Falsifikate wurden im Dezember 1870 entdeckt, weshalb am 4. Dezember die Anfertigung neuer 'l'ypen befohlen wurde, welcher Befehl jedoch nicht zur Ausführung gelangte. Im August 1871 fand man in Sevilla lalsche Marken zu 50 Mils, welche sich von den echten nur durch den weniger guten Stich und die Unregelmässigkeit in der Zähnung unterschieden. Im April 1872 entdeckte man in Sevilla und Murcia neue Falsifikate der 50 Mils-Marke, auch bei ihnen ist der Stich roher und die Zähnung abweichend (13 statt 14). Falsche Marken zu 400 Mils und 1 Esc. 600 Mils, im Herbst desselben Jahres auftauchend, sind an der mangelhaften und abweichenden Ausführung der Inschriften erkenntlich.

4. Die Essais zu dieser Ausgabe sind sehr zahlreich. Es kommen sämtliche Werte in grauschwarzer und blaner Farbe auf dickem und dünnem Papier ror, ansserdem die Marke zu 50 mils de esc. in blassgrin auf weissem Papier vergé, 19 cuartos in violett und 100 milș de esc. in blau, beide auf fleischfarbenem Papier; auch giebt es Abzige in blaner Farbe ohne Wertangabe. Am zahlreichsten sind die Essais zu 1 mila de esc. Dieselben giebt es in grauschwarz, gelbbrann, violett und rosa auf weissem Papier, schwarz auf blau und malvenfarbig auf blassgelbem Papier.

Von der Aufzählung der zahlreichen Doppeldrucke nehme ich Abstand.

Ansser diesen Probedrucken der angenommenen Typo giebt es noch eine Reihe sehr schöner Entwïrfe, von denen einige jedoch so eigenartig erscheinen, dass selbst die Autorität eines Iloens und Duro mir nicht genügt, sie als Essais für Postwertzeichen anzuerkennen. Hierher gehören:

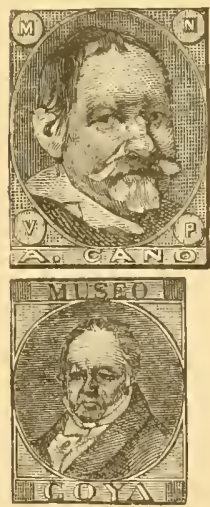

Kopf des Malers und Bildhauers Alonso Cano (nach einem im Museo del Prado zu Madrid befindlichen Gemälde von Velasquez) nach rechts im Oval mit quadrirtem Untergrund; in den Ecken vier kleine Kreise mit den Buchstaben M, N, V, P (Museo nacional, Velasquez pinxit), unten auf viereckigem Schild: A. CANO. In Kupferstich in schwarz, dunkelbraun, gelbgriin, dunkelgelb, blauıriin, dunkelrot, bronzegrün, weiurot, scliwarzviolett und dunkelblan auf weissem Papier, ausserdem in blaı, dunkelblaı, rosa, chamois und griin auf farbigem Papier.

Biiste des Malers Goya nach links in einem kreisförmigen Rałımen mit quadrintem Untergrund; oben in viereckigem Schild: MUSEO, unten in eluensolchem: GOYA. Das Essai ist in Kupferstich ausgeführt und nur in schwarzgrauem Druck aut gelblichem Papier bekannt.

Goya geniesst allerdings in Madrid, dessen Bewohner seine Werke im Museo del Prado stets vor Augen haben, einer lokalen Beruhmtheit, Alonso Cano aber dürfte als Künstler wohl den wenigsten Spaniern bekannt sein, beide verschwinden jedenfalls unter den zahllosen illustren Namen, welche die Geschichte Spaniens, namentlich in Bezug auf bildende Kunst zu verzeichnen hat, es 
dürfte deshalb schwer zu erklären sein, weshalb man gerade die Köpfe dieser beiden Männer als Verzierung für Postwertzeichen gewälllt haben sollte. Grösse. Art der Zeichnung, Inschriften pp. lassen vielwehr darauf schliessen, dass diese Entwïrfe für eine andere Bestiminung gemacht und erst später aus Grïnden der Spekulation als postalische Essais ausgegeben wurden.

Philatelistisch wertvoller erscheinen dagegen folgende Essais:

Kopf der España mit Mauerkrone in viereckigem Rahmen

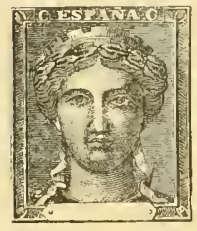
mit liniirtem Untergrund; oben C. ESPA T̃A C., unten weissgelassener Schild für die Wertangabe. In Kupferstich ausgeführt. in zwanzig verschiedenen Farben auf Papier und Karton, und zwar:

blassblau, lebhaft blau, gelbgrüı, grtin, lebhaft grün, schwarz, grauschwarz, gelbbramn, braun, zeisiggrün, goldgelb, blassgelb, rot, karminrot, bramrot, zinnoberrot, blassmalven, lehhaft malven, braunmalven, hellrosa auf weissem Papier, schwarz auf weissem Karton und

schwarz und nltramarinblan auf grlacirtem Papier;

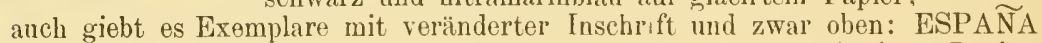
ohne die beiden C, unten: P. del P.E., in brauncr und graner Farbe aut weissem Papier.

Kopf Guttenbergs en face in einen Oval; um dasselbe ein viereckiger Rahmen mit Inschriften und zwar oben: España, unten: Correns, rechts: Franquen, links: Impresos, zwischen Oval und Rahmen links die Ziffer 10, rechts ms (maravedis.) In Lithographie hergestellt, nur schwarzblau auf weissem Papier bekamt. (Eine Abbildung des :iusserst seltenen Essais war leider nicht zu beschaffen.)

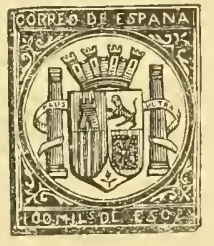

Spanisches Wappen mit Mauerkrone in kreisrundem Rahmen mit weissem Untergrund; über demselben : CORREOS DE ESPANA, unten Wertangabe. Existirt für die Werte 50 und 100 Mils de esc. in griuner und ziegelroter Farbe anf weissem Papier.

Fin ähnliches Essai unterscheidet sich von diesem nur eine Untergrund des Kreises, kleinere Krone und

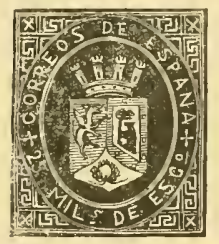

Grosses Wappen der Stadt Madrid (siche Einleitung: Heraldisches) mit Mauerkrone ur ovalem Rahmen mit farbigem Untergrund; im Rahmen: CORREOS DE ESPA $\widetilde{N A}$ und Wertangabe in weissen Buchstaben; um das Wappen viereckiger Rahmen mit griechischer Bordüre. Bekannt ist mur der Wert von 25 mils in blan auf weissem Papier.

5. Mit Begiun des Jahres 1870 wurde ein neuer Entwertungsstempel eingeführt, der bei vielen Postanstalten heute noch in Gehranch ist. Es ist ein Punktstempel in Form eines schiefwinkeligen Parall logranims, siehe Taf. VII, 78. Neben diesem Stempel der Haupt-Postanstalten tind'n wir bei den Carterías und Estafetas völlig abweichende Modelle in Gebrauch, iiber deren Einführung und Verwendung offizielle Daten nicht zul erlangen waren. Es gehören hierler No. 79. 80 und 81 T'af. VII, doch existiren noch einige andere Abarten.

Zur Bezeichnung der eingeschriebenen Briefe wurden im Laufe des Jahres 1870 nene Stempel eingeführt. Dieselben haben zumeist die Form eines Rechtecks mit abgestumpften Ecken und tragen die Inschrift: CERTIFICADO, oder anch abgekürzt: CERTIF.

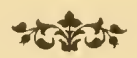




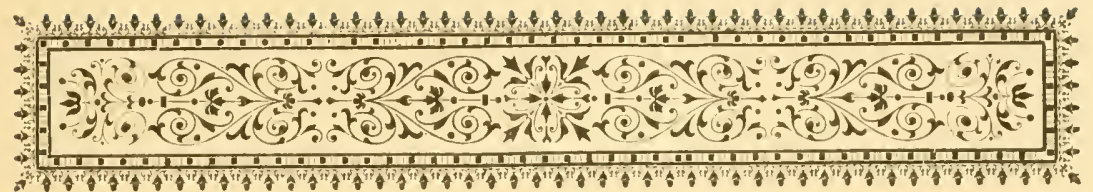

\section{(. Marken aus der Zeit der Regiermon des Kinigs Amadeo I.}

\section{Ausgabe:}

vom 1. Oktober bis 31. Dezember 1872 und 30. Juni 1873.

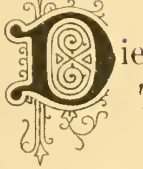

ie Ausgabe setzt sich zusammen aus 12 Werten in vier Typen.

1. Type: Zeitungsmarke. Grosses Quadrat ans vier Marken à $1 / 4$ céntimos de peseta bestehend: in der Mitte einer jeden Marke ein Oval mit der Ziffer $1 / 4$, darunter: de cents de peseta, darïber die Königskrone; um das Ganze ein quadratischer Rahmen, in demselben oben und unten: Correos España, rechts und links Wertangabe. Farbiger Druck auf weissem Papier, ungezähnt. (Taf. VI, 82.)

135. $1 / 4$ cent $\$$ de peseta blau in zwei Abstufungen.

135 a) $1 / 4$ cents de peseta blau, $135 \mathrm{~b}) 1 / 4$ blassblau. 
IT. Type: Zeitungsmarke, ähnlich derjenigen der XVII. Ausgabe, um Wertangabe verändert und an Stelle von "Correos" die Bezeichnung "COMUNIC- (commicaciones).

Farbiger Druck anf weissem Papier, gezähnt 14 . (Taf. VI, 83).

136. 2 (Dos) CENTS DE PESETA violett und grau in verschiedenen Schattirungen.

$\begin{array}{llll}136 \text { a) } & 2 & \text { CENTS DE PESETA } & \text { violett, } \\ 136 \text { b) } & 2 & " & \text { hellviolett, } \\ 136 \text { c) } & 2 & " & \text { grau, } \\ 136 \text { d) } & 2 & " & \text { blangrau. } \\ 136 \text { e) } & 2 & " & \end{array}$

137. 5 (Cinco) CENTS DE PESETA grün in vier Schattirungen.

137 a) 5 CENTS DE PESETA gelbgrün,

137 b) $5 \quad$ blaugrün,

137 c) $5 \quad, \quad$ hellblangriun,

137 d) $5 \quad$, graugrün.

III. Type: Büste des Königs Amadeo zn 3/4 nach rechts in einem Oval mit liniirtem Untergrund; ïber demselben: COMUNICACIONES; in den beiden mnteren Ecken Wertangabe in Zahlen: dazwischen: C. ESPAÑA C.

Farbiger Druck auf weissem Papier; gezähnt 14. (Taf. VI, 84.)

138. 6 C. (céntimos) blau in zwei Abstufungen.

138 a) 6 C. hellblau,

138 b) 6 C. blassblau.

139. $10 \mathrm{C}$. violett in drei Abstufungen.

139 a) $10 \mathrm{C}$. violett,

$139 \mathrm{~b}) 10 \mathrm{C}$. blassviolett,

$139 \mathrm{c}) 10 \mathrm{C}$. dunkelviolett.

140. 12 C. lila in zahlreichen Schattirungen.

140 a) 12 C. lila,

$140 \mathrm{~b}) 12 \mathrm{C}$. hellilia,

140 c) 12 C. blassviolett,

$140 \mathrm{~d}) 12 \mathrm{C}$. blauviolett,

140 e) 12 C. grau.

141. 25 C. braun in zwei Schattirungen.

141 a) 25 C. braun,

141 b) 25 C. gelblichbraun. 
142. 40 C. rötlichbraun in drei Schattirungen.

142 a) 40 C. rötlichbraun,

142 b) 40 C. hellbraun,

142 c) 40 C. dunkelbraun.

\section{5o C. blaugrün in zwei Abstufungen.}

143 a) 50 C. blaugrün,

$143 \mathrm{b)} 50 \mathrm{C}$. dunkelblaugrün.

IV. Type: Kopf des Königs nach rechts in einem Oral mit liniirtem Untergrund: darïber: CONUNICACIONES, darunter auf viereckigem Schild Wertangabe: in den Ecken unten zwischen Oval und Wertangabe: ESP., auf dem Halsabschnitt der Name des Kupferstecher's Julia.

Farbiger Buchdruck auf weissem Papier; gezähnt 14. (Taf. VI, 85.)

14. UNA PESETA violett in zwei Abstufungen.

144 a) UNA PESETA violett,

144 b),$\quad$ hellviolett.

145. CUATRO PESETAS gelbbraun in zwei Abstufungen.

145 a) CUATRO PESETAS gelbbraun,

$145 \mathrm{~b}) \quad$ blassgelbbram.

146. DIEZ PESETAS grün in zwei Abstufungen.

146 a) DIE\% PESETAS blaugriin,

146 b) , hellgrün.

Bemerkungen.

1. Im Oktober 1872 war die neue Münzwährnug eingeführt worden, Jaher die veränderte Wertbenemung.

2. Die Marke zu $1 / 4$ cents de peseta konnte einzeln oder in Ganzen ( $4 / 4$ ) gebraucht werden; bei ihrer Herstellung hatte die Marke zu 4 Gute Groschen vou Brannschweig als Muster gedient.

3. Die Marken zu 2, 5 und 40 céntimos (No. 136, 137 und 142) existiren auch ungezähnt.

4. Die Essais zu dieser Ausgabe sind wieder sebr zahlreich. Es sind bekannt: in Type I:

in Type Il:

$1 / 4$ cent. de pes. schwarz auf chamois Papier.

dos cents de peseta karmin auf dickem, weissem, satinirtem Papier,

cinco cents de peseta grün, nltramurin und violett auf ebensolchem Papier. 
in 'Type III:

5 c. d. p. grïn und blan auf dickem. weissem, satinirtem Papier,

6 c. d. p. blau auf weissem Papier,

blasshlan, gelbgriin und blassgelbgriin auf dickem, weissem, satinirtem Papier,

10 c. d. p. blau, gelbgrin und blassgelbgrïn auf ebensolchem Papier.

12 c. d. p. blan, gelbgrïn und blassgelbgrïn anf ebensolchem Papier,

25 c. d. p. gelbbraun, braungelb und grün anf weissem Papier,

grün, blau und schwarz auf dickem, weissem, satinirtem Papier.

40 c. d. p. blau, malven, violett, griin und braungelb auf weissem Papier, grün, blau, dunkelbraun, rotbraun und violettbraun auf chainois Papier,

grïn, dunkelblau, orange, schwarz und violett auf dickem, weissem, satinirtem Papier.

50 c. d. p. grün, gelbbraun auf weissem Papier,

griin und schwarz auf dickem, weissem, satinirtem Papier.

in Type IV:

Una peseta grün, blassgrün, blau, dunkelblan, braun, violett und schwarz auf dickem, weissem, satinirtem Papier,

Cuatro pesetas blau auf gelbem Papier,

grïin, blan und schwarz auf dickem, weissem, satinirtem Payier',

Diez pesetas grün, blau und schwarz auf dickem, weissem, satinirtem Papier; mit schwarzer Borde um die Marke:

Una peseta schwarz auf dickem, weissem, satinirtem Papier.

Ohne Angabe des Wertes:

blau, dunkelblau, orange, lebhaft orange, gelbgrün, blaugrïn, gelbbraun, braungelb, dunkelbraun, karmin und rosa.

Ansser diesen Essais in den angenommenen Typen giebt es noch eine Reilhe sehr' schöner, nicht angenommener Entwürfe:

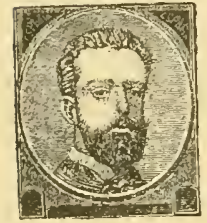

Kopt des Königs Amadeo 3/4 nach rechts in Kreise mit liniirtem Untergrund (ähnlich Type III); in den beiden oberen Ecken: España auf dunklem Ciruud, unten in den Ecken auf kleinem sechseckigem Schild Wertangabe, dazwischen Cent. de peseta. Das Essai kommt auch ohne jegliche Inschrift und Wertangabe vor.

Es sind in dieser Zeichnung bekannt:

a) nit Wertangabe 12 cent. de peseta: gelbgrün, grün, lila, malven, violett, rosa, gelblicbbraun, blat und schwarz.

b) mit Wertangabe 12 cent. de peseta, Kopf mit Umrandung, Rechteck ausserhalb des Kreises und Inschriften in 3 verschiedenen Farben und zwar:

Kopf blau, Rechteck schwarz, Inschriften und obere Ecken rot,

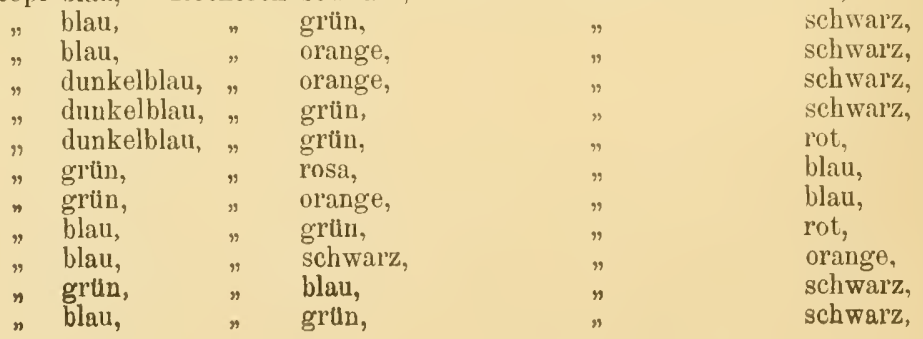




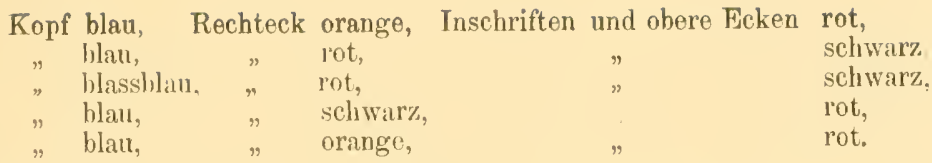

c) olne Wertangabe und ohne Inschifit:

sehway, blass- mod dumkellila, griun, losa, blau, dunkelblau, orange und lobliaft orange,

in zwei Farben: Kopf blau, Leken grrïn,

" blau, " orange.

Typus der Philippinen-Marken des Jahres 1872 (siehe Philippinen,

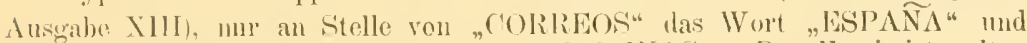
"COMINTCA "IUNES" an Stelle von .FILIPINAS". Das lissai ist selten unk nur mit Wertangabe 12 cents de pesetas in schwarzer Farbe anf weissem Papier hekannt

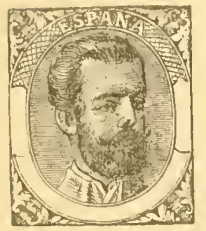

Kopf des Königs zu $3 / 4$ mach rechts imerhalb eines ovalen Rahmens mit liniirtem Untergrund; oben in demsellen: ESPA $\widetilde{N} A$, der nntere Teil ist weiss gelassen zur Aufnahmo der Wertbezeichnnng; in den Ecken Verzierungen.

Das Essai kommt, in Kupferstich ausgefiihrt, in verscliedenen Farben vor:

auf weissem Kartnn in schwarz, zinnober, fleischfarben, griuln, bronzegrïn, dunkelblan und dunkelrot,

anf glacirtem Papier in schwarz, violett, blassgrun, blau, orange, perlgrau und weinrot.

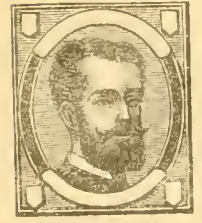

Kopf des Königs zu $3 / 4$ nach rechts innerhalb eines ovalen Rahmens mit liniirtem Untergrand; der Rahmen ist zum Teil weiss gelassen für die Inschriften; in den Ecken kleine weisse Schilder für die Wertangabe.

Das Essai existirt, in Kupferstich ausgeführt, in verschiedenen Farben, und zwar:

auf weissem Karton in blau und gelbbraun,

auf glacirtem Papier in braunviolett, schwarz und blassgriin.

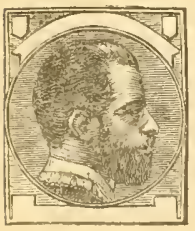

Kopf des Königs nach lechts in einem Kreise mit liniirtem Untergrund; über dem Kreise ein weissgelassenes Band und zwei kleine Schilder, unten ein grösseres Schild zur Aufnahme der Inschrifteu.

Das in Kupferstich hergestellte Essai kommt auf weissem, glacirtem Papier in schwarzer, dunkelblauer, braunvioletter, dunkelbrauner und violetter Farbe vor.

Kopf des Königs nach links in einem Oral mit liniirtem

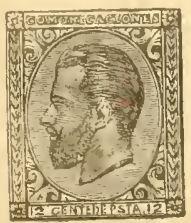
Untergrund. um das Oval viereckiger Rahmen, an den Seiten und in den Ecken Verziermngen, oben: COMUNICACIONES, unten: Wertangabe.

Das Essai existirt. in Kupferstich ausgeführt, für den Wert von 12 Cents.

auf weissem, glacirtem Papier in lila, blau und gelbbraun, auf weissem Karton in schwarzer Farbe. 


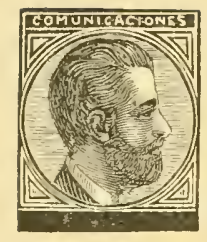

Kopf des Königs nach rechts in einem Kreise mit liniirtem Untergrund; ïber den Kreis ein viereckiger Schild mit: COMUNICACIONES, nuten ein ebensolcher mit Wertangabe. bekannt.

Ist auf weissem und glacirtem Papier in lila und blau

Kopf des Königs nach rechts in einem ovalen Rahmen mit liniirtem Untergrund; die Ecken sind mit wagerechten Strichen ausgefïllt; unten ein weissgelassener Ralımen zur Aufnahme der Inschrift.

Ist nur in schwarzem und braunem Druck (Kupferstich) auf weissem Papier bekannt.

Kopf des Königs in Hochrelief nach links in einem Perlenoval mit farbigem Untergrund; über dem Oval ein länglicher, an den Ecken abgerundeter Schild mit der Insehrift: ESPAN A, COMUNICACIONES, CORREOS oder IMPRESOS, unten ein ebensolcher mit der Wertangabe; zwischen beiden arabeskenartige Verzierungen. Existirt für verschiedene Werte auf weissem und farbigem Papier und zwar:

a) mit "COMUNICACIONES" im oberen Schild:

25 MIMS DE EO rot und blassrot,

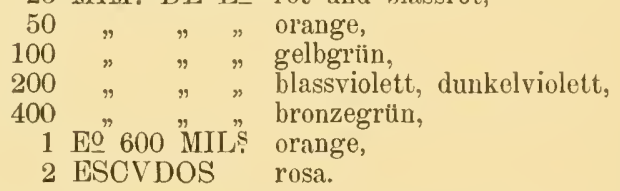

h) mit "CORREOS 1871" im oberen Schild:

25 MILS DE ESCQ orange,

$50 "$ " $"$ weinrot,

$100 " \quad " \quad "$ dunkelviolett,

$200 " \quad " \quad$ gelbgriun,

$400 ", "$ orange,

1 ESCo 600 MILS bronzegriin,

2 ESCVDOS rot,

c) mit "IMPRESOS“ im oberen Sehild:

1 MILA DE EO rot auf gelbem Papier,

$1 "$ " " gelb auf lila Papier,

10 MILS " " $"$ violettrosa anf blanem Papitr,

10 " " grüin anf lila Papier.

d) mit "ESPA NA “ in oberen Schild:

10 MILS DE ESCọ rosa anf blanem Papier,

grỉn auf rosa Papier,

12 CUARTOS schwarz auf rosa Papier,

19 schwarz auf gelbem Papier. 
Grosse Wertziffer in einem Oval mit liniirtem Untergr'und, niber und unter demselben auf einem in den Ecken Kreise bildenden Band: ESPA $\widetilde{N A}$ bezw. Wertangabe; in den Eckkreisen Wiederholung der Wertangabo. Das Fissai kommit in Reliefdruck und gewöhnlichem Buchdruck vor:

a) in Reliefdruck:

5 MILS. DE Eo orange, grün und schwarz auf' weissem Papier.

b) ohue Relief:

5 MILS DE E() gelbgrin, lila, schwarz, grauschwarz und rot auf weissem Papier.

\section{Ausgabe:}

vom 1. Januat bis 30. Juni 1873.

III. Type der vorigen Ausgabe, nur Aender'ung der Farben und der Wertangabe. (Taf. VI, 84.)

Farbiger Buchdruck auf weissem Papier; gezähnt 14.

\section{5 C. karmin in zwei Abstufungen.}

147 a) 5 C. karmin,

147 b) 5 , karminrosa.

148. 10 C. blau in zwei Schattirungen.

148 a) 10 C. ultramarinblau,

148 b) 10 ,blassblau.

149. 20 C. violett in zwei Abstufungen.

149 a) $20 \mathrm{C}$. violett,

149 b) 20 . blassviolett. 


\section{Bemerkungen.}

1. Am 1. Januar 1873 traten folgende Portotarif-Aenderungen ein: einfache Briefe (bis $15 \mathrm{gr}$.) innerhalb Spaniens . . . 10 Céntimos, einfache Stadtbricfe . . . . . . . . . . 5 " Drucksachen, Manuscripte und Waarenproben bis $15 \mathrm{gr}$. 5 , Eingeschriebene Briefe . . . . . . . . . 50 "

Infolge dieses Tarifes wurden am 1. Januar die Marken zu 5, 6, 10 und 12 céntimos eingezogen und dureh solche zu 5 und $10 \mathrm{cs}$. in anderen Farben ersetzt; der Wert 20 C. wurde nen geschaffen.

2. Von den Marken zu 5 und 20 céntimos giebt es Essais in abweichenden Farben auf diekem, weissem, satinirtem Papier und zwar:

$$
\begin{aligned}
& 5 \text { C. de p. grïin und dunkelblau, } \\
& 5 \text { " gelbgrinn und dunkelblau. }
\end{aligned}
$$

3. Briefe mit dem Aufdruck "Por vapor" in rechteekigem Rahmen von 34:19 mm Grösse stammen aus der Stadt Bilbao, welehe im Jahre 1873 von den Carlisten belagert und von jedem Verkehr zu Lande abgeschlossen, einen Dampfer ansgeriistet hatte, $n m$ die Postsendungen auf dem Rio Nervion nach Castro, Santona und Santander zu befördern. Die hierdureh verursachten Kosten wurden dureh ein Zuschlagporto von 25 céntimos de real pro Brief gedeckt. Das ursprünglich private Unternehmen ging im April 1873 in die Hände der Regierung iiber, was eine Erhöhnng des Zuschlagportos auf 10 céntimos de peseta zur Folge hatte.

Der als Zeichen des bezahlten Zuschlagportos anfgedriickte Strmpel existirt in zwei Abarten, von denen die eine etwas grössere und gerundetere Buchstaben besitzt. Beide finden sich in schwarzer und blauer Farbe vor. (Tatel VIl, No 86). 


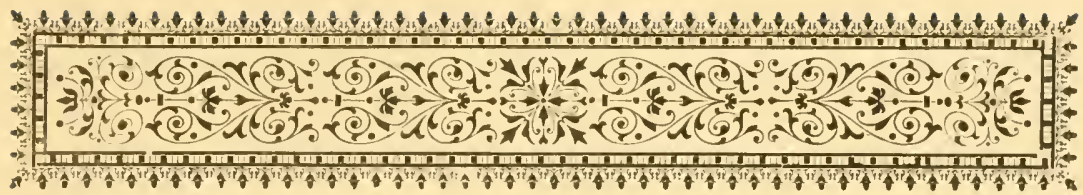

\section{Marken der Republik.}

\section{Ausgabe:}

vom 1. Juli 1873 bis 30. Juni 1874.

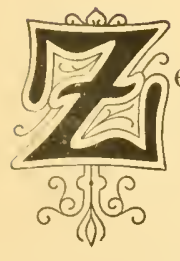

eichnung der X. Ausgabe von Span. Westindien, uur Aender'ung der Inschriften: España, als sitzende Frauengestalt dargestellt, in der rechten Hand einen Olivenzweig, den linken Arm auf ein Wappenschild stiitzend, liniirter Untergrund; oben auf einem Band: COMUNICACIONES, zu beiden Seiten in weissen Buchstaben auf dunklem Grund: ESPAÑA, unten Werthangabe; rechts unten in der Ecke: E. J., Initialen des Kupferstechers Eugenio Julia.

Farbiger Buchdruck auf weissem Papier; gezähnt 14. (Taf.VI,87).

150. 2 C. D. PESETA (céntimos de P.) orange in drei Abstufungen.

150 a) 2 C. D. PESETA orange,

150 b) 2 " blassorange,

150 c) 2 lebhaft orange.

151. 5 C. D. PESETA rosa in drei Schattirungen.

151 a) 5 C. D. PESETA rosa,

151 b) $5 \quad "$ blassrosa,

151 c) $5 \quad " \quad$ schmutzigrosa. 
152. 10 C. D. PESETA grü in vier Schattirungen.

152 a) $10 \mathrm{C}$. D. PESETA grïn,

152 b) $10 \quad$ blaugrin,

152 c) $10 \quad " \quad$ hellblaugrin,

152 d) $10 \quad$ " gelbgrün.

153. 2o C. D. PESETA mehr oder weniger intensiv schwarz.

153 a) 20 C. D. PESETA schwarz,

153 b) $20 \quad$ " grauschwarz.

154. 25 C. D. PESETA braun in zwei Schattirungen.

154 a) 25 C. D. PESETA braun,

154 b) $25 \quad$ " gelbbraun.

155. 40 C. D. PESETA violett in zwei Abstufungen.

155 a) 40 C. D. PESETA violett,

155 b) 40 " " blassviolett.

156. 5o C. D. PESETA blau in drei Abstufungen.

156 a) 50 C. D. PESETA blau,

156 b) 50 blassblau,

156 c) $50 \quad, \quad$ dunkelblau.

157. UNA PESETA lila in drei Schattirungen.

157 a) UNA PESETA lila,

157 b) UNA " blasslila,

157 c) UNA " blaugrau.

158. 4 PESETAS braun in zwei Schattirungen.

158 a) 4 PESETAS rotbraun,

158 b) $4 \quad "$ braungelb.

159. 10 PESETAS violettbraun in drei Schattirungen. 159 a) 10 PESETAS violettbraun,

159 b) $10 \quad \#$ blassbraun,

159 c) $10 \%$ bräunlich.

$\mathrm{Zu}$ diesen zehn Werten kommt noch hinzu:

Zeitungsmarke: Zeichnung der XXI. Ansgabe, nur statt der Königskrone die sogen. Mawerkrone. (Tafel VI. 88.)

Farbiger Buchdruck auf weissem Papier; ungezähnt.

160. $1 / 4$ Cent de peseta grün in drei Schattirungen. 160 a) $1 / 4$ Cent de peseta grün,

$160 \mathrm{~b}) 1 / 4, "$, blaugrtin,

$160 \mathrm{c}) 1 / 4, \%$, gellbgrin. 


\section{Bemerkungen:}

1. Die Marke zu $1 / 4$ c. d. p. blieh in Gebrauch bis zum Oktober 1877, nach andern Angaben sogar bis zum Frïhjahr 1878.

2. Im November 1873 wurden in Sevilla zwei verschiedene Fälschungen der Marken zu 10 céntimos entdeckt. Die Eine ist daran erkennbar, dass sie im Untergrund 88, anstatt 82 Linien besitzt, die Buchstaben der Inschriften grösser und fetter sind, die Linien des sechseckigen Rahmens sich nicht bis unten hin verlängern, der Fuss der España den liniirten Raum uberragt und die Initialen E. Julia's fehlen. Die Andere hat dagegen 99 Linien im Untergrund, bei España fehlt der Tilde über dem n, der Fuss der España ist $1 \mathrm{~mm}$ von der Unfassungslinio entfernt, der Löwe im Wappenschilde ist magerer, der Turm dagegen breiter; die Buchstaben E. J. fehlen.

3. Von Essais zu dieser Ausgabe ist nur die Marke zu 10 Pesetas in gelbbrauner und grüner Farbe bekannt.

\section{A usgabe:}

von 1. Juli bis 30. September 1874 und 31. Juli 1875 .

Weibliche Figur mit den Attributen der Gerechtigkeit innerhalb eines Kreises. Im Kreise links: COMUNICACIONES, rechts Wertangabe, unten Jahreszahl; unter dem Kreise: ESPA $\widetilde{N A}$ zwischen Wertangabe in Ziffern.

Farbiger Buchdruck auf weissem Papier; gezähnt 14. (Taf. VI.89.)

161. 2 C. D. PESETA gelb in zwei Schattirungen. 161 a) 2 C. D. PESETA schwefelgelb, 161 b) 2 blassgelb.

162. 5 C. D. PESETA violett in drei Schattirungen. 162 a) 5 C. D. PESETA violett, 162 b) 5 blassviolett, 162 c) 5 rotviolett.

163. 10 C. D. PESETA blau in zwei Abstufungen. 163 a) 10 C. D. PESETA blau, 163 b) $10 \quad "$ blassblau.

164. 20 C. D. PESETA grün in zwei Abstufungen. 164 a) 20 C. D. PESETA dunkelgrün, 164 b) 10 hellgrün. 
165. 25 C. D. PESETA rotbraun in zwei Abstufungen.

165 a) 25 C. D. PESETA rotbraun,

165 b) 25 blassrotbraun.

166. 40 C. D. PESETA violett in zwei Abstufungen.

166 a) 40 C. D. PESETA violett,

166 b) 40 blassviolett.

167. 50 C. D. PESETA gelb und orange in verschiedenen

Schattirungen.

167 a) 50 C. D. PESETA orange,

167 b) $50 \quad$ gelborange,

$167 \mathrm{c)} 50 \quad$ gelb,

167 d) $50 \quad$ " blassgelb.

168. UNA PESETA grün in drei Schattirungen.

168 a) UNA PESETA gelbgrün,

168 b) UNA " blassgelbgrun,

168 c) UNA " grün.

169. 4 PESETAS karmin und rot in verschiedenen Schattirungen.

169 a) 4 PESETAS karmin,

169 b) $4 \quad " \quad k a r m i n r e s a$,

$169 \mathrm{c}) 4 \quad r \quad$ rot.

170. 10 PESETAS mehr oder weniger intensiv schwarz.

170 a) 10 PESETAS schwarz,

170b) $10 \quad$ grauschwarz.

Bemerkungen.

1. Um die leeren Staatskassen etwas zu füllen, hatte die Regierung der Republik am 1. Juli $1874 \mathrm{zu}$ dem traurigen Mittel gegriffen, die Herstellung und deu Vertrieb aller Post-, Telegraphen- und Stempelmarken einer Gesellschaft, der "Sociedad de timbre" in Entreprise zu geben. Der Vertrag bestand bis zum 30. Juni 1878.

2. Die Ausgabe des Jahres 1874 war ursprünglich als Judicialmarke für Portorico angefertigt, daher die eigentümliche Darstellung der España als „Justitia“.

3. Die Marke zu $10 \mathrm{C}$. de peseta wurde im Laufe des Jahres 1874 mehrfach gefälscht, die Fälschungen lassen sich an abweichender Zeichnung und Inschrift, sowie an der unregelmässigen Zähnung unschwer erkennen. Von den Marken zu 4 und 10 Pesetas existiren vorzügliche Fälschungen. Kennzeichen derselben sind: Unterschiede der Buchstaben $\mathrm{S}$ und $\mathrm{E}$ in Pesetas, $\mathrm{S}$ in España, und der Ziffer 0 in 10 und zwar: bei den Fälschungen ist der obere und untere Teil des S gleich, während sie bei den echten Marken differiren, der wagerechte Mittelstrich des $\mathrm{E}$ ist bei den Fälschungen zu weit nach oben, 
während er bei den Originalen sich genan in der Mitte befindet, die Ziffer 0 vol Pesetas ist bei den Fälschungen zil schlank, während sie bei den Originalen breiter und fetter erscheint. Ausserdem ist bei den Fälschungen die Farbe meist grall, bei den Originalen dagegen schwarz.

Die Gleichheit dieser Merkmale bei der 4 und 10 Pesetas-Marke lassen auf den nämlichen Urheber schliessen. Beide Falsifikate werden vielfach, selbst von renommirten Händlerı als echt verkauft.

4. Von Essais giebt es die Marken zu $10 \mathrm{e}$ d. p. in ultramarinblan, die zu $20 \mathrm{c}$. in schwarzer, diejenige zu 25 cs. in violetter und karminroter, diejenige zil 40 cs. in brauner Farbe, die beiden ersten ungezähnt.

Von nicht angenommenen Typen kennt man:

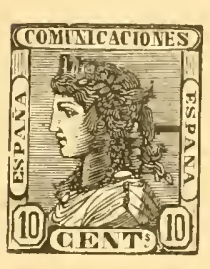

Frauenkopf mit Mauerkrone (España) nach links in einem viereckigen Rahmen; in demselben oben: COMUNICACIONES, rechts und links: España, unten und in den unteren Ecken Wertangabe. Man behauptet, dieses Essai wäre zur Ausgabe fertig gestellt gewesen, die Ausgabe wäre aber durch die Thronhesteignug König Alfonso's verhindert worden. Es existirt für den Wert von $10 \mathrm{c}$. in blauer, carminroter, gelber und schwarzer Farbe anf weissem, schwarz auch auf grünem Papier.

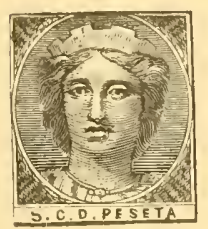

Frauenkopf mit Mauerkrone en face in einem Kreise mit liniirtem Untergrund; unter den Kreise auf einem viereckigen Schild: Wertangabe.

Das Essai existirt für den Wert von 5 c. d. Peseta in schwarzer, gelbgriiner, blauer, gelbbrauner und roter Farbe auf weissem Karton, in schwarz und hellbraun auch auf weissem Papier.

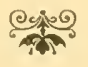

\section{Ausgabe:}

vom 1. Oetober 1874 bis 31. Juli 1875.

Spanisches Wappen mit Manerkrone, Lorbeerzweige auf beiden Seiten, Untergrund liniirt; oben in achteckigem Schild: COMUNICACIONES, unten Wertangabe.

Farbiger Druck auf weissem Papier; gezähnt 14. (Taf. VI, 90.)

171. 10 CENTS PESETA braun in vier Schattirungen.

171 a) 10 CENTSS PESETA braun,

171 b) 10

$171 \mathrm{c}) 10$

dunkelbraun,

$171 \mathrm{~d}) 10$

gelblichbraun,

rotbraun. 


\section{Bemerkungen.}

1. Die Marke wurde notwendig, wegen der zahlreichen Fälschungen der 10 CentsMarke der vorigen Ausgabe.

2. Von ihr sind eine Reihe mangelhafter Drucke bezw. Felldrucke bekannt und zwar:
a) eine runde 3 an Stelle des $\mathrm{S}$ in CENTS
b) eine eckige 3
c) $\quad=$
d) $\operatorname{\theta in} \mathrm{C}$
e) ein $\mathrm{Z}$

$" n$

3. Einige Bogen der Ausgabe entgingen der Zähnung und wurden ungezähnt postalisch verwendet.

4. Von Essais existirt die angenommene Type in blauer Farbe auf weissem Papier

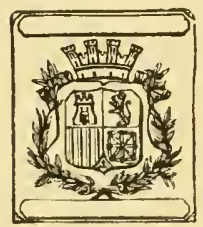
und in bram auf weissem Karton; auch giebt os dieselbe in unvollendeter Ausführung, d. h. ohne Schraffirung des Untergrundes und ohne Inschriften in blaner Farbe auf hellblanem Papier.

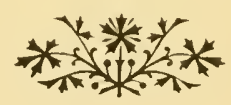




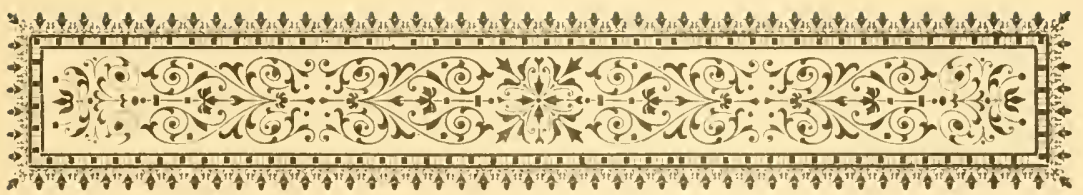

\section{E. Marken ans der Zeit der Regierung des Königs Alfonso XII.}

\section{Ausgabe:}

vom 1. August 1875 bis 31. Mai 1876 bezw. 30. Juni 1878.

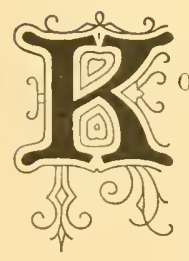

opf des Königs Alfons XII, nach rechts in einem Oval mit liniirtem Untergrund: $11 \mathrm{~m}$ das Oval ein viereckiger Rahmen, ansgefüllt in den vier Ecken mit den Wappen von Castilien und Leon, an den Seiten mit Ornamenten, oben durch das IVort: COMUNICACIONES, unten durch die Wertangabe; anf dem Halsabschnitt E. J., Initialen des Kupferstechers Engenio Julia. Auf der Rückseite befinden sich Kontrollziffern von 1 bis 100 innerhalb eines Tierecks, entsprechend nebenstehender Abbildung.

Farbiger Buchdruck anf weissem Papier: ge-

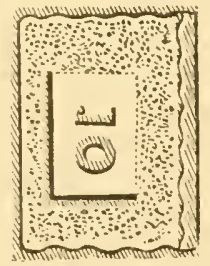
zähnt 14. (Taf. VI, 91).

172. 2 C: PESETA rotbraun in drei Schattirungen.

172 a) 2 CS PESETA rotbram,

172 b) 2 CS " hellrotbraun,

172 c) 2 Cs " gelblichbraun. 
173. 5 C . PESETA violett in drei Schattirungen.

173 a) 5 CS PESETA blasslila,

173 b) 5 CS " rötlichviolett,

$173 \mathrm{c}) 5 \mathrm{CS}, \quad$ braunviolett.

174. 10 CS PESETA blau in drei Schattirungen.

174 a) 10 CS PESETA blau,

174 b) $10 \mathrm{CS} \%$ blassblau,

$174 \mathrm{c}) 10 \mathrm{CS}, \quad$ mattblau.

175. $20 \mathrm{C}$ PESETA braungelb in zwei Abstufungen.

175 a) 20 CS PESETA braungelb,

175 b) $20 \mathrm{CS}, \quad$ blasshraungelb.

176. $25 \mathrm{C}$ SESETA rosa und karmin in drei Schattirungen.

176 a) 25 CS PESETA rosa,

176 b) 25 CS $"$ karminrosa,

176 c) 25 CS $"$ karmin.

177. $40 \mathrm{CS}$. PESETA braun in drei Abstufungen.

177 a) 40 CS PESETA braun,

177 b) $40 \mathrm{CS}$, dunkelbraun,

177 c) $40 \mathrm{CS}$, blassbraun.

178. 5o CS PESETA violett in vier Schattirungen.

178 a) 50 CS PESETA violett,

178 b) 50 Cs , blassviolett.

$178 \mathrm{c}) 50 \mathrm{CS} \quad " \quad$ rötlichlila,

178 d) 50 CS " " bläulichlila.

179. 1 PESETA mehr oder weniger intensiv schwarz.

179 a) 1 PESETA schwarz,

179 b) $1 "$ grauschwarz.

180. 4 PESETAS grün in drei Schattirungen.

180 a) 4 PESETAS dunkelgrün,

180 b) $4 \quad \cdots \quad$ grün,

180 c) $4 \quad$ graugrün.

181. 10 PESETAS blau in zwei Abstufungen.

181 a) 10 PESETAS ultramarinblau,

181 b) 10, blassblau.

Bemerkungen.

1. Die Marke zu 2 Cs peseta blieb in Gebrauch bis zum 30. Juni 1878.

2. Wie schon erwähnt, hatte die republikanische Regierung den Verkauf der Postwertzeichen der' Sncielad de timbre in Entreprise gegeben, welche, um ihren Gewinn nicht zu schmiälern, mit allen Mitteln das Fülschen der Marken zu verhindern oder doch zu erschweren suchte. Daher die Einführung der 
Kontrollziffern. Trotzdem tanchten nach kurzer Zeit falsche Marken zu 1, 4 und 10 pesetas auf, die sich von den echten nur durch die etwas abweichende Form der Buchstaben in "Comunicaciones" und "Pesetas" erkennen lassen.

3. Von den Marken zu 2, 5 und $10 \mathrm{CS}$ haben sich einig, Bogen der Zälumug entzogen.

4. Von Essais wurden bekannt:

10 CS Peseta blan auf weissem und dunkelgrünem Papier, gelbbraun auf blassgrünem Papier, gezïhnt,

25 CS Peseta karmin auf blassgrtinem Papier,

40 CS Peseta karmin anf blassgrinem Papier, gezähnt.

1 Peseta schwarz auf weissem Papier, mit Koutrollnummern auf der Rückseite.

5. Durch Erlass vom 1. April 1874 wurde die Anfertigung neuer Datumstempel angeordnet und dieselben am 1. August 1874 in Madrid, im Januar 1875 in den Provinzen verausgabt, der Stempel des Jahres 1857 wird jedoch heute noch von einzelnen Post-Anstalten gebraucht. Der neue Stempel zeigt die gewöhnlichen Angaben und unterscheidet sich von den bisher ublichen Modellen durch die Grösse, Taf. VIII, 92 und IX, 93. Neben diesem Stempel giebt es bei einigen Post-Anstalten ein kleines Modell (Tafel VIII, 94), auch tanchen um dieselbe Zeit an verschiedenen Orten Stempel in achteckiger Form anf ('Tafel VIII, 95). Anf' Einheitlichkeit der Post-Utensilien scheint man in Spanien keinen Werth gelegt zu haben.

Ein in nämlichen Jahre neu verausgabter Certificado-Stempel besteht aus einem Rechteck mit abgestumpften Ecken, welcher in 3 Reihen: Certificado, Datum nnd Aufgabeort angiebt. Er ist noch heute in Gebrauch, (siehe Taf. VIII, 96 und IX, 97) und existirt in mehreren Grössen.

Ein Rundschreiben der G. P. D. vom 29. October 1874 ordnet die Entwertung der Marken ausschliesslich durch Datumstempel an. Dieser Befehl scheint jedoch bald wieder aufgehohen worden zu sein, wio die verschiedenen Formen von nen eingefïhrten Entwertungsstempeln auf Tafel VIII (98-101) beweisen.

\section{乘策}

\section{Ausgabe:}

vom 1. Juni 1876 bis 30. Juni 1878.

Büste des Künigs Alfons XII zu 3/4 nach rechts innerhalb eines Perlen-Ovals mit liniirtem Untergrund; um das Oval quadratischer verzierter Ralımen, dariiber rechteckiger Schild mit CONUNICACIONES, darunter in den Ecken Wertziffern und zwischen beiden Wertbezeichnung.

Farbiger Druck auf weissem, satinirtem und nicht-

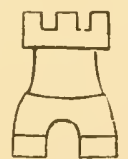
satinirtem Papier mit Wasserzeichen (Turm); gezähnt 14. (Taf. VI, 102.) 
A. 1876. Auf weissem, satinirtem Papier.

182. 5 C PESETA braun in drei Schattirungen.

182 a) 5 CS PESETA gelhbraun,

182 b) 5 CS " rotbraun,

$182 \mathrm{c}) 5 \mathrm{CS} "$ dunkelbram.

183. 10 CS PESETA blau in zwei Abstufungen.

183 a) 10 CS PESETA hellblau,

$183 \mathrm{~b}) 10 \mathrm{CS} \quad "$ dunkelblau.

184. 20 CS PESETA russischgrün in zwei Abstufungen.

184 a) 20 OS PESETA russischgrun,

184 b) $20 \mathrm{CS} \quad "$ blassrussischgrün.

185. $25 \mathrm{C}$ PESETA rotbraun in zwei Abstufungen.

185 a) 25 CS PESETA rotbraun,

185 b) 25 C " dunkelrotbram.

186. 40 C: PESETA schwarzbraun in zwei Abstufungen. 186 a) 40 CS PESETA schwarzbraun,

186 b) $40 \mathrm{CS}$, blassschwarzbraun.

187. 50 CS PESETA grün in drei Schattirungen.

187 a) 50 CS PESETA gelbgrün,

187 b) 50 CS " hellgelbgrün,

$187 \mathrm{c)} 50 \mathrm{CS} \quad " \quad$ grün.

188. 1 PESETA blau in drei Schattirungen.

188 a) 1 PESETA blau,

188 b) $1 \quad "$ dunkelblau,

$188 \mathrm{c}) 1 \%$ indigoblau.

189. 4 PESETAS rötlichviolett in drei Abstufungen.

189 a) 4 PESETA rötlichviolett,

189 b) 4 " blassrötlichviolett,

189 c) $4, \quad$ lebhaft rotviolett.

190. 10 PESETAS zinnoberrot.

B. 1877. Auf wenig oder gar nicht satinirtem, dünnerem Papier: die Platten sind etwas aufgearbeitet. was besonders an den Inschriften erkenntlich ist.

191. 5 C PESETA braun in zwei Schattirungen. 191 a) 5 CS PESETA olivenbram, 191 b) 5 CS " rotbram.

192. 10 C: PESETA lebhaft blau. 
193. 25 CS PESETA braun.

194. 50 CS PESE'TA grün.

195. 1 PESETA blau (mit dünneren, schlankeren Wertziffern).

196. 4 PESETAS rötlichviolett.

197. 10 PESETAS blasszinnoberrot.

\section{Bemerkungen.}

1. Nach den schlechten Erfahrungen, welche man bisher mit den in Madrid angefertigten Marken gemacht liatte, entschloss sich die Sociedad de timbre diese Ausgabe in London anfertigen zu lassen. Die Ausfuhrung derselben ist vorzüglich gelungen, und wenn auch die Kosten dieser Emission sich anf 160000 Pesetas beliefen, so konnte man sich doch rühmen, dass während der achtzehnmonatlichen Verkehrsdauer derselben auch nicht eine einzige Fälschung bekanut wurde. Leider kehrte die Postverwaltung in Jahre 1878 ans falscher Sparsamkeit wieder zur Fábrica nacional de sellos zurïck. und sofort tauchten auch wieder Fälschungen auf.

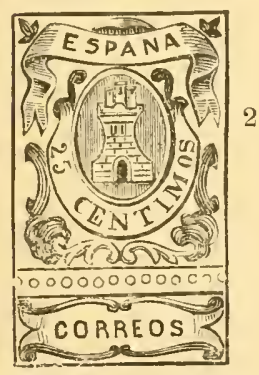

2. Um eine Wiederbenutzung von gebrauchten Postwertzeichen unmöglich zu machen, wurde im Jahre 1877 der Vorschlag gemacht, die Marken mit einem abtrembaren Coupon zu versehen. Die nebenstehende Type, privaten Ur'sprungs, verdankt diesem Gedanken ihr Dasein. Sie wurde jedoch aus praktischen Gründen zurïckgewiesen.

3. Merkwlirdigerweise hatte man noch keine Stempelschwärze gefunden, welche den Bemühungen der Portodefraudanten erfolgreichen Widerstand zu leisten vermochte. So lieferte im Jahre 1875 der $\Lambda$ potheker Escalera zu Gijon eine grosse Zahl von Marken an die Postverwaltung ein, hei welchen die Entwertungsstempel vermittelst einer Ammoniaklösung abgewaschen waren, und welche somit zum zweitenmal zur Frankirung dienen konnten. Es wurde infolgedessen vorübergehend eine Entwertung vermittelst flüssigen Karmins eingeführt, indem man mit einem kleinen Pinsel einen dicken Strich in dieser Farbe uber die Marke zog, s. Tafel VIII, Nr. 103. Dieses Verfahren erwies sich sehr bald als durehaus unpraktisch, und da auch andere Versuche, die Marken den Manipulationen der Portodefraudanten gegenüber dauernd zu entwerten, zu keinen brauchbaren Ergebnissen geführt, der zu dieser Zeit ebenfalls probirte Durchlochungsstempel aber von der öffentlichen Meinung einstimmig verurteilt worden war, so kehrte man nach kurzer Zeit (Ellass vom 30. Oktober 1876) wieder zur bisherigen Entwertung durch Datumstempel und Druckerschwärze zurtack.

Durch Erlass vom 18. Jauuar 1878 wurde ein neuer Typus eines Datumstempels eingeführt. Derselbe zeigt die bisher ublichen Angaben und unter- 
scheidet sich von dem bisherigen, der im Uebrigen von einer grossen Zahl Post-Anstalten weiter benutzt wird, durch die Grösse und das Mittelschild. ('Tafel IX, Nr. 104.) Man findet diesen Stempel häufig auch in blaner Farbe,

Fur die Administraciones ambulantes wurde am 7. Dezember 1878 ein neues Stempelmodell eingeführt. Dasselbe ist ein längliches Viereck mit abgestumpften Ecken und trägt in drei Reihen die Bezeichnung: Administracion ambulante, Datum und Aufgabeort.

Von Entwertungsstempeln finden sich auf den Marken dieser Ausgabe neue Typen von Punktstempeln, teils mit, teils ohne einen Stern in der Mitte.

\title{
XXVIII. Ausgabe:
}

vom 1. Oktober 1877 an.

Zeitungsmarke in der Zeichnung der XXI. Ausgabe, nur etwas veränderte Königskrone.

Farbiger Buchdruck auf weissem Papier; ungezähnt. ('Tafel VI, 105.)

\author{
198. $1 / 4$ de cents de peseta grün in drei Schattirungen. \\ 198 a) $1 / 4$ de cents de peseta gelbgriln, \\ 198 b) $1 / 4 \quad$ " blaugrün, \\ 198 c) $1 / 4 \quad " \quad$ dunkelgrin.
}

Bemerkungen.

1. Ueber das Ausgabedatum dieser Marke findet man abweichende Angaben. Duro rechnet sie zur vorigen Ausgabe, bemerkt aber, dass sie erst, nachdem die gleichwertige Marke der XXI. Ausgabe (mit Manerkrone) völlig aufgebraucht. d. h. nicht vor Januar 1878, in Gebrauch genommen wire.

2. Gezïhnte Exemplare sind privaten Ursprungs.

3. Es giebt einen Fehldruck mit umgekehrter 1 in der We tangabe.

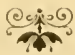




\section{Ausgabe:}

vom 1. Juli 1878 bis 30 . April 1879 .

Kopf des Königs nach rechts in einem Oval mit liniirtem Untergrund; darüber in rechteckigem Schild: CONUNICACIONES, darunter Wertangabe; die Ecken zwischen Oval und Inschriften sind mit Ornamenten ausgefiillt; auf dem Halsabschnitt der Name des Kupferstechers Julia.

Farbiger Buchdruck auf weissem Papier; gezälnt 14. (Taf. VI, 106).

199. 2 CENT. PESETA lila in zwei Abstufungen. 199 a) 2 CENT. PESETA rötlichlila, 199 b) $2 "$ blassrötlichlila.

200. 5 CENT. PESETA orange in drei Schattirungen. 200 a) 5 CENT. PESETA gelborange, 200 b) 5 " " blassgelborange, 200 c) $5 "$ " " blassrötlichgelb.

201. 10 C. DE PESETA braun in zwei Abstufungen. 201 a) 10 C. DE PESETA braun, 201 b) 10 " " dunkelbraun.

202. 2o CENT. PESETA mehr oder weniger intensiv schwarz. 202 a) 20 CENT. PESETA schwarz, 202 b) $20 \quad$ " grauschwarz.

203. 25 CENT.PESETA gelblichbraun in vier Schattirungen. 203 a) 25 CENT. PESETA gelblichbraun, 203 b) $25, "$, blassgelblichbraun, 203 c) $25 \quad " \quad$ dunkelgelblichbraun, 203 d) $25 \quad " \quad$ oliven.

204. 40 CENT. PESETA braunrot in zwei Abstufungen. 204 a) 40 CENT. PESETA bramnot, 204 b) $40 \quad " \quad$ blassbraumrot.

205. 5o C. DE PESETA blaugrün in zwei Abstufungen. 205 a) $50 \mathrm{C}$. DE PESETA blaugrün, 205 b) 50 " " blassblaugrün.

206. UNA PESETA graulila in zwei Abstufunger. 206 a) UNA PESETA graulila, 206 b) " " blassgraulila. 


\title{
207. 4 PESETAS dunkelviolett.
}

\author{
208. 10 PESETAS blau in zwei Abstufungen. \\ 208 a) 10 PESETAS dunkelblau. \\ 208 b) 10 hellblau.
}

Bemerkungen,

1. Die Marke zu 2 cents peseta existirt auch ungezähnt.

2. Im September 1878 wurden in Bilbao falsche Marken zu 1 und 4 pesetas entdeckt. Ein Rundschreiben der Postrerwaltung giebt folgende Kennzeichen derselben:

a) Die falschen Marken à 1 Peseta zeigen Unterschiede im Umriss des Kopfes des Königs, insbesondere ist die Nasenspitze runder;

b) Die Entfernung vom Augenwinkel zur Nasenwurzel ist grösser;

c) Die Buchstaben des Wortes "Comunicaciones" sind schmaler;

d) Die Haut des Königs, welche bei den echten Marken durch Gruppen von schön geschweiften Linien bezeichnet wird, besteht bei don falschen aus einer Reihe unordentlich gezeichneter Linien.

Die falschen Marken à 4 Pesetas zeigen dieselben Unvollkommenheiten des Stiches, ausserdem aber in der Schattirung des Gesichts und des Untergrundes weisse Stellen in Folge nicht scharf genug gezogener Linien.

3. Von Essais wurden bekannt: ausserdem:

sämtliche Werte in grün, blau, karminrot, gelblichbraun und dunkelbraun,

2 cents d. p. schwarz, gunmirt, auch gezähnt,

10 cents $d$. p. orange und lila,

1 peseta rosa und weinrot auf blasschamois Papier,

10 pesetas weinrot.

Von den Ilarken zu 40 cents giebt es Essais mit der Inschrift: Correos

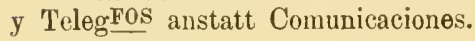




\section{Ausgabe:}

vom 1. Mai 1879 bis 1 . Oktober 1889.

Kopf des Königs nach links in einem Oval mit liniirtem Untergrund; iiber dem Oval anf rechteckigem Schild: CORREOS Y TELEGS, unten Wertangabe; zwischen Oval und Inschrift Ornamente; auf dem Halsabschnitt der Name Julia.

Farbiger Buchdruck auf weissem Papier; gezähnt 14. (Taf. VI, 107.)

209. 2 CENTIMOS mehr oder weniger intensiv schwarz. 209 a) 2 CENTIMOS schwarz, 209 b) 2 grauschwarz.

210. 5 CENTIMOS blaugrün in drei Abstufungen.

210 a) 5 CENTIMOS blaugrün,

210 b) 5 " blasshlaugrün,

210 c) $5 \quad "$ dunkelblaugrün.

211. 10 CENTIMOS karmin in vier Schattirungen.

211 a) 10 CENTIMOS karmin,

211 b) 10 " karminrosa,

211 c) $10 \quad \% \quad$ blassrosa,

211 d) $10 \quad \%$ bräunlichrosa.

212. 20 CENTIMOS gelblichbraun in zwei Abstufungen.

212 a) 20 CENTIMOS geJblichbraun,

212 b) $20 \quad$ blassgelblichbraun.

213. 25 CENTIMOS blau in zahlreichen Schattirungen.

213 a) 25 CENTIMOS ultramarinblau,

213 b) 25 " blassblau,

213 c) $25 \quad " \quad$ lilablau,

213 d) $25 \quad " \quad$ graublau,

213 e) $25 \quad$ grau.

214. 40 CENTIMOS braun in zwei Abstufungen.

214 a) 40 CENTIMOS braun,

214 b) 40 blassbraun.

215. 5o CENTIMOS gelb in zahlreichen Schattirungen.

215 a) 50 CENTIMOS gelb,

215 b) 50 blassgelb,

215 c) $50 \quad " \quad$ braungelb,

$215 \mathrm{~d}) 50 \quad " \quad$ orangegelb,

215 e) $50 \quad "$ lebhaft orange,

$215 \mathrm{f}) 50 \quad$ blasszinnoberrot. 
216. UNA PESETA karmin in drei Schattirungen.

216 a) UNA PESETA karmin,

216 b) UNA " $\quad$ karminresa,

216 e) UNA " $"$ blassrosa.

\section{4 PESETAS grau in $z$ wei Abstufungen. 217 a) 4 PESETAS grau, 217 b) 4 , dunkelgrau.}

\section{10 PESETAS oliven in zwei Abstufungen. 218 a) 10 PESETAS olivengelb, 218 b) 10 " blassoliven.}

\section{Bemerkungen.}

1. Die Ausgabe wurde aus zwei Gründen notweudig, einerseits, weil infolge internationalen Uebereinkommens die Farben der Werte von 5, 10 und 25 céntimos in grün, karmin und blan festgesetzt, andererseits, weil dureh Erlass vom 27. Februar 1879 die Kriegsstenermarken eingezogen, ihr Wert aber zum Porto zugeschlagen wurde. Die Portosätze verïnderten sieh dementsprechend wie folgt:

flur Briefe im Ortsverkehr . . . . . . 10 céntimos,

für Briefe im Innern Spaniens und den Adjacentes 25"

für Briefe nach Cuba und Portorico. . . . 40"

für Briefe nach den Plilippinen . . . . . 65"

Die Zeiehnung dieser Ausgabe war urspruinglich für eine neue Ausgabo dor Kriegssteuermarken bestimmt.

2. Die Marken zu 2 und 25 céntimos kommen auch ungezïhnt vor.

3. Die grosse Zahl von Essais zu dieser und der uachfolgenden Ausgabe in der angenommenen Type lässt den Verdaeht aufsteigen, dass hier von der NationalNarkenfabrik ein neuer Handelsartikel geschaffen werden sollte. Es existirun sämtliche Werte der Ausgabe auf diekem, weissem Papier:

a) in den offiviellen Farben,

b) in den Farben: lila, gelbbraun und blau,

c) in braunrot; ausserdem noch die Marken zu 25 e. u. 1 pes. in grüner Farbe.

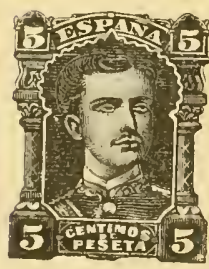

Von nieht angenommenen Typen ist ein sehr sehönes Essai der Amerikanisehen Banknoten-Conpagnie hekannt, welches den König in einem ogivalen Rahmen zu 3/4 nach rechts darstellt; in den Ecken Wertziffern, oben España, unten Wertangabe.

Das Essai existirt in folgenden Farben:

2 eéntimos de peseta grün,

\section{5}

10

20

25

40

50 braun, rot, schwarz, grün, blau, zimoberblau, rot und violett,

sehwarz,

bräunlichrot, zinuoberrot, gelblichbraun, 


\begin{abstract}
1 peseta dunkelblau,
4 pesetis karminrot,

10 malvenfarbig.

Neuredings wurden noch Essais bekannt, welche sich von der angenomunenen Type nur dachurch unterscheiden, dass die Bezeichnung Correos y TelegFos durch Comunicaciones ersetzt ist. Man kennt die Werte 5 céntimos in blau, 10 céntimos in grïn und 15 céntimos in violett.
\end{abstract}

\title{
XXXI. Ausgabe:
}

vom 1. Januar 1882 bis 30. September 1889.

Kopf des Königs nach links in einem Oval mit liniirtem Untergr'und, worïber in hufeisenförmigem Rahmen: CORREOS Y TELEGFOS, unten Wertangabe; auf dem Halsabschnitt der Name Julia.

Farbiger Druck auf weissem Papier; gezälnt 14. (Taf. VI, 108.)

219. 15 CENTIMOS zinnoberrot in drei Schattirungen. 219 a) 15 CENTIMOS zinnoberrot, 219 b) $15 \quad$ blasszinnoberrot, 219 c) $15 \%$ fleischfarben.

220. 3о CENTIMOS violett in zwei Abstufungen.

22. a) 30 CENTIMOS violett, 220 b) $30 \quad "$ blassviolett.

\section{75 CENTIMOS lilablau.}

\section{Benerkungen.}

1. Da die durch die verschiedenen Bürgerkriege zerrittete Finanzlage des Staates sich allmählig etwas gebessert hatte, so wurde durch Erlass vom 1. Januar 1882 rine Herabsetzung der Portosätze angeordnet und dieselben, wie folgt, festgesetzt:

tül einfache Briefe im Ortsverkehr für einfache Briefe innerhalb Spaniens und der Adjacenten 15

für einfache Briefe nach Cuba und Portorico

10 céntimos

für einfache Briefe nach den Philippinen und Fernando Póo 50 
2 Die Ausgabe zeichnet sich vielfach durch mangelhafte Zähnung aus; von den Marken zu 15 céntimos giebt es einen fehlerhaften Druck mit 5 anstat 15 céntimos.

3. Von den Marken zu 15 céntimos sieht man häufig Stücke in blassgelber Farhe; diese Schattirung entsteht durch längeres Liegen im Wasser. Die Marke zu 30 céntimos kommt halbiert postalisch gebraucht vor.

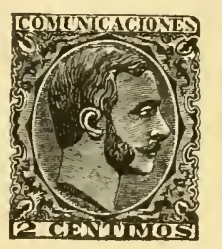

4. Eine neue Type war zur Ausgabe fertig gestellt, als König Alfons XII. starb. Sie zeigt den Kopf des Königs nach rechts in einem Oval mit liniirtem Untergrund; darüber auf rechteckigem Schild: COMUNICACIONES, darunter Wertangabe. Es existiren in dieser Type 13 Werte in verschiodenen Farben auf weissem Papicr und zwar:

$$
\begin{aligned}
& 2 \text { céntimos dunkelschieferblau und grau, } \\
& 5 \text { " lebhaft blau und rot, } \\
& 10 \quad " \quad \text { grün nnd blau, } \\
& 15 \text { " rot, braun, schieferblau, griin, blau und rotbraun, } \\
& 20 \text { " grün und rotbram, } \\
& 25 " \text { dunkelschieferblau und rot, } \\
& 30 \text { " dunkelschieferblau und gelblichbraun. } \\
& 40 \text { " violettrot, grün und blau, } \\
& 50 \text { " rot und gelblichbraun, } \\
& 75 \text {, grün und rotbraun, } \\
& 1 \text { peseta gelblichbraun und schieferblau, } \\
& 4 \text { pesetas dunkelschieferblau, } \\
& 10 \text { " lebhaft blau. }
\end{aligned}
$$

5. Von Essais existiren die sämtlichen Werte der Ausgabe, ausserdem aber nuch diejenigen zu 5 und 10 céntimos in abweichenden Farben und Papiersorten und zwar:

5 céntimos blau auf dickem, weissem Papier,
$10 \quad$, grïn auf dickem, weissem Papier,
15 " blau, lebhaft blau, braunrot, lila und gelblichbraun auf dickem, weissem Papier, orange auf dünneren, weissem Papier, gelblichbraun auf grünem Papier, auch gezähnt,
25 " gelblichbrann und karminrot auf dickem, weissem Papier, blan auf dickem, weissem Papier,
30 " malvenfarbig auf dünnerem, weissem Papier,
75 " schieferblau auf dünnerem, weissem Papier, violett, lebhaft blau auf dickem, woissem Papier.

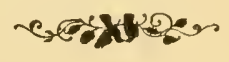




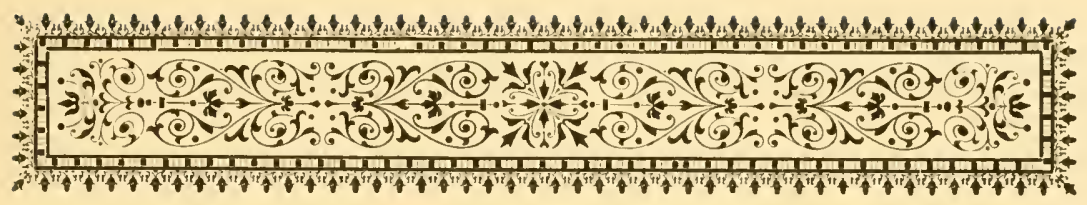

\title{
F. Marken aus der Zeit der Regentschalt der Königin Maria Christima bezw. der Regierung des Königs Alfonso XIII.
}

\author{
XXXII. Ausgabe:
}

vom 1. Oktober 1889 an.

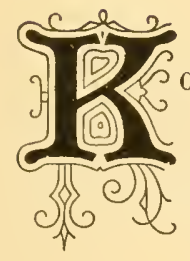

opf des Königs Alfonso XIII. nach rechts in einem Oval mit liniirtem Untergrund; oben auf rechteckigem Schild: COMUNICACIONES, miten Wertangabe; Ecken zwischen Oval und Schild mit Verzierungen ansgefüllt; auf dem Halsabschnitt der Name Julia.

Farbiger Buchdruck auf weissem Papier; gezälnnt 14. (Taf. VI, 109.)

222. 2 CENTIMOS grün in drei Abstufungen. 222 a) 2 CENTIMOS blaugrün, 222 b) 2 blassgrüun, 222 c) 2 dunkelblaugrün.

223. 5 CENTIMOS blau in zwei Abstufungen. 223 a) 5 CENTIMOS blau, 223 b) $5 \quad \#$ dunkelblau. 
224. 10 CENTIMOS rotbraun in drei Abstufungen.

224 a) 10 CENTIMIOS rotbraum,

$2: 4$ b) $10 \quad \cdots \quad$ blassrotbraun,

224 c) $10 \quad, \quad$ lebhaft rotbraun.

225. 15 CENTIMOS braunviolett in drei Abstufungen.

225 a) 15 CENTIMOS braunviolett,

$225 \mathrm{~b}) 15$ dunkelbraunviolett,

225 c) $15 \quad " \quad$ blassbraunviolett.

296. 2o CENTIMOS gelbgrün.

227. 25 CENTIMOS dunkelblau in zwei Schattirungen.

227 a) 25 CENTIMOS schwarzblau, 227 b) $25 \quad$ stablblau.

228. 30 CENTIMOS russischgrün in zwei Abstufungen. 228 a) 30 CHNTINOS russischgrün, 228 b) $30 \quad$ hellrussischgrün.

229. 40 CENTIMOS dunkelbraun.

230. 50 CENTIMOS rosa in drei Schattirungen. 230 a) 50 CENTIMOS rosa, 230 b) $50 \quad "$ bräunlichrosa, 230 c) $50 \quad "$ dunkelkarmin.

231. 75 CENTIMOS orange in zwei Schattirungen.

231 a) 75 CENTINIOS rotorange,

231 b) $75 \quad$ gelborange.

232. UNA PESETA dunkelviolett.

233. 4 PESETAS lebhaft karmin.

234. 10 PESETAS zinnoberrot in drei Schattirungen.

234 a) 10 PESETAS zinnoberrot,

234 b) $10 \quad$ blasszinnoberrot,

234 c) $10 \quad " \quad$ fleischfarben.

\section{Bemerkungen.}

1. Die Marken zu 2, 15 und 30 céntimos kommen halbirt gebraucht vor (sieho Taf. XIII, 151).

2. Von der Marke zu 15 céntimos giebt es einen angeblichen Fehldruck in rötlichbraun oder gelbbraun. Derselbe wird in nenerer Zeit - wohl mit Recht als chemische Fälschung erklärt. 
3. Vou der Marke zu 15 céntimos giebt es zwei, von derjenigen zu 25 c. drei verschiedene Fälschungen, welche man trotz ihrer mangelhaften Ansfuhrung häufig postalisch entwertet findet.

4. Von allen Werten giebt es ungezähnte Exemplare.

5. Von Essais der angenommenen Zeichnung in abweichenden Farben sind his jetzt bekannt:

25 céntimos dunkelblan auf grangrünlichem Papier,

blau auf blassgrangrifinlichem Papier,

blau auf sehmutziggraublauem Papier,

ungezähnt: dunkelblau auf blassrosa Papier;

5 céntimos dunkelıltramarinblau auf weissem Papier,

25 céntimos dunkelsehwarzblau auf weissem Papier.

Von Essais in abweichender Zeichnung kennt man nur folgendes:

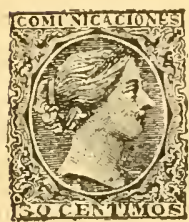

Kopf der Königin-Regentin in ovalem Rahmen nach rechts, alles ubrige Detail wie bei den eingefüurten Marken. Das Essai findet sich für den Wert von 30 céntimos in den Farben: karminrosa, dunkelkarmin, zinnoberrot, orangegelb, blau, hell- und dunkelviolett, violettbraun, braunrot, gelblichbraun, dunkelbraun, bronzegrün, blaugrün, gelbgrün, ultramarinblau und stahlblau, sïmtlich auf weissem Papier, ungummirt.

Der Timbre-Poste vom Februar 1893 ueldet das Essai einer für die spanische Post in Marokko bestimmten Marke. Dasselbe ist in der Zoichnumg der XXXI. Ausgabe ausgeführt, trägt oben die Inschrift: ESPANA-CORREOS, unten: 15 CT: MARRUECOS und ist in blauer Farbe auf weissem Papier gedruckt. Von einer Einführung dieser Marke wurde bis jetzt nichts bekannt.

6. Zu der grossen Zahl der vorhandenen Stempelmodelle tritt Ende 1892 ein neves fiur Madrid. Dasselbe scheint für sümtliche Postanstalten zur Beschafinng in Aussicht genommen zu sein. (Taf. XIII, 152). Markenentwertungsstempel werden in neuerer Zeit nicht mehr verwendet, sondern die Postwertzeichen dureh den Aufgabestempel entwertet.

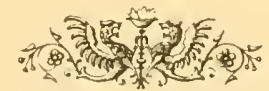





\section{II.}

Dienstmarken, Marken für Privatpersonen, Kriegssteuermarken.

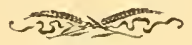




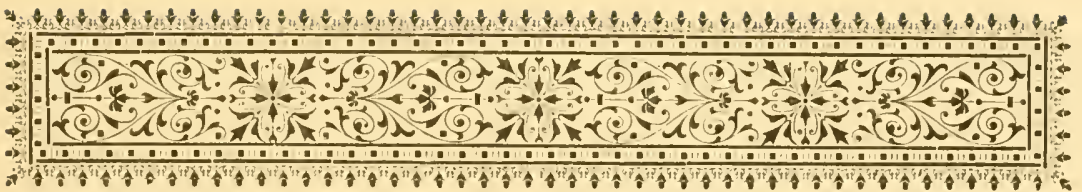

\section{A. Dienstmarken.}

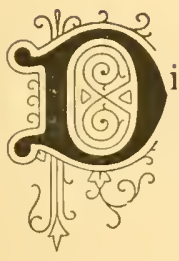

ie Marken für dienstliche Korrespondenzen wurden eingefïlırt durch Königlichen Erlass vom 16. März 1854. Sie wurden nur ver'wendet bei dienstlichen Schreiben einer Behörde an eine andere, waren dagegen unverwendbar bei Briefen, welche die Adresse einer Privatperson trugen, anch wenn dieselben von einer Behörde ausgingen und dienstlichen Inhalt hatten. Die Berechtigung, sich solcher Marken bedienen zu dürfen, musste durch Beifügung des Dienstsiegels der betreffenden Behörde documentirt werden, fehlte dasselbe, so hatte die Dienstmarke keinerlei Giiltigkeit. Eine Eigentuimlichkeit der spanischen Dienstmarken besteht darin, dass sie nicht die Höhe des Portos, sondern das Höchstgewicht der Sendung angeben, welches der betreffenden Marke entspricht. Die Dienstmarken wurden durch den oben angefïhrten Erlass anch in den Kolonien eingefiilırt, am 4. Juli 1866 in Spanien, einige Wochen später anch in den Kolonien wienter abgeschafft und durch handschriftlichen oder auch vorgedruckten Vermerk der Behörden mit beigedrucktem Dienstsiegel ersetzt. (Taf. IX, 105.)

Es existiren zwei Ausgaben: 


\section{Ausgabo:}

vom 1. Juli bis 31. Dezember 1854.

Spanisches Wappen mit Krone, umgeben von dem Orden des goldenen Vliesses; oben auf rechteckigem Schild: CORREOS 1854, unten das Höchstgewicht, für welches die Marke gebraucht werden durfte.

Schwarzer Buchdruck auf farbigem Papier, ungezähnt. (Taf. IX, 110.)

1. MEDIA ONZA gelb.

2. UNA ONZA rosa in zwei Abstufungen.

2 a) UNA ONZA rosa,

2 b) UNA " dunkelrosa.

3. CUATRO ONZAS grün.

4. UNA LIBRA lila-blau.

Bemerkungen:

1. Von der I. Ausgabe giebt es mehrere Fälschungen, die Zeichnung des Wap. pens und der Inschriften sind jedoch bei allen derart nngeschickt ausgeführt, dass nur ein Anfänger durch sie getäuscht werden kann.

2. Von Essais ist die angenommene Zeichnung in den verschiedensten Farben bekannt und zwar:

MEDIA ONZA

UNA ONZA

CUATRO ONZAS

UNA LIBRA weiss, lila, leblaft rosa, violettrosa, dunkelchamois, gelblichchamois und dunkelgelb, dunkelviolett, lila, hell- und dunkelchamois, weiss, strohgelb, violett, rosa, blassblau und lila, weiss, blau, blassblau, lila und blasschanois.

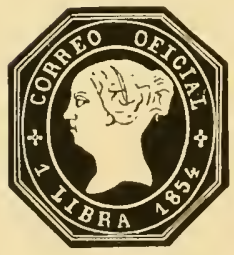

Von nicht angenommenen Typen kennt man nur folgende:

Kopf der Königin Isabella im Relief ohne Krone nach links in einem ovalen Rahmen: oben im Rahmen: CORREO OFICIAL, unten: 1 LIBRA 1854, dazwischen auf jeder Seite ein Stern; das Fssai ist nur in griner Farbe auf gelblichem Papier bekaunt. 


\section{Ausgabe:}

vom 1. Januar 1855 bis 31. Juli 1866.

Spanisches Wappen mit Krone in einem Oval; oben zu beiden Seiten der Krone: CORREO OFICIAL, unten Gewichtsangabe.

Schwarzer Buchdruck auf farbigem Papier; ungezähnt. (Taf. IX, 111.)

5. MEDIA ONZA gelb in drei Schattirungen.

5 a) MEDIA ONZA orangegelb,

5 b) MEDIA " strohgelb,

$5 \mathrm{c}$ MIEDIA " blassgelb.

6. UNA ONZA rosa in vier Schattirungen.

6 a) UNA ONZA rosa,

6 b) UNA " dunkelrosa,

6 c) UNA " blassrosa,

6 d) UNA " fleischfarben.

7. CUATRO ONZAS grün in drei Schattirungen.

7 a) CUATRO ONZAS grin,

7 b) CUATRO, gelbgrün,

$7 \mathrm{c)}$ CUATRO " blassgrün.

8. UNA LIBRA blau in zwei Schattirungen.

8 a) UNA LIBRA blau,

8 b) UNA $n$ graublau.

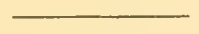

Bemerkungen:

1. Von diesen Marken sind grosse Restbestände in die Hände der Händler abergegangen, trotzdem giebt es einige Fälschungen. Es gilt auch uber diese das in Bemerkung 1 zur I. Ausgabe Gesagte.

2. Von Essais giebt es zahlreiche Abzuge in abweichenden Farben und zwar:

MEDIA ONZA weisslichgrau,

UNA ONZA weisslichgrau, rosa, lebhaft rosa, weiss und gelblichchamois,

CUATRO ONZAS weiss,

UNA LIBRA schwarzgrau, grün, gelblichbraun, gelbgriln, lila, malven, blau und brouzegriun,

Ohne Inschriften weisslichgrau. 


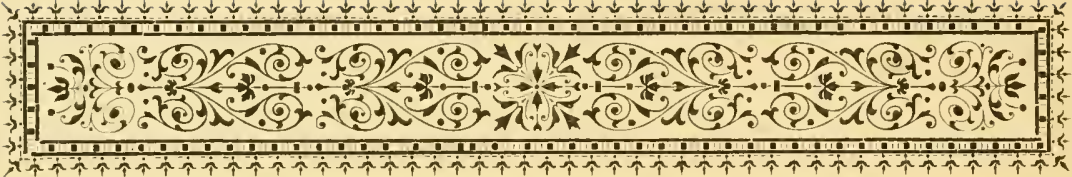

\section{B. Marken fiir Privatpersonen.}

e hierher gehörigen Marken sind Erzengnisse zweier spekulativen Spanier, denen für die Heransgabe eines Buclies bezw. zu dem Versande desselben von der spanischen Postverwaltung auf eine gewisse Zeit Portofreiheit bewilligt worlen war.

I. Durch Erlass vom 22. Dezember 1868 wurde dem Lithographen Diego Castell für die Veröffentlichung eines Werkchens, betitelt: "Cartilla postal," welches eine Anleitung zum richtigen Schreiben von Briefadressen pp. enthielt und für die Schüler der Volksschulen bestimmt war, Portofreiheit auf die Daner von sechs Monaten - vom 1. Jamuar bis 1 . Juli 1869 - für den Versand dieses Buchesgewährt. Castell erfand zu diesem Zweck eine Marke, welche einen Brief innerhalb eines Ovals mit der Umschrift: "CARTILLA POSTAL DE ESPA NA" zeigt. Blaner Druck auf weissem Papier, ungezälnt. (Taf. IX, 112.)

1. Ohne Wertangabe blau.

IT. In gleicher Weise wurde im Juni 1881 dem Verfasser der Geschichte und Beschreibung der spanischen Postwertzeichen 
("Reseña histórico-descriptiva de los sellos de correos de España"), Don Antonio Duro, eine sechsmonatliche Portofreiheit für den Versand dieses Werkes bewilligt, zı welchem Zwecke derselbe ebenfalls eine Narke anfertigen liess: Aufgeschlagenes Buch mit der Inschrift: „Sellos de correos Reseña histórica" in einem Oval mit liniirtem Untergrund, um dasselbe ein rechteckiger Rahmen mit der Inschrift: Franquicia Postal (Portofrei).

Schwarzer Dr'nck auf farbigem Papier, ungezähnt. (Taf. IX,113.)

\section{Ohne Wertangabe schwarz auf chamois.}

Bemorkungen.

1. Fs ist klar, dass derjenige, welcher die Dienstmarken in seine Sammlung anf* nimmt, logischerweise auch dieser Erzeugnisse des Erfindungsgeistes nicht entbehren darf. Der hohe Preis, welchen die Händler fiur diese beiden IIarken beanspruchen, ist jedoch in keiner Weise gerechtfertigt, umsoweniger als nichts zu der Annahme berechtigt, dass die Platten zu diesen Marken vernichtet und Neudrucke unmöglich sind.

2. Von Marken No. 1 werden Stücke in schwarzem Druck auf blaugrauem Papier vielfach als Essais betrachtet und verkauft. Dieselben stammen von dem Titelblatt des Werkchens und sind daher völlig wertlos.

3. Beide Marken findet man selten postalisch entwertet. Am häufigsten tragen sie den Entwertungsstempel 114, Taf. IX.

4. Ende November 1893 meldeten politische und philatelistische Blätter die Ausgabe (1) ESPANAACORREOS-8 einer Feldpostmarke für die Soldaten des gegen die Kabylen

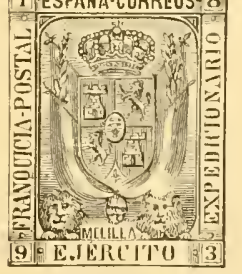
ausgerüsteten Expeditionscorps in Melilla. Dieselbe zeigt das spanische Wappen, umgeben von Fahnen und Lorbeerzweigen, darüber die Königskrone, darunter ein Postament aus zwei ruhenden Löwen mit der Anfschrift: NELILLA; um das Markenbild ein rechteckiger Rahmen mit folgenden Inschriften : links: FRANQUICIA-POSTAL, oben: ESPA NACORREOS, unten und rechts: EJERCITO EXPEDICIONARIO (Expeditionscorps), in den Ecken die Jahreszahl 1893 in einzelnen Ziffern.

Die Marke wurde in dreifarbigem Druck schwarz, roth und gelb oder auch blau, rot und gelb hergestellt und kommt sowohl gezähnt, als auch ungezahhnt vor. Ihre mangelhafte Ausfuhrung zeigte sofort, dass es nicht ein offiziell ausgegebenes Postwertzeichen, sondern ein Erzengnis der Privatspekulation war. Thatsiichlich hat bis zum November 1893 keine Portofreiheit für die Truppen in Afrika bestanden; die Briefe derselben waren wie gewöhnlich zu frankiren und wurden gesammelt dem Postamt in Malaga übergeben und dort vorschriftsmässig entwertet. Durch Königlichen Erlass vom 5. No- 
vembor 1893 wurde den Soldaten Portofreiheit fïr die Daner des Feldzuges gewälırt, das :üssere Zeichen derselben bildete der Dienststempel des betreffenden Truppenteiles. Die obige Marke ist daher, auch wenn sie mit einem postalischen Stempel versehen, völlig wertlos.

Das gnte Geschäft, welches der Anfertiger der Marken - ein MarkenHăndler in Malaga - machte, erzeugte im Januar 1894 eine rege Konkurrenz. Nicht blos erschien eine neue, der ersten ahnlichen Type in bedeutend besserer Ausführung, welche für jeden in Melilla befindlichen Truppenteil in besonderer Farbe und mit Aufschrift der Regiments-Nummer (z. B. Regto de Infantes blau, Regto de Toledo blasskarnin, Regto de Asia braun, Cazres (Jäger)

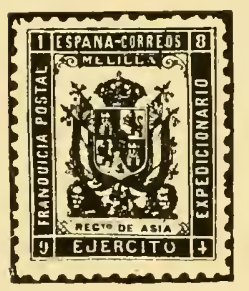
de Cataluña blassrosa u. s. w.) hergestellt wurde, sondern es wurden anch Markenbilder angefertigt und in einigen 1000 Exemplaren an die Soldaten in Melilla unentgeltlich verteilt, welche an Stelle des spanischen Wappens Ansichten einzelner Gebäude pp. Melillas (z. B. Cabrerizas altas, Camellos u. A.) zeigen. Damit nicht genug, wurden auch die Matrosen der an der afrikanischen Küste kreuzenden Kriegsschiffe mit besonderen Marken beglückt, welche

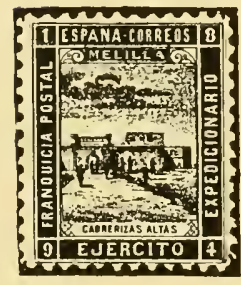
in einem Oval das Bild des betreffenden Panzers und die Inschrift ESCUADRA DE OPERACIONES (Operations - Geschwader) tragen. Es ist zu hoffen, dass gerade die Masslosigkeit dieser Spekulation die Sammler vor dem Ankauf dieser völlig wertlosen und auf der Stufe der Dauth'schen Soldaten - Briefmarken stehenden Machwerke ab-

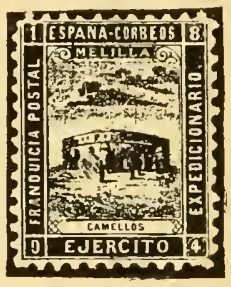
halten wird.
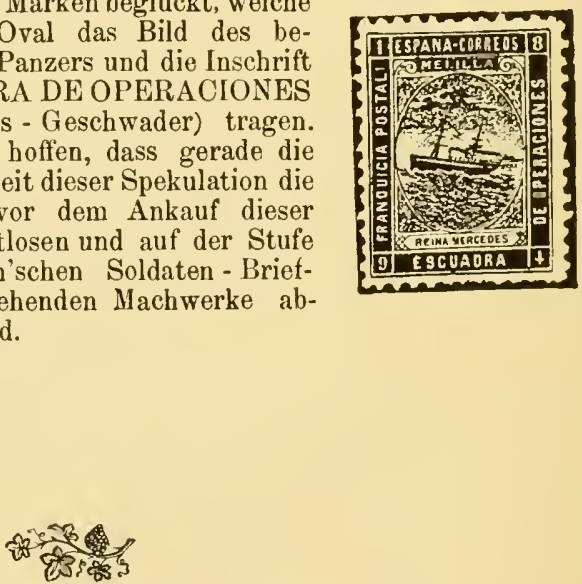


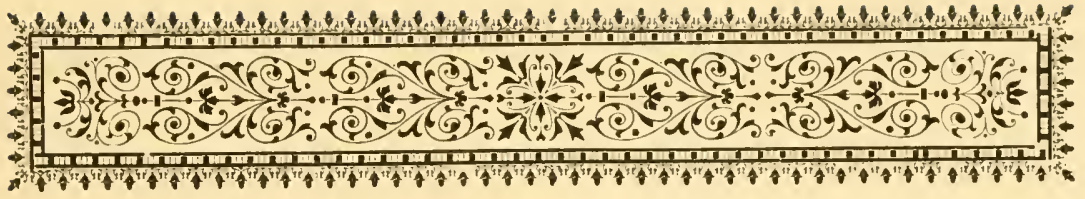

\section{Kriegsstenerminken.}

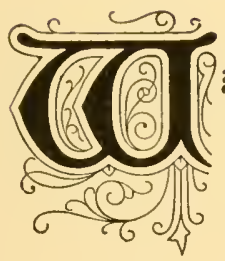

ährend die grosse Masse der Sammler die philatelistisch recht geringwertigen Dienstmarken anstandslos in ilre Sammlungen aufnimmt und keil Vordruck-Album ihmen bis jetzt einen Platz verweigert hat, machte sich in den letzten Jahren merkwürdigerweise in Bezug anf die Kriegsstenermarken eine entgegengesetzte Strömung geltend: man erklärte sie für philatelistisch wertlos. 'Die Ausscheidung derselben aus unseren philatelistischen Handbiichern und Alben vollzog sich allerdings nur langsam und zögernd, gewissermassen mit innerem IViderstreben. Während Moens die Kriegsstenermarken schon seit vielen Jahren als rein fiskalische Wertzeichen auffasste, komnte die Mehrheit der Philatelisten ïber diese Marken entschieden nicht in's Klare kommen; man stiess sich zwar allentlialben an der Bezeichnung "Stenermarken", konnte aber andererseits offenbar nicht einsehen, wie Marken, welche in Forn und Aussehen nach allen Richtıngen den Postmarken Spaniens gleich waren, die sich in Verwendung und Behandlung seitens der Post ebensowenig von den letzteren unterschieden und ïber welche eine Menge postalischer Erlasse vorlagen, für den Postwertzeichensammler völlig wertlos sein könnten. Erst das 
El'scheinen des Moens'schen Spezialwerkes: „Histoire des timbresposte employés en Espagne" scheint diese Frage endgïltig zu Ungunsten der Kriegsstenermarke entschieden zu haben, indem dieselben in neneren Auflagen unserer verbreitetsten Alben nicht mehr erwähnt, kaum noch in den Preislisten unserer Händler aufgefülırt werden.

In Nachfolgendem sollen daher die Gründe, welche "für" und "gegen" die Sammelberechtigung der Kriegsstenermarken sprechen, ausfïhrlich besprochen werden, der Leser mag sich dann selbst sein Urteil bilden.

Der Carlistenkrieg, der Aufstand in Cartagena und der Bürgerkrieg auf Cuba hatten direkt und indirekt durch Brachlegen jeglichen Handels und Verkehrs und damit auch Verminderung der Stenerkraft des Landes die Kassen des Staates auf's Aeusserste erschöpft. Um der Regierung die Mittel zur Fortführung des Krieges zu verschaffen, wurde von dem Präsidenten der Republik, Emilio Castelar, durch Gesetz vom 2. Oktober 1873 die Einführung einer Kriegsstener (Impuesto de guerra) angeordnet, welche im Betrage von 5 und 10 céntimos anf die verschiedenartigsten Dinge aufgeschlagen wurde und in Form von Marken zul bezahlen war.

Der Artikel 3 des erwälınten Gesetzes besagt, dass die Marke zu 5 céntimos auf jedem im Innern der Halbinsel zirkulirenden oler von da nach den Kolonien gehenden Brief, die Marke zu 10 céntimos anf jedem Lotterieloos, Theaterbillet, Eisenbahn-Falı'karte, anf allen gestempelten Papieren, Wechseln, Affichen, Diplomen, Kauf- und Mietskontrakten zu verwenden sei.

Eine provisorische Instruktion der Regierung vom 22. Oktober 1873 erläutert die Verwendung dieser Marken noch nälıer und ein Rundschreiben der General-Post-Direktion giebt speziell die in Bezug auf postalische Verwendung nötigen Erklärungen. Da uns diese am meisten interessiert, so möge dieses Rundschreiben hier in wortgetrener Uebersetzung nachfolgen. Dasselbe lantet:

„Der Erlass vom letzten 2. Oktober schreibt in seinem Art. 3 die Einführung einer provisorischen Steuer vor, welche unter dem Namen: „Impuesto 
de guerra" unter den nachfolgonden, in dom genannten Artikel angegebenen Bedingungen erhoben werden soll.

In Uebereinstimmung mit dem $\S 2$ desselben Erlasses unterwirft der Art. 3 der provisorischen Instruktion vom 22. Dezember, gegeben zur Ausfürung genannten Erlasses, der Bezahlung dieser aussergewöbnlichen, vorubergehend eingeführten Stener alle Briefe, zirkulirend auf der Halbinsel und den Adjacenten, ebenso wie diejenigen, welche nach den uberseeischen Provinzen vermittelst spanischer Postschiffe befördert werden.

Jeder Brief muss tragen den Wert von 5 céntimos, ausgedrickt durch eine eigens für diesen Zweck geschaffene Marke, welche von dem Absender auf dem Umschlag und der Seite der Adresse zu befestigen ist, ohne Beeinträchtigung der nach den bestehenden Portotarifen zur Frankirung der Briefe nötigen Marken.

Diese nene Stener wird in Kraft treten am 1. Januar 1874. Infolge hiervon werden die Postanstalten von diesem Tage an alle diejenigen Briefe zurückbehalten, welche nicht mit dieser Spezialmarke versehen sind und die Adressaten davon benachrichtigen in der Form, welche für unfrankirte Bricfe vorgeschrieben ist.

Um alle Zweifel und Anfragen zu vermeiden, glaube ich hinzufugen zu sollen, dass von dieser Verfügung ausgeschlossen ist alle internationale Korrespondenz, da Vorschriften eines internen Reglements nicht ein durch Postverträge abgeschlossenes Uebereinkommen aufzuheben vermögen.

In gleicher Weise sind ausgenommen die Postkarten, welche der Erlass vom 2. Oktober nicht einschliesst, da eine Erhöhung des Portos derselben im Widerspruch stände mit den Ideen, welche zu deren Finfürung führten.

Madrid, 15. Dezember 1873.

Der General-Direktor: Antonio del Val."

Diesem Rundschreiben ist noch ergänzend hinzuzufügen, dass laut Instruktion vom 23. Oktober anch die Briefe im Ortsverkehr diese Stener nicht zahlten und dass durch Erlass vom 13. März 1874 die Steuer von 5 céntimos anch auf die T'elegramme ausgedehnt wurde.

Heben wir aus diesen Erlassen und Bestimmungen nochmals diejenigen Sätze hervor, welche für die Geschichte und Verwendung der Kriegssteuermarken besonders wichtig sind, so ergiebt sich:

1. dass die Kriegsstenermarken durch ein Finanz- und Stenergesetz ins Leben gerufen wurden;

2. dass dieses Gesetz die Marke zu 10 céntimos für die verschiedenartigsten Dinge, diejenige zu 5 céntimos aber ganz ausschliesslich für postalische Zwecke bestimmt und ferner 
3. dass diese 5 céntimos als ein integrirender Bestandteil des fiir die Frankirung eines Briefes zu bezahlenden Portos zu betrachten sind, da ohne Bezahlung derselben der Brief als unfrankirt angesehen und - da in Spanien Frankirungszwang besteht - als solcher nicht befördert wurde.

Schon hiernach, sollte ich meinen, könnte jeder unbefangen Urteilende nur zu dem Schlusse kommen, dass die Marke zu $10 \mathrm{c}$. allerdings rein fiskalischen Charakters ist, dass aber die Marke zu 5 c. einen entschiedenen Doppelcharakter, d. h. neben dem stenerfiskalischen einen postalischen besitzt, also anch in eine Postwertzeichen-Sammlung gehört. Doch gehen wir auf die Sachlage näher ein!

Dass die Kriegsstenermarken durch ein Finanzgesetz ins Lebengerufen, dass sie in allen angeführten Erlassen als eine „Steure"“ bezeichnet werden, ist nach Obigem ebenso unbestreitbar, als dass sie die Bezeichnung „Impuesto de guerra“ an der Stirne tragen. Wenn man jedoch hieraus folgert, dass die Marken zu 5 c. um diese handelt es sich in Nachfolgendem ganz besonders deshalb rein fiskalische Marken seien, und wemm man hierans einen wesentlichen Unterschied zwischen ihnen und den Postmarken konstruiren will, so ist dies spanischer Auffassung und spanischem Sprachgebrauch röllig entgegen. „Impuesto" bedeutet nach dem Diccionario de la academia española nicht blos Auflage, Steuer, Tribut und dergl., sondern iiberhanpt: Jegliche auferlegte Verbindlichkeit. Nach spanischer Auffassung ist daher das für die Beförderung eines Briefes zu zahlende Porto ebenso ein ,impuesto“, wie die an den Stenererheber in baarem Gelde zu entrichtende Abgabe. Es wäre eine leichte Sache, zahlreiche postalische Erlasse, philatelistische und andere Aufsätze zu zitiren, in welchen das Wort „impuesto“ an Stelle des Wortes porte oder franqueo gebraucht wird, finden sich doch selbst in den von Moens übersetzten und Jedem zugänglichen Erlassen derartige Stellen. So lautet der Artikel 1 des carlistischen Eriasses ïber die Einführung der Briefmarken in Catalonien in Moens'scher Uebersetzung:

„Est établi un impôt (impuesto) sur la correspondance qui sera perȩu par le moyen de timbres spéciaux, qui reproduisent le buste de S. M. le Roi Don Carlos VII. La valeur de chaque timbre sera etc." 
Also anch hier ist das Wort „impuestu“ für das dem Sinne nach gemeinte "Briefporto" gesetzt, ohne dass es jemals einem Menschen eingefallen wäre, die carlistische 16 maravedis-Marke als eine Stenermarke anzusehen.

Dass nach spanischer Auffassung das Briefporto als eine "Stener" anzusehen ist, gelit anch dentlich daraus hervor, dass die Anfertigung und der Verkauf der Postmarken, ebenso wie derjenige aller Stenermarken der Direccion de las Rentas estancadas, d. l. derjenigen Behörde unterstellt ist, welche die indirekten Stenern zu erheben hat. Man kauft in Spanien Post-, Wechselund Stempelmarken aller Art gleichmässig in den Bureaux dieser Stenerbehörde oder bei den diesen unterstellten Lotterie-Einnehmern, Tabak- nnd Salz-Verkäufern*), das Geld für alle diese, von philatelistischem Standpunkt aus betrachtet, so sehr verschiedenen Marken fliesst in eine und dieselbe Kasse. Auch das spanische Strafgesetzbuch macht keinen Unterschied und verurteilt den PortoDefraudanten nach demselben Paragraphen, nach welchem es "Contrebando" d. h. Steuerhinterziehung bestraft.

Es dürfte aus dem Gesagten klar und dentlich hervorgehen, dass in Spanien der scharfe Unterschied, den man in anderen Ländern zwischen Post- und fiskalischen Marken macht, nicht besteht, dass also auch die Folgerungen, die man aus der Bezeichnung „inupuesto de guerra“ zieht, irrige sind. Im Uebrigen hindert uns bei der vielfachen Bedentung des Wortes impuesto nichts, impuesto de guerra mit "Kriegs-Porto oder Kriegszuschlag-Porto“ zu übersetzen, eine Uebersetzung, die auf jeden Fall den Vorteil hätte, dass sie das Wesen der Sache deutlicher kennzeichnete.

Doch gehen wir weiter!

Dass die Kriegsstener von 5 céntimos als ein integrierender Teil des Briefportos anzusehen ist, geht aus dem Erlass vom 15. Dezember 1873 deutlich hervor. Ein jeder mbefangen Urteilende wird zugeben, dass unter solchen Verhältnissen der Unterschied zwischen Post- und Kriegsstenermarke nur ein ideeller, in praxi nicht vorhandener war. Der Absender liatte für die Beförderung seines Briefes einfach 5 c. mehr zu bezahlen, ob man dieselben

*) A nmerkung: Die Vorsteher der Tabak-Estancos, sowie diejenigen der Salz-Niederlagen sind, da Spanien diese Artikel staatlich mınopolisirt hat, als eine Klasse vou Steuerbeamten anzusehen. 
"Steuer" oder "Porto“ nannte, konnte für ilın gleichgültig sein; für den Postbeamten war es ganz einerlei, ob auf einem Briefe eine Kriegsstenermarke oder eine Postmarke fehlte, in jedem Fall galt der Brief als unfrankirt und musste nach den für unfrankirte Briefe eigenartigen Bestimmungen behandelt werden. Dass zwischen beiden Arten von Jarken von den Postbeamten kein Unterschied gemacht wurde, beweist die grosse Zahl mir vorliegender Briefumschläge, auf denen das Porto völlig in Kriegssteuermarken bezahlt jst, ebenso wie auch solche zahlreich vorkommen, bei denen die Kriegssteuermarke durch eine Postmarke ersetzt ist.

Aber, wird man fragen: Weshalb hat man nicht, wenn die Kriegssteuer als ein integrierender Teil des Portos anzusehen ist, das Briefporto einfach erhöht mnd zm Bezahlung desselben höherwertige Marken verwendet? Die Frage liegt nahe und kamn ich aus bester Quelle mitteilen, dass dieser Vorschlag auch im Seltember 1873 von Seiten des General-Post-Direktors Antonio del Val gemacht, aber aus folgenden Gründen abgelehnt wurde:

Hätte man die Kriegsstener für Briefe dem Porto zugeschlagen und durch höherwertige Postmarken erhoben, so wäre eine Aenderung sämtlicher Posttarife nötig gewesen. Diese Aenderung hätte der im Lande naturgemäss sehr unbeliebten Stener leicht das Ansehen einer „dauernd beabsichtigten" gegeben. Es lag" aber" im Interesse der republikanischen Regierung, dass dieselbe als eine provisorische, nur für vorübergehende Bedürfnisse eingeführte und vielleicht schon nach einigen Monaten wieder abgeschaffte, angesehen wurde. Man wusste auch nicht, ob die Finanzlage des Staates nicht in Kurzem - wie es auch thatsächlich der Fall war - eine weitere Erhöhung dieser Stener nötig mache, dann hätte man von Neuem eine Aenderung der Tarife vornehmen müssen. Das von der Regierung angenommene Verfahren hatte den Vorteil, dass man jederzeit die Kriegsstener aufheben kounte, ohne anderweitige gesetzliche Bestimmungen ändern zu müssen, die postalischen Tarife blieben damn einfach anf dem status quo ante.

Als sich im Jahre 1879 heransstellte, dass der Staat infolge seiner traurigen Finanzlage diese Kriegsstener für die nächsten Jahre nicht entbehren könne, so schlng man sie einfach zum Porto, wie aus dem Vergleich der Tarife beider Jahre hervorgeht: 


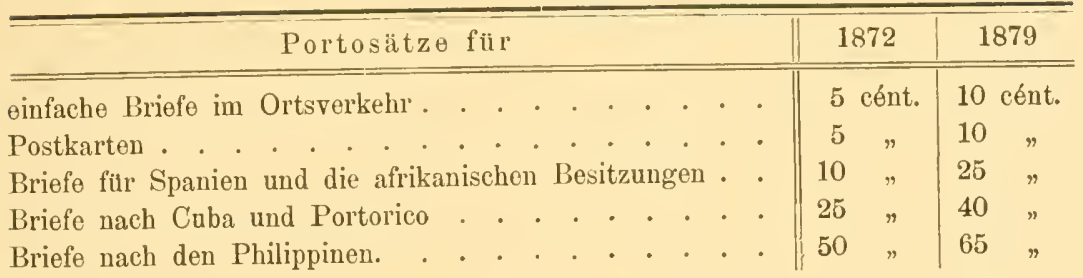

Die Kriegssteuer blieb alșo thatsächlich bestehen, wurde nur in anderer Form erhoben, also auch "ideell" existirt kein Unterschied zwischen ihr und dem tarifmässigen Porto.

Wie man nach allem diesem an dem postalischen Wert der Kriegsstenermarken zweifeln kann, ist mir deshalb völlig unverständlich. Thatsächlich ist dies auch während beinahe zweier Dezennien von keiner Seite geschehen. Die grössten philatelistischen Autoritäten aller Nationen erkannten sie stets als sammelberechtigte Objekte an, und wenn von Seiten der Bearbeiter philatelistischer Handbücher und der Herausgeber von Alben ein Fehler gemacht wurde, so war es gewöhnlich nur der, dass man nicht scharf genug zwischen den postalisch und fiskalisch gebrauchten unterschied, d. h. dass man auch vielfach solche Kriegsstenermarken aufnahm, welche mit der Post absolut nichts zu thun hatten. Ausdriicklich betont muss dabei werden, dass diese frühere Auffassung der Kriegssteuermarken nicht etwa auf Unkenntnis der bezüglichen Gesetze beruhte, denn alle neuerdings von Moens ins französische ïbertragenen, auf diese Marken bezüglichen Erlasse sind seit vielen Jahren bekannt, mehrmals gesammelt herausgegeben und in andere Sprachen iibersetzt worden.

Aber selbst, wenn alle diese angeführten Gründe nicht ausreichend wären, den Wert und die Sammelberechtigung der Kriegssteuermarken nachzuweisen, wenn dieselben trotz Allem nicht in den, durch die Entwicklung der Philatelie und durch den Usus gezogenen Rahmen hineinpassten, so würde dies meines Erachtens noch lange nicht gegen die Aufnahme derselben in unsere Sammlungen sprechen, sondern nur dafür, dass diese durch die Sammler selbst gezogenen Grenzen aus logischen Gründen zu erweitern wären. Die Kriegsstenermarken gehören mit den sogen. Habilitados und den Carlistenmarken zu den interessantesten Wertzeichen Spaniens, nicht weil sie etwa besonders schön ausge- 
führt sind oder sich in anderer Beziehung von den gewöhnlichen Briefmarken auszeichnen, sondern weil sie eine Krise in dem Leben und der Geschichte des spanischen Volkes, einen wichtigen Vorgang in der Entwicklungsgeschichte des spanischen Postwesens auf's Deutlichste zum Ausdruck bringen. Sollen unsere Postwertzeichen-Sammlungen mehr sein, als eine blosse Aneinanderreihung buntbedruckter Papierchen, sollen sie wirklich das sein, was sie für den denkenden Philatelisten sind, ein zwar kleiner, aber immerhin interessanter Beitrag zur Kulturgeschichte eines Volkes, eine Illustration zur Entwickelungsgeschichte eines der wichtigsten Verkehrsmittel unseres Jahrhunderts - und nur eine solche Auffassung kann es rechtfertigen, dass so viele Männer jeden Alters und jeden Standes Zeit und Geld anf diese Sache verwenden dann dürfen Marken wie die Kriegssteuermarken in ihnen nicht fehlen.

Für denjenigen Sammler, welcher die Berechtigmng dieser angeführten Gründe und somit anch den postalischen Wert einzelner Kriegsstenermarken anerkennt, bleibt somit nur noch die Frage zu beantworten, welche Werte derselben in Laufe der Jahre postalische Verwendung gefunden haben. Bis zum Jahre 1877 blieb dies nur die Marke zu 5 céntimos, da die Erhöhung der Kriegssteuer im Jahre 1876 (Ausgabe von Narken zu 5, 10 und 25 c., 1 und 5 pesetas) sich nicht auf den Briefverkehr bezogen hatte. Erst durch Erlass vom 28. August 1877 wurde eine Erhöhung der Kriegsstener für Postsendungen und die Ausgabe der Werte zu 15 und 50 céntimos, letzterer für eingeschriebene Briefe angeordnet. Leider wurde durch diesen Erlass auch eine vorübergehende Benutzung anderer Werte zu postalischen Zwecken herbeigeführt und hierdurch die bisherige scharfe Trennung der Bestimmung aufgehoben. Da nämlich der Erlass vom 28. August schon am 1. September in Kraft treten sollte, bis dahin aber unmöglich die nemen Werte zu 15 und 50 c. an die Verkanfstellen in den Provinzen übermittelt sein konnten, so wurde von der GeneralPostdirektion befohlen, dass bis zum Vorhandensein der nenen Werte die Kriegssteuermarken zu 5, 10 und 25 c. der Ausgabe 1876, von denen die beiden letzteren bisher anderen Zwecken gedient hatten, zu verwenden seien.

Durch die Instruktion vom 22. Oktober 1873 war auch die 
Art und Weise der Entwertung der Kriegssteuermarken für jeden einzelnen Fall genau bestimmt worden. Man erkennt hiernach die postalisch verwendeten Marken an der Entwertung durch Poststempel, während die zu anderen Zwecken gebrauchten gewöhnlich durch Aufschrift des Datums, Durchlochung (bei Eisenbahnkarten), Halbirung (bei Theaterbillets) oder auf andere Weise unbranchbar gemacht wurden.

\section{Ausgabe:}

vom 1. Januar bis 31. Dezember 1874.

Spanisches Wappen mit Manerkrone in einem Oval mit liniirtem Untergrund; $\mathrm{nm}$ das Oval ein Rahmen mit Inschriften, oben: IMPUESTO DE GUERRA, unten : 5 CENT. PESETA, dazwischen auf beiden Seiten je ein Stern; um das Ganze eine griechische Bordüre.

Schwarzer Buchdruck auf weissem Papier: gezälnt 14. (Taf. IX, 115.)

1. 5 CENT. PESETA schwarz in zwei Abstufungen.

1 a) 5 CENT. PESETA schwarz,

1 b) $5 \quad$ grauschwarz.

Bemerkungen.

1. Einige Bogen dieser Ausgabe entgingen der Zähnung. Marken derselben kommen postalisch entwertet vor.

2. Im Juli 1874 tauchten Fälschungen dieser Marke auf, die nach einem Rundschreiben der General-Post-Direktion sich hauptsächlich an der etwas grösseren Zahl „5“, sowie an den beiden Sternen, welche bei den Fälschungen grösser und anstatt kreisrund mehr oval sind, erkennen lassen.

3. Essais der 5 céntimos-Marke existiren in blauer und grüner Farbe auf dickem weissem Papier. 


\section{Ausgabe:}

vom 1. Januar 1875 bis 31. Mai 1876.

Spanisches Wappen mit Mauerkrone in einem Oval mit liniirtem Untergrund; um das Oval ein Rahmen mit der Inschrift: ESPANA auf beiden Seiten; unten: CENT., rechts und links davon Wertziffern im Kreise; oben auf flatterndem Bande: IMPTO DE GUERRA.

Farbiger Buchdruck auf weissem Papier; gezähnt 14. (Taf. IX, 116.)

2. 5 CENT. (de peseta) grün in zahlreichen Schattirungen.

2 a) 5 CENT. grün,

2 b) 5 dunkelgrtin,

2 c) 5, gelbgrün,

2 d) 5 hellgelbgrün,

2 e) $5 "$ graugrün.

Bemerkung.

Auch von dieser Marke existiren ungezähnte Exemplare.

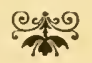

\section{Ausgabe:}

vom 1. Juni 1876 bis 1. Mai 1879.

Kopf des Königs Alfonso XII. nach links in einem Oval mit liniirtem Untergrund; im das Oval ein Rahmen mit Inschriften und zwar oben: IMPUESTO DE GUERRA, unten Wertangabe; in den Ecken Verzierungen; auf dem Halsabschnitt der Name Julia.

Farbiger Buchdruck auf weissem Papier; gezähnt 14. (Taf. IX, 117.)

3. 5 CENT. PESETA grün in drei Schattirungen.

3 a) 5 CENT. PESETA grün,

3 b) 5 dunkelgrun,

c) $5 \quad " \quad$ graugrỉn. 


\section{Bemerkungen.}

1. Auch diese Marke kommt ungezähnt postalisch entwertet vor.

2. Fälschungen dieser Marke unterscheiden sich durch scblechte Ausführung und gröberes Papier. Erstere zeigt sich besonders in den Linien der Buste und des Untergrundes, welche vielfach weisse Stellen zeigen. Die Farbe ist ein helleres, matteres grün.

3. Essais sind folgende bekannt:

a) auf weissem Papier und ungezähnt in schwarz, blau, gelblichbraun, malven, braun, gelb, griin, orange und braunviolett;

b) auf dem nämlichen Papier, gezähnt in schwarz, ultramarinblau, ockerbraun, orange, rothbraun, violett, violettrot und lila;

c) auf gelbem Papier in griin.

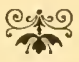

\section{Ausgabe:}

vom 1. September 1877 bis 1. Mai 1879.

Zeichnung der vorigen Ausgabe.

4. 10 CENT. PESETA blau in zwei Abstufungen.

4 a) 10 CENT. PESETA blau,

4 b) 10 lebhaft blau.

\section{25 CENT PESETA schwarz.}

October 1877. Kopf des Königs nach links in einem Oval mit liniirtem Untergrund; oben und unten auf rechteckigem Schild: $\mathrm{IMP}_{\mathrm{T} 0}$ DE GUERRA bezw. Werthangabe; in den Ecken Verzierungen; auf dem Halsabschnitt der Name Julia.

Farbiger Buchdruck auf weissem Papier; gezähnt 14. (Taf. IX, 118.)

6. 15 C. DE PESETA braunrot in zwei Abstufungen.

6 a) 15 C. DE PESETA braunrot,

6 b) $15 \mathrm{C}$. "

7. 50 C. DE PESETA orange in zwei Schattirungen.

7 a) 50 C. DE PESETA orange,

7 b) 50 C. $\quad$ gelborange. 


\section{Bemerkungen.}

1. Wie auf Seite 118 bemerkt, waren die Marken zu 10 und 25 céntimos schon im Juni 1876 ausgegeben worden, hatten aber bis zum September 1877 nur steuerfiskalischen Zwecken gedient. Durch Verfügung der General-Postdirektion vom 28. Angust 1877 wurden sie bis zur Fertigstellung der Marken No. 6 u. 7 zur postalischen Verwendung bestimmt. Ob sie nach deren Ausgabe im Oktober 1877 postalischen Zwecken weiter dienen durften, ist aus den Erlassen nicht ersichtlich.

2. Die Marke zu 15 céntimos wurde im Jahre 1878 in Barcelona gefälscht. Man erkennt die Fälschungen an der helleren Farbe, den ungleichmässigen Strichen des Untergrunds, der gestreckteren Nase des Königs und den helleren, häufig durch weisse Stellen unterbrochenen Haaren desselben.

3. Von Essais zu dieser Ausgabe sind folgende bekannt:

10 c. de pes. schwarz, blau, grtin, braun und rosa,

25 schwarz und griin,

10 u. 25 c, d. pes. grün auf gelbem Papier.

In Zeichnung der Marke von 1877 giebt es:

$5 \mathrm{c}$ de peseta blau und braun auf weissem, satinirtem Papier,

blau, braun und vioiett auf hell- und dunkelgelbem Papier,

10 c. de peseta blan, grün und rotbraun anf weissem, hell- und dunkelgelbem Papier,

15 c. de peseta blau und grün auf weissem Papier,

blau, grïn, violett, braun und rotbraun auf hell- ind dunkelgelbem Papier,

rot, blau und grün auf rötlich chamois,

2. c. de peseta grün und rotbraun anf weissem Papier, blau, grau und rotbraun auf hell- und dunkelgelb,

50 c. de peseta blau und violett auf weissem Papier, braun, blau und violett ant hell- und dunkelgelbem Papier.

Als die Königliche Ordre vom 4. Februar 1879 die Verwendung der Kriegssteuermarken nach dem 1. Mai verbot, war eine neue Ausgabe derselben schon fertig gestellt. Dieselbe wurde, nachdem an Stelle von "IMPTO DE GUERRA “ die Bezeichnung „CORREOS Y TELEGS়" getreten, zur Herstellung de. XXX. Ausgabe benutzt. Mit der alten Inschrift giebt es die Werte:

$\begin{array}{rcl}5 & \text { Céntimos } & \text { blau, } \\ 10 & \# & \text { karminrosa, } \\ 15 & " & \text { lila, } \\ 25 & " & \text { braun, } \\ 50 & " & \text { schwarzgrün, } \\ 1 & \text { peseta } & \text { gelblichbraun. } \\ 5 & \text { pesetas } & \text { graulila. }\end{array}$

ausserdem auf dickem, satinirtem Papier die sämtlichen Werte in grün, blau, lila und gelblichbraun, die Werte zu 15 céntimos, 1 und 5 pesetas ausserdem noch in dunkelkarmin. 


\section{III.}

Marken des Carlistischen Aurstandsgebietes.

I. 



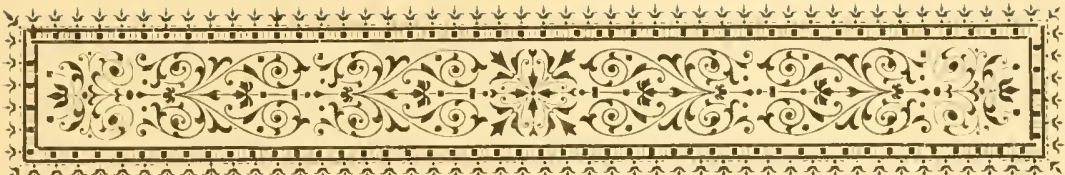

\section{Marken des Carlistischen Iufstandsgebietes.}

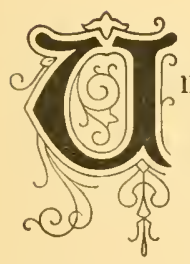

nter der Regiermug ıles Königs Amadeo erhob der Thronprätendent Infant Don Carlos die Fahme des Aufstandes, der sich, beginnstigt durch eine lange Kette von Umständen nnd Verhältnissen, deren Schildernng den Rahmen dieses Buches überschreiten würde, sehr bald über einen grossen Teil des nördlichen Spaniens ausbreitete. Es kamen nach und nach unter die Herrschaft „König Karls VII.":

1. die vereinigten Nordprovinzen: Navarra, Vizcaya, Guipuscoa und Alava mit den angrenzenden Teilen Asturiens, Castiliens und Ober-Aragons;

2. der grösste Teil von Catalonien (jedoch olme Barcelona);

3. das sogen. Maestrazgo, d. l. ein Landstrich, gebildet aus dem südlichen Teil von Nieder-Aragon und dem nördlichen der Provinz Valencia (olne die Stadt gleichen Namens).

Von diesen Gebieten blieben jedoch mur die baskischen Provinzen und Navarra melırere Jahre unuterbrochen und unangefochten im Besitz der Carlisten, in allen übrigen 'Teilen ihres Gebietes wurde ihre Herrschaft vielfach auf kürzere oder längere Zeit, je nach dem wechselnden Gliick der Waffen, unterbrochen. Anch in den danernd in ihrer Hand befindlichen Provinzen gelang 
es ihnen nicht, sich in den Besitz der sämtlich befestigten Hauptstädte zu setzen, und Pampeluna, Vitoria, Bílbao und Santander, die inmitten carlistischen Gebietes gelegenen Zentren des nordspanischen Handels, deren Besitzergreifung für die Carlisten von unberechenbaren Folgen gewesen, gehorchten nach wie vor der Madrider Regierung.

Mit der Besitznahme eines Landstriches durch carlistische Streifkorps hörte selbstverständlich die Thätigkeit der spanischen Postverwaltung auf, ohne dass dafür von carlistischer Seite sofort ein Ersatz durch Organisation eigener Verkehrseinrichtungen geschaffen werden konnte. So kam es, dass in den Jahren 1872 und 1873 der Briefverkehr in den genannten Provinzen fast ganz stockte, wenigstens nur unter den grössten Schwierigkeiten mit Hilfe der noch in einigen Städten befindlichen Garnisonen oder durch Privatboten, Schmnggler etc. aufrecht erhalten werden konnte. Der carlistisch gesinnte Teil der Bevölkerung half sich im internen Verkehr der Provinzen durch private Bestellung, selbstverständlich ohne Benutzung von Postwertzeichen, im Verkehr mit dem Auslande durch Inanspruchnahme der französischen Grenzpostanstalten mit Benutzung französischer Briefmarken. Diese letzteren erhielten von Seiten der Carlisten - wie Moens mitteilt, spanische Quellen erwähnen hiervon nichts - einen Handstempelaufdruck, bestehend aus einem fünfeckigen Stern mit Lilie, ein Aufdruck, der später auch als Entwertungsstempel diente. Nach Moens sollen folgende französische Marken mit diesem Aufdruck existiren:

von der Ausgabe 1862: 5 centimes grün, von der Ausgabe 1872: 1 centime bronzegrün,

$\begin{array}{rll}2 & \text { centimes } & \text { braunrot, } \\ 5 & \quad & \text { grün, } \\ 15 & \text { h } & \text { hellbraun, } \\ 20 & \quad & \text { blau, } \\ 25 & \text { " } & \text { blau, } \\ 40 \quad " & \text { orange, } \\ 80 \quad \# & \text { karmin. }\end{array}$

Als sich die Herrschaft der Carlisten infolge der Schwäche der Madrider Regierung, deren personelle und materielle Kräfte noch durch die Aufstände in Cartagena und auf Cuba in Anspruch genommen waren, melr und mehr festigte, zwangen schon 
militärische Gründe, aber noch mehr die Notwendigkeit, dem Aufstande neue Geldquellen zn eröffnen, dazu, das Post- mud Telegraphenwesen besser zu organisiren. Navarra machte den Anfang, Vizcaya schloss sich ihm an und schon im Frïhjahr 1874 sehen wir den Post- und Telegraphendienst der vier Nordprovinzen einheitlich geordnet. Derselbe hatte anfänglich begreiflicherweise mit grossen Schwierigkeiten zu kämpfen, wurde aber nach und nach immer mehr vervollkommet und funktionirte schliesslich in der Zeit vom Herbst 1874 bis zum Frühjahr 1876 mit ziemlicher Sicherheit.

Was cie Organisation anbelangt, so begnïgte sich die carlistische Zentraljunta damit, von dem Zentrum Navarras und der ideellen Hauptstadt des carlistischen Staates, der Stadt Estella aus, eine Reilıe von Hauptkurirlinien nach der französischen Grenze (Bayonne) zı organisiren, indem sie es den Provinzialjuntas iiberliess, die weniger wichtigen Punkte des Landes an diese anzuschliessen. So entstand allmählich ein dichtes Netz von Post- und Telegraphenlinien über das ganze carlistische Nordspanien. Die Generaldirektion des Verkehrswesens, ganz der spanischen nachgebildet, lıatte unter der den Carlisten wohlwollenden Präsidentschaft Mac Mahons und dem Ministerium Décazes ihren Sitz in Bayonne, wurde aber im Juli 1874 nach 'Tolosa verlegt; Direktionen waren in Elizondo, Vergara, Durango und Alava etablirt.

Das Porto betrug innerhalb des Aufstandsgebietes für Briefe bis zu 15 gr. 1 Real (= 25 céntimos de peseta), für jede weiteren 15 gr. oder T'eile dieses Gewichts je 1 Real mehr; dienstliche Korrespondenzen waren portofrei. Für Briefe nach dem Auslande war ein carlistisches Porto bis zur französischen Grenzstation (Bayonne) zu bezahlen und ausserdem das französische Porto (pro je 10 gr. 1 Real) beizufügen. Diese Briefe waren infolgedessen doppelt zu couvertiren, das äussere Couvert trug die Aufschrift: "Al encargado de la correspondencia Carlista - Bayona“, (siehe Tafel X) oder anch: "Al encargado general de la correspondencia de Francia - Bayona, (sielıe Tafel XI), war mit den carlistischen Marken beklebt und enthielt in seinem Innern ausser dem Brief das französische Porto in Geld oder in ungebrauchten carlistischen oder französischen Briefmarken. Von der Grenze ab galt der innere Umschlag, welcher in gewöhnlicher Weise Namen und Wohnort des Adressaten anzugeben hatte. Für alle Korrespon- 
denzen war der Frankirungszwang eingefülırt, unfrankirte Briefe zahlten im Gebiete des Aufstandes das doppelte Porto, meist wurden sie jedoch einfach verbrannt.

Was die carlistischen Freimarken der vier Nordprovinzen anbelangt, so wurden dieselben in Bayonne angefertigt und zwar die erste Ausgabe wahrscheinlich schon vor der oben geschilderten Organisation der Postlinien (Dezember 1873) im - Herbst 1873. Ob sie vor Frühjahr 1874 thatsächlich zur Verwendung kamen, ist zweifelhaft, da erst von dieser Zeit an eine gewisse Ruhe und Sicherheit der Verhätnisse eintrat. Ihre Verwendung war im Uebrigen, anch nachdem die Organisation der Post vollendet, eine verhältnismässig seltene, da die Zentren des Handels und der Industrie Nordspaniens nie in die Gewalt des Prätendenten kamen, die Landbewolmer der baskischen Provinzen aber meist des Schreibens unkundig sind, auch keine Veranlassung zu Korrespondenzen latten. Viele der kleineren Postanstalten besassen scheinbar iiberhaupt keine Marken oder kamen nur unregelmässig in den Besitz derselben und mussten sich deshalb meist mit einem handschriftlichen Frankirungsvermerk behelfen. So ist die Zahl der in Sammlungen oder im Handel befindlichen ngebrauchten " carlistischen Marken eine sehr geringe, umsomehr, als die Marken aller ins Ausland gerichteten Briefe nicht in den Besitz des Adressaten gelangten, sondern anf der carlistischen Postagentur zu Bayonne in den Papierkorb wanderten.

Ganz anders entwickelten sich die postalischen Verhältnisse der Carlisten anf den beiden anderen Kriegsschauplätzen, der Provinz Catalonien und dem Maestrazgo.

Während in den baskischen Provinzen und in Navarra die Gesamtheit der Bewohner die Sache des Don Carlos zu der ihrigen machte, die Organisation der Regierung und des Heeres sich infolge dessen leicht und rasch vollzog, während dort die geographische Beschaffenheit des Landes eine Verteidigung ungemein erleichterte und infolge hiervon wiederum eine längere Zeit ungestörten Besitzes und ruhiger Entwickelung eintreten konnte, entbehrten die Verhältnisse in Catalonien und in Maestrazgo jeglicher Stabilität. Die fast ausschliesslich von Handel und Industrie lebenden Catalanen und Valencianer schlossen sich nur in verhältnis- 
mässig geringer Zahl dem Aufstande an, der infolge dessen nur langsame Fortschritte machte. Während in den Nordprovinzen schon zu Ende 1874 eine Armee von fast 100000 Mann gut gekleideter, vorziiglich bewaffneter und von tüchtigen Offizieren geführter Truppen vorhanden war, blieben die sogenannten Armeen von Catalonien und Valencia bis zuletzt nur ein disziplinloser Haufen von zusammengelaufenen Abenteurern, welche den Truppen der Regierung in Madrid dauernd die Spitze zu bieten nicht imstande waren.

Unter diesen Verlıältnissen ist es begreiflich, dass die Organisation des Post- und 'T'elegraphenwesens hier' erst beinahe ein Jahr später in die Hand genommen und dass der Postdienst niemals so sicher funktionirend werden konnte, wie in den baskischen Provinzen. Anf die Daten der uns ïberlieferten carlistischen Erlasse ist kein besonderer Wert zu legen, da die Verhältnisse ihre Befolgung in den meisten Fällen illusorisch machten.

Die Organisation des Postwesens in Catalonien ist analog derjenigen der Nordprovinzen, nur dass die Briefe in's Ausland nicht nach Bayonne, sondern nach Pratts de Mollo gesandt wurden. Das Porto betrug für Briefe im Aufstandsgebiet pro $10 \mathrm{gr}$. $=4$ cuartos $=16$ maravedis (etwa $1 / 2$ Real); Briefe in's Ausland wurden genan wie in den baskischen Provinzen behandelt.

Ueber die Organisation der Post im Maestrazgo sind Details nicht bekannt geworden, allem Anschein nach bestand eine solche nur auf dem Papier. Gebrauchte Marken dieser Provinz sind sehr selten, die mir bis jetzt vor Augen gekonmenen Abstempelungen waren sämtlich gefälscht.

\section{A. Marken für die Baskischen Provinzen und Navarra.}

\section{Ausgabe:}

vom 1. Januar bis 1 . Juli 1874 .

Kopf des Prätendenten Don Carlos in einem Oval mit linïrtem Untergrund; das Haar ist in der Mitte gescheitelt, die Nase durch Punkte schattirt: zwischen den Augenbranen befindet sich eine weisse Stelle, um den Bart lässt sich auf der linken Seite eine 
weissgebliebene Umrandung erkennen; das Ende des Schnurrbartes ist lang, hängt herab und kränselt sich dann wieder nach oben; der Umriss des Ovals berïhrt den Narkemrand auf der linken Seite; ïber dem Oval in weissem Schild: FRANQUEO, unten in den Ecken Wertangabe, dazwischen ESPANA oder ESPA $\widetilde{N} A$.

Farbiger Druck (Lithographie) auf weissem, verschieden starkem Papier: ungezähnt. (Taf. XI, 119.)

I. Type: ESPANA falsch geschrieben, $d$. h. ohne tilde iiber $\operatorname{dem} \mathrm{N}^{*}$ ):

1. 1 rl (real) blau in mehreren Abstufungen auf verschiedenem Papier.

1 a) $1 \mathrm{rl}$ blau auf dünnem Papier,

1 b) $1 \mathrm{rl}$ blassblau auf dünnem Papier,

1 c) $1 \mathrm{rl}$ blau auf dickem Papier,

1d) $1 \mathrm{rl}$ hellblau auf dickem Papier.

II. Type: ESPA $\widetilde{N} A$ mit $\widetilde{\mathrm{N}}$, olne weisse Linie ïber diesem Wort.

\section{2. $1 \mathrm{rl} \mathrm{blau}$ in zwei Schattirungen.}

2 a) 1 rl blau,

2 b) 1 il lebhaft blau.

\section{Bemerkungen.}

1. Moens bezeichnet in seiner "Histoire des Timbres-poste employés en Espagne" als das Ausgabedatum der I. Type den 1. Juli 1873, als dasjenige der II. Type den September 1873. Nach glaubwürdigen Mitteilungen ist es allerdings nicht ausgeschlossen, dass die I. Type, wie auch oben erwähnt, schon vor der geschilderten Organisation des cal listischen Postwesens gedruckt war; thatsächlich zur Verwendung kam diese Marke jedoch frühestens vom Januar 1874 an. Von der Marke existirten zwei Platten, eine mit 84 Marken (7 Reihen à 12) und eine mit 121 Marken (11 Reihen à 11). Die II. Type wurde geschaffen, nachdem man das Feblen des tilde über dem $\mathrm{N}$ - ein für ein spanisches Auge grober Fehler - bemerkt hatte, indem man auf der einen Platte die weisse Linie üher dem Worte España entfernte und nur so viel von ihr stehen liess, als zur Bezeichnung eines tilde über dem $\mathrm{N}$ nötig war. Die vorhandenen Bestände der I. Type wurden gleichzeitig mit der II. Type aufgebraucht.

-) Das Zeichen ther dem n, tilde genannt, ist nicht, wie man huufig liest, ein Accent. Das spanische Alphabet unterscheidet vielmehr scharf zwischen $n$ und $\bar{n}$, beide als besondere Buchstaben mit ganz verschiedener Aussprache betrachtend. Das Fehlen dieses Zeichens lisst stets auf auslandischen Ursprung schliessen. 
2. Von beiden Typen sind zahlreiche Nendrucke vorbanden. Moens gieht als Datum der Anfertigung derselben den August 1881 an. Meines Wissens belinden sich jetzt die Platten beider 'Typen im Besitzo zweier Händler (von denen der eine in Dentschland wohnt), welche Neudrucke joder Zeit und ganz nach Belieben: herstellen. Die Giite derselben hat in den letzten Jahren bedi utend abrenonmen. Man erkennt die Neudrucke leicht an dem weiteren Auseinanderstehen der Schraffirungslinien anf der rechten Seite über der Wertangabe. (Vergloiche Taf. X, 120 (Nendruck) und 121 (Original).

3. Von der Marke No. 1 kommt, wahrscheinlich aus dem Jahre 1875, eine Fälschung $\nabla \circ \mathrm{r}$, welche, da sie einen gut nachgeahmten Entwertungsstempe] besitzt, vielfach als echt gekauft wird. Sie unterseheidet sich von dem Original in folgenden Punkten: Das Har des Prätendenten ist nicht gescheitelt, die Nasenspitze nicht durch Punkte schattirt, die Augenbranen treffen beinahe zusammen, nu den Bart ist keine weiss gebliebone Umrandung, sondern die Schattirungsstriche gehen dicht an denselhen lieran, der Halsabschnitt steht näher an dem ovalen Rahmen, der Schnurrbart ist ganz kurz und reicht nur bis an den Mundwinkel, das Oval berührt auf der linken Seite nicht die Umrandung.

4. Von beiden Typen giebt es Abzüge in verschiedenen Farben, von denen jedoch nur zwei in schwarz und karmin, (I. Type) den Namen von Essais verdienen; alle iibrigen sind Spekulationsprodukte.

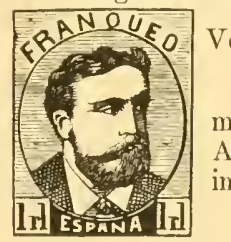

Von nicht angenommenen Typen ist folgende bekannt:

Kopf des Prätendenten zu $3 / 4$ nach rechts in einem Oral mit liniirtem Untergrund; alles Uebrige wie bei der offiziellen Ausgabe. Das sehr seltene Essai kommt nit und ohne tilde in blanem Druck (Lithographie) auf weissem Papier vor.

5. Die Art und Weise der Eutwertung der carlistischen Marken war ganz in das Belieben der Postbeamten gestellt, die hierzu nöthigen Utensilien hatten sich dieselben, falls sie nicht von der spanischen Post entnommen werden konnten, selbst zu beschaffen. Wir finden daher in der ersten Zeit meist Entweriung durch Tintenstriche oder Stempel spanischen Modells, siehe z. B. Taf. X, 121, sowie Taf. XI, 122 und 123. Man thut gut, diesen letzteren immer mit einigem Misstrauen zu begegnen, da sich unter ihneu häufig solche vorfinden, welche die Bezeichnung von Orten tragen, die sich thatsächlich niemals im Besitz der Carlisten befanden. Zur Feststellung der Echtheit ist daher der Besitz einer Karte des carlistischen Gebietes, sowie die Kenntnis der Ansdehnung desselben in den verschiedenen Phasen des Anfstandes erforderlich

Allmählich tauehen neuhergestellte carlistische Stempel auf, zuerst bei den wichtigeren Postanstalten. Die Typen derselben sind verschieden, da eine einheitliche Anfertigung unnöglich war. Hierher gehören der Stempel der Hauptstadt Estella, Taf. X, 124, sowie derjenige der carlistisehen Post-Agentur Bayonne, Taf. X, 125.

Besassen die Post-Anstalten einen besonderen Eutwertungsstempel, so stammte derselbe anfänglich in den meisten Fällen aus dem Utensil der spanischen Postverwaltung. So finden wir den spanischen Punktstempel des Jahres 187- ungemein zahlreich: Taf. XI 126. Von diesem Stempel giebt es eine Fälschung, welche sich von dem Original hauptsächlich dadurch unterscheidet, dass die Punkte nicht rund, sondern fast quadratisch, auch etwas grösser sind.

Der erste Entwertungsstempel carlistischen Ursprungs ist der allgemein bekannte Sternstempel, ein funfspitziger Stern mit einer Lilie in der Mitte. 
Taf. X1, 119. Er diente urspringlich zur Bezeichnnng der oftiziellen Korrespondenz, nach Moens auch zum Ueberdruck der im Beginn des Aufstandes henutzten Marken der französischen Republik, wurde später, nachdem die carlistischen Behörden Dienststempel nach spanischem Muster erhalten hatten, ansschliesslich zur Entwertung der Marken benutzt.

Etwas später taucht der Balkenstempel Taf. XI, 127 auf. Er besteht aus neun unter einander stehonden und ein Viereck bildenden Strichen, ein Stempel primitivster Ausführung.

Die Farbe der Entwertungsstempel ist meist blau, selten schwarz.

Ausser diesen vorstehend erwähnten Poststempeln finden sich anf carlistischen Briefen noch Dienst- und Militärstempel aller Art, welche aber als Zeichen der gewährten Portofreiheit nicht in den Rahmen dieses Buches aufgenommen wurden.

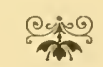

\section{Ausgabe:}

vom 1. Juli 1874 bis 28 . Februar 1875.

Kopf des Prätendenten mit Lorbeerkranz nach rechts in einem Kreise mit farbigem Untergrund; darïber anf flatterndem Bande: ESPANA, unten in den Ecken Wertangabe in Zahlen, dazwischen auf viereckigem schild: FRANQLEO.

Farbiger Druck (Lithographie) anf weissem Papier; ungezähnt. (Taf. X, 129.)

3. 1 rl lila in drei Schattirungen.

3 a) 1 rl lila,

3 b) 1 rl rötlichlila,

3 c) $1 \mathrm{rl}$ graulila.

\section{Bemerkungen.}

1. Die Ausgabe dieser Marke hängt mit dem Wechsel der an der Spitze des Verkehrswesens (Direccion general de las comunicaciones) stehenden Personen und der infolge dentschen Protestes erfolgten Verlegung des Sitzes der Generalpostdirektion von Bayonue nach Tolosa zusammen.

2. Von der Marke dieser Ausgabe giebt es eine vorzïgliche Fälschung: Sie unterscheidet sich von dem Original in folgenden Punkten: Das Papier ist gelblichweiss, anstatt weiss, die Nase ist spitzer, der tilde über España sieht 
mehr ans, wie eine Verdickung der Bandlinie und steht nicht getrennt von dieser, die untere Spitze des Buchstaben F in Franqueo stelt iber der Linie der übrigen Buchstaben, an der Unterlippe und an der Seite des Kinnes sind weisse Punkte, welche die Originale nicht besitzen, der unschattirte Teil des Halses geht nicht bis an das Ohr, sondern reicht nur bis in Höhe des Mundes, die Linie zwischen Nase und Mundwinkel fehlt. l)je Fälschungen sind ungummirt.

3. Von den Marken No. 3 giebt es Essais in blaner odel karminroter Farbe.

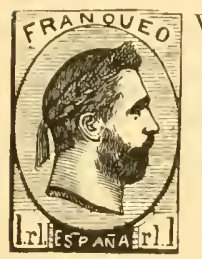

Von nicht angenommenen Typen ist nur folgende bekannt:

Kopf des Infanten mit Lorbeerkranz nach rechts in einem Oval mit liniirtem Untergrund; alle ibbrigen Details, wie bei der I. Ausgabe. Das Essai existirt in blauer, schwarzer, roter und grüner Farbe in lithographischen Druck auf weissem Papier.

\section{Ausgabe:}

vom 1. März 1875 bis zu Ende des Aufstandes: Februar 1876.

Kopf des Prätendenten mit Lorbeerkranz nach rechts innerhalb eines Kreises mit farbigem Untergrund; um den Kreis ein viereckiger Rahmen, in demselben oben die carlistische Devise: DIOS PATRIA REY (Gott, Vaterland. König), rechts und links eine griechische Borde und minten: ESPA $\widetilde{N A}$ und Wertangabe.

Farbiger Druck (Lithographie) auf verschiedenem Papier: ungezähnt. (Taf. X, 130.)

\section{5o C. (céntimos) grün in vier Schattirungen auf ver- schieden starkem Papier.}

4 a) 50 C. grün anf dünnem Papier,

4 b) 50 C. gelbgrün auf' dickem Papier,

4 c) 50 C. dunkelgrüin auf dickem Papier,

4 d) 50 C. hellgrin auf dickem Papier.

5. 1 R. (Real) braun in zwei Abstufungen auf dickem, verschieden gefärbtem Papier.

5 a) 1 R. braun anf weissem Papier,

5 b) 1 R. dunkelbraun auf weissem Papier,

5 c) 1 R. braun auf gelblichem Papier. 


\section{Bem'erkungen.}

1. Ein Erlass der General-Postdirektion zu Tolosa vom 9. Februar 1875 setzt vom 1. März ab folgende Portosätze fest:

für einen einfachen Brief (bis zu $15 \mathrm{gr}$.) im immeren Ver-

kehr einer Provinz $(1 / 2$ real $\Rightarrow)$. . . . . . 50 céntimos,

für den äusseren Umschlag eines in's Ausland gehenden

Briefes (Porto bis zur französischen Grenze) . . . . 50

für einfache Briefe aus einer Provinz in die andere : 1 Real.

Dementsprechend erfolgte die Ausgabe der beiden obigen Werte.

2. Von Essais in nicht angenommener Type wurde nur folgendes bekannt:

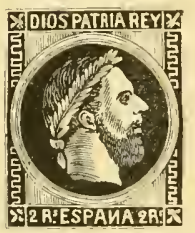

Aehnlich der offiziellen Type, nur etwas grössere Inschriften und veränderter Wert: 2 Rs.

Das Essai existirt in schwarzer und griner Farbe auf weissem Papier (Lithographie).

Eine Marke so geheimnisvollen Ursprungs, dass man allen Grund hat, sie als Phantasieprodukt eines spekulativen carlistischen Postbeamteu zu halten, ist folgende:

Spanisches Wappen im Kreise mit liniirtem Untergrund, darüber im Bogen: CARLOS SEPTIMO, darunter: REY DE LAS ESPANAS; ganz oben: CORREOS; unten Wertangabe: TRES CUARTOS. (Taf. X, 132.)

Die Marke kommt auch auf Briefimschlägen vor; Nachahmungen haben das Wappen auf weissem Untergrund.

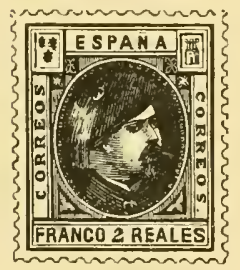

Ein offenbares Spekulationsprodukt ist das nebenstehende Essai, welches, in Brüssel angefertigt, den spanischen Boden wohl niemals gesehen hat.

Es existirt in mehreren Farben.

3. Das auf Seite 131 uber die Abstempelungen Gesagte behält zwar auch noch für die letzte Zeit des Aufstandes seine Richtigkeit, es taucht jedoch im Frühjahr 1875 in den baskischen Provinzen ein neuer Stempel auf, der einen siehtlichen Beweis für die unterdessen eingetretene Vervollkommunng der Organisation des Postwesens abgiebt. Es ist dies ein viereckiger Stempel von 15:12 mm Grösse, der in einfacher Umrandung die neue Nummer der Post-Anstalt enthält. (Taf. X, 131.)

Die Farbe des Stempels ist gewöhnlich blau (in Lichtdruek leider schlecht sichtbar). 


\section{B. Marken für die Provinz Catalonien.}

\section{Ausgabe:}

vom April 187.4 bis zu Finde des Autstandes.

Kopf des Prätendenten nach rechts in einem Oval mit liniirtem Untergrund: das Haar hinter den Ohren ist nach dem Halse zu kurz abgeschnitten, der Schatten auf der Stirn ist hell, der Bart lässt sich leicht von den Schattenstrichen des Halses unterscheiden. Ueber dem Kopf befindet sich ein Band mit der Devise: DIOS PATRIA REY; die Schattenstriche dieses Bandes sind auf der rechten Seite etwas dicker und kürzer, als anf der linken. Links vom Kopfe anf weissem Schild: A $\widetilde{N} O$ DE 1874, rechts: CATA-

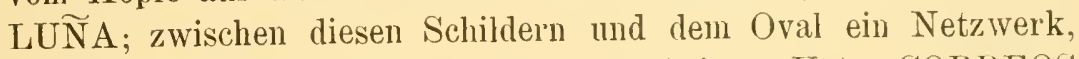
dessen Linien wellenförmig gekrümmt erscheinen. Unten CORREOS und Wertangabe, zwischen beiden ein Punkt.

Farbiger Druck (Lithographie) anf weissem Papier, ungezälınt. (Taf. X, 133).

6. $16 \mathrm{M}: \mathrm{V}$ (maravedis vellon $=\mathrm{ca}^{1 / 2} \mathrm{Rl}$.) rosa in zwei Abstufungen.

6 a) 16 MS VN rosa,

6b) $16 \mathrm{MS}$ VN hellrosa.

Bemerkungen.

1. Auf der schlecht ausgefuhrten Marke kommen folgende Inschriftfehler vor:

Dios . Pairia . Rfy,

Dios . Pairia . Kfy,

Dios . Patria . Rfy,

Cataliña statt Cataluña,

Cataiuña

10 statt 16 MsVn" und MsV7,

año en statt año de.

2. Von der Marke dieser Ansgabe giebt es eine Fälschung, welche, da auch der Entwertungsstempel gut nachgeahmt ist, häufig als echt angesehen wird. Sie unterscheidet sich vom Original in folgendem: Das Papier ist etwas dïnner, 
ANO und CATALUNA laben keinen tilde, nach Correos ein Strich anstatt eines Punktes, das $N$ von VN ganz undeutlich, das Haar des Hinterkopfes ist länger und gleicht einer Perrücke, die Stirne hat dickere Schattenstriche und die Schattenstriche des Halses laufen mit denjenigen des Bartes zusammen, sodass sie ein Ganzes bilden; das Netzwerk besteht aus geraden Linien und die Schattenstriche auf dem oberen Bande sind auf der rechten Seite sehr viel länger, als auf der linken.

3. Die thatsächliche Verwendung dieser Marken war sehr gering, da Catalonien niemals in ruhigen, unangefochtenen Besitz der Carlisten kam. Gebrauchte Marken sind daher sehr selten, ihre Entwertung besteht meist in Tintenstrichen. Entwertung durch spanische Datumstempel sind stets mit Misstrauen zu betrachten. Der in Ausgabe I erwähnte falsche Punktstempel findet sich auch auf Marken dieser Ausgabe.

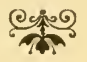 \\ C. Marken für das Maestrazgo.}

\section{Ausgabe:}

von September 1874 bis zu Ende des Aufstandes.

Kopf des Prätendenten nach rechts in einem Oval mit liniirtem Untergrund; darïber anf flatterndem Band: ESPA ÑA VALENCIA, darunter auf ebensolchem: CORREOS und Wertangabe; rechts und links des Ovals Lilien, um dasselbe nach allen Seiten strahlenförmig vom Mittelpunkt ausgehende Linien.

Von der Marke giebt es vier verschiedene Typen.

Farbiger Druck (Lithographie) auf weissem Papier; ungezähnt.

\section{Type: Das Band mit der Inschrift: ESPA ÑA VALENCIA} berührt die obere Einfassungslinie; España Valencia bilden zwei getrennte Worte; das Oval hat links 31 , rechts 30 wagerechte Linien; zwischen dem Kopfe und der oberen Einfassungslinie des Ovals liegen drei Linien: die Ziffer $1 / 2$ steht in der Mitte zwischen Correos und Real. (Taf. X, 134.) 
7. $1 / 2$ REAL rosa in zwei Abstufungen.

7 a) $1 / 2$ REAL rosa,

7 b) $1 / 2 \quad n$ dunkelrosa.

II. Type: Das Band mit ESPANA VALENCIA steht 1/2 mm von der oberen Eínfassungslinie ab; die beiden Worte der Inschrift stehen so dichtznsammen, dass sie ein Wort zu bilden scheinen: das Oval hat links 34, rechts 32 wagerechte Linien: zwischen dem Kopf und der oberen Einfassungslinie des Ovals liegen nur 2 Linien; die Ziffer 1/2 stelıt dicht an Real. ('Taf. X, 135.)

\section{8. $1 / 2$ REAL rosa.}

IIT. Type: Das obere und nntere Band mit den Inschriften berühren die Einfassungslinie; die Buchstaben der Inschriften stehen dicht nebeneinander; das Oval hat rechts 40, links 43 wagerechte Linien; zwischen Kopf und oberer Einfassungslinie des Ovals liegen 4 Linien. (Taf, $\mathrm{X}, 136$. )

\section{9. $1 / 2$ REAL zinnoberrot.}

IV. Type: Das obere Band mit der Inschrift ist $1 / 2 \mathrm{~mm}$ von der Umfassungslinie entfernt; das Oval enthält anf der linken Seite 30, auf der rechten 29 wagerechte Linien; zwischen Kopf und Einfassungslinie des Ovals befinden sich 3 Linien: die Ziffer $1 / 2$ steht dicht an Real, der Kopf scheint etwas länger, der Hals magerer.

10. $1 / 2$ REAL zinnoberrot. 


\section{Bemerkungen.}

1. Die Marken sind äusserst mangelhaft ausgeführt und bilden, wie "The Philatelist" mit Recht bemerkt, ein passendes Pendant zu dem Kopfe der Königin Isabella auf den Philippinen-Marken, Ausgabe 1854. Die beiden ersten Typen finden sich auf den Markenbogen derart verteilt, dass abwechselnd eine Reihe Marken in I., die darauf folgende in II. Type folgt, sodass also zwei in vertikaler Richtung zusammenhängende Marken beide Typen enthalten. Type III und IV wurden erst nach Beendigung des Carlistenkrieges bekannt und werden vielfach als Fälschungen angesehen.

2. Von Type III ist ein Fehldruck mit $4 / 2$ statt $1 / 2$ Real vorhanden. (Taf. X, 136.)

3. Von der Type II giebt es eine gute Fälschung. Sie unterscheidet sich von dem Original in folgenden Punkten: Dickeres Papier, links nur 33 wagerechte Linien, Farbe anstatt rosa ein tiefes Rot, fast karminrot, ungummirt.

4. Marken mit zweifellos echten Abstempelungen sind äusserst selten.

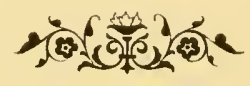




\title{
IV.
}

Briefumschlägge, Postkarten, Kartenbriefe.

\author{
2to
}





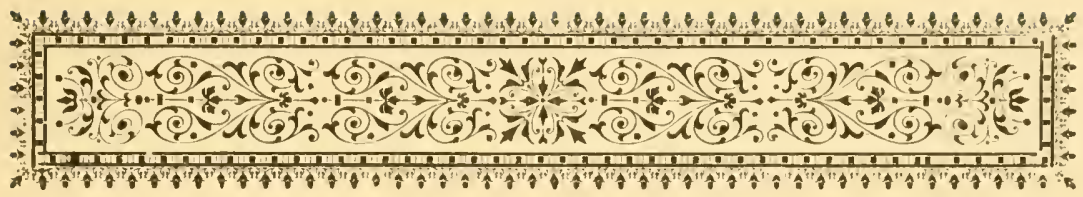

\section{Briefumschligge.}

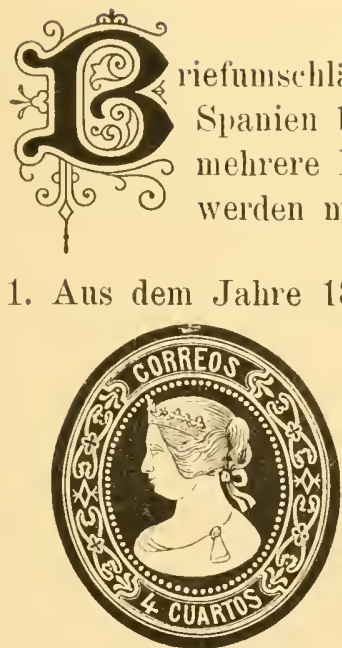

Grosses Oval mit der Büste der Königin Isabella nach links in Prägedruck: um das Oral ein Rahmen mit Inschriften und Verzierungen; oben: CORREOS, unten Wertangabe: 4 CUARTOS.

Existirt in grïner, gelber, roter, schwarzer und rosa Farbe auf weissem Papier.

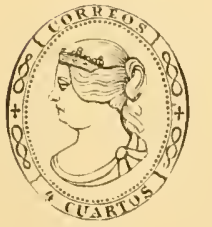

Kleines Oval mit der Büste der Königin nach links in Prägedruck; im übrigen ähnlich dem obigen. Kommt vor:

in blall und grïn auf weissem Karton, ferner in weiss, rosa, blassgrün, orange, citronengelb und blassblan anf verschiedenfarbigem Papier. 
2. Aus dem Jahre 1875.

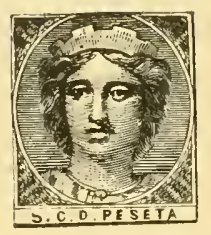

Franenkopf mit Mauerkrone en face in einem Kreise, Untergrund mit wagerechten Linien ausgefüllt: unter dem Kreise auf viereckigem Schild Wertangabe: 5. C. D. PESETA; Grösse 140:72 mm. Findet sich:

a. auf orangegelbem Papier in blau, r'lssischgrïn, schwarz, gelblichbraun, karmin, lila und orange;

b. auf weissem Papier in blaugrï, schwarz, orange, russischgriin. gelblichbraun, karminrosa und zinnoberrot;

c. anf weissem, geripptem Papier in gelb, gelbbraun und blau.

Bemerkung.

Ueber ein aus dem Jahre 1869 stammendes Umschlag-Essai mit dem Kopf Alonso Canos gilt das XX. Ausgabe, Bemerkung 4 Cesagte; über einen carlistischen 3 cuartos-Umschlag vergleiche Seite 134, Bemerkung 2. 


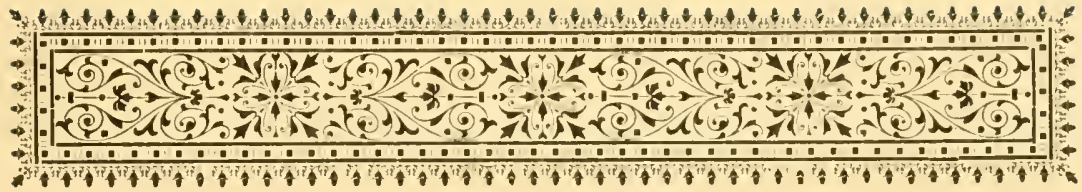

\section{Postkarten.}

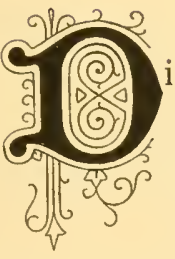

ie Postkarten wurden durch Gesetz vom 10. Mai 1871 in Spanien eingefiihrt. Eine am 10. Juni 1871 veröffentlichte Anleitung über den Gebrauch der Postkarten setzt das Porto auf 6 céntimos fest und gestattet anch die Recommandirung derselbelr; das Porto für eingeschriebene Postkarten betrug 50 céntimos. Die Herstellung der Postkarten war der Staatsdruckerei übertragen worden, da diese aber zu jener Zeit mit anderweitigen, dringenden Arbeiten überluäuft und nicht in der Lage war, den Auftrag sofort auszuführen, so bemächtigte sich alsbald die Privat-Industrie der Anfertigung. Die Postverwaltung hinderte den Gebranch dieser Privat - Postkarten, welche philatelistisch ohne besonderes Interesse sind, erst durch Rundschreiben vom 8. November 1873, welches zugleich die Ansgabe der ersten offiziellen Postkarten für den 1. Dezember anzeigte. Das Porto war unterdessen durch die Posttarifänderung vom 15. September 1872 auf 5 céntimos ermässigt worden. 


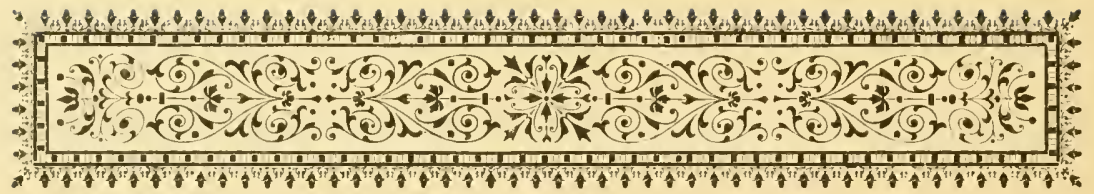

\section{A. Postkarten der Republik.}

\section{Ausgabe:}

vom 1. Dezember 1873 bis 2. April bezw. 31. Juli 1875.

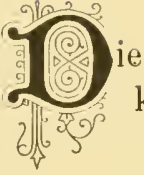

ie Ausgabe besteht aus einer einfachen und einer Doppelkarte, jede mit einer Reilıe von Abarten:

Die einfache Karte: Rechteck ans weissem, verschieden dickem Karton, 132-125: 88 mm; Marke oben in der Mitte: Grosses Oval mit Wertangabe, darüber kleineres nit dem Symbol der Republik, beide getrennt durch ein Band mit der Inschrift: CORREOS: im unteren Teil ruhender Löwe auf einem viereckigen Schild mit der Aufschrift: ESPA $\widetilde{N}$ A. Marke, sowie Umrandung der Karte in farbigem Druck (Lithographie).

Aufschriften in schwarzem Druck: Rechts und links der llarke: REPÚBLICA ESPAÑLA, darunter: TARJE'TA POS'TAL (Postkarte): zwei Adresslinien mit Vordruck: C/乞. D. (Señor Doul) und DIRECCION (Bestimmungsort); unten: Minfn: Lo que debe escribirse se hará en el reverso é irá firmado por el remitente. (Bemerkung: Das, was man zu schreiben hat, ist anf die Rückseite zu setzen und von Absender zu unterschreiben.) (Taf. XII, 137.) 
1. 5 CENTIMOS (de peseta) blau in drei Abstufungen auf dickem und dünnem Karton.

1 a) 5 CEN'TIMOS blau auf dickem Karton,

\begin{tabular}{|c|c|c|c|}
\hline b) & & & \\
\hline (c) 5 & $\eta$ & dunkelblau & \\
\hline d) 5 & $"$ & blau auf diunnen & Karton, \\
\hline e) 5 & $"$ & blassblau & \\
\hline & n & dunkelblau & \\
\hline
\end{tabular}

Nämliche Ausführung, nur hinter REPÚBLICA ESPAÑOLA kein Punkt und das Wort TARJET'A mit "G" anstatt mit „J" geschrieben. (Taf. XII, 138.)

2. 5 CENTIMOS blau in drei Abstufungen auf verschieden starkem Karton.

2 a) 5 CENTIMOS blau auf dickem Karton,

2 b) 5 " blassblau

2 c) 5 dunkelblau $"$

2 d) 5 " blau auf dünnem Karton,

2 e) 5 blassblau

2 f) 5 dunkelblau

Nämliche Ausführung wie No. 2, nur hinter ESPA TOLA kein Punkt, die Ecken der um das Oval mit der Wertangabe befindlichen Verzierungen sind quadrirt, drei statt zwei Linien für die Adresse.

3. 5 CENTIMOS blau in zwei Abstufungen auf verschieden starkem Karton.

3 a) 5 CENTIMOS blassblau auf dickem Karton,

3 b) 5 dunkelblau

3 c) 5 " blassblau auf ausserge wöhnlich dickem Karton,

3 d) 5 blassblau auf dünnem Karton,

e) 5 dunkelblau "

Doppelkarte (Karte mit bezahlter Rückantwort).

Zwei Rechtecke aus weissem, verschieden starkem Karton in den nämlichen Abmessungen, wie bei der einfachen Karte. Zeichnung der Marken, Umrandung und Aufschrift auf beiden Karten verschieden.

Vordere Karte und Marke: Büste der España mit phrygischer Mütze in kreisförmigem Rahmen, darüber: ESPA NA, darmnter Wertangabe. Aufschrift wie bei der einfachen Karte, nur noch rechts und links der Marke: CONTESTACION PArADA (Antwort bezahlt) und TARJETA DE ID (Karte für hin). (Taf. XII, 139.) 
Antwortkarte und Marke: Wertziffer in ovalem Rahmen, darunter auf weissem Schild: CENTIMOS: über dem Oval: CORREOS, darunter: ESPA ÑA. Umrandung von derjenigen der vorderen Karte verschieden; Anfschrift ist die gleiche, nur an Stelle von TARJETA DE IDA die Worte: TARJETA DE VUELTA (Karte für zurück); zwischen beiden Karten Trennungsstrich. Marke und Karte in farbigem, Aufschrift in schwarzem Druck. (Taf. XII, 140.)

4. 5+5 CENTIMOS gelbgrün auf verschieden starkem Karton.

4 a) $5+5$ CENTIMOS gelbgrün auf dickem Karton,

4 b) $5+5 \quad$ gelbgriin auf dünuem Karton.

Nämliche Ausführung. Die beiden 5 der Wertangabe sind infolge Aufarbeitung der Platte etwas verschieden, die rechten mi unteren Umrandungslinien der Marke der vorderen Karte sind schraffirt.

5. 5+5 CENTIMOS gelbgrün auf verschied en starkem Karton.

5 a) $5+5$ CENTIMOS gelbgrün anf dickem Karton,

5 b) $5+5$ gelbgrün auf dunnem Karton.

Nämliche Ausfülırung wie bei No. 4, nur fehlt Trenungsstrich.

6. 5+5 CENTIMOS gelbgrün auf verschieden starkem Karton.

6 a) $5+5$ CENTIMOS gelbgrün auf dickem Karton,

6 b) $5+5 \quad, \quad$ gelbgrüu anf dïmnem Karton.

Nämliche Ausführung wie bei No. 4, mur fellt Punkt linter ESPA ÑOLA.

7. $5+5$ CENTIMOS gelbgrün auf verschieden starkem Karton.

7 a) $5+5$ CENTIMOS gelbgriin auf dickem Karton,

7 b) $5+5 \quad$ gelbgriin auf diinnem Karton.

Nämliche Ausführung wie bei No. 7, nur fehlt anch noch derTrennungsstrich.

8. 5+5 CENTIMOS gelbgrün auf verschieden starkem Karton.

8 a) $5+5$ CENTIMOS gelbgrin anf dicken Karton,

8 b) $5+5 \quad$ gelbgrïn anf dïnuem Karton.

Nämliche Ansführung wie bei No. 7, nur "TARJETA" mit „St" anstatt mit ${ }^{\mathrm{J}}$ " geschrieben. (Taf. XII, 139.) 


\section{5+5 CENTIMOS gelbgrün auf verschieden starkem Karton.}

9 a) $5+5$ CENTIMOS gelbgrïn anf dickem Karton,

9 b) $5+5$ gelbgrin auf diunem Karton.

Nämliche Ansführung wie bei No.9, un fehlt noch der Trennungsstrich.

10. 5+5 CENTIMOS gelbgrün auf verschieden starkem Karton.

10 a) $5+5$ CENTIMOS gelbgrinu anf diekem Karton,

10 b) $5+5 \quad$ gellygrin anf diunem Karton.

\section{Bemerkungen.}

1. Die Ausgabe war in Madrid bis zum 2. April, in den Provinzen bis zum 31. Juli 1875 in Grbranch. Verbrancht wurden von Karte No. 1 2,000,000, von Karte No. 2 1,000,000 Exemplare.

2. Die Karten No. 2, 6, 7, 8, 9 und 10 sind eigentlich Probedrucke und waren wegen ihrer kleinen Abweichungen nicht zur Ansgabe bestimmt; als aber im Jahre 1874 voriibergehend ein Mangel an Postkarten eintrat, wurden ca. 500 Exemplare an das Publikum vêkanft. Die Schreibweise des Wortes Tarjeta mit $\mathrm{g}$ ist im iibrigen kein Fehler, sondern nur veraltet.

3. Die Karte mit quadrirten Ecken (No. 3) stammt ans dem Jahre 1874 und verdankt ihren Ursprung einem Aufarbeiten der Platte; vielfach wird sie daher als besondere Ausgabe aufgefïhrt.

4. Von der Doppelkarte No. 4 giebt es einen Fehldruck mit vertanschter Insehrift, d. h. "Tarjeta de Ida" auf der zweiten, "Tarjeta de vuelta" auf der ersten Karte.

5. Vou Essais wurden hekannt: Die einfache Karte (No. 1) ohne Adresslinien, die Karte No. 2 und die vorlere Hälfte der Doppelkarte No. 4 in sepiabramer Farbe, erstere anch auf blänlichem anstatt weissem Karton. Abdrücke der Markenbilder allein sind in verschiedenen Farben vorhanden und zwar: gelblichbraun und braunrot anf weissem Papier, schwarz und brannrot anf weissem Karton. 


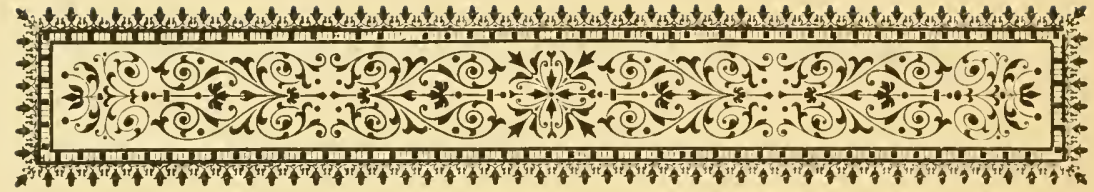

\section{B. Postkarten ans der Zeit der Regiermng Alfonso's XII.}

\section{Ausgabe:}

vom 3. April, bezw. 1. August bis 14. Oktober 1875 .

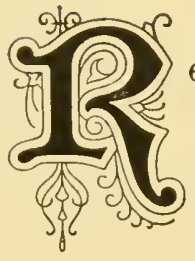

echteck aus satimirtem orter nicht satinirtem Karton in chamois Farbe. Grösse: 148 : $100 \mathrm{~mm}$; Marke: die 10 Céntimos-Marke der XXV. Ausgabe, nur mit veränderter Wertangabe; links der Marke: TARJEIA, reclits davon: POSTAL; vier Adresslinien, die erste mit $\mathscr{S}$. O . beginnend; ein bald mehr, bald weniger stark hervortretender Unterdruck zeigt in $2 \mathrm{~cm}$ hohen englischen Buchstaben: 'TARJETA POSTAI, umgeben von Kreisen, Strichen und sonstigen Verzierungen; unter der vierten Adresslinie: NotA. Lo que debe escribirse se hará en el reverso é irá firmado por el remitente. Marke, Anfschrift und Umrandung in violetter, Unterdruck in blassgelbgrünlicher Farbe. (Taf. XII, 141.)

11. 5 CENTS PESETA violett in mehreren Schattirungen auf verschiedenem Karton.

11 a) 5 CENTSS PESETA lebhaft violett auf satinirtem Karton, 11 b) $5 \quad "$ dunkelviolett auf satinirtem Karton,

11 c) $5 \quad " \quad$ hellviolett auf nicht satinirtem (rauhem) Karton,

11 d) $5 \quad$, dunkelviolett auf nicht satinirtem 11 e) $5 \quad$ braunviolett auf nicht satinirtem (rauhem) Karton. 
Bemerkungen.

1. Die Karte war schon unter der Regierung der Republik angefertigt, daher noch Mauerkrene und das Wappen ohne Bourbonisches Mittelschild. Sie wurde in Madrid am 3. April, in den Provinzen am 1. August ausgegeben.

2. Nach Angabe des bekannten spanischen Philatelisten Dr. Thebussem gieht es auch ron dieser Ausgabe Probedrucke mit denselben Fellern im Vordruck, wie bei den Karten der I. Ausgabe. Dieselben - 200 Sttick - wurden jedoch nie von der Post verkauft, sondern nur an einige hervorragende Sammler verschenkt, sind daher äusserst selten.

3. Von nicht angenommenen Essais existirt der schon mehrfach erwähnte Frauen-

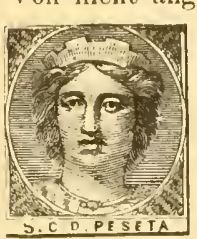
kopf mit Mauerkrone en face im Kreise pp. auch auf Postkarte; Umrandung mit verzierten Ecken, Marke oben rechts; Grösse 117:63 mm.

Die Karte existirt in weissem, grauem und blaugrtinlichem Papier, sowie in weissem Karton, das Markenbild in blangriin, schwarz, orange, russischgrun, gelblichbraun und zinnoberrot.

\section{A usgabe:}

vom 28. August bezw. 15. Oktober 1875 bis zum 30. Dezember 1881.

Rechteck aus dunkel- oder hellchamois Kartonpapier mit der 10 céntimos-Marke der XXVI. Ausgabe, nur mit veränderter Wertangabe; Aufschrift, wie bei der vorigen Ausgabe, Untergrund ähnlich; Marke, Umrandung und Aufschrift in blauem, Untergrund in blassgelblichgrïnem Druck.

Von der Karte giebt es mehrere Abarten, die sich in der Farbe, sowie in der Länge der untenstehenden Nota unterscheiden. (Taf. XII, 142.)

Die Nota ist $90 \mathrm{~mm}$ lang.

\section{5 C? PESETA blau.}

Ebenso, nur Untergrund völlig unsichtbar.

\section{5 CS PESETA blau.}

Die Nota ist $91 \mathrm{~mm}$ lang.

\section{5 CS PESETA hellblau.}


Ausfïhrung besser, Untergrund schärfer hervortretend; die Nota ist $92 \frac{1}{2} \mathrm{~mm}$ lang.

\section{5 CS PESETA blau in drei Schattirungen.}

15 a) 5 CS PESETA ultramarinblau,

15 b) 5 CS " hellblau,

15 c) 5 C $\$$ grünlichblau.

Die Buchstaben von 'TARJETA POSTAL (rechts und links del' Marke) sind etwas weiter auseinanderstehend; die Nota ist $90 \mathrm{~mm}$ lang.

\section{5 C PESETA ultramarinblau.}

\section{Bemerkungen.}

1. Die Karte wurde in Madrid am 28. August, in den Proviuzen am 15. Oktober ausgegeben.

2. Von dieser Ausgabe sind mehrere Fehldrucke vorhanden und zwar:

a) mit "esbribirse" anstatt escribirse in der Nota;

b) mit einem auffallend kleinen A am Ende des Wortes TARJETA;

c) mit einem kleingedruckten lo anstatt Lo in der Nota.

Ausserdem mangelhafte Drucke ohne Punkt hinter Sr und I anstatt L am Anfang der Nota.

3. Schon im Frühjahr 1875 war die National-Markenfabrik mit der Herstellung von Postkarten beauftragt worden, welche die Embleme der wiederhergestellteu Nonarchie tragen sollten. Sie lieferte ein weitverbreitetes Essai mit der Büste des Königs Alfons in ovalem Rahmen auf der einen, dem spanischen Wappen und der Wertangrabe auf der ander'n Seite; zwischen beiden: ESPA NA, darunter: TARJETA POSTAL, dann 4 Adresslinien, deren erste mit Sr.D., die zweite mit POBLACION (Ort) beginnt.

Grösse: $119: 73 \mathrm{~mm}$. Zeichmumg und Umrandung in orangeroter, Inschrift in schwarzer Farbe.

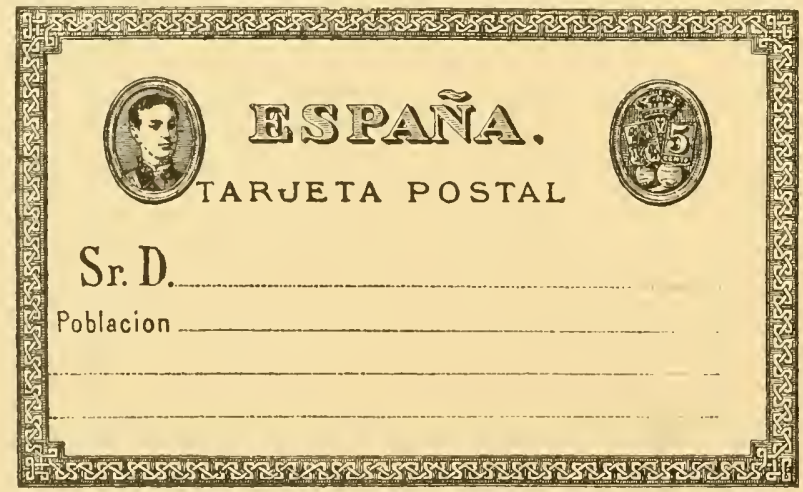




\section{Ausgabe: \\ vom 1. Januar 1882 bis 28. Februar 1884.}

Rechteck aus chamois Kartompapier mit der am nämlichen Tage verausgabten Marke (XXXI. Ausgabe). Umrandung und Anfschrift in blan, sonst wie die vorige Ansgabe, nur ohne die Zeichnung des Untergrundes.

Die Ausgabe besteht aus einer einfachen und einer Doppelkarte; von ersterer giebt es sechs, von letzterer zwei Abarten.

Die Nota ist $91 \mathrm{~mm}$ laug, $\mathrm{r}$ in $\mathscr{C}_{\ell}$ mit Punkt, das $\mathscr{E}_{\ell}$ von dem daranffolgenden $\mathscr{D}$ weit abstehend.

17. 10 CENTIMOS blassblau.

Die Nota ist $89 \mathrm{~mm}$ lang und in etwas kleineren Lettern gedruckt, $r$ in $\int_{/}$mit Punkt.

18. 10 CENTIMOS blassblau.

Ebenso, nur Nota in etwas grösseren Lettern gedruckt.

19. 10 CENTIMOS blassblau.

Ebenso, nur $r$ in $\mathscr{f}_{\varepsilon}$ mit Schleife.

20. 10 CENTIMOS blassblau.

Ebenso, mur Nota 88 mm lang.

21. 10 CENTIMOS blassblau.

Notid $94 \frac{1}{2} \mathrm{~mm}$ lang, $\mathrm{r}$ in $\mathscr{S}_{\hat{\imath}}$ mil Punkt, die Buchstaben in TARJE'TA POSTAL etwas weiter auseinanderstehend.

2.2. 10 CENTIMOS blassblau.

Doppelkarte. Ansfïhrmig wie bei der einfachen Karte, nur unter der unteren Umrandungslinie die Bemerkungen: Contestacion pagada (Antwort bezalılt) bezw. L La otra tarjeta es para la contestacion (die andere Karte ist für die Antwort); ohne Trenmmosstrich. 
La otra tarjeta usw. ist $50^{1 / 2} \mathrm{~mm}$ lang.

\section{3. $15+15$ CENTIMOS blassgrün.}

La otra tarjeta usw. ist $491 / 2 \mathrm{~mm}$ lang.

\section{4. $15+15$ CENTIMOS blassgrün.}

\section{Bemerkungen.}

1. Die Farbe des zu tieser Ausgabe verwendeten Kartons ist manchmal etwas heller, manchmal etwas dunkler chamois, der Unterschied ist jedoch zu unbedeutend, um hier besonders aufgef ührt zu werden.

2. Von den Karten dieser Ausgabe existiren zahlreiche mangelhafte Drucke, die teilweise wohl auf eine Beschädigung der Platte zurïckgeführt werden müssen. Ich el'wähne, als am meisten vorkommend:

$\mathrm{S}$ von Sr mit fehlender oberer Schleife, [ von POSTAL zerbrochen, $R$ von TARJETA desgleichen, $L$ in $\mathrm{LO}$ unvollständig, Umrandungslinie an verschiedenen Stellen unterbrochen, Sr. D., sowie remitente ohne folgenden Punkt u. dergl.

\section{Ausgabe:}

vom 1. März 1884 his 30. November 1889.

Rechteck aus dickem oder dünnem, satinirtem oder rauhem Kartonpapier mit der Marke der XXX. Ausgabe rechts oben (Inschrift: COMUNICACIONES). Die Ausgabe besteht aus zwei einfachen und zwei Doppelkarten.

Einfache Karte für den Verkehr mit Portugal und Gibraltar. Aufschrift: đariefa Trafal (gothisch) para PORTUGAL Y GIBRALTAR. - ESPA NA. in vier Zeilen; drei punktirte Adresslinien, die erste mit $\mathscr{C}$ beginnend; unten links: En este lado se escribe solamente la direccion (auf diese Seite schreibt man nur die Adresse). (Taf. XIII, 145.) 
25. 5 CENTIMOS grün auf verschiedenem Karton.

25 a) 5 CENTIMOS grtin auf dimuem, glattem Karton, 25 b) 5 " grïn auf diunnen, rauhem Karton, 25 c) $5 \quad$ " grtin auf dickem, glattem Karton, 25 d) $5 \quad$ " grün auf dickem, rauhem Karton.

Ebenso, nur ESPAÑA olne darauffolgenden Punkt.

26. 5 CENTIMOS grün auf verschiedenem Karton. 26 a) 5 CENTIMOS grün auf dünnom, glattem Karton, 26 b) 5, griin auf dinnem, rauhem Karton, 26 c) $5 \quad$ grün anf dickem, glattem Karton, 26 d) $5 \quad n \quad$ grin auf dickem, rauhem Karton.

Doppelkarte fïr den Verkehr mit Portugal und Gibraltar. Aufschrift wie bei der einfachen Karte, nur tritt noch hinzu: La otra tarjeta es para la respuestu, bezw. : RESPUESTA (Antwort).

27. $5+5$ CENTIMOS grün auf verschiedenem Karton.

27 a) $5+5$ CENTIMOS grün auf dïnnem, glattem Karton, 27 b) $5+5 \quad "$ grín auf dïnnem, ranhem Kíarton, 27 c) $5+5 \quad$ griin auf dickem, glattem Karton, 27 d) $5+5 \quad$ " grlin auf dickemı, rauhem Karton.

Einfache Karte für den Weltpostverkehr. Aufschrift in spanischer und französischer Sprache: Intion Fofful Intuer|al - UNION POSTALE UNIVERSELLE - ESPAÑNA. in drei Zeilen, teils in gothischen, teils in lateinischen Lettern gedruckt: drei punktirte Adresslinien, welche infolge schlechten Druckes vielfach als gezogen erscheinen, die erste limie mit (C/ beginnend: unten Bemerkung, wie gewölnnlich. (Taf. XII, 144.)

28. 10 CENTIMOS karminrot in zwei Abstufungen auf hell- oder dunkelchamois Karton.

28 a) 10 CENTIMOS hellkarmin auf hellchamois Karton, 28 b) 10 hellkarmin auf dunkelchamois Karton, 28 c) 10 lebhaft karmin auf hellchamois Karton,

28 d) $10 \quad " \quad$ lebhaft karmin auf dunkelchamois Karton.

29. 15 CENTIMOS braun in zwei Abstufungen auf helloder dunkelchamois Karton.

29 a) 15 CENTIMOS braun auf hellchamois Karton,

29 b) 15 braun auf dinkelchamois Karton,

29 c) 15 dunkelbraun auf hellchamois Karton,

29 d) 15 " dunkelbraun auf dunkelchamois Karton. 
Doppelkarte für den Weltpostverkehr. Ausführung wie bei der einfachen Karte, Vordruck wie gewöhnlich. Bemerkung: En este lado usw. ist $53 \mathrm{~mm}$ lang.

30. 10+10 CENTIMOS karminrot in zwei Abstufungen auf hell- oder dunkelchamois Karton.

30 a) $10+10$ CENTIMOS hellkarmin auf hellehamois Karton,

30 b) $10+10$ hellkarmin auf dunkelchamois Karton,

30 c) $10+10 \quad " \quad$ lebhaft karmin auf hellehamois Karton,

$30 \mathrm{~d}) \quad 10+10 \quad \%$ leblaft karmin auf dunkelchamois Karton.

Bemerkung: En este lado usw. ist $54 \mathrm{~mm}$ lang.

31. 10+10 CENTIMOS karminrot in zwei Abstufungen auf hell- oder dunkelchamois Karton.

31 a) $10+10$ CENTIMOS hellkarmin auf hellchamois Karton,

31 b) $10+10$ " hellkarmin auf dunkelehamois Karton,

31 c) $10+10 \quad " \quad$ lebhaft karmin auf hellchamois Karton,

31 d) $10+10 \quad$ lebhaft karmin auf dunkelchamois Karton.

32. $15+15$ CENTIMOS braun auf hell- oder dunkelchamois Karton.

32 a) $15+15$ CENTIMOS braun auf hellchamois Karton,

32 b) $15+15 \quad "$ braun auf dunkelchamois Karton.

Bemerkungen.

1. Bei allen Karten dieser Ausgabo giebt es infolge schlechten Druckes Exemplare nit hie und da fehlenden Punkten auf dem $i$ und $j$, sowie hintor den Worten Direceion und Respuesta, vielfach ist anch der Druck der Markenbilder völlig verwischt.

2. Ein Erlass der General-Postrlirektion rom 31. Dezember 1886 gestattet die Verwendung von privatim hergestellten Postkarten unter der Bedingung, dass ihre Grösse, Aufsehrift und Frankirung genau mit der offiziellen übereinstinnt.

3. Eine in Frühjahr 1885 ersehienene Karte mit der Aufschrift: „Por no haber en venta de la de 5 céntimos" ist nicht offiziell und seheint ein Spekulationsprodukt zu sein.

4. Essais der Markenbilder ohue Karte giebt es in verschiedenen Farben auf dickem, weissem Papier und zwar:

5 céntimos blau,

10 grïn,

$15 "$ lebhaft malven. 


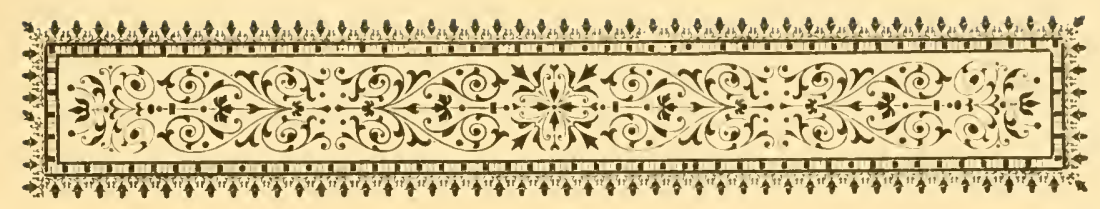

\section{Postkarten ans der Zeit der Regentschaft der} Königin Maria Christina bezw. Her Regierung des Königs Alfouso XIII.

\section{Ausgabe:}

vom 1. Dezember 1889.

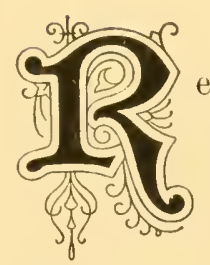

echteck aus chamois Kartonpapier mit der Marke der XXXII. Ausgabe. Die Ausgabe hesteht ans drei einfachen und zwei Doppelkarten.

Karte für das Inland. Aufschrift und Umrandung in branner Farbe, wie bei rler Karte des Jahres 1882; Marke in der Mitte. Grösse $148: 100$. (Taf. XIII, 146.)

33. 10 CENTIMOS braun.

Karte für den Verkehr mit Portugal und Gibraltar. Narkenbild oben rechts, ohne Umrandung; Vordruck wie bei der Karte des Jahres 1884. Grösse $142: 100$. (Taf. XIII, 147.)

34. 5 CENTIMOS hellgrün auf glattem und rauhem Karton. 34 a) 5 CENTIMOS hellgrïn anf glattem Karton, 34 b) 5 " hellgrün auf rauhem Karton. 
Doppelkarte für den Verkehr mit Portugal und Gibraltar. Ausfiihrung wie bei der einfachen Karte, Vordruck wiegewöhnlich.

35. $5+5$ CENTIMOS hellgrün auf glattem und rauhem Karton.

35 a) $5+5$ CENTIMOS hellgriin auf glattem Karton, 35 b) $5+5 \quad$ hellgrïn auf rauhem Karton.

Karte für den Weltpostverkehr. Markenbild oben rechts, ohne Umrandung, Vordruck wie bei der Karte les Jahres 1884. Grösse 142 : 100. (Taf. XIII, 148.)

Nota ist $52 \frac{1}{2} \mathrm{~mm}$ lang.

36. 10 CENTIMOS karmin in zwei Abstufungen auf hellund dunkelchamois Karton.

36 a) 10 CEN'TIMUS hellkarmin auf hellchamois Karton,

36 b) 10 dunkelkarmin auf dunkelchamois Karton.

Nota ist $54 \mathrm{~mm}$ lang.

37. 10 CENTIMOS karmin in zwei Abstufungen auf hellund dunkelchamois Karton.

37 a) 10 CANTIMOS hellkarmin auf hellchamois Karton.

37 b) 10 dunkelkarmin auf dunkelchamois Karton.

Doppelkarte fïr den Weltpostverkelır. Ausfülırung wie bei der einfachen Karte, Vordruck wie gewöhnlich.

38. 10 + 10 CENTIMOS karmin in zwei Abstufungen auf hell- und dunkelchamois Karton.

38 a) $10+10$ CENTINOS hellkarmin auf hellchamois Karton, 38 b) $10+10$ dunkelkarmin auf dunkelchamoisKarton.

\section{Bomerkungen.}

1. Die Karten für den Verkehr nit Portugal und Gibraltar waren zwar in Dezember 1889 schon angefertigt, scheinen aber erst im Frühjahr 1890 zur Ausgabe gelangt zu sein.

2. Auch bei diesen Karten giebt es Exemplare in mangelhaftem Druck, mit einzelnen unvollständigen oder schiefstehenden Buchstaben, fehlenden Punkten ibler $\mathrm{i}$ und $\mathrm{j}$, unterbrochenen Umrandungslinien i. drgl. 


\section{Ausgabe:}

September 1890.

Rechteck aus glattem und rauhem Karton in chamois Farbe mit der Marke der XXXII. Ansgabe oben links; TAR.JEI'A POS'J'AL., darunter spanisches Wappen mit Krone, umgeben ron der Kette des goldenen Vliesses; vier Adresslinien, die er'ste mit $\mathcal{C} /$ beginnend: unten Bemerkung, wiegewölnnlich. Grösse 145: 100. (Taf. XIII, 149.)

Bemerkung $60 \mathrm{~mm}$ lang: Adresslinien dick punktirt: auf dem o in dirección der Bemerkung ein Accent.

39. 10 CENTIMOS braun auf verschiedenem Karton.

39 a) 10 CENTIMOS braun auf glattem Karton,

39 b) $10 \quad$ " braun auf rauhem Karton.

Bemerkung 601/2 $\mathrm{mm}$ lang; Adresslinien dïnner punktirt: auf dem 0 in direccion der Bemerkung kein Accent.

40. 10 CENTIMOS braun auf rauhem, etwas dickerem Karton.

Ohne Punkt hinter POSTAL

41. 10 CENTIMOS braun auf verschiedenem Karton.

41 a) 10 CENTIMOS braun auf glattem Karton,

41 1) 10 " braun anf rauhem Karton.

Doppelk art te in gleicher Ansfïhrung mit dem gewöhnlichenVordrıck. 4.. $15+15$ CENTIMOS blau.

$$
\text { Bemerkung. }
$$

Von der Karte No. 39 anf glattem Karton existirt ein mangelhafter Druck ohne den unteren Punkt in dem Buchstaben $J$ des Wortes TARJETA. 


\section{$-158-$ \\ VIII. Ausgabe :}

Ende 1891.

Karte für den Weltpostverkehr. Vordruck wie gewöhnlich, nur durchweg lateinische Lettern; drei Adresslinien, die erste mit $C /$ beginnend; unten links die gewöhnliche Bemerkung. Grösse $142: 100$. (Taf. XIII, 150.)

43. 10 CENTIMOS karmin auf verschiedenem Karton.

43 a) 10 CENTIMOS karmin auf glattem Karton,

$43 \mathrm{~b}) 10 \quad$ karmin auf rauhem Karton.

Bemerkungen:

1. Das Markenbild steht bei dieser Karte nicht immer gleich weit vom Kartenrand und unterscheiden daher Spezialsammler vielfach Exemplare mit 16, 18, $201 / 2$ und $21 \mathrm{~mm}$ Abstand.

2. Von Karte No. 43 existirt ein Fehldruck mit drei $\mathrm{c}$ in dem Worte direcion.

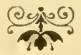 \\ IX. Ausgabe: \\ 1892.}

Mai? 1892. Karte für den Verkehr mit Portugal und Gibraltar. Ausfiilrung und Vordruck wie bei der Karte vom Dezember 1899, nur durchweg in lateinischen Letterı. Grösse 140:90. (Taf. XIII, 151.)

\section{5 CENTIMOS grün auf chamois Karton.}

Juni 1892. Karte in gleicher Ansfïhrung, wie diejenige von Dezember 1889, nur Aenderung der Farbe und Wertangabe. Grösse $140: 88$.

45. 15 CENTIMOS braun auf gelblichem Karton. 
Doppelkarte in der Ausführung der Karte No.42, nur Marke rechts.

46. $15+15$ CENTIMOS blau auf chamois Karton.

Juli 1892 Doppelkarte, ähnlich der Karte ron Mär\% 1890, mi1 entsprechend verändertem Vordruck.

17. $5+5$ CENTIMOS grün auf chamois Karton.

September 1892. Karte für den Weltpostverkelir. Wappen oben links, Marke rechts, zwischen beiden die gewöhnliche 1nschrift in 3 Keilen und lateinischen Buchstaben; drei Adresslinien, die erste mit (A) beginnend; unten links die ïbliche Bemerkung. Grösse 145:92. (Taf. XIII, 152.)

Bemerkung 54 mm lang, dirección mit Accent auf dem o.

48. 10 CENTIMOS karmin auf chamois Karton.

Bemerkung 55\% $12 m$ lang.

49. 10 CENTIMOS karmin auf chamois Karton.

Bemerkung 55 $\frac{1}{2} \mathrm{~mm}$ lang. direcion ohne Accent auf dem 0.

50. 10 CENTIMOS karmin auf chamois Karton.

Doppelkarte in gleicher Ausfïhrung, mit entsprechender Aenderung des Vordrucks.

51. $10+10$ CENTIMOS karmin auf chamois Karton.

Dezember 1892. Karte in der Ausfülunng von No. 44, nur dass oben links noch das Wappen beigefügt ist. Grösse 146:93.

52. 5 CENTIMOS grün auf chamois Karton.

Doppelkarte für den Verkehr mit Portugal und Gibraltar in der Ausführung von No. 44.

53. $5+5$ CENTIMOS grün auf chamois Karton. 


\section{$-160-$ \\ Kartenbriefe.}

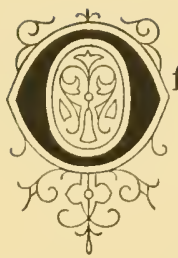

ffizielle Kartenbriefe existiren in Spanien nicht, jedoch wurde durch Königlichen Erlass vom 3. Juni 1892 einem Privaten, dem Kartonnage-Fabrikanten Fabregas in Barcelona, das Privilegium erteilt, sich Kartenbriefe mit eingedrucktem Wertstempel in der National-MarkenFabrik anfertigen zu lassen und dieselben äusserlich mit Annoncen bedrucken zu dürfen. Die Ausgabe sollte am 1. November 1892 erfolgen, verzögerte sich jedoch bis zum Juni 1893.

\section{Ausgabe:}

Juni 1893.

Rechteck aus strohgelbem Papier, oben rechts Marke der XXXIr. Ausgabe, links daneben: CARTA-TARJETA (Kartenbrief), drei Adresslinien, das Ganze in einfacher Umrandung mit kleinen Verzierungen in den Ecken; anf drei Seiten perforirt, unter der unteren Perforirungslinie die Bemerkung: Abrase por la linea perforada (Man öffne vermittelst der durchlochten Linie).

1. 15 CENTIMOS braun auf strohgelbem Papier.

\section{Ausgabe:}

Nov'nuber 1893.

Rechteck, wie oben. Unter CARTA-TARJETA die Worte: Vendida por 10 céntimos (verkauft für 10 céntimos); oben über der Umrandungslinie: Empresa anunciadora en cartas-tarjetas con Real privilegio (Gesellschaft für Annoncen auf Kartenbriefen mit Künigl. Privilegium): unten unter der Durchlochungslinie: Segunda edicion (Zweite Auflage).

2. 10 CENTIMOS braun auf strohgelbem Papier.

Bemerkung.

Nach dem Beispiele des Herrn Fabregas liessen sich viele Industrielle Kartenbriefe anfertigen, allerdings olne eingedruckte Marke. Sie sind selbstverständlich philatelistisch völlig wertlos.

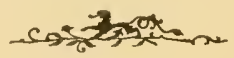




\section{T'afel I.}
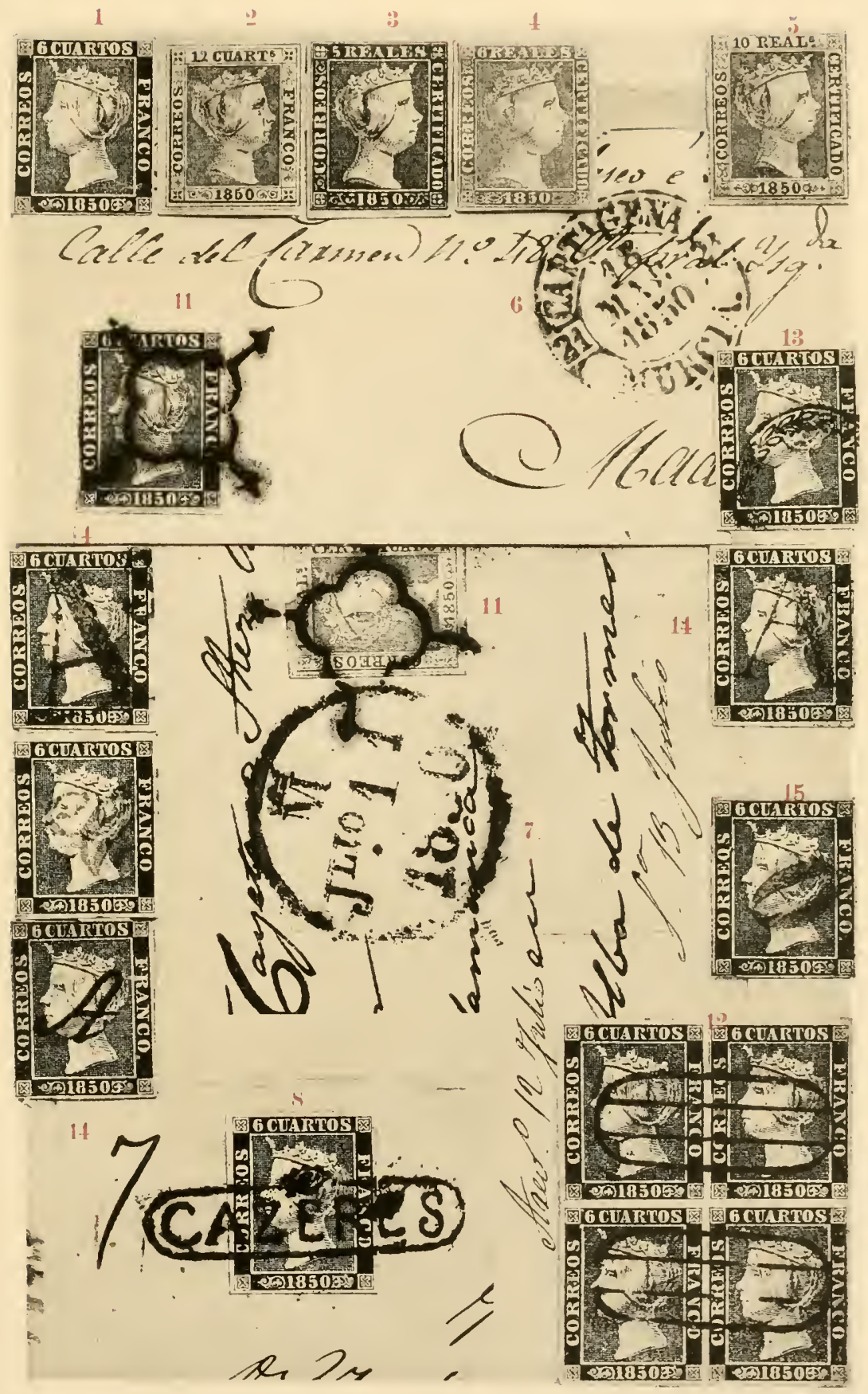



\section{'I'afel II.}

16

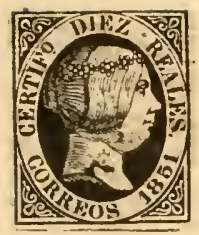

$\because 6$

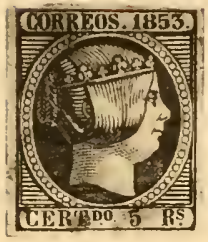

2):3

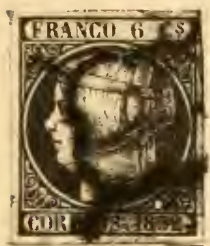

17

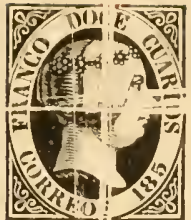

27

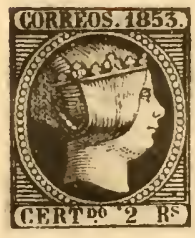

19)

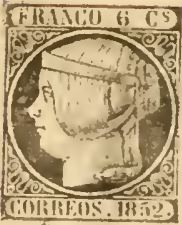

28

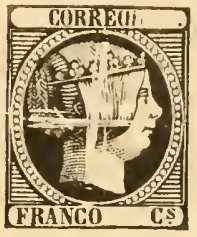

D)
20
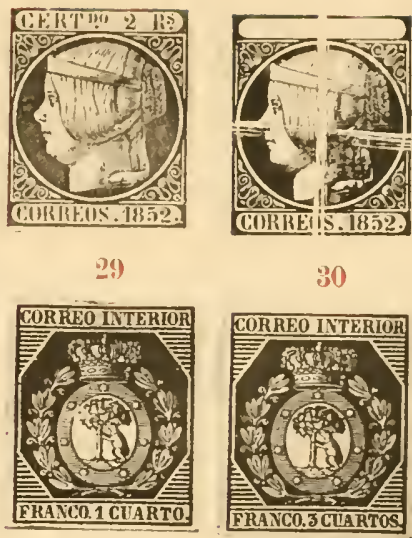

2.2
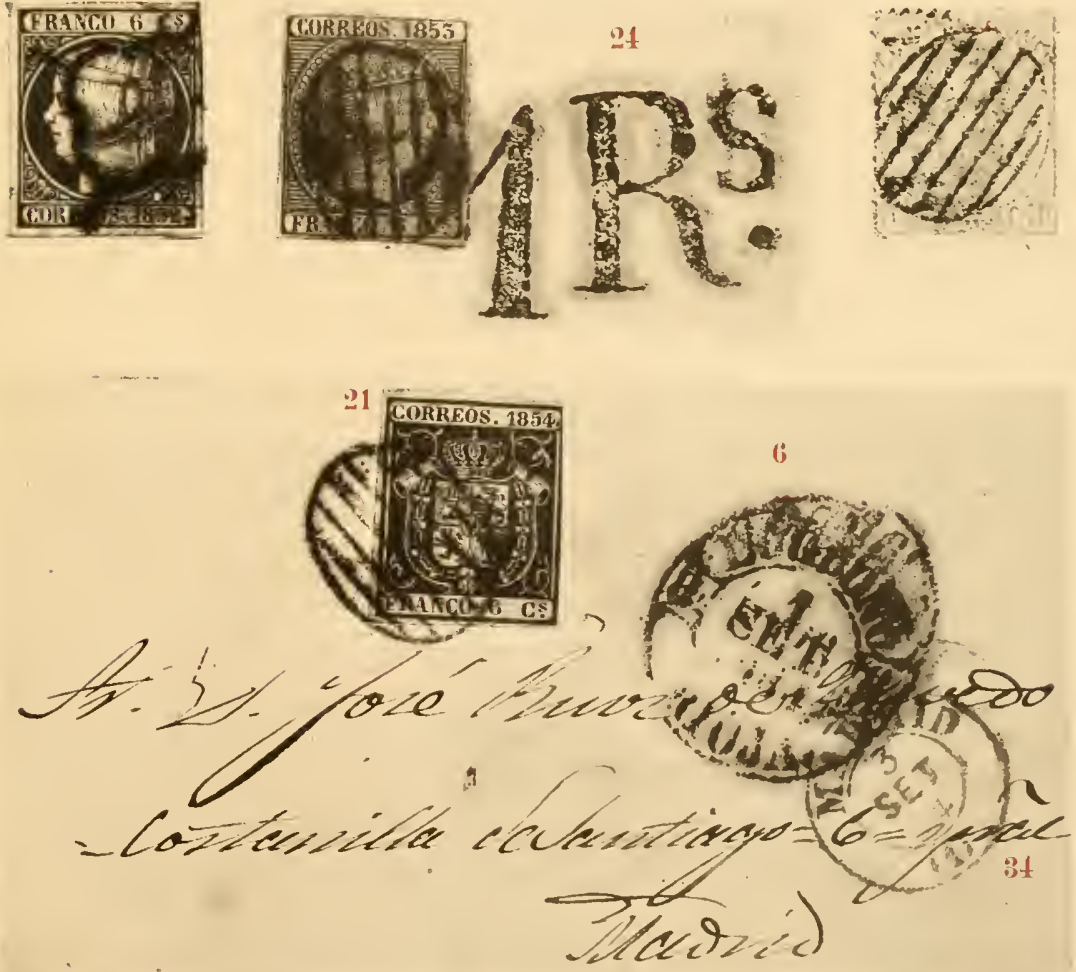

Friederich, Die Postwertzeichen Spaniens und seiner Kolonien (I. Teil.) Verlag von Dr. H. Brenlicke in Berlin W. 57. 



\section{'I'afel III.}
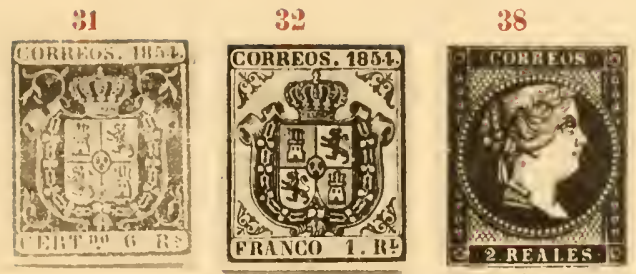

$\$ 9$
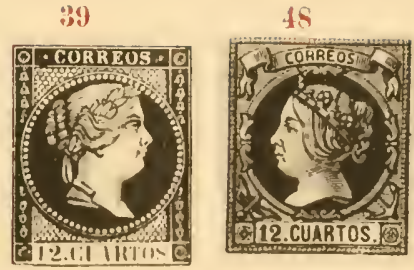

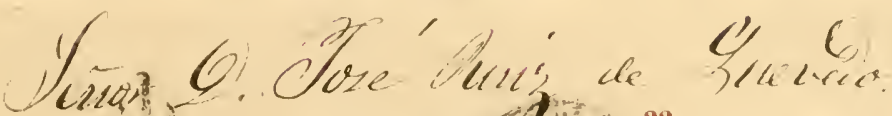
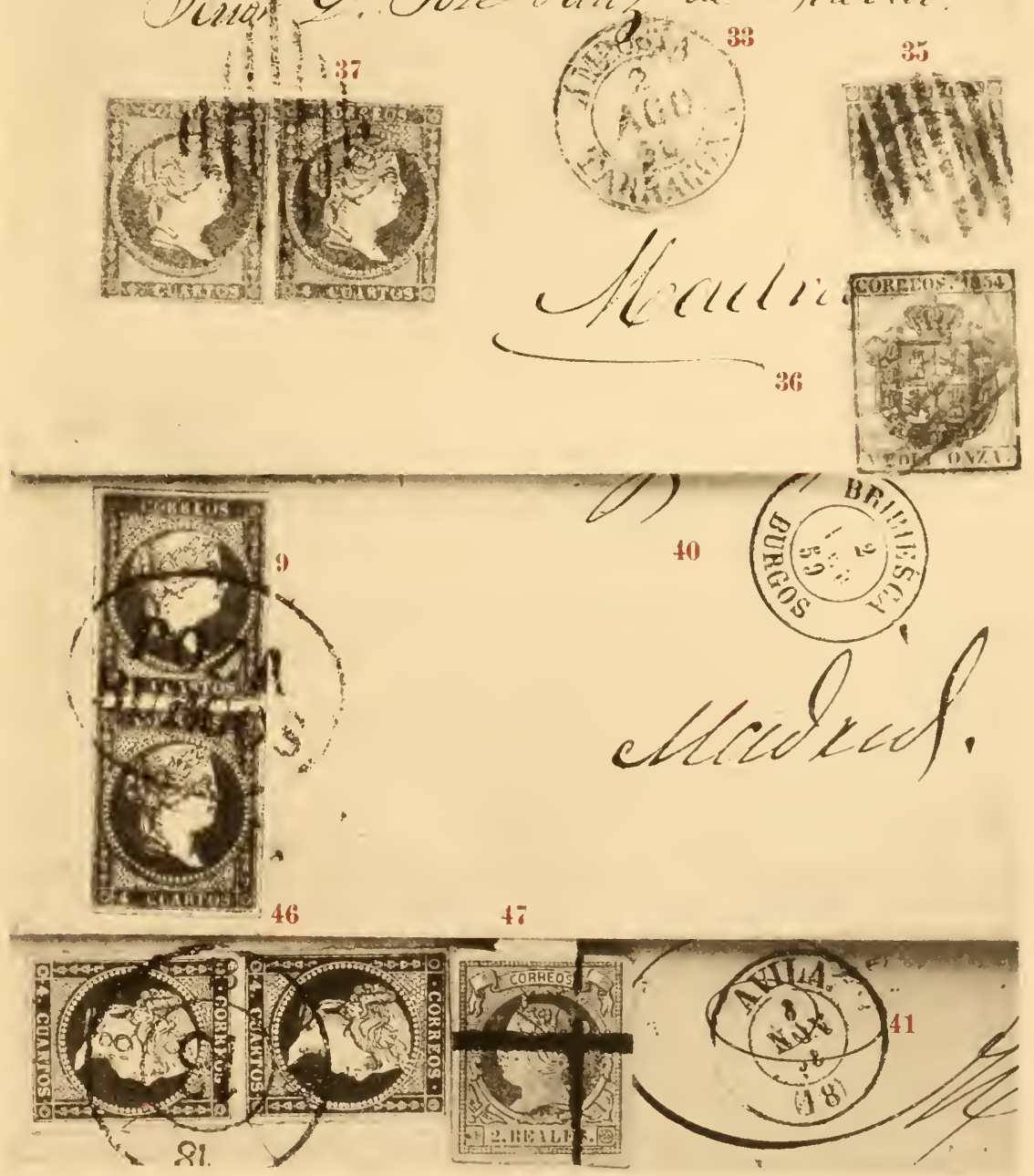

Friederich, Die Postwertzeichen Spaniens und seiner Kolonien (I. Teil). Verlag von Dr. H. Brendicke in Berlin W. 57 



\section{'Tafel IV.}
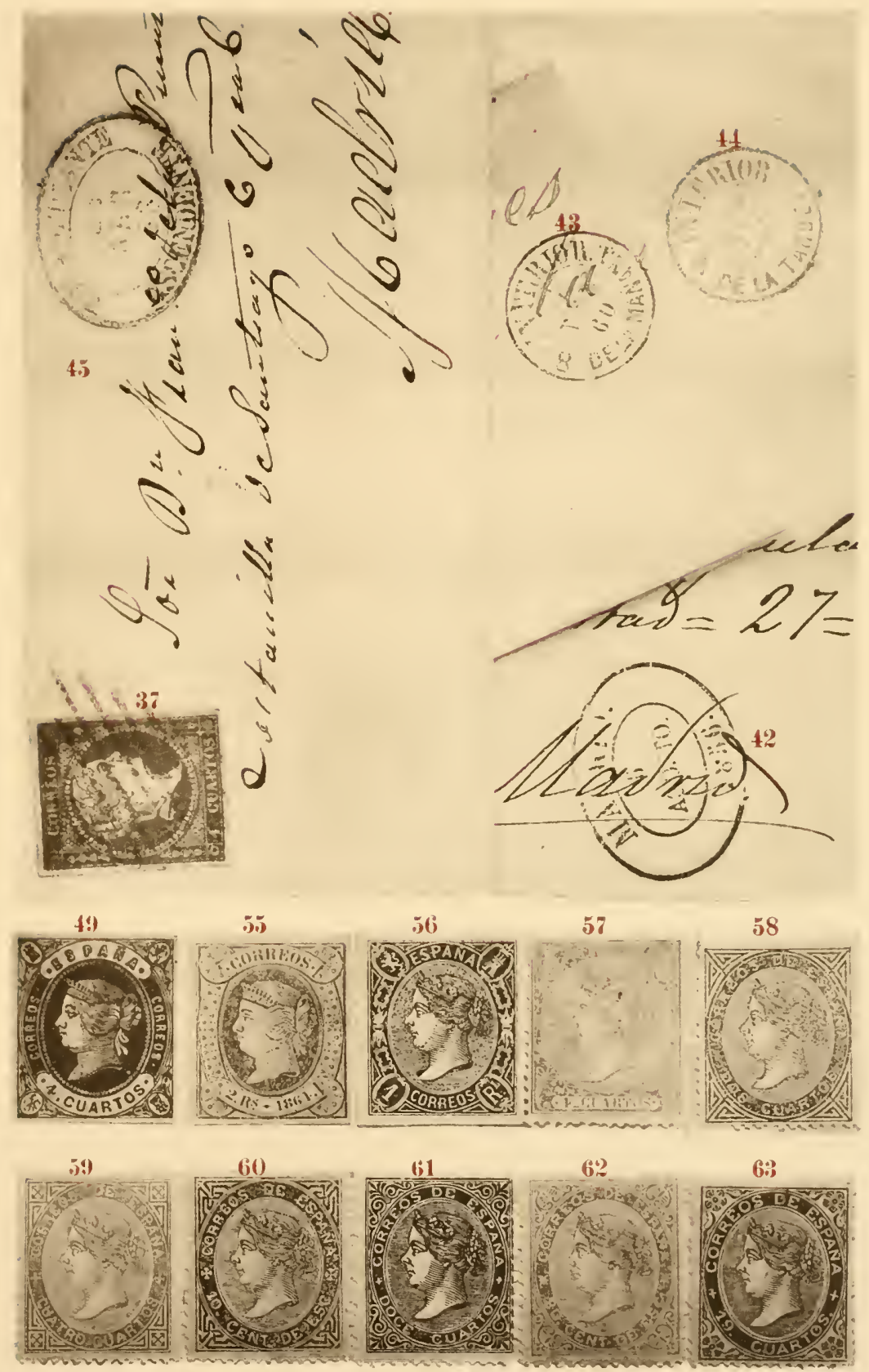

6 ?

6:3

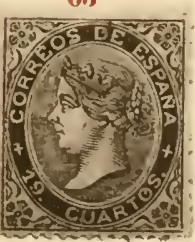

Friederich, Die Postwertzeichen Spaniens und seiner Kolonien (I. Teil). Verlag von Dr. H. Brendicke in Berlin W.57. 



\section{Tafel V.}

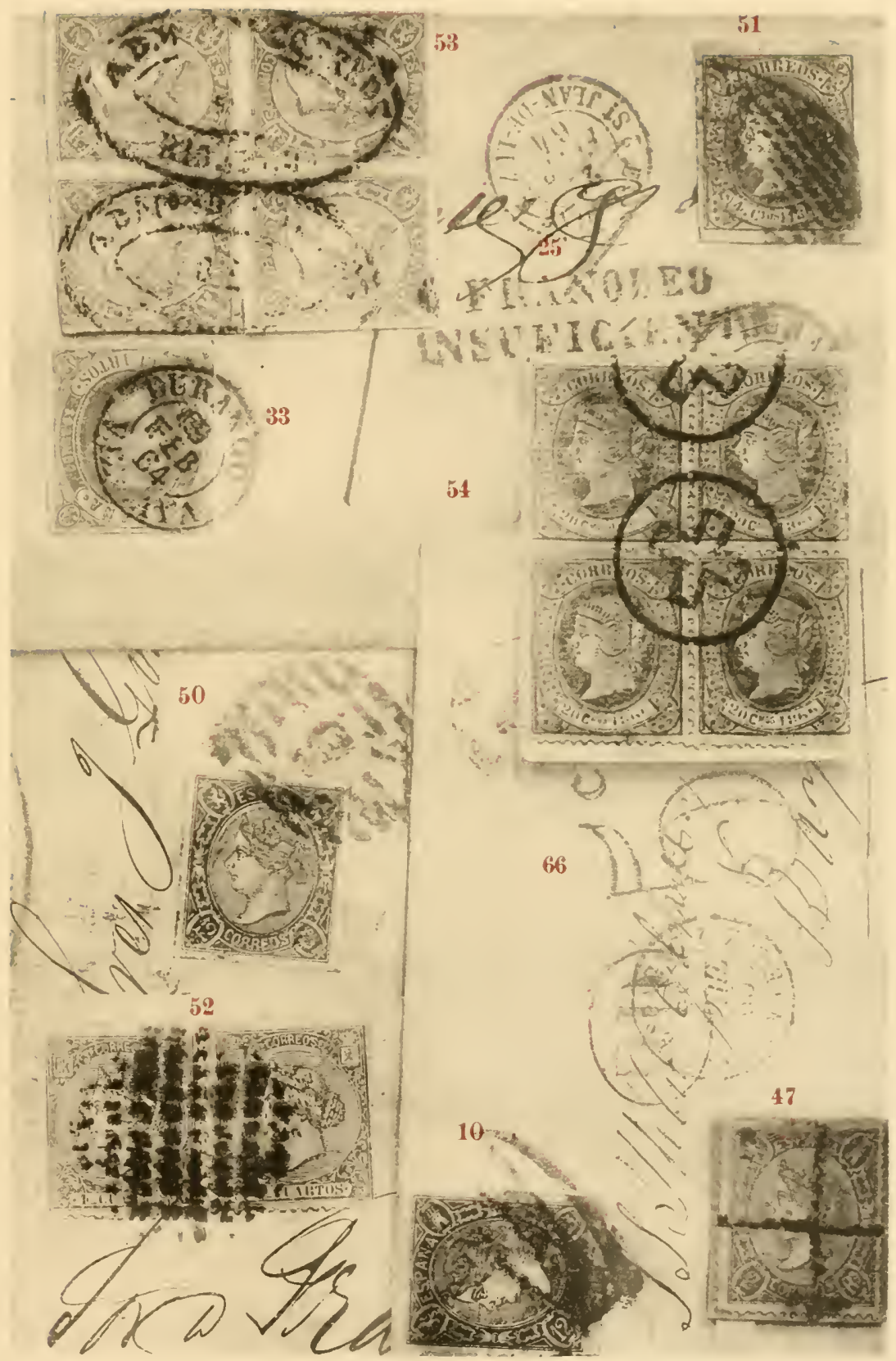

Friederich, Die Postwertzeichen Spaniens und seiner Kolonien (I. Teil). Verlag ron Dr. H. Brendicke in Berlin W.57. 



\section{Tafel VI.}

64

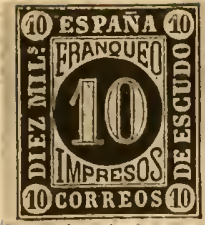

70

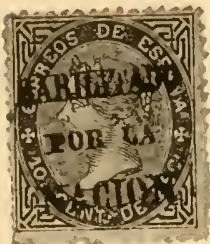

75

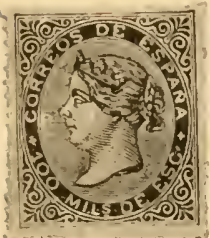

85

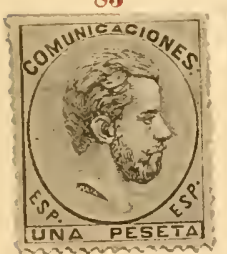

102
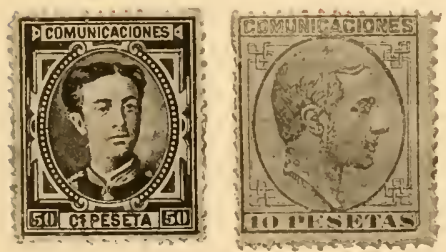

82

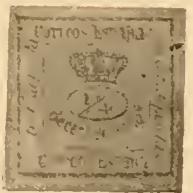

67

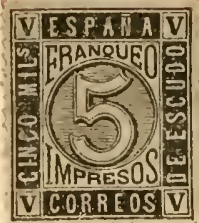

90

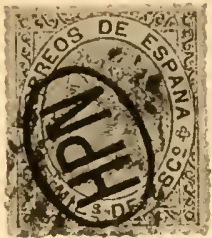

78

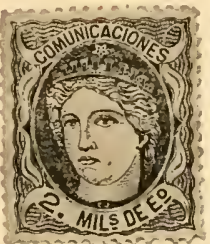

89

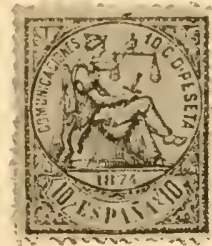

107

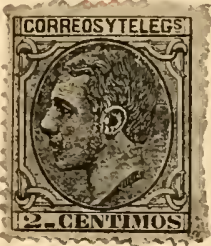

S8

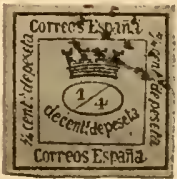

(is

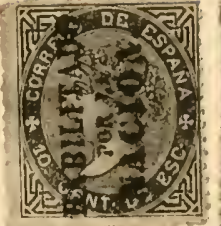

78

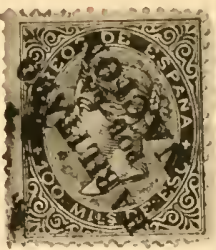

83

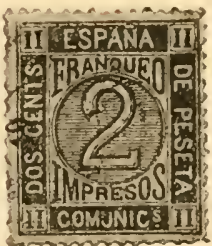

(x)

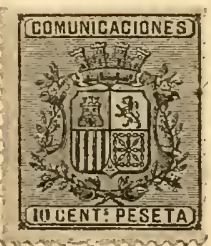

108

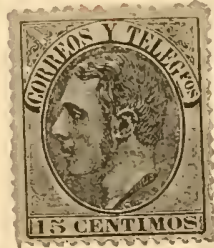

105

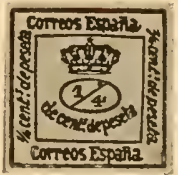

69

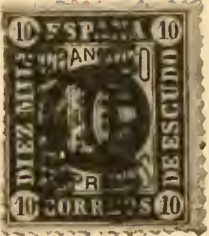

74

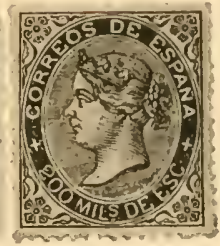

84

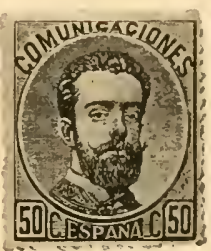

91

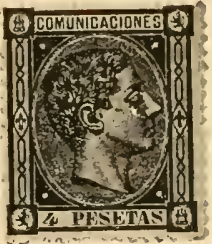

109

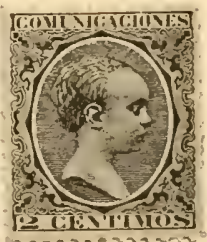

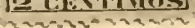

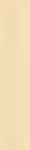

Friederich, Die Postwertzeichen Spaniens und seiner Kolonien (I. Teil) Verlag von Dr. H. Brendicke in Berlin W. 57. 



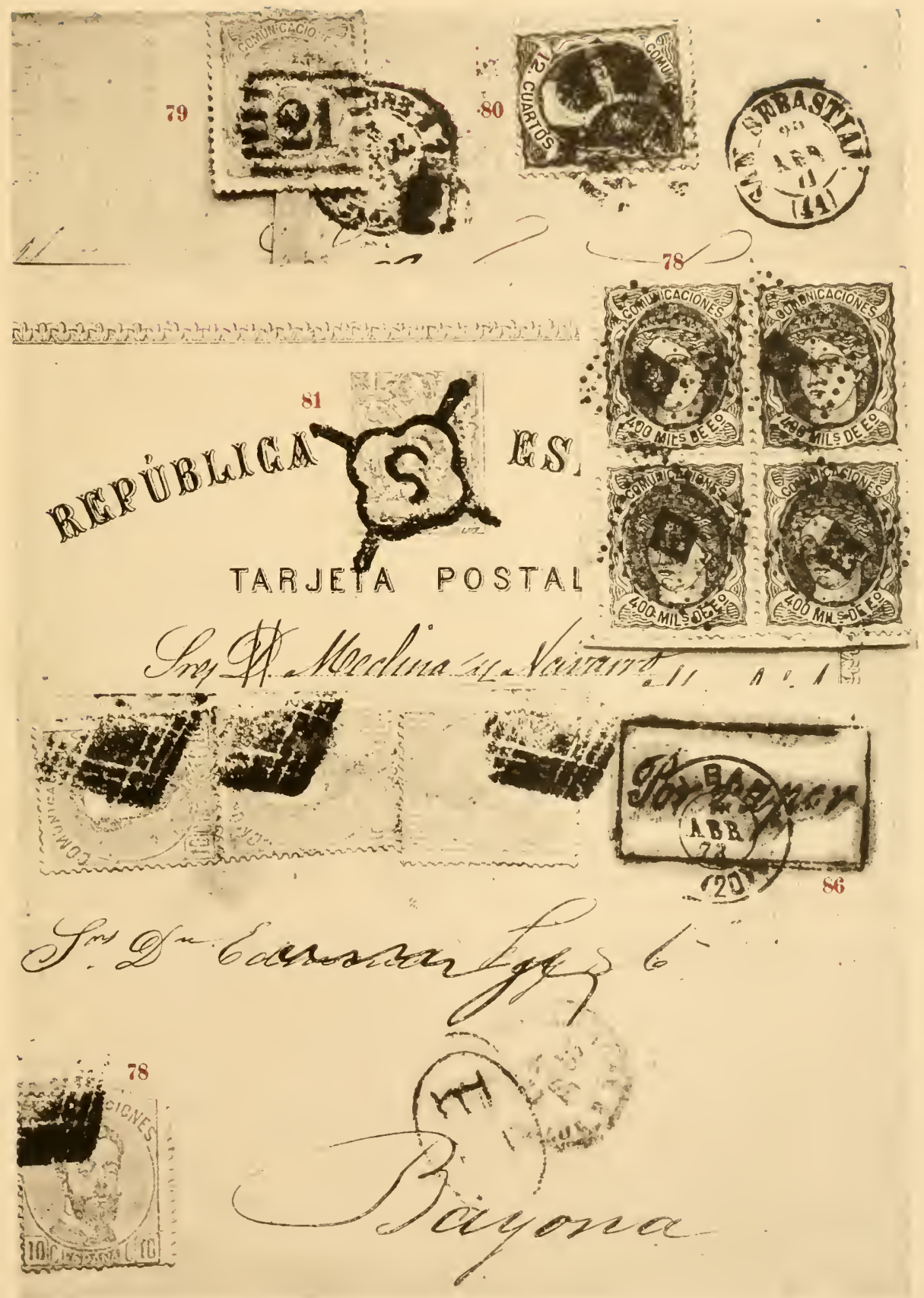

Friederich, Die Postwertzeichen Spaniens und seiner Kolonien (I. Teil) Verlag von Dr. H. Brendicke in Berlin W.57. 



\section{Tafel VIII.}

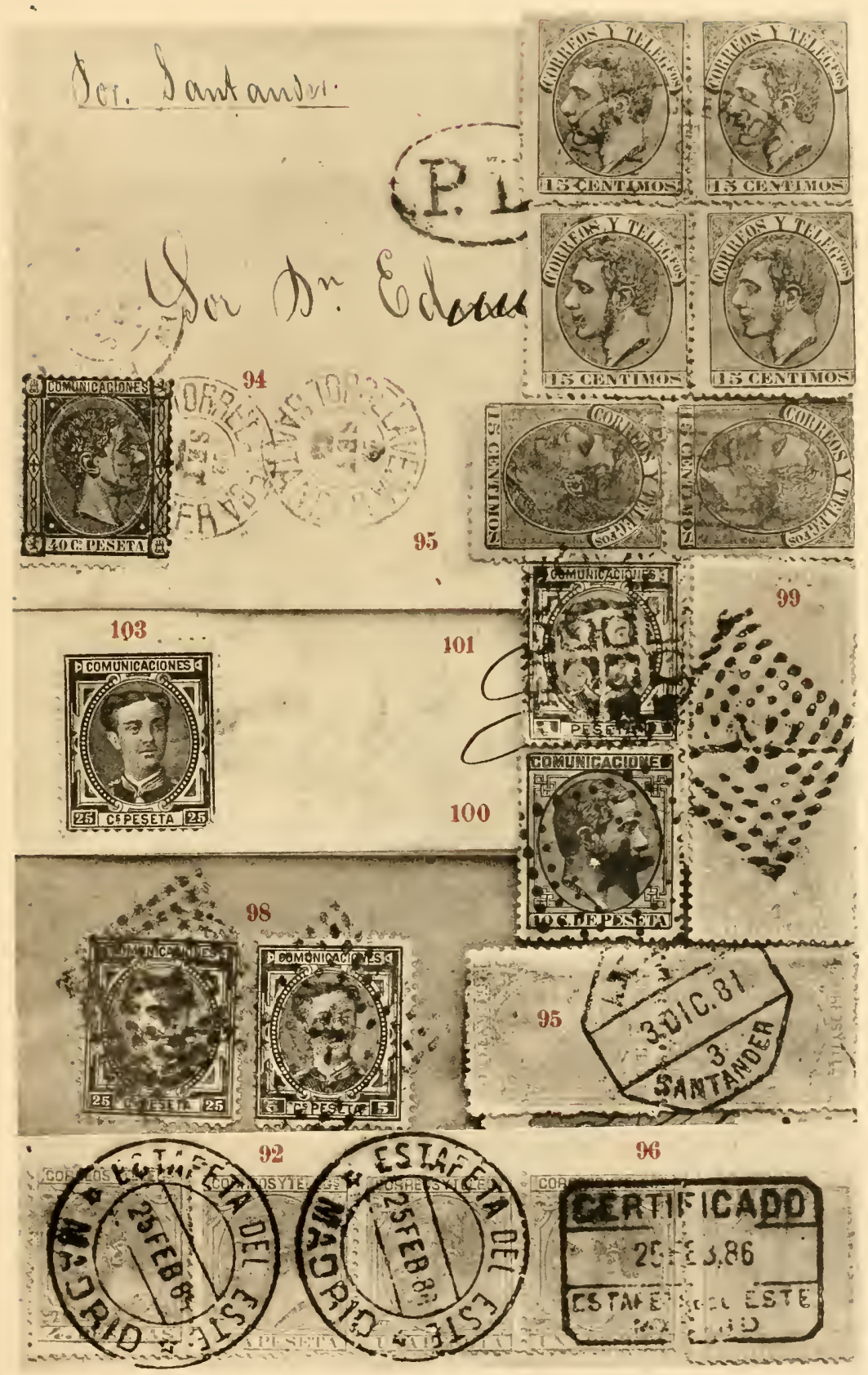

Friederich, Die Postwertzeichen Spaniens und seiner Kolonien (I. Toil) Verlag von Dr. H. Brendicke in Berlin W.57. 

105

SEREICIO DE CORREOS.

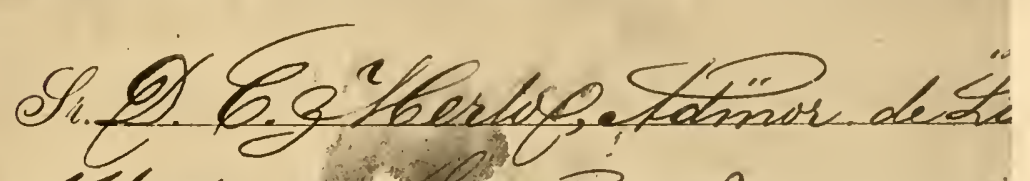

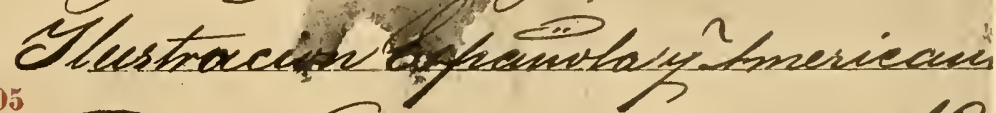
105

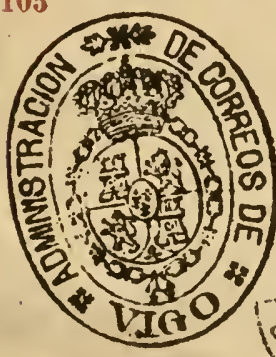
Calle de Carretas

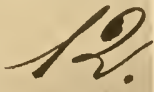
$\begin{array}{rl}270 \\ 15 & 80,9\end{array}$

93

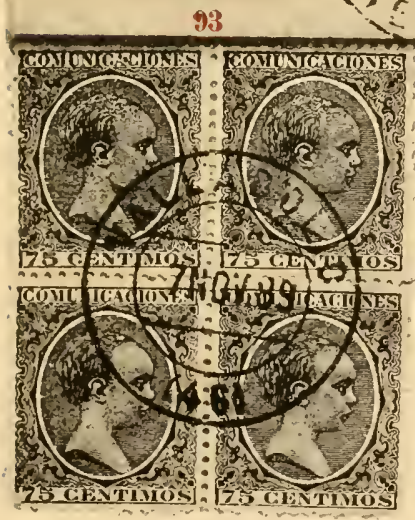

110

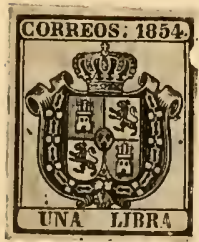

111

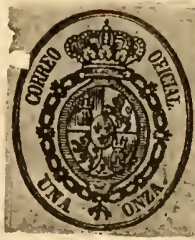

97

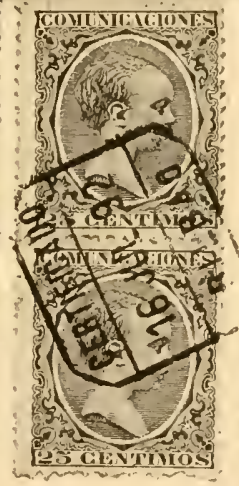

113

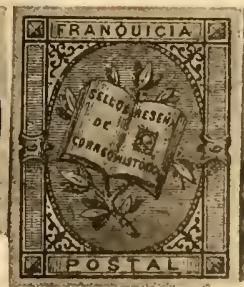

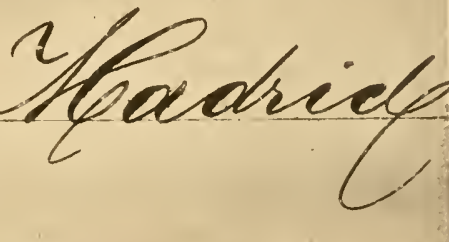

110

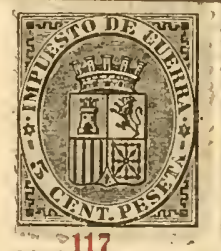

116.
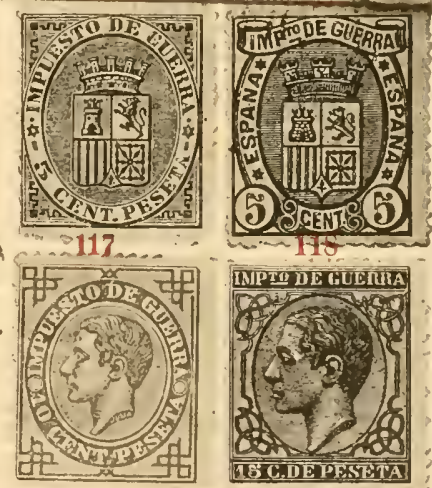

111

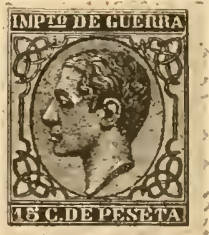

112
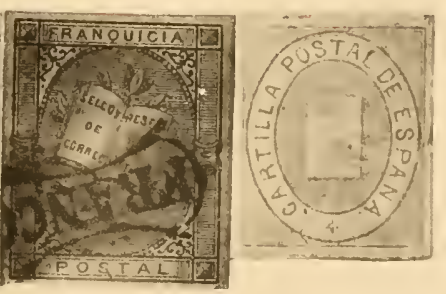

Friederich, Die Postwertzeichen Spaniens und seiner Kolonien (I. Teil) Verlag von Dr. H. Brendicke in Berlin W. 57. 

120
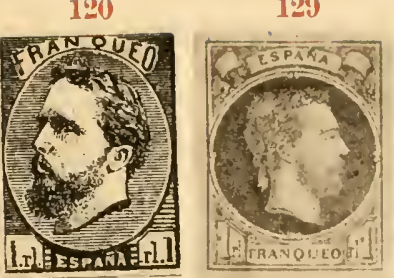

134

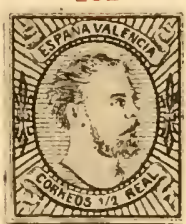

133

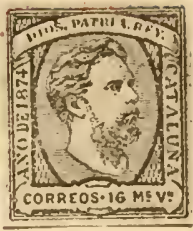

136

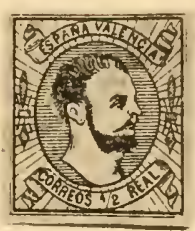

124

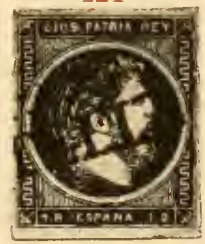

132

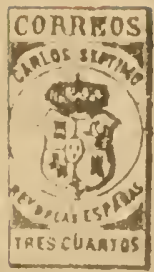

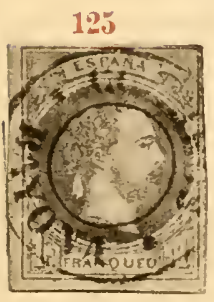

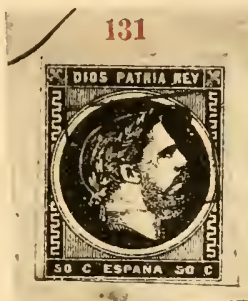

128
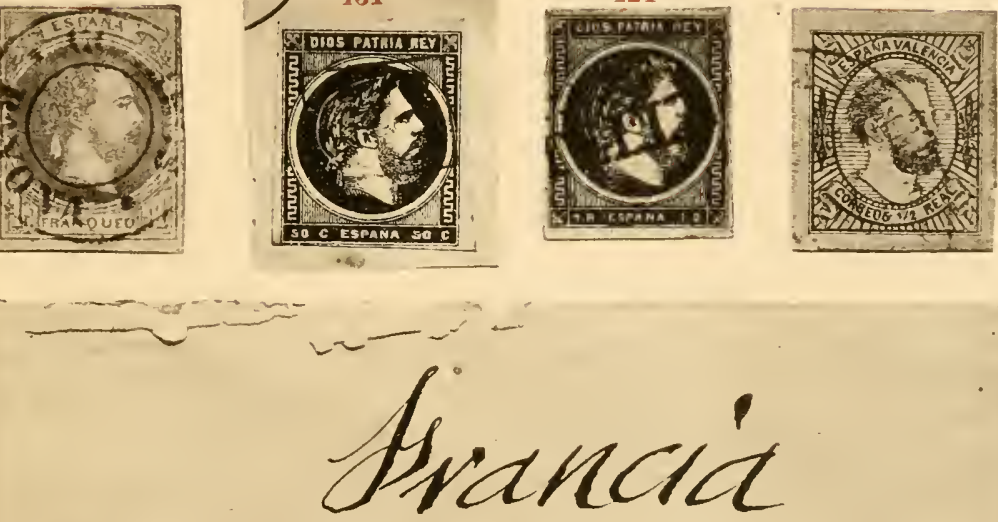

Señor Encargado dela Cor ondenciáciulista; en
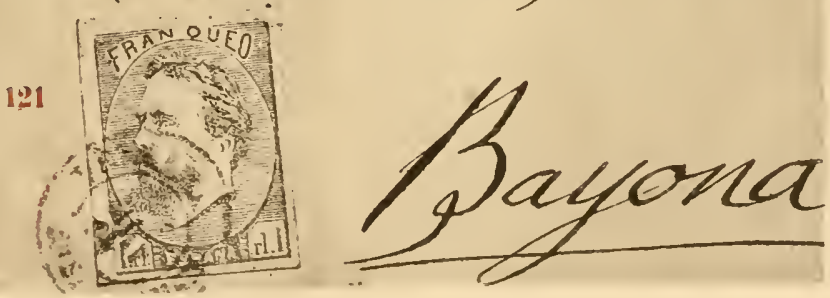

Friederich, Die Postwertzeichen Spaniens und seiner Kolonien (I. Teil) Verlag von Dr. H. Brendicke in Berlin W. 57. 



\section{Tafel XI.}

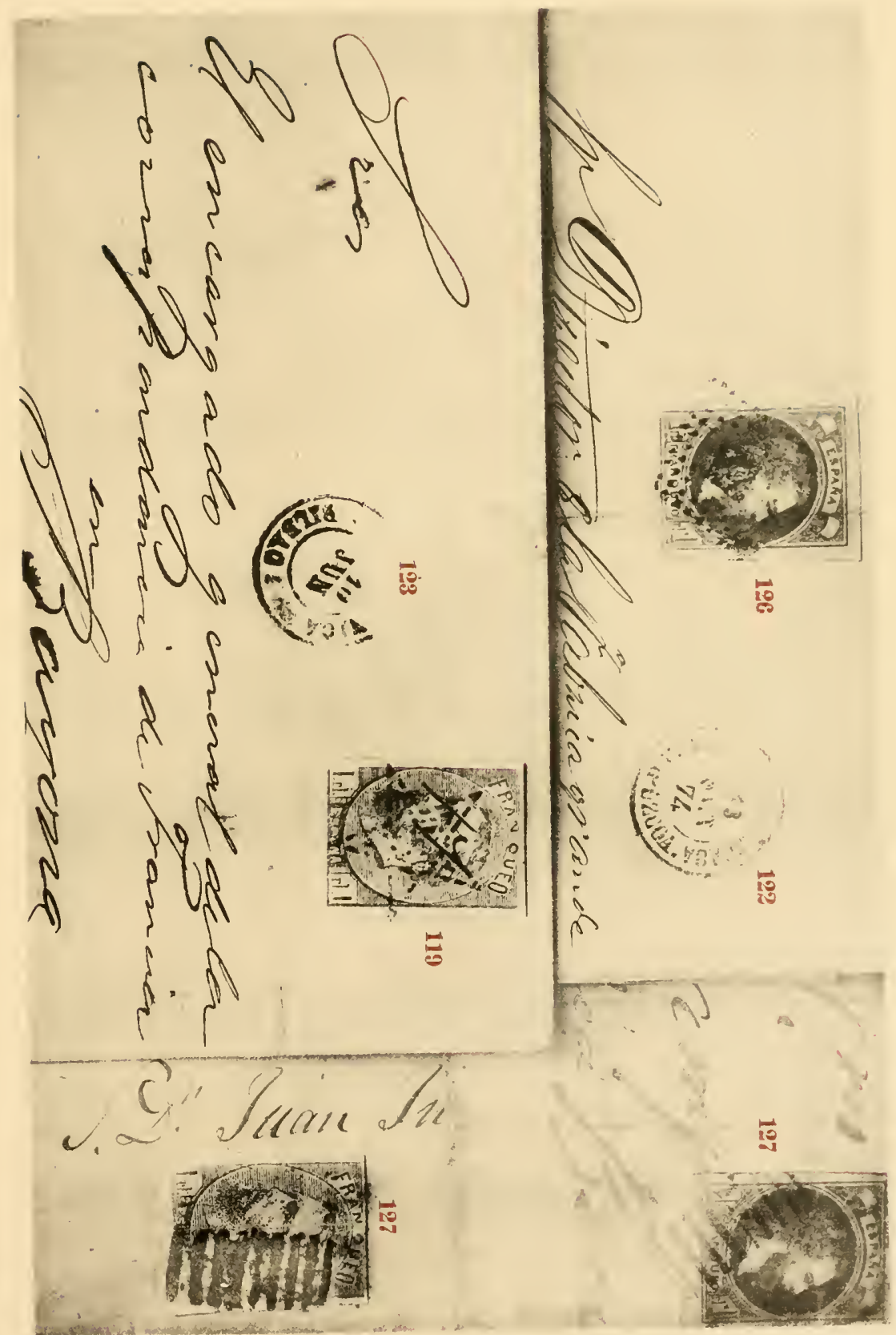

Friederich, Die Postwertzeichen Spaniens und seiner Kolonien (I. Teil) Verlag von Dr. H. Brendicke in Berlin W. 5 ?. 



\section{Tafel XII.}

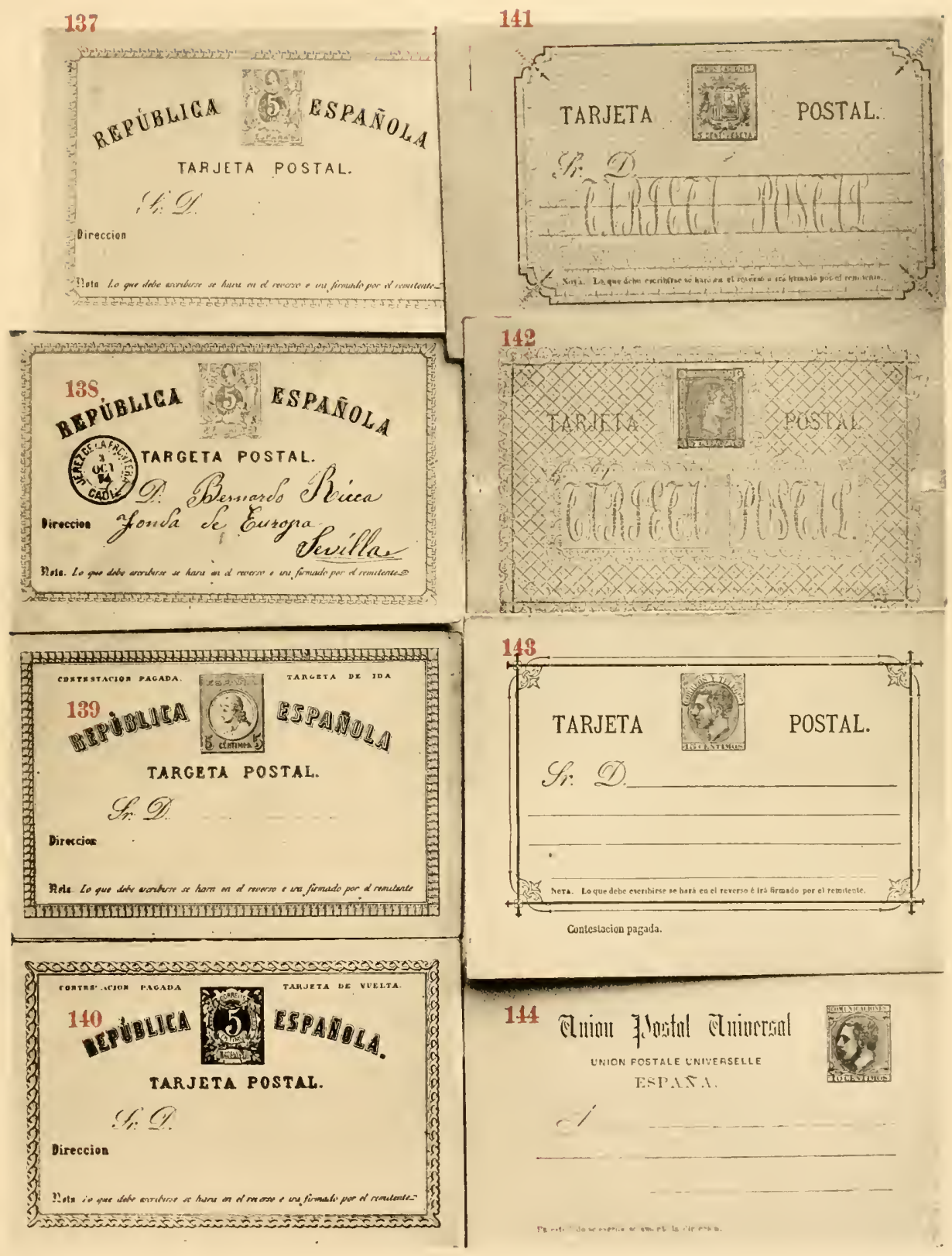

Friederich, Die Postwertzeichen Spaniens und seiner Kolonien (I. Teil) Verlag von Dr. H. Brendicke in Berlin W. 57. 



\section{Tafel XIII.}

145

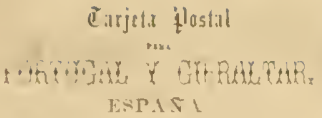
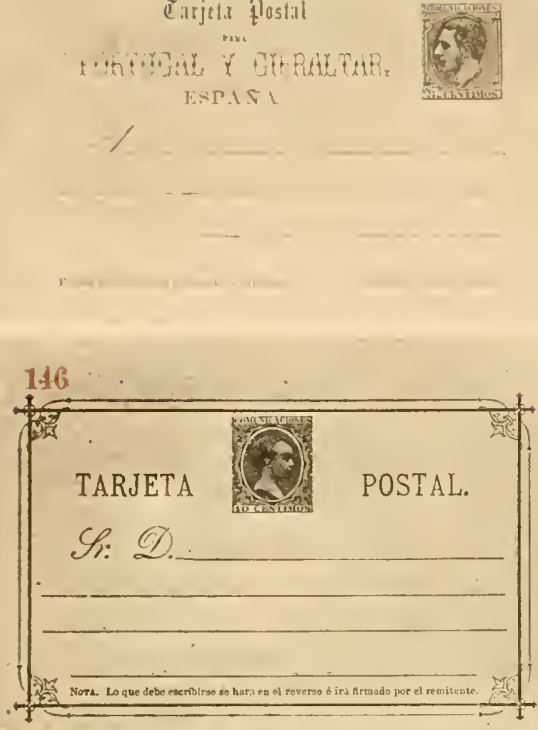

147

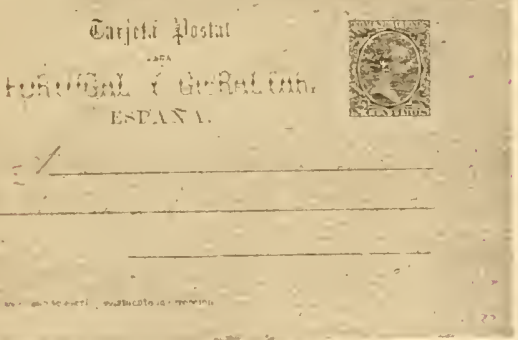

148

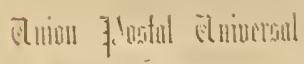
LNIOX FOSTALE LNI:ERSELLE ENPAS A.
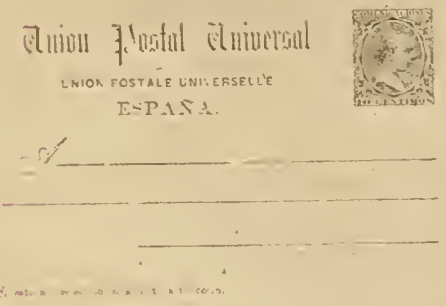

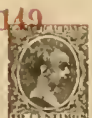

TAIJIFT:I POSTAI.

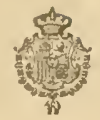

$$
\text { Of. }
$$

150

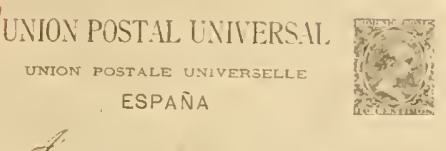

\section{1 \\ T.ARJETA POST.HL \\ : PURTLGAL Y GIBJALTAR}
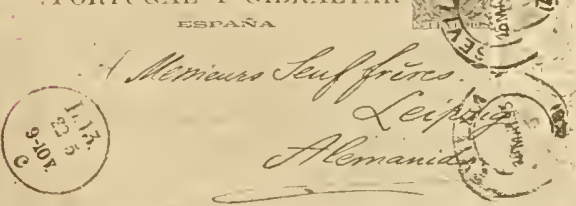

152

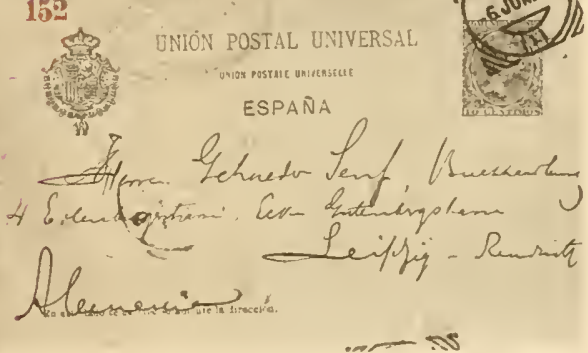



Die

\title{
Postwertzeichen
}

\section{Spaniens und seiner Kolonien.}

\author{
Bearbeitet \\ von \\ Rudolf Friederich,
}

Mitglied des Berliner Philatelisten-Clubs.

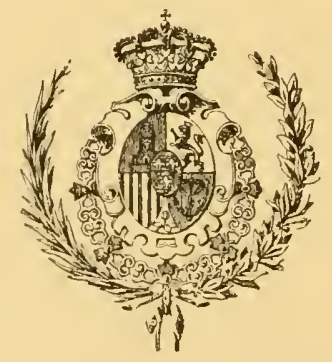

Mit 20 Tafeln in Lichtdruck und zahlreichen Abbildungen im Text.

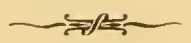

BERLIN 1894.

Verlag von Dr. H. Brendicke, Potsdamer-Strasse 61. 


\author{
Die
}

\title{
Postwertzeichen der spanischen Kolonien.
}

Von

\section{Rudolf Friederich.}

Mitglied des Berliner Philatelisten-Clubs.

Mit 7 Tafeln in Lichtdruck und 14 Abbildungen im Text.

BERLIN 1894.

Verlag von Dr. H. Brendicke Potsdamer-Strasse 61 . 
Alle Rechte vorbehalten. 


\section{Vorwort.}

Dem Vorwort zum ersten Teil habe ich an dieser Stelle nur Weniges hinzuzufïgen.

Eine Monographie der Postwertzeichen der spanischen Kolonien erscheint in so ausführlicher Bearbeitung zum ersten NIal. Brauchbare Vorarbeiten waren nur wenige vorhanden, anch die wenigen sind zum grössten T'eil veraltet; offizielle Aktenstïcke, postalische Verfïgungen u. dergl. sind selbst in den spanischen Archiven nur in geringer Zahl vorzufinden, Jahrgänge älterer Zeitungen sind in Deutschland nicht aufzutreiben. Die in den letzten Jahren in dem spanisch sprechenden Amerika erschienenen philatelistischen Zeitschriften waren für die Zwecke des Buches völlig wertlos, da illr dürftiger Inhalt zumeist europäischen Blättern entnommen ist. So ist es begreiflich, dass die Bearbeitung auf zahlreiche, kaum zu bewältigende Hindernisse stossen musste und dass sie, im Jahre 1888 begonnen, erst in diesem Jahre vollendet werden komnte, auch erklärlich, dass sich trotz grösster Bemühungen noch vielfach Lücken und Unklarheiten, vielleicht sogar Fehler vorfinden werden. Wenn irgendwo, so ist hier ein Mitarbeiten der gesammiten Sammlerwelt geboten, will man das Dunkel, welches über einigen Abschnitten dieses Teiles noch schwebt, lichten, ehe es iiberhaupt hierzu zu spät ist.

Gliederung und Behandlung des Stoffes ist analog dem ersten Teil. Bemerkungen allgemein-historischen Inlalts fielen fast gänzlich weg, da die geschichtlichen Ereignisse, welche sich im 19. Jahrhundert in denjenigen spanischen Kolonien abspielten, um welche es 
sich hier handelt, nur ein schwacher Widerhall der Kämpfe sind, von welchen das Mutterland heimgesucht wurde und welche, soweit es für die Zwecke dieses Buches nötig, im ersten Teil Besprechung gefunden haben.

Ueber die Entwickelung der postalischen Verlältnisse in den verschiedenen Kolonien ist wenig bekannt geworden, selbst in den einschlägigen spanischen Werken findet sich wenig Bemerkenswertes; das Wenige wurde in der Einleitung zusammengestellt.

Wie im ersten Teil, so wurde auch hier auf genaue Beschreibung der Postwertzeichen, Angabe aller bekannten Farbenund Papierverschiedenheiten, Fehldrucke u. dergl. grosser Wert gelegt und keine Mühe geschent, diese Angaben zu vervollständigen. Die Liste der Essais dürfte in dieser Vollständigkeit noch nirgends veröffentlicht sein.

Die Schwierigkeit, spanisch-koloniale Marken auf ganzem Brief aufzutreiben, hat es zwar unmöglich gemacht, von allen existirenden Abstempelungen deutliche Abbildungen zu bringen, immerhin aber dürfte das Gebotene genïgen, dem Spezialsammler den nötigen Ueberblick iiber dieselben zu verschaffen. 


\section{I n h a $1 \mathrm{t}$.}

Seite:

Vorbemerkung

\section{Einleitung:}

\section{Spanisch Westindien.}

Cuba:

Geographisches

Geschichtliches

Verkehrswesen

Geldwährung pp.

Portorico: Geographisches

Geschichtliches

Verkehrswesen

Geldwährung pp.

Ia. Cuba und Portorico.

\section{Briefmarken:}

A. Marken aus der Zeit der Regierung der Königin Isabella II.

I. Ausgabe $1855 / 64$.

II. Ausgabe $1862 / 64$

III. Ausgabe $1864 / 66$. . . . . . . . . . . . . . . 24

IV. Ausgabe 1866. . . . . . . . . . . . . . . . 25

V. Ausgabe 1867 . . . . . . . . . . . . . . . 26

V1. Ausgabe 1868 . . . . . . . . . . . . . . 27

B. Marken der provisorischen Regierung.

VII. Ausgabe 1868. . . . . . . . . . . . . 28

VIII. Ausgabe 1869 . . . . . . . . . . . . . . . . 30

IX. Ausgabe 1870 . . . . . . . . . . . . . . . . 31

X. Ausgabe 1871/72 . . . . . . . . . . . . . . . 32

\section{Briefmarken:}

Ib. C u ba.

A. Marken aus der Zeit der Regierung des Königs Amadeo.

I. Ausgabe 1873

B. Marken der Republik.

II. Ausgabe 1874 . . . . . . . . . . . . . . . . 41

III. Ausgabe 1875 . . . . . . . . . . . . . . . . 42 
C. Marken aus der Zeit der Regierung des Königs Alfonso XII.

Seite :

IV. Ausgabe 1876.

V. Ausgabe 1877 .

VI. Ausgabe 1878

VII. Ausgabe 1879 .

VIII. Ansgabe 1880 .

IX. Ausgabe 1881 .

X. Ausgabe 1882/83

XI. Ausgabe 1884/87 .

XII. Ausgabe 1888/89 .

D. Marken aus der Zeit der Regentschaft der Königin Maria Cristina bezw. der Regierung des Königs Alfonso XIII.

XIII. Ausgabe 1890/91 . . . . . . . . . . . . . . . 57

XIV. Ausgabe 1891/93. . . . . . . . . . . . . . . 58

XV. Ausgabe von 1894 an . . . . . . . . . . 60

\section{Postkarten:}

A. Postkarten ans der Zeit der Regierung Alfonso's XII.
I. Ausgabe 1878 .
II. Ausgabe 1879 .
III. Ausgabe 1880 .
IV. Ausgabe 1881
V. Ausgabe 1882 .
VI. Ausgabe 1888/89

B. Postkarten aus der Zeit der Regentschaft der Königin Maria Cristina bezw. der Regierung des Königs Alfonso XIII.

VII. Ausgabe 1890

VIII. Ausgabe 1893

IX. Ausgabe 1894

I. Briefmarken:

\section{Ic. Portorico.}

A. Marken aus der Zeit der Regierung des Königs Amadeo.

I. Ausgabe 1873/74 .

B. Marken der Republik.

II. Ausgabe 1874 . . . . . . . . . . . . . . . . 81

III. Ausgabe 1875 . . . . . . . . . . . . . . . . 82

C. Marken aus der Zeit der Regierung des Königs Alfonso XII.

IV. Ausgabe 1876 . . . . . . . . . . . . . . . . 83

V. Ausgabe $1877 / 78$. . . . . . . . . . . . . . 84

VI. Ausgabe $1878 / 79$. . . . . . . . . . . . . . . . . 86

VII. Ausgabe 1879. . . . . . . . . . . . . . . . 87

VIII. Ausgabe 1880 . . . . . . . . . . . . . . . . 88

IX. Ausgabe 1881 . . . . . . . . . . . . . . . . 89

X. Ausgabe 1882/83 . . . . . . . . . . . . . . . . . . . . . 90

XI. Ausgabe $1884 / 89$. . . . . . . . . . . . . . . . . . . 92

D. Marken aus der Keit der Regentschaft der Königin Maria Cristina bezw. der Regierung des Konigs Alfonso XIII.

XII. Ausgabe 1890/91 . . . . . . . . . . . . . . . 93

XIII. Ausgabe 1891 . . . . . . . . . . . . . . . . 94

XIV. Ausgabe 1892/93 . . . . . . . . . . . . . . . 95

XV. Ausgabe: 13 November 1893 . . . . . . . . . . 96

XVI. Ausgabe 1894 . . . . . . . . . . . . . . . . . . . 97 
II. Postkarten:

Seite:

A. Postkarten aus der Zeit der Regierung des Königs Alfonso XII.

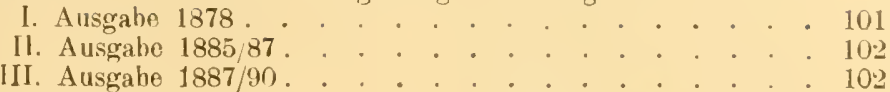

B. Postkarten aus der Zeit der Regentschaft der Königin Maria Cristina bezw. der Regierung des Königs Alfonso XIIl.

IV. Ausgabe 1890/92 . . . . . . . . . . . . . . 103

V. Ausgabe $1892 / 93$.

VI. Ausqabe 1892 . . . . . . . . . . . . . . . 104

Einleitung :

\section{Philippinen.}

Geographisches . . . . . . . . . . . . 107

Geschichtliches . . . . . . . . . . . 107

Verkehrsverhältnisse. . . . . . . . . . . 107

Geldwährung $\mathrm{pp}$. . . . . . . . . . . . . 10s

\section{Briefmarken :}

A. Markon aus der Zcit der Regierung der Königin Isabella II.

I. Ansgabe 1854/59 . . . . . . . . . . . . . . 111

II. Ausgahe 1855/59 . . . . . . . . . . . . . . . 114

III. Ausgabe 1856,63 . . . . . . . . . . . . . . 115

IV. Ausgabe $18 \varepsilon 9 / 61$. . . . . . . . . . . . . . 116

V. Ausgabe 1861/62. . . . . . . . . . . . . . . 118

VI. Ausgabe 1862/63. . . . . . . . . . . . . . . 119

VII. Ausgahe 1863 . . . . . . . . . . . . . 119

VIII. Ausgabe 1863 . . . . . . . . . . . . . . 121

IX. Ausgabe 1864/70. . . . . . . . . . . . . . . 123

B. Marken der Provisorischen Regierung.

X. Ausgabe $1868 / 69$. . . . . . . . . . . . . . 124

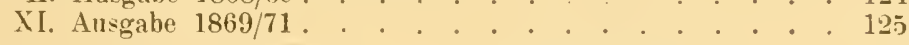

C. Marken ans der Zeit der Regierung des Königs Amadeo I.

XII. Ausgabe 1871/72 . . . . . . . . . . . . . . 126

XIII. Ausgabe 1872/73 . . . . . . . . . . . . . . 127

D. Marken der Republik

XIV. Ausgabe 1873/74 . . . . . . . . . . . . . 129

XV. Ausgabe $1874 / 75$. . . . . . . . . . . . . . . 130

E. Marken aus der Zeit der Regierung des Königs Alfonso XII.

XVI. Ausgabe 1876/77. . . . . . . . . . . . 13 l

XVII. Ausgabe $1878 / 79$. . . . . . . . . . . . . . 133

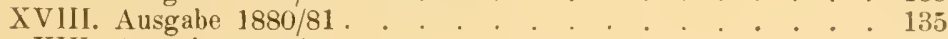

XIX. Ausgabe 1881/82 . . . . . . . . . . . . . 136

XX. Alisgabe $1882 / 83$. . . . . . . . . . . . . . . . 139

XXI. Ausgabe $1883 / 89$. . . . . . . . . . . . . . . 140

XXII. Ausgabe 1883/87. . . . . . . . . . . . . . . 145

XXIII. Alisgahe 1885. . . . . . . . . . . . . . . . 145

XXIV. Ausgabe 1886/89 . . . . . . . . . . . . . . . . 146

XXV. Ausgabe $1887 / 89$. . . . . . . . . . . . . . . 146

XXVI. Ausgabe $1887 / 89$. . . . . . . . . . . . . . . 147

XXVII. Ausgabe $1888 / 89$. . . . . . . . . . . . . . . $14 \overline{7}$

XXVIII Ausgabe 1889. . . . . . . . . . . 149

XXIX. Ausgabe 1889 . . . . . . . . . . . . . . . 150

XXY Ausgahe 1889. . . . . . . . . . . . . 150 
F. Marken aus der Zeit der Regentschaft der Königin Maria Cristina bezw. der Regierung des Königs Alfonso XIII.

XXXI. Ausgabe 1890/93. . . . . . . . . . . . . . . 151

XXXII. Ausgabe 1891/93 * . . . . . . . . . . . . . . . 152

XXXIlI. Ausgabe 1893. . . . . . . . . . . . . . . . 154

XXXIV. Ausgabe 1894. . . . . . . . . . . . . . 155

\section{Postkarten:}

A. Postkarten aus der Zeit der Regierung des Konigs Alfonso XII.

I. Ausgabe 1878 . . . . . . . . . 159

II. Ausgabe 1879/80 . . . . . . . . . . . . . . . 160

III. Ausgabe 1881/91 . . . . . . . . . . . . . . . 161

IV. Ausgabe 1889/91. . . . . . . . . . . . . . . . . 161

B. Postkarten aus der Zeit der Regentschaft der Köuigin Maria Cristina bezw. der Regierung des Königs Alfonso XIII.

V. Ausgabe 1892 .

Einleitung :

\section{Fernando Póo.}

Geographisches. Geschichtliches . . . . . . . . . 167

\section{Briefmarken:}

A. Marken aus der Zeit der Regierung der Königin Isabella U.

1. Ausgabe 1868 . . . . . . . . . . . 171

B. Marken aus der Zeit der Regierung des Königs Alfonso XiI.

II. Ausgabe 1879/81. . . . . . . . . . . . 173

III. Ausgabe $1882 / 93$. . . . . . . . .

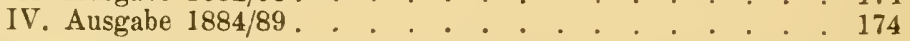

C. Marken aus der Zeit der Regentschaft der Königin Maria Cristina bezw. der Regierung des Königs Alfonso XIII.

V. Ausgabe 1890 . . . . . . . . . . . . . . . . 175

VI. Ausgabe 1893 . . . . . . . . . . . . . . . . 176

VII. Ausgabe 1894. . . . . . . . . . . . . . . 176 
Die spanischen Kolonien, spanisch mit dem Gesamtnamen „El Ultramar" bezeichnet, umfassen die grossen Antillen-Inseln Cuba und Portorico, die Philippinen, Sulu-Inseln, Marianen, Carolinen und Palaos, ferner die Guinea-Inseln: Fernando Póo, Annobon, Corrisco und Elobey und schliesslich die Gebiete des Rio de Oro und von Adras, im Ganzen ein Territorium von 1,129,370 qkm nit etwa 8,200,000 Einwohner.

Von philatelistischem Standpunkt aus betraclitet lassen sie sich in drei Gruppen einteilen: 1. Die Antillen, nach dentschem Sprachgebrauch Spanisch Westindien genamnt, 2. Die Philippinen und 3. Die Guinea-Inseln. Während die zahlreichen Inseln des Philippinen-Archipels ebenso wie diejenigen der Guinea-Inseln sich stets gemeinsamer Postwertzeichen bedienten, war dies innerhalb der Antillen-Gruppe nur bis zum Jahre 1873 der Fall; von diesem Jahre an wurden für Cuba und Portorico besondere Ausgaben hergestellt. Wir haben dementsprechend in Nachfolgendem zu betrachten:

I. Die Postwertzeichen von Westindien und zwar

Ia. von Cuba und Portorico,

Ib. von Cuba,

Ic. von Portorico;

II. die Postwertzeichen der Philippinen und

III. diejenigen von Fernando Póo. 



\section{Spanisch Westindien.}

Ia. Cuba und Portorico.

का 



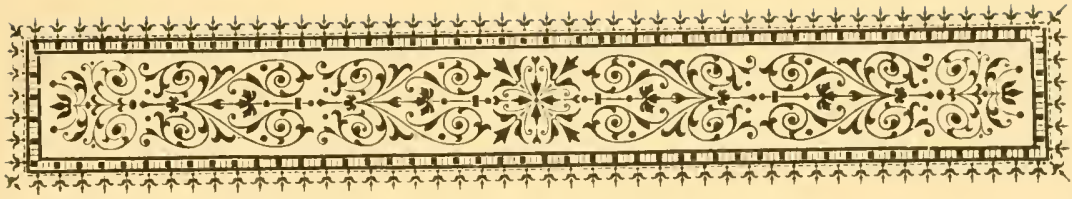

\section{Einleitung.}

Mit dem Namen "Spanisch Westindien“ bezeichnet man gewöhnlich die zu den Grossen Antillen gehörenden Inseln: Cuba und Portorico; in Spanien selbst ist für dieselben meist nur die Bezeichnung "Las Antillas" gebräuchlich.

\section{C U B A.}

Geographisches. Cuba, die bedeutendste der Grossen Antillen, zwischen $19^{\circ} 48^{\prime}$ und $23^{\circ} 15^{\prime}$ nördlicher Breite und zwischen $72^{\circ} 2^{\prime}$ und $84^{\circ} 55^{\prime}$ westlicher Länge gelegen, hat einen Flächeninhalt von 118,833 qkm mit 1,631,687 Einwohner (1887). Sie ist administrativ in sechs Provinzen eingeteilt, welche nach den Hauptstädten benannt werden. An der Spitze der Regierung steht der GeneralKapitän mit fast absoluter Gewalt, ihm zur Seite ein Ministerium von fünf Mitgliedern.

Sitz der Behörden ist La Habana mit ca. 210,000 Einwohnern.

Geschichtliches. Die Geschichte Cuba's ist, soweit sie für unsere Zwecke in Frage kommt, die spanische. Von Colon auf 
der ersten Reise entdeckt (1492), mass man der Insel, so lange die Kolonialpolitik Spaniens vorwiegend auf Ausbentung der Goldund Silberminen gerichtet wăr, keine besondere Wichtigkeit bei. Handelsmonopole, denen zufolge der Aus- und Einfuhrhandel allein von Cadiz beherrscht wurde, hinderten fast gänzlich die Aufschliessung des reichgesegneten Landes. Erst seitdem Spanien ans seinen festländischen Besitzungen von Amerika verdrängt ist, hat die Hebung der Landeskultur, des Handels und der Industrie kräftigen Aufschwung genommen. Die Ausfuhır, welche im Jahre 1828 nur 48 Mill. Mark betrug, war im Jahre 1890 schon auf 290 Millionen gestiegen. Unter diesen Umständen ist die Begehrlichkeit, mit welcher eine nordamerikanische Annexionspartei nach der Perle der Antillen schielt, leicht begreiflich. Nordamerikanischem Geld und nordamerikanischen Abenteurern ist denn auch der zehn Jahre lang(1868 - 78) w ährende A ufstand der Farbigen zuzuschreiben, von dessen nachteiligen Folgen die Insel sich erst jetzt wieder zu erholen beginnt.

Verkehrsverhältnisse. Im Vergleich zu Mittel-Amerika giebt es auf Cuba eine beträchtliche Anzahl guter Strassen. An Eisenbahnen sind über $1800 \mathrm{~km}$ in Betrieb, die Telegraphenlinien haben eine Ausdehnung von $3548 \mathrm{~km}$ mit 167 Stationen, die Post beförderte 1889/90 zusammen ca. 8,000,000 Sendungen und hatte eine Einnahme von ca. 2 Millionen Mark.

Der Postdienst Cuba's steht nicht unter dem spanischen Ministerium des Innern (de la gobernacion), sondern unter demjenigen der Kolonien (del ultramar), ist also vollständig von demjenigen des Mutterlandes getrennt; die Organisation ist jedoch völlig derjenigen Spaniens nachgebildet; die Zuverlässigkeit der Beamten und die Sicherheit des Dienstbetriebes steht auf niederer Stufe.

An der Spitze des gesammten Post- und Telegraphenwesens steht die General-Direktion, welche ilıren Sitz in La Habana hat. Drei Administraciones principales befinden sich in Matanzas, Puerto Principe und Santiago de Cuba, den nach La Habana wichtigsten Städten der Insel. Ausserdem existiren noch 5 Administraciones I. Classe, 10 II. Classe, 12 III. Classe und 48 Carterías für die kleineren Niederlassungen, im Ganzen also 157 Postanstalten. 
Die Versendung der Postsendungen in's Innere und umgekehrt geschieht entweder per Eisenbahn oder durch Wagen oder durch Boten zu Pferd und zu Fuss, an der Kïste durch Postschiffe. Die Verbindung mit Europa wird durch Postdampfer hergestellt, welche fuir ihre Fahrt etwa 18 Tage gebrauchen; vielfach bedient man sich anch des Weges über die Vereinigten Staaten, wie überhaupt die Dienste französischer, englischer und deutscher Postdampfer häufig in Anspruch genommen werden.

Geldwährung. Wie im Mutterlande, so wechselte auch in den Kolonien die Geldwährung mehrfach. Die Schwierigkeit, die Hölıe der Portosätze genau beurteilen zu können, wird noch erhöht dadurch, dass der Peso duro, sowie der Silberreal einem steten Kurswechsel unterworfen waren.

\section{Bis 1866 :}

1 Peso duro $=8$ Reales de plata fuerte $=4$ Mark.

1 Real plata fuerte $=2 \frac{1}{2}$ spanische Reales de vellon $=0,50$ Mark.

$$
\text { Von } 1866 \text { bis 1870: }
$$

1 Peso duro $=2$ Escudos à 2 Mark.

1 Escudo $=100$ Céntimos de Esco $=1000$ Milesimas de Esco. 10 Cent. de esc $\underline{0}=100$ mil $\stackrel{\mathrm{s}}{=}=1$ spanischer Real de vellon. 20 Cent. de $\operatorname{esc} 0=1$ Real de pl. f.

$$
\text { Von } 1871 \text { bis } 1881 \text { : }
$$

1 Peso $=5$ Pesetas $=4$ Mark.

1 Peseta $=100$ Céntimos de peseta $=0,80$ Mark.

\section{Von 1881 an:}

1 Peso $=100$ Céntimos de peso $=1000$ Milesimas de peso.

Bei Umrechnung der Werte in Céntimos ist demnach genau darauf zu achten, ob es Céntimos (d. h. 1/100) de peso, de escudo oder de peseta sind.

Gewicht. Wie in Spanien. 


\section{POR T O I C O.}

Geographisches. Portorico, spanisch Puertorico oder PuertoRico, zwischen $17^{\circ} 51^{\prime}$ und $18^{\circ} 31^{\prime}$ nördlicher Breite und $65^{\circ} 37^{\prime}$ und $67^{\circ} 16^{\prime}$ westlicher Länge gelegen, hat einen Flächeninhalt von $9620 \mathrm{qkm}$ mit ca. 800,000 Einwolnern. Der Sitz des an der Spitze der Regierung stehenden General-Kapitäns ist auf San Juan (de Puertorico), einer kleinen, mit Puertorico durch einen Damm verbundenen Insel; eine Repräsentativverfassung existirt nicht. Portorico wird administrativ in 7 Departements eingeteilt.

Geschichtliches. Die von Colon im Jahre 1493 entdeckte Insel wurde erst 1510 völlig von den Spaniern in Besitz genommen. In Bezug auf culturelle Entwickelung gilt das bei Cuba Gesagte, die Geschichte der Insel, soweit sie für philatelistische Zwecke in Betracht kommt, ist die spanische.

Verkehrsverhältnisse. Dieselben, lange Zeit vernachlässigt, haben sich in den letzten Decennien bedeutend gebessert. An Eisenbahnen waren $189018 \mathrm{~km}$ in Betrieb, $546 \mathrm{~km}$ in Ball oder projektirt, Telegraphenlinien giebt es $778 \mathrm{~km}$.

Ueber Organisation des Postwesens gilt das in Bezug auf Cuba Gesagte. Sitz der General-Direktion ist San Juan; Administraciones principales bestehen in Humacao, Mayaguez, Ponce und Caguas; in den kleineren Städten befinden sich Administraciones I., II. und III. Classe mit 56 Carterías und Estafetas. Die Beförderung der Postsendungen und die Verbindung mit Europa ist wie auf Cuba.

Geldwährung, Maass und Gewicht, wie auf Cuba.

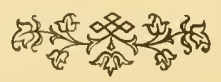




\section{Briefmarken.}

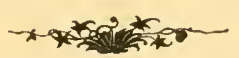





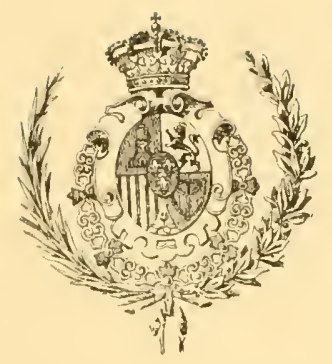

\section{A. Marken aus der Zeit der Regierung der Königin Isabella II.}

\section{Ausgabe:}

vom 1. Januar 1855 bis Ende 1862, bezw. his Januar 1864.

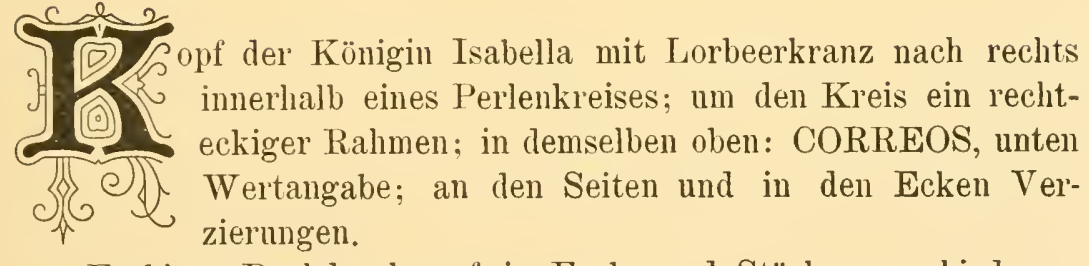

Farbiger Buchdruck auf in Farbe und Stärke verschiedenem Papier, mit und olne Wasserzeichen; ungezähnt. (Taf. I, 1.)

\section{A. Für Cuba und Portorico.}

a. Anf mehr oder weniger intensiv blänlichem, manchmal grünlichem, rauhem und verschieden starkem Papier. Wasserzeichen: Schlingen;

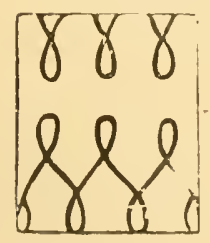
angefertigt vom 1. Januar bis 31. Dezember 1855.

1. $1 / 2$ RI PLATA F. (fuerte) blau und blaugrün in vier Abstufungen.

1 a) $1 / 2 R_{1}^{L}$ PLATA $F$ blaugruin,

$1 \mathrm{~b})$ dunkelblaugran,

$1 \mathrm{c})$ schwarzgrtin,

1 d) $\quad$ dunkelblau. 
2. 1 RL PLATA F. grün in vier Schattirungen.

2 a) 1 Ru PLATA F. flaschengrün,

2 b) $1 \quad$ lebhatt dunkelgrün,

2 c) $1 \quad$ helleres grün,

2 d) 1 gelblichgrün.

3. 2 R PLATA F. braun und orangerot in zahlreichen Schattirungen.

3 a) 2 RS PLATA F. braunrot - lebhaft braunrot,

3 b) 2 dunkelkarmin,

3 c) $2 \quad "$ orangerot,

3 d) 2 blassorangerot,

3 e) 2 gelblichbraun,

3 f) 2 ziegelrot.

b. Auf weissem oder gelblichweissem, rauhem, dickem Papier.

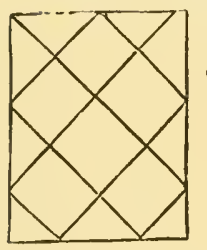

Wasserzeichen: Gekrenzte Linien; angefertigt vom Januar bis April 1856.

4. $1 / 2 R$

4 a) $1 / 2$ RL PLATA F. dunkelblaugrün,

4 b) $1 / 2$ " blaugrün,

4 c) $1 / 2$ dunkelgelbgrtin.

5. 1 RI PLATA F. gelblichgrün in drei Schattirungen.

5 a) 1 RL PLATA F. gelbgrün,

5 b) 1 olivengriin,

5 c) 1 lebhaft grün.

6. 2 RS PLATA F. orangerot in zwei Abstufungen.

6 a) 2 RS PLATA F. orangerot,

6 b) 2 lebhaft orangerot.

c. Auf weissem, glattem und verschieden starkem Papier ohne Wasserzeichen; angefertigt vom April 1856 bis Januar 1864.

7. $1 / 2 R_{1}$ PLATA $F$. blau in zahlreichen Abstufungen.

7 a) $1 / 2$ R! PLATA F. blau,

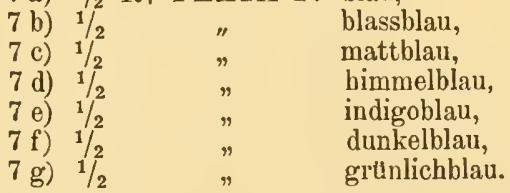

8. 1 R PLATA F. grün in fünf Schattirungen.

8 a) 1 RL PLATA F. gelbgrün,

8 b) 1 blassgelbgrtin,

8 c) $1 \quad$ grün,

8 d) 1 lebhaft griln,

8 e) 1 olivengrin. 
9. 2 R PLATA F. rosa und orangerot in drei Schattirungen.

9 a) 2 R\& PLATA F. rosa,

$\begin{array}{lll}9 \text { b) } 2 & & \\ 9 \text { c) } & 2 & \end{array}$

B. Stadtpostmarke für La Habana.

Marke zu2R PLATA F. der Ausgabe a und c nit schwarzem Aufdruck von $\mathrm{Y}^{1} \frac{1}{4}$ in verschiedenen Typen, vom 19 . Nov. 1855 bis Ende 1862.

a. Auf mehr oder weniger intensiv bläulichem, nanchmal grünlichem Papier mit Wasserzeichen (Schlingen) vom 19. November 1855 bis Ende 1858. Aufdruck $\mathrm{Y}^{1 / 4}$ in 9 Typen.

I. Type: Höhe des Y $5^{1 / 4} \mathrm{~mm}$, auffallend dicker Grundstrich, Bruch steht dicht am $\mathrm{Y}$ und hat gleiche Höhe mit demselben, arabische 1 mit spitzwinkeligem Anstrich auffallend kleine 4. (Taf. I, 2.)

10. $Y^{1 / 4}$ auf 2 RS PLATA F. schwarz auf dunkelkarmin, braun- und orangerot in verschiedenen Schattirungen. 10 a) $Y^{1} / 4$ auf 2 RS PLATA F. schwarz auf dunkelkarmin, $10 \mathrm{~b}) \mathrm{Y}^{1} / 4$ schwarz auf braunrot, $10 \mathrm{c}) \mathrm{Y}^{1} / 4 \quad, \quad$ schwarz auf gelblichbraun.

II. Ty pe: Höhe des Y nur 41/2 mm. dünnerer Grundstrich, der Bruch steht $3^{1 / 2} \mathrm{~mm}$ vom $Y$ entfernt und ist fast $2 \mathrm{~mm}$ höher, arabische 1 mit fast wagerechtem Anstrich, grössere 4. (Taf. I, 3.)

11. $Y^{1 / 4}$ auf 2 R PLATA F. auf denselben Farben wie No. 10.

III. Type: Schlankeres Y, Höhe $5^{1 / 4} \mathrm{~mm}$, der Grundstrich fast eine gerade Linie bildend, Zahlen des Bruches und Entfernung desselben vom $\mathrm{Y}$ wie bei Type II. (Taf. I, 4.)

12. $Y^{1 / 4}$ auf 2 R PLATA F. auf denselben Farben wie No. 10.

IV. Type: $Y$ wie in Type III, die 1 des Bruches ist etwas länger und hat spitzwinkeligen Anstrich.

13. $Y^{1 / 4}$ auf 2 R PLATA F. auf denselben Farben wie No. 10.

V. Type: Höhe des $\mathrm{Y} 5 \frac{1}{4} \mathrm{~mm}$, oberer Abstand der beiden Arme etwas grösser, Zahlen des Bruches etwas dicker 
und länger, die 1 mit wagerechtem Anstrich, ganze Höhe des Bruches grösser. (Taf. I, 5.)

14. $Y^{1 / 4}$ auf 2 R PLATA F. auf denselben Farben wie No. 10.

VI. Type: Höhe des Y nur 5 mm, sonst Type III ähnlich.

15. $Y^{1 / 4}$ auf 2 R PLATA F. auf denselben Farben wie No. 10.

VII. Type: Höhe des Y 5 $1 \frac{1}{2} \mathrm{~mm}$, dickerer Grundstrich, Zahlen des Bruches, besonders die 1 nicht so hoch, in Folge dessen der ganze Bruch das $\mathrm{Y}$ wenig überragend. (Taf. I, 6.)

16. $Y^{1 / 4}$ auf 2 R PLATA F, auf denselben Farben wie No. 10.

VIII. Type: Wie Type VII, nur die 4 des Bruches oben nicht abgestumpft, sondern spitz zulaufend.

17. $\mathrm{Y}^{1 / 4}$ auf 2 RS PLATA F. auf denselben Farben wie No. 10.

IX. Type: Y auffallend laug: $6 \mathrm{~mm}$, alles Uebrige wie bei Type III. 18. $\mathrm{Y}^{1 / 4}$ auf 2 R PLATA F. auf denselben Farben wie No. 10.

b. Auf weissem, glattem Papier ohne Wasserzeichen, von Ende (?) 1858 bis Ende 1862. Aufdruck $\mathrm{Y}^{1 / 4}$ in 2 Typen mit 2 Abarten.

I. Type: Höhe des Y $5^{1 / 3} \mathrm{~mm}$, dicker Grundstrich, arabische 1 mit spitzwinkeligem Anstrich, der Bruchstrich hat an seinen Enden kleine Vertikalstriche. (Taf. I, 8.)

19. $Y^{1 / 4}$ auf 2 R PLATA F, rosa.

Ia. Type: Ebenso, nur der Bruchstrich ganz herausgeschoben. (Taf. I, 8.)

20. $Y / 4$ auf 2 R PLATA F. rosa.

Ib. Type: Ebenso, nur die 1 des Bruches verkehrt. (Taf. I, 10.)

21. $Y^{1 / 4}$ auf 2 RS PLATA F. rosa.

II. Type: Y ebenso, die Zahlen des Bruches dünner und schlanker, auch nicht ganz so hoch, wie bei Type I. (Taf. I, 9.)

22. $Y^{1 / 4}$ auf 2 R PLATA F. rosa. 


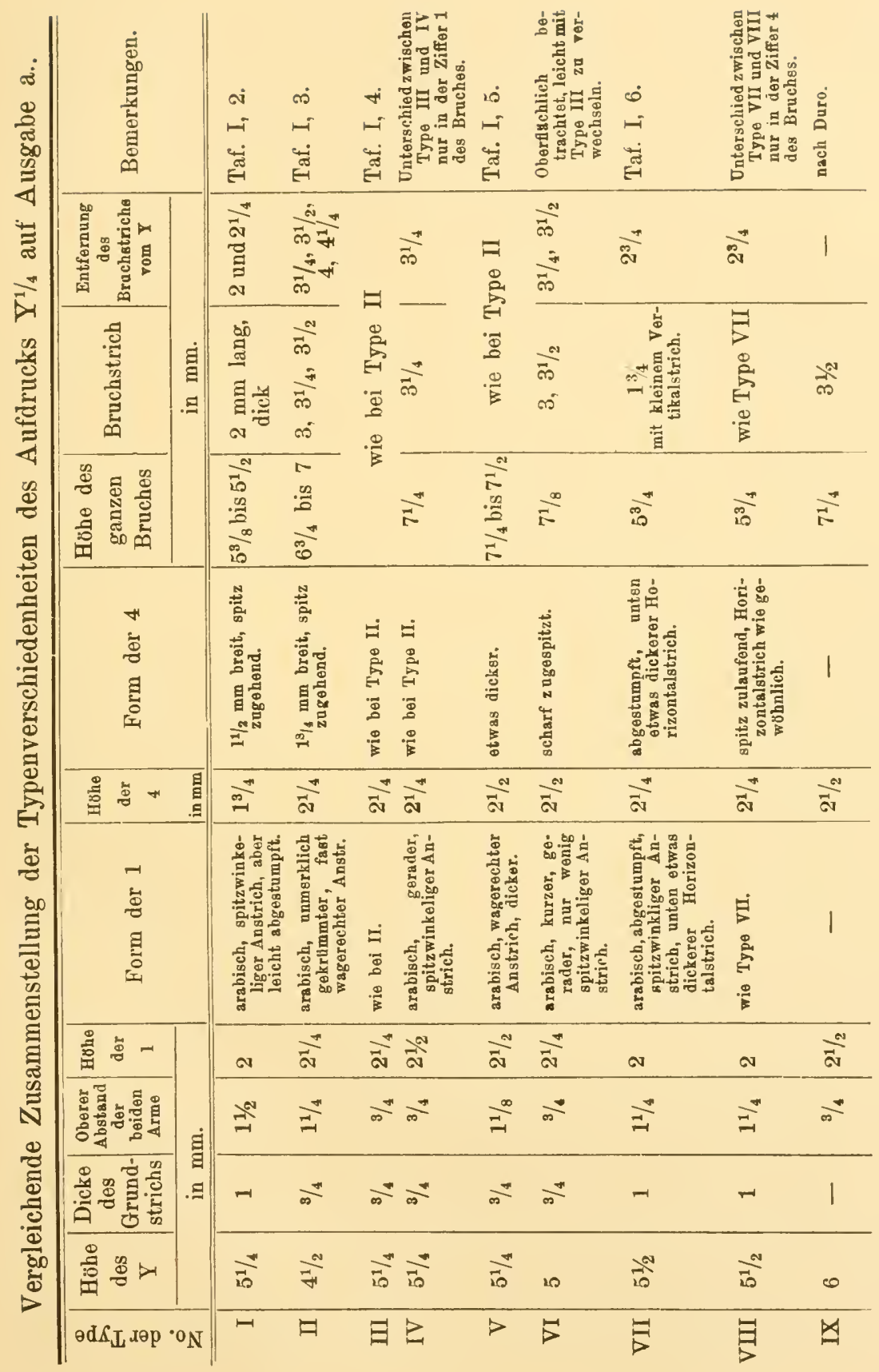




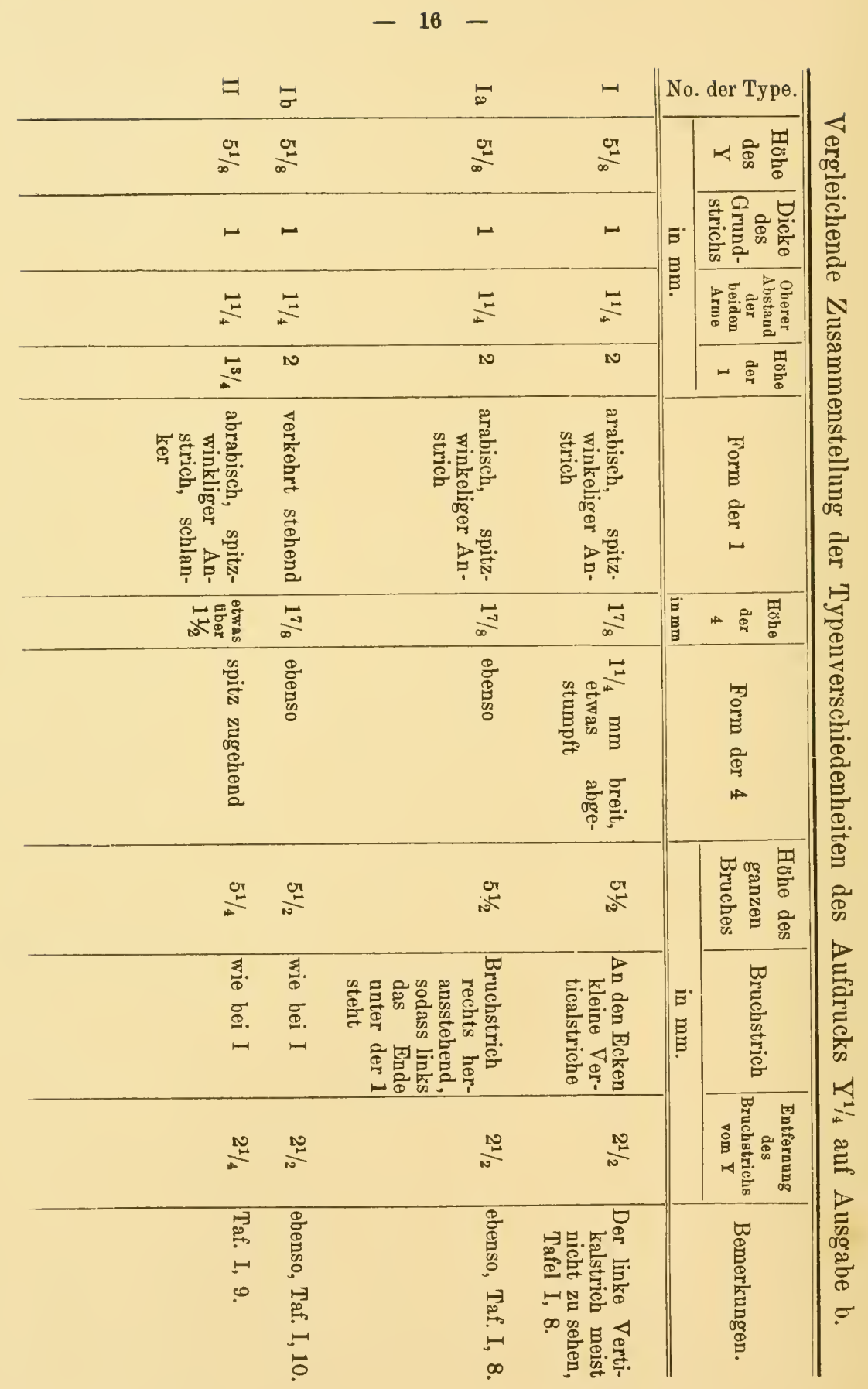




\section{Bemerkungen.}

1. Durch Verfügung vom 18. Dezember 1854, deren Bestimmungen jedoch erst am 1. März des folgenden Jahres in Kraft' traten, wurden die Portosätze wie folgt festgesetzt:

für einfache Briefe für das Innere oder von Cuba nach Portorico und umgekehrt . . . . . . . $1 / 2 \mathrm{Rl}$,

für einfache Briefe nach Spanien und den Adjacentes. . $1 / 2$,

für einfache Briefe nach den Philippinen . . . . . . 1 ,

Als einfache Briefe wurden diejenigen angesehen, deren Giewicht $1 / 2$ onza nicht überschritt; für jede $1 / 2$ onza mehr musste der angegebene Portosatz nochmals bezahlt werden.

Diese Portosätze erhielten durch Verfügung vom 7. November 1856 eine Ergänzung in Bezug auf Drucksachen, deren Porto auf $1 / 2 \mathrm{Rl}$ pro onza ermässigt wurde.

Durch Erlass vom 20. Mai 1859 wurden - vom 7. September in Kraft tretend - die Portosïtze erböht, begrïndet durch die grösseren Kosten, welche die Beförderung durch Dampfschiffe verursachte und zwar wurde das Porto für Briefe von den Antillen nach Spanien, deu Philippinen und unter sich gleichmässig auf 1 Real pro $1 / 2$ onza testgesetzt; das Porto für Drucksachen blieb unverändert.

Die Frankirung vermittelst Briefmarken war vom 1. Januar $1857 \mathrm{ab}$ obligatorisch.

2. In Bezug auf die Marken der I. Ausgabe gilt das Teil I, X. Ansgabe Bemerk. 2, Gesagte, sie bilden eine einzige Emission, deren Verschiedenheit in bezung auf Papier und Farbe eine Folge von Zufälligkeiten hei der Herstellung ist. Die Ausgabedaten der verschiedenen Papiersorten werden verschieden angegeben, können jedoch nicht zweifelhaft sein. Die Marken aut Papier a. wurden laut Verfügung vom 1. September 1854 am 1. Januar 1855 verausgabt, also früher, als die glciche Narke in Spanien. Von Januar 1856 an fertigte die Nationald ruckerei in Mladrid keine Marken mehr auf diesem Papier, von April 1856 an wurde nur noch Papiel ohne Wasserzeichen verwendet. Selbstverständlich durften auch in den Kolonien die vorhandenen Bestände aufgebraucht werden.

Die Werte zu 1 und 2 Reales wurden in den Jahren 1856-63 auch auf den Philippinen, von 1862-65 auch in dem zeitweilig besetzten Gebiet der Dominikanischen Republik gebraucht.

Von Ausgabe c sind die Restbestände später in Händlerhand ibergegangen.

3. Ueber die Marken mit dem Aufdrucke $\mathrm{Y}^{1} / 4$ existiren in den meisten Katalogen und philatelistischen Handbüchern falsche Angaben, es erscheint deshalb nötig, hier etwas näher auf dieselben einzugehen.

Am 15. November 1855 erliess die G. P. D. in Habana folgende Bekanntmachung:

„Nachdem durch S. Excellenz den Generalkapitän die Einrichtung einer Stadtpost für diese Stadt und ihre ausserhalb der Mauern gelegenen Stadtviertel für den 19. c. zur Feier des Geburtstages unserer geliebten Königin Doña Isabel II (welche Gott behitten möge) angeordnet wurde, hat die Postverwaltung die Genugthuung, dem Publikum mitzuteilen, dass an genanntem Tage diese Verbesserung, welche dem lokalen Handelsverkehr die grösstmögliche Bequemlichkeit zu mässigen Preisen gewähren soll, in s Leben treten wird.

Die Korrespondenzen im Ortsverkehr sind dem Frankirungszwang unterworfen und müssen mit einer Marke zu $1 / 4$ Rl plata, welche zu diesem Zwecke bestimmt ist und welche man in denjenigen Häusern kaufen kann, an welchen sich Briefkasten befinden, beklebt werden. 
Das Porte für Postsendungen im Ortsverkehr wird nicht von dem Gewichte abhängig sein, da eine einzige Marke zu 1/4 Rl zur freien Beförderung genügen wird, sei das Gewicht auch, welches es sei.

Habana, den 15 . November 1855.

\section{Narcisso de Torre Marin."}

Der Inhalt dieses durch den Generalkapitän Don José de la Concha veranlassten Erlasses bildete einen gewaltigen Fortschritt in der postalischen Entwickelungsgeschichte der Stadt Habana. Während im Mutterlande in Madrid schon im Jahre 1852 eine Stadtpost geschaffen und diese Einrichtung im darauffolgenden Jahre auf fast alle grössere Städte Spaniens ausgedehnt worden war, fehlte in der Hauptstadt der Antillen 3 Jahre später noch jegliche Briefbestellung. Die Postverwaltung begnigte sich damit, dem Publikum die Ankunft bezw. Abfahrt der Postschiffo mitzuteilen, das Abholen der Sendungen von der Post blieb, ebenso wie die Beförderung nach derselben Sache des Einzelnen. Während somit ein Kaufmann für die Beförderung eines Briefes nach Madrid nur 1 Real zu bezahlen hatte, kostete ihn eine solche nach den ausserhalb der eigentlichen Stadtumwallung gelegenen Vorstädten Cerro oder Jesís del Monte mehr als 1 Peso, oder er war gezwungen, einen Diener hinzusenden, dessen Dienstleistungen ihm alsdann fast einen halben Tag entzogen waren. Diese ungenïgenden postalischen Verhältnisse machten sich um so fühlbarer, als gerade in den letzten Jahren die Stadt bedeutend an Ausdehnung gewonnen und zahlreiche industrielle Etablissements iu den Vorstädten entstanden wareı, deren Besitzer in dem Mittelpunkte der Stadt wohnten.

Die Organisation der Stadtpost zu Habana gab nun die Veranlassung zur Ausgabe einer Marke, welche bis zum heutigen Tage den Sammlern und philatelistischen Schriftstellern das grösste Kopfzerbrechen verursacht hat. Da nämlich eine Marke in Werte von $1 / 4$ Real fehlte, die Anfertigung einer solchen in Madrid aber die Einrichtung auf viele Monate verzögert haben würde, so entschloss man sich dazu, die wenig gebrauchten und daher in grossen Beständen vorhandeueu 2 Reales-Marken mit einem entsprechenden Aufdrucke zu versehen. Die Marken mit dem Aufdruck $\mathrm{Y}^{1 / 4}$ verloren also ihren hisherigen Wert und konnten nur zu dem angegebenen Zwecke verwandt werden.

In Europa, wo man den Zusammenhang der Dinge und den Ursprung und die Verwendung dieser Marken nicht kannte, war der Aufdruck rätselhaft und den verschiedenartigsten Deutungen unterworfen. $\mathrm{Da}$ " $\mathrm{Y}^{*}$ in der spanischen Sprache „und" bedeutet, so glaubte man den Wert dieser Marken gleich $2^{1 / 4}$ Rs und verzeichnete sie dementsprechend in den Katalogen, ein Fehler, der noch im Jahre 1880 von der Philatelistischen Gesellschaft in London bei der Herausgabe des "Catalogue of Postage stamps of Spain", ja sogar noch im Jahre 1887 von Lietzow in seinem "Handbuch der Philatelie" gemacht wurde. Duro war der erste, der" in seiner "Reseña histórico-descriptiva de los sellos de correos de España y del Ultramar" den oben citirten Erlass anführte und die Marken dementsprechend katalogisirte; aber auch or vermochte keine Er. klärung des Aufdrucks Y zu geben und erklärte ihn einfach als einen Fehler, eine Ansicht, welche schon deshalb unhaltbar ist, weil der Aufdruck 6 Jahre lang in Gebrauch war und in mehreren Auflagen hergestellt wurde.

Da die Erklärung des Y mit "und" nach dem Bekanntwerden der postalischen Verfügung vom 15. November 1855 nicht mehr aufrecht zu erhalten war, so suchte man nach einer anderen. Pemberton, Evans u. A. glaubten dieselbe darin zu finden, dass sie das Y als Abkürzung des Wortes "Interior" bezeichneten. Sehon wir von anderen Grüuden ab, so ist diese Erklärung schon deshalb nicht annehmbar, weil Interior niemals und nirgends mit $Y$ geschrieben wurde. Man glaubte zwar eine Begrïindung dieser Schreibweise in dem Bestreben zu finden, ein leicht mögliches Missverständnis des 
Aufdrucks zu vermeiden, indens ein I leicht für eine römische 1 gehalten werden und der Aufdruck dementsprechend als $11 / 2 \mathrm{Rl}$ gelesen werden konnte; die Idee, sechs Jabre lang absichtlich einen orthographisehen Fehler zı machen, erscheint jedoch zu naiv, um ernst genommen $\mathrm{zu}$ werden.

Nach dem Verfasser aus denkbar bester Quelle zugegangenen Mitteilungen ist das $Y$ nichts anderes, als die zn jener Zeit auf Cuba übliche Abkürzung fur Silber-Real (Real de Plata fuerte). Dass dieses Zeichen in unserer Zeit selbst in Spanien wenig mehr bekannt ist, findet darin seine Erklärung, dass der Silber-Real ausschliesslich in den Kolonien gebraucht wurde, wälırend das Mutterland nach dem Kupfer-Real (Real de vellon) rechnete, dass diese Münze mit dem Jahre 1866 - nach anderen Angaben 1862 - schon ausser Kurs gesetzt wurde und dass selbst in der Zeit ihrer Circulation die Kauflente von Cuba ihre Rechnungen mit Spanien in Pesos duros ausdrïcken mussten.

Wie über Ursprung und Verwendung, so sind anch über die Art und Weise der Herstellung des Aufdruckes, iber die Zahl der vorhandenen Typen und iiber die Daten der Ausgabe pp. irrige Ansichten verbreitet

Eine genanere Untersuchuug ergiebt deutlich, dass der Aufdruck rermittelst Buchdruckes hergestellt ist. Der dentliche, die Ränder scharf' abhebende, tiet in das Papier eindringende und die Papierfaserung manchmal zerschneidende Druck, die gleichmässige Stellung des Aufdruckes und das Aussehen der Druckerschwärze lassen sich durch Handstempelung nicht erreichen, man vergleiche $n m$ den vermittelst Handstempel erzeugten Aufdruck: „Habilitado por la uacion“. Ein genanerer Vergleich zahlreicher Aufdrucke ergiebt ferner, dass der Aufdruckstempel aus vier Teilen: dem Y, der 1, der 4 und dem Bruchstrich zusammengesetzt war. Man erkennt dies deutlich aus der verschieden grossen Entfernung des Bruches vom $Y$, der Stellung der 1 zur 4 des Bruches, aus der schiefen oder umgekehrten Stellung einzelner oder der Vereinigung mehrerer nicht zusammen gehöriger Teile. Aus diesen Eigentimlichkeiten del' einzelnen Aufdrucke und aus der grossen Verschiedenartigkeit der einzelnen Teile der Aufdrucktype geht hervor, dass die weit verbreitete Ansicht, als wären die verschiedenen Aufdrucktypen das äussere Zeichen einer jedesmaligen neuen Druckauflage, eine irrige ist, dass vielmehr sämtliche Typen auf einmal entstanden siud und auf dem Markenbogen vereinigt waren, ebenso wie dies später bei den Arabesken-Aufdrucken des Jahres 1882 der Fall war, oder mit anderen Worten, dass die verschiedenen Aufdrucktypen ihr Dasein nur dem Umstande zu verdanken haben, dass die mit der Herstellung des Aufdrucks beauftragte Druckerei nicht so viele gleiche Drucktypen besass, um auf einmal die 200 Marken des Markenbogens mit gleichen Aufdrucken versehen zu können. Diese Ansicht wird durch andere Thatsachen bestätigt. Aus Bemerkung 2 geht bervor, dass die Fábrica nacional de sellos in Madrid das Papier mit dem Wasserzeichen Schlingen nur bis zum 31. Dezember 1855 verwandte, vom 1. Januar bis 1. April 1856 Papier mit Wasserzeichen gekreuzte Linien und von April an Papier ohne Wasserzeichen gebranchte. Da die Organisation der Stadtpost in Habana am 19. November 1855 in's Leben trat, so hätte im Falle eiuer neuen Druckauflage das Papier mit Scblingen kaum mehr zur Verfügung gestanden und man luätte das Papier mit gekrenzten Linieu oder dasjenige ohne $\mathrm{W}$ asserzeichen verwenclen miissen, auf jeden Fall aber wäre dies der Fall gewesen, wenn neun verschiedene Auflagen hergestellt worden wären. Wir haben es demnach bezüglich des Aufdruckes auf dem Schlingen-Papier nur mit einer einzigen Druckauflage $z u$ thun, welche aber in gewaltiger Ueberschätzung des Verbrauches dieser Marken so stark war, dass sie für mehrere Jahre ausreichte.

Was die Zah! der existirenden Typeu aubelangt, so herrschte auch hieruber bisher keine Uebereinstimmung in den verschiedenen Katalogen. Nach Moens nahm man gewönlich vier Typen an, eine von dem Verfasser im Laufo des 
vorigeu Jahres angestellte Untersuchung, bei welcher ihm über 1600 Exemplare der Ausgabe 1855 zur Verfügung gestellt wurden, ergab das Vorhandensein der auf Seite 13, 14 und 15 beschriebenen Typen I-VIII. Type IX wurde aus der Duro'schen Reseña übernommen, da bej der genauen Beschreibung derselben ein Zweifel an dem Vorhandensein derselben nicht am Platze zu sein schien. Dass mit der Zahl neun alle Typenverschiedenheiten erschöpft sind, lässt sich nicht annehmen.

Die einzelnen Typen sind in Bezug auf ihr Vorkommen nicht gleich, ebenso wie dies bei den Arabesken-Aufdrucken des Jahres 1882 der Fall ist. Es verrät also Unkenntnis der Verhältnisse, sie bezüglich des Sammelwertes über einen Kamm zu scheeren. Von den von mir untersuchten 1605 Exemplaren gehorten an:

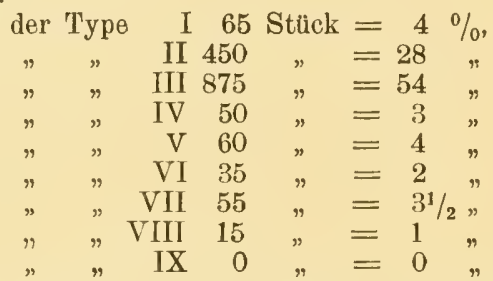

Wenn diese Prozentsätze auch vielleicht nicht vollständig richtig sind, bezw. sich bei einer grösseren Zahl Marken etwas verschieben würden, so vermögen sie doch wohl einen allgemeinen Anhalt für die Beurteilung des Wertes der einzelnen Typen abzugeben.

Ueber die Aufdrucktypen auf dem Papier ohne Wasserzeichen können Zweifel nicht obwalten, da hier grössere Restbestände in Händlerhände ühergingen, mithin noch ganze Bogen existiren. Es sei nur bemerkt, dass sich der Aufdruck mit umgekehrter 1 (Tafel I, 10) zweimal, der Aufdruck mit herausgeschobenem Bruchstrich (Taf. I, 8) einmal auf jedem Bogen befindet.

Bezüglich der Ausgabedaten geht aus dem oben Gesagten deutlich hervor, dass die bisher allgemein tibliche Bezeichnung: Ausgabe 1855, 1856 und 1857 eine irrtiumliche ist. Die erste Auflage auf Schlingenpapier war vielmehr eine so starke, dass sie, wie $17 \mathrm{mir}$ vorliegende, auf ganzen Briefen befindliche Exemplare beweisen, bis zum Jahre 1858 ausreichte; erst gegen Ende 1858 scheint die Ausgabe b allgemein in Gebrauch gesetzt worden zu sein. Nur so lässt sich auch das verhältnismässig zahlreiche Vorkommen der Ausgabe a erklären. Eine genauere Feststellung der Ausgabedaten erscheint schwierig.

Wenn aber die erste Ausgabe thatsächlich bis zum Jahre 1858 in Gebrauch war, - und hierüber ist jeder Zweifel ausgeschlossen -, so ist damit auch bewiesen, dass es eine Ausgabe auf dem Papier mit Wasserzeichen gekreuzte Linien nicht gegeben hat, da dieses von der National-Markenfabrik nur vom 1. Januar bis 1. April 1856 zur Herstellung von Marken verwandt wurde. Die an Unanffindbarkeit grenzende Seltenheit dieser Marke, sowie der Umstand, dass die wenigen Exemplare, welche überhaupt bekannt sind, nur einer einzigen Type angehören (Type VI), lässt darauf schliessen, dass wir es im gtinstigsten Falle mit einem Essai, wenn nicht mit einer offenbaren Fälschung zu thun haben.

Fälschungen des Aufdruckes sind ungemein zahlreich vorhanden; selbstverständlich stammen dieselben aus neuerer Zeit. Im Allgemeinen lassen sie sich jedoch mit Leichtigkeit erkennen, da sie - von der Ausgabe b abgesehen - naturgemäss nicht vermittelst Buchdruckes hergestellt sein können, der Handstempel aber niemals die Deutlichkeit und Schärfe des Buchdrucks besitzen kann. Von Ausgabe a sind ungebrauchte Markenbogen nicht vorhanden; bierdurch ist die Fälschung des Aufdrucks wesentlich erschwert, da die Fälscher 
den Aufdruck auf den Entwertungsstempel setzen müssen, was sich mikroskopisch leicht erkennen lässt. Gewölnnlich werden deshalb aus grösseren Blocks stammende Exemplare benutzt, deren IIitte vom Entwertungsstempel nicht beruhhrt wurde. Da diese aber zumeist auf zwei Seiten einen Teil des Entwertungsstempels tragen, zwei zusammenhängende Exemplare der Marke aber nach dem oben angeführten Einführungserlass nie vorkommen können, so betrachte man alle Marken nit zwei Stempelteilen von vornherein mit Misstranen.

Von Ausgabe $b$ giebt es noch einige Reste ungebrauchter 2 RealesMarken in ganzen Bogen; hier konnten deshalb auch die Fälscher Buchdruck anwenden; es ist jedoch bis jetzt nichi gelungen, den Original-Aufdruck genau nachzuahmen.

Eine weitverbreitete Fälschnng ist Tafel I, 7 abgedruckt; sie existirt auf den drei Papiersorten, ist stets durch Tintenstrich entwertet und wird von vielen Händlern als echt verkauft. Sie ist es auch, welche meist als Ausgabe 1856 in den Sammlungen sich befindet. Meine Nachforschungen nach dem Ursprung dieser Marke haben ergeben, dass dieselbe kurz nach 1870 von einer sonst als reell bekannten Hamburger Firma in grossen Massen aus Habana importirt und unter Garantie der Echtheit verkauft wurde. Man kann daher nur annehmen, dass es eine in Hahana hergestellte Fälschung oder ein anf Bestellung hergestellter Neudruck ist, bei welchem aber die alte 'Type nicht mehr zur Verfügung stand. Postalisch entwertet ist sie nicht bekannt.

4. In Ausgabe 1857 existiren von der Marke zu $1 / 2$ R! fehlerhafte Drucke mit CORRFOS und CORRLOS anstatt CORREOS.

Von der Marke zu $1 \mathrm{RL}$ aller drei Ausgaben giebt es eine Abart ohne Punkt unter dem L der Wertangabe. Da dieser Punkt auch auf Stucken von sonst tadellosem Druck fehlt, so scheint hier eine Typenverschiedenheit vorzuliegen.

Vou der Marke zu 1/2 Rt der Ausgabe 1855 gibt es Stücke mit einem Strich anstatt eines Punktes unter dem L der Wertangabe.

5. Gegen Ende des Jahres 1857 tauchten in Habana gefälschte Marken zu 1/2 und $1 R_{1}^{\prime}$ auf. Ein Rundschreiben des Gouverneur's von Cuba, veröffentlicht in der Gaceta oficial vom 9. Februar 1858, giebt folgende Erkennungszeichen derselben:

a. Die falschen Marken sind in der Hohe $11 \mathrm{~m} 1$ Linie kleiner als die echten.

b. Das Profil des Gesichtes, insbesondere der Nase der Königin in der Nähe des Auges weicht in der Zeichnung etwas ab; die Striche des Haares sind gröber ausgefüihrt.

c. Die Punkte zwischen Rahmen und Perlenkreis sincl von mangelhafter Ausführung und weichen in der Zahl von den echten ab; während die echten Marken oben rechts 32, oben links 27, unten rechts 27 und unten links 28 Punkte besitzen, haben die falschen an den betreffenden Stelleu nur 24, 18, 27 und 20.

d. Das erste $\mathrm{R}$ von CORREOS ist unvollkommen ausgeführt und beruhrt das zweite.

Andere Fälschererzeugnisse, welche im Jahre 1860 anftauchten, sind die Marken zu $1 / 2$ und 1 RL in Lithographie. Da diese Fälschungen vielfach postalisch entwertet vorkommen, so wurden sie lange Zeit für echt gehalten, ungebraucht auch als Essais verkauft. Eine genauere Beschreibung derselben ist unmöglich, da die Marke zu $1 / 2 R_{1}$ in ca. 15, diejenige zu $1 R_{1}$ in ca. 6 Typen bekannt ist.

Die Bekanntmachung dieser Fälschungen in der Gaceta oficial scheint im Uebrigen ihren 'Zweck nicht erreicht zu haben, denn der Gouverneur von Cuba berichtet in den folgenden Jahren noch mehrfach uber getälschte Marken 
nach Madrid. Ein Königl. Erlass von 26. November 1862 ordnet endlich die Ausgabe einer neuen llarkenzeichnung au und befiehlt, um den Gebrauch falscher Marken in Zukunft zu erschweren, eine alljährliche Aenderung der Postwertzeichen in Zeichnung, Farbe und Beschafienheit des Papieres, ein Befelıl, der jedoch infolge der Indolenz der spanischen Behördeu, nicht zur Ausfiihrung gelangte.

6. Essais der ersten Ausgabe in der angenommenen Zeichnung, jedoch in abweichenden Farben und auf verschieden gefärbtem Papier sind folgende bekannt:
$1 / 2$ real
blau, blaugrïı, graublau auf weissem Papier,
grünblau auf gelblichem Papier,
graugrün auf rosa Papier,
1 real
grün auf rosa Papier,
grtiu auf strohgelbem Papier,
grün auf weissem Papier,
gelbgrïn auf grünem Papier,
dunkelgrün auf lebhaft grünem Papier,
dunkelgr'in auf hellgrtinem Papier,
karmin auf weissem Papier,
karmin auf blauem Papier,
karmin auf gelblichem Papier,
karmin auf rosa Papier,
karmin auf rötlichchamois Papier,
rosa auf grủnem Papier,
zimnober auf fleischfarbenem Papier,
zinnoher auf gelblichem Papier,
dunkelrot auf orange Papier,
blau auf bläulichem Papier,
dunkelviolett auf bläulichem Papier,
dunkelbraun auf grünem Papier,
2 reales rot auf rosa Papier.

$\mathrm{Ob}$ diese Marken jedoch thatsächlich den Namen "Essais" vordienen, erscheint fraglich, da sie nach anderen Angaben erst zu Ende des Jahres 1863 angefertigt wurden, um Papier und Farben der Ansgabe 1864 festzustellen.

7. In Bezug auf die Abstempelungen giit für die spanischen Kolonien im Allgemeinen das bei Spanien Gesagte. Der durch Verfügung vom 15. Mai 1842 in Spanien eingefïhrte Datumstempel war zu gleicher Zeit auch in deu Kolonien eingeführt worden. (Taf. II, 11.) Die Farbe desselben war, wie in Spanien meist rot. seltener schwarz oder blau.

Im Jahre 1854 wurde dieser Stempel bei den meisten Postanstalten abgeschafft und wie in Spanien, durch das Nodell 1853 ersetzt; zu gleicher Zeit erhielten die Postanstalten und Kolonien eine eigene, vom Mutterlande unabhängige Nummerirung (Habana $=$ No. 1). (Taf. II. 12.) Die Farbe dieses Stempels ist meist schwarz, seltener blau. Der spanische Stempel des Jahres 1857 (Taf. II. 13) scheint dagegen erst später und auch nur bei einigen Postanstalten eingeführt zu sein, man findet ihn selten auf Briefen vor dem Jahre 1860.

Zeigte sich hierin eine Uebereinstimmung mit dem Mutterlande, so waren dafür die Marken - Entwertungsstempel um so abweichender. Die hierfür in den Kolonien eingeführten Stenpelmodelle sind so zahlreich, dass es scheint, als wäre auch hier die Beschaffung dieses wichtigen Post-Utensils den einzelnen Postamstalten äberlassen geblieben. Die Haupt-Postämter benutzten einen ovalen Gitterstempel (18:30 mm), dessen zehn sich kreuzende Linien an den Schnittpunkten kleine Sterne bilden. (Taf. II, 14.) Seine Farbe ist blau oder schwarz. Er blieb bis zum Jahre 1871 allgemein in Gebrauch und wird bei einzelnen Postanstalten noch bis zum heutigen Tage benutzt. Die kleineren Postanstalten 
und Carterías besassen anfïnglich überhaupt keinen Entwertungsstempel, sondern entwerteten die Marken durch Tintenstriche. Erst später und ganz allmählich wurden auch bei ibnen Entwertungsstempel beschafft; die Formen derselben sind so mannigfaltig, dass anf eine genanere Beschreibung verzichtet und auf die Abbildungen auf Tafel II, 15-24 hingewiesen werden muss. Ueber das Datum ihrer Einführung etc. liisst sich natnrgemäss nichts Genaueres sagen.

\author{
II. Ausg abe: \\ von Ende 1862 bis Januar 1864.
}

Stadtpostmarke für Habana. Zeichnung der X. Ausgabe Spaniens: Kopf der Königin mit Krone nach links in einem an den vier Seiten durch Verzierungen unterbrochenen Kreise: die den Kreis umgebenden Felder sind durch wagerechte Striche ausgefüllt; nnten links ein Hermesstab, rechts ein Anker; über dem Kreis auf flatterndem Band: CORREOS, mnten auf rechteckigem Schild Wertangabe.

Farbiger Buchdruck auf dickem, leicht chamois gefärbtem Papier; ungezähnt. (Taf. I, 25.)

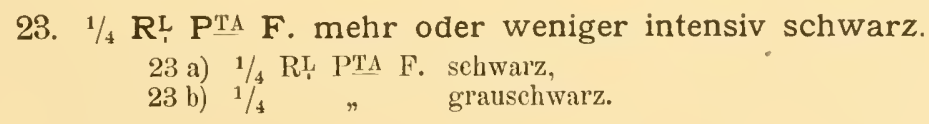

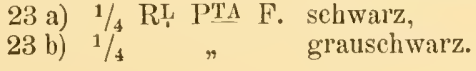

Bemerkung.

Die Marke war bestimmt, den Aufdruck $\mathrm{Y}^{1} / 4$ zu ersetzen, also dem Stadtpostverkehr von Habana zu dienen. Sie war mit den übrigen Werten bis zum Januar 1864 in Gebrauch, selbstverständlich, wie auch die späteren Marken dieses Wertes, nur anf Cuba. Die Marke wurde wegen ihres seltenen Vorkommens in gebrauchtem Zustanle lange Zeit als Essai angesehen. 


\section{Ausgabe: \\ von Januar 1864 bis Januar 1866.}

Zeiclmung der XII. Ausgabe Spaniens: Kopf der Königin mit Diadem nach links in ovalem, mit Verzierungen ausgefülltem Rahmen, welcher in den vier Ecken Kreise bildet; oben auf einem Band: CORREOS, unten Wertangabe (olne Jahreszahl).

Farbiger Buchdruck auf verschieden gefärbtem Papier; ungezähnt. (Taf. I, 26.)

\section{A. Fiir Cuba und Portorico.}

24. $1 / 2 R_{1}^{L}$ PLATA $F$. grün in zwei Abstufungen auf verschieden gefärbtem Papier.

24 a) $1 / 2$ RI PLATA F. grün auf dickem, blass-fleischfarbenem Papier,

24 b) $1 / 2 \quad$ dunkelgrin auf fleischfarbenem Papier, 24 c) $1 / 2 \quad " \quad$ grün auf dünnem, lebhaft rosa Papier, 24 d) $1 / 2 \quad " \quad$ dunkelgrün auf dünnem, lebhaft rosa Papier.

25. $1 R^{\mathrm{L}}$ PLATA $\mathrm{F}$. blau in zwei Abstufungen auf lachsfarbenem Papier.

25 a) 1 RL PLATA F. blau auf lachsfarbenem Papier,

25 b) $1 \quad$ " blau auf gelblichrosa Papier,

25 c) 1 dunkelblau auf lachsfarbenem Papier.

26. $2 \mathrm{R}$ ? PLATA $\mathrm{F}$. zinnoberrot in zwei Abstufungen auf verschieden gefärbtem und verschieden starkem Papier.

26 a) 2 RS PLATA F. zinnoberrot auf dünnem, violett-rosa

26 b) 2

26 c) 2

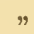

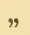
Papier,

lebhaft zinnoberrot auf dünnem, violettrosa Papier,

zinnoberrot auf dickem, blass - fleischfarbenem, fast weissem Papier.

B. Fïr die Stadtpost in Habana.

27. 1/4 R! PLATA F. schwarz auf dünnem chamois Papier. 
 \\ IV. Ausgabe: \\ von Jannar 1866 bis Januar 1867.}

Nämliche 'Zeichnung, nur veränderte Wertangabe und Beiflïgung der Jahreszahl.

Farbiger Druck auf weissem Papier; ungezähnt. (Taf. I, 27.)

\section{A. Fïr Cuba und Portorico.}

28. $10 \mathrm{C} \frac{\mathrm{MOS}}{\mathrm{b}}$ blau in zwei Abstufungen.

28 a) 10 CMos blau,

28 b) $10 \ldots$ dunkelblau.

29. $20 \mathrm{C}^{M 0 S}$ grün in zwei Abstufungen.

29 a) 20 CMos grün,

29 b) 20 " dunkelgrün.

30. $4^{\circ} \mathrm{C}^{110}$ rosa in zwei Abstufungen.

30 a) 40 CMos rosa,

30 b) 40, blassrosa.

\section{B. Fiir die Stadtpost in Habana.}

31. 5 CHos lila.

Von Herbst 1866 an: 1/4 R,-Marke der III. A nsgabe mit schwarzem Aufdruck von 66. (Taf. I, 28.)

32. $1 / 4$ R!, PLATA F. schwarz auf chamois Papier.

Dieselbe Marke mit Aufdruck von "1866" in kleineren und mageren Ziffern.

33. $1 / 4 R_{1}^{L}$ PLATA F. schwarz auf chamois Papier.

\section{Bemerkungen.}

1. Die Marken dieser, wie auch der folgenden Ausgabe sind auffallend schlecht gedruckt, so dass vielfach Teile der Zeichnung, namentlich aber der Jahreszahl fehlen.

2. Die dem Stadtverkehr von Habana dienende Marke zu 5 CMos war im Herbst 1866 aufgebraucht; man uberdruckte daher die Restbestände der 1/4 R-Marke der vorhergehenden Ausgabe mit der Jahreszahl 66. Der Aufdruck wurde mehrfach gefälscht.

Da die Marke wenig mehr als 3 Monate in Gebrauch war, ist sie postalisch entwertet sehr selten. Die Restbestände gelangten später in die Hände der Händler. 
Der Aufdruck "1866" in schmaleren Ziffern war wohl ursprünglich Essai, der nur durch Zufall in einigen Exemplaren zur postalischen Verwendung kam. Es gibt auch Exemplare mit doppeltem Aufdruck von 1866 und 66 dartiber oder darunter. Diese Aufdrucke gehören zu den grössten Raritäten.

\section{Ausgabe:}

vom Januar 1867 bis Januar 1868.

Zeichnung der vorhergehenden Ausgabe, nur Aenderung der Jahreszahl.

Farbiger Druck auf weissem Papier; gezähnt 14. (Taf. 1, 27.)

\section{A. Für Cuba und Portorico.}

34. 10 CMOS blau in zwei Abstufungen.

34 a) 10 CMOS blau,

34 b) $10 \%$ dunkelblau.

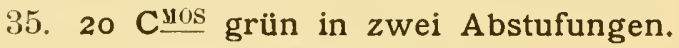

35 a) 20 CMOS grün,

35 b) $20 \%$ dunkelgrün.

36. $40 \mathrm{C} \stackrel{\mathrm{M} O \mathrm{~S}}{\mathrm{r}}$ rosa in zwei Abstufungen.

36 a) 40 CMOS rosa,

36 b) $40 "$ blassrosa.

\section{B. Für die Stadtpost in Habana.}

37. 5 CMOS lila in zwei Abstufungen.

37 a) 5 CMos lila,

37 b) 5 CMOS blasslila.

\section{Bemerkungen.}

1. Die Marken zu 5, 10 und 20 CMOS giebt es auch ungezähnt.

2. Neben den in Ausgabe I erwähnten Datumstempeltypen tauchte im Jahre 1867 (?) bei verschiedenen Postanstalten ein neues Modell auf, welches jedoch nur kurze Zeit in Gebrauch gewesen zu sein scheint. (Taf. II, 30.) 


\section{Ausgabe: \\ vom Januar 1868 bis Januar 1869.}

Kopf der Königin mit Krone nach links in einem Kreise, dessen Untergrund mit wagerechten Linien ausgefïllt ist; über und unter dem Kreise zwei viereckige Rahmen mit Inschriften in weissen Buchstaben auf farbigem Grund und zwar oben: ULTRAMAR, unten Wertangabe und Jahreszahl; in den Ecken je ein Buchstabe C, O, R und R (correos); zwischen Kreis und Rahmen Verzierungen in weiss auf farbigem Grund.

Farbiger Druck anf weissem Papier; gezähnt 14. (Taf. I, 29.)

\section{A. Fuir Cuba und Portorico.}

38. so CENT. blau in drei Abstufungen.

38 a) 10 CENT. blau,

38 b) $10 \quad$, blassblau,

38 c) $10 \%$ dunkelblau.

39. 20 CENT. grün in drei Abstufungen.

39 a) 20 CENT. grün,

39 b) $20, \quad$ blassgrün,

39 c) $20, \quad$ dunkelgrün.

40. 40 CENT. rosa in zwei Abstufungen.

40 a) CENT. rosa,

$40 \mathrm{~b}) \quad, \quad$ karmin.

\section{B. Fiir die Stadtpost in Habana.}

41. 5 CENT. lila in zwei Abstufungen.

41 a) 5 CENT. lila,

41 b) 5 , blasslila.

B emerkung.

Die Marke zu 10 und 20 CENT. kommt halbirt postalisch gebraucht vor.

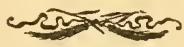




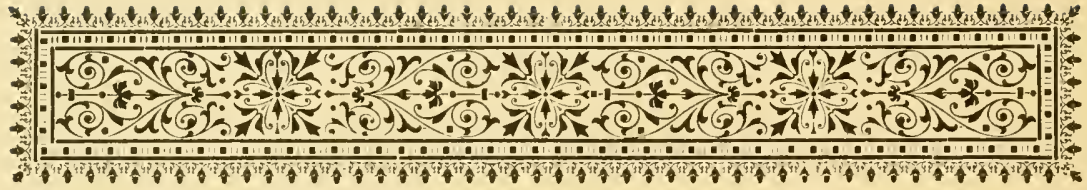

\section{B. Marken der Provisorischen Regierung.}

VII. Ausgabe:

vom Dezember 1868 bis Januar 1869.

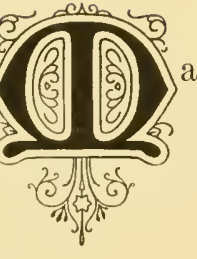

rken der vorigen Ansgabe mit schwarzem Aufdruck: Habilitado por la nacion im Typus von Vizcaya (vergl. Teil I, Seite 51).

A. Fiir Cuba und Portorico.

42. 10 CENT, blau in drei Abstufungen. 42 a) 10 CENT. blau,

42 b) 10 "blassblau,

$42 \mathrm{c)} 10 \%$ dunkelblau.

43. 20 CENT. grün in drei Abstufungen.

43 a) 20 (EN'T. griunn,

43 b) $20 \quad$ "blassgriün,

43 c) $20, \quad$ dunkelgrün.

44. 40 CENT. rosa in zwei Abstufungen.

44 a) 40 CENT. rosa,

44 b) $40, \quad$ karminrosa. 


\section{B. Fiir die Stadtpost in Habana. \\ 45. 5 CENT. lila in zwei Abstufungen. \\ 45 a) 5 CENT. lila, \\ 45 b) 5 " blasslila.}

Bemerkungen.

1. Fast gleichzeitig mit der Revolution in Spanien, brach auf Portorico die sogenannte Bewegung von Lares aus, ein Aufstand, der sich scheinbar gegen die neuen Steuern, in $\mathrm{W}$ ahrheit aber gegen den Verband mit Spanien richtete, jedoch so schwach war, dass er im Laufe einer Woche mit wenigen Soldaten unterdrïckt werden konnte. Einige Tage später erhob sich in Yara auf Cuba eine Anzahl von Eingeborenen, die zwar anfänglich auch die neuen Stenern zum Vorwand nahmen, nach der Nachricht von der SeptemberRevolution in Madrid aber ganz offen die Trenuung von Spanien zum Wahlspruch machten. Der Aufstand bildete den Anfang eines Bürgerkrieges, der, genährt durch amerikanisches Geld, bis zım Jahre 1878 dauerte.

Unter diesen Verhältnissen konnte der Befehl der Provisorischen Regierung in Madrid vom 26. October 1868, alle Postwertzeichen, Stempelmarken u. drgl. mit dem Aufdruck: "Habilitado por la nacion" zu verseben, anfänglich nur wenig Beachtung finden. Die gegen Ende Novemher erst ankommenden Stempel, - vierunddreissig für Cuba, dreizehn für Portorico, - wurden zwar an die Bureaus der Rentas Estancadas vertheilt, im Jahre 1863 aber in Portorico nur wenig, in Cuba fast gar nicht benutzt, umsoweniger, als der anf Cuba kommandirende Generalkapitän Lersundi durchans bourbonisch gesinnt war und sowohl an den öflentlichen Gebäuden, als auch in den amtlichen Urkunden, Titel und Abzeichen des gestürzten Herrscherhauses beibehielt. Dem Befehl der Provisorischen Regierung wurde erst Folge geleistet, nachden Lersundi seiner Stellung enthoben und im Dezember durch deu General Dulce ersetzt worden war.

Die Zahl der habilitirten Marken vom Jahre 1868 kann hiernach nur eine ganz unbedeutende sein.

Die von Madrid nach den Kolonien gesandten Handstempel gehören sämtlich dem Typus von Vizcaya an; abweichende Typen haben sich sämtlich als Fälschungen erwiesen.

2. Im Sommer 1868 tauchten in Habana falsche Marken zu 20 und 40 cent. auf. Die Unterschiede zwischen echten und falschen Stäcken waren so gering, dass erstere fast anstandslos von der Post angenommen wurden. 


\section{Ausgabe: \\ von Januar 1869 bis Januar 1870.}

Zeichnung der vorigen Ausgabe, nur Aenderung der Jahreszahl. Farbiger Druck auf weissem Papier; gezähnt 14.

I. Mit schwarzem Aufdruck: Habilitado por la nacion:

\section{A. Fiir Cuba und Portorico.}

46. 10 CENT braun in drei Schattirungen.

46 a) 10 CENT. gelbbraun,

46 b) 10, blassgelbbrann,

46 c) $10 \%$ chocoladenbraun.

47. 20 CENT. orange in zwei Schattirungen.

47 a) 20 CENT. orangegelb,

47 b) 20 , orangerot.

48. 40 CENT. lila in zwei Abstufungen.

48 a) 40 CENT. lila,

48 b) $40 \%$ dunkellila.

B. Fiir die Stadtpost in Habana

49. 5 CENT. rosa in drei Abstufungen.

49 a) 5 CENT. rosa,

49 b) $5 "$ blassrosa,

49 c) $5 "$ karmin.

II. Die nämlichen Marken ohne Aufdruck:

\section{A. Fiir Cuba mil Portorico.}

50. 10 CENT. braun in drei Schattirungen.

50 a) 10 CENT. gelbiraun,

50 b) $10 \%$ blassgelbbrann,

50 c) $10 "$ chocoladenbraun.

51. 2o CENT. orange in zwei Schattirungen.

51 a) 20 CENT. orangegelb,

$51 \mathrm{~b}) 20$ orangerot.

52. 40 CENT. lila in zwei Abstufungen.

52 a) 40 CENT. lila,

52 b) $40 "$ dunkellila. 


\author{
B. Fïr die Stadtpost in Hahana. \\ 535 CENT. rosa in drei Abstufungen. \\ 53 a) 5 CENT. rosa, \\ 53 b) 5 " blassrosa, \\ $53 \mathrm{c}) 5 \%$ karmin.
}

Bemerkungen.

1. Es erscheint wunderbar, dass noch im Jahre 1869 neue Marken mit dem Bilde der Königin Isabella ausgegeben wurden, nachdem dieselbe schon iiber drei Monate aufgehört hatte zu regieren. Die Erklärung hierfür liegt darin, dass die Ausgabe fur 1869 schon im Herbst 1868 fertig gestellt war und die politischen und finanziellen Verhältnisse Spaniens eine Neuanfertigung von Marken in so kurzer Zeit nicht erlaubte.

Was die Habilitirung der Marken anbelangt, so geschah dieselbe auch nach dem Eintreffen des neuen Generalkapitäns nur selten und schlief allnählich ein. Sicher ist, dass nach April 1869 weder in Cuba, noch in Portorico Marken mit einem Aufdruck versehen wurden.

2. Zwischen den Marken der VI. und VIII. Ausgabe bestehen trotz Gleichheit der Zeichnung einige kleine Unterschiede, auf welche hier aufmerksam gemacht werden soll, weil sie bei Fälschungen meist vergessen werden. Die Ausgabe 1868 hat nach dem Worte ULTRAMAR, wie auch nach der Jahreszahl 1868 je einen Punkt, welche bei der Ausgabe 1869 fehlen. Umgekehrt steht bei der Ausgabe 1869 vor dem Worte CENT. der Wertangabe ein senkrechter weisser Strich, welcher bei der Ausgabe 1868 nicht zu sehen ist.

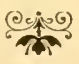

\author{
IX. Ausgabe: \\ vou Januar 1870 bis Januar 1871.
}

Zeichnmg der XX. Ausgabe Spaniens: Allegorische Figm der España (Franenkopf mit Manerkrone, darüber ein Stern) in einem ovalen Ralımen mit farbigen Untergrund; über und unter dem Rahmen flatternde Bänder mit Inschrift und zwar oben: CORREOS, unten Wertangabe und Jahreszahl. Unter dem Halsabschnitt die Initialen des Kupferstechers E. J. (Eugenio Julia). Farbiger Druck auf weissem Papier; gezähnt 14. (Taf. I, 31.) 


\section{A. Fiur Cuba und Portorico.}

54. $10 \mathrm{C}-$ grün in zwei Abstufungen.

54 a) $10 \quad C \underline{S}$ grün,

$54 \mathrm{bj} 10 \mathrm{C}$ s dunkelgriłn.

55. $20 \mathrm{C}-$ braun in zwei Abstufungen.

55 a) $20 \mathrm{CS}$ gelbbrain,

55 b) $20 \mathrm{C} \underline{\mathrm{S}}$ blassgelbbraun.

56. $40 \mathrm{C}-$ rosa in zwei Abstufungen.

56 a) $40 \mathrm{CS}$ rosa,

56 b) $40 \mathrm{C}-\mathrm{S}$ lebhaft rosa (karmin).

B. Fiir die Stadtpost in Habana.

57. $5 \mathrm{C}-$ blau in zwei Schattirungen.

57 a) 5 CS blau,

57 b) $5 \mathrm{C}-$ indigoblau.

\section{Bemerkung.}

Die Marken zu 10 und $20 \mathrm{CS}$ kommen halbirt postalisch gebraucht vor. Ein kundschreiben der General-Post-Direktion vom 5. Mai 1870 verbietet zwar für die Zukunft den Gebrauch halbirter Marken, ohne dass dieselben jedoch in den nächsten Jahren seltener werden Die Ursache ist darin zu suchen, dass bei den entlegeneren Post-Aemtern häufig der eine oder der andere Wert aufgebraucht war, ohne dass man sich bemuht hatte, rechtzeitig für Ersatz zu sorgen.

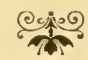

\section{Ausgabe:}

von Januar 1871 bis gegen Ende 1872.

Allegorische Figur der Españ, dargestellt als sitzende Framengestalt nach links gedreht, in der rechten Hand einen Oelzweig, den linken Ar'm anf ein Schild mit dem Wappen Spaniens gestïtzt: Untergrund durch wagerechte Striche ansgefuillt; oben anf einem Band: ULTRAMAR 1871, unten in rechteckigem Rahmen Wert- 
angabe in Céntimos de peseta, zu beiden Seiten: CORREOS. In der rechten unteren Ecke die Initialen des Kupferstechers E. J. Farbiger Druck auf weissem Papier; gezähnt 14. (Taf. I, 32.)

\section{A. Fïr Cuba und Portorico.}

58. 25 C. DE PESETA blau in zwei Abstufungen.

58 a) 25 C. DE PESETA ultramarinblau,

58 b) $25 \quad$ " blassultramariublau.

59. 50 C. DE PESETA grün in drei Abstufungen.

59 a) 50 C. DE PESETA grlin,

59 a) 50 " blassgrün,

59 c) 50 dunkelgrün.

60. 1 PESETA braun in zwei Abstufungen.

60 a) 1 PESETA gelbbraun,

60 b) 1 blassgelbbraun.

\section{B. Fiir die Stadtpost in Habana.}

61. 12 C. DE PESETA lila in drei Schattirungen.

$\begin{array}{llll}61 \text { a) } & 12 & \text { C. DE } & \text { PESETA } \\ 61 \mathrm{~b}) & 12 & " & \text { graulila, } \\ 61 \mathrm{c}) & 12 & " & \text { lebshaft lila. }\end{array}$

Bemerkungen.

1. Die ganze Ausgabe existirt auch ungezähnt.

2. Im März 1871 auftauchende Fälschungen zeigen folgende Unterschiede:

a) Nase und Stirn der España bilden einen Winkel, anstatt einer geraden Linie;

b) die Ziffer 8 in 1881 ist in ihrem oberen Teil dicker, während sie bei den echten Marken uberall die gleiche Stärke besitzt;

c) zwischen Rahmen und Kopf befinden sich sechs, austatt fünf Linien;

d) der Punkt nach D der Wertangabe befindet sich in gleicher Höhe mit demjenigen nach C, während er bei den echten Marken höher steht;

e) die Strahlen der Sterne in den unteren Ecken sind gleich lang, während bei den echten Marken die vier Eckstrahlen länger sind;

f) der Stab der España berührt die Randlinie, während er bei den echten in geringer Entfernung von derselben endigt.

3. Von Essais wurden folgende bekannt:

12 C. DE PESETA schwarz und grun auf weissem Karton und weissem Papier, blau auf weissem Papier, 
25 C. DE PESETA schwarz auf weissem, auch auf gelblichem, dickerem Karton, hellgrün, dunkelgrün, blau, lila, blassviolett, braunrot und fleischfarben auf weissem Karton,

50

1 PESETA grau, violett, braunrot und blau auf weissem Papier, blau auf weissem Karton, blau auf weissem Karton.

Mit der X. Ausgabe endigen die auf Cuba und Portorico gleichzeitig gehrauchten Marken. Allerdings tragen auch die nachfolgenden Ausgaben bis zum Jahre 1876 die gemeinsame Bezeichnung: Ultramar, da sie aber in Portorico ohne Aufdruck eines oder mehrerer Namenszüge nicht gebraucht werden durften, in Cuba aber umgekehrt mit Paraphe nicht $\mathrm{zu}$ verwenden waren, so erscheint es richtiger, die Marken beider Inseln schon vom Jahre 1873 an getrennt zu behandeln. 


\section{Spaniseh Westindien.}

\section{Ib. Cuba.}

2) 



\section{I.}

\section{Briefmarken.}

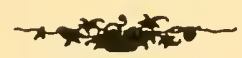





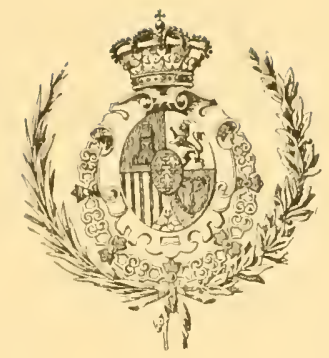

\section{A. Marken aus der Zeit der Regierung des Königs Amadeo.}

\section{Ausgabe:}

von Januar 1873 bis Januar 1874.

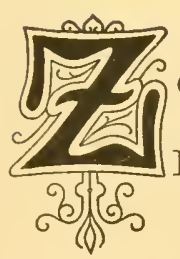

eichnung der XXI. Ausgabe(III) Spaniens in zwei Typen:

I. Type: Kopf des Königs Amadeo im Oval nach rechts; Untergrund ausgefüllt durch wagerechte Linien; über dem Oval in bogenförmigem Rahmen: ULTRAMAR 1873, unten in den Ecken im Viereck: Wertziffer, zwischen beiden C. DE PESETA: über dem unteren Rand des Rahmens: E. Julia.

Farbiger Druck auf weissem Papier; gezähnt 14. (Taf. I, 34.)

1. $12 \frac{1}{2}$ C. DE PESETA grün.

2. 25 C. DE PESETA lila in drei Schattirungen.
2 a) 25 C. DE PESETA lila,
2 b) 25
2 c) 25
graulila, blaulila.

3. 5o C. DE PESETA braun in zwei Abstufungen.
$\begin{array}{ll}3 \text { a) } & 50 \\ 3 \text { b) } & 50\end{array}$
braun,
hellbraun. 
II. Type: Oberer Teil der Marke wie bei Type I, unten statt der Wertziffern im Viereck pp. ein bogenförmiger Rahmen mit der Inschrift: UNA PESETA.

Farbiger Druck auf weissem Papier; gezähnt 14. (Taf. I, 35.)

\section{UNA PESETA rötlichbraun.}

\section{Bemerkungen.}

1. Die Marken zu 25 und 50 c. de peseta kommen auch ungezähnt vor.

2. Die Marke zu 1 Peseta kommt halbirt postalisch entwertet vor.

3. Eine Marke zu 12 CENTS DF PESETA war zur Ausgabe fertig gestellt, kam jedoch wegen Aenderung der Portotarife nicht zur Verwendung. Das sehr schön ausgeführte Markenbild (Taf. I, 33) zeigt den Kopf des Königs in ovalem, weissem Rahmen zu 3/4 nach links; in den vier Ecken Kreise mit dem Buchstaben $\mathrm{C}$ (correos), unten auf rechteckigem Schild Wertangabe in weissen Buchstaben auf dunklem Untergrund; gezähnt 14 oder auch ungezähnt. Die Marke war in schwarz geplant, os giebt jedoch Essais in abweichenden Farben und zwar:

in braun violett, tiefviolett, schwarz, blau und milchblau auf weissem Karton,

in braun und zinnoberrot auf weissem Papier, gezähnt,

in braun, karmin, zinnoberrot und grün auf weissem Papier, ungezähnt.

Von Essais in der angenommenen Type kennt man:

12 c. d. p. grün und blau, $12 \frac{1}{2}$ c. grän, 25 c. grün, braun und und rotbraun, $50 \mathrm{c}$. blau, Una peseta grün und blau.

Von Essais in nicht angenommener Zeichnung sind zwei bekannt:

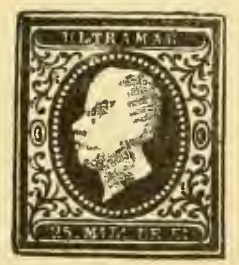

Kopf des Königs in Hochrelief nach links in einem Perlenoval auf farbigem Untergrund; über dem Oval ein länglicher, an den Ecken abgerundeter Schild mit der Inschrift: ULTRAMAR, unten ein ebensolcher mit der Wertangabe; zwischen beiden arabeskenartige Verzierungen. Man kennt:

25 MILS DE Eo schwarz auf rosa,

50 schwarz auf blau,

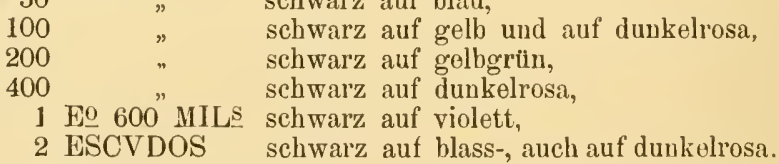

Kopf des Königs in Type II der XIII. Ausgabe Philippinen (Taf. VI,), nur im unteren Schild ULTRAMAR an Stelle von FILIPINAS. Existirt nur für den Wert UNA PESETA in karminroter Farbe; ungeziant.

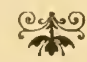




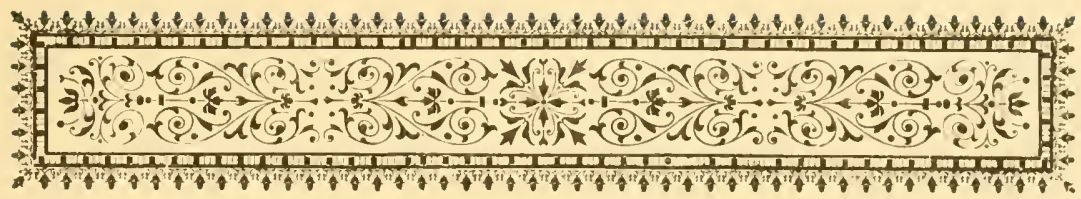

\title{
B. Marken der Republik.
}

\author{
II. Ausgabe: \\ vom Januar 1874 bis Januar 1875.
}

eichnung der X. Ansgabe von Cuba und Portorico, nur Aenderung der Jahreszahl.

Farbiger Druck auf weissem Papier; gezähnt 14. (Taf. I, 3\%.)

5. $12 \frac{1}{2}$ C. D. PESETA braun in zwei Abstufungen.

5 a) $12 \frac{1}{2}$ C. D. PESETA braun,

5 b) $12 \frac{1}{2} \quad, \quad$ dunkelbraun.

6. 25 C. D. PESETA blau in zwei Abstufungen.

6 a) 25 C. D. PESETA ultramarinblau,

6 b) $25 \quad n$ dunkelultramarinblau.

7. 50 C. D. PESETA violett in vier Schattirungen.

7 a) 50 C. D. PESETA lebhaft violett,

7 b) $50 \quad " \quad$ blassviolett,

7 c) $50 \quad$ grantiolett,

7 d) $50 \quad, \quad$ stahlblau.

8. 1 PESETA karmin in zwei Abstufungen.

8 a) 1 PESETA karmin,

8 b) 1 karminrosa. 


\section{Bemerkungen.}

1. Die Marke zu 1 Peseta kommt auch ungezähnt vor.

2. Im Jahre 1875, also während des auf Cuba noch immer tobenden Bürger-

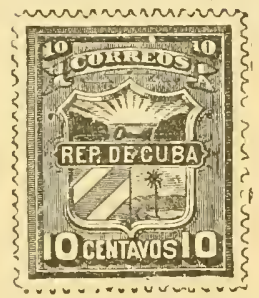
krieges, tauchten bei verschiedenen Händlern Marken mit der Aufschrift: República de Cuba auf. Man behauptete, dieselben würden im inneren Verkehr des aufständischen Gebietes benutzt, etwa wie die carlistischen Marken im nördlichen und nordöstlichen Teile von Spanien. Die Marken waren von vorzüglicher Ausführung. Sie zeigten in der Mitte ein Wappenschild, welches durch eine Querleiste mit der Inschrift: REP. DE CUBA in drei Felder geteilt wurde. Das oberste Feld zeigt eine aufgehende Sonne, welche ihre Strahlen über einen im Vordergrund durch zwei Inseln verengten Meeresteil entsendet; das Fahrwasser zwischen den Inseln ist durch einen Schlüssel gesperrt. Von den beiden unteren Feldern zeigt das linke drei silberne Schrägbalken im blauen Feld (heraldisch angedeutet), das rechte eine am Meeresufer stehende hochragende Palme. Oberhalb des Wappenschildes befindet sich auf flatterndem Band die Inschrift: CORREOS, unten, sowie in den oberen Ecken die Wertangabe 10 CENTAVOS(!). Die Marke war grün auf weissem Papier und gezähnt; ob es noch andere Werte gab, ist unbekannt.

Längere Zeit für echt gehalten und verhältnismässig teuer bezahlt, erwies sich die Marke später als das Erzeugnis eines New-Yorker SchwindlerConsortiums.

\section{encinge \\ III. Ausgabe: \\ von Januar 1875 bis Januar 1876.}

Zeichnung der XXV. Ausgabe Spaniens: Wappen Spaniens, umgeben von Lorbeerzweigen, darüber Mauerkrone; oben und unten in länglichem, an den Ecken abgerundetem Schild: ULTRAMAR 1875 bezw. Wertangabe; Untergrund mit wagerechten Strichen ausgefüllt.

Farbiger Druck auf weissem Papier; gezähnt 14. (Taf. I, 36.)

9. $12 \frac{1}{2}$ CENTS PESETA violett in drei Schattirungen.

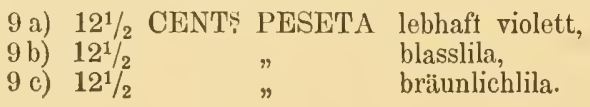


10. 25 CENT PESETA blau in zwei Schattirungen. 10 a) 25 CENTS PESETA ultramarinblau, 10 b) $25 \quad$ dunkelblau.

11. 5o CENTS PESETA grün in zwei Abstufungen. 11 a) 50 CENTS PESETA grün, $11 \mathrm{~b}) 50 \quad, \quad$ dunkelgrün.

12. UNA PESETA braun in zwei Schattirungen.

12 a) UNA PESETA gelblichbram,

12 b) UNA " braun.

Bemerkungen.

1. Die Marken zu $12 \frac{1}{2}, 25$ und 50 Cents gibt es auch ungezähnt.

2. Die Marken zu 25 und 50 Cents kommen halbirt postalisch entwertet vor. 


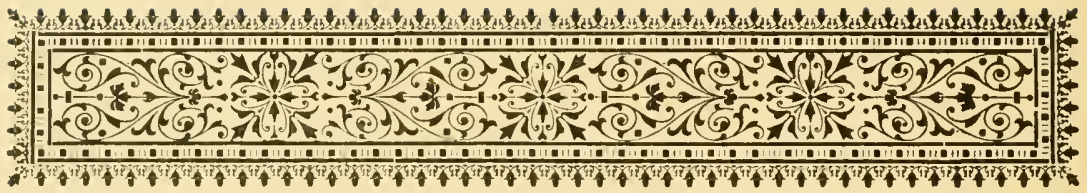

\title{
C. Marken aus der Zeit der Regierung des Königs Alfonso XII.
}

\author{
IV. Ausgabe: \\ vom 1. Januar 1876 bis 1 . Januar 1877.
}

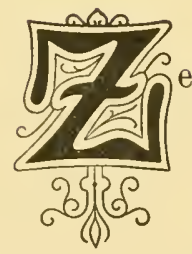

eichnung der XXVI. Ausgabe Spaniens mit kleinen Veränderungen: Kopf des Königs Alfonso XII in ovalem Rahmen nach rechts, Untergrund mit wagerechten Strichen ausgefüllt; um das Oval ein rechteckiger Rahmen, darin oben: ULTRAMAR. 1876, rechts und links: CORREOS in ovalem Schild und griechischer Borde, unten Wertangabe; in den vier Ecken die Wappen von Leon und Castilien, zwischen Oval und Rahmen die bourbonischen Lilien; auf dem Halsabschnitt die Initialen des Kupferstechers J. G. Farbiger Druck auf weissem Papier; gezähnt 14. (Taf. I, 37.)

13. $12^{1} \frac{1}{2}$ CS PESETA hellgrün.

14. 25 C PESETA lila in vier Schattirungen.

14 a) $25 \mathrm{C}:$ PESETA blasslila,

14b) $25 \quad n \quad$ rotlila,

14 c) 25 " bläulichlila,

14 d) $25 \quad$ blaugrau. 


\section{50 CS PESETA blau in zwei Schattirungen. \\ 15 a) 50 CS PESETA ultramarinblau, 15 b) 50 hellblau.}

\section{1 PESETA mehr oder weniger intensiv schwarz. 16 a) 1 PESETA schwarz, 16 b) 1 grauschwarz.}

\section{Bemerkungen.}

1. Die Marken zu 25 und $50 \mathrm{CS}$ kommen halbirt postalisch gebraucht vor.

2. Die Marken zu $50 \mathrm{CS}$ und 1 PESETA existiren auch ungezähnt.

3. Von Essais sind die Werte 25 und $50 \mathrm{Cs}$, sowie derjenige zu 1 Peseta in schwarzer und rotbrauner Farbe auf grünen Papier bekannt.

4. Während bis zum Jahre 1876 die in Ausgabe I von Cuba und Portorico erwähnten Stempelmodelle in Gebrauch blieben, beginnt mit dem Jahre 1876 sich allmählich ein Wechsel bei den meisten Postanstalten zu vollziehen, indem die auch in Spanien seit dem Jahre $\mathbf{1 8 7 4}$ gebrauchten modernen Formen eingeführt worden. Von einer Gleichmässigkeit ist jedoch keine Rede und finden wir auf den Marken eines und desselben Jahres Stempel, welche zwar im Allgemeinen dem spanischen Modell 1874 ähneln, im Detail aber doch grosse Verschiedenheit zeigeu. Ein den Colonien eigentümlicher, heute noch viel gebrauchter Datumstempel ist Tafel II, 38 abgebildet: Grosses Oval, oben Correos, unten Ort, in der Mitte Datum, gewöhnlich in karminroter Farbe.

In gleicher Weise tauchen auch vom Jahre 1876 an vielfach neue Entwertungsstempel auf, von denen die am häufigsten vorkommenden Typen auf Tafel II, 39-43 abgebildet sind. Bei dem Mangel an amtlichem Aktenmaterial und bei der Seltenheit Cubanischer Marken auf ganzem Brief ist eine Angabe des Einfithrungsdatums ebenso unmöglich, wie eine Bezeichnung der Postanstalten, wo sie gebraucht wurden.

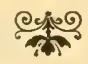

\section{Ausgabe:}

vom 1. Januar 1877 bis Januar 1878.

Nämliche Zeichnung, nur oben CUBA, anstatt ULTRAMAR und veränderte Jahreszahl.

Farbiger Druck auf weissem Papier; gezähnt 14. 
17. 10 CS PESETA grün in zwei Abstufungen.

17 a) 10 CS PESETA grün,

17 b) $10 \quad "$ hellgriun.

18. $12 \frac{1}{2}$ CS PESETA lila in drei Schattirungen.

18 a) $12 \frac{1}{2}$ CS PESETA lila,

$18 \mathrm{b)} 12 \frac{1}{2} \quad "$ blasslila,

18 c) $12 \frac{1}{2} \quad " \quad$ grauviolett.

19. 25 CS PESETA dunkelgrün in zwei Schattirungen.

19 a) 25 CS PESETA dunkelgrüu,

19 b) $25 \quad$ dunkelblaugrtin.

20. 50 CS PESETA mehr oder weniger intensiv schwarz. 20 a) 20 CS PESETA schwarz,

20 b) $20 \quad$ grauschwarz.

21. 1 PESETA braun in zwei Schattirungen.

21 a) 1 PESETA gelblichbraun,

21 b) 1 braun.

Bemerkung.

1, Die Werte zu $12^{1} / 2,25$ und $50 \mathrm{CS}$ existiren auch ungezähnt.

2. Von Essais ist nur die Marke zu $50 \mathrm{CS}$ in blau (gezähnt) bekannt.

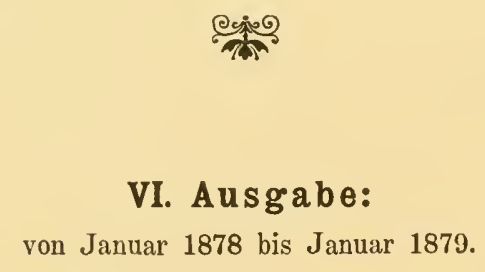

Nämliche Zeichnung, nur veränderte Jahreszahl.

Farbiger Druck auf weissem Papier; gezälnt 14.

22. 5 CS PESETA blau.

23. 10 CS PESETA tiefschwarz.

24. $12 \frac{1}{2}$ C PESETA gelblichbraun in zwei Schattirungen.

24 a) $12 \frac{1}{2}$ CS PESETA gelblichbraun,

24 b) $12 \frac{1}{2}, \quad, \quad$ bräunlichgelb. 
25. $25 \mathrm{C}$. PESETA grün in drei Schattirungen. 25 a) 25 CS PESETA grün,

25 b) $25 \quad$ blassgrin,

25 c) $25 \quad$ gelbgrün.

26. 5o CS PESETA dunkelgrün.

27. 1 PESETA karmin.

\title{
Bemerkung.
}

Sämtliche Werte kommen auch ungezähnt ror.

\author{
VII. Ausgabe: \\ von Januar 1879 bis Januar 1880.
}

Nämliche Zeichnung, nur Veränderung der Jahreszahl.

Farbiger Druck auf weissem Papier; gezähnt 14.

28. 5 CS PESETA grünschwarz.

29. 10 CS PESETA braunorange in zwei Schattirungen. 29 a) 10 CS PESE'TA braunorange, $29 \mathrm{b)} 10 \quad$ " gelborange.

30. $12 \frac{1}{2}$ CS. PESETA rosa in zwei Abstufungen. 30 a) $12^{1} / 2$ CS PESETA karminrosa, 30 b) $12 \frac{1}{2} \quad "$ blassrosa.

31. 25 CS PESETA ultramarinblau in zwei Abstufungen. 31 a) 25 CS PESETA ultramarinblau, 31 b) $25 \quad "$ dunkelultramarinblau.

32. 5o CS PESETA graulila.

33. 1 PESETA olivenbraun. 


\section{Ausgabe: \\ vom Januar 1880 bis Januar 1881.}

Zeichnung der XXIX. Ausgabe Spaniens: Kopf des Königs Alfonso XII. nach rechts in ovalem Rahmen; iiber und unter dem Oval je ein rechteckiger Schild mit Inschriften und zwar oben: CUBA 1880 zwischen zwei Sternen, unten Wertangabe; in den Ecken zwischen Oval und Schild ornamentale Verzierungen; der Untergrund der ganzen Marke ist mit wagerechten Strichen ausgefüllt; auf dem Halsabschnitt der Name des Kupferstechers Julia.

Farbiger Druck auf weissem Papier; gezälnt 14. (Taf. I, 45.)

34. 5 CENT. PESETA blassgrün.

35. 10 CENT. PESETA karminrosa.

36. $12 \frac{1}{2} 2$ CENT. PESETA grau.

37. 25 CENT. PESETA blassultramarinblau.

38. 50 CENT. PESETA braun in zwei Abstufungen. 38 a) 50 CENT. PESETA braun, 38 b) 50 dunkelbraun.

39. UNA PESETA rotbraun.

\section{Bemerkungen.}

1. Die für das Jahr 1880 geschaffene Markenzeichnung ist - von Kleinigkeiten abgesehen - für alle Colonien gleich; sie bleibt, oberflächlich betrachtet und die Inschriften ausser Acht gelassen, bis zum Jahre 1889, also 9 Jahre lang, unverändert. Betrachten wir jedoch die im Laufe dieser 9 Jahre ausgegebenen Marken genauer, so erkennen wir bei den am meisten gebrauchten Werten mit Leichtigkeit drei verschiedene Typen, die sich nicht unwesentlich von einander unterscheiden. Diese Unterschiede, welche von der grossen Masse der Sammler wenig beachtet werden, bestehen hauptsïchlich in der /eichnung der Haare des Königs und in derjenigen des ovalen Rahmens um den Kopt Alfonso's. Die Ausgabe des Jahres 1880, welche wir als Type I bezeichnen wollen, hat die Haare tiber den Schläfen in einem spitzen Winkel schart eingebogen und unterhalb dieses fast in einen Punkt endigenden Winkels nach rechts bogenförmig herabfallend. Der ovale Rahnien, der den Kopf des Königs einschliesst, wird durch zwei Linieu gebildet. deren Stärke überall die gleiche 
ist. (Ueber Type II vergl. X. Ausgabe C, ther Type IJI XI. Ausgabe C. Auf Tafel 1. 45. 46 und 47 sind die 3 Typen nebeneinauder gestellt.)

2. Die llatke zu 25 CENT. PVSLTA konmt mehtinch infolge beschädigung der Platte uit muvollstindjeren llouck des luschriften ror und zwar: ohne den linken bekstern. CTBPA whe (', CUBA ohne CU, CUbA mit mangelhatten B, sowie mit unvollstindigen Zahlen bei der Wertangibe.

3. Eine vielfach erwähnte Marke zn 15 cent. peseta in roter F'arbe sclıeint Essai zu sein, da sie gebraucht nicht bekannt ist.

4. Ton sämtlichen Marken der VIIl. Ausgabe grebt es Essais in abweichenden Farben auf weissem Karton und zwar:

5 Cent. Peseta dunkelkarmin (dieses Essai auch auf' gelblichem Karton), 10 C. de Peseta violett, $121 / 2$ C. de P. blau, 15 C. de P. violett, 25 Cent. Peseta braun, 50 C. de P. griin, UNA Peseta dunkelkarmin. Von dem Werte 25 Cent. Peseta giebt es anch ein Essai in dunkelkarmin mit dem Unterdruck der 25 C. d. P. blall von Spanien, gezähnt 14 .

5. Im Jahre 1880 erhielten die Post-Anstalten Cuba's - ob sämtlich oder nur bestimmte Kategorien ist unsicher - Entwertungsstempel mit der im Jahre 1854 gegebenen Nummer (Taf. II, 44). Der Stempel ist dem spanischen auf Taf. $\mathrm{V}, 50$ ähnlich. Auch ein nener Certificado-Stempel taucht bei mehreren Post-Anstalten anf: Grosses Rechteck, dessen lange Seiten leicht rollenartig gekrünıt sind, in drei Zeilen untereinander: YSLA DE CUBA. Name der Postanstalt, Nummer': rechts daron ein grosses R, links: CERTIFICADO.

In Bezug auf Datumstempel finden mehrere moderne spanische Stempelmodelle Einführung.

\section{Ausgabe:}

vom 1. Januar 1881 bis 1. Januar 1882.

Nämliche Zeichumg, nur Aenderung der Jahreszahl und Ausdruck des Wertes in Céntimos de peso.

Farbiger Druck auf weissem Papier: gezähnt 14.

\section{UN C. DE PESO blassgrün.}

\section{2-C. DE PESO karminrosa.}

$122^{\prime}, \mathrm{C}$. DE PESO nlivenhraun.

1:1. 5-C. DE PESO blassultramarinblaı. 
44. $10 \mathrm{C}$. DE PESO rotbraun in zwei Abstufungen. 44 a) 10 C. DE PESO rötlichbraun, 44 b) $10 \quad$ dunkelrotbraun.

45. 20 C. DE PESO schwarzbraun.

Bemerkungen.

1. Die Marken zu 5 und $10 \mathrm{C}$. de Peso kommen halbirt postalisch entwertet vor.

2. Von sämtlichen Werten giebt es Essais in abweichenden Farben auf weissem oder gelblichweissem Kartonpapier und zwar:

UN C. de Peso dunkelkarmin, 2 C. de P. grün, 21/2 C. de P. blau, 5 C. de P. dunkelkarmin, 10 C. de P. hellblau, sämtlich auf weissem Karton, 3 C. de Peso und $20 \mathrm{C}$. de Peso perlgran auf gelblichweissem Karton. Ausserdem existirt der Wert 10 C. de Peso braun mit dem Unterdruck der 25 cent. de peseta blau von Spanien, gezähnt 14 .

\section{Ausgabe:}

von 1. Januar 1882 bis 1. Januar 1884.

Nämliche Zeichnmmg, nur Fortfall der Jahreszahl.

Farbiger Druck auf weissem Papier; gezähnt 41. (Tafel I, 46.)

A. Ohne Aufdruck: vom .Januar 1882 bis Juni 1883 und wieder von Ende September 1883 bis Januar 1884.

46. UN C. DE PESO blassgrün.

47. 2-C. DE PESO karminrosa.

48. $2^{1 / 2}$ C. DE PESO braun in $z$ wei Schattirungen.

48 a) $2 \frac{1}{2}$ C. DE PESO rotbraun,

48 b) $2 \frac{1}{2}, \quad$ braunoliven.

49. 5-C. DE PESO blassultramarinblau.

50. 10 C. DE PESO olivenbraun. 
51. 20 C. DE PESO braun in zwei Abstufungen.

51 a) 20 C. DE PESO braun.

51 b) $20 \quad$ dunkelbraun.

B. Mit farbigem Aufdruck eines Linien-Ornaments in fünf verschiedenen Ausführungen: von Juni bis Ende September 1883. (Tafel I, 48.)

I. Aufdruck-Type:

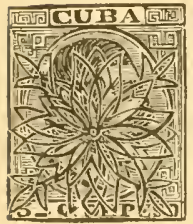

53. 10

54. 20

52. 5-C. DE PESO Aufdruck zinnoberrot oder karmin auf blassultramarin.

52 a) 5-C. DE PESO Aufdruck zinnoberrot auf blassultramarin, 52 b) 5 - C.

Aufdruck lebhaft karmin auf blassultramarin.

C. DE PESO Aufdruck blau auf olivenbraun.

C. DE PESO Aufdruck schwarz auf braun.

II. Aufdruck-Type:

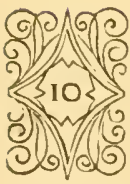

55. 5-C. DE PESO Aufdruck zinnoberrot oder karmin auf blassultramarin.

55 a) 5-C. DE PESO Aufdruek zinnoberrot auf blassultramarin,

55 b) 5-C. , Aufdruck lebhaft karmin auf blassultramarin.

56. 10 C. DE PESO Aufdruck blau auf olivenbraun.

57. 20 C. DE PESO Aufdruck schwarz auf braun.

III. Aufdruck-Type:

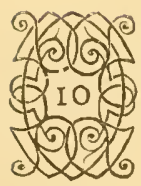

58. 5-C. DE PESO Aufdruck zinnoberrot oder karmin auf blassultramarin.

58 a) 5-C. DE PESO Aufdruck zinnoberrot auf blass58 b) $5-C$. ultramarin,

Anfdruck lebhaft karmin auf blassultramarin.

59. 10 C. DE PESO Aufdruck blau auf olivenbraun.

60. 20 C. DE PESO Aufdruck schwarz auf braun. 
IV. Aufdruck-Type:

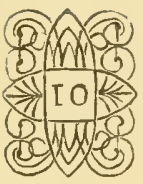

61. 5 C. DE PESO Aufdruck zinnoberrot oder karmin auf blassultramarin.

61 a) 5 C. DE PESO Aufdruck zimnoberrot auf hlassultramarin,

61 b) 5 C. DE PESO Aufdruck lebhaft karmin auf blassultramarin.

62. 10 C. DE PESO Aufdruck braun auf olivenbraun.

63. 20 C. DE PESO Aufdruck schwarz auf braun.

V. Aufdruck-Type:

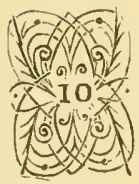

64. 5 C. DE PESO Aufdruck zinnoberrot oder karmin auf blassultramarin.

64 a) 5 C. DE PESO Autdruck zinnoherrot auf blassultramarin,

64 b) 5 C. , Aufdruck lebhatt ultramarin.

65. 10 C. DE PESO Aufdruck blau auf olivenbraun.

66. 20 C. DE PESO Aufdruck schwarz auf braun.

C. Vom Herbst 1883 bis Frühjahr 1886. Etwas veränderte Type(II): Das Haar des Königs ist über die Stirn etwas schärfer gebogen, der Winkel ïber den Schläfen ist grösser, endigt nicht in einen Punkt, sondern ist etwas alsgerundet, das Haar fällt infolgedessen in etwas gestreckterer Linie nach unten ab. Die äussere Linie des den Kopf des Königs umschliessenden ovalen Rahmens ist auf der rechten Seite stärker als auf der linken. (Tafel I, 46.)

67. 5 C. DE PESO ultramarinblau in zwei Abstufungen. 67 a) 5 C. DE PESO blassultramarinblau,

67 b) 5 C. " $\quad$ lebhaft ultramarinblau.

Bemerkungen.

1. 'Zu Ende Mai 1883 waren in Habana grosse Mengen Marken zu 5, 10 u. 20 C. de peso gestohlen und nach auswärts zum Verkauf angeboten worden. Um diese wertlos zu machen, liass dis: G. I'. D. die vorhandenen Pestiande, sowis alle dinjenigen Marken, welchs hei den grossen Handlungshäusern der Inswl noch 
unbenutzt zu finden waren, mit einem schwierig nachzuahmenden Aufdruck versehen. Der Aufdruck erhielt filnf verschiedene Typen, von denen die erste keinerlei Wertbezeichnnng führt, während die vier anderen die entsprechenden Wertziffern zeigen. Die verschiedenen Aufdrucktypen finden sich auf' den einzelnen Markenbogen derart verteilt vor, dass die erste Type am seltensten vorkommt; die Gruppirung der Typen war jedoch sehr verschieden und scheiut mebrfach gewechselt zu haben; es ist bis jetzt nicht gelungen, alle existirenden Zusammenstellungen mit Sicherleit anzugeben. bekannt:

Nach zuverlässig erscheinenden Quellen sind folgende Zusammenstellungen

a. für diø Marko zu 5 c. de peso:

133333333333

$\begin{array}{lllllllllll}1 & 3 & 3 & 3 & 3 & 3 & 3 & 3 & 3 & 3\end{array}$

$\begin{array}{llllllllll}1 & 3 & 3 & 3 & 3 & 2 & 2 & 2 & 2 & 2\end{array}$

$\begin{array}{llllllllll}1 & 2 & 2 & 2 & 2 & 2 & 2 & 2 & 2 & 2\end{array}$

1222222224

1444444444

1444444444

1444555555

$\begin{array}{llllllllll}1 & 5 & 5 & 5 & 5 & 5 & 5 & 5 & 5 & 1\end{array}$

15555555551 $\begin{array}{llllllllll}1 & 3 & 3 & 3 & 3 & 3 & 3 & 3 & 3 & 3\end{array}$

$\begin{array}{llllllllll}1 & 3 & 3 & 3 & 3 & 3 & 3 & 3 & 3 & 3\end{array}$

$\begin{array}{lllllllll}1 & 3 & 3 & 3 & 3 & 2 & 2 & 2 & 2\end{array}$

$\begin{array}{llllll}12 & 22 & 2 & 2 & 2 & 2\end{array}$

1222222224

$144+444+44$

1444444444

1544455555

$\begin{array}{llllllllll}1 & 5 & 5 & 5 & 5 & 5 & 5 & 5 & 5 & 1\end{array}$

155555555551 $\begin{array}{llllllllll}5 & 3 & 3 & 3 & 3 & 3 & 3 & 3 & 3 & 3\end{array}$ $\begin{array}{llllllllll}5 & 3 & 3 & 3 & 3 & 3 & 3 & 3 & 3 & 3\end{array}$ $\begin{array}{llllllllll}5 & 3 & 3 & 3 & 3 & 3 & 2 & 2 & 2 & 2\end{array}$ 52222222222 5222222224 5444444444 5444444444 5444555555 555555555555 5555555555

\section{$\begin{array}{llllllllll}3 & 3 & 3 & 3 & 3 & 3 & 3 & 3 & 3 & 3\end{array}$ \\ $\begin{array}{llllllllll}3 & 3 & 3 & 3 & 3 & 3 & 3 & 3 & 3 & 3\end{array}$ \\ $\begin{array}{lllllllllll}3 & 3 & 3 & 3 & 3 & 3 & 3 & 3 & 3 & 3\end{array}$ \\ $\begin{array}{lllllllll}2 & 2 & 2 & 2 & 2 & 2 & 2 & 2 & 2\end{array}$ \\ 2222222222 \\ $\begin{array}{llllllllll}3 & 2 & 2 & 2 & 2 & 2 & 2 & 2 & 2 & 2\end{array}$ \\ 4444444444 \\ 44444444444 \\ 4444444444 \\ 55555555555}

2222222222

$22 \div 2222222$

2222222222

$\begin{array}{llllllllll}3 & 3 & 3 & 3 & 3 & 3 & 3 & 3 & 3 & 3\end{array}$

$\begin{array}{llllllllll}3 & 3 & 3 & 3 & 3 & 3 & 3 & 3 & 3 & 3\end{array}$

$\begin{array}{llllllllll}2 & 3 & 3 & 3 & 3 & 3 & 3 & 3 & 3 & 3\end{array}$

4444444444

$\begin{array}{llllllllll}4 & 4 & 4 & 4 & 4 & 4 & 4 & 4 & 4 & 4\end{array}$

44444444444

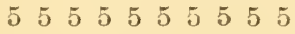

b. für die Marke zu 10 c. de peso:

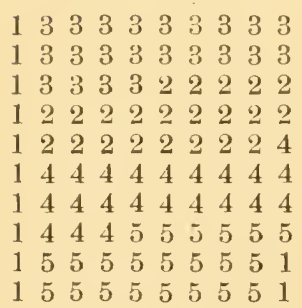

1222222222 $\begin{array}{lllllllll}1 & 2 & 2 & 2 & 2 & 2 & 2 & 2 & 2\end{array}$

$\begin{array}{llllllllll}1 & 2 & 2 & 2 & 2 & 3 & 3 & 3 & 3 & 3\end{array}$

$\begin{array}{llllllllll}1 & 3 & 3 & 3 & 3 & 3 & 3 & 3 & 3 & 3\end{array}$

$\begin{array}{llllllllll}1 & 3 & 3 & 3 & 3 & 3 & 3 & 3 & 3 & 4\end{array}$

1444444444

1444444444

1444444444

$\begin{array}{llllllllll}144 & 4 & 5 & 5 & 5 & 5 & 5 & 1\end{array}$

$\begin{array}{llllllllll}1 & 5 & 5 & 5 & 5 & 5 & 5 & 5 & 5 & 1\end{array}$

1222222222

$\begin{array}{llllllll}12 & 2 & 2 & 2 & 2 & 2 & 2\end{array}$

$\begin{array}{lllllllll}1 & 2 & 2 & 2 & 2 & 3 & 3 & 3 & 3\end{array}$

$\begin{array}{llllllllll}1 & 3 & 3 & 3 & 3 & 3 & 3 & 3 & 3 & 3\end{array}$

$\begin{array}{llllllllll}1 & 3 & 3 & 3 & 3 & 3 & 3 & 3 & 3 & 4\end{array}$

1444444444

1444444444

15444455555

$\begin{array}{llllllllll}1 & 5 & 5 & 5 & 5 & 5 & 5 & 5 & 5 & 1\end{array}$

15555555551
1222222222 $\begin{array}{llllllllll}1 & 2 & 2 & 2 & 2 & 2 & 2 & 2 & 2 & 2\end{array}$ $\begin{array}{lllllllll}1 & 2 & 2 & 2 & 2 & 3 & 3 & 3 & 3\end{array}$ $\begin{array}{llllllllll}1 & 3 & 3 & 3 & 3 & 3 & 3 & 3 & 3 & 3\end{array}$ $\begin{array}{llllllllll}1 & 3 & 3 & 3 & 3 & 3 & 3 & 3 & 3 & 4\end{array}$ 1444444444 1444444444 1444555555 155555555555 1555555555 
c. für die Marke zu 20 c. de poso:

$\begin{array}{llllllllllllllllllllllllllllllll}1 & 3 & 3 & 3 & 3 & 3 & 3 & 3 & 3 & 3 & & 3 & 3 & 3 & 3 & 3 & 3 & 3 & 3 & 3 & 3 & & 2 & 2 & 2 & 2 & 2 & 2 & 2 & 2 & 2 & 2 \\ 1 & 3 & 3 & 3 & 3 & 3 & 3 & 3 & 3 & 3 & & 3 & 3 & 3 & 3 & 3 & 3 & 3 & 3 & 3 & 3 & & 2 & 2 & 2 & 3 & 2 & 2 & 2 & 2 & 2 & 2 \\ 1 & 3 & 3 & 3 & 3 & 2 & 2 & 2 & 2 & 2 & & 3 & 3 & 3 & 3 & 3 & 3 & 3 & 3 & 3 & 3 & & 2 & 2 & 2 & 2 & 2 & 2 & 2 & 2 & 2 & 2 \\ 1 & 2 & 2 & 2 & 2 & 2 & 2 & 2 & 2 & 2 & & 2 & 2 & 2 & 2 & 2 & 2 & 2 & 2 & 2 & 2 & & 3 & 3 & 3 & 3 & 3 & 3 & 3 & 3 & 3 & 3 \\ 1 & 2 & 2 & 2 & 2 & 2 & 2 & 2 & 2 & 4 & & 2 & 2 & 2 & 2 & 2 & 2 & 2 & 2 & 2 & 2 & & 3 & 3 & 3 & 3 & 3 & 3 & 3 & 3 & 3 & 3 \\ 1 & 4 & 4 & 4 & 4 & 4 & 4 & 4 & 4 & 4 & & 3 & 2 & 2 & 2 & 2 & 2 & 2 & 2 & 2 & 2 & & 2 & 3 & 3 & 3 & 3 & 3 & 3 & 3 & 3 & 3 \\ 1 & 4 & 4 & 4 & 4 & 4 & 4 & 4 & 4 & 4 & & 4 & 4 & 4 & 4 & 4 & 4 & 4 & 4 & 4 & 4 & & 4 & 4 & 4 & 4 & 4 & 4 & 4 & 4 & 4 & 4 \\ 1 & 4 & 4 & 4 & 5 & 5 & 5 & 5 & 5 & 5 & & 4 & 4 & 4 & 4 & 4 & 4 & 4 & 4 & 4 & 4 & & 4 & 4 & 4 & 4 & 4 & 4 & 4 & 4 & 4 & 4 \\ 1 & 5 & 5 & 5 & 5 & 5 & 5 & 5 & 5 & 1 & & 4 & 4 & 4 & 4 & 4 & 4 & 4 & 4 & 4 & 4 & & 4 & 4 & 4 & 4 & 4 & 4 & 4 & 4 & 4 & 4 \\ 1 & 5 & 5 & 5 & 5 & 5 & 5 & 5 & 5 & 1 & & 5 & 5 & 5 & 5 & 5 & 5 & 5 & 5 & 5 & 5 & & 5 & 5 & 5 & 5 & 5 & 5 & 5 & 5 & 5 & 5\end{array}$

2. Durch Nachlässigkeit beim Druck bezw. bein Einschieben der Ziffer entstanden bei den Aufdrucktypen II-V eine Reihe von Abarten mit falscher oder verkehrter Wertziffer, bei der 5 cents-IIarke mit Punkt vor der „5“ oder rechts oben derselben, auch mit Konma anstatt mit Punkt hinter der 5; hänfig, besonders bei den Aufdrïcken in karminroter Farbe, fehlt der Punkt gänzlich. Von der Marke zu $20 \mathrm{C}$. de Peso giebt es einen Fehldruck mit 10 (anstatt 20) in Type IV.

3. Der "Philatelist" vom März 1884 meldet einen Fehldruck der Marke zu $2^{1} / 2$ c. de peso in violett anstatt braun (Hartmann-Berlin) und einen ebensolchen der 10 cents-Marke in hellbraun anstatt olivenbrann (v. d. Beeck-Moskau.) Es sind mit dieser Meldung wohl die entsprechenden Werte der XI. Ausgabe gemeint.

4. Die Marken zu 5 und 10 c. d. peso (49 und 50) kommen halbirt postalisch entwertet vor.

5. Die Ausgabe der 5 cent-Marke in II. Type lässt sich zeitlich nicht genau feststellen. Sicher ist, dass sie auf Briefen von November 1883 gefunden wurde, mit Arabeskenaufdruck, der bis Ende September gebraucht wurde, aber nicht existirt.

6. Von simtlichen Werten der X. Ausgabe (ohne Aufdrucke) existiren Essais in blaner Farbe auf weissem, manchmal gelblichweissem Kartonpapier.

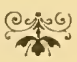

\section{Ausgabe :}

vom 1. Januar 1884 bis 1. Januar 1888.

Nämliche Zeichnung, nur Farbenänderung. Farbiger Druck auf weissem Papier; gezähnt 14.

\section{A. In Type I:}

68. UN C. DE PESO graugrün. 
69. $2^{1 / 2}$ C. DE PESO violett in vier Schattirungen. 69 a) $2 \frac{1}{2}$ C. DE PESO leblaft violett, $69 \mathrm{~b}) \quad 2 \frac{1}{2} \quad, \quad$ blassviolett, 69 c) $2 \frac{1}{2} \quad, \quad$ lila, 69 d) $2 \frac{1}{2} \quad " \quad$ bläulichlila.

70. 20 C. DE PESO olivenbraun.

B. In Type II (vergl. X Ausgabe C.):

71. 10 C. DE PESO braun in zwei Abstufungen.

71 a) 10 C. DE P'Eso hram,

71 b) 10 hellbraun.

C. Von Frühjaln 1886 bis Januar 1890. III. Type: Der spitze Winkel des Haares des Königs über der Schläfe ist völlig verschwunden und das Haar bildet statt dessen einen sanft ausgerundeten Bogen, von dem aus es noch etwas gestreckter, wie bei Type II, nach unten fällt. Der ovale Rahmen ist wie bei Type II. (Taf. I, 47.)

72. UN C. DE PESO blassgrün.

73. 5-C. DE PESO blassbląu.

Bemerkungen.

1. Einige Kataloge erwähuen mit dem Ausgabedatum vom Dezember 1883 eine Narke zu $2^{1 / 2}$ c. de peso blaulila. Ein zweimaliger Farbenwechsel eines Wertes innerhalb weniger Wochen ist aber, da alle Mlarken in Madrid hergestellt wurden und von da nach Cuba gesandt werden mussten. kaum glaublich; viel eher ist die Ansicht gerechtfertigt, dass diese Marke eine Schattirung der Marke No. 69 ist, welehe auf irgend eine Weise schon ror Januar 1884 zur Verwendung kam. Die Ansgabe der UN C. DE PESO-Narke in III. Type verlegt Moens irrtümlich erst in den Dezember 1886.

2. Die Marke zu 5 c. de peso (Type III) kommt halbirt postalisch entwertet vor.

3. Die Marken zu $2 \frac{1}{2}$ c. de peso (No. 69) und zu 10 c. de peso (No. 71) existiren auch in Punkten durchstochen.

4. Von der Marke zu 10 c. de peso giebt es Fälschungen - häufig postalisch entwertet - die sich an der zu hoch gestellten oberen griechischen Borde, an dem etwas zu oval geratenen O des Wortes PESO nnd dem schlecht ausgeführten Namen Julia erkennen lassen. 


\section{Ausgabe: \\ von Januar 1888 bis Januar 1890.}

Nämliche Zeichnung, nur Farbenänderung.

Farbiger Druck auf weissem Papier: gezälnt 14 .

74. 21/2 C. DE PESO (Type I) braun.

75. 10 C. DE PESO (Type II) blau in zwei Abstufungen. 75 a) 10 C. DE PESO hellblau, 75 b) $10 \quad$ dunkelblau.

76. 20 C. DE PESO (Type I) lilagrau.

Ausserdem für Drucksachen: Nämliche Zeichmung, nur oben mit Inschrift: CUBA-IMPRESOS, sämtlich in Type III.

Farbiger Druck auf weissem Papier; gezähnt 14. (Taf. I, 47.)

77. $1 / 2$ MILA DE PESO schwarz.

78. 1 MILA DE PESO schwarz.

79. 2 MIL DE PESO schwarz.

80. 3 MIL: DE PESO schwarz.

81. 4 MIL DE PESO schwarz.

82. 8 MIL: DE PESO schwarz.

Die Marke zn 10 c. de peso (75) kommt halbirt postalisch entwertet ror

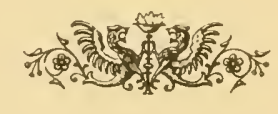




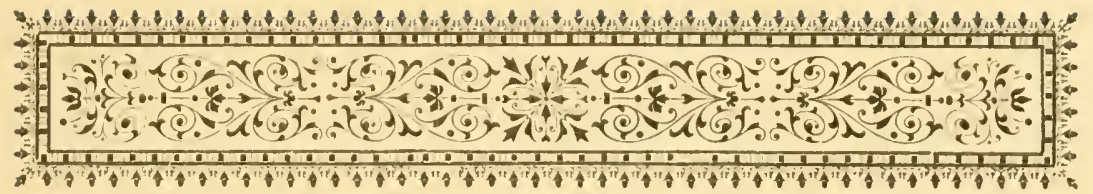

\section{Marken ans der Zeit der Regentschaft der Königin Maria ('hristina bezw. der Regiermng des Kiiniess Alfonso XIII.}

XIII. Ausgabe:

vom Januar 1890 bis Oktober 1891 bezw. 1892.

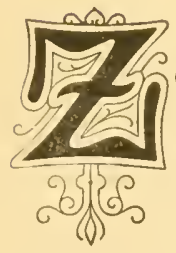

eichunng der XXXII. Ausgabe Spraniens: Kopf des Königs Alfonso XIII. wach rechts in ovalem Rahmen, um denselben ornamentenartige V'erziermugen, Untergrund mit wagerechten Strichen ansgefiillt; oben anf rechteckigem Schild: ISLA DE CUBA, unten auf ebensolchem Wertangabe: auf dem Halsabschnitt Name des Kupferstecher's .JULIA.

Farbiger Druck auf weissem Papier; gezähnt 14. (Taf. I, 49.)

83. UN C. DE PESO graubraun.

84. 2 C. DE PESO schieferblau.

85. $2^{1 / 2}$ C. DE PESO blaugrün.

86. 5 C. DE PESO oliven.

87. 10 C. DE PESO violettbraun. 
88. 2o C. DE PESO dunkelviolett.

Ausserdem für Drucksachen: Nämliche Zeichnung, nur oben Inschrift: CUBA IMIPRESOS.

Farbiger Druck auf weissem Papier; gezähnt 14. ('Taf. I, 50.)

89. $1 / 2$ MILA DE PESO blassrotbraun.

90. 1 MIL ${ }^{\wedge}$ DE PESO blassrotbraun.

91. 2 MIL: DE PESO blassrotbraun.

92. 3 MIL $\$$ DE PESO blassrotbraun.

93. 4 MIL: DE PESO blassrotbraun.

94. 8 MIL DE PESO blassrotbraun.

\section{Bemerkung.}

Von No. 86 und 87 giebt es Fälschungen, die man häufig postalisch entwertet findet. Bei genanem Vergleich mit dem Original findet man leicht den Unterschied: schlechter Druck, Abweichungen in der Zeichnung, bei No. 87 ausserdem unregelmässige und engere Zähnung. Diese Fälschungen wurden die Ursache der Farbenänderung der nächsten Ausgabe.

\section{Ausgabe:}

vom Oktober 1891 bis 31. Dezember 1893.

Nämliche Zeichnung, nur Farbenänderung.

Farbiger Druck auf weissem Papier; gezälnt 14.

95. 5 C. DE PESO hellgrün.

96. 10 C. DE PESO blassrosa.

1892. 97. UN C. DE PESO olivengrün. 
98. 2 C. DE PESO braun.

99. $2 \frac{1}{2}$ C. DE PESO orange.

100. 20 C. DE PESO ultramarinblau.

Marken für Drucksachen: Nämliche Zeichnung wie in voriger Ausgabe.

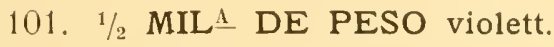
10\%. 1 MILA DE PESO violett.
103. 2 MILS DE PESO violett.
104. 3 MIL: DE PESO violett.
105. 4 MILS DE PESO violett.
106. 8 MILS DE PESO violett.

\section{Bemerkungen.}

1. Die Marke zu 5 C. de peso der XIII. Ansqabe war schon Mitte September anfoebraucht gewesen, weshalb durch Verfuigung vom 20. dieses Monats der Gebrauch halbirter 10 Cents-Marken gestattet wurde. Nach dem Eintreffen der nenen Marken wurde diese Erlaubniss zurückgezogen. Es geht aber hieraus hervor, dass die Marken der XIV. Ausgabe nicht, wie vielfach angegeben, schon im Angust oder September gebrancht worden sein können.

2. Von beiden Werten dieser Ausgabe giebt es Fälschungen in Lithographie. Die falsche $5 \mathrm{C}$. de peso-Marke ist an der etwas abweichenden Zeichnung und der dunkleren Farbe, die falsche $10 \mathrm{C}$. de peso auch an der unregelmässigen Zühnung (12) zu erkemmen. 


\section{Ausgabe \\ vom 1. Januar 1894 an.}

Nämliche Zeichnung, nur Farbenänderung.

Farbiger Druck auf weissem Papier; gezähnt 14.

107. UN C. DE PESO blau.

108. 2 C. DE PESO rosa.

109. $2 \frac{1}{2}$ C. DE PESO violett.

110. 20 C. DE PESO braun.

Marken für Drucksachen: Nämliche Zeichnung, wie bisher, nur Farbenänderung.

111. $1 / 2$ MIL AE PESO rosa.

112. 1 MILA DE PESO rosa.

113. 2 MILS DE PESO rusa.

114. 3 MILS DE PESO rosa.

115. 4 MIL DE PESO rosa.

116. 8 MIL: DE PESO rosa.

Bemerkung.

Die Ausgabe war znm 1 Januar 1894 fertig gestellt, die einzelnen Werte gelangten jedoch erst nach und nach zur Verwendung. Die Marken zu 5 und 10 C. de peso bleiben scheinbar unverändert.

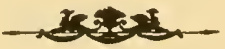


II.

Postkarten.

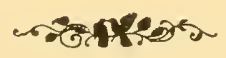





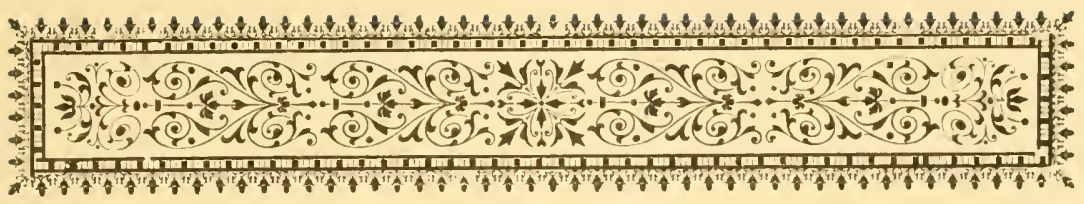

\title{
A. Postkarten aus der Zeit der Regiermng Alfonso's XII.
}

\author{
I. Ausgabe: \\ vom 1. Januar bis 31. Oktober 1878.
}

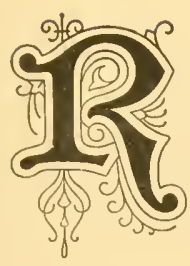

echteck aus dunkelchamois Karton, Grösse 145 : $98 \mathrm{~mm}$ : Marke in Zeiclnnung der IV. Ausgabe oben in der Nitte, im oberen Rahmen derselben: ISLA DE CUBA: links der Narke: TARJETA, rechts: POSTAL: vier Adresslinien, auf der ersten in Schreibschrift: $\mathscr{C} / \mathscr{Q}$; ein bald mehr, bald weniger stark hervortretender Unterdruck zeigt in $2 \mathrm{~cm}$ holren englischen Buchstaben: Tarjeta Postal, umgeben von Kreisen, Strichen und Verzierungen; unten: NoTs: Lo que debe escribirse se hará en el reverso é irá firmado por' el remitente.

Marke, Vordruck und Umrandung in blaner, Unterdruck in orange Farbe. (Taf. III, 51.)

1. $25 \mathrm{C}$ PESETA blau in zwei Abstufungen auf verschieden starkem Karton.

1 a) 25 CS. PESETA blau auf dickem chamois Karton,

1 b) 25 dunkelblau auf dickem chamois Karton,

1 c) $25 \%$ blau auf dünnem, etwas dunkler gefärbtem Karton. 
Bemerkung.

Von Karte No. 1 giebt es einen fehlerhaften Druck mit gebogenen Adresslinien, auch giebt es Exemplare mit "se hará en el reverso" in der Nota, anstatt: "en el reverso".

\section{的}

\section{Ausgabe:}

vom 1. Januar bis 31. Dezember 1879.

Karte der vorigen Ausgabe, nur veränderte Inschrift im oberen Rahmen der Marke: CUBA 1879 und Farbenänderung. (Taf. III, 52.)

2. 25 CS PESETA karmin in zwei Abstufungen auf hellchamois Karton.

2 a) 25 CS PESETA karmin,

2 b) $25 \quad$ blasskarmin.

\section{Bemerkung.}

Von Karte No. 2 existiren mangelhafte I)rucke, bei welchen Teile des Wertstempels, der oberen dicken Einfassungslinie oder der ersten Adresslinie zerbrochen nder verbogen erscheinen. Ob die Karte jemals in Verkehr gekommen ist, erscheint zweifelhaft.

\section{Ausgabe: \\ rom 1. Januar 1880.}

Karte für den Weltpostverkelur: Rerhteck aus weissem Karton-

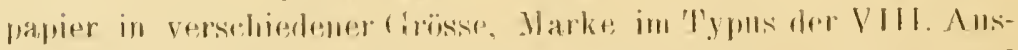
gabe oben rechts; links daseben fïmtzeiliger Vordruck mud 
zwar untereinander stehend: ULTRA.MAR - UNION POSTAL UNIVERSAL - UNION POSTALE UNIVERSELLE - ESPAÑA. - En este lado se escribe solamente la direccion; darunter drei Adresslinien, die erste mit $\mathcal{O} /$ beginnend, ohme Umrandung. (Taf. III, 53.)

Grösse $133: 89$.

3. 10 C. DE PESETA karmin.

Grösse 133 : 99.

4. 10 C. DE PESETA blasskarmin.

Doplelkarte in ähnlicher Ausführung; auf der ersten Karte ist links unten die gewöhnliche Bemerkung in verschiedener Länge, auf der zweiten Karte steht dafür RESPUESTA; Marke auf der ersten Karte links oben, auf der zweiten Karte rechts oben; Grösse verschieden.

Bemerkung anf der ersten Karte ist $39 \mathrm{~mm}$ lang.

5. $10+10$ C. DE PESETA karmin in drei Schattirungen.

5 a) $10+10$ C. DE PESETA karmin,

5 b) $10+10 \quad " \quad$ blasskarmin,

5 c) $10+10 \quad "$ dunkelrosa.

Bemerkung ist $41 \mathrm{~mm}$ lang, ohne Punkt am Schluss.

6. $10+10$ C. DE PESETA karmin in zwei Schattirungen.

6 a) $10+10$ C. DE PESETA blasskarmin,

6 b) $10+10$ dunkelrosa.

Karte in gleicher Ausfïhrung wie No.3, nur Aenderung des Wertes.

Grösse $133: 89 \mathrm{~mm}$. (Taf. III, 53.)

7. 15 C. DE PESETA karminrosa.

Ebenso, nur Druck blasser; Grösse 133 : $99 \mathrm{~mm}$.

8. 15 C. DE PESETA blasskarminrosa.

Doppelkarte in gleicher Ausführung wie No. 5, mit deu gewöhnlichen Zusätzen im Vordruck. 
Bemerkung 39--40 mm lang:

9. $15+15$ C. DE PESETA karminrosa in zwei Abstufungen.

9 a) $15+15$ C. DE PESETA karminrosa,

9 b) $15+15$ blasskarminrosa.

Bemerkung $38 \mathrm{~mm}$, ohne Punkt am Schluss.

10. $15+15$ C. DE PESETA karminrosa.

\section{Bemerkung.}

Die Karten der III. Ausgabe verdanken den im Juni 1878 in Paris getroffenen Vereinbarungen des Weltpostvereins ihre Entstehung, sie wurdeu früher in Verkehr gesetzt, als die entsprechenden Werte des Mutterlandes.

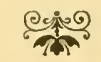

\section{Ausgabe:}

vom 1. Januar bis 31. Dezember 1881.

Karte in nämlicher Ausfïlırung wie No. 3, nur Marke in Zeichnumg der IX. Ausgabe und Wertangabe in C. DE PESO. Dïnnes weisses oder hellchamois Papier, Grösse $133: 99 \mathrm{~mm}$.

\section{2 C. DE PESO karmin auf verschiedenem Papier.} 11 a) 2 C. DE PESO karmin anf weissem Papier, 11 b) 2 karmin auf hellchamois Papier.

Doppelkarte in gleicher Ausfühnung, mit den gewöhnlichen Bemerkungen; Marke auf der ersten Karte links, auf der zweiten rechts oben; dïmnes weisses Papier, Grösse 133: $99 \mathrm{~mm}$.

Bemerkung $39 \mathrm{~mm}$ lang.

12. $2+2$ C. DE PESO karmin in zwei Abstufungen.

12 a) $2+2$ C. DE PESO karmin,

12 b) $2+2$ " blasskarmin. 
Bemerkung $41 \mathrm{~mm}$ lang, auf der ersten Karte fehlen die Punkte hinter direccion und Respuesta.

\section{3. $2+2$ C. DE PESO blasskarmin.}

Karte in gleicher Ausfiihrung wie No. 11, nur A enderung des Wertes: weisser oder gelblichweisser Karton oder gelblichweisses Papier.

Zweite Adresslinie $103 \mathrm{~mm}$ lang.

14. 3 C. DE PESO rosa in zwei Schattirungen auf verschiedenem Karton oder Papier.

14 a) 3 C. DE PESO rosa auf weissem Karton,

14 b) $3 \quad$ blassrot auf gelblichweissem Karton,

14 c) $3 \quad " \quad$ blassrot auf gelblichweissem Papier.

Zweite Adresslinie nur $94 \mathrm{~mm}$ lang.

15. 3 C. DE PESO rosa in zwei Abstufungen auf verschiedenem Karton.

15 a) 3 C. DE PESO rosa auf weissem Karton,

15 b) 3 blassiot auf gelblichweissem Karton.

Doppelkarte in gleicher Ausführung mit den gewöhnlichen Bemerkungen; weisser oder gelblich weisser Karton, Grösse 133: $94 \mathrm{~mm}$.

Bemerkung auf der ersten Karte $39 \mathrm{~mm}$, zweite Adresslinie $103 \mathrm{~mm}$ lang.

16. $3+3$ C. DE PESO rosa auf verschiedenem Karton.

16 a) $3+3$ C. DE PESO rosa auf weissem Karton,

16 b) $3+3 \quad$ " rosa auf gelblichweissem Karton.

Bemerkung $39 \mathrm{~mm}$, zweite Adresslinie $94 \mathrm{~mm}$ lang, hinter Respuesta der zweiten Karte kein Punkt.

17. $3+3$ C. DE PESO rosa auf verschiedenem Karton.

17 a) $3+3$ C. DE PESO rosa auf weissem Karton,

17 b) $3+3 \quad$ rosa auf gelblichweissen Karton.

Bemerkung 41 mm, zweite Adresslinie 103 mm lang.

18. $3+3$ C. DE PESO rosa auf verschiedenem Karton.

18 a) $3+3$ C. DE PESO rosa auf weissem Kartou,

18 b) $3+3 \quad$ rosa auf gelblichweissem Karton. 
Bemerkung.

Von No. 11a, $11 \mathrm{~b}$ und $12 \mathrm{a}$ giebt es Stucke ohne Punkt hinter dem Worte direccion der Bemerkung, von No. 12 solche ohne Punkt hinter direccion und hiuter Respuesta, von No. 16 solche mit lädirtem E in ESPA $\widetilde{N}$, von 16 b ohne Punkt hinter Respuesta.

\section{อง \\ V. Ausgabe: \\ vom 1. Januar 1882.}

Karte für den Weltpostverkehr in ähnlicher Ausfïhrung wie No. 11, nur Marke in Zeichnung der X. Ausgabe; drei Adresslinien von verschiedener Länge; weisser oder gelblichweisser Karton, Grösse 133 : 99 mm.
19. 2 C. DE PESO karmin in zwei Abstufungen auf ver- schiedenfarbigem Karton.
19 a) 2 C. DE PESO karmin auf weissem Karton,

$\begin{array}{lll}19 \mathrm{~b}) & 2 & \text { blasskarmin auf weissem Karton, } \\ 19 \mathrm{c}) & 2 & \text { karmin auf gelblichweissem Karton, } \\ 19 \mathrm{~d}) & 2 & \end{array}$

Doppelkarte in gleicher Ausführung mit den gewöhnlichen Bemerkungen; Marke anf der ersten Karte links, auf der zweiten Karte rechts oben; weisser oder gelblichweisser, verschieden starker Karton, Grösse $133: 94 \mathrm{~mm}$.

Bemerkung auf der ersten Karte ist $39 \mathrm{~mm}$ lang.

20. $2+2$ C. DE PESO karmin auf verschiedenem Karton. 20 a) $2+2$ C. DE PESO karmin auf weissem Karton, 20 b) $2+2 \quad " \quad$ karmin auf gelblichweissem Karton, 20 c) $2+2 \quad " \quad$ karmin auf dünnem, weissem Karton.

Bemerkung nur $38 \mathrm{~mm}$ lang.

21. $2+2$ C. DE PESO karmin auf weissem Karton.

Bemerkung ist $40 \mathrm{~mm}$ lang.

22. $2+2$ C. DE PESO karmin auf gelblichweissem Karton. 
Bemerkung ist $41 \mathrm{~mm}$ lang.

\section{3. $2+2$ C. DE PESO karmin auf weissem Karton.}

Karte in gleicher Ausführung wie No. 19, nur veränderter Wert: weisser oder gelblichweisser, verschieden starker Karton, Grüsse 133 : $99 \mathrm{~mm}$.

24. 3 C. DE PESO blassrot auf verschiedenem Karton. 24 a) 3 C. DE PESO blassrot auf weissem Karton, 24 b) $3 \quad$ blassrot auf gelblichweissem Karton, 24 c) $3 \quad$ blassrot auf bläulichweissem Karton, 24 d) $3 \quad " \quad$ blassrot auf ganz dünnem, weissem Karton.

Doppelkarte in gleicher Ausführung wie No. 24 mit den gewöhnlichen Bemerkungen.

Bemerkung $39 \mathrm{~mm}$ lang.

25. $3+3$ C. DE PESO blassrot auf weissem Karton.

Bemerkung auf der ersten Karte 28 mm lang.

26. $3+3$ C. DE PESO blassrot auf weissem Karton.

Bemerkung $40 \mathrm{~mm}$ lang.

27. $3+3$ C. DE PESO blassrot auf gelblichweissem Karton.

Erste Adresslinie der ersten Karte $5 \mathrm{~mm}$ rerkürzt.

28. $3+3$ C. DE PESO blassrot auf weissem Karton.

Karte für das Inland in gleicher Ausführung wie No. 1, nur mit der Marke der X. Ausgabe; Marke, Vordruck und Umrandung in griiner, Unterdruck in gelbroter Farbe; chamois Karton, Grösse $145: 98 \mathrm{~mm}$. (Taf. III, 54.)

Bemerkung $82 \mathrm{~mm}$ lang.

29. 2 C. DE PESO grün auf chamois Karton.

Bemerkung $82 \mathrm{~mm}$ lang in etwas grösseren Lettern.

30. 2 C. DE PESO grün auf chamois Karton. 
Bemerkung $79 \mathrm{~mm}$ lang.

31. 2 C. DE PESO grün auf chamois Karton.

Bemerkung $79 \mathrm{~mm}$ lang in etwas grösseren Lettern.

32. 2 C. DE PESO grün auf chamois Karton.

Karte in gleicher Ausfüln'ung wie No. 29, nur veränderter Wert.

Bemerkung $82 \mathrm{~mm}$ lang.

33. 4 C. DE PESO karmin auf chamois Karton.

Bemerkung $82 \mathrm{~mm}$ lang in etwas grösseren Lettern.

34. 4 C. DE PESO karmin auf chamois Karton.

Bemerkung $79 \mathrm{~mm}$ lang.

35. 4 C. DE PESO karmin auf chamois Karton.

Bemerkung $79 \mathrm{~mm}$ lang in etwas grösseren Lettern.

36. 4 C. DE PESO karmin auf chamois Karton.

Karte in gleicher Ausführung, nur veränderter Wert.

Bemerkung in kleinen Lettern.

37. 10 C. DE PESO blau.

Bemerkung in grösseren Tuettern.

38. 10 C. DE PESO blau.

\section{Bemerkung.}

Von Karte No. 19 giebt es einen Fehldruck ohne tilde uber dem n von España.

Von Karte No. 20 giebt es einen Fehldruck, bei welchem die Markenbilder falsch eingedruckt sind, d. h. anf der ersten Karte rechts, auf der zweiten Karte links, statt umgekehrt. Von Karte No. 29 giebt es mangelhafte Drucke mit OEBE anstatt DEBE in der' Bemerkung. Von simtlichen Karten der Ausgabe giebt es Exemplare olne Punkt hinter direccion oder Respuesta.

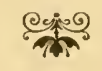




\section{Ausgabe:}

von Juli 1888 bis 1 . Januar 1890.

Karte in gleicher Ausführung wie No. 29, nur ohne farbigen Unterdruck; chamois Karton, Grösse 145:98. (Taf. III, 55.)

Das $r$ von $\int_{\ell}$ mit Punkt, Nota in grossen Buchstaben 94 mm lang.

39. 2 C. DE PESO grün.

40. 4 C. DE PESO karmin.

Das r von $\mathscr{C}_{\ell}$ bildet eine Schleife nach oben, Nota in grossen Buchstaben und $88^{1 / 2} \mathrm{~mm}$ lang.

41. 2 C. DE PESO grün.

42. 4 C. DE PESO karmin.

Nota in kleinen Buchstaben $89 \mathrm{~mm}$ lang.

43. 2 C. DE PESO grün.

44. 4 C. DE PESO karmin. 


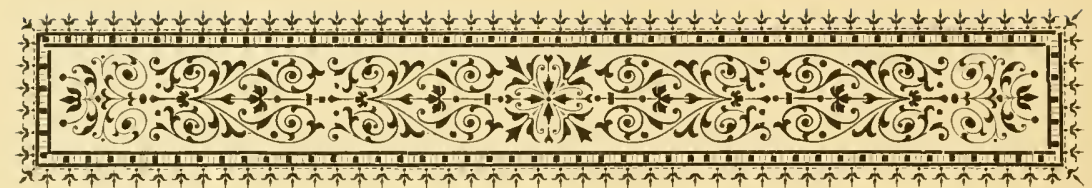

\section{B. Postkarten aus der Zeit der Regentschaft der Königin Maria Cristina bezw. der Regierung des Königs Alfonso XIII.}

\footnotetext{
VII. Ausgabe:

vom 1. Januar 1890 an.

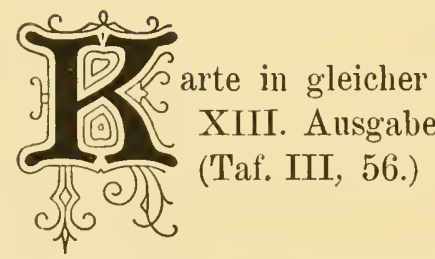

45. 2 C. DE PESO grün.

46. 3 C. DE PESO rosa.

47. 4 C. DE PESO karmin.
} 


\section{Ausgabe:}

vom August (?) 1893 an.

Rechteck ans chamois Karton, Grösse 145: 102: Marke der' XIII. Ausgabe oben in der Mitte; links der Marke: 'TAR.JETA, rechts: POSTAL: vier Adresslinien, die erste mit $\mathscr{C}$. Q . begimnend: unten links die gewöhnliche Bemerkung. (Taf. III, 57.)

48. 2 C. DE PESO grün.

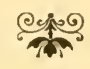

\section{Ausgabe:}

vom 1. Januar 1894.

Karte in gleicher Ausfülırung wie No. 48. (Taf. III, 57.)

49. 5 C. DE PESO grün. 


\section{Spanisch Westindien.}

\section{Ic. Portorico.}

yेर 

I.

\section{Briefmarken.}

totot 



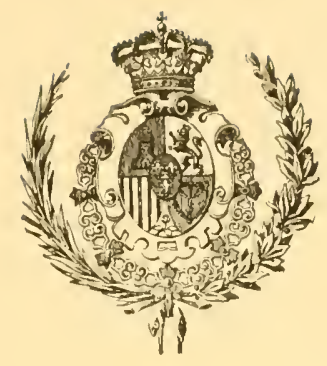

\section{A. Marken aus der Zeit der Regierung des Königs Amadeo.}

\section{Ausgabe:}

von Juni 1873 bis (?) 1874 bezw. Januar 1875 .

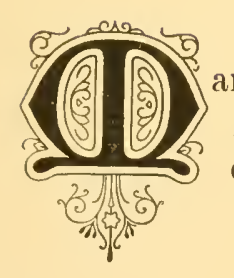

arken der I. Ausgabe von Cuba: Kopf des Königs Amadeo (vergl. Seite 39) mit schwarzem Aufdruck eines Namenszuges.

Farbiger Druck auf weissem Papier: gezälnut 14. (Taf. IV, 58, anch Taf. I, 34 und 35.)

I. Type*:

1. 25 C. DE PESETA lila in drei Schattirungen.
1 a) 25 C. DE PESETA lila,
1 b) $25 \quad$ " blasslila,
1 c) $25 \quad$ graublau.

2. 50 C. DE PESETA braun.

II. Tyре*:

3. UNA PESETA rotbraun. 
Bemerkungen.

1. Die Marken wurden von Seiten des Chefs der Intendantur mit einem aufgedruckten Namenszug versehen, um zu verhindern, dass in Cuba gekaufte Markeu in Portorico gebraucht wïrden. Spekulanten kauften nämlich die in Cuba wegen der niedrigeren Papierwährung billigeren Marken, um sie in Portorico, welches Silberwährung hatte, mit Gewinn wieder zu verkaufen.

2. Wie schon bei Cuba erwähnt, diente die Marke zu $121 / 2$ C. de peseta ausschliesslich dem Stadtverkehr von Habana, sie existirt also nicht mit $\mathrm{Na}$ menszug.

3. Die Marke zu 25 C. d. p. war in Gebrauch bis zum Jahre 1874, diejenigen zu 50 C. d. p. und 1 Peseta blieben in Verkehr bis zum Januar 1875.

4. In Bezug auf Abstempelungen gilt auch für Portorico das bei SpanischWestindien und Cuba Gesagte. Die Abbildungen auf Tafel IV geben die gebräuchlichsten Stempelmodelle, nur zwei von ihnen gehören ausschliesslich Portorico an, No. 59 und 61, alle übrigen finden sich auch in den übrigen Colonien, bezw. in Spanien. (No. 60 und 64 Certificado-Stempel, No. 65 Dienststempel der Civilbehörden.) 


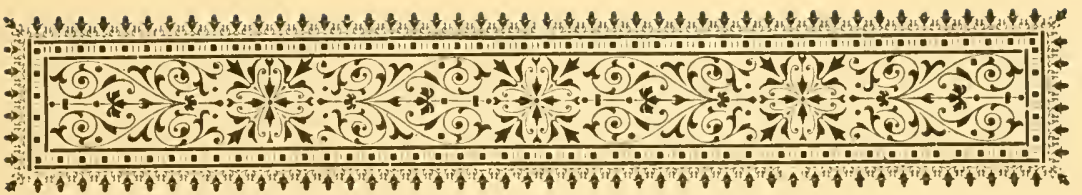

\title{
B. Marken der Republik.
}

\author{
II. Ausgabe: \\ von (?) 1874 bis Januar 1875.
}

(1)

arken der II. Ausgabe von Cuba (vergl. Seite 41): Allegorische Figur der España mit schwarzem Aufdruck von zwei Namenszïgen.

Farbiger Druck anf weissem Papier; gezälınt 14. (Taf. IV, 66.)

4. 25 C. DE PESETA ultramarinblau in zwei Abstufungen. 4 a) 25 C. DE PESETA ultramarinblau,

4 b) $25 \quad n$ dunkelultramarinblau.

\section{Bemerkung.}

Die Marke trägt ausser dem Namenszug des Chefs der Intendantur auch noch denjenigen des General-Capitäns. Die Werte zu 50 C. d. p. und 1 peseta erhielten diesen zweiten Namenszug nicht. 


\section{Ausgabe: \\ von Januar 1875 bis Januar 1876.}

Marken der III. Ausgabe von Cuba (vergl. Seite 42): Wappen Spaniens mit Aufdruck von zwei Namenszügen.

Farbiger Druck auf weissem Papier; gezähnt 14. (Taf. IV, 67.)

5. 25 CENT SESETA ultramarinblau.

6. 5o CENT PESETA dunkelgrün.

7. UNA PESETA braun.

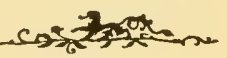




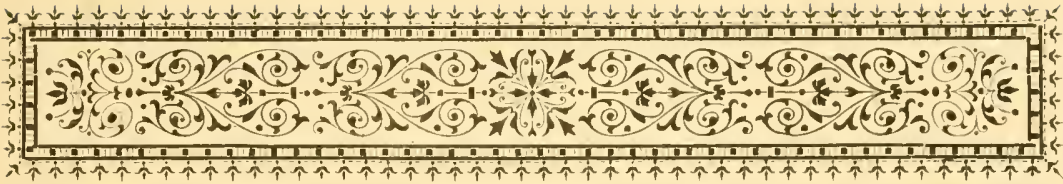

\section{Marken aus der Zeit der Regierung des Königs Alfonso XII.}

\section{Ausgabe:}

von Januar 1876 bis 1. Januar 1877.

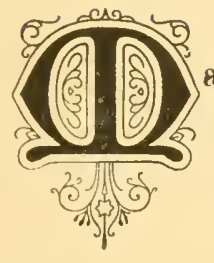

arken der IV. Ausgabe von Cuba (vergl. Seite 44.): Kopf des Königs Alfonso XII. mit einem, zwei oder drei in schwarz aufgedruckten Namenszïgen.

Farbiger Druck auf weissem Papier; gezähnt 14.

A. Mit einem Namenszug (Taf. IV, 68):

8. 25 C S PESETA blassviolett.

9. 1 PESETA grauschwarz.

B. Mit zwei Namenszügen (Taf. IV, 69):

10. 25.CS PESETA blassviolett in drei Schattirungen. 10 a) 25 CSS PESETA blassviolett, $10 \mathrm{b)} 25 \quad$ grauviolett, 10 c) $25 \quad$ blasslila.

11. 50 CS PESETA ultramarinblau. 
12. 1 PESETA mehr oder weniger intensiv schwarz. 12 a) 1 PESETA schwarz,

12 b) 1 " grauschwarz.

C. Mit drei Namenszügen (Taf, IV, .70):

13. 25 CS PESETA blassviolett in drei Schattirungen. 13 a) 25 CS PESETA blassviolett.

13 b) $25 \quad " \quad$ graublau,

13 c) $25 \%$ blasslila.

14. 1 PESETA grauschwarz.

Bemerkungen.

1. Die beiden ersten Aufdrucke wurden aus dem schon angeführten Grunde gemacht, um die Verwendung der in Cuba gekauften Marken in Portorico unmöglich zu machen. Der dritte (wagerechte) Aufdruck dagegen wurde veranlasst, um einem durch Rundschreiben der General-Postdirection vom 22. Juni mitgeteilten Diebstahl von 325,800 Marken à 25 CS und 19,000 Marken à 1 Peseta zu begegnen. Da Marken zu 50 c. d. p. nicht gestohlen waren, so erhielt dieser Wert den dritten Aufdruck nicht.

2. Die Marken zu 25 und 50 c. d. p. soll es nach Moens auch mit vier Namenszügen (davon zwei horizontal) geben. Es sind dies natürlich durch Versehen entstandene Doppeldrucke.

\section{Ausgabe:}

vom 1. Januar 1877 bis 1. Januar 1878 bezw. wieder vom 1. Juli 1878 bis 1. Januar 1879.

Zeichnung der vorigen Ausgabe, nur oben die Inschrift PT0 RICO 1877.

Farbiger Druck auf weissem Papier; gezähnt 14. (Taf. IV, 71.

15. 5 CS PESETA gelbrötlichbraun.

16. 10 CS PESETA karminrosa. 


\section{15 CS PESETA dunkelgrün.}

\section{8. $25 \mathrm{C}$. PESETA ultramarinblau in drei Abstufungen. 18 a) 25 CS PESETA ultramarinblau, 18 b) 25 hellultramarinblau, 18 c) $25 \quad "$ dunkelultramarinblan.}

19. 5o C PESETA gelbbraun in zwei Abstufungen. 19 a) 50 CS PESETA gelbbraun, 19 b) $50 \quad, \quad$ hellgelbbraun.

\section{Bemerkungen.}

1. Mit dem Jahre 1877 beginnt die Ausgabe besonderer Marken für Portorico.

2. Die Restbestände der Marken zn 5, 10 und 15 C. d. p. wurden im darauffolgenden Jahre Mangels dieser Werte aufgebraucht. Sie circulirten im Jahre 1878 vom 1. Juli ab bis zum Schlusse des Jahres.

3. Der Philatelist (Ne. 1, 1885) teilt die Existenz von postalisch entwerteten Fehldrucken der 5 und 10 Cs-Marken mit, erstere lackfarben, letztere rotbraun (Dr. Vedel-Copenhagen). Von der Marke zu 5 CS giebt es ausserdem einen Fehldruek in karmin.

4. Sämtliche Werte kommen auch ungezähnt vol; von der Marke zu $10 \mathrm{CS}$ wurden Stucke bekannt, welche nur eine wagerechte Ziihnung besitzen.

5. Marken zu 25 C. d. p. mit einem in Tinte aufgeschriebenen oder auch aufgedruekten $\mathrm{R}$ sind nicht postalisch gebraucht, sondern haben fiskalischen Zwecken gedient. Im .Jahre 1877 wurde nämlich in Portorico die Quittungsstener eingeführt und Mangels einer besonderen Marke diejenigen der Post dazu verwendet; sie erhielten als Zeichen ihrer Verwendung ein aufgesehriebenes oder aufgedrucktes $R$ (Recibos). Später tritt an Stelle dieses $R$ ein kreisrunder Entwertungsstempel, der oben Reeibos, unten Puerto-Rico, in der Nitte das Datum trägt. 


\section{Ausgabe:}

vom 1. Januar 1878 bis 1. Januar 1879 und nach kurzer Unterbrechung bis 1. Januar 1880.

Zeichnung der vorigen Ausgabe, nur Veränderung der Jahreszahl.

Farbiger Druck anf weissem Papier; gezähnt 14 .

20. 5 CS PESETA olivenbraun.

21. 10 CS PESETA dunkelbraun.

22. $25 \mathrm{C}$ S PESETA grün in zwei Abstufungen. 22 a) 50 CS PESETA grün, 22 b) $50 \quad "$ dunkelgrün.

23. 50 CS PESETA blau in zwei Schattirungen. 23 a) 50 CS PESETA ultramarinblau, 23 b) 50 hellblau.

24. 1 PESETA gelbbraun in drei Schattirungen.

24 a) 1 PESE'TA dunkelgelbbraun,

24 b) 1 gelbbraun,

24 c) $1 "$ olivenbraun,

\section{Bemerkungen.}

1. Nach kurzem Umlauf (bis 1. Juli) dieser Ausgabe waren die Werte zu 5, 10 und 25 C. d. p. aufgebraucht und die Regierung verfugte deshalb die Verwendung der entsprechenden Werte, sowie der Marke zu 15 C. d. p. des vorhergehenden Jahres. Gegen Ende des Jahres trafen von Madrid neue Marken dieser Werte ein, gelangten jedoch im Jahre 1878 nicht mehr zur Verwendung (vergl. Bemerkung 1 zur folgenden Ausgabe).

2. Die Marken zu 5, 10 und 50 C. d p., sowie diejenige zu 1 PESETA kommen auch ungezähnt vor. 


\section{Ausgabe:}

vom 1. Januar 1879 bis 1. August 1879 bezw. bis zum 1. Januar 1880.

Zeichnung der vorigen Ausgabe, nur Veränderung der Jahreszahl.

Farbiger Druck auf weissem Papier; ungezähnt 14, (Taf. IV, 71.)

25. 5 CS PESETA rotviolett in zwei Schattirungen auf verschiedenem Papier.

25 a) 5 CS PESETA rotviolett auf weissem Papier,

25 b) 5 " braunrot auf gelblichem Papier.

26. 10 CS PESETA braun.

27. 15 CS PESETA grünlichschwarz.

28. 25 CS PESETA blau in zwei Schattirungen.

28 a) 25 CS PESETA blau,

28 b) $25 \quad \cdots \quad$ ultramarinblau.

29. 5o CS PESETA dunkelgrün.

30. 1 PESETA lilagrau.

Bemerkungen.

1. Die Marken zu 5 und 10 C. d. p. waren nach kurzer Zeit aufgebraucht, es wurde» daher von August an die bis dahin nicht gebrauchten entsprechenden Werte des vorhergehenden Jahres in Verkehr gebracht.

2. Ton der Marke zu 5 C. d. p. giebt es einen fehlerhaften Druck mit PT0 RICC. 


\section{Ausgabe:}

rom 1. Januar bezw. 1. Juli 1880 bis 1. Januar 1881 .

Zeichnung der VIII. Ausgabe von Cuba (vergl. Seite 48): Kopf des Königs Alfonso XII. nach rechts in ovalem Rahmen, oben: PUERTO-RICO 1880.

Farbiger Druck auf weissem Papier; gezähnt 14. (Taf. IV, 72.)

1. Januar 1880.

31. 5 CENT. PESETA blassgrün.

32. 10 C. DE PESETA rosa in zwei Abstufungen. 32 a) 10 C. DE PESETA karminrosa, 32 b) $10 \quad " \quad$ blassrosa.

33. 15 CENT. PESETA gelbbraun.

34. 25 CENT. PESETA blassultramarinblau.

35. 40 CENT. PESETA grau.

36. 50 C. DE PESETA gelbbraun.

37. UNA PESETA olivenbraun.

1. Juli 1880.

38. $1 / 4$ C. DE PESETA dunkelgrün.

39. $1 / 2$ C. DE PESETA karmin.

40. 1 CENT. PESETA rotviolett.

41. 2 CENT. PESETA graulila.

42. 3 CENT. PESETA blassgelb.

43. 4 CENT. PESETA schwarz.

\section{Bemerkungen.}

1. Bezüglich Typen gilt auch für Portorico das bei Cuba in Bemerkung 1 zur VIII. Ausgabe Gesagte. Die nbige Ausgabe gehört der Type I an. 
2. Die Werte von $1 / 4$ bis 4 Cent. de Peseta dienten zur Frankirung von Drucksachen. Die Bezeichnung "Impresos“ wurde wohl nur wegen Raummangels weggelassen.

3. Von Essais giebt es die Marken No. 31 bis 37 in abweichenden Farben auf weissem Karton und zwar:

5 CENT. Peseta blau, 10 C. de Peseta griu, 15 Cent. Peseta braun, 25 Cent. Peseta karmin. (hell und dunkel), 40 Cent. Peseta violett (hell und dunkel), $50 \mathrm{C}$. de Peseta blau, UNA Peseta violett.

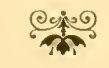

\author{
IX. Ausgabe: \\ vom 1. Jannar 1881 bis 1. Januar 1882.
}

Zeichnung der vorigen Ausgabe, nur Veränderung der Jahreszahl und Wertangabe.

Farbiger Druck auf weissem Papier: gezälnnt 14.

44. $1 / 2$ MILA DE PESO karmin in zwei Abstufungen.

44 a) $1 / 2$ HILA DE PESO karmin,

44 b) $1 / 2, \quad$ karmiurosa.

45. 1 MILA DE PESO lila.

46. 2 MIL: DE PESO blassrosa.

47. 4 MIL DE PESO gelbgrün.

48. 6 MIL DE PESO blasslila.

49. 8 MILS DE PESO blau in zwei Schattirungen.

49 a) 8 MILS. DE PESO hellultramarinblau,

49 b) $8 \quad$ stahlblau.

50. UN C. DE PESO graugrün.

51. 2 C. DE PESO karmin in zwei Abstufungen.

51 a) 2-C. DE PESO karmin,

51 b) 2-C. " karminiosa.

52. 3 C. DE PESO braun.

53. 5 C. DE PESO blassblau. 
54. 8 C. DE PESO braun auf verschiedenem Papier. 54 a) 8 C. DE PESO braun auf weissem Papier, 54 b) 8 braun auf chamois Papier.

55. 10 C. DE PESO lilagrau.

56. 20 C. DE PESO olivenbraun.

\section{Bemerkungen.}

1. Die Werte von 1 Milạ bis 8 Mils dieser, wie der nüchsten Ausgaben, dienten zur Frankirung von Drucksachen.

2. Von sämtlichen Werten giebt es Essais in abweichender Farbe auf weissem Karton und zwar:

$1 / 2$ MilA de Peso karmin, 1 MilA de Peso blan, 2 Mils de Peso violett und blassviolett, 4 Mils de Peso grün, 6 Mils de Peso blau, 8 Mils de Peso violett, UN C. de Peso blau, 2 C. de Peso karmin, 3 C. de Peso violett und blassviolett, $5 \mathrm{C}$. de Peso grïn, $8 \mathrm{C}$. de Peso karmin, $10 \mathrm{C}$. de Peso violett und blassviolett, $20 \mathrm{C}$. de Peso grin, ausserdem ein Doppeldruck von 6 Mils de Peso in brann auf weissem Papier.

\section{Ausgabe:}

vom 1. Januar 1882 bis 1. Januar 1884.

Zeichnung der vorigen Ausgabe, nur Wegfall der Jahreszahl.

Farbiger Druck auf weissem Papier; gezähnt 14. (Taf. IV, 73.)

A. In Type I:

57. $1 / 2$ MILA DE PESO rosa in zwei Abstufungen.

57 a) $\frac{1}{2}$ MILA DE PESO karmin,
57 b) $1 / 2$

58. 1 MILA DE PESO karmin.

59. 2 MILS DE PESO violett in zwei Schattirungen.

59 a) MILS DE PESO hellviolett,

$59 \mathrm{~b}) \quad$ blauviolett. 
60. 4 MILS DE PESO lila in zwei Schattirungen.

60 a) MILS DE PESO rotlila.

$60 \mathrm{~b})$ lilabraun.

61. 6 MILS DE PESO gelbbraun.

62. 8 MILS DE PESO hellgrün.

63. UN C. DE PESO graugrün.

64. 2 C. DE PESO karmin.

65. 3 C. DE PESO gelb in zwei Schattirungen. 65 a) 3 C. DE PESO orangegelb, 65 b) 3 blassgelb.

66. 5 C. DE PESO blassultramarinblau.

67. 8 C. DE PESO braun in zwei Abstufungen. 67 a) 8 C. DE PESO braun,

67 b) 8 dunkelbraun.

68. 10 C. DE PESO blaugrün.

69. 20 C. DE PESO graulila.

70. 40 C. DE PESO blau in zwei Abstufungen. 70 a) 40 C. DE PESO blau, 70 b) 40 dunkelblau.

71. 8o C. DE PESO olivenbraun.

B. Ende des Jahres 1883. In Type II (vergl. Cuba: VIII. Ausg., Bemerk. 1 und X. Ausgabe C.).

7.. 5 C. DE PESO blassultramarinblau.

Bemerkungen.

1. Mit dem Jahre 1882 wurden für Portorico keine Telegraphenmarken mehr angefertigt und die Marken zis 40 und 80 c. de peso auch für Telegraphenzwecke verwandt.

2. Die Ausgabe der 5 c. de peso-Marke in Type II. wird häufig in das nächste Jahr verlegt; da jede amtliche Angabe hieruber fehlt und die Ausgabe der II. Type bei allen übrigen Kolonien zwischen 1 . Oktober 1883 und 1. Januar 1884 erfolgte, so erscheint dieses Ausgabe-Datum wohl auch bei Portorico am richtigsten.

3. Von der Marke zu 8 c. de peso existirt ein Fehldruck in gelb, entstanden dadurch, dass ein Cliché dieser Marke aus Versehen in die Platte der 3 c. do peso-Marke eingeschoben wurde. 
4. Von der Marke zu 40 c. de peso erschienen im Frühjahr 1883 Fälschungen, welche zur Folge hatten, dass dieser Wert zeitweise von der Postverwaltung nicht mehr ausgegeben wurde. Die Fülschung ist eine derartig ungeschickte, dass eine Beschreibung nicht nötig erscheint.

5. Von sämtlichen Werten existiren Essais in blauer Farbe auf weissem Kartonpapier.

\section{Ausgabe:}

vom 1. Jauuar 1884 bis 1 . Januar 1890.

Zeichnnng der vorigen Ausgabe, nur Aenderung der Farbe. Farbiger Druck auf weissem Papier; gezähnt 14.

A. in Type $I$.

73. $1 / 2$ MILA DE PESO karmin.

71. 1 MILA DE PESO blassrosa.

75. UN C. DE PESO blassgraugrün.

76. 3 C. DE PESO braun.

B. 1886. In Type II. (vergl. Cuba: VIII. Ausg. Bemerk. 1 und XI. Ausgabe C.)

77. 5 C. DE PESO blassultramarinblau.

Bemerkungen.

1. Die Marke zu UN C. DE PESO unterscheidet sich in der Farbe wesentlich von der gleichwertigen Marke der X. Ausgabe. Sie ist auf keinen Fall als eine blosse Farbenschattirung der letztgenannten anzuseben, da diese vom Jahre 1884 an nicht mehr zur Verwendung kommt, auch in Cuba zu der nämlichen Zeit der gleiche Farbenwechsel eintritt.

2. Von Marke No. 77 giebt es Essais in dunkelbrauner, roter und grüuer Farbe auf weissem Kartonpapier.

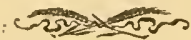




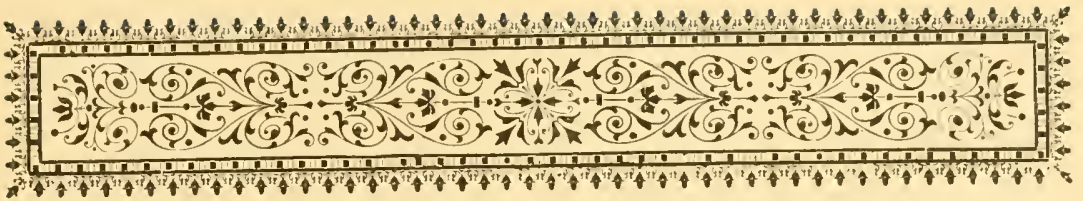

\section{Marken aus der Zeit der Regentschaft der Königin Maria Cristina bezw. der Regierung des Königs Alfonso XIII.}

XII. Ausgabe:

vom 1. Januar 1890 bis 31. Dezember 1891.

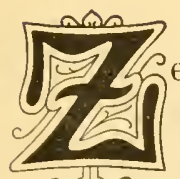

eichnung der XIII. Ausgabe Cuba's (vergl. Seite 57): Kopf des Königs Alfonso XIII. nach rechts in ovalem Rahmen pp.; oben auf rechteckigem Schild: PUERTO-

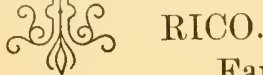

Farbiger Druck auf weissem Papier; gezähnt 14 . (Taf. IV, 74.)

78. $1 / 2$ MIL 1 DE PESO schwarz.

79. 1 MILA DE PESO blaugrün.

80. 2 MIL DE PESO rosa in zwei Abstufungen.

80 a) 2 MILSS DE PESO rosa,

80 b) 2 blassrosa.

81. 4 MILS DE PESO graugrün.

82. 6 MILS DE PESO braun. 
83. 8 MILS DE PESO olivenbraun.

84. UN C. DE PESO gelbbraun in zwei Schattirungen. 84 a) UN C. DE PESO gelbbraun, 84 b) UN " hellgelbbraun.

85. 2 C. DE PESO dunkelviolett.

86. 3 C. DE PESO dunkelblau.

87. 5 C. DE PESO violettbraun in zwei Abstufungen. 87 a) 5 C. DE PESO violettbraun, 87 b) $5 \quad "$ blassviolettbraun.

88. 8 C. DE PESO hellultramarinblau.

89. 10 C. DE PESO rosa.

90. 20 C. DE PESO zinnoberrot (lachsfarben).

91. 40 C. DE PESO rotgelb.

92. 8o C. DE PESO gelbgrün.

\section{Ausgabe:}

von (?) 1891 bis 1. Januar 1892.

Nämliche Zeichnung: nur Farbenänderung.

Farbiger Druck auf weissem Papier; gezähnt 14.

93. UN C. DE PESO blaugrün.

94. 5 C. DE PESO gelbgrün. 


\section{Ausgabe:}

vom 1. Januar 1892 bis 31. Dezenber 1893.

Nämliche Zeichnung, nur Farbenänderung.

Farbiger Druck auf weissem Papier; gezähnt 14.

95. $1 / 2$ MILA DE PESO graugrün.

96. 1 MILA DE PESO violett.

97. 2 MIL $\$$ DE PESO lilabraun.

98. 4 MIL DE PESO ultramarinblau.

99. 6 MIL DE PESO rosa.

100. 8 MILS DE PESO blassgelbgrün.

101. 1 C. DE PESO gelbbraun.

102. 2 C. DE PESO weinrot.

103. 3 C. DE PESO ziegelrot.

104. 5 C. DE PESO blaugrün.

105. 8 C. DE PESO braun.

106. 10 C. DE PESO karminrosa.

107. 2o C. DE PESO lila.

108. 40 C. DE PESO dunkelblau.

109. 8o C. DE PESO rotgelb.

Juli 1893:

110. 5 C. DE PESO braun.

\section{Bemerkung.}

Ein Rundschreiben des Ministeriuns der Kolonien vom 13. Dezember 1891 giebt als Gründe der Farbenänderung an: Aehnlichkeit der Farben verschiedener Werte und Nichtübereinstimmung der Farben mit den Vereinbarungen des Weltpostrereins. 


\section{Ausgabe:}

für den 19. November 1893.

Für den Verkehr im Inneru: Marke zur vierhundertjährigen Gedenkfeier der Entdeckung Portorico's: Im Hintergrund Portorico, rechts das Schiff des Colon, links ein Landungsboot

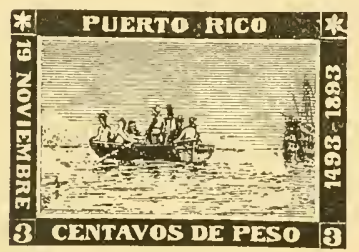
gefüllt mit Spaniern und Indiern; um das Ganze ein Rahmen mit Inschriften und zwar oben: PUERTO-RICO, links: 19 NOVIEMBRE, rechts: 1493-1893, unten Wertangahe: 3 CENTAVOS DE PESO. Grösse $37: 26 \mathrm{~mm}$.

Farbiger Druck auf weissem Papiel'; gezähnt 12.

\section{3 CENTAVOS DE PESO dunkelgrün.}

\section{Bemerkungen.}

1. Die Eutdeckung Portoricos geschah auf der zweiten Reise des Columbus, die Landung der Spanier am 19 November 1493 an dem Punkte, wo heute Mayaguez liegt. Die Jubiläums-Marke durfte daher nur von der Post-Anstalt dieser Stadt und nur an 19. November veransgabt werden. Die Marke wurde in Portorico selbst von Privaten angefertigt, ist daher von primitiver Ausführung. Narh Verfügung der Central-Verwaltung von Portorico vom 6. November 1893 sollte die Anfertigung unter Beisein eines Delegirten der General-Intendantur geschehen, die Platten nach Abzug der für nötig erachteten Zahl Marken $(20,000)$ zerstört, die am 19. November nicht verkauften Exemplare aber verbrannt werden. Die Verwendung der Jubiläums-Marke an Stelle der officiellen Marken war in das Belieben des Publikums gestellt.

Im Widerspruch hiermit steht die Mitteilung eines Sammlers aus Mayaguez, veröflentlicht in der "Union filatélica“, wonach die erste Auflage von einer englischen Firma völlig aufgekauft, und von der Generalverwaltung infolge dessen die Anfertigung einer zweiten, mit der ersten genau übereinstimmenden Auflage befohlen worden wäre. Die Verwendung der Marke wäre ausserdem bis zum 31. Dezember gestattet worden. - Näheres ist bis jetzt hierüber nicht bekannt geworden, für die Wahrheit der letzterwähnten Mitteilung scheint jedoch das rasche Fallen des Preises zu sprechen.

2. Von der Jubiläums-Marke giebt es Probe-Abzüge in 12 verschiedenen Farben; jede Farbe existirt in 20 Exemplaren, welche an einige höhere Beamte und hekannte Sammler Portoricos und Spaniens verteilt wurden. Ausserdem existiren aber noch Essais der Marke, welche als Hauptunterschied die Inschriften in schwarz auf weissem Grund, anstatt weiss auf farbigem Grund zeigen. 


\section{Ausgabe:}

vom 1. Januar 1894 an.

Nämliche Zeichnung, nur Farbenänderung.

Farbiger Druck auf weissem Papier; gezähnt 14 .

112. UN C. DE PESO braun.

113. 2 C. DE PESO violett.

114. 3 C. DE PESO oliven.

115. 4 C. DE PESO violett.

116. 5 C. DE PESO braunrot.

117. 6 C. DE PESO braunrot.

118. 8 C. DE PESO dunkelviolett.

119. 10 C. DE PESO olivengrün.

120. 20 C. DE PESO lebhaft rosa.

121. 40 C. DE PESO braunrot (braun).

122. $1 / 2$ MILA DE PESO hellbraun.

123. 1 MILA DE PESO blau.

124. 2 MILS DE PESO fleischfarben.

125. 4 MIL SE PESO gelbbraun.

\section{Bemerkung.}

Die Marken waren zum 1. Januar 1894 fertig gestellt und werden seit diesem Tage successive dem Verkehr ubergeben. Bis jetzt (Mai 1894) sind noch nicht alle Werte erschienen, die Farben einzelner Werte werden noch verschieden angegeben. 



\section{II.}

\section{Postkarten.}

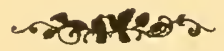





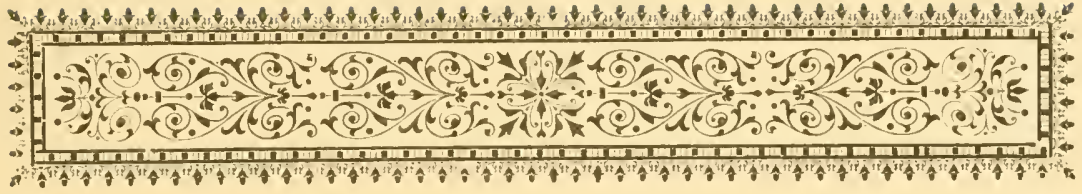

\section{* A. Postkarten aus der Zeit der Regierung des Königs Alfonso XII.}

\section{Ausgabe:}

vom 1. Januar bis Ende Juni 1878.

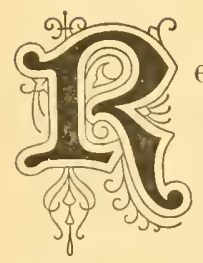

echteck aus chamois Karton, Grösse 145:98 mm; Narke in Zeichnung der $\mathrm{V}$. Ausgabe oben in der Mitte, links davon: 'TARJETA, rechts: POSTAL; vier' Adresslinien, vor der ersten in Schreibschrift: $\mathscr{C}_{\hat{\imath}} \mathscr{D}$; ein bald mehr, bald weniger stark hervortretender Unterdruck zeigt in $2 \mathrm{~cm}$ hohen englischen Buclistaben: Tarjeta Postal, umgeben von Kreisen, Strichen und sonstigen Verzierungen; unten: Nota: Lo que debe escribirse se hará en el reverso é irá firmado por el remitente. Marke, Vordruck und Umrandung in dunkelgrüner, Unterdruck in orangegelber Farke. (Taf. III, 52.)

1. 25 CS PESETA dunkelgrün auf chamois Karton.

Bemerkung.

Die Karte wurde den Vereinbarungen des Weltpostrereins entsprechend zu Ende Juni ausser Verkehr gezogen und bis zum Jahre 1885 durch keine Neu-Ausgabe ersetzt.

* Anmerkung: Da die Postkarten Portorico's sich von denjenigen Cuba's nur durch die Inschriften auf aem Markenbilde unterscheiden, so wird von nu an stets auf die Abbildungen jener verwiesen. 


\section{Ausgabe:}

vom 1. Januar 1885 bis Herbst 1887.

Karte für den Weltpostverkehr: Rechteck aus weissem Karton olıne Unterdruck, Grösse 132 : $95 \mathrm{~mm}$; Marke der $X$. Ausgabe oben rechts; links davon in fünf Zeilen untereinander: ULTRAMAR - UNION POSTAL UNIVERSAL UNION POSTALE UNIVERSELLE - ESPA $\widetilde{N} A$. - En este lado se escribe solamente la direccion; darunter drei Adresslinien, die erste mit $\mathscr{A}$ beginnend.

Marke und Vordruck in dunkelbrauner Farbe.

2. 3 C. DE PESO dunkelbraun auf weissem Karton.

\section{Ausgabe:}

von Herbst 1887 bis Herbst 1890.

Karte in gleicher Ausführung wie No. 2, nur Aênderung der Farbe des Kartons.

3. 3 C. DE PESO dunkelbraun auf verschiedenem Karton. 3 a) 3 C. DE PESO dunkelbraun auf chamois Karton,

3 b) 3 dunkelbraun auf dickem, dunkelchamois Karton.

\section{Bemerkungen.}

1. Von Karte No. 3 giebt es Stiicke mit links seitwärts verschobener Bemerkung: En este lado usw. (das n von direccion schneidet mit dem Punkte hinter ESPA NA ab), auch finden sich häufig mangelhafte Drucke ohne Punkt hinter direccion oder mit unvollständig gedruckten Buchstabeu im Vordruck.

2. Abzüge des Markenbildes allein existiren in blauer Farbe auf weissem Kartonpapier.

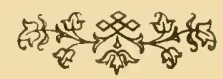




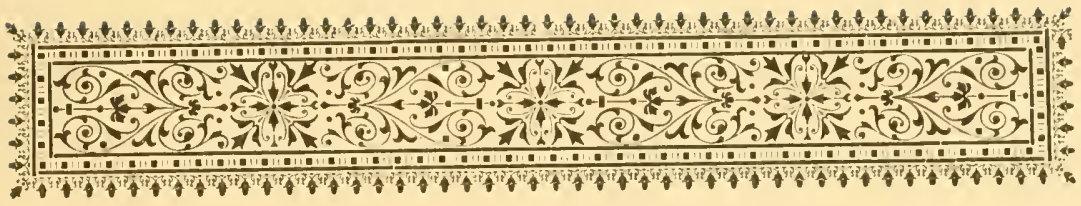

B. Postkarten aus der Zeit der Regentschaft der Königin Maria Cristina bezw. der Regierung des Königs Alfonso XIII.

IV. Ausgabe:

von Herbst 1890 bis Herbst 1892.

\footnotetext{
月圆 arte für den Weltpostverkehr: In gleicher Ausführung wie No.2, nur Marke der XII. Ausgabe.

4. 3 C. DE PESO grün auf chamois Karton.
}

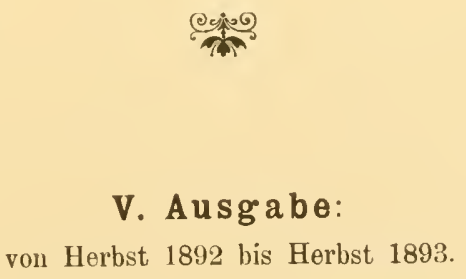

Karte für den Weltpostverkehr: In gleicher Ausfülırung wie

No.2 bezw. 4, nur Farbenänderung.

5. 3 C. DE PESO dunkelblau auf chamois Karton. 
Doppelkarte in gleicher Ausführung mit den gewöhnlichen $\mathrm{Zu}$ sätzen im Vordruck.

6. $3+3$ C. DE PESO dunkelblau auf chamois Kartun.

\author{
อxa? \\ VI. Ausgabe: \\ von Herbst 1892 an.
}

Rechteck aus chamois Karton, Grösse 145 : 98; Marke der XII. Ausgabe oben in der Mitte; links davon: TARJETA, rechts: POSTAL: darunter vier Adresslinien, die erste mit $\mathcal{O A}$ beginnend; unten links: En este lado debe escribirse solamente la dirección.

Marke und Vordruck in dunkelblauer Farbe. (Taf. III, 57.)

7. 3 C. DE PESO dunkelblau auf chamois Karton. 
II. Philippinen.

| 



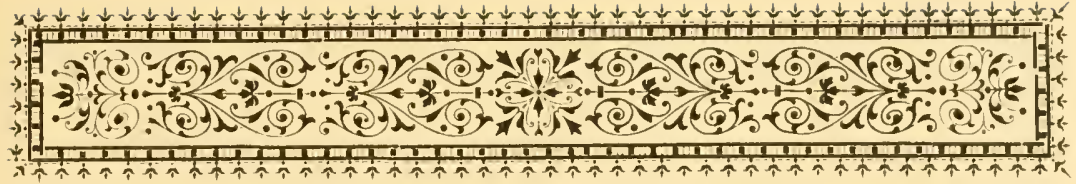

\section{Einleitung.}

Geographisches. Die Philippinen, nach König Philipp II. Islas Filipinas genannt, zwischen dem 5 und $20^{\circ}$ nördlicher Breite und dem 117 und $126^{\circ}$ östlicher Länge gelegen, bestehen ans etwa 1400 grösseren und kleineren Inseln; von denen aber nur ca. 400 bewohnt sind. Sie haben zusammen einen Flächeninhalt von 293,726 qkm. mit 6-7 Millionen Einwohner. Die Hauptinsel ist Luzon mit der Hauptstadt Manila.

An der Spitze der Verwaltung steht der auf sechs Jahre ernannte und mit absoluter Gewalt ausgestattete General-Capitäı, dem auch die Marianen und Carolinen unterstellt sind. Die administrative Einteilung unterscheidet 52 Provinzen, von denen 29 auf Luzon entfallen.

Die Geschichte der Philippinen ist, soweit sie für unsere Zwecke in Frage kommt, die spanische.

Die Verkehrsverhältnisse waren bis in die neueste Zeit äusserst vernachlässigt, wohl deshalb, weil auf dem Archipel nur ca. 10,000 Spanier leben, für die Eingeborenen aber Strassen zu banen, man nicht für nötig eraclitete. An Eisenbahnen giebt es nur die $192 \mathrm{~km}$ lange Linie von Manila nach Dagupán; die Telegraphenlinien haben eine Gesamtlänge von ca. $1200 \mathrm{~km}$ mit 40 Stationen.

Die Post war bis vor kurzer Zeit derart organisirt, dass alle Postsendungen von der Hauptpost in Manila an die Chefs der Proviuzial-Verwaltungen abgeliefert wurden, welche für die Weiter- 
befürderung Sorge zu tragen hatten und welche für ihre Arbeit mit $10 \%$ der verkauften Freimarken entschädigt wurden; jetzt ist das spanische System - siehe Cuba - auch hier eingefïhrt.

Die General-Direction hat íhren Sitz in Manila. Administraciones I. Klasse bestehen in Albay, Camarines-Sur, Ildilo, Pangatinam, Pampa, Cebu und Zamboanga; II. Klasse bestehen 7, III. Klasse 15 und IV. Klasse 24, im Ganzen 53 Postanstalten, denen wiederum eine gewisse Zahl von Carterías und Estafetas unterstellt sind.

Der Transport der Postsendungen nach dem Innern vollzieht sich per Wagen oder Pferd, an der Küste durch kleine schnellfahrende Boote. Die Verbindung mit Europa geschieht durch spanische, englische oder französische Dampfer über Brindisi, zweimal monatlich. Fahrzeit von Luzon bis Cadiz etwa 48 Tage.

Geldwährung. Ueber die Geldwährung der Philippinen zu den verschiedenen Zeiten sich ein richtiges Bild zu machen, ist ungemein schwer, da die Angaben in den verschiedenen einschlägigen Werken sich sehr widersprechen. Wir finden auf den Postwertzeichen:

bis 1864 :

1 Peso duro oder Peso fuerte $=8$ Reales de plata fuerte $=4 \mathrm{Mk}$. 1 Real de plata $\mathrm{f}$. $=2 \frac{1}{2}$ span. Reales de vellon $=0,50 \mathrm{Mk}$. 1 Real de pl. f. $=20$ cuartos. von 1864 bis 1871:

1 Peso fuerte $=100$ Céntimos de peso f. $=1000$ milésimas. von 1871 bis 1872 :

1 Peso fuerte $=2$ Escudos à $2 \mathrm{Mk}$.

1 Escudo $=100$ Céntimos de $\mathrm{E}^{0}=1000 \mathrm{Mil} \stackrel{\mathrm{s}}{\mathrm{a}}$ de $\mathrm{E}_{-}^{\mathrm{O}}$.

1 Peso $=5$ Pesetas. von 1872 bis 1876 .

1 Peseta $=100$ Céntimos de peseta $=0,80 \mathrm{Mk}$. von 1876 an:

1 Peso $=100$ Céntimos de peso $=1000$ milésimas.

Auf den Anshilfs-Marken der Jahre 1881-89 finden wir merkwürdigerweise wiederum Reales und Cuartos, ein Beweis dafüi, dass diese alten Mrünzen noch immer im praktischen Leben als Rechnungsmünze dienell.

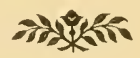




\section{I.}

\section{Briefmarken.}

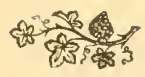





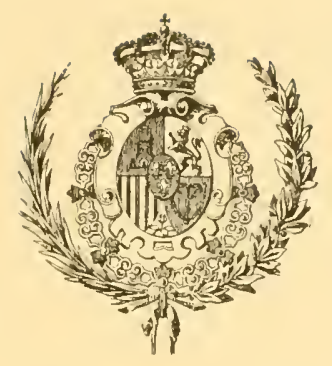

\section{A. Marken aus der Zeit der Regierung der Königin Isabella II.}

\section{Ausgabe:}

vom 1. Februar 1854 bis Juni 1855 bezw. 1856 und 1859.

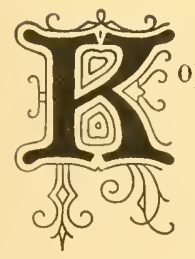

opf der Königin Isabella mit Diadem nach rechts innerhalb eines ovalen Perlenrahmens; oben und unten je ein viereckiger Schild mit Inschrift; die Ecken zwischen Rahmen und Schild mit mehr oder weniger dicken wagerechten Linien ausgefüllt. Die Ausgabe besteht aus vier Werten in zwei Typen und je 40 verschiedenen Ausführungen der Zeichnung.

In Kupfer gestochen und farbig gedruckt auf dickem, weissem und gelblichweissem Papier; ungezähnt.

I. Type: Inschrift oben: CORREOS $1854 \mathrm{Y}$ 1855, unten: FRANCO und Wertangabe.

1. 5 C (cuartos) orange in drei Schattirungen auf weissem Papier. (Taf. V, 75.)

1 a) $5 \mathrm{CS}$ orange,

$1 \mathrm{b)} 5 \mathrm{CS}$ rotorange,

$1 \mathrm{c}) 5 \mathrm{CS}$ blassorange.

2. $10 \mathrm{C}$ rot in vier Schattirungen auf weissem und gelblichem Papier. (Taf. V, 76.)

2 a) $10 \mathrm{CS}$ dunkelrot auf weissem Papier,

2 b) $10 \mathrm{CS}$ dunkelrot auf gelblichem Papier, 
2 c) 10 Cs karminrot auf weissem Papier,

2 d) $10 \mathrm{CS}$ blasskarmin auf weissem Papier,

2e) $10 \mathrm{CS}$ schmutzigrot auf weissem Papier.

II. Type: Aehnliche Zeichnung, Inschriften umgekehrt, oben: FRANCO und Wertangabe; unten: CORREOS und Jahreszahlen; gelbliches Papier.

3. 1 RI F FE (Real fuerte) blau und blauviolett in zahlreichen Schattirungen. (Taf. V, 77.)

3 a) 1 RI FIE lebhaft blau,

3 b) 1 " schieferblau,

3 c) 1 grünblau,

3 d) 1 " schmutzigblau,

3 e) 1 , preussischblau,

3) $1 \cdots$ blauviolett,

$3 \mathrm{g)} 1$ n grauviolett.

4. 2 R $\mathbf{R}^{\mathrm{TE}}$ (Reales fuerte) grün in zahlreichen Schattirungen.

4 a) 2 RS FTE gelbgrün,

4 b) $2 \%$ dunkelgelbgrin,

4 c) $2 \%$ grün,

4 d) 2 " lebhaft grün,

4 e) $2 "$ oliven,

4 f) $2 "$ bräunlich.

\section{Bemerkungen.}

1. Ueber eine Ausgabe Philippinen-Marken vom Jahre 1847 ist s. Zt. viel geschrieben und gestritten worden. Heute lohnt es nicht mehr, auf diesen Gegenstand näher einzugehen, da die Forschungen von Rondot, Moens, Maurin̄o, Argiles und Duro mit zweifelloser Sicherheit ergeben haben, dass allerdings im Jahre 1847 in Luzon die Absicht bestanden hat, die Frankirung der Briefe vermittelst Marken einzuführen und dass zu diesem Zwecke auch Marken-Entwürfe ausgeführt wurden, dass aber dieser Plan nicht die Billigung der spanischen Regierung und die Marken niemals Verwendung gefunden haben.

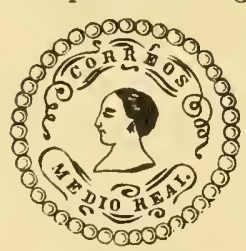
Immerhin sind diese „ersten Marken der Philippinen", welche beute im Archiv der General-Post-Direktion zu Manila aufbewahrt werden, für jeden Philatelisten von grossem Interesse. Sie bestanden aus vier Werten, waren rund und trugen in kreisförmigem, verschieden gezeichnetem Rahmen auf guillochirtem Untergrund das Bild der Konigin Isabella; über dem Kopf

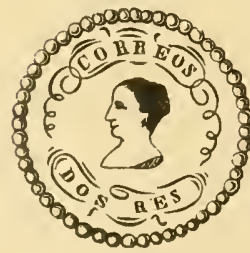
der Königin: CORREOS, darunter Wertangabe und zwar:

$\begin{array}{ll}\text { MEDIO REAL } & \text { grün, } \\ \text { DOS RES } & \text { gelb, } \\ \text { CUATRO RES } & \text { blau, } \\ \text { UN PESO } & \text { rosa, } \\ \text { ich auf weissem } & \text { Papier. }\end{array}$
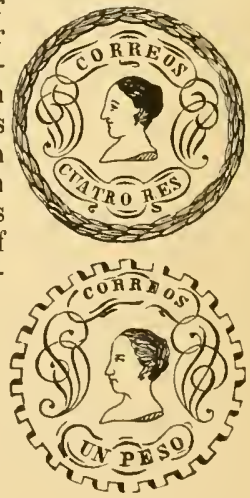
2. Die erste antliche Ansgabe von Postwertzeichen wurde durch Verfugung vom 7. Dezember 1853 angeordnet, naehdem dureh Königlichen Erlass vom 12. Januar 1853 dem General-Capitän befohlen war, die nötigen Schritte für die Einftihrung des Frankirungszwanges im inneren Verkehr der Philippinen zu treffen und dio erforderlichen Marken anfertigen zu lassen.

In den Ausfihrungsbestimmungen vom 7 Dezember 1853 wird angeordnet:

Jeder Brief für den Verkehr im Innern des Archipels ist vermittelst Briefmarken zu frankiren; Briefe his zu 1/2 onza Gewicht gelten als einfache, alle übrigen als doppelte; alle Briefe zahlen das gleiche Porto und zwar:

$$
\begin{aligned}
& \text { einfache Briefe . . . . . . . . . . . . } 5 \text { cuartos, } \\
& \text { von } 1 / 2 \text { bis } 1 \text { onza excl. . . . . . . . . } 10 \text { cuartos, } \\
& \text { ron } 1 \text { bis } 1 \frac{1}{2} \text { onza . . . . . . . . . } 1 \text { real, } \\
& \text { usf. für jede } 1 / 2 \text { onza mehr. . . . . . . . . } 10 \text { cuartos, } \\
& \text { Eingeschriebene Briefe ausser diesem Porto noch . } 2 \text { reales. }
\end{aligned}
$$

Auch auf privatem Wege beförderte versehlossene Briefe waren diesen Portosätzen entsprechend zu frankiren, widrigenfalls sie als Kontrebande angesehen wurden. Die amtliche Korrespondenz der Behörden war frei; später, am 24. Februar 1858, wurden für diese die in Spanien gebrauchten Dienstmarken eingeführt.

Diese in Manila getroffenen Bestimmungen wurden am 18. Dezember 1854 von Madrid aus dahin ergänzt, dass das Porto für einfache Briefe von den Philippinen nach Spanien vom 1. Juni 1855 ab auf 1 Real, dasjenige der eingeschriebenen Briefe auf 2 Reales festgesetzt wurde. Am 22. Juni 1855 wurde der Frankirungszwang auch auf die Briefe nach Spanien ausgedehnt

3. Die Marken der I. Ausgabe wurden auf Veranlassung der Generaldirektion der indirekten Steuern in Manila angefertigt und eharakterisiren sich als eine äusserst mangelhafte Nachahmung der spanisehen Marken des Jahres 1853. Sie wurden in Kupfer gestochen und jede Platte enthielt 40 Marken (8 Reihen a 5), welehe, da jede Marke einzeln gravirt wurde, ebensoviel Verschiedenheiten in Zeichnung des Kopfes der Königin, in den Buchstahen und im Beiwerke zeigen. Auf der Platte der 1 Real-Marke (1. der 6. Reihe) befindet sich eine Type mit CORROS anstatt CORREOS.

Das zur Verwendung gelangte Papier ist derart spröde und brüchig, dass heute sehon die Mehrzahl der noch existirenden Stücke Verletzungen aufzuweisen haben. Nur durch eine äusserst sorgsame Behandlung wird es möglich sein, diese interessanten Marken der Nachwelt zu überliefern.

4. Von der I. Ausgabe war die Marke zu 5 cuartos bis zum Juni 1855, die Marken zu 1 und 2 Reales bis zum Januar 1856 und diejenige zu 10 cuartos bis zum Jahre 1859 in Verkehr.

5. Die mangelhafte Austuhrung in Stich und Druck, sowie die Verschiedenartigkeit in der Zeichnung erleichterten den Fälschern naturgemäss sehr das Geschäft. Schon im Jahre 1855 tauchte eine Fälschung der Marke zu 5 cuartos auf, welehe, auf gelblichem Papier in dunkelgelber Farbe gedruckt, sich von den echten hauptsäehlich durch bessere Ausfunrung des Kopfes der Königin und der Inschriften unterscheidet; auch besitzt sie vicht die weissen Stellen in dem oberen Teile des Kopfes und am Halse, welche die echten Marken zeigen, sondern die Schattenstriche sind bis an den Rand der das Profil andeutenden Linie durchgezogen.

Die in grosser Menge vorkommenden Fälschungen der abrigen Werte sind Erzeủgnisse späterer Jahre.

6. In Bezug auf Abstempelungen gilt fur die Philippinen das bei Cuba (I. Ausgabe, Bemerkung 7) Gesagte. Auch hier ist der älteste Datumstempel der im Jahre 1842 für die ganze Monarchie eingefuhrte. Er trägt oben den Namen Manila, unten die Bezeichnung: Islas Filips, zwischen beiden die No. 31 
(Taf. V u. VII, 78). Die Stempelfarbe ist meist scbwarz, seltener rot oder blau. Es scheint, als habe nur die Hauptstadt Manila dieses Stempelmodell besessen, wie ja auch die Zahl der Postbezirke, in welche Spanien eingeteilt. war, mit Manila (31) endigte. Neben diesem Stempel findet man, jedoch sehr selten, ein zweites, etwas kleineres Modell, welches an Stelle von Islas Filip den Namen Luzon trägt, es ist wahrscbeinlich der für die später in's Leben gerufenen Postanstalten eingeführte Stempel. - Mit dem Jahre 1856 scheinen beide Stempel durch einen dem spanischen Modell 1853 ähulichen ersetzt worden zu sein (Tat. VII, 79); das Einführungsdatum desselben lässt sich bei der Seltenheit von Marken auf ganzem Brief nicht genau bestimmen. Das Gleiche gilt von dem spanischen Modell 1857. welches einige Jahre später auftaucht. - Was Entwertungsstempel anbelangt, so besass die Post von Manila den bekannten, auch auf den Antillen eingeführten Gitterstempel (Taf. VII, 80). Denselben erhielten später auch noch andere Postanstalten, welche ihn zum Teil, wie No. 81 auf Taf. VII beweist, noch bis in die jüngste Zeit gebrauchten. $\mathrm{Ob}$ der Punktstempel, Taf. $\mathrm{V}, 82$ und 83 , zu gleicher Zeit oder vor Einfuhrung des Gitterstempols ausschliesslich gebraucht wurde, lässt sich nicht mit Bestimmtheit sagen, jedenfalls findet er sich in vereinzelten Fällen ebenfalls bis in die neueste Zeit vor.

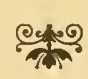

\author{
II. Ausgabe: \\ von Juni 1855 bis Januar 1859.
}

Aehnlich der vorigen Ausgabe: Kopf der Königin mit Diadem nach rechts in einem kreisrunden Rahmen, mit glattem, farbigem Untergrund; Inschriften wie bei Type I der vorigen Ausgabe; Linien zwischen Rahmen und Schildern dïmner.

Lithographirt und farbig gedruckt auf dünnem, weissem Papier; ungezähnt. (Taf. V, 83.)

\title{
5. 5 CS rot in drei Schattirungen.
}

5 a) 5 CS zinnoberrot,

5 b) 5 CS ziegelrot,

$5 \mathrm{c)} 5 \mathrm{CS}$ bräunlichrot.

\section{Bemerkungen.}

1. Die Marke wurde in Gruppen zu vier einzeln lithographirt, infolge dessen giebt es vier Abarten, die in Zeichnung, Grosse und Ausfuhrung der In- 
schriften mehr oder weniger von einander abweichen. Der Ursprung einer fünften Type, welche sich von den vier übrigen durch die Grösse $\left(18^{1} / 2: 21 \mathrm{~mm}\right.$ anstatt 19 und 191/2: $22 \mathrm{~mm}$ ), durch die Ausfïhrung des Perlenkreises, sowio durch etwas kleinere und magere Buchstaben der Inschriften unterscheidet, ist bis jetzt nicht anfgeklärt.

2. In Anbetracht des Umstandes, dass die Marke dieser Ausgabe drei und ein halbes Jahr in Verkehr gewesen, ist ihre heutige Seltenheit schwer begreiflich. Thatsächlich war ihre Verwendung jedoch nur gering, da sie nur im inneren Verkehr der Inseln gebraucht werden durfte, dieser aber bei der unbedeutenden Zabl des Schreibens kundiger Bewohner nur minimal gewesen sein konnte. Nach uns iberkommenen Nachrichten gewöhnten sich uberdies die Einwohner nur sehr langsam an die neue Frankirungsmethode und zogen noch Jahre lang die bisher ubliche Beförderung "durch Gelegenheit" vor. Besonders aber begten sie anfänglich - wahrscheinlich durch Thatsachen gerechtfertigt - ein schwer zu überwindendes Misstrauen gegen die Vorausbezahlung des Briefportos.

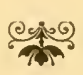

\section{Ausgabe:}

vom 1. Januar 1856 bis Ende 1864.

Marken der I. Ausgabe (A) von Cuba und Portorico (vergl. Seite 12): Kopf der Königin mit Lorbeerkranz nach rechts im Perlenkreise mit einfarbigem Untergrund; um den Kreis rechteckiger Rahmen, ausgefüllt an den beiden Seiten und in den Ecken mit Verzierungen, oben: CORREOS, unten Wertangabe. Farbiger Druck auf in Farbe und Stärke verschiedenem Papier mit Wasserzeichen (Schlingen); ungezähnt. (Taf.VII, 80.)

6. 1 R! PLATA F. grün auf bläulichem oder grünlichem Papier in zahlreichen Schattirungen.

6 a) $1 \mathrm{RL}$ PLATA F. flaschengrü,

6 b) 1 lebhaft dunkelgrtin,

6 c) $1 \quad n$ belleres grin,

6 d) 1 gelblichgrun.

7. 2 R PLATA F. braun- und orangerot auf ebensolchem Papier in zahlreichen Schattirungen.

7 a) 2 RS PLATA F. braunrot - lebhaft braunrot,

7 b) 2 " dunkelkarmin,

7 c) $2 \quad$ orangerot,

7 d) 2 blassorangerot,

7 e) 2 gelblichbraun,

7f) 2 ziegelrot. 
Bemerkung.

Ueber die Verwendung dieser Marken auf den Philippinen schweigen die meisten philatelistischen Handbïcher, gerade hierüber sind uns jedoch einige genügend aufklärende Verfügungen, einesteils des spani»chen Ministeriums der Kolonien (del Ultramar), andererseits der Finanzbehörden in Manila tiberliefert. Nur die Unbekanntschaft mit diesen amtlichen Aktenstiicken, sowio die Seltenheit dieser Marken auf ganzem Brief oder mit deutlichem Ortsstempel macht die geringe Beachtung begreiflich, welche diese Ausgabe bis jetzt gefunden.

Nach einem Königlichen Erlass vom 1. September 1854 sollten beide Marken auf den Philippinen vom 1. April 1855 an für die Postsendungen nach Spanien und dem Ausland zur Verwendung gelangen. Um die Bestände der vorhergehenden Ausgabe aufzubrauchen, wurde durch eine Verfügung vom 18. Dezember desselben Jahres dieser Zeitpunkt zuerst auf den 1. Juni 1855, dann auf den 1. Junuar 1856 verschoben. Von diesem Tage an waren beide Marken bis gegen Ende des Jahres 1864 in Verwendung. Eine Unterbrechung erlitt ihre Verwendung im Jahre 1863 aus den in Bemerkung 1 zur VIII. Ausgabe angegebenen Gründen. Warum sie auch noch im Jahre 1864, also nach Einfuhrung der IX. Ausgabe, weiterverwandt wurden, ist unerklärlich, da eine Verfügung der General-Postdirektion in Madrid vom 10. November 1864 wohl die ihr durch die Finanzbehörde von Manila angegebenen Gründe der Weiter-Verwendung billigt, dieselben aber nicht näher angiebt, der Bericht dieser letzteren Behörde uns aber nicht erhalten ist.

\section{Ausgabe:}

Januar 1859 bis (?) 1861.

Kopf der Königin Isabella mit Lorbeerkranz nach rechts in einem Perlenkreise mit einfarbigem Untergrund; um den Kreis ein viereckiger Rahmen, rechts und links mit Verzierungen, oben: CORREOS - INTERIOR (beide Worte getrennt durch einen Punkt), unten: FRANCO und Wertangabe entlialtend.

Lithographirt und farbig gedruckt auf weissem oder gelblichweissem, verschieden starkem Papier; ungezälnt.

8. $5 \mathrm{CS}$ rot in zahlreichen Abstufungen auf verschiedenem Papier. (Taf. V, 84.)

8 a) $5 \mathrm{CS}$ dunkelrot auf dickem, weissem Papier,

8 b) 5 CS lebhaft rot auf dickem, weissem Papier,

$8 \mathrm{c}) 5 \mathrm{CS}$ zinnoberrot auf dickem, weissem Papier,

8 d) $5 \mathrm{CS}$ lebhaft zinnoberrot auf dickem, weissem Papier,

8 e) 5 CS blassorange auf dickem, weissem Papier,

8 f) 5 CS dunkelorange auf dickem, weissem Papier, 
8 g) 5 CS zinnoberrot auf dickem, rauhem Papier (vergé),

$8 \mathrm{~h}) 5 \mathrm{CS}$ rotorange auf dickem, rauhem Papier (vergé),

8 i) 5 CS zinnoborrot anf dickem, gelblichem Papier,

$8 \mathrm{k}) 5 \mathrm{CS}$ zinnoberrot auf dünnem, weissem Papier,

81) 5 CS rotorange auf dünnem, weissem Papier (uni),

$8 \mathrm{~m}) 5 \mathrm{CS}$ blassrotorange auf dünnem, weissem Papier (uni),

$8 \pi) 5 \mathrm{CS}$ rot auf dünnem, gelblichem Papier,

8 o) 5 CS zinnoberrot auf dünnem, gelblichem Papier.

9. $10 \mathrm{C}$ s rosa in drei Abstufungen auf verschiedenem Papier. (Taf. V, 85.)

9 a) $10 \mathrm{CS}$ rosa auf dickem, weissem Papier,

9 b) 10 CS blassirosa auf dickem, weissem Papier,

9 c) 10 CS karminrosa auf dickem, weissem Papier,

9 d) 10 CS rosa auf dünnem, weissem Papier,

9 e) 10 CS rosa auf dickem, gelblichem Papier.

\section{Bemerkung.}

Die Bogen dieser Ausgabe setzen sich zusammen aus Gruppen von je vier Marken, welche einzeln lithographirt sind; es giebt demnach von jedem Wert vier Abarten (Taf. V, 84 und 85). Die Zahl der Gruppen auf den Bogen war in den verschiedenen Druckanflagen wechselnd, von der 5 cuartos-Marke sind wenigstens Bogen zu 56, 130 und 192 Marken bekannt, bei der Marke zu $10 \mathrm{Cs}$ wird die Anordnung wohl ebenso gewesen sein. Jede Gruppe war durch eine Einfassunglinie von der nebenstehenden getrenut; nur bei den Bogen zu 130 Marken fehlt dieselbe. Man scheint niemals grössere Mengen auf einmal gedruckt zu haben, wie aus den zahlreichen Farben- und Papier-Unterschieden hervorgeht. Die ver schiedene Dicke des Papiers hatte auch eine Verschiedenheit der Grösse der Marken zur Folge, dieselbe wechselt zwischen $18^{3 / 4}: 22^{1} / 4,18^{1} / 2: 231 / 4$ und $19: 23^{1} / 4 \mathrm{~mm}$.

\begin{tabular}{|l|l|}
\hline 1 & 2 \\
\hline 3 & 4 \\
\hline
\end{tabular}

Obgleich die Abweichungen der vier Typen nur unbedeutend sind und sich ans Tafel V, 84 und 85, leicht erkennen lassen, sollen sie doch für Spezialsammler kurz angegeben werden, wobei vorausgeschickt werden muss, dass die Anordnuug der Typen innerhalb der Gruppen in nebenstehender Weise getroffen war.

I. Type: Der Buchstabe C von CORREOS steht schräg, derart, dass sich der obere Teil etwas nach links neigt; die Zahl der Maschen des Netzwerkes in den unteren Ecken zwischen Perlenkreis und Rahmen ist auf der untersten Reihe auf beiden Seiten $5 \frac{1}{2}$; die Bisste der Königin ist unten in gerader, fast wagerecht laufender Linie abgeschnitten.

II. Type: Im unteren Teil des Rahmens befinden sich auf der rechten Seite drei volle blumenartige Verzierungen, während die drei übrigen Typen deren nur 2 bezw. $2 \frac{1}{2}$ besitzen: auf der unteren Linie liegen links vier, rechts fünf Maschen; die Büste der Königin ist schräg und zugleich etwas ausgerundet abgeschnitten.

III. Type: Das C von CORREOS wie bei Type I; auf der untersten Reihe links 5 , rechts $4 \frac{1}{2}$ Maschen; die Büste ist unten schräg und leicht ausgerundet abgeschnitten.

IV. Type: Der Buchstabe $N$ von INTERIOR steht auffallend nach rechts geneigt, unter ihm findet sich bei der Marke zu 5 Cs meist, bei derjenigen zu 
10 Cs fast stets eine weisse Stelle in der Zeichnung; der Kopf der Königin erscheint etwas zierlicher, die obere Haarlinie mehr gerundet; auf der unteren Linie links $4 \frac{1}{2}$, rechts 5 Maschen; der Abschnitt der Buste wio bei Type III. einstimmend.

Die Typenverschiedenheiten beider Werte der Ausgabe sind vőllig uber-

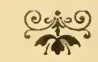

\section{Ausgabe: \\ von (?) 1861 bis August (?) 1862.}

Aehnliche Zeichnung wie vorige Ausgabe, nur die Buchstaben der Inschriften grösser, die Perlen des Kreises kleiner, die Linien der Zeichnung des Kopfes schärfer hervortretend: Punkte an Stelle der bei der vorigen Ausgabe netzwerkartigen Füllung des Raumes zwischen Kreis und Rahmen.

Lithographirt und farbig gedruckt auf dünnem, weissem oder gelblichem Papier; ungezähnt. (Taf. V, 86.)

\section{0. $5 \mathrm{CS}$ zinnoberrot in drei Abstufungen auf verschiedenem Papier.}

10 a) 5 CS zinnoberrot auf weissem Papier,

10 b) 5 CS lebhaft zinnoberrot auf weissem Papier,

10 c) 5 CS ziegelrot auf weissem Papier,

$10 \mathrm{~d}) 5 \mathrm{CS}$ zinnoberrot aut gelblichem Papier.

\section{$B \theta m e r k u n g$.}

Das Datum der Einziehung dieser Marke ist zweifelhaft, da die in den Händen des Publikums befindlichen Stiicke wahrscheinlich anfurebraucht werden durften. Während mir einerseits zwei Stacke mit deutlichem Stempel vom Januar 1863 vorlagen, spricht andererseits ein Königlicher Erlass vom 18. September 1863 an den General-Kapitän der Philippinen von einer Ausgabe, welehe am 8. August 1862 angeordnet worden. Dem ganzen Zusammenhang des Schrift. stluckes nach kann damit uur die folgende Ausgabe gemeint sein. 


\title{
VI. Ausgabe: \\ von August 1862 bis Januar 1863.
}

Aelnnliche Zeichnung, wie bisher, nur Kopf der Königin und Buchstaben der Inschriften etwas kleiner; der Kreis berührt oben und unten nicht den Rahmen; die netzwerkartige Füllung zwischen Kreis und Rahmen ist weitmaschiger.

Lithographirt und farbig gedruckt auf dickem, weissem Papier; ungezähnt. (Taf. V, 87.)

\section{1. $5 \mathrm{C}$. rot in vier Abstufungen.}

11 a) 5 CS rot,

11 b) 5 CS lebhaft rot,

$11 \mathrm{c)} 5 \mathrm{CS}$ blassrot,

11 d) 5 CS dunkelrot.

\section{Bemerkungen.}

1. Die Richtigkeit der oben angegebenen Gebrauchsdaten ist nicht unbestreitbar.

2. Von Marke No 13 giebt es Abarten mit zwei Punkten hinter CORREOS, einem Punkt nach FRANCO und zwei Punkten hinter CS:, Unterschiede, welche wohl durcb den vielfach mangelhaften Druck hervorgerufen wurden.

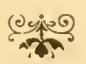

\author{
VII. Ausgabe: \\ von Januar bis Dezember 1863.
}

Aehnliche Zeichnung, nur bessere Ausführung: zwischen CORREOS und INTERIOR zwei Punkte (:); die netzwerkartige Füllung des Raumes zwischen Kreis und Rahmen wieder enger. Die Ausgabe erschien in zwei Typen, welche jedoch nur geringe Unterschiede anfweisen.

Lithographirt und farbig gedruckt auf dickem, weissem oder gelblichem Papier; ungezähnt. 
1. Type: Nach INTERIOR kein Punkt, die Buchstaben der Inschriften kleiner, der viereckige Rahmen oben und unten schmaler.

12. $5 \mathrm{CS}$ zinnoberrot in drei Abstufungen. (Taf. V, 88.)

12 a) $5 \mathrm{CS}$ zinnoberrot,

12 b) $5 \mathrm{Cs}$ lebhaft zinnoberrot,

12 c) 5 CS ziegelrot.

13. 10 CS rosa in zwei Abstufungen auf verschiedenem Papier. (Taf. V, 89.)

13 a) $10 \mathrm{CS}$ rosa auf weissem Papier,

$13 \mathrm{~b}) 10 \mathrm{CS}$ karminrosa auf weissem Papier,

$13 \mathrm{c}) 10 \mathrm{CS}$ karminrosa auf gelblichem Papier.

II. Type: Nach INTERIOR ein Punkt, die Buchstaben der Inschriften etwas grösser, der viereckige Rahmen oben und unten breiter.

14. $1 \mathbf{R}^{\mathrm{L}}$ violett. (Taf. V, 90.)

15, 2 R ș blau. (Taf. V, 91.)

Bemerkungen.

1. Zur Herstellung der Marken zu $10 \mathrm{CS}$ wurde die Platte der $5 \mathrm{CS}$ benutzt, indem man die Ziffer 5 entferute und durch 10 ersetzte. Während alle 5 CSMarken völlig gleich sind, giebt es auf dem Bogen der 10 CSS-Marken ebenso vicl Verschiedenheiten als Marken, indem die Ziffer 10 in Form und Grösse fast bei jeder Marke verschieden ist. Vielfach lassen sich noch zwischen der 1 und der 0 die Reste der 5 erkennen. In gleicher Weise wurde zur Herstellung der $1 \mathrm{RL}=$ Marke diejenige $\mathrm{zu} 2 \mathrm{RS}$ verwandt, indem die Ziffer 2 und das $\mathrm{S}$ von $\mathrm{R}$ S durch 1 und $\mathrm{R}_{t}^{\mathrm{L}}$ ersetzt wurden.

2. Da die Marken zu 1 und $2 \mathrm{R}$, sehr selten postalisch entwertet gesehen wurden uud alle im Jahre 1863 von den Philippinen kommenden Briefe entweder die RealMarken der III. oder der VIII. A usgabe trugen(vergl. Bener kung 1 zur VIII. Ausgabe), so hielt man lange die Inschrift: INTERIOR für einen Fehler und glaubte die Marken wegen dieses Fehlers alsbald ausser Verkehr gesetzt. Dies wal jedoch nicht der Fall, beide Marken waren vielmehr. wie die luschrift besagt, nur für den inneren Verkehr bestimmt und ihre Seltenheit in gebrauchtem Zustand erklärt sich sehr einfach dadurch, dass Briefe über 1 onza Gewicht (vergl. Tarif: Bemerk. 2 zur I. Ausgabe) nur ausnahmsweise zur Versendung gelangten. 


\section{Ausgabe: \\ von Frihjahr bis gegen Ende November 1863.}

A ushilfs-Marken. A ehnliche Zeichnung wie vorige Ansgabe, nur zum Teil wieder schlechtere Ausführung; Inschrift: CORREOS anstatt: CORREOS INTERIOR.

Lithographirt und farbig gedruckt auf weissem und gelblichweissem Papier; ungezähnt.

I. Frühjahr 1863. Mittelstiick der vorigen Ausgabe, Ausführung teilweise mangelhaft, Inschriften vielfach undeutlich und verschwommen, Punkte vor' und hinter CORREOS, sowie hinter dem $\mathbf{F}$ der Wertangabe manchmal fehlend. (Taf. V, 9.2.)

16. 1 RU PLATA F. grün in zahlreichen Schattirungen auf weissem oder gelblichweissem Papier.

16 a) 1 RL PLATA F. flaschengrun auf weissem Papier,

16 b)

$16 \mathrm{c}) 1$

russischgrun

16 d) 1

dunkelblaugrin

dunkelgraugrün

16 e) 1

blassgraugrün

16 f) 1

graugrün auf gelblichem Papier.

II. Sommer 1863. Ausführung besser, Kopf der Königin unbedentend verändert, Büste in einer Spitze endigend, der Perlenkreis ans weniger und dickeren Perlen bestehend, Inschriften grösser und deutlicher, Verzierungen immerhalb des Rahmens grösser'. (Taf. V, 93.)

17. $1 \mathrm{R}_{1}^{\mathrm{PLATA}} \mathrm{F}$. grün in drei Schattirungen.

17 a) $1 R$, PLATA $F$. gelbgrün,

17 b) $1 \quad$ grasgrün,

17 c) $1 \quad$ graugrün.

Bemerkungen.

1. Ueber Charakter, Entstehungsweise, Typen und Gebrauchsdaten der in Jahre 1863 anf den Philippinen ausgegebenen 1 Rl.-Marken, sowie uber ihr Verhältnis zu den gleichwertigen und gleichzeitig gebrauchten Marken der III. Ausgabe herrscht vielfach Unklarheit.

Durch Königlichen Erlass vom 1. September 1854 war bestimmt worden, dass in Zukunft nur noch die fiur den Verkehr im Inneren des Archipels bestimmten Werte zu 5 und $10 \mathrm{CS}$ in Manila angefertigt, die für den Verkohr mit Spanien und dem Ausland zur Verwendung gelangenden Marken zu $1 \mathrm{R}$ ! ınd $2 \mathrm{R}$. dagegen aus Madrid bezogen werden sollten. Gründe für dicse 
Anordnung waren nicht angegeben, sie bestanden aller Wahrscheinlichkeit nach darin, dass man sich schämte, die lächerlich primitiven Erzeugnisse der Philippinischen Technik dem Auslande vor Augen zu führen, der Bedarf an Marken für den inneren Verkehr aber damals sich schwer übersehen liess. Aus den in Bemerkung 1 zur III. Ausgabe angegebellen Ursachen verzögerte sich die Verwendung der in Madrid hergestellten Marken bis zum 1. Januar 1856, von diesem Tage an bis zum Januar 1864 aber waren dieselben die einzigen offiziell gültigen Markenwerte für den Verkehr mit dem Ausland.

Aus einem uns überlieferten Rundschreiben der G. P. D. zu Madrid vom 24. September 1863 geht nun herror, dass die Finanzbehörde zu Manila infolge eingetreten n Mangels an Marken zu 1 R G gezwungen gewesen war, 30,000 Marken dieses Wertes herstellen zu lassen und gebeten hatte, der Zirkulation derselben in Spanien kein Hindernis in den Weg zu legen, d. h. Briefe, welche mit derartigen Marken beklebt seien, nicht als unfrankirt anzusehen. Dies sind die Marken der VIII. Ausgabe.

Wir haben es laher mit "Aushilfsmarken" zu thun, welche nur so lange in Verwendung kamen und kommen durften, als der Mangel an Marken der III. Ausgabe andauerte, d. h. bis gegen Ende November. Leider giebt das erwähnte Rundschreiben weder das Ausgabedatum der in Manila angefertigten Marken an, noch enthält es eine Mitteilung darüber, ob mit der Zahl 30,000 beide oben aufgeführten Typen gemeint sind. $\mathrm{Da}$ uns sonst kein amtliches Aktenstlick über diese Marken erhalten ist, so dürfte es unmöglich sein, das Ausgabedatum beider Typen mit Genauigkeit anzugreben.

Aus dem Charakter einer eiligst hergestellten Aushilfsmarke erklärt sich auch die in der Februar-Nummer 1894 des T. P. beschriebene Herstellung der Marke No. 16. Nach dieser Beschreibung besteht die Marke No. 16 aus 2 Teilen, dem Mittelstück (Kopf der Königin mit Perlenkreis) und dem Rahmen, welche in der Art der zweifarbig gedruckten Marken in einander eingeschoben sind. Das Mittelstïck sei von den Marken der VII. Ausgabe entnommen, der Rahmen neu hinzugefügt worden; da das Mittelstück nicht immer genau in der Mitte stehe, sondern sich vielfach mehr einer oder der anderen Seite des Rahmens nähere, so gäbe es auf dem Bogen ebensoviele Typen, als Marken (uach Moeus 50, nach anderen Augaben nur 24, d. h. 4 Reihen à 6); die Befestigungspunkte des Mittelstückes, welche ursprünglich weisse Stellen ergaben, seien durch die farbige Ziffer 1 verdeckt worden.

2. Von Marke No. 16 unterschied mau bisher stets zwei Typen, von welchen sich die eine durch bessere Ausfïhrung und deutlichere Inschriften auszeichnen, während die andere dünne und unvollständig zum Ausdruck gebrachte Inschriften, ausserdem aber einen Punkt hinter dem Wort CORREOS haben sollte.

Neuere Forschungen haben jedoch ergeben, dass von einer Typenverschiedenheit keine Rede sein kann, dass es vielmehr nur zwei in der Farbe allerdings sebr verschiedene Abzüge von einer und derselben Platte sind, von denen der letzte infolge starker Abnutzung der Platte und Anwendung zu flussiger Druckfarbe eine Reihe von mangelhaften Drucken (fehlende Punkte vor und hinter CURREOS, sowie hinter dem F der Wertangabe, OORREOS anstatt CORREOS u. a) aufweist. Damit ist auch die Seltenheit der Marke ohne Punkt hinter Correos erklärt. Die starke Abnutzung der Platte ist dann wahrscheinlich die Ursache der Herstellung der neuen Type No. 17 gewesen. -

3. Mit dieser Ausgabe endigen die in Manila angefertigten Marken. Ihre schlechte Ausführung in Zeichnung und Druck, der häufige Wechsel der Papiersorte, die zahlreichen Farbenschattirungen, ferner der Mangel an ausreichendem amtlichem Aktenmaterial, sowio schliesslich die Schwierigkeit, Stücke derselben auf ganzem Brief oder mit deutlichem Aufgabestempel zu erhalten, - Alles dies macht eine genane Urdnung ungemein schwierig. 


\section{Ausgabe: \\ von Januar 1864 bis Januar 1870.}

Zeichnung der XII. Ausgabe Spaniens: Kopf der Königin mit Diadem nach links in ovalem, mit Ornamenten ausgefïlltem Rahmen, welcher in den Ecken Kreise bildet; oben auf einem Bande: CORREOS, unten Wertangabe.

Farbiger Druck auf dickem, mehr oder weniger stark gefärbtem Papier : ungezähnt. (Taf. VI, 94.)

18. $3^{1 / 8}$ CENT. Po $F^{\mathrm{E}}$ (Céntimos de peso fuerte) schwarz auf chamois Papier.

19. $6^{2} / 8$ CENT. P $\mathrm{F}^{\mathrm{E}}$ grün in zwei Abstufungen auf mattrosa gefärbtem Papier.

19 a) $6 \frac{2}{8}$ CENT. $\mathrm{P}_{1}^{0} \mathrm{FE}$ grün auf mattrosa Papier,

19 b) $6 \frac{2}{8}, \quad$ dunkelgriin auf mattrosa Papier.

20. $12^{4} / 8$ CENT. $P^{0} F^{E}$ blau in zwei Abstufungen auf fleischfarbenem Papier.

20 a) $12 \frac{4}{8}$ CENT. Po FE blau auf fleischfarbenem Papier,

20 b) $12^{4}: 8$ dunkelblau auf fleischfarbenem Papier.

21. $25 \mathrm{CENT}$. Po $\mathrm{F}^{\mathrm{E}}$ rot in zwei Abstufungen auf mattrosa, manchmal fast weissem Papier.

21 a) 25 CENT. Po FE rot auf mattrosa Papier,

21 b) 25 zinnoberrot auf mattrosa Papier.

Bemerkuug.

Das Gesetz vom 19. Juli 1849 hatte für Spanien und seine Kolonien das metrische System für die Geldwährung angenommen und das Jahr 186.2 als Einführungsjahr desselben bestimmt. Die Ausführung des Gesetzes vèrzögerte sich im Mlutterlande bis zum Jahre 1866, auf den Philippinen bis zum Jahre 1864. Die vier Werte dieser Ausgabe entsprechen den bisherigen Marken zu 5 und 10 cuartos, 1 und 2 Reales. 


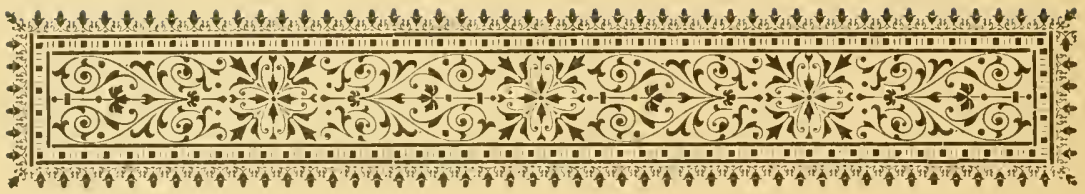

\section{B. Marken der Provisorischen Regierung.}

\section{Ausgabe:}

von Dezember 1868 bis Januar 1870.

ie Marken der vorigen Ausgabe mit schwarzem Aufdruck von: Habilitado por la nacion.

29. $3^{1 / 8}$ CENT. P $\mathrm{F}^{\mathrm{E}}$ (Céntimos de peso fuerte) schwarz auf chamois Papier.

23. $6 \frac{2}{8}$ CENT. $P^{0} \mathrm{~F}_{i}^{\mathrm{E}}$ grün in zwei Abstufungen auf mattrosa gefärbtem Papier.

23 a) $6 \frac{2}{8}$ CENT. Po FF grün auf mattrosa Papier,

23 b) $6 \frac{2}{8}, \quad$ dunkelgriun auf mattrosa Papier.

24. $12 \%$ CENT. $P^{0} F_{i}^{E}$ blau in zwei Abstufungen auf fleischfarbenem Papier.

24 a) $124 / 8$ CENT. Po FE blau auf fleischfarbenem Papier,

24 b) $12^{4} / 8$ dunkelblau auf fleischfarbenem Papier.

25. 25 CENT. $P^{0} F^{E}$ rot in zwei Abstufungen auf mattrosa, manchmal fast weissem Papier.

25 a) 25 CENT. PO FE rot auf mattrosa Papier,

25 b) $25 \quad$ zinnoberrot auf mattrosa Papier.

Bemerkungen.

1. Am 21. Oktober 1868 waren an den Civilgouverueur der Philippinen 27 Stempel "HABILITADO POR LA \ACION" abgesandt worden mit dem Befehl, die zirkulirenden Marken pp. damit zu überdrucken. Da die 
Stempel erst Mitte Dezember in die Hände der betreffenden Behorden gelangten, so ist es klar, dass im Jahre 1868 nur wenige Marken iberdruckt werden knnnten. Die grosse Mchrzahl der in Sammlungen befindlichen Stiicke ist daher ungebraucht und wohl erst nachträglich habilitirt. Die Stempel gehörten sămtlich dem Typus von Vizcaya an (vergl. Teil I, Seite 51). Ueber die Habilitimng anderer' Werte vergl. XII. und XIV Ausgabe.

2. Wie bei allen mit der Hand ausgefubrten Aufdrucken ist der Sitz derselben sebr unregelmässig, bald wagerecht, bald senkrecht, oft auch verkehrt. Von der Aufzahlung dieser philatelistisch ganz gleichgultigen Abarten wird hier und später Abstand genommen.

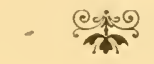

\section{Ausgabe:}

von Anfang 1870 bis gegen Ende 1871.

Zeichnung der XX. Ausgabe Spaniens: Frauenkopf mit Mauerkrone, darüber ein Stern, in einem Oval mit glattem, farbigem Untergrund; über und unter dem Oval auf einem um dasselbe sich schlingenden Band: CORREOS bezw. Wertangabe; unter dem Halsabschnitt die Initialen E. J. (Eugenio Julia).

Farbiger Druck auf weissem Papier; gezälnt 14. (Taf. VI, 95.)

26. 5 CS DE E? (Céntimos de escudo) blau in zwei Abstufungen. 26 a) 5 CS DE EO blau, 26 b) 5 dunkelblau.

27. $10 \mathrm{C} S \mathrm{DE} \mathrm{E}^{?}$ grün in zwei Abstufungen.

27 a) $10 \mathrm{CSS}$ DE Ẹ grün,

27 b) $10 \quad "$ dunkelgrin.

28. $20 \mathrm{CS} \mathrm{DE}$ E: gelblichbraun.

29. $40 \mathrm{CS}$ DE $\mathrm{E}^{0}$. karmin in zwei Schattirungen.

29 a) 40 CS DE E? leblaft karmin,

29 b) $40 \quad "$ karminrosa.

\section{Bemerkung.}

Von sämtlichen Werten giebt es Essais in blauer Farbe auf weissem Kartonpapier. Auch giebt es in gleicher Zeichnung den Wert $12 \mathrm{CS}$ DE PTA karminrot auf weissem Papier, gezähnt. 


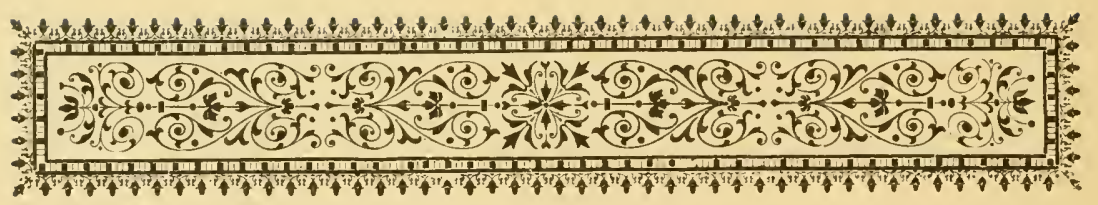

\section{Marken aus der Zeit der Regierung des Königs Amadeo.}

XII. Ausgabe:

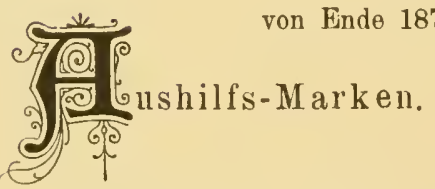

I. Ende 1871. Ausgabe des Jahres 1863 (VIII) mit schwarzem Aufdruck von "HABILITADO POR LA NACION" im Typus von Vizcaya (vergl. I. Teil, Seite 51).

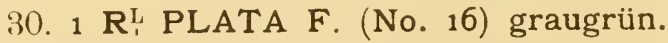

31. 1 R! PLATA F. (No. 17) grün in zwei Schattirungen. (Taf. V, 93.)

31 a) 1 Rl PLATA F. gelbgrün,

31 h) 1 grasgrün.

II. Anfang 1872. Ausgabe des Jahres 1863 (VII) mit dem nämlichen Aufdruck.

32. 5 CS zinnoberrot.

33. $1 \mathbf{R}$ ! violett.

34. $2 \mathrm{R}$ \$̣ blau. 
III. Desgleichen 1872. Ausgabe vom 1. Januar 1856 (III) mit dem nämlichen Aufdruck.

35. $1 R_{\text {c }}^{\mathrm{L}}$ PLATA F. grün.

36. 2 R PLATA F. rot.

\title{
Bemerkung.
}

Gegen Ende des Jahres 1871 waren die Marken der XI. Ausgabe aufgebraucht. Da ein Ersatz aus Spanien ausblieb, so war die General-Post-Direktion in Manila gezwungen, die Restbestände fruherer Ausgaben wieder in Verkehr zu setzen.

\author{
XIII. Ausgabe: \\ von Oktober 1872 bis Ende 1873.
}

Kopf des Königs Amadeo zu 3/4 nach rechts imnerhalb eines viereckigen Rahmens, Untergrund mit wagerechten Linien ausgefiillt; im Rahmen auf vier, an den Ecken abgerundeten Schildern Inschriften und zwar oben: CORREOS, zu beiden Seiten Wertangabe, unten: FILIPINAS. Die Ausgabe besteht aus zwei Typen.

Farbiger Druck auf weissem Papier; gezähnt 14. (Taf. VI, 96.)

I. Type: Buchstaben der Wertangabe in dïnnen, einfachen Buchstaben.

37. 12 CENTS, DE PESETA rosa in zwei Schattirungen. 37 a) 12 CENTS. DE PESETA rosa,

37 b) 12 karmin.

38. 25 CENTS. DE PESETA lila in zwei Schattirungen. 38 a) 25 CENTS. DE PESETA lila, 38 b) 25 grau. 
39. 1 PESETA 25 CENTS. braun in drei Schattirungen.

39 a) 1 PESETA 25 CENTS. braun,

39 b) 1 " 25 , gelblichbraun,

$39 \mathrm{c)} 1 \quad, \quad 25 \%$ rotbraun.

II. Type: Buchstaben der Wertangabe in doppelten Linien.

40. 16 CENTS. DE PESETA blau in zwei Schattirungen. 40 a) 16 CENTS. DE PESETA blau.

40 b) 16 graublau.

41. 62 CENTS. DE PESETA lila in zwei Schattirungen. 41 a) 62 CENTS. DE PESETA lila,

41 b) $62 \quad$ fliederfarben.

\section{Bemerkung.}

Von den Marken dieser Ausgabe giebt es Essais beider Typen in abweichenden Farben auf weissem oder farbigem Papier, gezähnt oder ungezähnt. Einige derselben sind auf irgend eine illegale Art postalisch entwertet worden und werden daher vielfach irrtümlich als Fehldrucke aufgeführt. Es wurden bekannt:

in I. Type: 12 Cents de Peseta rosa auf weissem Papier,

gelbiichbraun auf weissem Papier, 1 Peseta 25 Cents blau auf fleischfarben, gezähnt 14, gummirt,
in II. Type: 62 Cents de Peseta rosa, gelblichbraun, blassviolett, grauviolett und blau auf weissem Papier, gezähnt 14, gummirt, grün auf weissem Papier, rosa, gezähnt 14 , gummirt. 


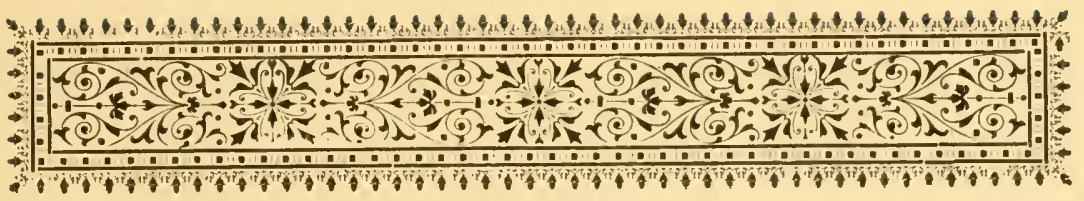

\section{Marken der Republik.}

\section{Ausgabe:}

1873 bis 1875 .

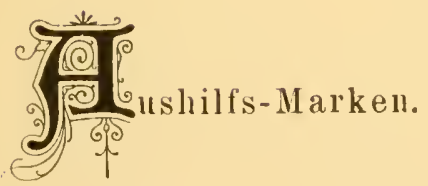

I. Ausgabe vom August 1862 (VI) mit schwarzem Aufdruck von "HABILITADO POR LA NACION" im Typus von Vizcaya. (Taf. V, 97).

42. $5 \mathrm{C}$. zinnoberrot in drei Abstufungen.
42 a) $5 \mathrm{CS}$ zinnoberrot,
42 b) 5 "lebhaft zinnoberrot,
$42 \mathrm{c)} 5$, ziegelrot.

I1. Ausgabe vom Jahre 1854 (I) mit dem nämlichen Aufdruck.

43. $1 \mathrm{R}^{\mathrm{L}} \mathrm{F}^{\mathrm{TE}}$ blauviolett.

11I. Ausgabe vom Jahre 1859 (IV) mit dem nämlichen Aufdruck.

44. 10 $\mathrm{C}$. rosa in zwei Abstufungen.

44 a) 10 Cs rosa,

44 b) 10, blassrosa. 
Bemerkungen.

1. Der Aufdruck wurde notwendig infolge der im Februar erfolgten Thronentsagung des Königs Amadeo.

2. Die Marke zu $10 \mathrm{CS}$ kommt mit Aufdruck in ihren vier Typen vor; von der Marke zu 1 RL des Jahres 1854 sollen im Ganzen nur sieben Stücke mit Aufdruck existiren, thatsächlich können auch die Restbestände dieser Marke im Jahre 1873 nur äusserst gering gewesen sein (vergl. Bemerk. zu Ausgabe III).

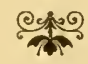

\section{Ausgabe:}

Ende 1874 bis Herbst 1875.

Zeichnung der $\mathbf{X}$. Ausgabe von Cuba und Portorico: España, als sitzende Frauengestalt dargestellt, in der rechten Hand einen Olivenzweig, den _linken Arm auf ein Wappenschild stützend; liniirter Untergrund; oben auf einem Band: FILIPINAS; zu beiden Seiten in weissen Buchstaben auf farbigem Grund: CORREOS, unten auf rechteckigem Schild Wertangabe zwischen zwei Ecksternen; in der rechten unteren Ecke: E. J., die Initialen des Kupferstechers Eugenio Julia.

Farbiger Druck auf weissem Papier; gezälnnt 14. (Taf.VI, 98.)

45. $12 \mathrm{C}$ DE PESETA lila in zwei Schattirungen.

45 a) 12 CS DE PESETA lebhaft lila,

45 b) 12 " graulila.

46. $25 \mathrm{C}$ DE PESETA ultramarinblau in zwei Schattirungen. 46 a) 25 CS DE PESETA lebhaft ultramarinblau, 46 b) $25 \quad "$ blassultramarinblau.

47. $62 \mathrm{C}$ DE PESETA rosa in zwei Abstufungen. 47 a) 62 CS DE PESETA lebhaft rosa, 47 b) 62 rosa.

48. 1 PESETA 25 CS braun.

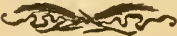




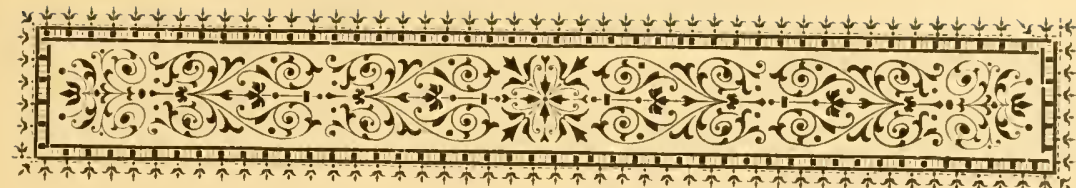

\title{
E. Marken aus der Zeit der Regierung des Königs Alfonso XII.
}

\author{
XVI. Ausgabe: \\ von Januar 1876 bis (?) 1877.
}

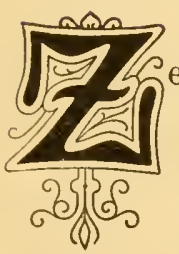

eichnung der XXVI. Ausgabe Spaniens: Kopf des Königs Alfonso XII. nach rechts in einem Oval mit liniirtem Untergrund; um das Oval ein rechteckiger Rahmen, ausgefüllt in den Ecken mit den Wappen von Castilien und Leon, an den Seiten mit Ornamenten, in deren Mitte sich ein kleiner Schild mit: CORREOS befindet, oben durch: FII,IPINAS zwischen zwei kleinen Sternen, und unten durch die Wertangabe; in den Ecken zwischen Oval und Rahmen die Lilien von Bourbon, auf dem Halsabschnitt die Initialen des Kupferstechers Julia: E. J.

Farbiger Druck auf weissem Papier; gezähnt 14. (Taf.VI,100.)

I. 1876 .

49. 2 C , DE PESO karminrosa in zwei Abstufungen.

49 a) 2 CS DE PESO rosa,

49 b) 2 narmin. 
50. 12 CS DE PESO lila in drei Abstufungen.

$$
\begin{array}{llll}
50 \text { a) } & 12 & \text { CS DE } & \text { PESO lila, } \\
50 \text { b) } 12 & " & \text { blasslila, } \\
50 \text { c) } 12 & " & \text { violett. }
\end{array}
$$

51. $20 \mathrm{C}^{\mathrm{S}}$. DE PESO braunviolett.

52. $25 \mathrm{CS}$ DE PESO grün.

II. 1877. Ergänzungswerte.

53. $6 \mathrm{C}$. DE PESO orange in zwei Abstufungen.

53 a) 6 CS DE PESO orange,

$53 \mathrm{b)} 6$, dunkelorange.

54. 10 CS DE PESO blau in drei Abstufungen.

54 a) $10 \mathrm{CS}$ DE PESO blau,

54 b) 10 lebhaft blau,

54 c) $10 \quad$ dunkelblau.

III. August 1877. A ushilfs-Marke: Marke No. 49 mit schwarzem Aufdruck: HABILITADO $-12 \mathrm{C}$, $\mathrm{P}^{\text {TA }}$ in zwei Zeilen imnerhalb eines rechteckigen, an den Ecken abgestumpften Rahmens $\left(16^{1 / 2}: 11 \mathrm{~mm}\right)$. (Taf. VI, 100.)

55. $12 \mathrm{C}$, auf $2 \mathrm{C}$. DE PESO karmin in zwei Abstufungen. 55 a) $12 \mathrm{CS}$ auf $2 \mathrm{C}$. DE PESO karmin,

55 b) $12 \quad 2 \quad, \quad$ karminrosa.

IV. Ende 1877.

56. 2 CS DE PESO blau.

\section{Bemerkungen.}

1. Die Marke zu 2 CS d. p. soll nach Moens schon im August 1875 verausgabt worden sein.

2. Die Marken zu 25, 10, 12 und 2 CS (rosa und blau) giebt es auch ungezähnt.

3. Von Essais sind nur bekannt:

2 CS DE PESO in dunkelblau, violett, braun, karmin, grün und orange, gezähnt und ungezähnt, meist gummirt,

25 CS DE PESO braun auf grüem Papier, gezähnt und ungezähnt. 


\section{Ausgabe:}

vom Januar 1878 bis Januar 1880.

Zeichnung der vorigen Ausgabe, nur Aenderung der Wertangabe und Wegfall der beiden Sternchen vor und hinter dem Worte: FILIPINAS.

Farbiger Druck auf weissem Papier; gezähnt 14. (Taf.VI, 99.)

I. 1878 .

57. 25 MILS, DE PESO schwarz.

58. 50 MIL, DE PESO weinrot.

59. o,0625 DE PESO lila in zwei Schattirungen. 57 a) 0,0625 DE PESO lila, 57 b) 0,0625, graulila.

60. 100 MILS DE PESO karmin in zwei Abstufungen. 60 a) 100 MILS DE PESO lebhaft karmin, $60 \mathrm{~b}) 100 \quad "$ blasskarmin.

61. 125 MILS DE PESO blau in zwei Abstufungen. 61 a) 125 MILS DE PESO blau, 61 b) $125 \quad "$ blassblau.

II. 1878. A ushilfs-Marken. Marke No. 58 mit verschiedenfarbigem Aufdruck: HABILITADO $-12 \mathrm{C}$. P. Zeilen innerhalb eines rechteckigen, an den Ecken abgestumpften Rahmens (wie bei No. 55).

62. $12 \mathrm{CS}$, auf 25 MILS DE PESO schwarz auf schwarz.

63. 12 C , auf 25 MILS DE PESO blau auf schwarz.

III. 1879. Ergänzungswerte bezw. Farbenänderung.

64. 25 MILS, DE PESO grün.

65. 100 MILS DE PESO hellgrün.

66. 200 MILS DE PESO rosa in drei Schattirungen.

66 a) 200 MILS DE PESO rosa, 66 b) $200 \quad " \quad$ karminrosa, 66 c) $200 \quad " \quad$ violettrosa. 
67. 250 MILS DE PESO gelblichbraun in zwei Abstufungen. 67 a) 250 MILS DE PESO gelblichbraun, 67 b) 250 dunkelgelbbraun.

IV. September 1879. Aushilfs-Marken: Marken No. 58 und 60 mit Aufdruck: CONVENIO - UNIVERSAL DE - CORREOS und neuer Wertangabe auf dem das Oval umschliessenden viereckigen Ralınen der Marke und HABILITADO innerhalb des Ovals. Von dem Aufdruck giebt es zwei Typen.

I. Type: Buchstaben des Aufdrucks dicht aneinander gerückt (Taf. VI, 101):

68. 2 cént. de peso auf 25 MILS schwarz auf grün.

69. 8 cént. de peso auf 100 MILS schwarz auf karmin in drei Abstufungen.

69 a) 8 CENT. DE PESO auf 100 MILS karmin,

69 b) 8

$69 \mathrm{c)} 8$

$100 "$ lebhaft karmin,

$100 "$ blasskarmin.

II. Type: Buchstaben des Aufdrucks weiter auseinander stehend ('Taf. VI, 102):

70. 2 cént. de peso auf 25 MILS schwarz auf grün.

71. 8 cént. de peso auf 100 MIL schwarz auf karmin in drei Abstufungen.

71 a) 8 CENT. DE PESO auf 100 MILS karmin,

71 b) $8 \quad$ " $\quad 100$ " lebhaft karmin,

$71 \mathrm{c)} 8 \quad " \quad 100 "$ blasskarmin.

\section{Bemerkungen.}

1. Da die Portotarife bei Einfihhrung der neuen Geldwährung nicht geändert werden sollten, so war die Fábrica nacional gezwungen, die Wertbezeichnung teilweise bis in die vierte Decimalstelle umzurechnen.

2. Die Marken zu 0,0625, 25 (schwarz und grün), 50, 100 (karmin und griın) und 200 Milș de peso kommen auch ungezähnt vor.

3. Von dem Aufdruck: CONVENIO - UNIVERSAL DE - CORREOS giebt es mehrele Fehldrucke uni zwar:

auf Marke No. 69: COREROS und CORRZOS anstatt CORREOS, auf Marke No. 70: CONVINIO anstatt CONVENIO;

auch finden sich häufig Exemplare, bei welchen nur einzelne Worte oder Buchstaben des Aufdruckes sichtbar sind. 
4. In Bezug auf Abstempelungen tritt bei den Orts- und Datumstempeln eine Vereinfachung, bei den Entwertungsstempeln dagegen die grösstmogliche Mannigfaltigkeit ein. Erstere nehmen die modernen, im Mutterland gebräuchlichen Formen an, ihre Farbe ist vielfach blau oder karminiot; letztere sind entweder Strichstempel (Taf. VII, 103) oder Sternstempel (Taf. VII, 104) nder Punktstempel in den verschiedensten Modellen. Ein um diese Zeit zuerst gesehener Certificado-Stempel hat viereckige Form mit abgestumpften Ecken.

\section{Ausgabe:}

von Januar 1880 bis Fruhjahr 1881.

Zeichnung der XXLX. Ausgabe Spaniens: Kopf des Königs Alfons XII. nach rechts in ovalem Rahmen; über und unter dem Oval je ein rechteckiger Schild mit Inschriften und zwar oben: FILIPINAS zwischen 2 Sternen, unten Wertangabe; in den Ecken zwischen Oval und Schildern ornamentale Verzierungen; der Untergrund der ganzen Marke ist mit wagerechten Strichen ausgefüllt; auf dem Halsabschnitt der Name Julia.

Farbiger Druck auf weissem Papier; gezähnt 14. (Taf. VI, 105.)

\section{2 C. DE PESO karmin in zwei Abstufungen.}

72 a) 2 C. DE PESO karmin,

72 b) 2 , karminrosa.

\section{3. $2 \frac{1}{2}$ C. DE PESO dunkelbraun.}

\section{8 C. DE PESO rotbraun in zwei Abstufungen.}
74 a) 8 C. DE PESO rotbraun,
74 b) 8 " blassrotbraun.

\section{B emerkungen.}

1. Von der Marke zu 2 C. de Peso giebt es Essais in violetter und blauer, von derjenigen zu $8 \mathrm{C}$. de Peso solche in blauor Farbe.

2. Bezüglich Typen dieser Zeichnung gilt auch für die Philippinen das bei Cuba in Bemerkung 1 zur VIII. Ausgabe Gesagte. Die obige Ausgabe gehört der Type I an. 


\section{Ausgabe:}

von Januar 1881 bis Ende Januar 1882.

Aushilfs-Marken. Post- und fiskalische Marken verschiedener Ausgaben mit verschiedenfarbigem Aufdruck der neuen Bestimmung und des nemen Wertes.

I. Die fiskalischen Judicialmarken von $1878 \mathrm{zu} 10$ Cuartos und 2 Reales: Spanisches Wappen mit Krone im Kreise, links um dasselbe: DERECHO, rechts: JUDICIAL; oben auf bogenförmigem Schild: FILIPINAS, unten auf ebensolchem Wertangabe; Untergrund mit wagerechten Strichen ausgefüllt; in den Ecken Verzierungen.

Farbiger Druck auf weissem Papier; gezähnt 14.

Aufdruck oval (14:17 mm), Farbe sclıwarz; oben: HABILI'IADO, unten Wertangabe, in der Mitte: PARA und darunter: CORREOS.

75. $2 \frac{4}{8}$ C $\widetilde{M S}$ auf 10 CUARTOS schwarz auf gelbbraun. (Taf. VI, 106.)

76. $2^{4} / 8$ CM S auf 2 REALES schwarz auf blau.

77. $8 \mathrm{CM}$ S auf to CUARTOS schwarz auf gelbbraun.

78. 8 CM S auf 2 REALES schwarz auf blau. (Taf.VI, 107.)

II. Nämliche Marke. Der Aufdruck etwas verändert: Der Halbkreis, welchen HABILITADO bildet, ist etwas kleiner und schneidet nicht mit dem $\mathrm{C}$ und $\mathrm{S}$ von CORREOS ab; kleiner Unterschied in einzelnen Buchstaben ( $\mathrm{H}$ und $\mathrm{B}$ schmaler), etwas veränderte Zahl 2 in der Wertangabe, abweichende Stellung von $4 / 8$.

79. $2^{4} / 8$ C $\widetilde{M S}$ auf 10 CUARTOS schwarz auf gelbbraun.

III. Nämliche Marke. Der Aufdruck etwas verändert: Oval etwats länger (14:18 mm), oben: HABILI'TADO, unten Wert- 
angabe, in der Mitte: CORREOS ohne PARA. (Aufdruck siehe Taf. VI, 105.)

80. 2 CENT DE PESO auf 10 CUARTOS schwarz auf gelbbraun.

IV. Briefmarke der XVIII. Ausgabe (No. 73). Nämlicher Aufdruck (olne PARA). (Taf. VI, 105.)

81. 2 CENT DE PESO auf $2 \frac{1}{2}$ C. DE PESO schwarz auf braun.

V. Fiskalische Marke Derechos de Firma von 1880 zu 200 Mils de peso: Spanisches Wappen mit Krone, umgeben von einem Lorbeerkranz, oben und unten auf viereckigem Schild: DERECHOS DE FIRMA bezw. Wertangabe; Untergrund mit wagerechten Strichen ausgefüllt.

Farbiger Druck auf weissem Papier; gezähnt 14.

Aufdruck kreisförmig (Durchmesser $16 \mathrm{~mm}$ ), oben: HABILITADO, unten Wertangabe, in der Mitte: P $\underline{A}$ U. POSTAL (Para Union Postal = für den Weltpostrerein).

82. 2 C $\widetilde{M S}$ auf 200 MILS DEPESO gelb auf grün. (Taf.VI, 108.)

VI. Fiskalische Judicialmarken von 1878 (siehe I): Aufdruck kreisfürmig (Durchmesser $15 \mathrm{~mm}$ ), oben: HABILITADO, unten Wertangabe, in der Mitte: $\mathrm{P}^{\mathrm{A}}$ CORREOS.

S3. UN REAL auf 10 CUARTOS schwarz aut gelbbraun. (Taf. VI, 109.)

84. DOS R R

Bemerkungen.

1. Nit dem Jabre $\mathbf{1 8 8 0}$ beginnt die Ausgabe einer langen Reihe von habilitirten Marken aller Arten. Wenn es auch bei der grossen Entfernung der Philippinen vom Mutterlande, bei der unbeschreiblichen Indolenz der spanischen Beamten und der geringen Voraussicht der Behörden begreiflich erscheint, dass hie und da ein oder der andere Markenwert vergriffen, bevor entsprechender Ersatz eingetroffen war, so ist es doch, selbst wenn man eine zeitweilige Ueber- 
lastung der Fábrica nacional de sellos in Madrid annimmt, schwer erklärlich, wie ein solcher Zustand mit kurzen Unterbrechungen Jahre lang andauern konnte. Vor Allem lässt der stete Wechsel der Aufdrucktypen und Aufdruckfarben den Verdacht gerechtfertigt erscheinen, dass es sich hier um eine Brandschatzung der Sammler handelte. Einzelne dieser Aufdrucke existiren in so wenigen Exemplaren und kommen postalisch entwertet so selten vor, dass es fraglich ist, ob dieselben nicht unter die Essais zu rechnen sind. Je nach dieser Auffassung ist die Katalogisirung in den verschiedenen philatelistischen Handbüchern und Alben verschieden. Ausdrücklich möge hierbei bemerkt werden, dass die amtlichen Erlasse, durch welche die Habilitirung angeordnet und die Zahl des zu habilitirenden Marken festgestellt wurde, in keiner Weise als unfehlbare Quellen anzusehen sind, da die thatsächliche Ausfuhrung dieser Verfiigungen in vielen nachweislichen Fällen aus irgend einem Grunde unterblieb.

Was die Ausgabedaten der verschiedenen Aufdrucktypen anbelangt, so lassen sich dieselben bei dem Mangel an amtlichem Aktenmaterial nur selten mit Sicherheit angeben, umsomehr als auch die Angaben in den philatelistischen 'Zeitschriften hierin sehr von einander abweichen. Es wurde deshalb von einer' Bezeichnung des Ausgabe-Monats ganz abgesehen; gewöhnlich wird angenommen, dass die Marken sub I im Jannar und April, diejenigen sub II im Juni 1881, die übrigen im Januar 1882 in Verkehr gegeben wurden, jedoch sind diese Daten nicht nnbestreitbar.

Sämtliche Aushilfsmarken existiren - wie dies bei Abstempelungen mit der Hand unvermeidlich - auch mit verkebrtem Aufdruck; da auf diese Abarten von philatelistischem Standpunkt wohl wenig Wert zu legen ist, so werden dieselben weder hier, noch später besonders aufgeführt. Das Gleiche gilt von Doppel-Aufdrucken in gleicher Farbe; philatelistisch interessanter sind dagegen Doppel-Aufdrucke in verschiedener Farbe und in verschiedenen Werten, da dieselben eher unserem Begriff von Fehldruck entsprechen.

2. Die Marken mit der Bezeichnung: Derecho judicial und Derechos de firma dienen zur Bezahlung einer für Ausfertigung gerichtlicher Urkunden pp. eingeführten Stempelsteuer.

3. Die Judicial-Marken zu 10 cuartos und 1 real von 1878 werden auch vielfach mit einem Aufdruck: HABILITADO PARA CORREOS in drei wagerechten Zeilen erwähnt. Von diesem Aufdruck giebt es zwei Typen, von denen sich die zweite von der ersten dadurch unterscheidet, dass sowohl die einzelnen Buchstaben, als auch die Zeilen weiter von einander abstehen. Nach zuverlässigen Quellen ist dieser Aufdruck ein Essai, welcher alsbald durch die ovale Form verdrängt wurde; das Fehlen jeglicher Wertangabe scheint dies zu bestätigen. Der Aufdruck hat bei der 10 cuartos-Marke blaue, bei derjenigen zu 1 real rote Farbe.

4. Die Aufdrucke:

$8 \widetilde{\mathrm{cms}}$ auf 10 cuartos (No. 77), $2 \frac{4}{8} \mathrm{cms}$ auf 2 Reales (No. 76) und DOS R RES auf 2 Reales (No. 84)

werden ebenfalls vielfach als Essais aufgefasst und dementsprechend in einzelnen Katalogen weggelassen. Dieser Auffassung widerspricht aber das mehrfach konstatirte Vorkommen der'selben mit zweifellos echter postalischer Entwertıng.

5. Die Judicial-Marke von 1878 zu 2 Reales existirt mit Doppel-Aufdruck un] zwar mit 8 cms in rot und Dos Reales in karmin. 


\author{
XX. Ausgabe: \\ von Januar 1882 bis März 1883.
}

Zeichnung der XVIII. Ausgabe.

Farbiger Druck auf weissem Papier; gezähnt 14.

85. $24 / 8$ C. DE PESO ultramarinblau in zwei Abstufungen. 85 a) $24 / 8$ C. DE PESO ultranarinblau, 85 b) $2 \frac{1}{8} \quad " \quad$ lebhaft ultramarinblan.

86. 5 C. DE PESO blau in zwei Schattirungen.

86 a) 5 C. DE PESO blassblau, 86 b) $5 \quad n \quad$ schieferblan.

87. 6\% C. DE PESO grün in zwei Abstufungen. 87 a) $62 \%$ C. DE PESO griin, 87 b) $6 \frac{2}{8} \quad " \quad$ dunkelgrüin.

88. $10 \mathrm{C}$. DE PESO lila in zwei Schattirungen. 88 a) 10 C. DE PESO bräunlichlila, 88 b) $10 \quad$ malvenfarbig.

89. $12 \frac{4}{8}$ C. DE PESO rosa in drei Schattirungen. 89 a) $12^{4 / 8}$ C. DE PESO rosa, 89 b) $12 \%$ " $1 / 8$ karminrosa, $89 \mathrm{c)} 12^{4} / 8 \quad " \quad$ gelblichrusa.

90. 20 C. DE PESO olivenbraun.

91. 25 C. DE PESO braun in zwei Abstufungen. 91 a) 25 C. DE PESO bram, 91 b) $25 \quad " \quad$ dunkelbraun.

\title{
Bemerkungen.
}

1. Es erscheint merkwurdig, dass in dieser Ausgabe die Werte zu 1 und 2 Reales. deren Nothwendigkeit doch durch die zahlreicheu Habilitirungen des vorhergehenden Jahres genilgend bewiesen war, nicht nou geschaffen wurden, sodass also sofort neue Aufdrucke nöthig wurden.

2. Von sämtlichen Werten giebt es Essais in abweichenden Farben auf weissem Karton und zwar:

24/8 C. de Peso braun, 5 C. de Peso violett, 62/8 C. de Peso blau, 10 C. de Peso violett, 12//8 C. de Peso blau, 20 C. de Peso violett und 25 C. de Peso karmin. 


\section{Ausgabe:}

von Eude Februar 1883 bis Ende 1889.

Anshilfs-Marken, verausgabt durch Erlass vom 22. Februar 1883.

I. Briefmarken der XVIII. und XX. Ausgabe (No. 74 und 86). Aufdruck kreisförmig (Durchmesser $15 \mathrm{~mm}$ ), Farbe verschieden: oben: HABILITADO, unten Wertangabe, in der Mitte: PA CORREOS. (Taf. VI, 110.)

Von dem Aufdruck: UN REAL giebt es fünf Typen:

Type I: Die Buchstaben von UN REAL stehen weit auseinander, unter dem A von $\mathrm{P}^{\mathrm{A}}$ langer Strich, das zweite $\mathrm{R}$ ron CORREOS magerer, als das erste.

Type II: UN REAL wie in Type I, kleiner Strich unter dem $A$ von $\mathrm{P}^{A}$, lie beiden $R R$ von CORREOS haben gleiche Breite.

Type III: Die Buchstaben ron UN REAL enger aneinanderstehend, Strich nnter dem A voll $\mathrm{P} A$ külzer, RR wie in Type II.

Type IV: Die Buchstaben von UN REAL noch enger aneinander stehend, das $\mathrm{H}$ von HABILITADO schmaler, das L offener.

Type V: Die Buchstaben von UN REAL weiter auseinanderstehend, das $\mathrm{R}$ ron REAL mehr nach links geneigt, BILI von HABILITADO breiter und RR von CORREOS magerer.

92. UN REAL in Type I auf $5 \mathrm{C}$. DE PESO grün auf blau.

98. UN REAL in Type III auf 5 C.DE PESO grün auf blau.

94. UN REALin Type IV auf 5 C. DE PESO grün auf blau.

95. UN REAL in TypeIauf 8 C. DE PESO grün auf braun.

96. 20 С $\mathrm{M}$ os auf 8 C. DE PESO schwarz auf braun.

II. Telegraphenmarke vom.Jahre 1882: Zeichnung der Briefmarken vom Jahre 1876 (XVI. Ausgabe), nur: TELEGRAFOS an Stelle von FILIPINAS mil Lilien an Stelle von CORREOS, ausserdem Sterne in den Ecken zwischen Uval und Rahmen. 
Aufdruck: HABIITTAIOO PA CORREOS DE IOOS R.Es, kreisförmig (Durchmesser $15 \mathrm{~mm}$ ) und in verschiedener Farbe. (Taf. VI, 111) Jer Aufdruck existirt in fünf 'l'ypen:

Type I in kleinen Buclistaben:

Type II in kleinen Buchstaben, aber mit verkehrtem s in DOS: Type J.II in kleinen Buchstahen, mit Punkt hinter RuEs;

'Type IV in grossen Buchstaben, aber breites O in IJOS: Type $\mathrm{V}$ in grossen Buchstaben, schmales $\mathrm{O}$ in DOS.

97. DOS RIAS in Type III auf 250 MILS DE PESO blau, Aufdruck rot in $z w$ ei Schattirungen.

97 a) DOS RLES auf 250 NILS rot auf ultramarinblau.

$97 \mathrm{~b})$ DOS $"$ rothraun auf ultramarinhlau.

98. DOS R R.ES in Type I auf 250 MIL schwarz auf ultramarinblau.

III. Fiskalische Judicialmarke von 1878 (vergl. XIX. Ausgabe, I) mit dem nämlichen Aufdruck.

99. UN REAL in Type I auf 10 CUARTOS grün auf gelblichbraun.

Verausgabt durch Erlass vom 4. Juni 1883.

IV. Fiskalische Marke: Derechos de Firma von 1878 (gleiche Zeichnung, wie Ausgabe XIX,V) mit dem nämlichen Aufilruck.

100. UN REAL in Type I auf UN PESO rot auf grün.

101. UN REAL in Type IV auf UN PESO rot auf grün.

102. UN REAL in Type $\mathrm{V}$ auf UN PESO rot auf grün.

V. Fiskalische Marke: Derechos de Firma von 1878: Spanisches Wappen in ovalem Rahmen, innerhalb desselben oben: DERECHOS J)E FIRIIA, unten Wertangabe: Im das Oval ein rechteckiger Rahmen, gnillochirter Untergrund.

Farbiger Druck auf weissem Papier; gezähnt 14. Aufdruck wie bisher.

103. UN REAL in Type I auf 10 PESETAS rot auf braun. 
VI. Fiskalische Judicialmarke von 1878 (vergl. XIX. Ausgabe, I) mit nämlichem Aufdruck in verschiedenen Farben.

104. UN REAL in Type I auf $12^{4 / 8}$ C. DE PESO rot auf blau. 105. UN REAL in Type I auf $12^{4} / 8$ C. DE PESO schwarz auf blau.

VII. Briefmarken der XVIII. und XX.Ausgabe (No. 72, 85 ı. 86) mit dem nämlichen Anfdruck in verschiedenen Farben.

106. UN REALin Type I auf 2 C. DE PESO grün auf karmin.

107. UN REAL in Type I auf 2 C. DE PESO rot auf karmin.

108. UN REAL in Type II auf 2 C. DE PESO rot auf karmin.

109. UN REAL in TypeIV auf 2 C. DE PESO rot auf karmin.

110. UN REAL in Type V auf 2 C. DE PESO rot auf karmin.

111. UN REAL in Type I auf 5 C. DE PESO rot auf blau.

112. UN REAL in Type II auf 5 C. DE PESO rot auf blau.

113. UN REAL in Type IV auf 5 C. DE PESO rot auf blau.

114. DOS R $\mathrm{RES}_{\mathrm{LS}}$ in Type I auf $2^{4} / 8$ C. DE PESO schwarz auf blau.

115. DOS R RES in Type II auf $2^{4} / 8$ C. DE PESO schwarz auf blau.

116. DOS R $\overline{\mathrm{LES}}$ in Type III auf $2^{4} / 8 \mathrm{C}$. DE PESO schwarz auf blau.

117. DOS R $\overline{\text { LES }}$ in Type IV auf $2^{4} / 8$ C. DE PESO schwarz auf blau.

118. DOS R $\overline{\mathrm{LES}}$ in Type $\mathrm{V}$ auf $2 / \frac{4}{8}$ C. DE PESO schwarz auf blau.

VIII. Telegraphenmarke vom Jahre 1882 (siehe oben II) mit nämlichem Aufdruck.

119. DOS RLES in Type I auf 250 MILS DE PESO schwarz auf blau. 
IX. Briefmarke der XVIII. Ausgabe (No. 72) mit dem kreisförmigen Aufdruck: HABILITA DO oben, Wertangabe unten, in der Mitte: $\mathrm{P}^{\mathrm{A}}$ U. POSTAL (para mion postal = für den Weltpostverein). (Taf. VI, 112.)

120. $8 \mathrm{C} \overline{\mathrm{M} O S}$ auf $2 \mathrm{C}$. DE PESO grün auf karmin.

Verausgabt durch Erlass vom 29. September 1883.

X. Briefmarken der XVIII. u.XX. Ansgabe (No.72n.85)mitkreisförmigem Aufdruck: HABILIT'ADO oben, unten Wertangabe, in der Mitte: PA CORREOS in verschiedenen Farben. (Taf. VI, 113.) Von dem Aufdruck: 10 CUARTOS gieht es 2 Typen:

Type I hat 10 in kleinen Ziffern,

Type II hat 10 in grossen Ziffer'n.

121. 10 CUARTOS in Type I auf 2 C. DE PESO grün auf karmin.

122. 10 CUARTOS in Type II auf 2 C. DE PESO grün auf karmin.

123. $16 \mathrm{C} \overline{\mathrm{TOS}}$ auf $2 \frac{1}{8}$ C. DE PESO rot auf blau.

XI. Fiskalische Judicialmarke von 1878 (siehe Ausgabe XIX,V) mit dem nämlichen Aufdruck.

124. $16 \mathrm{C}_{\mathrm{TOS}}$ auf 2 REALES gelb auf blau.

XII. Fiskalische Judicialmarke von 1882 (gleiche Zeichnung wie 1878) mit dem nämlichen Aufdruck. Der Aufdruck existirt in zwei Typen:

Type I hat ein kleines, ovales $\mathrm{C}$ in CORREOS;

Type II hat ein grosses, quadratisches $\mathrm{C}$ in CORREOS.

125. UNREAL in Type I auf $12^{4} / 8$ C. DEPESO schwarz auf blau. 126. UNREAL in Type II auf $12^{4} / 8$ C. DEPESO schwarz aufblau. 127. UN REAL in Type I auf $12^{4} / 8$ C. DE PESO rot auf blau. 128. UN REAL in Type II auf $12^{4} / 8$ C. DE PESO rot auf blau. 
Bemerkungen:

1. Trotzdem uns die Verfügungen der General-Post-Direktion bezüglich der Verwendung der in Ausgabe XXI zusammengefassten Aushilfsmarken vorliegen, das Ausgabe-Datum sich also genau bestimmen lässt, stösst die Katalogisirung dieser Marken dennoch auf die grössten Schwierigkeiten. Dieselben entspringen zum Theil aus den zahlreichen Typenverschiedenheiten der einzelnen Aufdrucke, mehr aber noch daraus, dass scheinbar eine grosse Zahl von Essais auf irgend einem Wege in die Hände der Sammler und Händler gelangt sind, sodass es sich bei vielen Aufdrücken kaum feststellen lässt, ob dieselben wirklich postalischen Zwecken gedient haben. Die postalische Entwertung bietet, wie bekannt, nicht immer einen schlagenden Beweis für die wirkliche Benutzung. Hier kann erst im Laufe der Zeit Klärung der Ansichten eintreten.

Die Aufdrucke wurden hergestellt vermittelst Handstempel, welche nach der Gaceta de Manila vom 29. September 1883 aus Messing angefertigt waren und nach Gebrauch in Gegenwart einer Kommission vernichtet wurden. Für die am meisten gebrauchten Werte wurden mehrere solcher Stempel hergestellt, welche in Bezug auf die Form der Buchstaben oder sonstiger Kleinigkeiten mehr oder weniger von einander abweichen. Diese Abweichungen als einfache Abarten ohne jegliche Bedeutung anzusehen, wie es meist geschioht, widerspricht allen philatelistischen Grundsätzen, es sind dies Typenverschiedeuheiten, die, wenn auch vielfach gering, logischerweise doch ebenso genau beachtet werden müssen, -wio es beispielsweiso bei den Habilitados Spaniens, bei den Marken von Ost-Rumelien mit bulgarischem Löwen und vielen anderen Provisorien herkömmlicherweise geschieht.

2. Mit Doppel-Auf:Iruck verschiedener Werte giebt es folgende Marken:

Telegraphen-Marke 250 MILS blau mit DOS RLES rot und 20 CMos schwarz. Dieselbe Marke mit

HABILITADO - PA CORREOS DE UN REAL in rot und

HABILITADO - PA CORREOS - 20 CMOS in schwarz,

Dieselbe Marke mit

HABILITADO - PA CORREOS DE UN REAL und

HABILITADO - PA CURREOS DE DOS R $\overline{L E S}$, beide Aufdrucke in schwarz.

Briefmarke 1880 . 2 C. DE PESO rot, mit

HABILITADO - PA U. POSTAL - 8 CMOS und

HABILITADO-PA CORREOS DE UN REAL, beide Aufdrucke in grín.

3. Von philatelistischen Zeitschriften wurden folgende zwar existirende, aher nicht mit Sicherheit postalisch verwendete Anfdrucke gemeldet:

Auf DERECHOS DE FIRMA von 1880:

1 REAL auf 200 MILS DE PESO rot auf gelbgriln.

Auf Briefmarken von 1880 und 1882:

10 CUARTOS auf 2 C. DE PESO schwarz anf karmin,

1 REAL anf 2 C. IE PESO schwarz auf karmin,

1 REAL auf $2^{4} / 8$ C. DE PESO schwarz auf blau.

Auf DERECHOS DE FIRMA von 1872:

1 REAL auf 10 PESETAS schwarz anf gelblichbraun.

Auf DERECHO JUDICIAL von 1878:

DOS RIES anf 2 REALES rot anf blan.

Auf Telegraphennarke von 1882:

20 CḾs auf 250 MILS gelb auf blau.

Auf DERECHO JUDICIAL von 1878:

$62 / 8$ C $\underline{S}$ auf $12^{4} / 8$ C. DE PESO rot auf blau. 


\section{Ausgabe:}

von Ende 1883 bis Endo 1887.

Zeichnung der XVIII. Ausgabe (1880), jedoch II. Type (vergl. hierïiber: Cuba Seite 48 und $52(\mathrm{C})$ ).

Farbiger Druck auf weissem Papier; gezähnt 14.

$129,2 \frac{2}{8}$ C. DE PESO ultramarinblau in zwei Abstufungen. 129 a) $2^{4} / 8$ C. DE PESO ultramarinblau, $129 \mathrm{b)} 2 \frac{4}{8} \quad$ "lebhaft ultramarinblau.

Bemerkung.

Von der Marke giebt es Essais in blauer und dunkelroter Farbe auf weissem Kartonpapier.

\section{A usgabe:}

vom 10. März 1885.

A ushilfs-Marke, verausgabt durch Erlass vom 10. März 1885: Fiskalische .Judicialmarke von 1882 (siehe Ausgabe XXI, XII) mit dem kreisrunden Aufdruck: HABILITADO CORREOS 6 $2 / 8$ CENT'.

Farbiger Druck auf weissem Papier; gezähnt 14.

130. $6 \frac{2}{8}$ C $\mathrm{N} 0 \mathrm{~s}$ auf $12^{4} / 8$ C. DE PESO rot auf blau. 
XXIV. Ausgabe:

von Frühjahr 1886 bis 31. Dezember 1889.

Marke für Drucksachen: Zeichnung der XVIII. Ausgabe, nur III. Type (vergl. hierüber: Cuba Seite 48 und 55 (C)) und oben Inschrift: FILIPAS . IMPRESOS. (Taf. VI, 120.)

Farbiger Drnck auf weissem Papier; gezähnt 14.

131. 1/8 DE CENTAVO gelbgrün.

B emerkung.

Von der Marke sind Essais in blauer Farbe auf weissem Kartonpapier bekannt.

XXV. Ausgabe:

von Januar 1887 bis Ende 1889.

A ushilfs-Marken. Briefmarke der XXII. Ausgabe (No. 129) mit verändertem kreisförmigem Aufdruck (Durchmesser 161/2 $\mathrm{nm}$ ), oben: HABILITADO, in der Mitte: U. POSTAL (ohne PA), unten Wertangabe. Farbe verschieden. (Taf. VI, 114.)

132. UN CENT 0 auf $2^{4} / 8$ DE PESO braunrot auf blau.

133. 10 CENT - auf $2 \frac{4}{8}$ DE PESO schwarz auf blau. 
XXVI. Ausgabe:

1887 bis 1889 .

Zeichnung der XXIV. Ausgabe, nur Inschrift: FILIPINAS. Farbiger Druck auf weissem Papier; gezähnt 14.

April 1887:

134. 5o MILESIMAS bräunlichgelb.

Januar 1888:

135. UN C. DE PESO graugrün.

136. 6 C. DE PESO braun.

\section{Ausgabe:}

von Januar bezw. 4. Oktober 1888 bis Februar 1889 bezw. Januar 1890.

Aushilfs-Marken: Brief-, Telegraphen- und fiskalische Marken verschiedener Ausgaben mit Aufdruck eines neuen Wertes.

I. Briefmarke der XXII. Ausgabe (No.129). Aufdruck: Ovaler Rahmen von verschiedener Grösse; im Rahmen oben: UNION GRAL (general) POS'TAL, unten: HABILITADO, in del' Mitte Wertangabe. Farbe rotviolett. (Taf. VI, 115.)

Der Aufdruck existirt in zwei Typen:

I. Type: Kleineres Oval $\left(20^{1 / 4}: 17 \frac{1}{2} \mathrm{~mm}\right)$, breitere 8 der IVertangabe, nach GRAL ein Punkt, ebenso nach CENT. II. Type: Grösseres Oval (21:181/4 mm); Buchstaben der Inschriften entsprechend grösser, die 8 der Wertangabe schlanker, hinter GRAL und CENT kein Pnnkt.

137. 8 CENT in TypeI auf $2 / 8$ C. DE PESO violettrot auf blau.

138. 8 CENT in TypeII auf $2^{4} / 8$ C. DEPESO violettrot auf blau. 
II. Briefmarke der XX. Ausgabe (No. 86). Aufdruck: Ovaler Ralımen wie bei I, nur veränderte Insclırift und zwar obelı: HABILITADO, unten: PARA COMUNICACIONES, zwischen beiden auf jeder Seite ein Sternchen, in der Mitte Wertangabe. (Taf. VI, 116.)

139. $2^{4 / 8} \overline{C M O S}$ auf 5 C. DE PESO violettrot auf blau.

III. Briefmarken der XXVI. Ausgabe (No. 134 und 135) mit nämlichem Aufdruck.

140. $2 \frac{4}{8} \overline{C M O S}$ auf UN C. DE PESO violettrot auf graugrün.

141. $2 \frac{4}{8} \mathrm{C} \overline{M O S}$ auf5 MILESIMAS violettrot aufbräunlichgelb.

IV. Telegraphenmarke vom Jahre 1888. Zeichnung der Briefmarken voll 1880, nur TELEGRAFOS an Stelle von FILIPINAS. Nämlicher Aufdruck. (Taf. VI, 117.)

142. $2^{4 / 8}$ CMOS auf UN C. DE PESO violettrot auf bräunlichgelb.

Verausgabt durch Erlass vom 4. Oktober 1888.

V. Briefmarke der XXIV. Ausgabe (No. 131) mit nämlichem Aufdruck. (Taf. VI, 119.)

143. $24 / 8$ CMOS auf $1 / 8$ de CENTAVO violettrot auf gelbgrün.

VI. Briefmarke vom Jahre 1888 mit nämlichem Aufdruck. 144. $2 \% / 8$ CMOS auf 10 C. DE PESO violettrot auf gelbgrün.

VII. Fiskalische Marken: DERECHOS DE FIRMA von 1883 und 1888 (vergl. XIX. Ausgabe, V.) mit nänılichem Aufdruck. (Taf. VI, 118.)

145. $2 \frac{4}{8} \overline{\mathrm{CMOS}}$ auf $200 \mathrm{MILS}$ DE PESO violettrot auf grün. 146. $2 \frac{4}{8} \overline{C M O S}$ auf 20 C. DE PESO violettrot auf braun. 


\section{Ausgabe:}

von Februar 1889 bis 1. Januar 1890.

Aushilfs-Marke, verausgabt durch Erlass vom 29. Februar 1889. Briefmarke der XXII. Ansgabe mit ähnlichem Aufdruck, wie bisher, nur veränderte Inschrift: RECARGO DE CONSUMOS, unten: HABILITADO, in der Mitte Wertangabe.

\section{7. $\$ 0,02^{4} / 8$ auf $2^{4} / 8$ schwarz auf blau.}

\section{Bemerkung:}

Die durch den Aufdruck: RECARGO DE CONSUMOS zu einer fiskalischen Steuermarke habilitirte Briefmarke zu $2^{4} / 8$ C. de peso musste infolge steten Mangels dieses Wertes wieder postalischen Zwecken dienen. Der Erlass vom «9. Januar 1889 bestimmt jedoch ausdrücklich nur diesen einen Wert für Post-, alle tibrigen Recargo-Marken für Telegraphen-Zwecke. Wenn in der Folge auch nuch die übrigen s. Zt. mit dem Recargo-Aufdruck versehenen Marken zur Brieffrankatur verwandt wurden, so ist dies nicht offiziell, sondern findet seine Ursache darin, dass die Postbeamten bei dem grossen Wirrwarr von Aufdrucken und entsprechenden Verfugungen schliesslich selbst nicht mehr wussten, was Post-, was Telegraphen-Marke war.

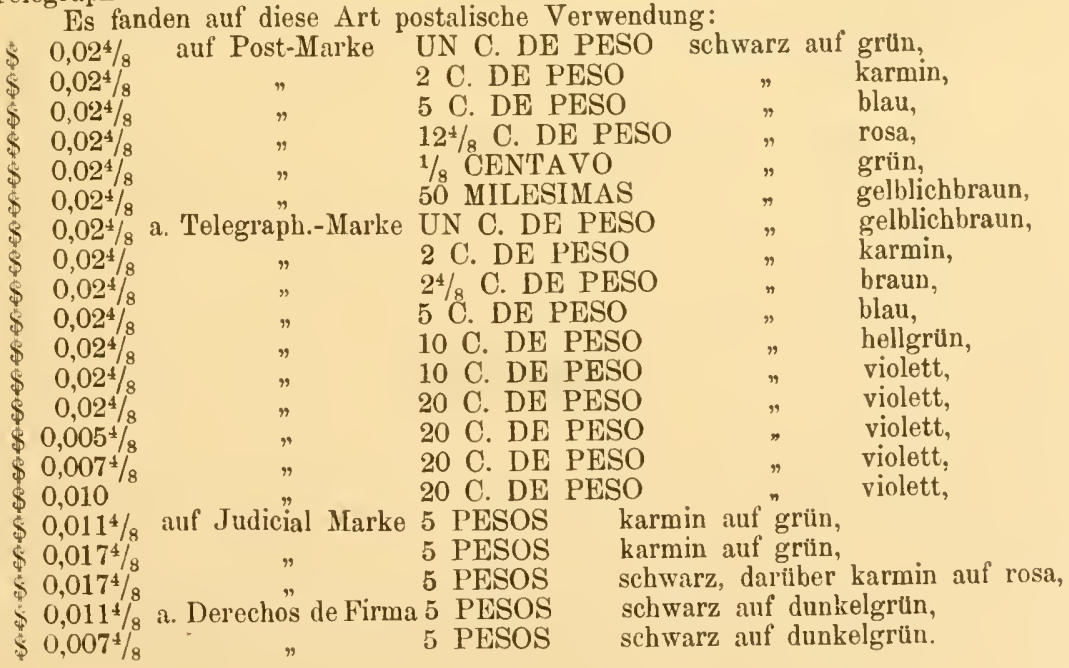


XXIX. Ausgabe:

vom 1. Mai bis 31. Dezember 1889.

Marken für Drucksachen. Zeichnung der XXIV. Ausgabe.

Farbiger Druck auf weissem Papier; gezähnt 14. (Taf. VI, 120.)

148. 1 MILA DE PESO rosa.

149. 2 MILS DE PESO hellblau.

150. 5 MIL DE PESO braun.

\section{Ausgabo:}

von Herbst 1889 bis Januar 1890.

Zeichnung der XXIV. Ausgabe, nur veränderte Inschrift und Farbenänderung (Type III, vergl. Cuba, Seite 48 und 55 (C)).

Farbiger Druck auf weissem Papier; gezähnt 14. (Taf. VI, 121.)

151. UN C. DE PESO hellgrün.

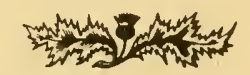




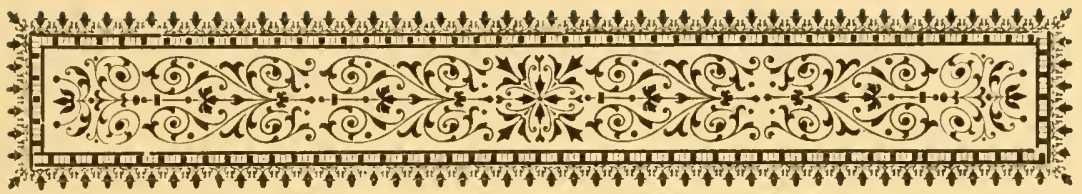

\section{F. Marken aus der Zeit der Regentschaft der Königin Maria Cristina bezw. der Regierung des Königs Alfonso XIII.}

\section{Ausgabe:}

vom 1. Januar 1890 bis 1891 bezw. 1892 und 1893.

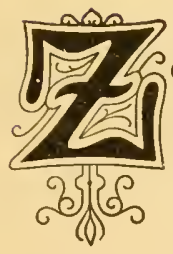

eichnung der XIII. Ausgabe Cuba's (vergl. Seite 57): Kopf des Königs Alfonso XIII. nach rechts in ovalem Rahmen, umgeben von ornamentalen Verziermngen; oben auf rechteckigem Schild: FILIPINAS zwischen zwei Sternen, unten auf ebensolchem Wertangabe; auf dem Halsabschnitt der Name: Julia.

Farbiger Druck auf weissem Papier; gezähnt 14. (Taf. VI, 122.)

152. 2 C. DE PESO karmin in zwei Schattirungen. 152 a) 2 C. DE PESO karmin, 152 b) 2 karminrosa.

153. $2 \frac{4}{8}$ C. DE PESO ultramarinblau.

154. 5 C. DE PESO blau in zwei Abstufungen. 154 a) 5 C. DE PESO dunkelblau, 154 b) 5 hellblau.

155. 5 C. DE PESO bronzegrün. 
156. 8 C. DE PESO gelbgrün.

157. 10 C. DE PESO blaugrün.

158. $12 \frac{4}{8}$ C. DE PESO dunkelgelbgrün.

159. 20 C. DE PESO rosa.

160. 25 C. DE PESO braun.

Marken für Drucksachen. Nämliche Zeichnung, nur oben: FILIPAS IMPRESOS. (Taf. VI, 123.)
161. $1 / 8$ DE CENTAVO dunkelviolett.
162. 1 MILA DE PESO dunkelviolett.
163. 2 MILS DE PESO dunkelviolett.
164. 5 MILS DE PESO dunkelviolett.

\section{Bemerkungen.}

1. Die Werte $5,10,20$ und 25 C. de peso blieben bis zum Fruhjahr 1891, die Marke zu 8 C. de peso, sowie die sämtlichen Zeitungsmarken bis zum Januar 1892, die Marke zu 24/8 C. sogar bis zum Januar 1894 in Verwendung.

2. Es fällt auf, dass zwei Marken zu 5 C. de peso verausgabt wurden; die eine in bronzegrün diente für den Verkehr im Innern des Archipels, die andere in dunkelblau für das Gebiet des Weltpostvereins.

3. Die Zeitungsmarke zu 5 MIL $\underline{S}$ de Peso existirt auch ungezähnt.

\section{Ausgabe:}

während der Jahre 1891 und 1893 bis zum Januar 1894.

Nämliche Zeichnung, nur Farbenänderung.

Farbiger Druck auf weissem Papier; gezähnt 14. 
Frühjahr 1891.

165. 5 C. DE PESO oliven.

166. 10 C. DE PESO karmin in zwei Schattirungen. 166 a) 10 C. DE PESO karmin, 166 b) $10, \quad$ karminrosa.

167. 20 C. DE PESO ziegelrot.

168. 25 C. DE PESO dunkelblau.

Herbst 1891. Ergänzungswerte, bezw. Farbenänderung.

169. 5 C. DE PESO blaugrün.

170. 6 C. DE PESO violettbraun.

171. 15 C. DE PESO hellrotbraun.

172. 20 C. DE PESO graubraun.

173. 40 C. DE PESO schiefergrau.

174. 8o C. DE PESO orange (gelbrot).

Marken für Drucksachen. Nämliche Zeichnung, nur oben: FIIIPAS IMPRESOS.

175. 6 MILS DE PESO rosa.

Januar 1892. Ergänzungswert.

176. 2 C. DE PESO violett in zwei Abstufungen. 176 a) 2 C. DE PESO violett, 176 b) 2 blassviolett.

177. 8 C. DE PESO hellblau.

Marken für Drucksachen. Nämliche Zeichnung wie No.176.

178. $1 / 8$ DE CENTAVO grün.

179. 1 MILA DE PESO grün.

180. 2 MILS DE PESO grün.

181. 5 MILS DE PESO grün. 
Bemerkung,

Die Ausgabedaten lassen sich nicht genau bezeichnen, da die verschiedenen Werte successive erschienen, die Meldung ihres Erscheinens Seitens der Philatelistischen Zeitschriften aber sehr ungenau und sich widersprechend erfolgte. Einzelne Werte sind bis jetzt noch so selten, dass selbst ihre Farbe verschieden angegeben wird. So ist es nicht unmöglich, dass Marke No. 165 identisch ist mit Marke No. 155; auch die Existenz von No. 173, 174 und 175 wird vielfach bestritten. Hier bedarf es also noch der Aufklärung.

\section{Ausgabe:}

von Juni (?) 1893 bis Januar 1894.

Nămliche Zeichnung, nur Farbenänderung.

Farbiger Druck auf weissem Papier; gezähnt 14.

182. UN C. DE PESO braunviolett.

183. $2^{4 / 8}$ C. DE PESO oliven.

184. 5 C. DE PESO violettbraun.

185. 15 C. DE PESO blassbraun.

Bemerkung.

Auch hier gilt die zur vorigen Ausgabe gemachte Bemerkung. 


\section{Ausgabo:}

vom 1. Januar 1894.

Nämliche Zeichnung, nur Farbenänderung.

Farbiger Druck auf weissem Papier; gezähnt 14.

186. 2 C. DE PESO karmin.

187. $2 / 8$ C. DE PESO grau.

188. 5 C. DE PESO gelbgrün.

189. 6 C. DE PESO ziegelrot.

190. 8 C. DE PESO violettbraun.

191. 10 C. DE PESO karmin.

192. $12 \frac{4}{8}$ C. DE PESO fleischfarben.

193. 15 C. DE PESO rosa.

194. 20 C. DE PESO braunviolett.

Marken für Drucksachen: nämliche Zeichnung, wie bisher.

195. $1 / 8$ C. DE CENTAVO hellbraun.

196. 1 MILA DE PESO oliven.

197. 2 MILS DE PESO oliven.

198. 5 MILS DE PESO oliven.

Bemerkung.

Die Werte werden successive verausgabt; bis jetzt (April 1894) sind noch nicht alle Werte im Verkehr, die Druckfarbe der verausgabten wird noch verschieden angegeben und sind die obigen Angaben möglicherweise zu verbessern.

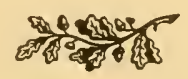



II.

Postkarten.

कहाँ 



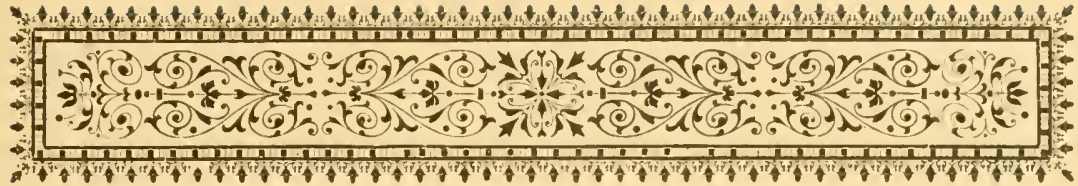

\section{${ }^{*}$ A. Postkarten aus der Zeit der Regierung des Königs Alfonso XII.}

\section{Ausgabe:}

von Frühjahr 1878 bis Januar 1879.

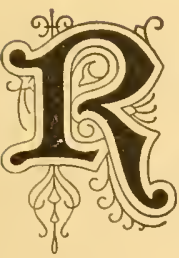

echteck aus dunkelchamois Karton, Grösse 145:97: Marke mit Zeichnnng der XVII. Ansgabe oben in der Mitte: links davon: TARJETA, rechts: POS'TAL, darunter vier Adresslinien, die erste mit É. Q . beginnend; ein bald mehr, bald weniger stark hervirtretender Unterdruck zeigt in $2 \mathrm{~cm}$ hohen englischen Buchstaben: Tarjeta Postal, umgeben von Kreisen, Strichen und sonstigen Verzierungen; unten: NoтA. Lo que debe escribirse se hará en el reverso é irá firmado por el remitente.

Marke, Vordruck und Umrandung in dunkelkarmin, Unterdruck in orange. (Taf. III, 52.)

1. 50 MILS DE PESO dunkelkarmin auf dunkelchamois. 
Bemerkungen.

1. Die Karte No. 1 wird von vielen Katalogen als nicht in Gebrauch gewesen bezeichnet. Moens sieht sie als blosse Abart der nächsten Ausgabe an und bezeichnet als Datum ihrer Emission den September 1879. Demgegeniber steht fest, dass die Karte postalisch entwertet mehrfach in Sammlungen vorkommt und zwar mit Abstempelungen aus dem Jahre 1878, welche den Verdacht eines Gefälligkeitsstempels vőllig ausschliessen.

2. Von der Karte giebt es mangelhafte Drucke ohne Punkt hinter Sr, sowie auch solche mit "cn el reverso" in der Nota, anstatt "en el reverso".

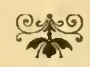

\section{A usgabe:}

von Sommer 1879 bis 31. Dezember 1880.

Karte der vorigen Ausgabe mit Aufdruck des in der XVII. Ausgabe IV, II beschriebenen Stempels, nur Aenderung der Wertangabe: CONVENIO links, UNIVERSAL DE oben, CORREOS rechts und haBILITADO 3 cént. de peso unten. (Taf. III, 124.)

2. 3 cént. de peso auf 50 MILS DE PESO schwarz auf dunkelkarmin.

\section{Bemerkung.}

Die Karte verdankt ihren Aufdruck den im Juni 1878 in Paris getroffenen internationalen Vereinbarungen. Abgesehen von verschiedenen mangelhaften Aufdrucken giebt es auch auf der Postkarte den bei den Marken vorkommenden Fehldruck: CORRZOS anstatt CORREOS. Die in Bemerkung 2 zur I. Ausgabe angefuhrten mangelhaften Drucke kommen naturlich auch mit Aufdruck vor. 


\section{Ausgabe:}

vom 1. Januar 1881 bis 31. Dezember 1891.

Karte für den Weltpostverkehr: Rechteck aus dünnem, weissem oder gelblichem Karton, Grösse 132:91; Marke in Zeichnung der XVIII. Ausgabe oben rechts; links daneben fünfzeiliger Vordruck und zwar unter einander stehend: ULTRAMAR - UNION POSTAL UNIVERSAL - UNION POSTALE UNIVERSELLE ESPA NA. - En este lado se escribe solamente la direccion; darunter drei Adresslinien, die erste mit $\mathscr{C}$ beginnend; ohne Umrandung. (Taf. III, 53.)

\section{3 C. DE PESO hellrosa auf verschiedenem Karton.}

3 a) 3 C. DE PESO hellrosa auf dunnem, weissem Karton,

\section{Bemerkung.} Karton.

Von der Marke dieser Karte giebt es Essais in grüner Farbe auf weissem

\section{Ausgabe:}

von Juli 1889 bis 31. Dezember 1891.

Rechteck aus verschieden starkem Karton in chamois Farbe, Grösse 140:98; Marke der XVIII. Ausgabe oben in der Mitte, links davon; TARJETA, rechts POSTAL; darunter vier Adresslinien, die erste mit $\mathscr{E}$ 々. $\mathscr{D}$. beginnend, unten: Nota. Lo que debe escribirse se hará en el reverso é irá firmado por el remiteute; mit Umrandung. Marke, Vordruck und Umrandung in dunkelbrauner Farbe. (Taf. III, 55.) 
4. 2 C. DE PESO dunkelbraun auf verschieden starkem Karton.

4 a) 2 C. DE PESO dunkelbraun auf dickem Karton in chamois 4 b) 2 Farbe, dunkelbraun auf ganz dünnem Karton in chamois Farbe.

Doppelkarte in gleicher Ausführung wie No. 4; auf der ersten Karte rehts unter der Umrandung: La otra tarjeta es para la contestacion, auf der zweiten Karte ebendaselbst: Contestacion pagada. Dicker Karton in chamois Farbe.

\section{5. $3+3$ C. DE PESO karmin auf chamois Karton.}

Bemerkung.

Von Karte No. 4 giebt es Stucke, bei welchen in dem Worte POSTAL die beiden letzten Buchstaben $2 \mathrm{~mm}$ von POST abstehen. 


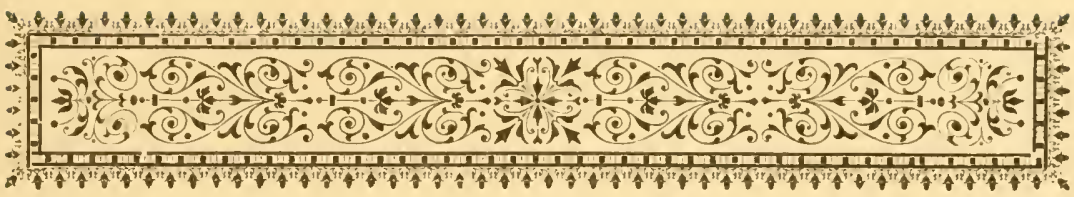

B. Postkarten aus der Zeit der Regentschaft der Königin Maria Cristina bezw. der Regierung des Königs Alfonso XIII.

\author{
V. Ausgabe: \\ vom 1. Januar 1892 an.
}

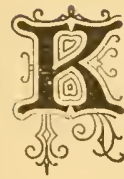

arte in gleicher Ausführung, wie No. 4, nur mit Marke der XXXI. Ausgabe. Vordruck und Umrandung in der Farbe der Marken. (Taf. III, 56.)

6. 2 C. DE PESO violettbraun auf verschiedenfarbigem Karton.

6 a) 2 O. DE PESO violettbraun auf hellchamois Karton,

6 b) $2 \quad$ violettbraun auf dunkelchamois (bräunlichem) Karton.

7. 3 C. DE PESO orangegelb auf verschiedenfarbigem Karton.

7 a) 3 C, DE PESO orangegelb auf hellchamois Karton,

7 b) $3 \quad$ orangegelb auf dunkelchamois Karton. 



\section{Fernando Póo.}

क्षेश 



\section{Einleitung.}

\section{Fernando Póo,}

von dem Portugiesen Feruão do Po 1471 entdeckt und im Jahre 1778 an Spanien abgetreten, liegt an der westafrikanischen Küste in der Bai von Biafra, etwa $36 \mathrm{~km}$ vom Festland (Kamerun) entfernt. Die Zahl der Einwohner wird bei einem Flächeninhalt von $1998 \mathrm{qkm}$ auf 25,000 angegebeu. Die Insel dient Spanien als Deportationsort und Kohlenstation. Hauptstadt ist das von den Engländern gegründete Clarencetown, heute Santa Isabel genannt, mit ca. 1000 Einwohnern.

Ueber die postalischen Verhältnisse der Insel ist nichts Näheres bekannt, Handel und Verkehr mit dem Mutterland sind unbedeutend.

Geldwährung, wie anf den Philippinen. 



\section{Briefmarken.}

tatow 



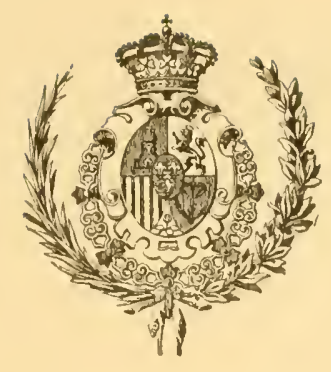

\section{A. Marken aus der Zeit der Regierung der Königin Isabella $\mathbf{I}$.}

\section{Ausgabe:}

vom 1. Juli 1868 bis 30. Juni 1879 (?).

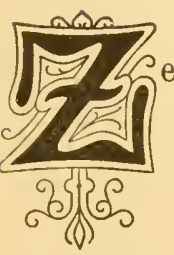

eichnung der VI. Ausgabe von Cuba mnd Portorico: Kopf der Königin Isabella II nach links in einem Kreise, dessen Untergrund mit wagerechten Linien ausgefüllt ist; über und unter dem Kreise zwei viereckige Schilder mit Inschriften in weissen Buchstaben auf farbigem Grund und zwar oben: FERNANDO POO, unten Wertangabe; in clen vier Ecken je ein Buchstabe $\mathrm{C}, \mathrm{O}, \mathrm{R}$ und $\mathrm{R}$ (Correos); zwischen Kreis und Schilder Verzierungen.

Farbiger Druck auf weissem Papier; gezähnt 14. (Taf. VII, 125.)

1. 20 CEN. DE ESC. braun.

Bemerkungen.

1. Durch Verfugung vom 4. Februar 1857 wurde das Porto für einfache Briefe (bis zu $1 / 2$ onza) von Fernando Póo nach Spanien auf 2 Reales Vn. (Reales 
de vellon $=$ Kupferrealen), fur jede weitere $1 / 2$ onza oder Teile dieses Gewichtes auf 2 weitere Realen festgesetzt. Da keine Marken existirten, so konnte das Porto in Fernando Póo nicht bezahlt, sondern musste vom Empfänger des Briefes erhoben werden. Durch Erlass vom 4. September 1860 wurde das Porto auf die Hälfte herabgesetzt. Eine Königliche Verfugung vom 4. Februar 1868 fuhrte die Freimarken und damit auch den Frankirungszwang ein. Das Porto fur Briefe nach Spanien und sämtlichen spanischen Kolonien wurde auf 200 Mils de esc. fur je $10 \mathrm{gr}$. oder Teile dieses Gewichtes festgesetzt. Im Widerspruch mit diesem Erlass ist auf der ausgegebenen Briefmarke der Wert in Céntimos de escudo ausgedrluckt.

2. Nach dem Timbre-Poste, wie auch nach dem Gr. Handbuch der Philatelie soll die Marke des Jahres 1868 schon am Ende desselben Jahres wieder eingezogen, die Restbestände an die Händler verkauft worden sein; es wären dann nach Einziehung derselben die gleichwertigen Marken von Span. -Westindien und Cuba, jedoch ohne irgend einen Aufdruck verwandt worden. Nach spanischen Quellen dagegen verblieb die Marke zu 20 Cen. de esc. bis zum 30. Juni 1878 in Gebrauch. Gegen letztere Angabe spricht jedoch das seltene Vorkommen gebrauchter Exemplare. Am wahrscheinlichsten erscheint eine von dritter Seite erfolgte Mitteilung, wonach von Ende 1868 bis zum 1. Juli 1879 auf Fernando Póo Marken uberhaupt nicht verwendet wurden.

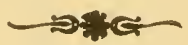




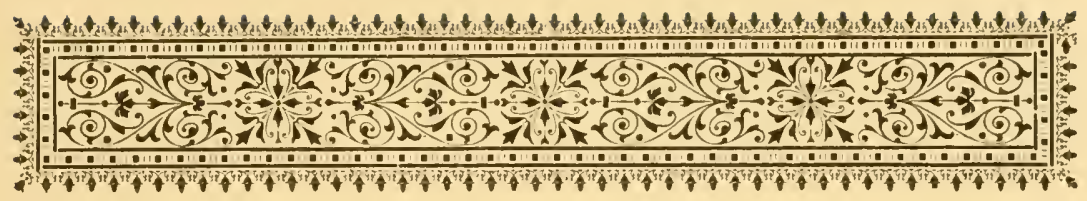

\section{B. Marken aus der Zeit der Regierung des Königs Alfonso XII.}

\section{Ausgabo:}

vom 1. Juli 1879 bis 31. Dezember 1881.

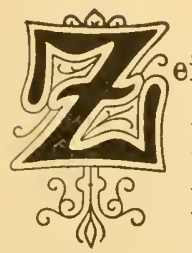

eichnung der XXIX. Ausgabe Spaniens: Kopf des Königs Alfonso XII. nach rechts in ovalem Rahmen: über und unter dem Oval ein rechteckiger Schild mit FERNANDO POO, bezw. Wertangabe; zwischen den Schildern und dem Oval ornamentale Verzierungen; auf dem Halsabschnitt der Name Julia.

Farbiger Druck auf weissem Papier; gezähnt 14. (Taf. VII, 126.)

2. 5 CENT. PESETA grün.

3. 10 C. DE PESETA karmin.

4. 50 C. DE PESETA blau in zwei Abstufungen.

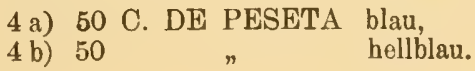

Bemerkungen.

1. Als Datum der Ausgabe wird vielfach fälschlich der 1. Januar 1880 angegeben.

2. Von den 3 Werten existiren Essais in schwarzer, brauner, violetter und grauer Farbe auf dickem, weissem Papier. 
3. Die Entwertung der Marken erfolgt vermittelst des Aufgabestempels. Derselbe trägt, den neueren spanischen Modellen entsprechend, oben die Bezeichnung: CORREOS, unten den Namen: FERNANDO POO, in der Mitte auf durchgehendem Mittelschild das Datum. (Taf. VII, $127 \mathrm{u} .128$ ).

\section{Ausgabe: \\ von Januar 1882 an bis Ende 1893.}

Nämliche Zeichnung, nur Aenderung der Wertbezeichnung.

Farbiger Druck auf weissem Papier; gezähnt 14. (Taf. VII,126.)

5. UN C. DE PESO grün.

6. 2 C. DE PESO karminrosa.

7. 5 C. DE PESO graublau.

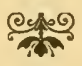

IV. Ausgabe:

von Juli 1884 bis (?) 1889.

Aushilfs-Marken: Marke der III. Ausgabe mit kreisförnigem Aufdruck: HABILITADO PARA CORREOS und neuer Wertangabe. (Taf. VII, 127.)

8. 50 CENT-PTA auf 2 C. DE PESO blau auf karminrosa.

9. 5o CENT-PTA auf 5 C. DE PESO blau auf graublau.

Bemerkungen.

1. Der Aufdruck hat manchmal eine dunkelblaue, schwarzgraue oder violette Färbung.

2. Der Aufdruck wurde im Jahre 1886 gefälscht. Erkennungszeichen der Fälschung sind: Die Ziffer 5 sowie $\mathrm{P}$ und $\mathrm{R}$ von PARA sind breiter, das $\mathrm{S}$ von CORREOS ist weniger offen, das $\mathrm{C}$ von Cent. ist anstatt wie bei dem echten Aufdruck etwas kleiner, von derselben Grösse wie die übrigen Buchstaben. 


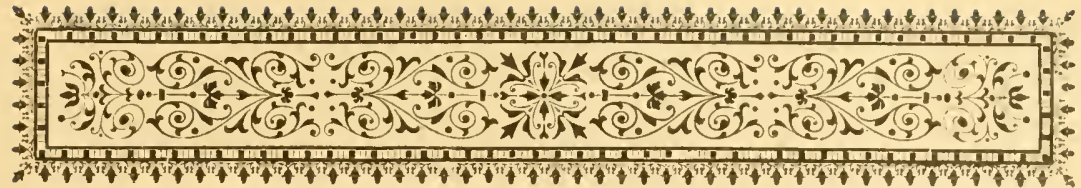

C. Marken aus der Zeit der Regentschaft der Königin Maria Cristina bezw. der Regierung des Königs Alfonso XIII.

\section{Ausgabe:} 1890.

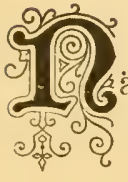

Gämliche Zeichnung (Kopf Alfonso's XII).

Farbiger Druck auf weissem Papier; gezähnt 14.

10. 10 C. DE PESO braun.

Bemerkung.

Während die Marken der II. und III. Ausgabe in Type I (vergl. Cuba Seite 48) hergestellt waren, zeigt diese Marke die III. Type (vergl. Cuba, Seite 55, C). 


\section{Ausgabe:}

Sommer 1893.

Aushilfs-Marke: Marke der III. Ausgabe mit Aufdruck: HABILITADO PARA CORREOS, 50 Cent-Pta.

11. 5o CENT-PTA auf UN C. DE PESO schwarz auf grün.

\section{Bemerkung.}

Der Mangel an Marken auf der Insel zwang zur Habilitirung auch der 1 Céntimos-Marke. Nachdem dieser Wert völlig aufgebraucht war, bevor Ersatz aus Spanien eingetroffen, half man sich durch Stempeln der Brief-Umschläge mit dem Aufdruck HABILITADO PARA CORREOS, 50 Cent. Pta. Der Aufdruck kommt in blauer und schwarzer Farbe vor.

\section{?}

\section{Ausgabe:}

von Fruhjahr 1894 an.

Zeichnung der XIII. Ausgabe von Cuba: Kopf des Königs Alfonso XIII. nach rechts in ovalem Rahmen mit liniirten Untergrund; oben in rechteckigem Schild: FERNANDO POO, unten in ebensolchem Wertangabe; zwischen beiden Schildern ausserhalb des Ovals ornamentale Verzierungen.

Farbiger Druck auf weissem Papier; gezähnt 14.

\section{10 C. DE PESO braunviolett.}

\section{Bemerkung.}

Die ubrigen zur Ausgabe bestimmten Werte sind zur Zeit noch nicht dem Verkebr ubergeben.

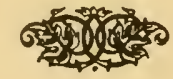




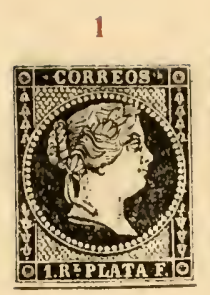

6

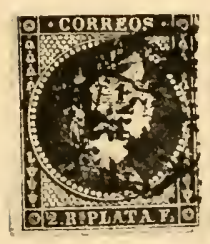

25

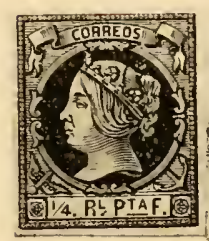

31

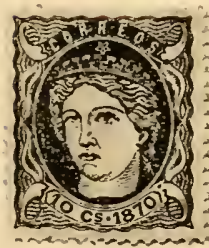

36

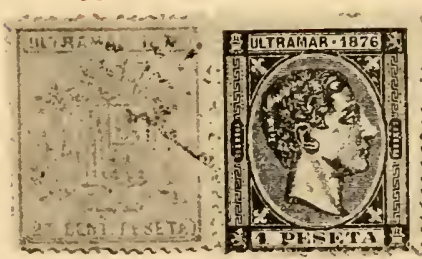

48

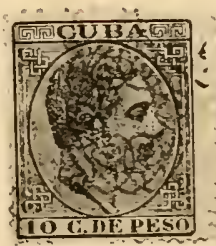

3

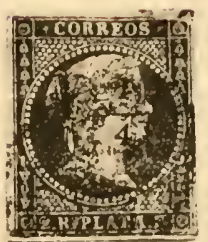

$\mathrm{S}$

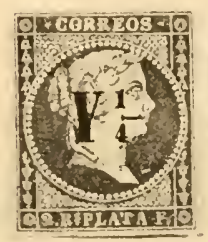

27

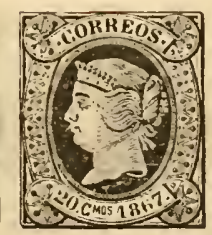

33

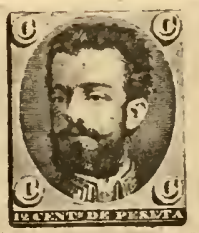

45

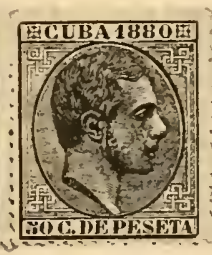

49

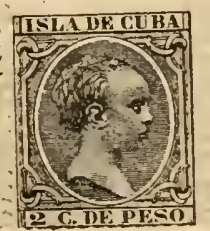

4

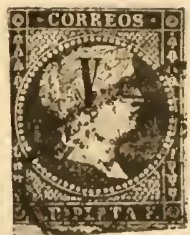

9

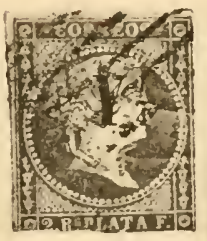

25

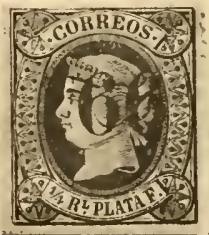

34

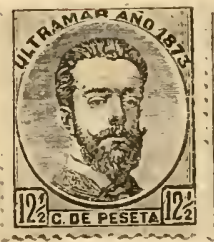

46

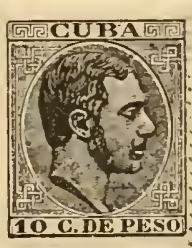

50

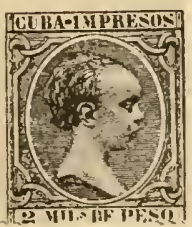

5)

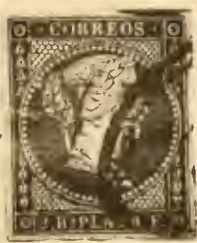

10

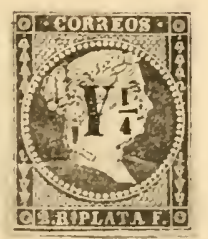

29

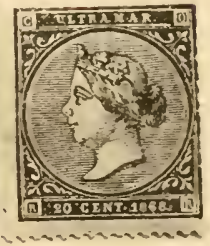

35

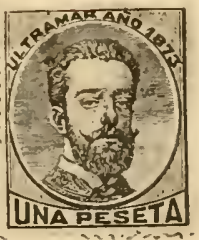

47

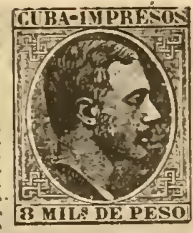

3 MILA DE PESO 


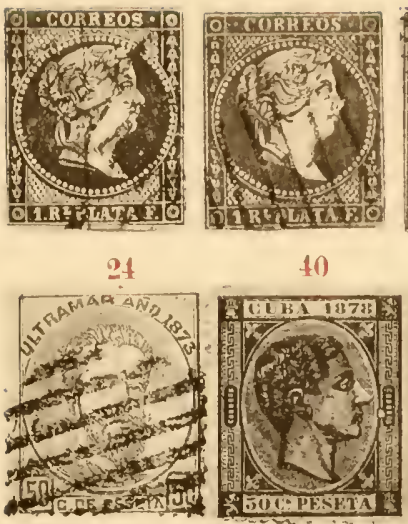

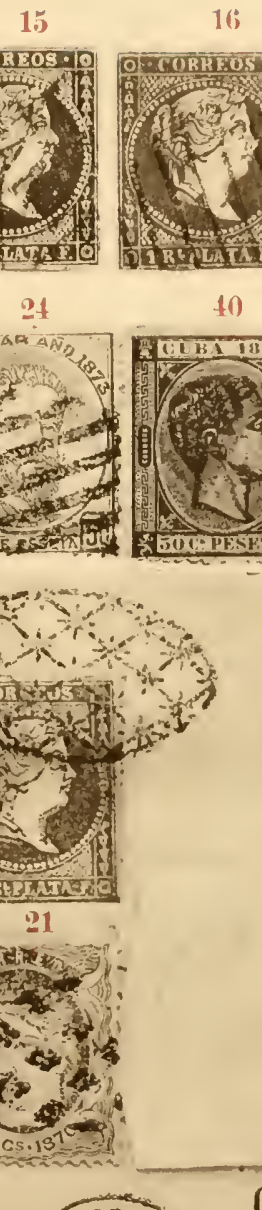

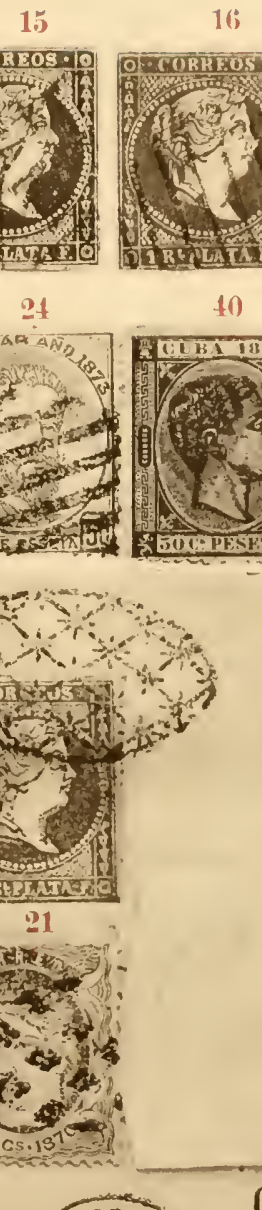

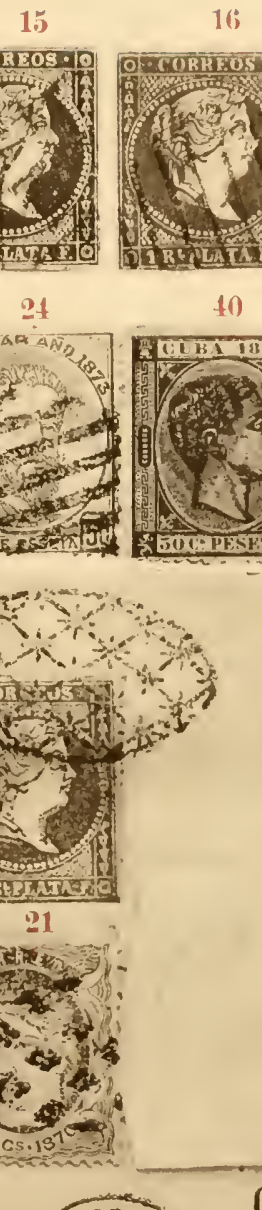
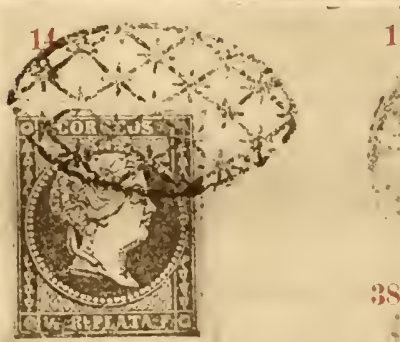

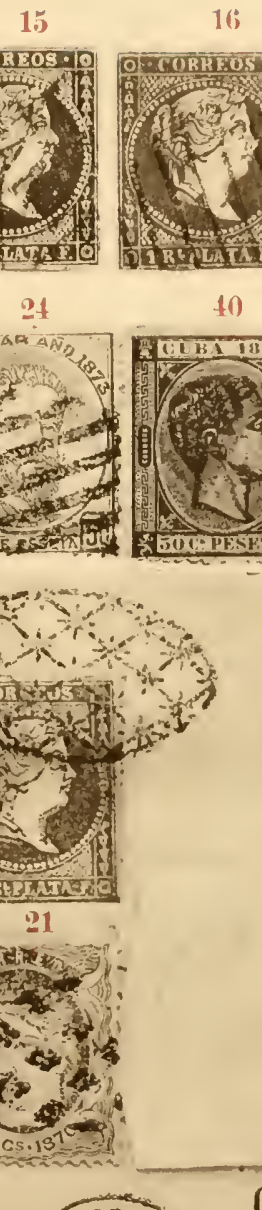

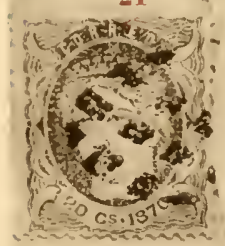

$=0$

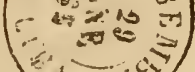

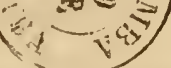

17

1s

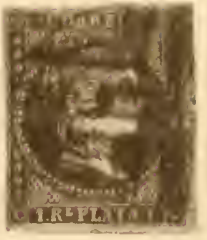

42

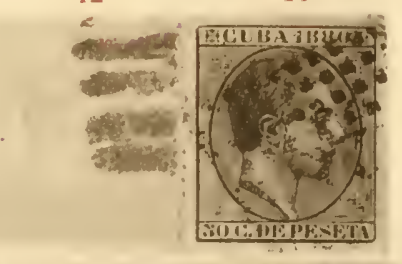

23

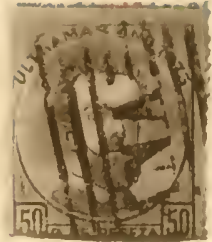

4:3

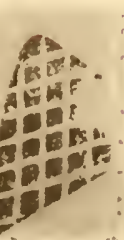

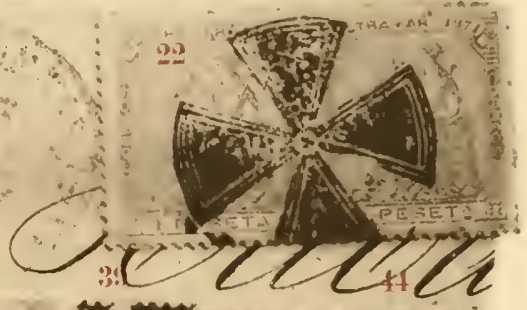
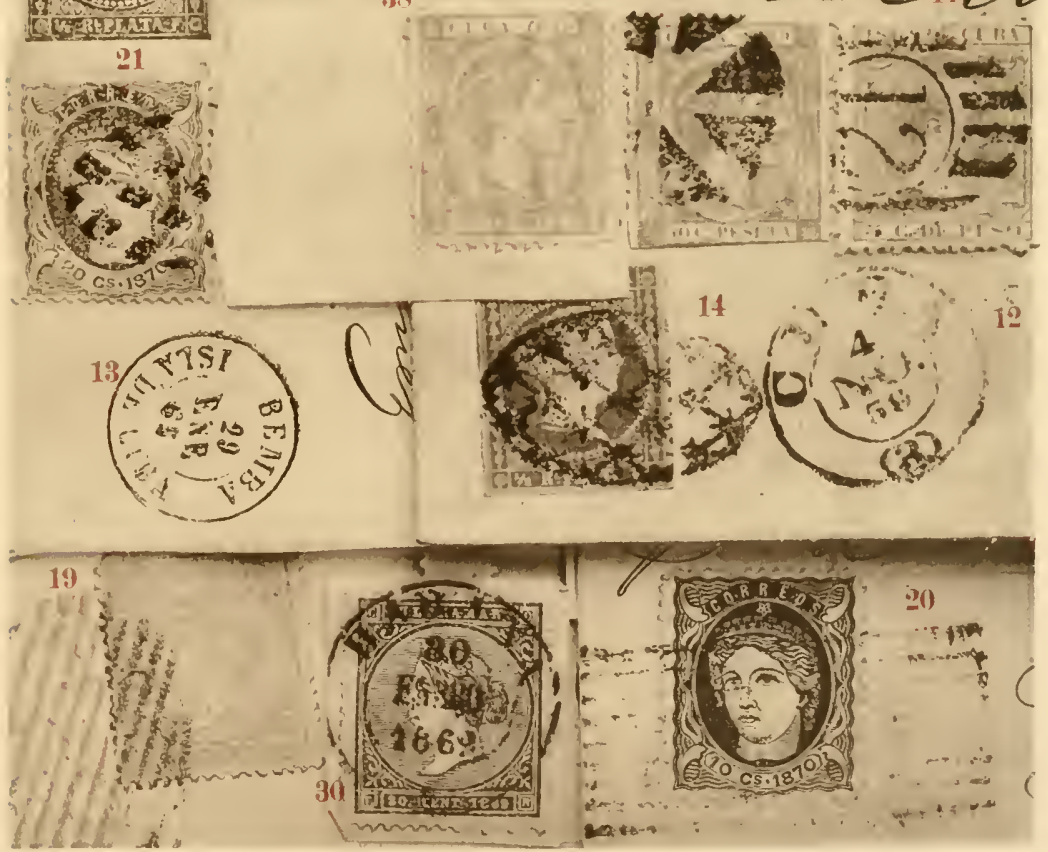

Friederich, Die Postwertzeichen Spaniens und seiner Kolonien (II. Teil) 



\section{Tafel III.}

51

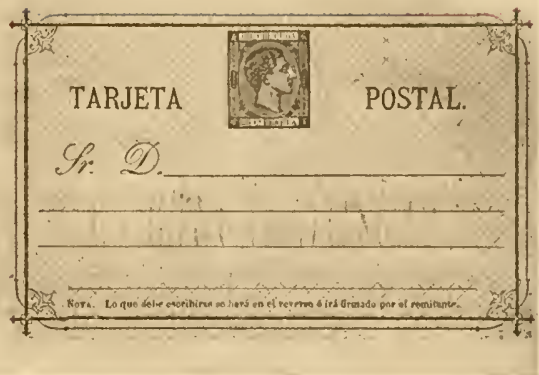

52

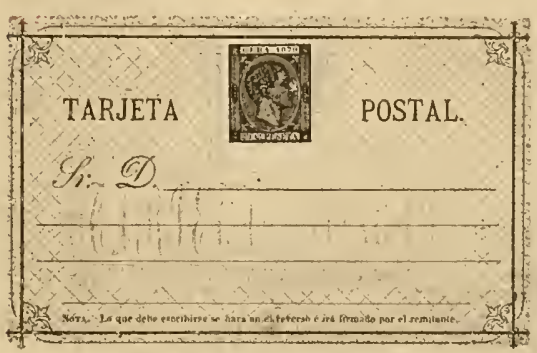

.53
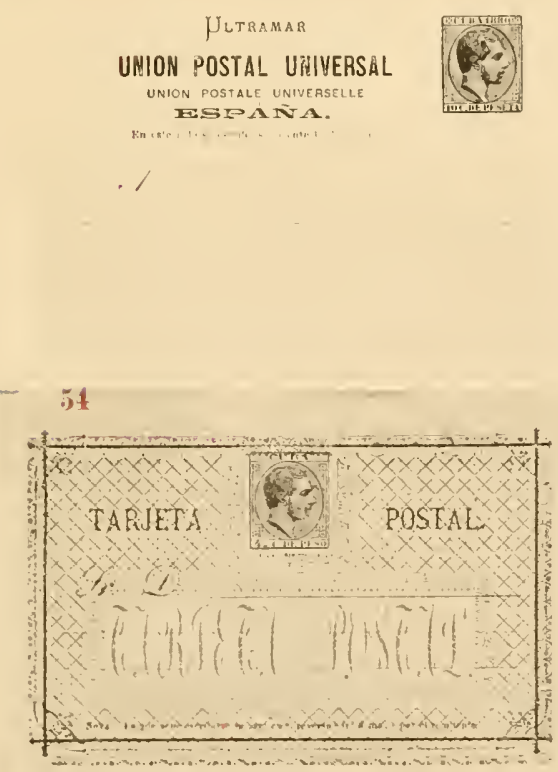

50
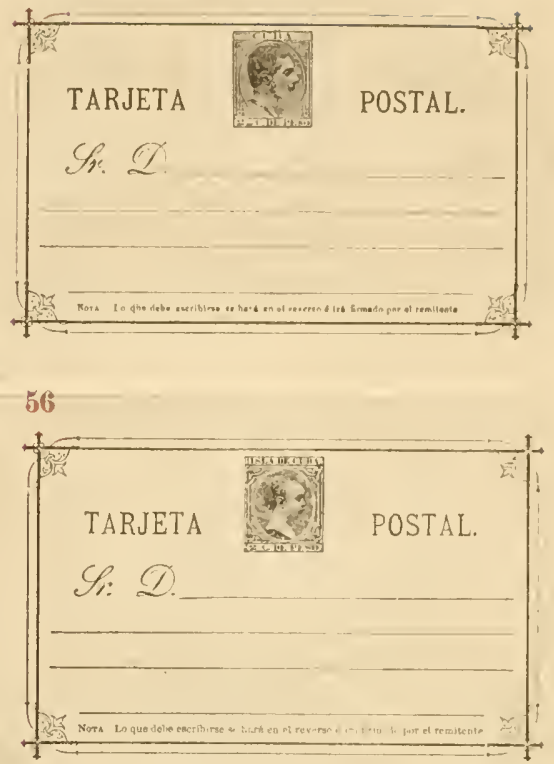

57

TAP.JETA

PCOTAI

$\mathcal{S P}_{i:}$

124

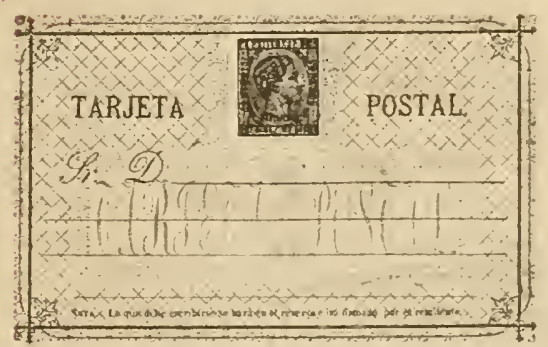

Friederich, Die Postwertzeichen Spaniens und seiner Kolonien (II. Teil) Verlag von Dr. H. Brendicke in Berlin W. 57. 



\section{Tafel IV.}

55

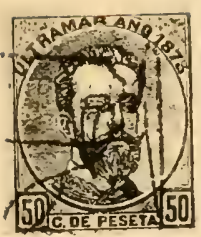

70

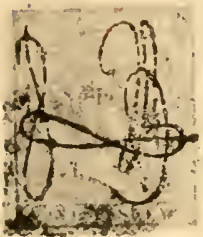

66

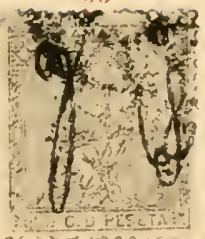

71

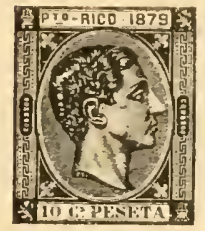

67

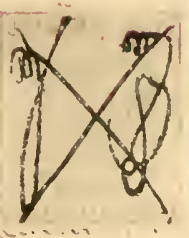

72

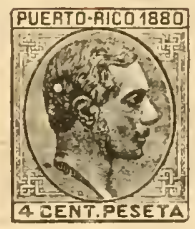

Gs

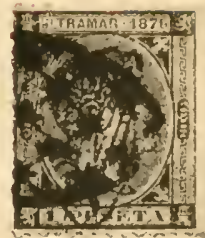

73

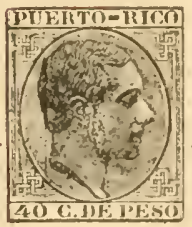

(i)

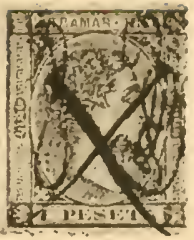

74

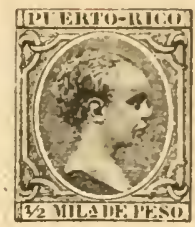

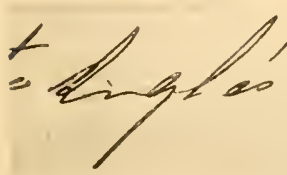

70
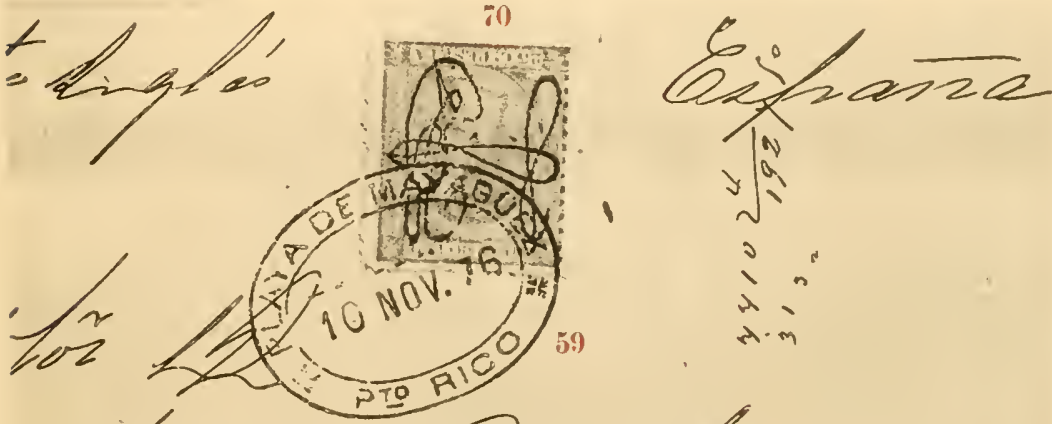

iो:
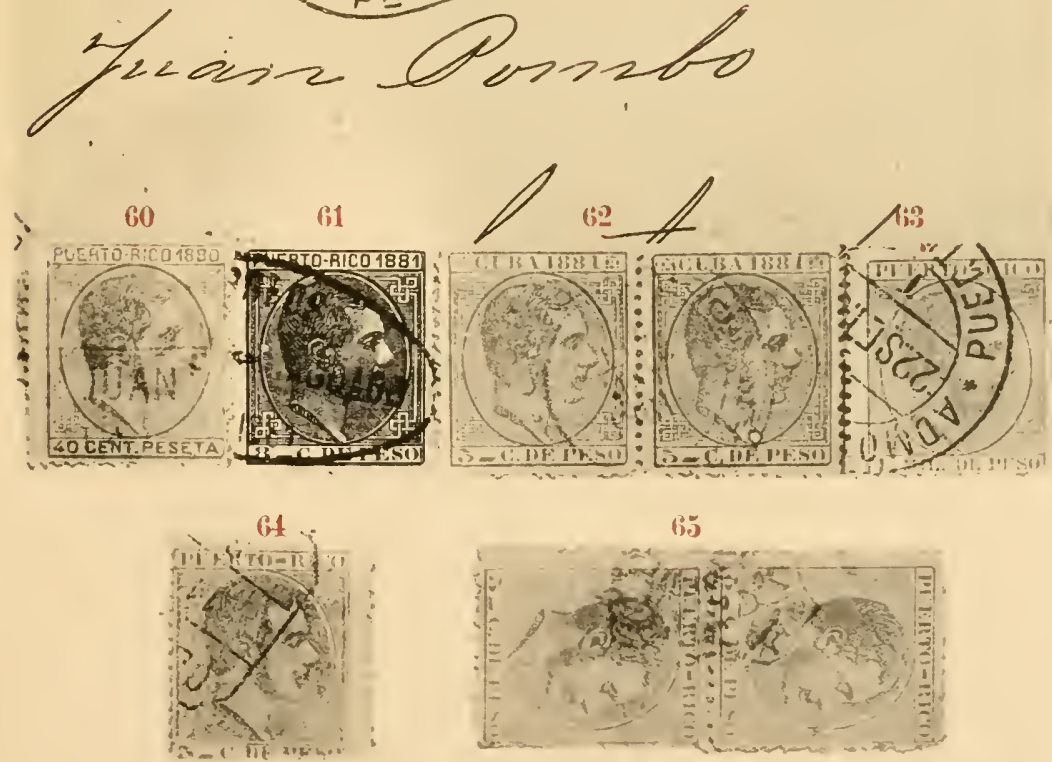

(65)

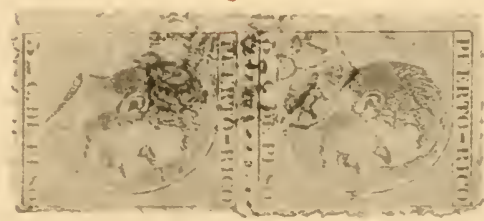

Friederich, Die Postwertzeichen Spaniens und seiner Kolonien (II. Teil) 



\section{Tafel V.}
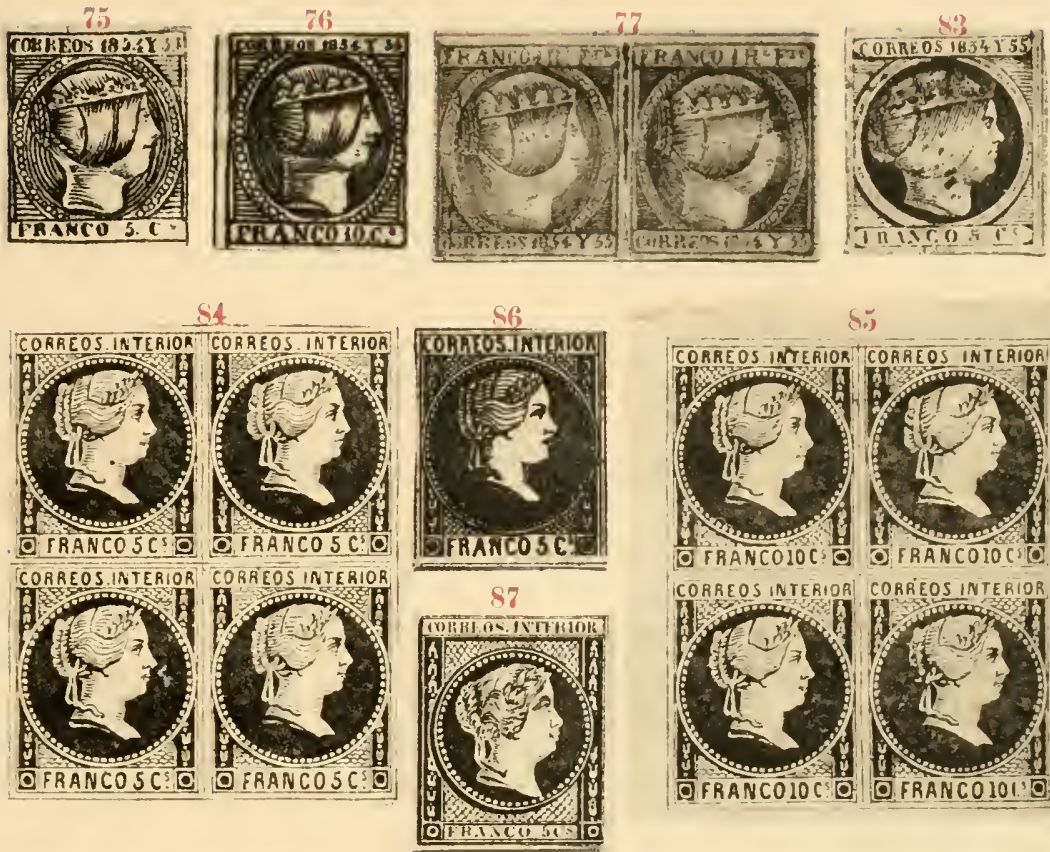

88
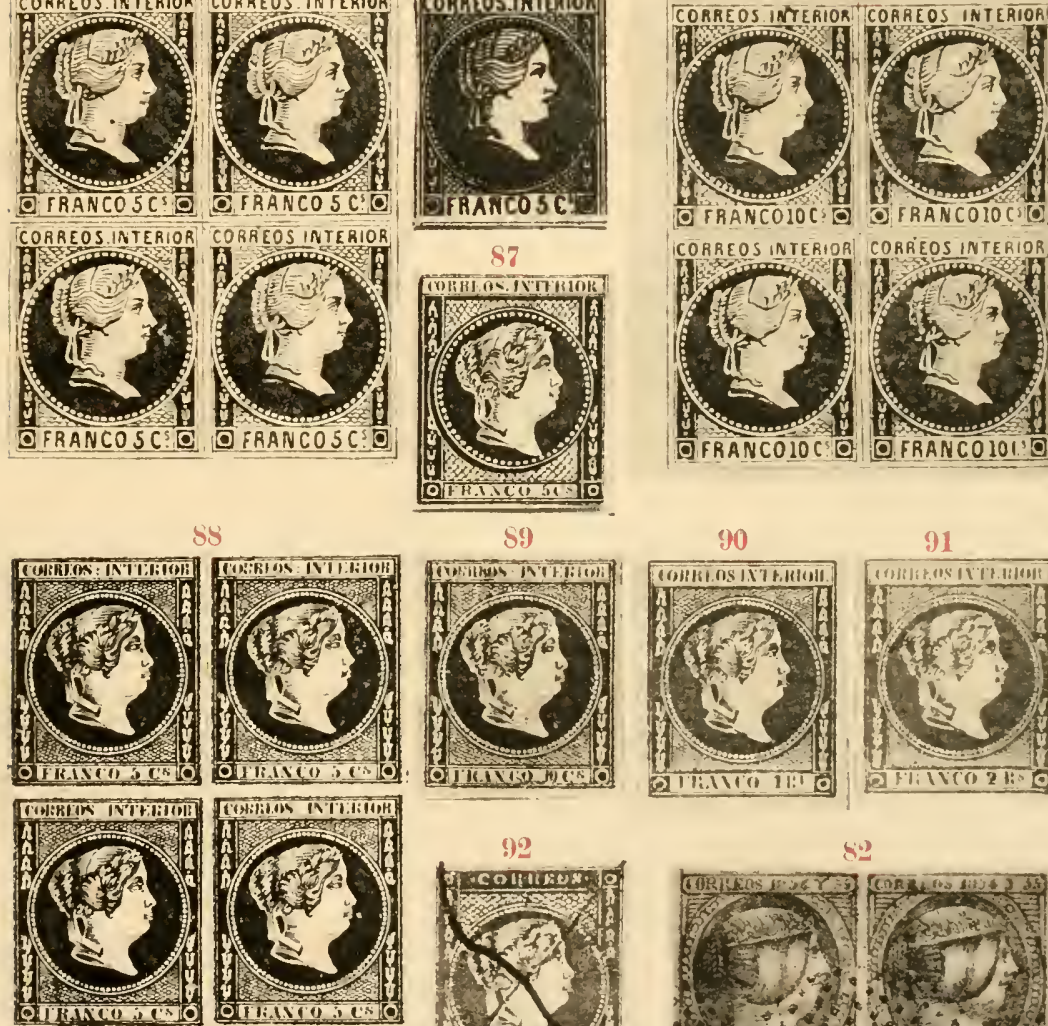

ICORREOS INTERIORI CORREOSINTERIOR
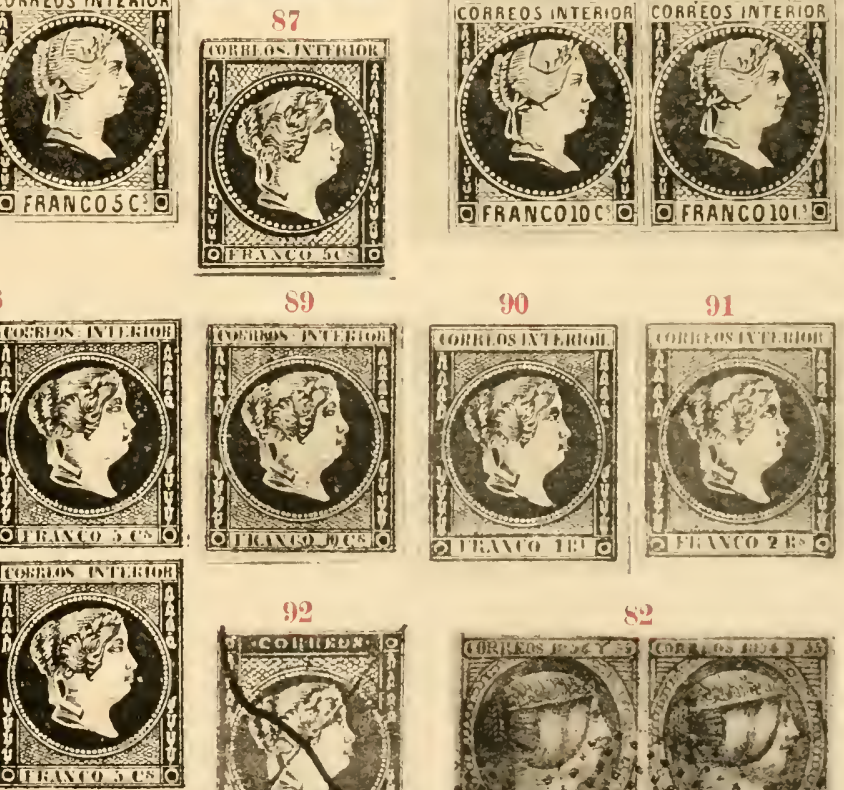

is

97

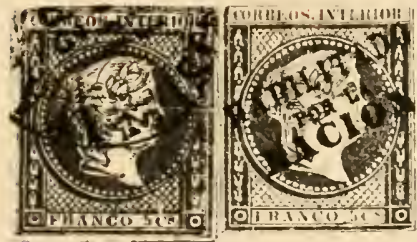

S?

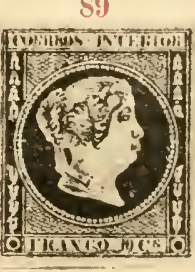

O0
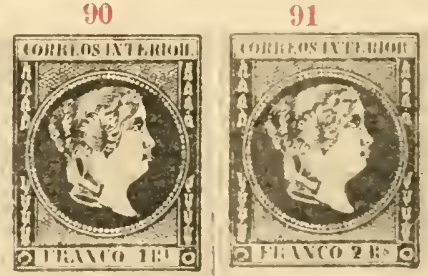

(iv)

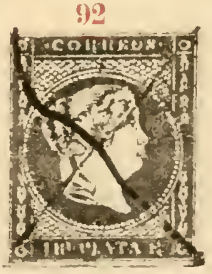

Q⿻日木
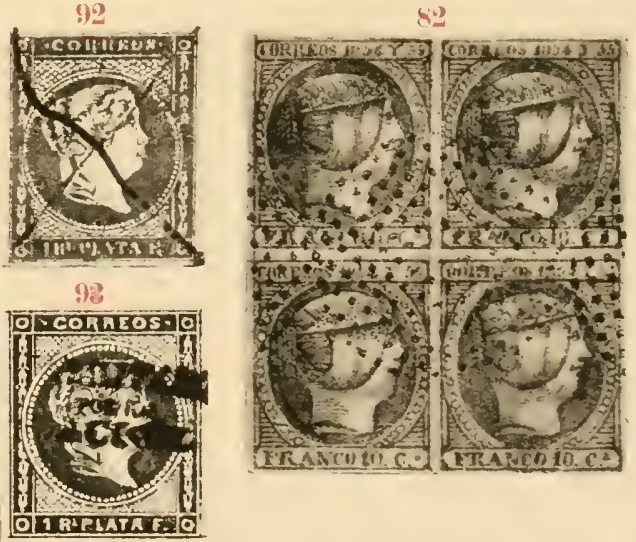



\section{Tafel VI.}
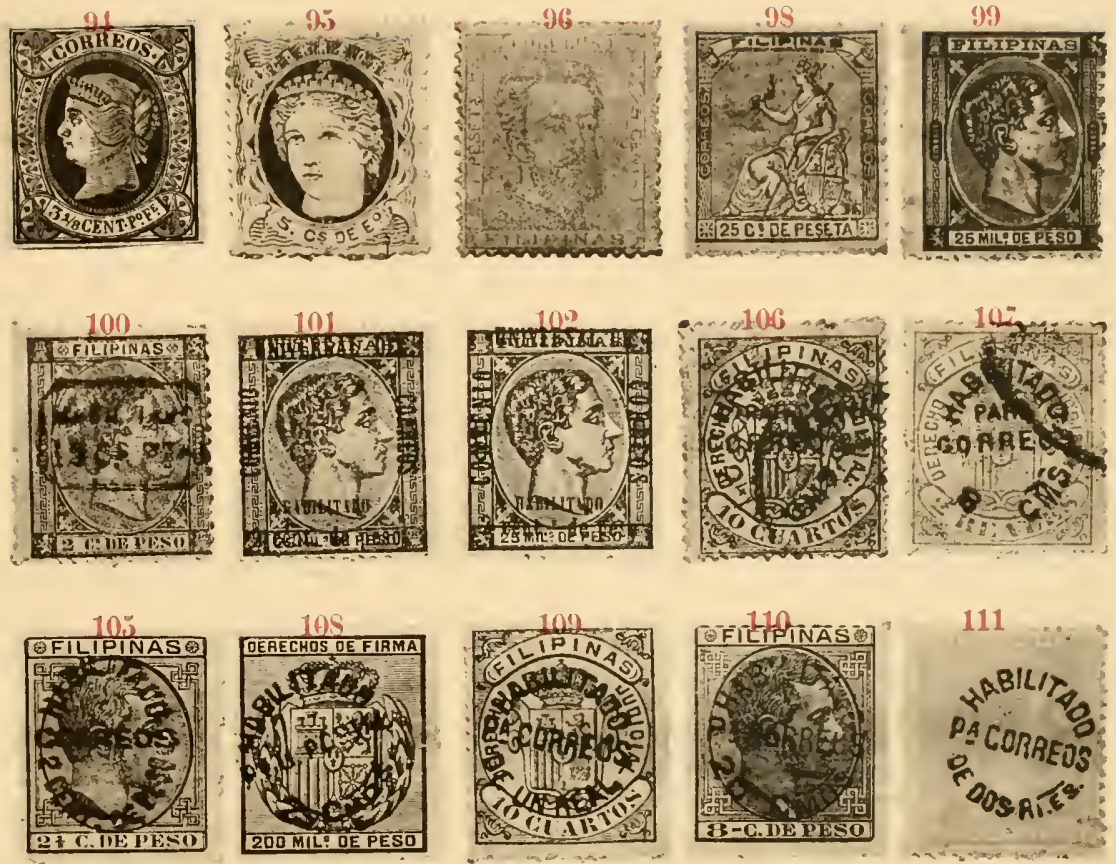

111
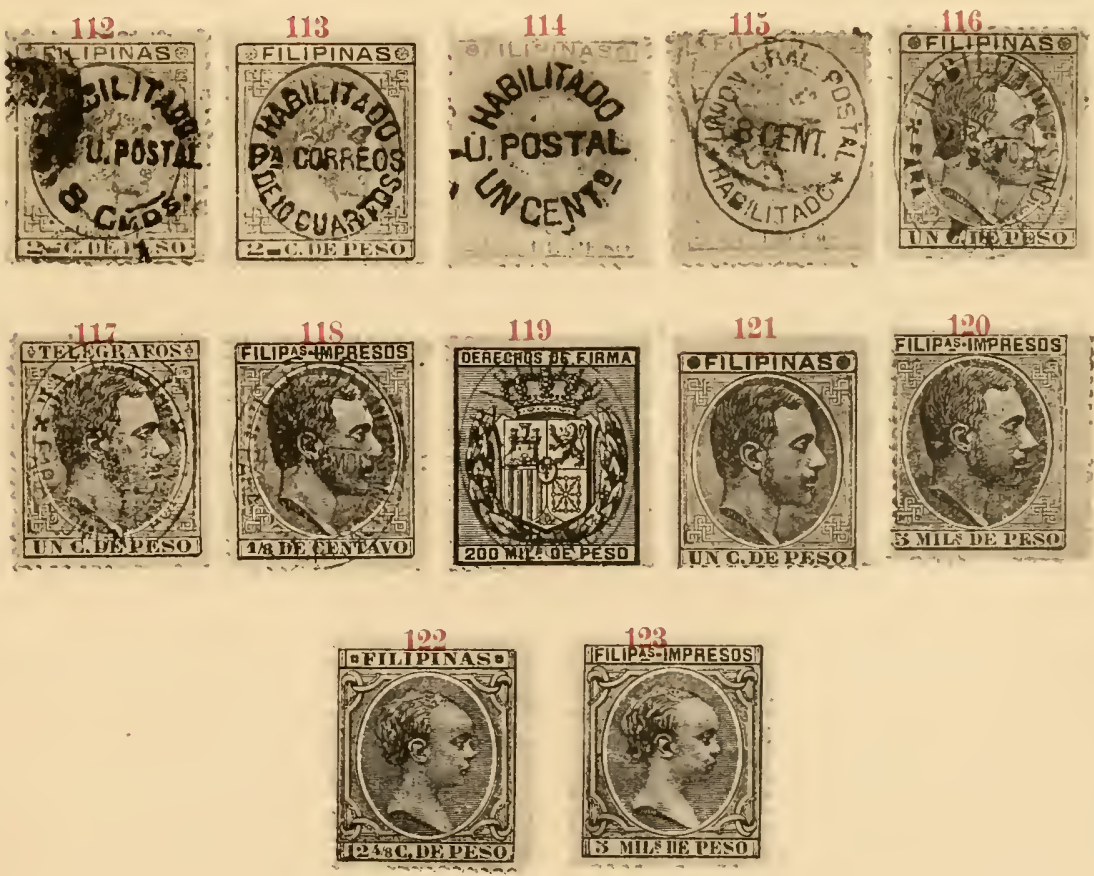



\section{Tafel VII.}
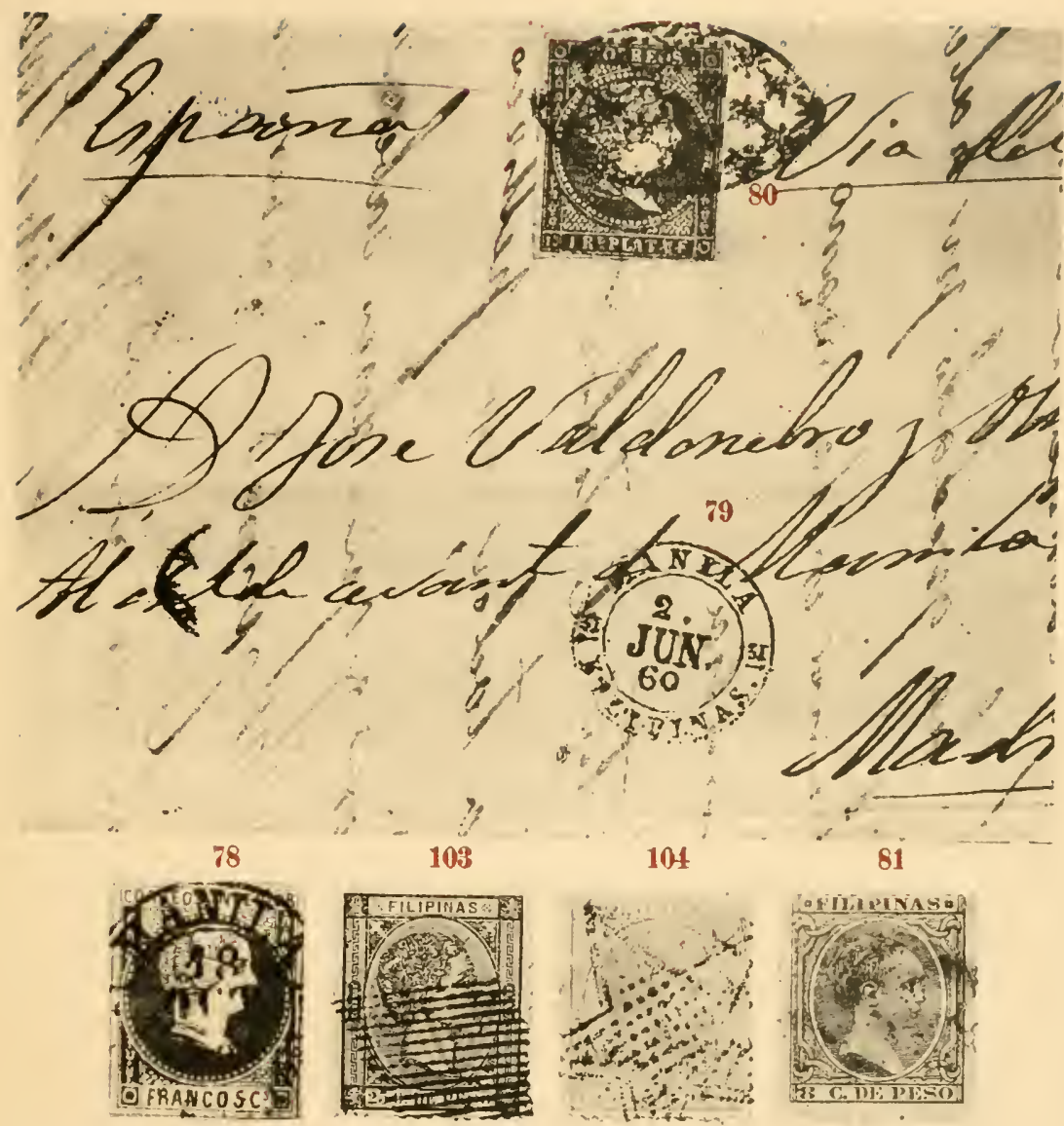

125

126

127
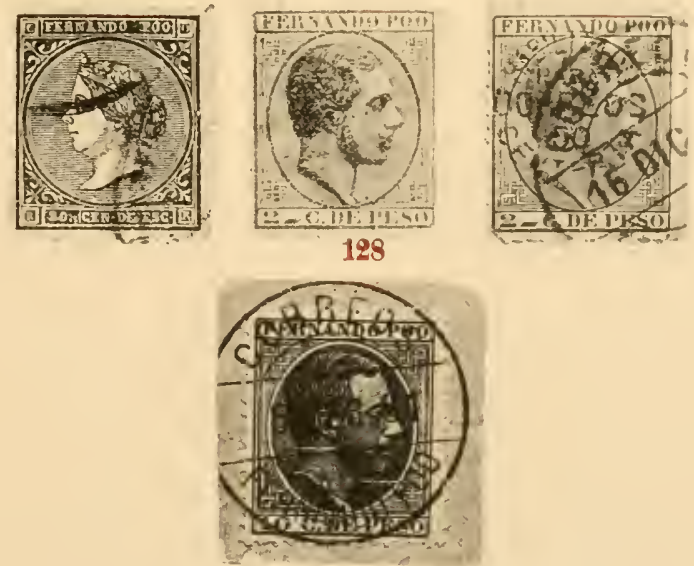

Friederich, Die Postwertzeichen Snaniens und seiner Kolonien (II. Teil) Verlag ron Dr. H. Brendicke in Berlin W.57. 



